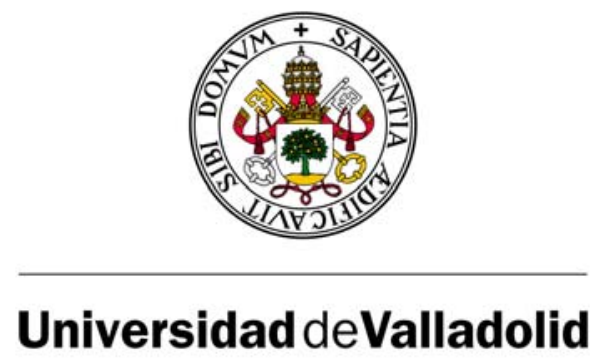

FACULTAD DE CIENCIAS ECONÓMICAS Y EMPRESARIALES

DEPARTAMENTO DE ORGANIZACIÓN DE EMPRESAS

Y COMERCIALIZACIÓN E INVESTIGACIÓN DE MERCADOS

TESIS DOCTORAL

\title{
GESTIÓN DE RECURSOS HUMANOS Y RETENCIÓN DEL CAPITAL HUMANO ESTRATÉGICO: ANÁLISIS DE SU IMPACTO EN LOS RESULTADOS DE EMPRESAS INNOVADORAS ESPAÑOLAS
}

\author{
Realizada por: \\ Da. Celia Martín Sierra
}

Bajo la dirección de:

Dra. Da. Ma. Pilar Pérez Santana

Dra. Da. Isabel Ma. Prieto Pastor

Valladolid, 2011 

A mi madre, Esther 



\section{AGRADECIMIENTOS}

Son muchas las personas que han influido positivamente, de una u otra manera, en la elaboración de esta tesis. A ellas quiero dedicar unas líneas que no van a ser suficientes para expresar $\mathrm{mi}$ agradecimiento. Espero que me excusen aquellas personas que pueda olvidar mencionar. Igualmente pido disculpas por los errores $\mathrm{u}$ omisiones de este trabajo, de los que soy la única responsable.

En primer lugar, quiero expresar mi agradecimiento, a mis directoras, Pilar Pérez Santana e Isabel Prieto Pastor, por conducir mis primeros pasos en el mundo de la investigación, por sus enseñanzas, por sus consejos, por su infinita paciencia con mi estilo de redacción y por compartir conmigo su valía profesional y personal. Pilar, gracias por haber confiado en mí desde el primer día y por tu apuesta por la investigación en el área de recursos humanos. Isabel, gracias por asumir este reto y por tu académica profesionalidad. Espero que ambas me disculpen por cuantos errores haya cometido en el desarrollo de este trabajo. También, quiero agradecer a Natalia Martín Cruz su guía e impulso durante la primera etapa de esta andadura. Y a Juan Hernangómez Barahona por su presencia y participación en los momentos más necesarios.

A Javier Rodríguez por su inestimable ayuda con la parte metodológica, por compartir sus conocimientos estadísticos y de PLS de forma tan generosa. A Carmen Camarero, por sus consejos. A mis compañeros del Departamento de Organización de Empresas y Comercialización e Investigación de Mercados, por estar siempre ahí con una palabra de ánimo y por ser para mí una referencia de esfuerzo y trabajo. Y de forma muy cariñosa, a mis compañeros de fatigas Isabel Estrada, Víctor Martín y Rebeca San José, por su amistad y muestras de apoyo en el día a día. También, a mis compañeros de la facultad de Ciencias del Trabajo del Campus La Yutera (Palencia), Ana Ortega y Miguel Lamoca, por su magnífica acogida en el mundo universitario y por su apoyo durante estos años.

A los profesionales y expertos que no han dudado en colaborar en el desarrollo de este trabajo. Diego Moñux, Guillermo Alexandre y Javier Gómez, por sus conocimientos sobre empresas tecnológicas. Rafael Cano y José Herrador, por su labor como mentores en mi desarrollo en el apasionante mundo de los recursos humanos, a ellos les debo mi orientación profesional. Los responsables de recursos humanos de las empresas Grupo Siro, Peguform, S.A., Grupo Antolín y RYA (Soraya Simón, Antonio López, Montserrat Santillán y Montserrat Martín, respectivamente), por sus apreciaciones que sirvieron para depurar el cuestionario de este trabajo. Asimismo, no puedo dejar de expresar mi agradecimiento a David, Florentino y Sara por su ayuda en la construcción de la base de datos de esta investigación.

A nivel personal, de un modo especial a Juan García, por su ejemplo e inestimable ayuda. Por estar a mi lado en la recta final de este viaje, por el tiempo robado, por empujarme en las cuestas arriba y sujetarme en las cuestas abajo, siempre con una sonrisa. Por no soltar mi mano. 
También a otras personas que han estado cerca de mi corazón en estos años, por su cariño, comprensión y apoyo. A Javier, por acompañarme en mis primeros pasos en la Universidad, por su escucha activa y su confianza en mi valía. A David, por su inestimable ayuda con la base de datos y su infinito cariño. A mis amigas de Palencia, por haberme aceptado como soy desde siempre. A mis amigos de Saucelle, a los de Valladolid -en especial a Laura- y a mis amigos de salsa, por no preguntar demasiado, por soportar mis ausencias y recibirme siempre con una sonrisa de ánimo. A todos vosotros, gracias por facilitarme reencontrarme conmigo misma y con mi esencia.

Y para terminar, quiero plasmar en estas líneas mi agradecimiento a las tres personas que siempre llevo en el corazón y han sido un soporte básico para mí en la realización de este trabajo. A mi padre, Florentino, por hacerme como soy, por sus consejos, por estar siempre ahí cuando lo necesito e, incluso, por hacer de becario. A mi madre, Esther, por su amor infinito, por sujetarnos a todos para que no decaigamos, por reconfortar siempre mi espíritu, por cuidarme y quererme como lo hace, de esa forma tan incondicional. Y a mi hermana, Esther, por su apoyo, comprensión y por su ejemplo de superación personal. Sin vosotros no sé si habría podido llegar hasta aquí.

Ahora comienza una nueva etapa. 
ÍNDICES 



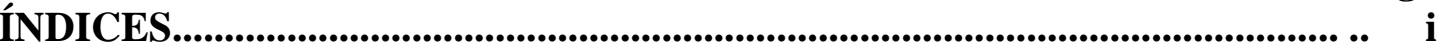

A. Índice General............................................................................. i

B. Índice de cuadros, figuras y tablas ................................................................ $\mathrm{v}$

A. ÍNDICE GENERAL

INTRODUCCIÓN............................................................................................................. 1

\section{SECCIÓN I. DESARROLLO TEÓRICO}

\section{CAPÍTULO 1. FUNDAMENTOS TEÓRICOS Y EMPÍRICOS DE LA}

INVESTIGACIÓN..

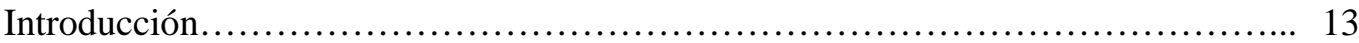

1.1. La visión de empresa basada en los recursos: el enfoque de recursos y

capacidades.

1.1.1. Enfoque de recursos y capacidades de la empresa........................................ 16

1.1.2. Conceptos básicos del enfoque de recursos y capacidades............................. 18

1.1.3. Postulados básicos del enfoque de recursos y capacidades....................... 23

1.1.4. Recursos y capacidades estratégicos y su relación con la ventaja competitiva de la organización............................................................................... 24

1.1.5. Principales limitaciones y aportaciones del enfoque de recursos y capacidades.

1.2. El enfoque estratégico de recursos humanos......................................................... 31

1.2.1. Del enfoque de recursos y capacidades al enfoque estratégico de recursos humanos.

1.2.2. Los recursos humanos y su valor estratégico. Los recursos humanos como capital estratégicos y su triple dimensión: intelectual, social y afectiva

1.2.2.1. Definición de recurso humano bajo el enfoque de recursos y capacidades

1.2.2.2. Recursos humanos y ventajas competitivas organizativas. Los empleados estratégicos.

1.2.2.3. Los recursos humanos como capital humano: intelectual, social y afectivo.

1.2.3. Prácticas de recursos humanos y ventajas competitivas sostenibles............ 54

1.2.4. Impacto de la gestión de recursos humanos sobre la organización: medidas de resultados, prácticas de recursos humanos y procesos mediadores. El caso particular de la innovación....

1.2.4.1. Impacto de la dirección estratégica de recursos humanos en los resultados organizativos: un conglomerado de medidas.

1.2.4.2. Prácticas de recursos humanos y resultados organizativos: los sistemas de prácticas

1.2.4.2.1. Trabajos tradicionales de clasificación de prácticas de recursos humanos.

1.2.4.2.2. Trabajos emergentes de clasificación de prácticas de recursos humanos

1.2.4.3. Procesos mediadores de la influencia de la gestión de recursos humanos en los resultados organizativos: la "caja negra" de recursos humanos 
1.2.4.4. Gestión de recursos humanos e innovación ..................................... 78

1.2.4.4.1. Concepto de innovación............................. 79

1.2.4.4.2. Diversidad de medidas de innovación................... 82

1.2.4.4.3. La gestión estratégica de recursos humanos y la innovación.

1.2.4.4.4. Prácticas de recursos humanos e innovación............. 87

1.3. Gestión de recursos humanos y retención de capital humano de la organización 91

1.3.1. Concepto de retención de empleados. Algunas taxonomías de la retención..... 94

1.3.2. Revisión de la literatura de investigación en retención de empleados............ 100

1.3.2.1. Los principales modelos de retención: un recorrido cronológico.... 103

1.3.2.2 Revisión de los trabajos que relacionan las prácticas de recursos humanos y la retención de empleados en la organización.....

1.3.2.2.1. Estudios que relacionan la retención del empleado y el diseño de puesto de trabajo.

1.3.2.2.2. Estudios que relacionan la retención del empleado y su desarrollo profesional: formación y promoción.

1.3.2.2.3. Estudios que relacionan la retención del empleado y su retribución.

1.3.2.2.4. Estudios que relacionan la retención del empleado y sus relaciones internas con la organización, con el superior y con los compañeros

1.3.2.2.5. Estudios que relacionan la retención del empleado y las condiciones y organización del trabajo.

1.4. Propuesta de una taxonomía de prácticas de recursos humanos orientadas a la retención de empleados estratégicos: prácticas transaccionales y prácticas relacionales.

CAPÍTULO 2. MODELO E HIPÓTESIS

Introducción.

2.1. Presentación general del modelo propuesto

2.2. Desarrollo del modelo: definición de variables.

2.2.1. Variables dependientes del modelo.

2.2.1.1. Capital humano

2.2.1.1.1. Capital intelectual. 148

2.2.1.1.2. Capital social. 149

2.2.1.1.3. Capital afectivo......................................................... 152

2.2.1.2. Resultados organizativos..................................................... 156

2.2.1.2.1. Capacidad de Innovación.............................................. 157

2.2.1.2.2. Resultados de las personas y resultados empresariales... 159

2.2.2. Variables independientes del modelo: prácticas de recursos humanos orientadas a la retención del capital humano de la organización 160

2.2.2.1. Prácticas de recursos humanos de naturaleza transaccional:

Diseño de puesto, Retribución, Desarrollo profesional del empleado y Conciliación entre vida laboral/personal.

2.2.2.2. Prácticas de recursos humanos de naturaleza relacional: Soporte del supervisor, Comunicación interna, Participación del empleado y Relaciones internas de apoyo entre compañeros 
2.2.3. Relaciones fundamentales entre las variables del modelo: formulación de hipótesis y subhipótesis.

2.2.3.1. Relación entre las prácticas de recursos humanos y la retención del capital humano de la organización.

2.2.3.1.1. Hipótesis relativas a las prácticas transaccionales.......... 175

2.2.3.1.1.1. Diseño enriquecido de Puesto: ................................. 174

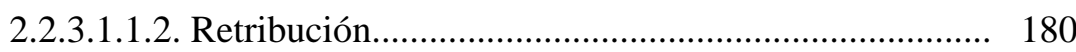

2.2.3.1.1.3. Desarrollo profesional del empleado......................... 186

2.2.3.1.1.4. Conciliación Vida laboral-personal........................... 194

2.2.3.1.2. Hipótesis relativas a las prácticas Relacionales.......... 200

2.2.3.1.2.1. Soporte del supervisor:........................................... 200

2.2.3.1.2.2. Comunicación Interna............................................. 205

2.2.3.1.2.3. Participación: ...................................................... 209

2.2.3.1.2.4. Relación con compañeros: H8a,b,c........................... 212

2.2.3.2. La relación entre el capital humano y los resultados intermedios.... 217

2.2.3.2.1. Capital humano y capacidad de innovación.................. 217

2.2.3.2.1.1. Capital intelectual y capacidad de innovación ........ 218

2.2.3.2.1.2. Capital social y capacidad de innovación................ 220

2.2.3.2.1.3. Capital afectivo y capacidad de innovación............. 221

2.2.3.2.2. Capital afectivo y resultados de las personas................. 223

2.2.3.3. La relación de la capacidad de innovación y de los resultados de las personas con el resultado empresarial................................... 224

2.2.3.3.1. Capacidad de innovación y resultados empresariales...... 225

2.2.3.3.2. Resultados de personas y resultados empresariales......... 226

2.2.4. Resumen de las hipótesis propuestas............................................. 227

\section{SECCIÓN II. DESARROLLO EMPÍRICO}

CAPÍTULO 3. DISEÑO DE LA INVESTIGACIÓN EMPÍRICA.............................. 231

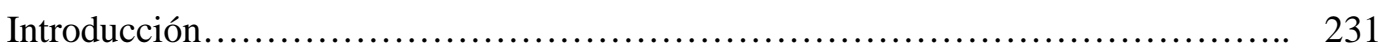

3.1. Diseño de la muestra..................................................................... 232

3.2. Diseño del cuestionario y obtención de datos...................................................... 235

3.2.1. Diseño del cuestionario............................................... 235

3.2.2. Obtención de datos....................................................... 240

3.2.2.1. Envío del cuestionario.................................................................... 240

3.2.2.2. Recepción del cuestionario........................................................ 242

3.2.2.3. Test de factor único de Harman........................................................ 242

3.2.3. Perfil de la muestra........................................................... 243

3.3. Metodología de análisis................................................................ 246

3.3.1. Comparativa CBSEM vs. PLS ........................................... 249

3.3.1.1. Distribución de las variables..................................................... 249

3.3.1.2. Finalidad y objetivo de la metodología............................................ 250

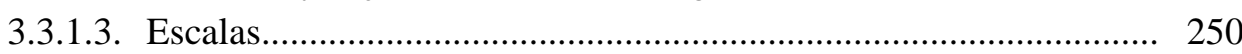

3.3.1.4. Relaciones entre variables y modelos de medida: reflectivos vs 251 
formativos.

3.3.1.5. Estadísticos de la bondad de ajuste del modelo............................... 254

3.3.2. Selección de la metodología para esta investigación............................. 255

CAPÍTULO 4. RESULTADOS DE LA INVESTIGACIÓN EMPÍRICA.................. 261

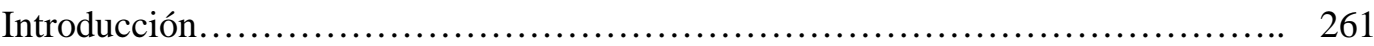

4.1. Estimación del modelo de medida.................................................................. 262

4.1.1. Validación de los índices formativos.......................................... 263

4.1.2 Validación de las escalas reflectivas....................................... 277

4.2. Análisis y evaluación del modelo estructural .......................................................... 288

4.2.1. Prácticas de retención de recursos humanos y capital humano. Contraste de hipótesis y subhipótesis.................................................................. 291

4.2.1.1. Prácticas de recursos humanos y retención de capital intelectual... 291

4.2.1.2. Prácticas de recursos humanos y capital social.............................. 294

4.2.1.3. Prácticas de recursos humanos y capital afectivo........................... 298

4.2.2. Capital humano y capacidad de innovación. Contraste de hipótesis y

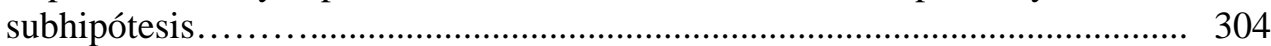

4.2.3. Impacto sobre los resultados de la empresa. Contraste de hipótesis.............. 305

4.3. Evaluación global del modelo propuesto.............................................................. 311

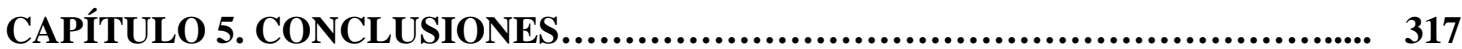

Introducción.................................................................... 317

5.1. Principales conclusiones de esta investigación........................................................ 319

5.1.1. Retención de capital humano y variables de resultado intermedio como mecanismos mediante los cuales las prácticas de recursos humanos contribuyen a mejorar el resultado empresarial.

5.1.1.1 Retención de capital humano de la organización y variables intermedias de resultado: capacidad de innovación y resultados de las personas

5.1.1.2. Variables intermedias de resultado organizativo y resultado empresarial

5.1.2. Efecto de las prácticas de recursos humanos propuestas sobre la retención del capital humano vinculado a los empleados estratégicos.

5.2. Contribuciones para la práctica empresarial.......................................................... 333

5.3. Limitaciones de la investigación........................................................................... 338

5.4. Futuras líneas de investigación............................................................................... 339

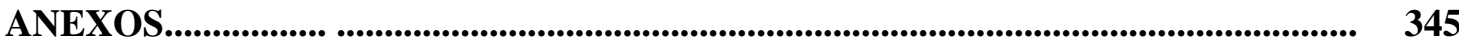

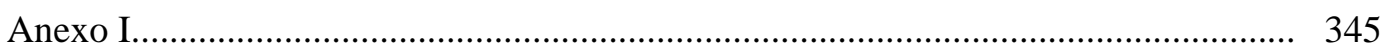

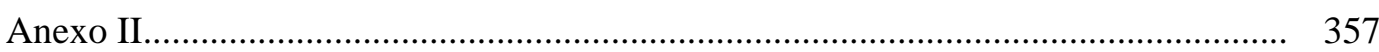

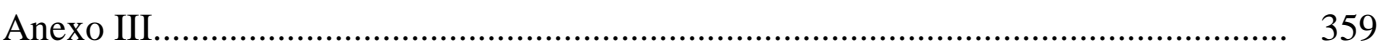

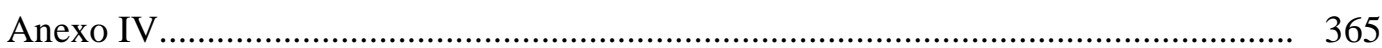

REFERENCIAS BIBLIOGRÁFICAS......................................................... 369 


\section{B. ÍNDICE DE CUADROS, FIGURAS, TABLAS Y ADJUNTOS DEL ANEXO} ÍNDICE DE CUADROS

Cuadro 3.1. Escalas de medición de las prácticas de recursos humanos de retención............................................................ 237

Cuadro 3.1bis. Escalas de medición de las prácticas de recursos humanos de retención..................................................... 238

Cuadro 3.2. Escalas de medición del capital humano -intelectual, social y afectivode los empleados estratégicos de la organización................................ 239

Cuadro 3.3. Escalas de medición de las variables de resultados organizativos........... 240

Cuadro 3.4. Ficha técnica de la investigación empírica............................ 242

Cuadro 3.5. $\quad$ Principales diferencias entre los modelos de ecuaciones estructurales basados en covarianzas y los basados en el enfoque de mínimos cuadrados parciales............................................. 248

Cuadro 3.6. Diferencias entre constructos reflectivos y formativos................ 252

Cuadro 3.7. Tipología de las variables de estudio............................ 256

Cuadro 4.1 Criterios para la validación de escalas de medida....................... 262

\section{ÍNDICE DE FIGURAS}

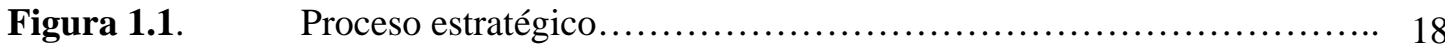

Figura 1.2. Clasificación de las capacidades............................... 22

Figura 1.3. Características de los activos estratégicos......................... 26

Figura 1.4. C Creación de ventaja competitiva a corto y largo plazo según el modelo conceptual de Barney (1991)............................................ 27

Figura 1.5. Definición de recurso humano................................ 37

Figura 1.6. Clasificación conceptual de capital intelectual...................... 46

Figura 1.7. Propuesta de Capital Humano de Gratton y Ghoshal.................. 48

Figura 1.8. Modelo de recursos humanos como fuente de ventaja competitiva sostenible......................................................... 57

Figura 1.9. Área de interés investigador de este trabajo......................... 58

Figura 1.10. Modelo Conceptual de Guest (1997) ............................. 71

Figura 1.11. Modelo de Paauwe y Richardson (1997)......................... 72

Figura 1.12. Modelo de Appellbaum, Bailey, Berg y Kalleberg (2000).............. 73

Figura 1.13 Modelo de Boselie et al. (2005)..................................... 73

Figura 1.14. Modelo de Boxal y Macky (2009).............................. 75

Figura 1.15. Clasificación de rotación de personal .............................. 98

Figura 1.16. Clasificación y ejemplos de rotación............................... 99

Figura 1.17. Dimensiones de análisis de la rotación voluntaria y de la retención..... 101

Figura 1.18. Estructura general de los modelos de retención basados en el soporte organizativo...................................................... 111

Figura 1.19. Esquema tradicional de estudios sobre rotación voluntaria/retención 114

Figura 1.20. Ámbito de estudio de este trabajo............................. 114

Figura 1.21. Taxonomía y propuesta de prácticas de recursos humanos orientas a las retención de empleados....................................... 139

Figura 2.1. $\quad$ Estructura del modelo de este trabajo basada en Boselie et al (2005) y Boxal y Macky (2009)....................................................................... 142 


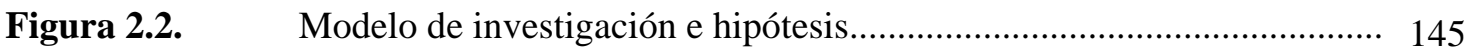

Figura 2.3. Conceptualización del capital humano.............................................. 147

Figura 2.4. Definición del capital afectivo............................................................. 153

Figura 2.5. Organización de las hipótesis y relaciones en este trabajo....................... 174

Figura 3.1. Sectores principales de actividad de la muestra.................... 243

Figura 3.2. Tamaño de las empresas por número de empleados................... 244

Figura 3.3. $\quad$ Edad media de las plantillas de empleados......................... 245

Figura 3.4. $\quad$ Antigüedad media de los empleados.............................. 245

Figura 3.5. Pertenencia a grupo corporativo y nacionalidad...................... 246

Figura 3.6. $\quad$ Escalas reflectivas versus Índices formativos........................ 252

Figura 4.1. Modelo con las principales hipótesis planteadas..................... 289

Figura 4.1bis. Modelo con subhipótesis objeto de contraste empírico estimado con Smart-PLS....................................................... 290

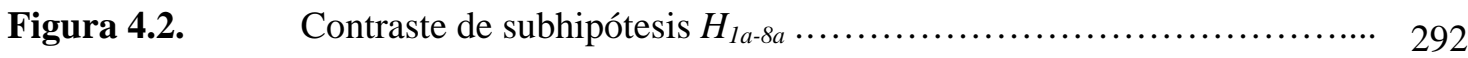

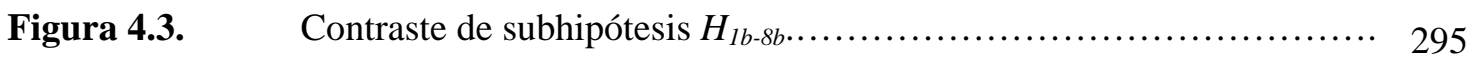

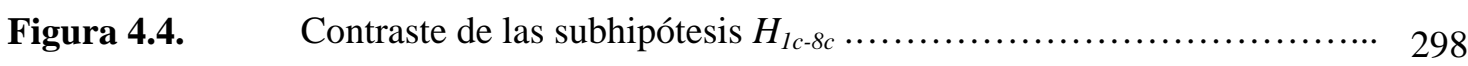

Figura 4.5. Contraste de las hipótesis H9a, H9b y H9c....................... 304

Figura 4.6. Contraste de las hipótesis H10, H11 y H12 ......................... 306

Figura 4.7. Contraste empírico del modelo con Smart-PLS: contraste de subhipótesis y evaluación del modelo.............................. 313

Figura 5.1. Secuencia causal analizada en este trabajo......................... 328

\section{ÍNDICE DE TABLAS}

Tabla i.

Tabla 1.1.

Tabla 1.2.

Tabla 1.3.

Tabla 1.4.

Tabla 1.5.

Tabla 1.6.

Tabla 1.7.

Tabla 1.8.

Tabla 1.9.

Tabla 1.10.

Tabla 2.1.

Tabla 2.2.

Tabla 2.3.

Tabla 2.4.

Tabla 2.5.
Estructura de esta investigación

Requisitos de los recursos para ser considerados estratégicos.

9

Principales medidas de resultado en estudios empíricos de dirección y gestión de recursos humanos.

Principales métodos de clasificación de los sistemas de prácticas de recursos humanos.

Principales definiciones de capacidad de innovación y de innovación... 81

Prácticas de recursos humanos vinculadas a la innovación.

Las ocho fuerzas del Modelo de Maerzt et al. (2001, 2004)

Definición de las dimensiones que forman el constructo inmersión en el trabajo.

Principales modelos de retención que incluyen prácticas de recursos humanos.

Ranking de las prácticas de recursos humanos más utilizadas en los modelos de retención/rotación voluntaria...

Resumen de las principales medidas de gestión de recursos humanos eficaces para la retención de empleados.

Prácticas de recursos humanos propuestas.

Hipótesis de las prácticas transaccionales y el capital humano.........

Hipótesis de las prácticas relacionales y el capital humano............... 228

Hipótesis del capital humano y variables intermedias de resultado........ 229

Hipótesis de las variables resultado y el resutaldo empresarial............. 229 
Tabla 4.1

Tabla 4.2.

Tabla 4.3.

Tabla 4.4.

Tabla 4.5.

Tabla 4.6.

Tabla 4.7.

Tabla 4.8.

Tabla 4.9.

Tabla 4.10.

Tabla 4.11.

Tabla 4.12.

Tabla 4.13.

Tabla 4.14.

Tabla 4.15-

Tabla 4.16.

Tabla 4.17.

Tabla 4.18.

Tabla 4.19.

Tabla 4.20

Tabla 4.21.

Tabla 4.22.

Tabla 4.23.

Tabla 4.24.

Tabla 4.25.

Tabla 4.26.

Tabla 4.27.

Tabla 4.27 bis

Tabla 4.28.
Pesos (weights) de los ítems de los índices formativos.

Correlaciones de los factores de la variable Diseño de puesto de trabajo. 266

FIV y Colinenalidad de los factores de la variable Diseño de puesto de trabajo. 267

Correlaciones de los factores de la variable Retribución. 268

Correlaciones de los factores depurados de la variable Retribución........ 269 FIV y Colinenalidad de los factores de la variable Retribución. 269 Correlaciones de los factores de la variable Desarrollo del empleado.... 271 Correlaciones de los factores depurados de la variable Desarrollo del empleado

FIV y Colinealidad de los factores depurados de la variable Desarrollo del empleado.

Correlaciones de los factores de la variable Conciliación.

Correlaciones de los factores depurados de la variable Conciliación.... 274

FIV y Colinealidad de los factores depurados de la variable Conciliación....................................................................................... 274

Resumen de la validación de índices formativos. Modelo de medida de los índices formativos depurados.

Cargas de los ítems de las prácticas de recursos humanos relacionales..

Análisis de la validez discriminante de los constructos reflectivos.

Correlaciones cruzadas (Crossloadings) de las escalas reflectivas.

Cargas de los ítems de las variables de capital humano estratégico....... 282

Cargas de los ítems de las variables de resultados.

Resumen de la validación de las escalas reflectivas.

Modelo de medida de los índices formativos depurados.

Modelo de Medida de las escalas reflectivas depuradas.

Contraste de las subhipótesis del efecto de las prácticas de recursos humanos sobre la retención del capital intelectual.....

Constraste de las subhipótesis del efecto de las prácticas de recursos humanos sobre el capital social.

Subhipótesis de influencia de las prácticas de recursos humanos sobre el capital afectivo.

Estimación de modelos alternado las variables comunicación interna y participación del empleado.

Resumen del contraste empírico de las hipótesis del modelo (Boostraping 2000 submuestras)......................................................... 308

Resumen de la validación de hipótesis y subhipótesis por dimensiones del capital humano.

Resumen de la validación de las hipótesis globales del modelo............. 310

Coeficientes de determinación y de relevancia predictiva de las variables dependientes.

\section{ÍNDICE DEL ANEXO}

ANEXO I

A.1.1. Noticias que manifiestan el interés por la retención en el mundo empresarial. 
Figura A1.1. Resultados de la encuesta......................................................... 346

Figura A1.2. Propuesta de las configuraciones de prácticas de recursos según Lepack y Snell....................................................................................... 347

Figura A1.3. Figura A1.3. Modelo de relación de empleo de Tsui y Wu (2005)......... 347

Figura A1.4. Esquema cronográfico de los principales modelos de rotación voluntaria y retención de empleados en la organización.......................... 348

Figura A1.5 Modelo de March y Simon (1958)...................................................... 349

Figura A1.6. Modelo Integrativo de Rotación voluntaria (Hom y Griffeth , 1995)..... 350

Figura A1.7. Modelo desplegado de rotación voluntaria de Lee y Mitchell (1994,

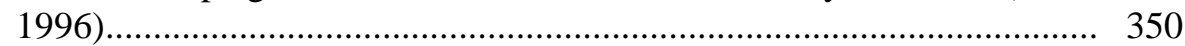

Figura A1.8. Modelo RETEN................................................................................... 353

Figura A1.9 Modelo organizativo de persistencia del empleado de Peterson (2004). 353

Figura A 1.10. Modelo básico de POS de Allen, Shore y Griffeth (2003)...................... 354

Figura A1.11. Modelo del sistema de retribución de Hom y Griffeth (1995)................ 354

Figura A1.12. Principales teorías psicológicas que contribuyen al estudio de la retención y de la rotación voluntaria....................................................... 355

ANEXO II

Figura A2.1: $\quad$ Modelo de las Características del Puesto (MCP) de Hackman y Oldham (1980).................................................................................... 357

ANEXO III

A3.1.

Carta de apoyo institucional a esta investigación..................................... 359

A3.2. $\quad$ E-mail de envío del cuestionario..................................................... 360

A3.3. Cuestionario de esta investigación.......................................................... 361

ANEXO IV

Tablas A4.1.- $\quad$ Tablas de análisis de multicolinealidad de los índices formativos depurados........................................................................................ 365 


\section{INTRODUCCIÓN}





\section{JUSTIFICACIÓN DE LA INVESTIGACIÓN}

En el presente trabajo se profundiza en el potencial de la gestión de recursos humanos para retener el capital humano estratégico de la organización como una vía para influir positivamente sobre la capacidad de innovación de la organización, contribuyendo, de este modo, a la mejora de sus resultados organizativos y de su competitividad.

Los diversos procesos por los que la gestión de recursos humanos influye en estos resultados siguen siendo un fenómeno desconocido, tal y como señalan algunas revisiones recientes del estado del arte en dirección estratégica de recursos humanos (Boselie, Dietz y Boon, 2005; Evans y Davis, 2005; Takeuchi, Chen y Lepack, 2009). De hecho, el debate sobre la “caja negra” que se encuentra entre las prácticas de recursos humanos y el rendimiento empresarial sigue acaparando, en gran medida, el interés de académicos y empresarios de todo el mundo. En este sentido, la investigación en dirección estratégica de recursos humanos sugiere la existencia de una serie de etapas o procesos intermedios que influyen sobre los comportamientos y actitudes de los empleados, condicionando los resultados de los empleados (tales como productividad, satisfacción laboral, rotación voluntaria, etc.) y, con ellos, los resultados de la organización (Guest, 1997; Paauwe y Richardson, 1997; Appelbaum, Bailcy, Berg y Kalleberg, 2000; Delery y Shaw, 2001; Boselie et al., 2005; Way y Johnson, 2005; Sun, Aryee y Law 2007; Boxal y Macky, 2009).

En esta cadena causal entre la gestión de recursos humanos y los resultados organizativos, las prácticas de recursos humanos juegan un papel protagonista debido a que permiten la adquisición, la retención y/o el desarrollo de los empleados con mayor potencial para contribuir al desempeño organizativo (Dolan, Valle, Jackson y Schuler, 2007). No obstante, aunque reconocemos la importancia estratégica de estas tres funciones -adquisición, retención y desarrollo-, su estudio conjunto es tan amplio que resulta difícilmente abarcable en una única investigación; por ello, en este trabajo hemos decidido centrarnos fundamentalmente en el ámbito de la retención de empleados. 
La importancia que tienen los recursos humanos para el éxito de las organizaciones es una cuestión ampliamente reconocida, tanto por las corrientes de estudio relacionadas con la gestión estratégica de recursos humanos (Wright et al., 1994; Beckert y Gerhart, 1996) como por las relacionadas con la visión de empresa basada en el conocimiento (Grant, 1996; Spender, 1996; Teece, 2000). Tal y como señalan Pérez-Cano y QuevedoCano (2006), los empleados son depositarios de la mayor parte de los conocimientos que maneja la organización, lo que les convierte en un recurso sumamente valioso que, además, posee dos cualidades claves desde el punto de vista de la teoría de los recursos y las capacidades: son difíciles de imitar y difíciles de sustituir (Barney y Wright, 1998; Barney, 1991, 1995; Lado y Wilson, 1994). Esta afirmación, si bien es cierta en todas las áreas de la organización y para todos sus trabajadores, lo es especialmente en el caso de aquellos empleados que manejan y poseen conocimientos y habilidades altamente valiosos. Este colectivo es denominado “empleados valiosos o estratégicos” y para muchos autores constituyen el verdadero capital humano estratégico a desarrollar y retener por la organización (Boxal, 1996; Lepack y Snell, 1999; López-Cabrales et al., 2007, 2008). Además, es precisamente este colectivo de empleados el que generalmente soporta el desarrollo de la capacidad de innovación en las organizaciones (Shipton et al., 2006). En consecuencia, desde el punto de vista de la dirección de recursos humanos, estos empleados estratégicos deben ser gestionados de un modo especial, a fin de favorecer su desempeño y asegurar el mantenimiento de su capital humano en la organización (Lepack y Snell, 2002; Morris et al., 2005; Pérez-Cano y Quevedo-Cano, 2006; Kang et al., 2007). En concreto, el mantenimiento de dicho capital humano en la organización implicará no sólo retener los conocimientos y habilidades de estos empleados sino, también, retener sus afectos, sus actitudes, sus relaciones y sus interacciones con otros compañeros; es decir, de este modo se asegura la permanencia en la organización del conjunto de atributos y dimensiones por las que las estos empleados aportan valor a la misma. Por ello, en esta tesis apostamos por una conceptualización ecléctica del capital humano, considerando que se compone de tres dimensiones: capital intelectual, capital social y capital afectivo, en línea con las propuestas de Gratton y Ghosal (2003) y Barney y Clark (2007). 
Holtom, Mitchel, Lee y Eberly (2008) afirman que la retención de los empleados estratégicos es, hoy en día, más importante de lo que ha sido nunca. Las tendencias del entorno (por ejemplo, la globalización, el aumento de trabajo intensivo en conocimiento, el avance acelerado de la tecnología) hacen indispensable que las organizaciones traten de adquirir y retener su capital humano. El análisis de los costes de reemplazamiento, así como la escasez de mano de obra especialmente cualificada, también ponen de relieve la importancia de retener a los empleados clave para el éxito organizacional. En respuesta a lo anterior, los gerentes de las organizaciones utilizan diversas prácticas de recursos humanos con el fin de reducir, en la medida de lo posible, la pérdida ${ }^{1}$ de dichos empleados (Fulmer, Gerhart, y Scott, 2003; Chew y Chan, 2008).

La retención de empleados o, dicho de otro modo, la rotación voluntaria como la otra cara de la misma moneda (Chawla, 2005), ha sido un tema de investigación recurrente en diferentes disciplinas como la organización de empresas y la psicología industrial, lo que ha dado lugar a una extensa y diversa gama de publicaciones sobre el tema en los últimos cincuenta años, desde el trabajo seminal de March y Simon (1958), como se extrae de algunos excelentes trabajo de revisión de este fenómeno (Hom y Griffeth 1995; Maertz y Campion, 1998; Shaw et al., 2005; Holtom et al., 2008; Hausknecht y Trevor, 2011). Tradicionalmente, se ha analizado esta cuestión desde la perspectiva del empleado (Maertz y Griffeth, 2004). Sin embargo, en los últimos diez años, el foco se ha desplazado hacia el nivel organizativo basado, especialmente, en los sistemas de gestión de recursos humanos (Shaw, Dineen, Fang y Vellella, 2009).

Las investigaciones más recientes sobre retención se centran en incluir nuevas dimensiones, incluso externas a la organización, como factores que favorecen la retención de empleados y sugieren que son múltiples las “fuerzas” que logran retener a los empleados más valiosos (Maerzt et al 2001, 2004; Mitchell, Holtom et al., 2001). Ello apunta a que no sólo las prácticas de recursos humanos habitualmente incluidas en la relación de empleo tradicional influyen sobre la retención, sino que, además, existen otras prácticas, vinculadas a la faceta relacional interna y externa del empleado, que adquieren importancia como factores favorecedores de la retención de empleados. En

\footnotetext{
${ }^{1}$ Esta marcha de la empresa se debe al deseo del empleado de abandonar de forma voluntaria dicho trabajo o empresa. También se denomina abandono voluntario o rotación voluntaria de empleados.
} 
línea con este argumento, sabemos que la relación de empleo tradicional ha evolucionado y actualmente incorpora nuevas concepciones (Tsui y Wu, 2005). Estas nuevas concepciones respaldan la idea de que la organización demanda un mayor abanico de comportamientos y un mayor compromiso a los empleados, ofreciéndoles incentivos diversos como contrapartida a sus contribuciones significativas. Para ello, la organización debe tratar de desarrollar relaciones estables, a largo plazo e indefinidas con los empleados, incluyendo no sólo aspectos transaccionales sino, también, relacionales. Así lo ponen de manifiesto diversos estudios que señalan la necesidad de diferenciar entre dos aspectos de la relación de empleo: un aspecto transaccional y un aspecto relacional (Coff, 1997; Alvesson, 2000; Lengnick-Hall y Lengnick-Hall, 2003; Hislop, 2005; Morris, Snell y Lepack, 2005; Kang, Morris y Snell, 2007; Tremblay et al., 2010).

Además, debemos señalar que la retención de empleados, especialmente de los empleados estratégicos, se relaciona con el éxito empresarial. De hecho, para muchas organizaciones los recursos humanos estratégicos juegan un papel muy relevante en su éxito y su supervivencia (Whitener, 2001; Chew, 2004). En concreto, hoy en día el éxito empresarial se encuentra muy vinculado a la capacidad de innovación y al desarrollo de innovaciones en la organización (Wan Ismail et al., 2010). Precisamente, es en el ámbito de la innovación donde los conocimientos, habilidades y competencias de los empleados son considerados recursos clave para el desarrollo de la innovación de los productos y servicios que ofrecen las organizaciones (López-Cabrales et al., 2009). De hecho, existe un amplio reconocimiento de la importancia del capital humano para la innovación (Jiménez-Sanz y Sabater-Sánchez, 2010). Por tanto, la gestión de recursos humanos, como función encargada de gestionar el capital humano de la organización, debe afrontar el reto de desarrollar e implementar las prácticas necesarias para influir positivamente sobre la capacidad de innovación (Laursen y Foss, 2003; Cabrera y Cabrera, 2005; Shipton et al., 2006). De hecho, debemos señalar que algunos estudios recientes manifiestan la necesidad de investigar la potencialidad de la gestión de recursos humanos para influir en el desarrollo de la innovación (Laursen y Foss, 2003; Lau y Ngo, 2004; Leede y Looise, 2005; Pérez-Cano y Quevedo-Cano, 2006; Saa-Pérez y Díaz-Díaz, 2007; Camelo et al., 2008, 2010; Chen y Huang, 2009; Jorgensen, Becker 
y Matthews, 2009; Jiménez-Jiménez y Sabater-Sánchez, 2010). En este sentido, Lane, Koka y Puthak (2006) señalan la existencia y la retención del conocimiento en la organización, como requisitos clave del desarrollo de la innovación; en consecuencia, la retención de ese capital humano estratégico poseedor de dicho conocimiento debe ser uno de los objetivos prioritarios de la función de recursos humanos de aquellas organizaciones que quieran fortalecer su capacidad de innovación.

Las consideraciones previas nos conducen a vincular la gestión de recursos humanos, la retención de empleados (reteniendo, por tanto, su capital humano) y la innovación en la organización como vía para impactar positivamente en los resultados organizativos. El capital humano es un factor extremadamente importante para el desarrollo de innovaciones que permitan a las organizaciones mantener su competitividad en entornos tan cambiantes como los actuales (Jorgensen et al., 2009). Ello se debe, en gran parte, a los conocimientos, habilidades, actitudes, relaciones, etc. vinculadas a los empleados estratégicos (Bontis, 1998; Alvesson, 2000) y, también, a los procesos que permiten explotar el conocimiento de este colectivo de empleados (Boxall y Purcel, 2003). En este contexto, la retención de empleados puede jugar un importante papel en beneficio de la innovación y, por ende, de la competitividad empresarial, permitiendo mantener en la organización el capital humano más valioso; valioso tanto por su dimensión intelectual como por sus dimensiones social y afectiva. De este modo, una organización puede potenciar su capacidad innovadora y, con ello, asegurarse un mejor desempeño y resultados organizativos. Sin lugar a dudas, lograr la retención de estos empleados en un marco en el que la naturaleza de la relación de empleo ha ido evolucionado (Tsui y Wu, 2005) y en el que los empleados valoran, cada vez más, nuevas facetas de su relación laboral, supone un reto para la gestión de recursos humanos

\section{TESIS Y OBJETIVOS DE INVESTIGACIÓN}

El propósito fundamental de esta investigación es examinar la contribución de la gestión de recursos humanos a los resultados organizativos, teniendo en cuenta el papel que puede jugar la retención del capital humano vinculado a los empleados valiosos de la organización. En concreto, nos planteamos analizar la forma en que determinadas 
prácticas de recursos humanos (transaccionales y relacionales) contribuyen a la retención del capital humano y cómo esto conduce a mejorar la capacidad de innovación y los resultados de la organización. Junto a este objetivo central de la investigación, emergen otros cinco objetivos relativos a las contribuciones que esperamos lograr con esta investigación.

En primer lugar, pretendemos clarificar los mecanismos por los que las prácticas de recursos humanos pueden contribuir a mejorar en los resultados organizativos, concretamente, los resultados de innovación. Existe una amplia evidencia de la relación entre la función de recursos humanos y el resultado organizativo, fundamentalmente, medido en términos financieros (Dyer y Reeves, 1995; Huselid, 1995; McDuffie, 1995; Bae y Lawler, 2000; Hutchinson et al., 2002, 2003). Sin embargo, el conocimiento sobre la contribución de la gestión de recursos humanos a la innovación en la organización resulta todavía escaso (Leede y Loise, 2005; JiménezJiménez y Sabater-Sánchez, 2010). Por tanto, un primer objetivo de este estudio es analizar la influencia de las prácticas de recursos humanos en la capacidad de desarrollo de innovaciones de la organización, así como en el resultado organizativo. Con este objetivo, además, pretendemos contribuir a la explicación de la "caja negra” de recursos humanos y, para ello, en este trabajo proponemos el papel mediador de la retención de recursos humanos en la relación causal entre la gestión de recursos humanos y los resultados organizativos.

El segundo objetivo responde al deseo de profundizar en el estudio de la retención de empleados, tratando de identificar qué tipo de prácticas de recursos humanos logran un mayor impacto en la retención de los empleados clave o estratégicos de la organización. Aunque la literatura sobre retención de empleados es muy extensa, todavía no se ha alcanzado un consenso generalizado sobre cuáles son los mecanismos clave al respecto. En este sentido, es necesaria nueva investigación en fórmulas y estrategias de retención, sobre todo, de aquellos empleados de alto valor para la organización (Griffeth y Hom, 2001). Con este fin, en este trabajo tendremos en cuenta las tendencias emergentes de los estudios de retención (Maerzt et al 2001, 2004; Mitchell, Holtom et al., 2001) y los cambios en la conceptualización de la relación de 
empleo (Tsui y Wu, 2005; Hom, Tsui et al., 2009). Sin embargo, no se prestará atención a la retención de empleados en general, sino que nos centraremos en el colectivo de empleados estratégicos de la organización.

En tercer lugar, y como acabamos de comentar, pretendemos contribuir al estudio de un grupo o categoría determinada de empleados, en particular, aquéllos considerados clave, valiosos, estratégicos para la organización. No todos los colectivos de empleados desarrollan las mismas percepciones, generan las mismas expectativas y aportan el mismo valor en la organización (López-Cabrales et al., 2007). Diversos investigadores del campo de la dirección estratégica de recursos humanos señalan la necesidad de adecuación de las prácticas de recursos humanos a determinados colectivos de empleados, como es el caso de los empleados estratégicos o especialmente valiosos para la organización. De ahí la necesidad de nueva investigación en este aspecto (Lepak y Snell, 1999; Wright y Boswell, 2002, Morris et al., 2005).

En cuarto lugar, buscamos profundizar en la relación entre las prácticas de recursos humanos y el capital humano de la organización. Por un lado, vinculando al recurso humano con el capital humano entendido de un modo global (incluyendo su dimensión intelectual, social y afectiva) y, por otro, acercando conceptos pertenecientes a diferentes disciplinas teóricas, como son la perspectiva estratégica de recursos humanos (Wright et al., 1994; Beckert y Gerhart, 1996) y la perspectiva de la empresa basada en el conocimiento (Grant, 1996). Hasta el momento, ambas disciplinas han sido estudiadas de forma separada y, recientemente, la literatura señala la necesidad de generar un acercamiento entre ambas (Carter y Scarbrough, 2001; Ordoñez de Pablos, 2003; Hislop, 2003; Oltra, 2005; Afiouni, 2007; Gloet et al., 2004, 2006; Pérez, Prieto y Martín, 2009; entre otros). Por tanto, como cuarto objetivo, pretendemos avanzar en la investigación conjunta de la perspectiva estratégica de los recursos humanos y de la perspectiva basada en el conocimiento.

En quinto y último lugar, este trabajo persigue no sólo contribuir con sus resultados al ámbito académico sino, también, identificar recomendaciones útiles para la práctica empresarial, en especial, para las organizaciones de naturaleza innovadora. Este colectivo de organizaciones constituye un sector clave para el desarrollo económico y 
competitivo de nuestro país. Es más, en estos momentos de crisis la apuesta por la I+D+i es considerada la principal vía para mejorar nuestra competitividad (Monzón de Cáceres, 2010). La Estrategia Europa 2020 establece el objetivo de que al menos el 3\% del PIB de la UE se invierta en I+D de cara a esa fecha, de tal forma que las ideas innovadoras puedan traducirse en productos y servicios que sirvan para crear empleos y estimular el crecimiento. La necesidad de innovación ha pasado de ser un objeto de debate a una máxima, especialmente en una economía como la europea, que se siente crecientemente vulnerable ante el peso de otras potencias.

Para poder alcanzar los citados objetivos de esta investigación, nos planteamos llevar el siguiente plan de trabajo que describimos a continuación.

\section{ESTRUCTURA DE LA INVESTIGACIÓN}

Esta investigación se estructura en dos secciones. La primera sección incluye los fundamentos teóricos y empíricos de este estudio y ofrece una revisión de la investigación previa y de los conceptos relevantes de este trabajo. Esto permite la posterior formulación del modelo objeto de investigación que plantea relaciones entre prácticas de recursos humanos, retención del capital humano, la capacidad de innovación y otros resultados organizativos. De estas relaciones emana la formulación de las correspondientes hipótesis. La segunda sección presenta la investigación empírica desarrollada, la metodología utilizada, el ámbito de estudio, los principales resultados obtenidos y su posterior discusión. Las dos secciones se dividen en cuatro capítulos: los dos primeros capítulos constituyen la sección conceptual y los dos siguientes capítulos constituyen la sección empírica (Tabla i). Finalmente, este trabajo se cierra con un quinto capítulo dedicado a la presentación y discusión de las principales conclusiones que se extraen del mismo. 
Tabla i. Estructura de esta investigación

\begin{tabular}{|c|l|l|}
\hline \multirow{2}{*}{$\begin{array}{c}\text { Sección I } \\
\text { (Desarrollo teórico) }\end{array}$} & Capítulo 1 & Fundamentos teóricos y empíricos: revisión \\
\cline { 2 - 3 } & Capítulo 2 & Modelo e hipótesis \\
\hline \multirow{2}{*}{$\begin{array}{c}\text { Sección II } \\
\text { (Desarrollo empírico) }\end{array}$} & Capítulo 3 & Metodología empírica de investigación \\
\cline { 2 - 3 } & Capítulo 4 & Resultados del trabajo empírico \\
\hline \multicolumn{2}{|c|}{ Capítulo 5 } & Conclusiones \\
\hline
\end{tabular}

\section{a) Sección I: Desarrollo teórico de la investigación}

El análisis de las relaciones entre la dirección y gestión de recursos humanos, la retención de capital humano y variables de resultado organizativo, nos conduce a tener en cuenta diversas disciplinas. Especialmente, se incluyen las aportaciones de dos campos de estudio como principales soportes conceptuales de este trabajo: el enfoque de recursos y capacidades -centrado en la dirección estratégica de recursos humanos- y la literatura relativa a la retención y rotación voluntaria de empleados.

Así, en el capítulo primero, analizamos la influencia de la gestión de recursos humanos sobre los resultados organizativos, haciendo especial hincapié en los resultados vinculados a la innovación. Con este fin, y en primer lugar, revisamos la literatura tanto del enfoque de recursos y capacidades como de la dirección estratégica de recursos humanos como principal base teórica de esta investigación. Esto nos permite, por un lado, poner de manifiesto la importancia de los recursos humanos y, en concreto, de los empleados estratégicos y de su capital humano y, por otro lado, indagar en las etapas que median en la influencia de la gestión de recursos humanos sobre los resultados de la organización, dirigiendo nuestro foco de atención a la retención de estos empleados. Así, en segundo lugar, revisamos la literatura relativa a la retención de empleados. Esto supone comenzar por la revisión de su concepto y de sus principales modelos de estudio. En concreto, nos centramos en la revisión de los principales trabajos que analizan las prácticas de recursos humanos como posible vía para favorecer la retención de su capital humano e identificamos las últimas tendencias en la investigación en retención. Como cierre de este primer capítulo, seleccionamos un conjunto de prácticas 
de recursos humanos, orientadas a la retención de empleados, que proponemos clasificar en transaccionales y relacionales.

En el capítulo segundo, presentamos el modelo propuesto, definimos las variables dependientes e independientes objeto de estudio y describimos las relaciones que emanan del mismo a través de la justificación de las correspondientes hipótesis. De este modo, examinamos cómo un conjunto de prácticas de recursos humanos -clasificadas en transaccionales y relacionales- influyen en la retención del capital humano estratégico, como vía para mejorar la capacidad de innovación y otros resultados organizativos de diversa naturaleza.

\section{b) Sección II: Desarrollo empírico de la investigación}

En el capítulo tercero describimos la investigación empírica realizada mediante la presentación de tres aspectos metodológicos. El primer aspecto alude a la muestra seleccionada y el proceso de recogida de datos. A través de la obtención de un directorio de empresas, del diseño del cuestionario que nos permitiera obtener información sobre nuestro objetivo investigador y de la elección del canal adecuado para su difusión (postal, mail, etc.) y su posterior recepción. El segundo aspecto incluido es la medida de las variables dependientes e independientes. La revisión de la literatura realizada permite identificar las dimensiones formantes de las variables del modelo propuesto en esta investigación. El tercer y último aspecto considerado es la justificación de la selección del método estadístico y del software más adecuado para contrastar las relaciones objeto de estudio. En el capítulo cuarto, procedemos a validar el modelo de medida de cada variable considerada en esta investigación y, posteriormente, llevamos a cabo la contrastación de las hipótesis planteadas en nuestro modelo, a partir de los datos obtenidos en una muestra de 239 empresas de base innovadora en el ámbito español.

Para cerrar este trabajo, en el capítulo quinto presentamos las principales conclusiones que podemos extraer de los resultados obtenidos, así como las principales limitaciones identificadas en esta investigación. También señalamos cuáles son las contribuciones más relevantes de la misma tanto en el ámbito académico como en el empresarial y, a modo de cierre, apuntamos las posibles líneas de extensión futura de esta investigación. 
Sección I

\section{DESARROLLO TEÓRICO}



Capítulo 1 FUNDAMENTOS TEÓRICOS Y EMPÍRICOS DE LA INVESTIGACIÓN 



\section{INTRODUCCIÓN}

El soporte teórico de este trabajo se asienta en la teoría de recursos y capacidades (Wernerfelt, 1984; Grant, 1991; Barney, 1991,1995; Barney y Wright, 1998), en concreto, nos centramos en uno de los enfoques derivados del enfoque de recursos y capacidades: el enfoque estratégico de recursos humanos (Cappelli y Singh, 1992; Pfeffer, 1994; Snell et al. 1994; Wright et al., 1994; Beckert y Gerhart, 1996) puesto que permite explicar la influencia de las prácticas y sistemas de gestión de recursos humanos sobre el resultado organizativo. Ambos enfoques teóricos justifican la importancia competitiva y estratégica de los recursos humanos permitiendo, por ende, destacar el interés que para la empresa puede tener su retención y el papel que las prácticas de recursos humanos pueden jugar para conseguir dicha retención, en especial, de empleados especialmente valiosos. De este modo, la empresa mantiene el capital humano vinculado y derivado de estos recursos valiosos. Capital que abarca no sólo sus conocimientos, habilidades y experiencias sino, también, sus relaciones con otros miembros de la organización y sus actitudes, a través de lo que se denomina capital intelectual, social y afectivo.

No obstante, aunque éstos sean los pilares teóricos de este trabajo, a lo largo de la presente investigación también haremos alusión implícita a constructos y aportaciones de otros enfoques, principalmente, derivados del enfoque de empresa basado en el conocimiento (Grant, 1991, 1996; Spender, 1996; Teece, 2000) y derivados de la teoría del comportamiento (March y Simon, 1958) que nos permitan explicar cómo las prácticas de recursos humanos tienen un efecto directo sobre el comportamiento y actitudes de los empleados que se traduce en mejoras de los resultados organizativos (Huselid, 1995; Guest, 1997; Takeuchi et al., 2003; Way y Johson, 2005; Tremblay et al., 2010). Estas teorías y sus correspondientes derivaciones son soportes conceptuales complementarios que permiten justificar y explicar los procesos por los que la gestión de recursos humanos, y los propios recursos humanos, influyen en la mejora de los resultados organizativos; ámbito en el que profundizamos en esta investigación. Así lo evidencia la literatura de dirección estratégica de recursos humanos, en la que se pueden identificar numerosos estudios basados tanto en el enfoque de recursos y capacidades 
(Wright y McMahan, 1992; Wright et al., 1994; Beckert y Gerhart, 1996; Kamoche, 1996; Valle Cabrera, 2003; Saa y García Falcón, 2004; Youndt y Snell, 2004) como en la teoría del comportamiento (Lawler, 1986; Huselid, 1995; Becker et al., 1997; Guest, 1997; Wayne, Shore y Linden, 1997; Appelbaum et al., 2000; Takeuchi et al., 2003, entre otros) y, también, en estudios que utilizan ambas perspectivas (Hernández Perlines y Peña García-Pardo, 2008)

\section{Estructura del capítulo}

La estructura de este capítulo de revisión teórica comienza, en su primer epígrafe, con una revisión de los postulados teóricos de la visión de la empresa basada en los recursos, desde la cuál se deriva una aproximación a la dirección estratégica de los recursos humanos que se aborda en segundo epígrafe. En este segundo epígrafe, profundizamos en la conceptualización de los dos pilares sobre los que se asienta el citado enfoque. En primer lugar: el recurso humano. Analizamos su contribución a la competitividad empresarial identificando las diversas dimensiones de capital humano vinculadas a los recursos humanos. Y, en segundo lugar: las prácticas y sistemas de prácticas de recursos humanos. Revisamos su influencia sobre los resultados de la organización, prestando especial atención a los relativos a la innovación.

A continuación, en el tercer epígrafe, revisamos la importancia de uno de los aspectos centrales de esta investigación: la retención del capital humano estratégico en las organizaciones. Realizamos un recorrido sintético sobre la evolución conceptual de la retención y revisamos la principal literatura que la aborda, desde una perspectiva de empresa basada en los recursos, centrándonos en la importancia de la retención de ciertos recursos estratégicos, en particular, de los empleados valiosos o clave. Además, profundizaremos en el papel que las prácticas de recursos humanos pueden jugar en la retención de este colectivo de empleados. Sobre la base de las anteriores consideraciones, en el epígrafe cuarto, proponemos una taxonomía de prácticas de recursos humanos que potencien la retención del capital humano estratégico de la organización. De este modo se podrán mejorar los resultados organizativos.

Así pues, en este primer capítulo presentamos las bases teóricas y empíricas que soportan la investigación que desarrollamos en este trabajo. 


\subsection{LA VISIÓN DE EMPRESA BASADA EN LOS RECURSOS: EL ENFOQUE DE RECURSOS Y CAPACIDADES}

Uno de los rasgos característicos del panorama empresarial actual es el aumento de la intensidad de la competencia en, prácticamente, todos los sectores de actividad. Como consecuencia del aumento de la competencia, existen pocos sectores donde todos los participantes tengan asegurada una rentabilidad a largo plazo; por tanto, poseer ventajas competitivas se revela como requisito fundamental para sobrevivir y alcanzar una rentabilidad superior a la de los competidores. Al hablar de ventaja competitiva, nos referimos al hecho de que ciertas características de la empresa pueden permitir diferenciarla de sus competidores y colocarla en una posición de superioridad con respecto a ellos.

En este sentido, el enfoque de recursos y capacidades (Wernefelt, 1984; Dierickx y Cool, 1989; Grant, 1991; Barney, 1986, 1995; Barney y Wright, 1998) parte del reconocimiento de la importancia que tiene para las empresas actuales el hecho de alcanzar y mantener una ventaja competitiva y, pone el acento, en el papel de los factores internos de la empresa como fuente principal para la creación y posterior mantenimiento de la ventaja sobre las demás ${ }^{1}$. Estos factores, derivados de la posesión y adecuada utilización de unos recursos determinados, que pueden variar mucho de unas empresas a otras, se consideran los más indicados para marcar diferencias y para asentar las bases de una ventaja competitiva.

No obstante, algunos de los factores internos de los que dispone la empresa, como tecnologías o activos que se pueden comprar en el mercado, no añaden a priori ninguna ventaja. Las diferencias entre empresas vendrán marcadas más por factores no observables, en su mayoría intangibles, como capacidades, habilidades de sus miembros o su cultura organizativa, etc. que por factores cuantitativos y tangibles.

\footnotetext{
${ }^{1}$ En principio, la aparición de una ventaja competitiva puede tener su origen en aspectos tanto externos como internos a la empresa. No obstante, respecto a los factores externos, la posibilidad de una utilización favorable por parte de todas las empresas de un sector es similar, ya que son factores ajenos a la propia empresa, aunque la habilidad de cada una para responder rápidamente a los cambios, sea la clave para la obtención de la ventaja.
} 
El enfoque de recursos y capacidades, al enfatizar la importancia de los aspectos internos como fuente de ventaja competitiva, resulta muy adecuado para destacar el papel de los recursos humanos y del conocimiento que en ellos reside sobre la competitividad empresarial. Por ello, será este enfoque y, en concreto, una de las corrientes conceptuales derivadas del mismo -la dirección estratégica de recursos humanos- la que aporte los pilares teóricos sobre los que se asienta este trabajo ${ }^{2}$. En los siguientes apartados revisamos las principales aportaciones y postulados de ambos enfoques.

\subsubsection{Enfoque de recursos y capacidades de la empresa}

Edith Penrose en 1959, adelantándose a los orígenes formales del enfoque de recursos y capacidades, señaló la importancia de los recursos de la empresa de cara a su posición competitiva. Esta autora concebía la empresa como "una colección de recursos productivos” (1959: 24).

Aunque Penrose y otros contemporáneos suyos destacaron la importancia de los recursos para la competitividad empresarial, tuvieron que pasar varias décadas para que esta idea se plasmara en una de las corrientes teóricas más relevantes en el campo de la Organización de Empresas, el denominado enfoque de recursos y capacidades o visión de la empresa basada en los recursos que arranca con el trabajo seminal de Wernerfelt $(1984)^{3}$ y las contribuciones básicas de otros autores como Prahalad y Hamel (1990), Barney (1991, 1995), Grant (1991) y Peteraf (1993), a quienes podemos considerar “padres conceptuales” de esta corriente. Tal como señalan De Saá y García (2000), el enfoque de recursos y capacidades se ha ido configurando a través de un conjunto de investigaciones teóricas y empíricas que tratan de dar respuesta a la relación existente entre los recursos de la empresa y la habilidad de la misma para obtener beneficios

\footnotetext{
${ }^{2}$ Ello no excluye que a lo largo de la investigación, también, se utilicen otras teorías, principalmente corrientes de corte psicológica derivadas de la teoría del comportamiento, como por ejemplo: los enfoques del intercambio social y del contrato psicológico que permiten explicar algunas de las relaciones objeto de estudio en este trabajo.

${ }^{3}$ En 1984 Wernerfelt publicó, en la revista Strategic Management Journal, el artículo titulado "A Resource-based View of the Firm", en el que apareció, por primera vez, el concepto de "visión de empresa basada en los recursos". No obstante, fue ignorado durante varios años, hasta que en la década de los noventa las aportaciones de otros autores consolidaron este enfoque. Prueba de ello, es que el referido trabajo es uno de los más citados en el ámbito de estudio de la dirección y organización de empresas.
} 
económicos de su uso, defendiendo la idea central de que el origen de la ventaja competitiva se encuentra en aquellos recursos valiosos que posean las empresas (Wernefelt, 1984; Grant, 1991; Barney, 1991,1995; Dierickx y Cool, 1989; Teece et al., 1994,1997; Barney y Wright, 1998, entre otros). Esto supone que, contrariamente a los modelos tradicionales de análisis estratégico (Porter, 1980,1985) que centran su atención en el vínculo existente entre el contexto externo y las decisiones estratégicas sobre el posicionamiento competitivo, el enfoque de recursos y capacidades asume que los recursos y atributos internos de una empresa son más importantes para mantener ventajas competitivas que las acciones de los competidores o la estructura de la industria en la que compita (Barney, 1997).

En la vertiente más práctica, los directivos de la empresa no empezaron a considerar el enfoque de recursos y capacidades como elemento estratégico hasta finales de los años noventa, inducidos por el artículo "The Core Competence” publicado en la Harvard Business Review por Prahalad y Hamel (1990). En este artículo, sus autores introducen la noción de propósito estratégico, haciendo hincapié en la necesidad de encontrar las competencias esenciales -basadas en recursos internos- de una empresa para adquirir ventajas competitivas sostenibles (Fernández Alarcón, 2004).

En consecuencia, Grant (1996) recomienda a las organizaciones que dediquen una atención preferente a identificar, desarrollar y proteger aquellos recursos y capacidades que aseguren el logro de una ventaja competitiva sostenible y, por tanto, lograr rentas superiores a las de sus competidores a largo plazo. Para ello, Grant (1996) propone tener en cuenta tres actividades: 1) la empresa debe identificar sus propios recursos y capacidades, 2) debe evaluarlos, es decir, determinar en qué medida son útiles y adecuados para conseguir una ventaja competitiva y poder mantenerla en el tiempo y, por último, 3) la empresa debe fundamentar su estrategia en la utilización de los recursos y capacidades más valiosos (Grant, 1996; Navas y Guerras, 1998; Lamoca y Ortega, 2000). Estas actividades deberían completarse con un proceso de retroalimentación (feedback) permitiendo, así, la adaptación y mejora del proceso. La Figura 1.1 esquematiza todo este proceso. 
Figura 1.1. Proceso estratégico

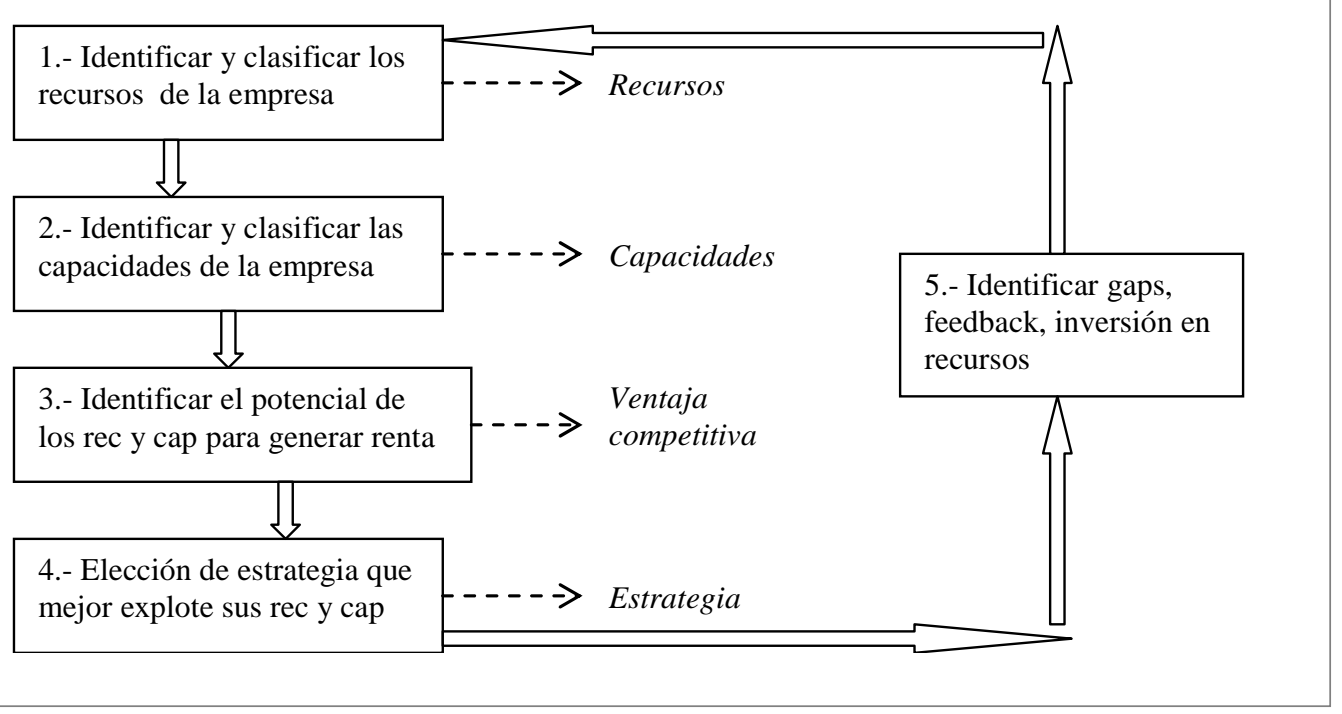

Fuente: Adaptado de Grant (1996)

\subsubsection{Conceptos básicos del enfoque de recursos y capacidades}

Para poder entender este enfoque necesitamos clarificar, previamente, los conceptos básicos que componen el mismo. Los dos conceptos centrales sobre los que se asienta este enfoque son los recursos y las capacidades. Algunos autores no distinguen entre recursos y capacidades y hablan únicamente de recursos, mientras que la gran mayoría sí distingue entre recurso y capacidad. Nosotros consideramos que son conceptos interrelacionados y representan dos niveles de agregación diferentes. Mientras que los recursos son la unidad básica de análisis, las capacidades se generan a partir de la adecuada combinación y gestión de un conjunto de recursos.

La literatura ofrece diversas definiciones del concepto de recurso. Inicialmente, Wernerfelt (1984) considera que son todos aquellos activos tangibles e intangibles vinculados a la empresa que permitan producir de forma eficiente una determinada oferta de productos que logre proporcionar valor en uno o varios segmentos del mercado. Posteriormente, desde un punto de vista organizativo y estratégico, Barney $(1991,2002)$ afirma que los recursos de una empresa incluyen todos los activos, procesos organizativos, atributos empresariales, información, conocimiento, etc., controlados por la empresa, que permitan a la misma concebir e implementar estrategias 
que mejoren su eficiencia y eficacia. En otras palabras, los recursos son el conjunto de factores o activos de los que dispone la empresa (Grant, 1992) y que elige y utiliza para implementar su estrategia (Barney, 2001; Marín, Segovia y Gázquez, 2006).

Existen multitud de criterios a la hora de clasificar los recursos (Marín et al., 2006). Así, Barney (1991) los agrupa dentro de tres categorías: recursos de capital físico, recursos de capital humano y recursos de capital organizacional. Grant (1991), por su parte, los clasifica en tangibles, intangibles y humanos; Hunt y Morgan (1995), a partir de los estudios previos (Barney, 1991; Day y Wensley, 1988; Hofer y Schendel,1978), amplían el número de categorías existentes y los tipifican en: financieros (reservas de caja, acceso al mercado financiero), físicos (planta productiva, equipamiento), legales (marcas registradas, licencias), humanos (habilidades y conocimientos de los empleados individuales), organizacionales (competencias, control, política, cultura), relacionales (relaciones con clientes y proveedores) y de información (conocimientos que resultan de la interacción con los clientes y proveedores). A pesar de las diferentes clasificaciones quizás la más aceptada, por su simpleza y claridad, sea la propuesta de Barney et al. (2001) distinguiendo entre recursos que son tangibles y los que son intangibles. Se consideran recursos tangibles aquellos que son más visibles como edificaciones, maquinaria o acceso a capital financiero, mientras que los recursos intangibles incluyen habilidades, información y conocimiento, rutinas organizativas, etc., los cuales no son observables directamente.

En un entorno tradicional los recursos tangibles han sido importantes fuentes competitivas pero, hoy en día, las empresas utilizan tanto recursos tangibles como intangibles para ejecutar sus estrategias. Debido a la naturaleza misma de los nuevos entornos de trabajo y competencia, los recursos intangibles han ganado en importancia a los tangibles, debido a que son más difíciles de imitar por los competidores y más escasos en el mercado. Dentro de estos recursos intangibles, el recurso humano es uno de los más importantes y críticos para el desarrollo de ventajas competitivas sostenibles de las empresas (DeNisi et al., 2003), como veremos en epígrafes posteriores.

Sin embargo, los recursos aisladamente considerados no permiten, sin más, desarrollar determinadas actividades. La actividad productiva de una empresa requiere de la 
cooperación y coordinación de conjuntos de recursos, lo que nos conduce a definir el concepto de capacidad. Según Amit y Schoemaker (1993) los recursos no son productivos por sí mismos, sino que necesitan de las capacidades para emprender una actividad concreta. Esta diferenciación permite otorgar a los recursos un carácter estático y a las capacidades un carácter más dinámico. Dierickx y Cool (1989) y Amit y Schoemaker (1993), entre otros, afirman que los recursos comprenden el aspecto estático, incluyendo el stock de factores productivos que la empresa posee o controla, mientras que las capacidades se consideran flujos, es decir, representan el aspecto dinámico, definiendo la forma en que la empresa emplea sus recursos para obtener outputs (Amit y Schoemaker, 1993). Dicho de otro modo, la diferencia entre recursos y capacidades estriba en que los primeros hacen alusión a lo que la empresa tiene y, las segundas, a lo que la empresa hace.

El profesor Cuervo (1993) ofrece una definición de capacidad más completa que la anterior, considerando a las capacidades como el conjunto de conocimientos y habilidades que surgen del aprendizaje colectivo de la organización, como consecuencia de la combinación de recursos y que se desarrollan mediante intercambios de información entre el capital humano de la empresa (Cruz Ros, 2001). Por su parte, Collins (1994) define las capacidades como el conjunto de rutinas que determinan la eficiencia con la que una empresa transforma físicamente inputs en outputs. Esta definición refleja dos importantes cuestiones señaladas, posteriormente, por Monreal Pérez (2009): primero, la noción de que las capacidades se manifiestan en las rutinas de la empresa, señalando que son producto de la organización en su conjunto y, por tanto, residen en la cultura organizativa y en las redes de relaciones de los empleados (Barney, 1986; Teece et al., 1982); y, segundo, su contribución a la transformación de inputs en outputs; en otras palabras, a través de las capacidades se logran transformar los inputs de la empresa en outputs o productos finales, de este modo, las capacidades permiten explicar el proceso por el que esto ocurre.

Por tanto y, a modo de resumen, consideramos que los recursos son factores que se poseen y se controlan de forma independiente, mientras que las capacidades surgen de la utilización conjunta y dinámica de dichos recursos (Cruz Ros, 2001). En 
consecuencia, una capacidad es la habilidad de una empresa para acometer una actividad concreta mediante el uso de un conjunto de recursos (De Saá y García, 2000). Como hemos comentado, las capacidades tienen un carácter colectivo, mientras que los recursos tienen un carácter individual. Bajo esta consideración, surge otro concepto básico del enfoque de recursos y capacidades: la rutina organizativa. Al igual que ocurre con las habilidades de cada persona, las capacidades sólo existen en la medida en que las personas colaboran entre sí para resolver un problema o realizar una actividad. Esta gestión colectiva de los recursos exige de patrones de coordinación complejos, que se han denominado rutinas organizativas (Nelson y Winter, 1982). Para que la empresa pueda realizar una actividad determinada no necesita, únicamente, de su base de recursos sino, también, de la propia habilidad para combinarlos, integrarlos y movilizarlos a través de diversas rutinas organizativas (Grant, 1991).

Además del concepto de capacidad, conviene diferenciar diversas formas para clasificarlas. Las capacidades, al igual que las rutinas sobre las que se fundamentan, están organizadas en estructuras jerárquicas (Collis, 1991; Teece et al., 1994; Grant, 1995). Algunas capacidades, muy específicas y relacionadas con tareas concretas, son las de nivel básico; otras, las de mayor nivel, suponen la integración de esas capacidades específicas. Siguiendo a Fernández y Suárez (1996), las capacidades podrían jerarquizarse en tres niveles: en el primer nivel estarían las capacidades estáticas asociadas a las actividades funcionales de la empresa; en el segundo nivel estarían las capacidades dinámicas (Teece et al., 1994); y, por último, en el tercer nivel, estarían las capacidades de aprender a aprender y aprender a coordinar y explotar lo que se posee (recursos) y lo que se sabe hacer (capacidades) mejor y más rápido que la competencia, que son las denominadas “metacapacidades” (Collis, 1994). De Saá y García (2000) señalan que a través de esta clasificación jerárquica de las capacidades se reconoce la importancia del conocimiento como factor que permite a las capacidades de orden superior integrar a las de orden inferior.

En línea con lo anterior, desde el punto de vista estratégico, la empresa debe ser capaz de desarrollar, dentro de su abanico de capacidades, aquellas capacidades distintivas que integran sus capacidades esenciales, aquellas formadas por el conjunto de habilidades y 
rutinas que más contribuyan a su éxito competitivo (Teece et al., 1997; Prahalad y Hamel, 1990).

No es posible enumerar todas las posibles capacidades que puede poseer una organización, ya que cada negocio desarrolla e implementa su propia estructura de capacidades, condicionada por su entorno competitivo y por sus compromisos pasados y futuros, sin embargo, Day (1994) realiza la siguiente clasificación en función de su orientación y del ámbito en el que se desenvuelven: capacidades orientadas al interior, capacidades orientadas al exterior y capacidades extensivas, como se resume en la Figura 1.2. Las capacidades orientadas al exterior son aquellas motivadas por los requerimientos del mercado, los retos competitivos y las oportunidades ofrecidas por el exterior. Las capacidades orientadas al interior tratan de conectar los procesos internos que definen el resto de las capacidades de la organización con el contexto externo, posibilitando a la empresa competir de forma más efectiva, anticipándose a los requerimientos del mercado $\mathrm{y}$, estableciendo, relaciones duraderas y estables con los clientes, proveedores y otros grupos de interés. Finalmente, las capacidades extensivas son necesarias para integrar las dos anteriores.

Figura 1.2. Clasificación de las capacidades

\begin{tabular}{|c|c|c|}
\hline $\begin{array}{c}\text { ÉNFASIS } \\
\text { EXTERNO }\end{array}$ & & $\begin{array}{l}\text { ÉNFASIS } \\
\text { INTERNO }\end{array}$ \\
\hline $\begin{array}{l}\text { Capacidades orientadas } \\
\text { al exterior }\end{array}$ & & $\begin{array}{l}\text { Capacidades orientadas } \\
\text { al interior }\end{array}$ \\
\hline & Capacidades extensivas & \\
\hline $\begin{array}{l}\text { Orientación al mercado } \\
\text { Conexión con el cliente } \\
\text { Vínculos con canales de } \\
\text { distribución } \\
\text { Etc. }\end{array}$ & $\begin{array}{l}\text { Cumplimiento de órdenes } \\
\text { de clientes } \\
\text { Precios } \\
\text { Compras } \\
\text { Desarrollo de estrategia } \\
\text { Etc. }\end{array}$ & $\begin{array}{l}\text { Desarrollo tecnológico } \\
\text { Gestión financiera } \\
\text { Control de costes } \\
\text { Logística integrada } \\
\text { Gestión de recursos humanos } \\
\text { Etc. }\end{array}$ \\
\hline
\end{tabular}

Fuente: Adaptado de Day (1994) cit. en Marín et al (2006:7) 
Siguiendo esta clasificación, y al objeto del interés investigador de este trabajo, dos son las capacidades en las se centra esta investigación. Por un lado, la capacidad de innovación, considerada una capacidad extensiva básica en las organizaciones que quieran ser competitivas. Parece existir consenso, tanto en esferas académicas como de negocios, en que uno de los mayores recursos de una empresa es su conocimiento tecnológico y, con ello, una capacidad fundamental es la de generar innovaciones (Galende, 2006). El factor tecnológico junto con la capacidad de innovar puede ser unas de las principales fuentes críticas de ventaja competitiva (Galende y Suárez, 1999; Martínez et al., 2001). Por otro lado, la capacidad de gestión de los recursos humanos, como capacidad orientada al interior, es aquélla encaminada a gestionar a las personas como poseedoras de conocimientos, habilidades y actitudes que participan de las actividades de la empresa y condicionan su competitividad (Park, Gardner y Wright, 2004), pudiendo llegar a ser una fuente de ventaja competitiva para la empresa.

\subsubsection{Postulados básicos del enfoque de recursos y capacidades}

Una vez señalados los conceptos centrales de este enfoque, también es necesario señalar los principales postulados y axiomas sobre los que se apoya (Barney, 1991; Fernández Alarcón, 2004; Evans et al., 2007). El primer axioma hace referencia a la heterogeneidad de recursos. Las empresas son heterogéneas respecto a los recursos estratégicos que controlan (Wernerfelt, 1984; Prahalad y Hamel, 1990; Barney, 1991). Los recursos no están distribuidos del mismo modo entre las empresas. Por ello, se considera que las organizaciones son diferentes entre sí, en función de los recursos y capacidades que poseen en un momento determinado, así como, por las diferentes características de las mismas. En otras palabras, el enfoque de recursos y capacidades considera que cada organización es un conjunto amplio y diferente de activos y capacidades tanto físicos como intangibles, no existiendo, por tanto, dos compañías idénticas, pues no es posible que a lo largo de su historia dos organizaciones hayan acumulado las mismas experiencias, adquirido los mismos recursos y habilidades y desarrollado la misma cultura organizativa (Marín et al., 2006).

El segundo axioma hace alusión a la inmovilidad de los recursos. Los recursos tienen problemas para transferirse de unas empresas a otras, en gran medida, porque sus 
mercados, o son muy imperfectos, o no existen (Dierickx y Cool, 1989; Rumelt, 1991; Peteraf, 1993). Los recursos no pueden ser transferidos desde una empresa a otra sin coste alguno y, por ende, los recursos no están disponibles para todas las empresas en las mismas condiciones. Esta característica es la que asegura la permanencia de la heterogeneidad en el tiempo y la que propicia la obtención de rentas únicas y extraordinarias para aquellas empresas que los poseen.

\subsubsection{Recursos y capacidades estratégicos y su relación con la ventaja competitiva de la organización}

Los postulados de la visión de empresa basada en los recursos indican que la mera posesión de éstos no es suficiente para disfrutar de una ventaja competitiva, ya que la posesión de activos que son similares a los que tienen las otras empresas competidoras o que éstas pueden adquirir fácilmente en el mercado no sitúan a la empresa en una posición privilegiada para competir (Barney, 2001). Sólo determinados recursos y capacidades permiten a la organización obtener ventajas competitivas, son los denominados recursos estratégicos o distintivos.

Pero, ¿qué características deben reunir los recursos y capacidades para que puedan ser considerados estratégicos? Cruz Ross (2001) identifica diversas clasificaciones de las características fundamentales que deben reunir los recursos para ser considerados estratégicos (Véase Tabla 1.1).

Tabla 1.1. Requisitos de los recursos para ser considerados estratégicos

\begin{tabular}{|l|l|l|l|}
\hline \multicolumn{1}{|c|}{$\begin{array}{c}\text { Barney } \\
\text { (1986a, 1991) }\end{array}$} & \multicolumn{1}{|c|}{ Grant (1991) } & \multicolumn{1}{c|}{ Peteraf (1993) } & \multicolumn{1}{c|}{$\begin{array}{c}\text { Amit y Schoemaker } \\
\text { (1993) }\end{array}$} \\
\hline Valiosos y escasos & Durabilidad & Heterogeneidad & Durables y escasos \\
\hline $\begin{array}{l}\text { No imitables: } \\
\text { dependencia histórica, } \\
\text { ambigüedad causal, } \\
\text { complejidad social. } \\
\text { No sustituibles }\end{array}$ & $\begin{array}{l}\text { Transparencia imperfecta } \\
\text { Replicabilidad Imperfecta }\end{array}$ & $\begin{array}{l}\text { Límites ex - post a la } \\
\text { competencia: } \\
\text { No imitables } \\
\text { No sustituibles }\end{array}$ & No imitables \\
\hline & $\begin{array}{l}\text { Apropiabilidad } \\
\text { Transferibilidad imperfecta: } \\
\text { geográfica, información, } \\
\text { recursos específicos e } \\
\text { inmovilización de capacidades }\end{array}$ & $\begin{array}{l}\text { Límites ex -ante a la } \\
\text { competencia. } \\
\text { Movilidad imperfecta }\end{array}$ & $\begin{array}{l}\text { No comercializables } \\
\text { Complementarios } \\
\text { (específicos) } \\
\text { Apropiabilidad }\end{array}$ \\
\hline
\end{tabular}

Fuente: adaptado de Camisón (1999b) en Cruz Ros (2001:26) 
Teniendo en cuenta estas premisas y tras analizar la importancia de los recursos para el sostenimiento de la ventaja competitiva, Barney (1991) señala que las características que hacen a un recurso estratégico y, por tanto, apto para crear ventajas competitivas sostenibles en el tiempo son: ser valioso, poco común, no imitable y no sustituible. Características, también, señaladas por autores contemporáneos, como Grant (1991) y Peteraf (1993).

En primer lugar, los recursos y capacidades deben ser valiosos, lo que significa que deben contribuir a crear valor para el cliente. En segundo lugar, deben ser poco comunes, escasos. Esto significa que no estén a disposición de todos los competidores. Si un recurso o capacidad es importante o imprescindible para desarrollar una actividad empresarial, pero es accesible a todas las empresas del sector, se convierte en una condición necesaria para competir pero no en un elemento diferencial que otorgue ventaja competitiva. En tercer lugar, deben ser difícilmente imitables. Esto significa que debe ser complicado para los competidores poder replicarlos. Si un determinado recurso o capacidad poseída por una empresa exitosa, no está al alcance de las empresas competidoras en el mercado, éstas pueden tratar de desarrollarlo con sus propios medios. En este sentido, algunos recursos o capacidades son fácilmente imitables, por lo que otras empresas pueden reproducirlos y anular la ventaja obtenida inicialmente. Pero otros, ya sea debido a las barreras legales, a la complejidad social, a la ambigüedad causal o al tiempo, son difícilmente imitables ${ }^{4}$. Y, en cuarto lugar, deben ser no sustituibles. Esto significa que los recursos y capacidades de una empresa no tengan alternativas que los sustituyan. Cuanto más difícilmente sustituibles sean, mayor valor tienen para la empresa que los posee.

\footnotetext{
${ }^{4}$ A veces existen barreras legales a la imitación, como es el caso de los productos o procesos patentados, con lo que dicha imitación es más difícil. La mejor protección de una empresa frente a la imitación es que las empresas competidoras tengan dificultades para llegar a conocer y entender la base sobre la que se asienta su ventaja. Por un lado, pueden ser socialmente complejas, es decir, estar formadas por un entramado de relaciones que sea muy difícil de imitar. Y, por otro lado, pueden gozar de ambigüedad causal. Este término hace referencia a esta cuestión y se puede definir como la incertidumbre acerca de las causas que explican el éxito de una empresa. Aún cuando no exista ambigüedad causal y la imitación de los recursos y capacidades sea posible, el tiempo juega a favor de la empresa que ya los posee. Efectivamente, muchas capacidades complejas requieren para su desarrollo de largos períodos de tiempo en los que se van acumulando activos, experiencia o conocimientos. Cuando la empresa imitadora trata de reproducir una capacidad valiosa, la empresa imitada ha tenido tiempo de seguir acumulando recursos y mantener, de este modo, consiguiendo así una diferencia a su favor.
} 
Además de estos requisitos, Dierickx y Cool (1989) y Teece et al. (1994) asientan las bases para incluir un quinto requisito: los recursos deben permitir a la empresa apropiarse de las rentas generadas por ellos. De nada le sirve a una empresa disponer de recursos y capacidades valiosos si no puede apropiarse de las rentas que generan. Dicho de otra forma, las condiciones que deben cumplir los recursos son generar rentas, permitir la sostenibilidad de dichas rentas en el tiempo y permitir que la empresa se apropie de ellas (Martínez, Charterina y Araujo, 2010). En principio, las rentas generadas deben corresponder al propietario de los recursos. Pero el tema de la propiedad no siempre está claro. En los recursos tangibles -activos físicos y financierosesos derechos de propiedad suelen estar bien definidos o puede darse el caso de que se establezcan derechos de propiedad en ciertos activos intangibles a través de patentes, registro de marcas, etc. No obstante, en el caso particular de las personas -recursos humanos- el problema de la apropiación de las rentas es mucho más complejo. La base de las capacidades de una empresa es la capacitación de sus trabajadores, pero dicha capacitación es propiedad de sus empleados y no suya, por ello, un asunto de importancia estratégica para la empresa será la manera por la cuál pueda asegurarse la apropiación de una proporción adecuada de los beneficios que generan las personas.

En resumen, el enfoque de recursos y capacidades señala el valor, la escasez, la imitabilidad imperfecta, la no sustituibilidad y la apropiación de rentas, como las cinco características necesarias en un recurso o capacidad para desarrollar ventaja competitiva sostenible en el tiempo. La Figura 1.3 resume dichas características.

Figura 1.3. Características de los activos estratégicos

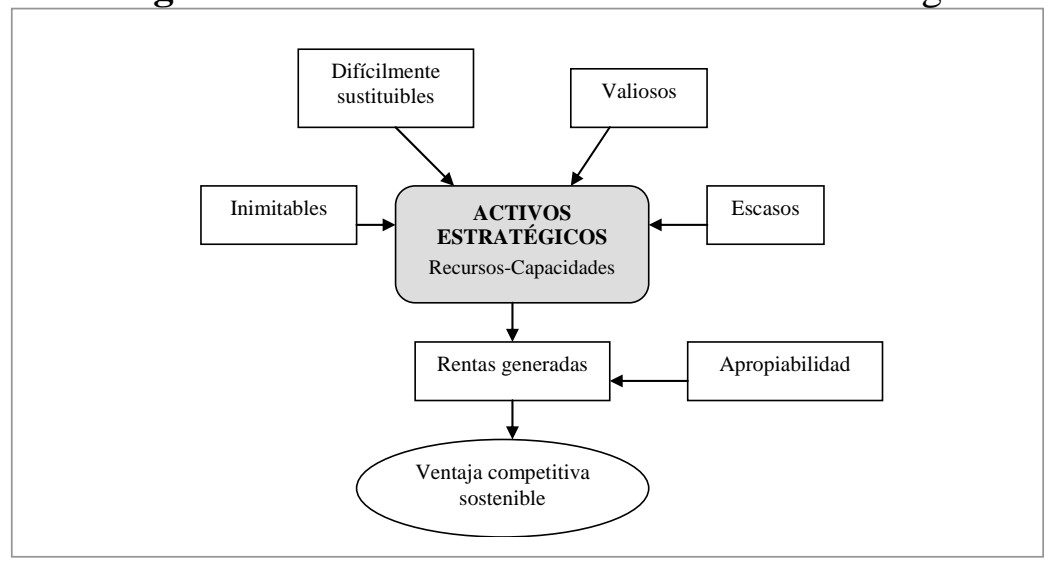

Fuente: Cruz Ros (2001:27) 
Hay que tener en cuenta que, aunque el enfoque de recursos y capacidades señala estas cinco características como las necesarias para lograr la sostenibilidad, tanto de la ventaja competitiva como del nivel de resultado, no siempre es fácil cumplir todos requisitos y, a menudo, los recursos y capacidades de las empresas sólo cumplen algunos. En este sentido, Snell y Lepack (1999) y Newbert (2007) identifican que son los dos primeros (valor y escasez) los más importantes, puesto que permiten a la empresa generar ventajas competitivas y buenos resultados, aunque no puedan asegurar su mantenimiento en el largo plazo (Barney, 1991), debido a que rápidamente pueden ser imitados o adquiridos por los competidores. De este modo, dependiendo de los requisitos cumplidos, podremos distinguir entre recursos que logran efectos más a corto plazo y aquéllos que logran efectos sostenibles en el largo plazo (Newbert, 2007), como se resume en la Figura 1.4.

Figura 1.4. Creación de ventaja competitiva a corto y largo plazo según el modelo conceptual de Barney (1991)

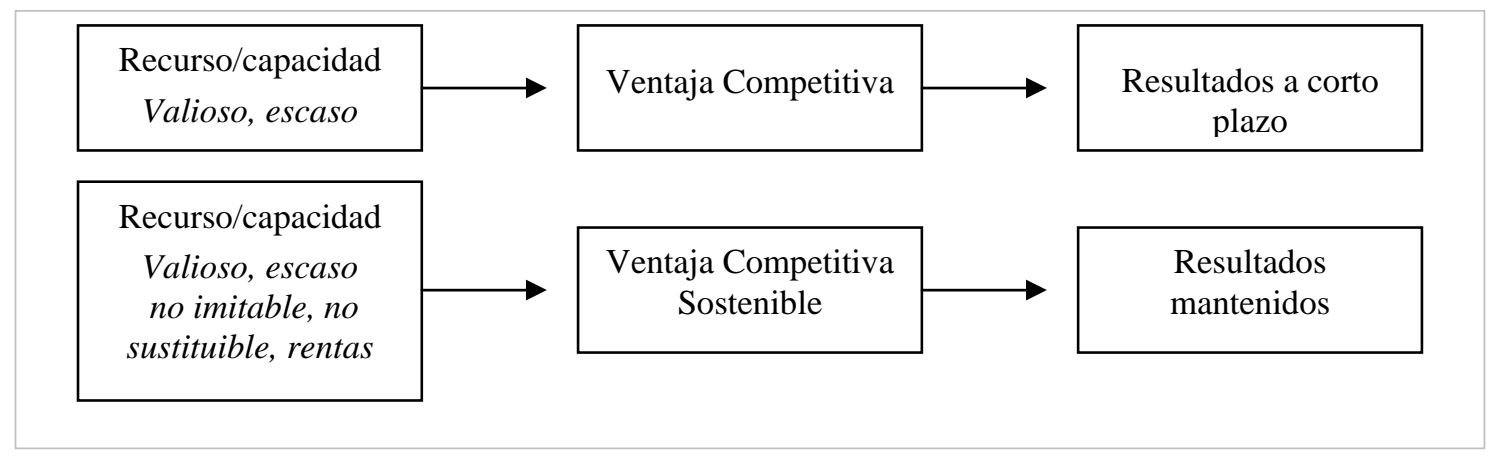

Fuente: Adaptado de Newbert (2007:123)

\subsubsection{Principales limitaciones $y$ aportaciones del enfoque de recursos $y$ capacidades}

Como cualquier teoría o enfoque, el enfoque de recursos y capacidades presenta ciertas limitaciones y aspectos criticables ${ }^{5}$ que algunos autores han recogido expresamente (López y Sabater, 2000; Priem y Butler, 2001; Barney, 2001; Gent y Andalaft, 2007).

\footnotetext{
${ }^{5}$ Entre los autores más críticos sobre la visión y teoría basada en recursos destacan Priem y Butler (2001). En el citado trabajo critican la visión dada por Barney (1991) en cuatro puntos: tautología, equitatividad, rol subdesarrollado de los mercados productivos y pocas implicaciones prescriptivas. Ante esta crítica, Barney (2001) respondió con un segundo artículo, refutando cada una de las críticas realizadas a su trabajo del 1991 (Fernández Alarcón, 2004).
} 
Haciendo una revisión de los últimos veinte años del desarrollo del enfoque de recursos y capacidades, Kraaijenbrink, Spender y Groen (2010) ${ }^{6}$ identifican ocho categorías en las que aglutinar la mayoría de las críticas recibidas por este enfoque: a) no ofrece implicaciones claras para la dirección; b) implica un gran retroceso; c) la aplicabilidad de este enfoque es limitada; d) la ventaja competitiva sostenible no es algo alcanzable; e) no puede ser considerada como una teoría de empresa; f) cumplir con todos los requisitos estratégicos no es necesario ni suficiente para alcanzar ventaja competitiva sostenible; g) el valor de un recurso es algo demasiado indeterminado para hacer posible una teoría fructífera y útil, y h) la definición de recurso es poco concreta y manejable. Estos autores destacan que son, precisamente, las últimas tres críticas las que suponen retos serios que deben afrontarse desde este enfoque si se quiere desarrollar su potencial para explicar la sostenibilidad de ventajas competitivas, especialmente en la actualidad, puesto que los entornos presentes y futuros ya no son ni estables ni predecibles.

Además de las anteriores, otra de las críticas a este enfoque es su excesivo foco hacia el interior de la empresa, descuidando el análisis externo (Priem y Butler, 2001) y, también, su carácter estático más que dinámico. No obstante, lo cierto es que poco a poco se ha incorporado una faceta más dinámica, lo que ha conducido a desarrollar el enfoque de capacidades dinámicas como una extensión del enfoque de recursos y capacidades (Teece et al., 1994). Así, hoy en día, existen numerosos análisis dinámicos basados en este enfoque (p.e. Barnet, Greve y Park, 1994); Levinthal y Myatt, 1994; Foss, Knudsen y Montgomery, 1995; Teece, Pisano y Shuen, 1997, citados en Fernández Alarcón, 2004). Por otro lado, otra de las limitaciones identificadas alude al concepto de empresa, puesto que es considerada un ente racional que toma decisiones y que compite en condiciones de equilibrio y, ello, no se corresponde exactamente con la realidad. También, se considera una limitación la considerable cantidad de términos empleados para expresar los mismos conceptos, tales como: “recursos”, “competencias”, “capacidades”, “activos”, etc., no quedando claro el límite entre ellos. A menudo, estos términos aluden a una misma realidad. En la actualidad, de forma gradual, se está alcanzando cierto estándar en la terminología empleada, permitiendo un

\footnotetext{
${ }^{6}$ Para profundizar en este tema, recomendamos la lectura del trabajo de Kraaijenbrink, Spender y Groen (2010).
} 
mayor entendimiento a nivel práctico (López y Sabater, 2000; Cruz Ross, 2001; Gent y Andalaft, 2007).

Por último, otra de las limitaciones o críticas es el excesivo énfasis puesto en los recursos valiosos en detrimento de los restantes, hasta el extremo que se podrían clasificar en dos grandes grupos: los valiosos y los demás. Esto hace que tengamos mucho conocimiento sobre los primeros y muy poco sobre los segundos. Debería existir un equilibrio entre ellos, puesto que unos son necesarios para la obtención de ventajas competitivas y, otros, para permanecer en el sector (López y Sabater, 2000; Gent y Andalaft, 2007). La identificación y valoración de los recursos constituye uno de los principales temas a superar por esta teoría. Sin embargo, esta tarea es muy complicada debido a que los recursos no se pueden evaluar de forma aislada, puesto que su valor viene dado por su interacción con otros recursos y con el mercado, dificultando enormemente poder conocer de forma empírica cuáles son los recursos que más aportan al resultado de la organización (Collis y Montgomery, 1995; Sepanenn, 2008).

Sin embargo, se debe señalar que muchas de estas limitaciones, presentes en los estadios de desarrollo iniciales de esta teoría, han ido desapareciendo en los planteamientos más recientes, que han mejorado determinados aspectos (Gent y Andalaft, 2007; López y Sabater, 2000). A pesar de las citadas limitaciones, que asumimos, el enfoque de recursos y capacidades, también, presenta ventajas significativas que lo convierten en uno los enfoques más utilizados en el ámbito de la organización de empresas y, en concreto, en la investigación en dirección de recursos humanos. En primer lugar, este enfoque, en un intento por responder a la cuestión estratégica fundamental de por qué algunas empresas son más eficaces que otras y qué base lo sostiene, fija su foco de atención en los recursos internos de la empresa, (Evans, Novicevic y Davis, 2007). De acuerdo con este enfoque, la explicación del éxito de unas empresas y fracaso de otras, se puede encontrar en sus recursos y capacidades internas. La ventaja de este enfoque es que permite identificar factores sobre los que las empresas sí pueden actuar, diseñar y ejecutar, en pro de su interés (identificando, evaluando los recursos y capacidades y diseñando estrategias en base a ellos), contrariamente a lo que ocurre con los factores de mercado, sobre los que las empresas no tienen prácticamente 
margen de actuación. Y, en segundo lugar, otra de las aportaciones de este enfoque, es que considera que los recursos pueden ser activos tanto tangibles como intangibles, incluyendo en estos últimos a factores como las habilidades, información, conocimiento o rutinas organizativas (Capelli y Singh, 1992; Barney et al., 2001). Dentro de estos recursos intangibles, el recurso humano se identifica, quizás, como el más importante y crítico para el desarrollo de ventajas competitivas sostenibles (DeNisi et al., 2003); justificando, por tanto la importancia estratégica de los recursos humanos en las organizaciones. Esta razón es la que aporta la principal ventaja de este enfoque en relación a otras perspectivas teóricas posibles. Por todo ello, no es de extrañar que en el campo de investigación que nos atañe en este trabajo -la dirección y gestión de recursos humanos- se identifique al enfoque de recursos y capacidades como el cuerpo teórico más utilizado y sea considerado “el santo grial de la investigación en recursos humanos” (Purcell y Kinnie, 2007: 533).

Una vez revisados los principales conceptos, postulados, aportaciones y limitaciones del enfoque de recursos y capacidades y, teniendo en cuenta, el objetivo de la presente investigación, creemos adecuado desarrollar nuestro trabajo bajo el enfoque general del recursos y capacidades y, el prisma particular, del enfoque estratégico de recursos humanos (Cappelli y Singh, 1992; Pfeffer, 1994; Snell et al. 1994; Wright et al., 1994; Beckert y Gerhart, 1996). Este enfoque, derivado del enfoque de recursos y capacidades, permite justificar, por un lado, la importancia estratégica del recurso humano y de la función que lo gestiona (la dirección estratégica de recursos humanos) y, por otro, permite explicar la influencia de las prácticas y sistemas de gestión de recursos humanos sobre el resultado organizativo. Los siguientes epígrafes nos servirán para profundizar en este enfoque, donde nuestros protagonistas tienen cabida y justificación: los recursos humanos y las prácticas para gestionarlos. 


\subsection{EL ENFOQUE ESTRATÉGICO DE RECURSOS HUMANOS}

Sin duda, uno de los recursos más importantes con los que cuenta cualquier tipo de empresa, son los recursos humanos. La necesidad de gestionar este recurso tan valioso ha hecho que, en las empresas, se dedique un área a su gestión y dirección, la denominada gestión de recursos humanos, quién, a través de diversas prácticas, trata de adquirir, retener y/o desarrollar dichos recursos. Desde una perspectiva académica, como una extensión del enfoque de recursos y capacidades, surge el enfoque de dirección estratégica de recursos humanos como una disciplina encargada de estudiar todo lo relativo al recurso humano, su gestión y su contribución al valor de la empresa y a su competitividad sostenible.

\subsubsection{Del enfoque de recursos y capacidades al enfoque estratégico de recursos humanos}

Como ya hemos anticipado, el enfoque de recursos y capacidades es el marco teórico básico de este trabajo, principalmente, porque es la disciplina que permite tender un puente conceptual entre la gestión de recursos humanos y la competitividad empresarial, así como por su capacidad para ofrecer “una explicación convincente sobre por qué las prácticas de recursos humanos permiten lograr ventaja competitiva” (Wright, Dunford y Snell, 2001:706). A pesar de las críticas (Priem y Butler, 2001), este enfoque se ha convertido en la teoría más utilizada en el campo de la dirección y gestión de recursos humanos (McMahan, Virick y Wright, 1999; Wright et al., 2001; Ferris et al, 1999; 2004; Wright y Boswell, 2002; Schuler y Jackson, 2005; Martin-Alcazar, RomeroFernández y Sánchez-Gardey, 2009; Holtbrugge, Friedmann y Puck, 2010, entre otros). En este sentido, Hernández y Peña (2008) señalan la utilidad del enfoque de recursos y capacidades al campo de la investigación en la dirección y gestión de recursos humanos, resumiéndola en tres grandes aportaciones que, además, representan los axiomas del enfoque de dirección estratégica de recursos humanos. Primero, permite reconocer la necesidad de aplicar sistemas o conjuntos de prácticas de recursos humanos para mejorar la competitividad de la empresa. Así, en el análisis de la relación entre los recursos humanos y los resultados, se ha pasado del estudio de prácticas aisladas al estudio de sistemas de prácticas coherentes entre sí. En segundo lugar, permite 
reconocer la importancia determinante del factor humano en el éxito de la organización (Capelli y Singh, 1992). Las diferentes políticas de recursos humanos -formación, selección, diseño de puestos, etc.- son herramientas que permiten que algunos recursos humanos cumplan las características deseables de todo recurso para constituirse como fuente de ventajas competitivas. Y, por último, la aproximación dinámica de esta teoría ha justificado la consideración de variables intermedias en la relación entre los recursos humanos y los resultados empresariales, como son el capital humano de la organización (Beckert, Huselid, Pickus y Spratt, 1997; Takeuchi et al., 2003; Saá y García-Falcón, 2004; Youndt y Snell 2004) o la cultura organizativa (Chan et al., 2004) o las interacciones entre diferentes dimensiones organizativas. Por tanto, desde la perspectiva de la dirección estratégica de recursos humanos, no sólo los propios recursos humanos tienen carácter estratégico y aportan valor, sino que, también, las prácticas y sistemas de prácticas de gestión de estos recursos pueden conducir a un mayor resultado empresarial y ser fuente de ventaja competitiva en sí mismos, puesto que los sistemas de prácticas son, a menudo, únicos, difíciles de imitar y poseen ambigüedad causal (Lado y Wilson, 1994).

Bajo las premisas del enfoque de recursos y capacidades, el proceso por el cuál el recurso humano aporta valor a la empresa es extremadamente complejo. Ello hace que sea difícilmente imitable por cualquier competidor, debido, principalmente, a la ambigüedad causal que caracteriza a los recursos humanos y, también, a los múltiples factores tangibles e intangibles que interactúan con ellos. Además, la complejidad creada a través de la inmersión social e histórica del proceso de creación de valor de los recursos humanos no puede comprobarse ni identificarse fácilmente. Estas consideraciones despertaron el interés de los académicos que, desde la óptica del enfoque de recursos y capacidades, pretendían estudiar cómo se podía generar ventaja competitiva a través de los recursos humanos de la organización.

Como respuesta a este interés, durante la década de los noventa, surgió una corriente de estudios que se engloba bajo la denominación de dirección estratégica de recursos humanos (Ferris et al., 1999), centrada en investigar un tipo de recursos humanos, aquéllos que sean estratégicos para la empresa y en identificar las mejores prácticas con 
las que gestionarlos. Este enfoque se ha desarrollado a través de la contribución de numerosos autores. Así, Ulrich (1986) fue uno de los autores pioneros en aplicar el enfoque de recursos y capacidades al campo de los recursos humanos. Se apoyó parcialmente en este enfoque para determinar cómo el personal de la empresa podía constituirse en fuente de ventaja competitiva. Posteriormente, Cappelli y Singh (1992) plantearon las bases para la denominada "gestión estratégica de recursos humanos”, subrayando la importancia de los recursos humanos en la generación de rentas, a partir de la creación de habilidades específicas para la empresa (Ordiz y Avella, 2002). Por su parte, Wright y McMahan (1992) definieron la dirección estratégica de recursos humanos como el modelo planificado de utilización, despliegue y actividades de los recursos humanos, orientado a favorecer que la organización alcance sus objetivos. Posteriormente, este enfoque se ha ido refinando con diversas contribuciones de otros autores, siempre bajo la premisa que los recursos humanos son potencialmente fuente de ventaja competitiva sostenible en el tiempo para la organización (Dyer, 1993; Pfeffer, 1994; Snell et al., 1996; Barney, 1997, entre otros).

Así, podemos afirmar que la dirección estratégica de recursos humanos tiene como objeto central de estudio a los recursos humanos y, también, su gestión y su dirección y las vías que permitan ponerlos a disposición de los intereses de la propia organización, de forma que converjan intereses de empleados y organización. Gestionado, todo ello, a través de diversas prácticas y distintas modalidades de relación de empleo. La dirección de recursos humanos se ocupa de atraer, retener, desarrollar y motivar a los recursos humanos de su empresa mediante diversas prácticas de recursos humanos, con el fin de poder contribuir a la generación de ventajas competitivas sostenibles en el tiempo y, con ello, lograr mejorar los resultados organizativos. En consecuencia, la investigación de dirección estratégica de recursos humanos ha indagado sobre cuáles son y cómo deben llevarse a cabo esas prácticas de recursos humanos (Ordiz y Avella, 2002). Bajo el enfoque de la dirección estratégica de recursos humanos, se concibe al sistema de recursos humanos como un conjunto de prácticas de recursos humanos, complementarias entre sí, que logran efectos más potentes que la suma de los efectos logrados de forma individual por cada una de ellas. Por ello, numerosos trabajos han tratado identificar sistemas de prácticas de recursos humanos diseñados para potenciar 
las habilidades de los empleados, su compromiso y productividad; de modo que, ese capital humano, llegue a ser fuente de ventaja competitiva que se traslade en mejora de los resultados para la empresa (Lawler, 1992; 1996; Pfeffer, 1998; Datta, Guthrie y Wright, 2005).

Esta nueva corriente de investigación-dirección estratégica de recursos humanos- se diferencia de la investigación tradicional de gestión de recursos humanos, al menos, en dos características, de acuerdo con Delery y Shaw (2001): primero, los estudios de dirección estratégica de recursos humanos tratan de explicar el rol estratégico que los recursos humanos pueden jugar potenciando la efectividad organizativa. Y, segundo, utilizan distinto nivel de análisis. Mientras que la investigación tradicional en gestión de recursos humanos se centra en el nivel del individuo, la dirección estratégica de recursos humanos estudia el nivel organizativo o de negocio (Datta et al., 2005).

Además, puesto que la investigación desarrollada bajo el enfoque de dirección estratégica de recursos humanos aglutina un extenso numero de trabajos, Ferris et al. (1999) proponen agruparlos en tres categorías, según la dimensión de la faceta estratégica que estudien. Primero, los trabajos que analizan la contribución de la dirección estratégica de recursos humanos a los resultados de la empresa; segundo, los que profundizan en la faceta estratégica de la dirección de recursos humanos, analizando las opciones estratégicas que se aplican en la empresa y cómo esto influye en los sistemas de recursos humanos que selecciona la empresa; y, en tercer lugar, los estudios que analizan el ajuste entre la estrategia empresarial y las prácticas y políticas de recursos humanos, como vía para lograr mejores resultados empresariales.

No obstante, el debate aún no está maduro. No está claro qué atributos o mecanismos constituyen en recurso estratégico al factor humano, debido a la dificultad para determinar con exactitud cuáles son las habilidades concretas relacionadas con los trabajadores que crean valor en la empresa (Kamoche, 1996; 2001), tampoco existe consenso sobre cual puede ser el mejor sistema de prácticas de recursos humanos para una gestión óptima empresarial. Y, por último, sigue sin estar claro cuáles son, exactamente, los procesos por los que los recursos humanos, las prácticas y la propia dirección de recursos humanos contribuyen a la competitividad empresarial (Brewster, 
Sparrow y Harris, 2005). Por tanto, en las siguientes páginas profundizaremos sobre estas cuestiones: el valor estratégico del recurso humano, las prácticas de recursos humanos y su relación con las ventajas competitivas y, en último lugar, los procesos de influencia de la gestión de recursos humanos sobre los resultados organizativos.

\subsubsection{Los recursos humanos y su valor estratégico. Los recursos humanos como capital humano y su triple dimensión: intelectual, social y afectiva}

Entre todos los recursos internos de la empresa, el recurso humano constituye el objeto de interés en este trabajo. Por ello, nos interesa clarificar su concepto desde el enfoque de recursos y capacidades, de modo que sirva de base teórica fundamental para esta investigación.

Los recursos humanos han sido considerados como una de las principales fuentes de ventaja competitiva sostenible de la empresa (Park, Gardner y Wright, 2004), ya que las características valiosas y únicas de los empleados y, principalmente, sus conocimientos, permiten crear lo que se ha denominado "ventaja del capital humano" o "ventaja a través de las personas” (Boxal, 1996). Por ello, el papel de los recursos humanos en la creación de ventajas competitivas de las empresas ha sido objeto de numerosas investigaciones bajo el soporte teórico del enfoque de recursos y capacidades (por ejemplo, Ulrich, 1986; Lado y Wilson, 1994; Wright, McMahan y McWillliams, 1994; Jackson y Schuler, 1995; Boxal, 1996; 1998; Snell, Youndt y Wright, 1996; Huselid, Jackson y Schuler, 1997; Lepack y Snell, 1999; Wright, Dunford y Snell, 2001; Hatch y Dyer, 2004, entre otros).

\subsubsection{Definición de recurso humano bajo el enfoque de recursos y capacidades}

La literatura ha ofrecido diversas definiciones del recurso humano, utilizando diversos términos como capital humano, activo humano, recurso humano, aportando diversos matices al concepto. Una de las primeras definiciones de recurso humano la ofrece Boudreau (1983) considerando que el factor humano, como recurso, es la habilidad innata o la capacidad de los trabajadores para aprender. Posteriormente, otros autores se refieren al recurso humano como el stock de conocimientos y destrezas acumulados por los trabajadores en la empresa a lo largo del tiempo (Cappelli y Singh, 1992). Por su 
parte, Amit y Schoemaker (1993) añaden la idea de propiedad y definen los recursos como los stocks de los factores disponibles en la empresa y sobre los que tiene el control y la propiedad. De forma más completa, Wright, McMahan y McWilliams (1994) definen los recursos humanos como la base de capital humano bajo el control de la empresa, considerando que está formado por el stock de habilidades, experiencia y conocimientos con valor económico para la empresa. De esta manera, el capital humano, en combinación con los demás recursos tangibles e intangibles de la empresa, contribuye a la generación de las capacidades que permiten crear ventajas competitivas sostenibles (Ordiz y Avella, 2002). Posteriormente, Jackson, Hitt y DeNisi (2003) consideran al recurso humano como un capital que incluye todos los recursos con los que los individuos contribuyen al desempeño de la organización, incluyendo su condición física, sus conocimientos, sus recursos sociales e, incluso, su reputación. Así, a través de estas últimas décadas, se ha ido “completando” la definición sobre el recurso humano, aunque aún no existe un consenso universal a este respecto.

Una de las definiciones más recientes y completas del recurso humano, es la definición de Barney y Clark (2007), puesto que recoge la multidimensionalidad de atributos que caracterizan a las personas y que éstas utilizan en su desempeño en la organización. Estos autores definen los recursos humanos de una empresa como el conocimiento, experiencias y habilidades y compromiso de los empleados con la empresa, así como sus relaciones con el resto de compañeros, subordinados o jefes, incluyendo, además, sus relaciones con aquéllos no pertenecientes a la empresa, como, por ejemplo, proveedores, clientes, etc.

Esta definición de recurso humano resulta muy completa y acorde a las evidencias empíricas logradas hasta el momento, ya que no sólo incluye las habilidades y conocimientos de las personas que forman la organización como claves para el desempeño y el éxito empresarial competitivo sino que, también, lo son las relaciones sociales de las que participan los empleados, así como, sus actitudes y sus afectos en relación a la organización. La Figura 1.5 representa gráficamente esta conceptualización del recurso humano. 
Figura 1.5. Definición de recurso humano

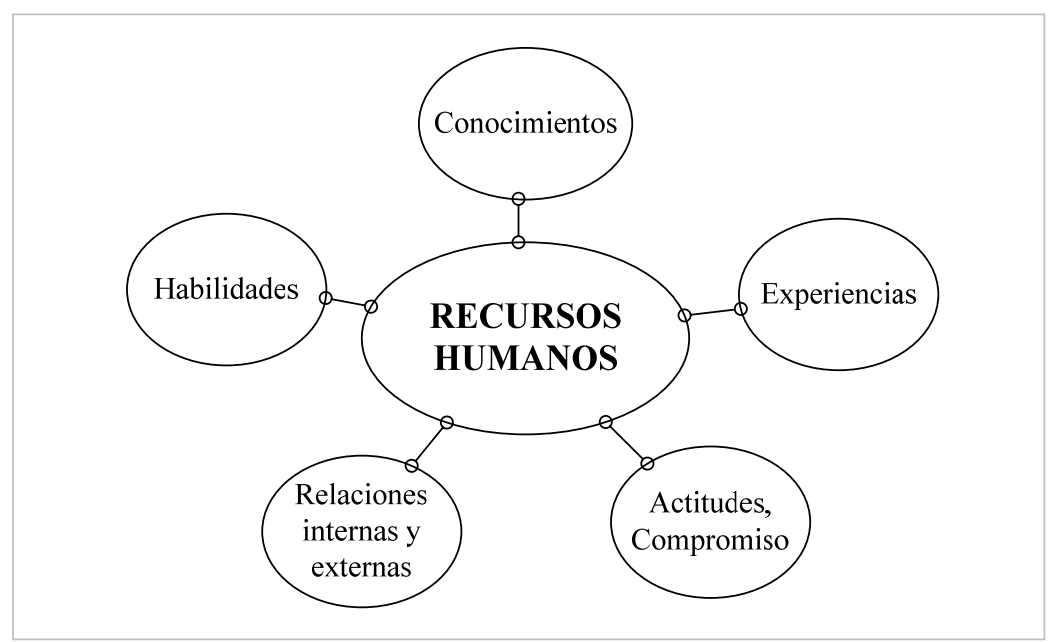

Fuente: Elaboración propia a partir de Barney y Clark (2007)

En esta misma línea, también Gendrom (2003, 2007) señala la necesidad de concebir al recurso humano en una triple dimensión: mano, cabeza y corazón, correspondiéndose, precisamente, con las dimensiones que plantean Barney y Clark (2007): comportamientos, habilidades-conocimientos-experiencias y afectos-emociones.

\subsubsection{Recursos humanos y ventajas competitivas organizativas. Los empleados estratégicos}

Utilizando los criterios desarrollados por Barney (1991), ya comentados en el epígrafe anterior, los recursos humanos son fuente de ventaja competitiva sostenible cuando son valiosos, escasos, difíciles de imitar y no tienen sustitutivos. Además, la empresa debe ser capaz de apropiarse de las rentas generadas, aunque esta característica es, especialmente compleja, en el ámbito del recurso humano.

Como se ha expuesto previamente, la idea básica del enfoque de recursos es que las empresas pueden ser conceptualizadas como conjuntos de recursos y, puesto que algunos aspectos de los recursos sólo pueden ser desarrollados internamente, son éstos, precisamente, los que tienen un mayor potencial para diferenciar positivamente a la empresa, de sus competidores (Wernerfelt, 1984; Barney, 1991; Grant, 1991). Así, los recursos internos, en lugar de las condiciones externas, se consideran factores clave del desempeño de la empresa y de su éxito. En este sentido, algunos recursos humanos son particularmente importantes porque están socialmente integrados en la organización 
(alta especificidad de empresa) y, por tanto, no pueden ser transferidos a otras empresas sin perder valor. Al mismo tiempo, los recursos humanos pueden trabajar en diferentes áreas (baja especificidad de tarea), en contraste con los recursos tecnológicos y físicos, y, por tanto, no se limitan obligatoriamente a un campo estrecho de actuación (Barney, 1991).

De acuerdo con Barney (1991), los recursos humanos pueden ofrecer la base para generar ventajas competitivas de forma sostenida, si una empresa es capaz de reclutar y retener el capital humano necesario, es decir, al grupo de empleados que sean, de forma simultánea: valiosos, raros (o escasos), imperfectamente imitables, difícilmente sustituibles y que generen rentas susceptibles de apropiación por parte de la empresa. En este sentido, autores como Lepak y Snell (1999) o Hoopes, Madsen y Walker (2003) identifican tres características como más significativas, puesto que consideran que "la escasez sólo es importante si un recurso es valioso y, para ello, el recurso no puede ser imitado por los competidores" (Hoopes, Madsen y Walker, 2003: 890). Desde este punto de vista, el valor, la singularidad y la inimitabilidad son las principales características de los recursos humanos que hacen que éstos puedan conducir hacia ventajas competitivas. Por lo tanto, las empresas pueden lograr ventaja competitiva sostenible, en el ámbito de la gestión de recursos humanos, cuando poseen una fuerza de trabajo cuyos conocimientos y habilidades sean valiosos, únicos y no puedan ser imitados por los competidores (Wright, McMahan y McWilliams, 1994; Boxall, 1996).

Por un lado, el valor de los recursos humanos se refiere, no sólo a empleados con una alta cualificación específica sino, también, a empleados con una cualificación extensa y amplia. De este modo, pueden llevar a cabo tareas diferentes y "permitir a una empresa concebir y aplicar estrategias que mejoren su eficiencia y eficacia" (Barney, 1991:106), por lo que se puede considerar que el capital humano con conocimientos y habilidades amplias puede ser más valioso para la empresa que el relativo a los empleados con una cualificación restringida a un ámbito. La heterogeneidad del mercado de trabajo hace que en él encontremos personas que difieren en sus capacidades y habilidades y, por tanto, en el grado de contribuciones que pueden realizar a la organización. Además, cabe destacar que, hoy en día, en la “era del conocimiento”, será, precisamente, este 
conocimiento el que hace que los recursos humanos resulten tan valiosos para las empresas, puesto que puede residir tanto en los propios empleados como en los procesos de relación que llevan a cabo con otras personas e, incluso, con la propia organización. Sin embargo, el mero hecho de contar con recursos humanos valiosos no garantiza la obtención de ventajas competitivas si éstos son de posesión generalizada, es decir, si no son escasos en el mercado de trabajo.

Por otro lado, la condición de escasez se relaciona con la dificultad de encontrar personas que garanticen altos niveles de rendimiento a la empresa. Ordiz y Avella (2002) sugieren que una medida útil para analizar la posible escasez del recurso humano es la base de conocimiento que acumula. Estos autores afirman que las empresas cuyos trabajadores poseen una elevada base de conocimiento, cuentan con recursos humanos escasos y superiores, lo que supone disfrutar de dicha ventaja en detrimento de las empresas rivales ${ }^{7}$. Ser escasos, raros, implica que la fuerza de trabajo tiene características difíciles de encontrar y, mucho más, si son específicas de la empresa y desarrolladas en el contexto de dicha empresa en particular. Esta especificidad hace que los empleados tengan menor movilidad en el mercado, puesto que su valor en la empresa actual puede no ser replicable ni superable en otras organizaciones, por tanto, es poco probable que dicho empleado cambie de empresa (Lepak y Snell, 1999). Además, puesto que la fuerza de trabajo específica de la empresa está inmersa socialmente en la misma, es menos propensa a poder favorecer y ser igual de valiosa en otras organizaciones. Todo ello, favorece su retención dentro de la misma, contribuyendo a que la condición de escasez tenga validez, sobre todo, a largo plazo.

En tercer lugar, la imitabilidad imperfecta. Los procesos deben desarrollarse de tal manera que sean demasiado complejos para poder ser imitados por los competidores. Para que este recurso pueda ser imitado es necesario que los competidores identifiquen qué personas o grupos son los que más contribuyen a lograr la ventaja competitiva y que sean capaces de replicarlos con exactitud. Sin embargo, imitar los conocimientos, habilidades, experiencias, comportamientos $y$ afectos de las personas $y$, las

\footnotetext{
${ }^{7}$ Existe evidencia de que la base de conocimiento de la organización es un atributo estable que sigue una distribución normal entre la población (Jenson, 1980) y, por tanto, los individuos con habilidades superiores son, por definición, escasos (Ordiz y Avella, 2002).
} 
circunstancias bajo las que éstos funcionan, no es una tarea sencilla. Podría pensarse, entonces, en adquirir esos recursos mediante su contratación, pero esto implica superar las barreras que dificultan la movilidad de los recursos humanos entre distintas empresas. La literatura del enfoque de recursos y capacidades identifica tres modos de crear barreras a la imitación: (1) momento único en el que ocurren, (2) la complejidad social y (3) la ambigüedad causal (Barney, 1991; Boxall y Purcell, 2003). En otras palabras, las diferencias históricas entre organizaciones, la ambigüedad causal de las relaciones de los recursos humanos con la ventaja competitiva y la complejidad social de las interacciones entre las personas hacen a los recursos humanos inimitables. Es, por ello, por lo que las organizaciones deben ser conscientes de la importancia de lograr retener dichos recursos.

Si no es posible imitar con exactitud a estos recursos, se puede recurrir a buscar un activo sustitutivo. Esta cuestión hace referencia a la posibilidad de que otra empresa pueda compensar una ventaja basada en el capital humano con otros recursos, como, por ejemplo, una tecnología superior. A este respecto, Ordiz y Avella (2002) resaltan dos cuestiones: en primer lugar, los recursos humanos pueden no volverse obsoletos. De hecho, determinados autores, como Ulrich (1998), afirman que es el único activo de la empresa que se aprecia si la empresa prospera. Aunque el cambio tecnológico ha creado nuevos puestos, dejando obsoletas determinadas habilidades, la puesta en práctica de programas de formación de reciclaje favorece que los trabajadores no se vuelvan obsoletos. En segundo lugar, cuando se manifiesta una habilidad superior de un trabajador, ésta es transferible a otros ámbitos de la empresa. De hecho, Schmidt et al. (1979, 1981) concluyen que las habilidades del personal de una empresa se pueden desarrollar en puestos de trabajo muy diferentes. Por tanto, los recursos humanos se consideran difícilmente sustituibles, por su potencial para resistir al paso del tiempo y no quedar obsoletos y, también, gracias a su habilidad para ser transferidos y moverse entre diferentes tecnologías, productos y mercados. Finalmente, también conviene recordar que los recursos humanos son el recurso que contribuye a integrar las capacidades elementales en otras de orden superior; desde esta perspectiva, resultan insustituibles (Ordiz y Avella, 2002). 
Por último, para terminar esta cuestión, es importante destacar la característica de la apropiación de las rentas generadas por los recursos humanos. La organización puede desarrollar mecanismos que garanticen la retención del valor añadido generado por los recursos en su propio beneficio, aunque, en el caso concreto de los recursos humanos, el problema de la apropiación del valor es especialmente complejo. Por un lado, nos encontramos, en primer lugar, con el limitado control que los contratos laborales ejercen sobre los beneficios derivados de la utilización de los recursos humanos. En segundo lugar, hay que considerar que en un contexto de recursos intangibles no existe una distinción clara entre el valor generado por la tecnología de la empresa y el derivado de los conocimientos de los individuos. Aún sin poder sustraerse a estos inconvenientes, para las empresas resulta más interesante que la ventaja competitiva se base en la actuación de un amplio número de empleados y no de un número reducido de ellos. En este último caso, la contribución de los individuos “clave” sería fácilmente identificable, éstos serían mucho más transferibles y estarían en condiciones de negociar con la empresa su posición y apropiarse de gran parte de las rentas que generan, en perjuicio de la entidad. La organización, por tanto, debe crear un contexto que favorezca la apropiación a través de la generación de capital humano específico, el aprendizaje colectivo, la complejidad social, las redes sociales y el desarrollo de procesos de gestión de conocimiento. Por ello, las empresas realizan actividades que favorezcan la retención de ese cuerpo de empleados de alto valor: los recursos humanos estratégicos de la organización o empleados "valiosos" .

Por otro lado, considerando que el valor más importante de los recursos humanos reside en sus conocimientos y habilidades, es decir, en activos intangibles que ellos poseen, la empresa se enfrenta al reto de motivar, incentivar y animar a que sus empleados quieran poner en práctica dichos conocimientos, creando, así, valor a la propia organización. Desde este punto de vista, las actividades que favorezcan el compromiso, la satisfacción, la confianza y la actitud positiva de los empleados hacia la organización, favorece el flujo y puesta en práctica de dichas habilidades y conocimientos,

\footnotetext{
${ }^{8}$ En este trabajo utilizaremos, indistintamente, ambos términos para aludir al colectivo de empleados que son, especialmente, valiosos para la organización debido a su capital humano, es decir, debido a sus conocimientos, habilidades, actitudes, contactos, afectos, etc.
} 
permitiendo que sea más sencillo para la empresa apropiarse del valor que dichos recursos generan.

En línea con lo anterior, como ya hemos señalado, no todos los empleados poseen las mismas habilidades que los hacen únicos y valiosos para una empresa (Stewart, 1997). Esto se debe a que no todos los recursos humanos son recursos homogéneos y, tampoco, todo el capital humano de una empresa logra un mismo resultado y nivel de desempeño. Generalmente, las empresas configuran sus fuerzas de trabajo en términos de diferentes tipos de empleados debido a que realizan diferentes contribuciones a la compañía (Atkinson, 1991; Lepack y Snell, 1999). Algunos de estos empleados constituyen el grupo de los empleados clave, los denominados “valiosos o estratégicos”, aquéllos cuyo trabajo es esencial para las actividades clave de la organización. Este grupo de empleados suele tener formación multidisciplinar, pertenece a la plantilla permanente de la empresa y está vinculado a las actividades más relevantes de la actividad empresarial (Atkinson, 1985; Handy, 1995; Lepack y Snell, 1999; Chew, 2004). Este colectivo es considerado el verdadero recurso humano estratégico, es decir, el capital humano que debe ser retenido y fidelizado, por contra, otros grupos de empleados se centran en tareas menos relevantes o periféricas respecto a la principal actividad de la compañía y, por tanto, no resultan especialmente estratégicos para la empresa (López-Cabrales et al., 2007, 2008).

En esta línea, Lepack y Snell (1999), bajo los postulados del enfoque de recursos y capacidades, definen a este grupo de empleados como el más valioso y específico capital de la organización, diferenciándolo de otras categorías de capital humano con conocimientos, habilidades y experiencias menos valiosas y únicas. Sin embargo, previamente ya se tenía constancia de su importancia estratégica.

En este sentido, Miles y Show (1984) constatan que, mientras muchas empresas suelen tener sistemas de prácticas de recursos humanos estandarizadas a lo largo de la organización, algunas han sido definidas ajustándolas a los conocimientos y habilidades de los diferentes grupos de empleados. Por su parte, Cohen y Pfeffer (1986) y Atkinson (1985) evidencian que muchas empresas invierten fuertemente en un grupo central de empleados (valiosos para la empresa), a la vez que mantienen un grupo periférico de 
empleados de quienes no se preocupan de igual manera. Posteriormente, Barney y Wright (1998) llegan a la conclusión de que sólo el capital humano con conocimiento valioso, único e inimitable es de interés estratégico. En esta línea de contribuciones, Boxal (1996) recomienda a las compañías seleccionar y retener a este tipo de empleados, ya que son ellos los que generarán, lo que se ha denominado "ventaja a través del capital humano”. Es más, también desde la literatura de capital intelectual se demuestra, empíricamente, que el capital humano de una organización llega a ser estratégico cuando dicho conocimiento es valioso e inimitable, generando una mayor competitividad y, en último lugar, mayor beneficio para la empresa (Youndt et al., 2004; Subramanian y Youndt, 2005).

Las consideraciones previas, por tanto, han conducido a las empresas a desarrollar diferentes formas de gestión según el tipo de empleado, puesto que diferentes empleados (poseedores de diferentes niveles de habilidades) influyen en que la empresa difiera en competitividad y en resultado empresarial con respecto a otras empresas (Lepack y Snell, 1999; Lepack y Snell, 2002). En concreto, Lepack y Snell (1999; 2002) proponen diferenciar diversas categorías de prácticas de recursos humanos según el tipo de empleado y según el tipo de relación de empleo que se establezca con dichos empleados, diferenciando cuatro situaciones. Así, en función del tipo de relación (relacional o transaccional) y del modo de relación de empleo (externalizada o internalizada), diferencian cuatro categorías: alianzas idiosincrásicas con socios, empleados estratégicos, contratos con trabajadores complementarios y relación tradicional de empleo. Además, discriminando entre la unicidad y valor de los empleados, definen un sistema de gestión de recursos humanos adecuado a cada una de las categorías anteriores: basado en la colaboración, basado en compromiso, basado en la conformidad y basado en la productividad, respectivamente- (Véase Figura A1.2. del Anexo I de este trabajo).

En esta línea de trabajos, también, podemos señalar los trabajos de Rousseau (1995) y Tsui, Pearce, Porter y Hitt (1995). Estos autores ponen de manifiesto las diferentes relaciones de empleo que pueden establecerse en la organización y, también, señalan que las prácticas de recursos humanos pueden diferir entre grupos diferentes de 
empleados. De forma análoga, Morris et al. (2005), revisando la literatura específica de recursos humanos y teniendo en cuenta una serie de factores como las diversas relaciones de empleo, la diferencia de conocimientos y habilidades de los empleados y las diferentes relaciones entre el empleado y empleador, concluyen que diferentes empleados son gestionados de formas diferentes.

Teniendo en consideración los argumentos previos, en esta investigación centramos nuestro foco de atención en este colectivo de empleados, es decir, en aquéllos considerados los recursos humanos estratégicos. Estos recursos humanos estratégicos contribuyen a la mejora del resultado organizativo a través de su capital humano. En este sentido, hoy en día, el empleado es un recurso cada vez menos manejable por la empresa, siendo un inversor de su propio capital humano. Este capital estará formado por la combinación de tres dimensiones: capital intelectual, capital social y capital afectivo (Gratton y Ghoshal, 2003), como veremos a continuación.

\subsubsection{Los recursos humanos como capital humano: intelectual, social y afectivo}

Como se extrae de las definiciones más recientes de recurso humano, antes comentadas, su dominio conceptual puede abarcar múltiples dimensiones (Barney y Clark, 2007). Ya hemos visto que el recurso humano puede ser estratégico y aporta valor a la organización. Esta aportación se debe a múltiples facetas: habilidades, conocimientos, desempeño, experiencias, relaciones sociales e, incluso, afectos y actitudes. En otras palabras, el recurso humano es valioso porque aporta valor a la organización debido a su capital intelectual, a su capital social y a su capital afectivo. A continuación, revisamos, brevemente, estos tres conceptos vinculados al capital humano que completamos con la propuesta integradora de capital humano de Gratton y Ghoshal (2003).

No obstante, antes de exponer estas revisiones, debemos hacer notar dos cuestiones relevantes. Primero, una característica común en las corrientes teóricas que estudian estas variables, como son el enfoque de capital intelectual, de gestión de conocimiento y de aprendizaje organizativo (Vera y Crossan, 2001), es la poca claridad en la definición de cada variable. Así, la frontera conceptual entre el capital humano y el capital intelectual es muy difusa y no existe un criterio universal en su conceptualización, ni tampoco en la conceptualización del capital social. Y, segundo, debemos clarificar qué 
es el capital humano, antes de profundizar en cada una de sus tres dimensiones intelectual, social y afectiva-.

El origen del concepto de capital humano se remonta a la década de los sesenta, con las aportaciones de Becker (1964) y Schultz (1961), considerados padres de la teoría del capital humano y pioneros en desarrollar una primera aproximación a dicho concepto ${ }^{9}$. Para comprender el capital humano, previamente, debemos tener claro el concepto que lo engloba: el capital intelectual de la organización. Así, Edvinsson y Malone (1997), definen el capital intelectual de la organización formado por dos componentes principales: capital humano (conocimiento, habilidades y experiencias de empleados) y el capital estructural (todo lo que envuelve, dinamiza, y la estructura que soporta al capital humano). Además, subdividen el capital estructural en dos componentes menores: capital organizativo (sistemas, herramientas y filosofía de actuación que acelere el flujo de conocimiento a través de la organización) y capital de cliente (relaciones de la empresa con los clientes). En la misma línea, Stewart (1997), concibe al capital intelectual como formado por capital humano, capital estructural y capital de clientes. Un salto cualitativo, respecto a lo anterior, ofrece la noción de capital relacional (Bontis, 1996), considerada una forma ampliada de capital de clientes que incluye el valor de las relaciones. Este concepto, propuesto por Bontis, es el mismo que desde el área sociológica y desde la teoría de la organización se denomina capital social (Adler y Kwon, 2002). Posteriormente, de forma integradora, Youndt y Snell (2004) conceptualizan el capital intelectual formado por tres categorías: capital humano, social y organizativo. El capital humano, se refiere a los conocimientos, habilidades y experiencias de los individuos. El capital social, no reside claramente ni en el nivel de un individuo ni en el de la organización, sino que es la forma intermedia de capital intelectual que abarca recursos de conocimiento imbuidos, inmersos entre, a través de, y derivados de redes de relación (Adler y Kwon, 2002; Nahapiet y Ghosal, 1998). El capital organizativo representa el conocimiento y experiencias ya institucionalizadas y

\footnotetext{
${ }^{9}$ Conciben el capital humano como el conjunto de las capacidades productivas que un individuo adquiere por acumulación de conocimientos generales o específicos (Becker, 1964). En esta línea, otros autores como Hudson (1993) describen el capital humano como la combinación de rasgos genéticos, el nivel educativo, las experiencias vividas y las actitudes hacia la vida y el trabajo (Bontis, 1998).
} 
codificadas en forma de rutinas, bases de datos, manuales, estructuras, etc. ${ }^{10}$; es el capital que la organización, realmente, posee de forma física.

Llegados a este punto, debemos matizar que las definiciones previas se refieren al capital intelectual de nivel organizativo por lo que, siguiendo a Youndt y Snell (2004), está formado por una dimensión puramente organizativa (capital estructural), una dimensión que puede abarcar tanto el nivel del individuo, como del grupo y de la organización (capital social) y una tercera dimensión que pertenece al ámbito de los empleados (capital humano). Nuestro interés investigador se circunscribe, sólo y exclusivamente, a esta tercera dimensión: al capital vinculado al nivel de las personas. Este capital humano, a su vez, se compone de un capital intelectual, un capital social y un capital afectivo (Gratton y Ghoshal, 2003) que no deben confundirse con el capital social ni con el capital intelectual del nivel organizativo. La Figura 1.6. recoge estas consideraciones y permite visualizar la confusión conceptual que pueden generar estas clasificaciones, debido a que se utilizan los mismos vocablos para aludir a conceptos diferentes y niveles de análisis, también, diferentes.

Figura 1.6. Clasificación conceptual de capital intelectual

\begin{tabular}{|c|c|c|c|}
\hline \multirow{3}{*}{$\begin{array}{c}\text { Capital } \\
\text { Intelectual } \\
\text { de la } \\
\text { organización }\end{array}$} & \multicolumn{2}{|l|}{ Capital Estructural } & $\begin{array}{c}\text { NIVEL DE } \\
\text { ORGANIZACIÓN }\end{array}$ \\
\hline & Capital Social & Cap. Intelectual & \\
\hline & Capital Humano & $\begin{array}{l}\text { Cap. Social } \\
\text { Cap. Afectivo }\end{array}$ & $\begin{array}{l}\text { NIVEL DEL } \\
\text { INDIVIDUO }\end{array}$ \\
\hline
\end{tabular}

A menudo, en la literatura, se habla indistintamente de capital humano y capital intelectual. Esto se debe a que, inicialmente, el capital humano se consideró formado, sólo y exclusivamente, por capital intelectual, es decir, por conocimientos, habilidades y experiencias de los empleados (Youndt y Snell, 2004; Edvinsson y Malone, 1997).

${ }^{10}$ Otros autores lo denominan capital estructural (Stewart, 1997). 
Posteriormente, el capital humano se consideró una capacidad de la organización, aquélla que permite extraer las mejores soluciones a través del conocimiento de los empleados y se incorporó la idea de que el capital humano abarcaba todo el conocimiento individual que posee una organización a través de sus empleados formado tanto por conocimiento tácito como explícito (Bontis et al., 2001; Bontis, 1998; Bueno, 2000; Ordóñez, 2003); de este modo, se dio entrada al concepto de capital social. Finalmente, recientes contribuciones (Gratton y Ghoshal, 2003) incorporan una tercera dimensión: el capital afectivo. En este sentido destaca la propuesta de capital humano de Gratton y Ghoshal (2003) utilizada, por ejemplo, por Foong, Yorston y Gratton (2003), que aglutina los tres componentes citados. Esta conceptualización amplia de capital humano es la que seguiremos en este trabajo. Además, da soporte a recientes propuestas conceptuales sobre el recurso humano como la de Barney y Clark (2007), ya revisada en epígrafes anteriores.

\section{Propuesta integradora de capital humano de Gratton y Ghoshal}

Para estas autoras existen tres tipos de recursos que poseen las personas (capital intelectual, capital social y capital emocional) que, de forma conjunta, constituyen su capital humano individual (Gratton y Ghoshal, 2003:2). El capital intelectual se refiere a los atributos cognitivos y la capacidad de aprendizaje, junto con los conocimientos, tanto explícitos como implícitos, habilidades y experiencias que el individuo posee a lo largo del tiempo. Dado que el conocimiento es algo esencial en el capital humano, pero no lo es todo, estas autoras incluyen, también, otros dos elementos: capital social y capital emocional. El capital social, es entendido como las relaciones y redes sociales que posee el individuo, influenciado por su sociabilidad y capacidad para inspirar confianza. Estas relaciones constituyen una forma de capital porque ofrecen la posibilidad de acceder a recursos que los otros miembros poseen o tienen acceso. Pero el conocimiento especializado y las redes de amigos y colegas, no es suficiente. Para convertir su conocimiento y relaciones en acciones concretas, para pasar a la acción, los individuos necesitan algo más: el capital emocional. El capital emocional se asienta en rasgos como el autoconocimiento, la autoestima y la integridad. Los individuos necesitan autococonfianza, basada en el autoconocimiento, valentía y capacidad de 
adaptación, flexibilidad, para transformar su conocimiento y relaciones en actos efectivos. Estos tres factores del capital humano están muy interrelacionados y deben entenderse de forma integrada y conjunta. El capital social en forma de extensivas, fluidas y recíprocas relaciones con otras personas, ayuda al individuo a desarrollar su capital intelectual a través del acceso a los conocimientos y habilidades que otros poseen. El capital emocional, facilita la integridad y autoconfianza para establecer relaciones sociales abiertas y de confianza, que permiten desarrollar el capital social. Y, a su vez, el aprendizaje e incremento de conocimientos y habilidades, desarrolla al individuo fortaleciendo su autoestima y autoconfianza, lo que mejora su capital emocional. Es, a través de este ciclo de interacción, como se mejora el capital humano del empleado, tal como se representa en la Figura 1.7.

Figura 1.7. Propuesta de Capital Humano de Gratton y Ghoshal

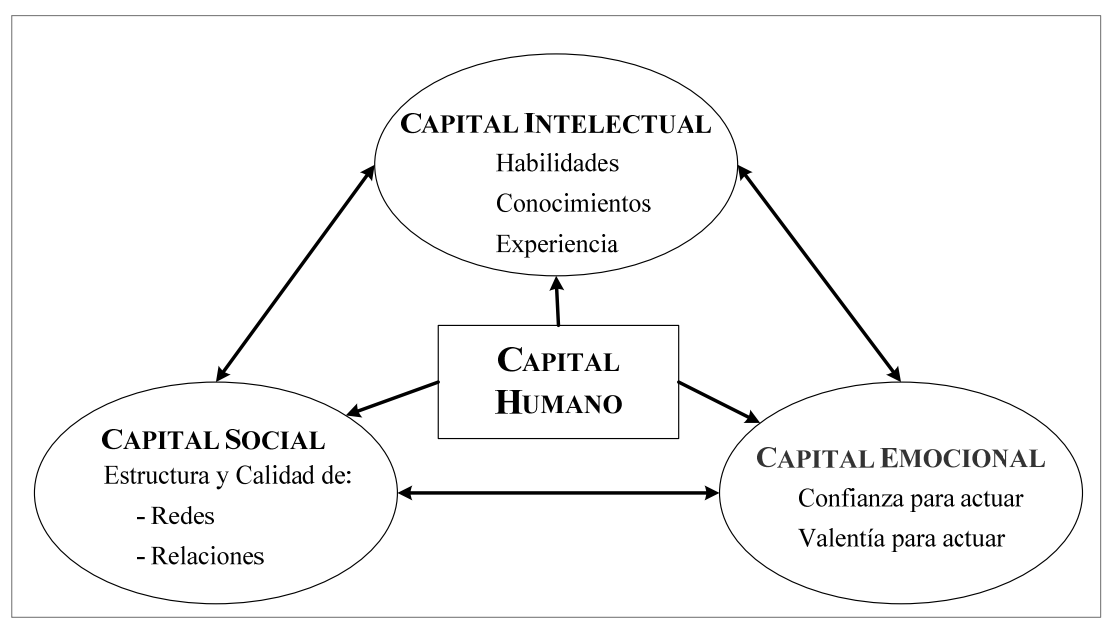

Fuente: Adaptado de Gratton y Ghoshal (2003:2).

Una clarificado el concepto de capital humano que estudiaremos en este trabajo, debemos revisar, con mayor dertalle, cada una de las dimensiones que lo componen. No siempre la investigación ha definido conjuntamente estas tres dimensiones. Todo lo contrario. Por ello, dedicamos las siguientes páginas a presentar una síntesis de las principales conceptualizaciones de los tres componentes del capital humano que hemos identificado en la literatura revisada. 


\section{$\underline{\text { El capital intelectual vinculado al capital humano }}$}

Como hemos anticipado, el capital intelectual del capital humano se ha asociado, de forma general, a los conocimientos, habilidades y experiencias que poseen los empleados (Edvinsson y Malone, 1997; Stewart, 1997; Youndt y Snell, 2004; Morris, Snell y Lepack 2005; Subramanian y Youndt, 2005; Lengnick-Hall y Lengnick-Hall, 2006), aunque, por otro lado, es considerado como la suma de todo el conocimiento y capacidades vinculadas al conocimiento que pueden ser utilizadas para ofrecer ventajas competitivas a la empresa (Stewart, 1997; Nahapiet and Ghoshal, 1998). Sin embargo, este concepto no siempre queda claro y, a menudo, lo que algunos autores definen como capital humano, otros, lo denominan capital intelectual. No obstante, a continuación, señalamos las principales definiciones sobre capital intelectual.

Tras la revisión realizada, hemos identificado que, de forma general, existe consenso en entender que el capital intelectual no es un constructo unidimensional sino que reside en varios niveles: individual, redes-interacción y organización. Es decir, para muchos autores, el capital intelectual no se circunscribe sólo al conocimiento poseído por los empleados sino que, también, incluye el conocimiento ubicado dentro y a través de la organización, mediante bases de datos, procesos organizativos, sistemas y relaciones (Youndt, Subramanian y Snell, 2004). En este sentido, podemos destacar las conceptualizaciones de Edvinsson y Malone (1997) y la de Stewart (1997), quienes consideran que el capital intelectual está formado, por un lado, por todo el conocimiento, habilidades y experiencias de los empleados, y, por otro, también está formado por todo aquello que envuelve, dinamiza, da estructura y soporta dicho conocimiento, habilidades y experiencias. También debemos hacer notar la propuesta de Bontis (1996), puesto que introduce la noción de capital relacional como una de las dimensiones del capital intelectual, en la que incorpora las relaciones, en concreto, con los clientes. Este concepto de Bontis, su capital relacional, se aproxima al que desde el área sociológica y de la teoría de la organización se ha denominado capital social (Adler y Kwon, 2002).

Además, queremos hacer notar la conceptualización de Youndt y Snell (2004), quienes apoyándose en las definiciones anteriores, entienden que el capital intelectual está 
formado tanto por los conocimientos, habilidades y experiencias de los individuos, como por los recursos de conocimiento imbuidos, inmersos entre, a través y derivados de redes de relación (Nahapiet y Ghosal, 1998; Adler y Kwon, 2002) y, también, por el conocimiento y experiencias ya institucionalizados y codificados en forma de rutinas, bases de datos, manuales, estructuras, etc.

Por último, debemos matizar que este trabajo se centrará, sólo y exclusivamente, en el capital vinculado al individuo y, por tanto, utilizaremos una conceptualización de capital intelectual adaptada al nivel de empleado.

\section{El capital social vinculado al capital humano}

El trabajo de Nahapiet y Ghoshal (1998) es, quizás, una de las propuestas más aceptadas sobre capital social. Estos autores consideran el capital social como "la suma de los recursos potenciales y actuales inmersos dentro, a través de y derivados de las redes de relación de un individuo o una unidad social” (1998:243) ${ }^{11}$. Estas redes de relaciones entre empleados y grupos (tanto dentro como fuera de la organización) provee de información, ayuda a resolver problemas, etc., añadiendo valor y potenciando la capacidad estratégica de la organización (Reagans y McEvily, 2003). Otra contribución importante, bajo la perspectiva organizativa, es la de Youndt y Snell (2004) que lo definen como la habilidad global de la organización para intercambiar y mover el conocimiento entre los empleados, proveedores, clientes, aliados estratégicos u otras empresas. En esta línea, también, se puede destacar la propuesta de Leana y Van Buren (1999), quienes tratan de dar un paso más allá, desarrollando el concepto de capital social organizativo ${ }^{12}$.

En base a las definiciones revisadas, hemos identificado tres elementos comunes en todas ellas: se requiere de la participación de actores -individuos y/u organización-, supone movimiento de conocimiento y se soporta sobre una estructura de interacciones o redes de relación. Esas interacciones o redes de relación dan soporte a procesos que

\footnotetext{
${ }^{11}$ Distinguen tres dimensiones de capital social: 1) la dimensión estructural del capital social se refiere a las conexiones entre los actores (quiénes y con qué frecuencia se comparte información), 2) la dimensión relacional hace alusión al tipo de relación personal que los individuos han desarrollado a través de sus interacciones, y 3) la dimensión cognitiva se refiere a aquellos recursos que provienen de interpretaciones compartidas, como son un lenguaje y códigos compartidos (Nahapiet y Ghoshal, 1998).

${ }^{12}$ Leana y Van Buren (1999) lo definen como el recurso que refleja el carácter de las relaciones sociales que se dan dentro de la organización, condicionado por dos dimensiones clave: asociabilidad y confianza.
} 
mueven el conocimiento entre individuos dentro y fuera de la organización, entre unidades de la propia organización e, incluso, entre diferentes organizaciones ${ }^{13}$ (Nahapiet y Ghoshal, 1998; Leana y Van Buren, 1999; Adler y Kwon, 2002; Leana y Pil, 2006). Esta variedad de posibilidades ha conducido a que, en la perspectiva organizativa, se distinga entre dos tipos de capital social: capital social interno y capital social externo (Leana y Pil, 2006). El interno alude a las interacciones entre los miembros de la organización (Coleman, 1990; Leana y Van Buren, 1999) y, el externo, a las interacciones entre la organización -o sus miembros- y colaboradores externos (Leana y Pil, 2006). Este estudio se centra en el ámbito del capital social interno. El capital social externo no se incluye puesto que supondría ampliar en gran medida el campo de análisis que consideramos factible poder llevar a cabo ${ }^{14}$.

\section{El capital afectivo vinculado al capital humano}

La faceta afectiva y/o emocional de las personas es una dimensión que juega un importante papel sobre la motivación y estímulo de los empleados (Goleman, 1999). Así se ha puesto de manifiesto desde diferentes disciplinas, principalmente, la psicología organizativa, la sociología industrial y la organización de empresas. Esto no es algo nuevo. Elton Mayo y su Escuela de las Relaciones Humanas, pioneros en el tema, lo evidenciaron durante la década de los años veinte y treinta del siglo pasado. Sin embargo, la conceptualización de un capital que recoja esa dimensión afectiva no es tarea sencilla y su incorporación al ámbito investigador empresarial es relativamente reciente, por lo que las contribuciones que hemos encontrado no son numerosas. Podemos señalar diferentes acepciones sobre este tipo de capital que, habitualmente, se ha venido a denominar capital afectivo o capital emocional.

Algunos autores, desde una óptica organizativa, lo consideran un concepto complementario de otras las dimensiones del capital humano. Así, algunos autores lo consideran complementario al capital social, formando la dimensión psicosocial y cultural del capital social. Por ejemplo, McGrath y Burskirk (1999) definen el capital

\footnotetext{
${ }^{13}$ Confirmando, también, su capacidad predictora del desempeño del grupo y de la propia organización.

${ }^{14}$ Ello supondría abordar la investigación sobre agentes externos a la empresa, faceta que queda fuera del objetivo de estudio de esta tesis doctoral pero que, sin embargo, podría llegar a ser una interesante línea futura de ampliación de la misma.
} 
emocional como la capacidad de la organización para evocar y mantener en el tiempo, mediante el uso de prácticas, símbolos y su cultura organizativa, una valoración positiva de pertenecer a la misma. Sin embargo, para otros autores, es considerado complementario al capital intelectual (Thomson, 1998; Thomson y Rodríguez, 2000; Ordóñez de Pablos, 2000). Thomson considera complementarios al capital intelectual y al capital emocional, describiéndolas como las dos caras de una misma moneda: “mentes y corazones”, respectivamente. Además, concibe al capital emocional como un capital de gran valor para las organizaciones que surge de la suma de la inteligencia emocional presente en las personas que forman la organización. En concreto, Thomson (1998) propone distinguir entre dos tipos de capital afectivo o emocional. Por un lado, el capital emocional externo es aquel presente en “el corazón de los clientes” y en los diversos grupos de interés de la organización; es descrito como el valor de la marca y se reconoce como un factor crítico para las compañías. Por otro lado, el capital emocional interno es aquel presente en el corazón de los empleados. Este capital emocional interno aglutina los sentimientos, las creencias y los valores de cada uno de los miembros que conforman el equipo humano de la organización y se corresponde con el capital afectivo vinculado al capital humano, como uno de los componentes de capital humano (Gratton y Ghoshal, 2003; Gendrom, 2004, 2007). De hecho, Gratton y Ghoshal (2003) definen este capital afectivo como lo que se necesita para pasar a la acción, aquel capital asentado en diversos rasgos como el autoconocimiento, la autoestima y la integridad. Puesto que los individuos necesitan de autococonfianza, autoconocimiento, valentía y capacidad de adaptación para poder pasar a la acción, es decir, para aplicar sus conocimientos y llevar a cabo actos concretos que beneficien a su organización.

Otra categoría de aportaciones, no tan directamente relacionadas con las concepciones previas, son las que aproximan el capital afectivo al concepto de inteligencia emocional (Goleman, 1999; Durán Juvé, 2004), considerando que surge de la suma de la inteligencia emocional que hay en las personas que forman la organización. Goleman (1999) define la inteligencia emocional como la capacidad para reconocer sentimientos 
propios y ajenos, así como para manejarlos ${ }^{15}$. Dentro de esta tendencia, cabe señalar el emergente enfoque del comportamiento organizativo positivo ${ }^{16}$ (introducido por Luthans, 2002; Luthans y Youssef, 2007) y su definición de capital psicológico. Este capital psicológico recoge el estado positivo de los individuos caracterizado por: la autoconfianza, para enfrentarse y desarrollar el esfuerzo necesario para alcanzar con éxito nuevas tareas; el optimismo, sobre el presente y el futuro; la perseverancia y esperanza en conseguir sus metas, y, la resistencia y capacidad de adaptación ante los problemas que puedan surgir (Luthans, Youssef, et al., 2007:3). Avey, Luthan y Jensen (2009) consideran que este capital psicológico forma parte del capital humano y, como tal, debe ser gestionado, puesto que condiciona las percepciones y los comportamientos de los empleados.

Como apunte final a la conceptualización del capital humano y teniendo en cuenta su triple dimensión (intelectual, social y afectiva) debemos señalar que, desde una perspectiva estratégica, el capital humano es considerado un recurso único e intangible que diferencia a una organización de otras y asienta la base para su capacidad competitiva $^{17}$ (Lengnick-Hall y Lengnick-Hall, 2006). Ello caracteriza al capital humano como estratégico (Youndt et al., 2004; Subramanian y Youndt, 2005) y, como tal, es fuente de ventaja competitiva sostenible en el tiempo (Barney, 1991). Además, se relaciona de forma positiva con la innovación en la empresa y tiene carácter renovable (Afiouni, 2007), ya que los empleados tienen la capacidad de aprender, incrementando, así, su propio capital humano y pudiendo, por tanto, crear nuevo conocimiento, contribuyendo al mantenimiento e, incluso, mejora de la competitividad de la organización.

\footnotetext{
${ }^{15}$ Goleman estima que la inteligencia emocional se puede organizar en cinco capacidades: conocer las emociones y sentimientos propios, manejarlos, reconocerlos, crear la propia motivación y gestionar las relaciones.

${ }^{16}$ El enfoque de comportamiento organizativo positivo se encarga del estudio y aplicación de las fortalezas de los recursos humanos en forma positiva y de sus capacidades psicológicas, de forma que puedan medirse, desarrollarse y gestionarse con eficacia, pudiendo lograr incrementos en desempeño y resultados (Luthans, 2002b:59).

${ }^{17}$ La capacidad competitiva se basa en la habilidad de la empresa para transformar su tecnología y sistemas operativos de modo que permitan adoptar nuevas perspectivas y llevar a cabo cambios en los sistemas sociales, favoreciendo y potenciando el capital social y el capital humano, logrando un conocimiento superior desde el que ser más competitivos (Lengnick-Hall y Lengnick-Hall, 2006).
} 


\subsubsection{Prácticas de recursos humanos y ventajas competitivas sostenibles}

De forma general, se asume que la función de recursos humanos tiene como principales finalidades atraer, retener y desarrollar al capital humano de la organización (Dolan, Valle, Jackson y Schuler, 2007), para poder contribuir, a través de este capital y de su propia forma de gestión, a la generación de ventajas competitivas sostenibles para la misma. Para ello, las empresas utilizan diversas prácticas que les permiten gestionar a sus recursos humanos, orientando y guiando sus comportamientos hacia los intereses y objetivos de la empresa (Wright et al., 1994; Elliot, 2003). Es decir, las empresas pueden crear y mantener competencias basadas en sus empleados a través de las prácticas de recursos humanos (Wright et al., 2001). Dentro del amplio abanico de prácticas de recursos humanos presentes en la literatura, las más habituales son: el reclutamiento, la selección, el diseño de puestos de trabajo, la formación, la promoción, la evaluación del desempeño, la retribución, la comunicación interna, los sistemas de participación del empleado, los sistemas de liderazgo, los sistemas de motivación e, incluso, otras más actuales, como el "empowerment” o las prácticas de conciliación entre vida personal/laboral, como algunas de las más utilizadas en el ámbito empresarial e investigadas en el ámbito académico.

Además, la investigación en dirección estratégica de recursos humanos postula que los sistemas de prácticas de recursos humanos pueden conducir a un mayor resultado empresarial y ser fuente de ventaja competitiva en sí mismo, porque estos sistemas de prácticas son, a menudo, únicos, difíciles de imitar y se caracterizan por su ambigüedad causal (Lado y Wilson, 1994). Delery y Doty (1996) evidencian que las prácticas de recursos humanos pueden mejorar el desempeño de la empresa cuando están internamente alineadas y orientadas a favorecer comportamientos que permitan alcanzar una determinada ventaja competitiva. En consecuencia, la elección del sistema de prácticas de recursos humanos dependerá de la ventaja competitiva que la empresa esté tratando de desarrollar en cada situación (Wright et al., 2001).

También, es importante destacar que las capacidades basadas en los empleados, desarrolladas a través de las prácticas de recursos humanos, son muy difíciles de imitar dado que estas prácticas son específicas de la empresa en cuestión, socialmente 
complejas y dependen unas de otras (Lado y Wilson, 1994). Incluso, si el sistema de prácticas de recursos humanos pudiera ser imitado, habrá una ventaja temporal entre el momento de la implementación del sistema y su impacto (Wright, et al., 2001). En consecuencia, no sólo los recursos humanos estratégicos, a través de su capital humano, generan valor y ventaja competitiva a la empresa, sino que, también, las propias prácticas, en sí mismas, pueden generar ventaja competitiva. Sin embargo, no todas las prácticas de recursos humanos podrán ser fuente de ventajas competitivas, sino que, sólo lo serán aquéllas que logren desarrollar o dar soporte a recursos y/o competencias que den valor a la empresa (Wright et al, 2001; Collins y Clark, 2003).

Las argumentaciones previas conducen hacia un debate abierto en la investigación de recursos humanos: ¿la ventaja competitiva se desarrolla en las propias prácticas de recursos humanos o en los recursos humanos? (Park, Gardner y Wright, 2004). Aún no está claro qué es lo que realmente ofrece valor a la organización: si los recursos humanos o su gestión-dirección (Kazlauskait y Buciunien, 2008). A pesar de que el enfoque de recursos y capacidades, a través del enfoque de dirección estratégica de recursos humanos, ha puesto de relieve el crítico papel de los recursos humanos y de su capital humano en la generación de ventajas competitivas sostenibles, los investigadores de dirección estratégica de recursos humanos no han alcanzado un consenso claro sobre quiénes deben considerarse los recursos clave bajo el paradigma del enfoque de recursos y capacidades, si las prácticas de recursos humanos (Schuler y McMillan, 1984; Huselid, 1995; Huselid et al., 1997; Schuler y McMillan, 1984) o los propios recursos humanos a través de sus capacidades (Ulrich y Lake, 1990; Capelli y Cocker-Hefter, 1996).

Por un lado, las prácticas de recursos humanos, especialmente, cuando se agrupan en conjuntos o sistemas que se ajustan a la estrategia de negocio la empresa, están relacionadas con mayores niveles de resultados en términos de ventas, beneficios y rotación voluntaria $\mathrm{y}$, por tanto, se consideran fuente de ventajas competitivas (Boudreau y Berger, 1985; Arthur, 1994; Huselid, 1995; Delaney y Huselid, 1996; Huselid, Jackson y Schuler, 1997). 
Sin embargo, por otro lado, las capacidades de los recursos humanos también pueden ser consideradas fuente de ventaja competitiva. Estas capacidades se entienden como las rutinas en las se ve inmerso el conocimiento tácito e implícito de los miembros de la organización y a través de las que es adquirido, desarrollado, nutrido, utilizado y redistribuido por los recursos humanos, en un contexto dinámico de competitividad (Ulrich y Lake, 1990; Kamoche, 1996; Teece et al., 1997; Boxal, 1998). Su vinculación con la ventaja competitiva se debe a que se ven inmersas en el conocimiento colectivo de los miembros de la empresa (inimitabilidad), se desarrollan a través del tiempo (escasez) y son valiosas (valor), ya que las rutinas a través de las que se gestiona a los empleados también pueden guiar el talento y el comportamiento de los empleados hacia los objetivos de la empresa y, de este modo, crear valor del que se pueda apropiar la empresa (Wright et al., 1994).

Respecto a este debate, Elliot (2003) argumenta que desde la perspectiva basada en los recursos y capacidades, las prácticas de recursos humanos, en teoría, tendrían poco potencial para ser una fuente de ventaja competitiva sostenida (Wright et al., 1994). Por tanto, la fuente de ventaja competitiva sostenida se encuentra en los propios recursos humanos y no en las prácticas utilizadas para atraer, utilizar y conservar a los mismos (Boxall, 1996; Wright et al., 1994).

Sin embargo, hay autores que proponen una tercera opción. Wright et al. (1994) y Boxall (1996) consideran que, aunque las prácticas de recursos humanos no sean por sí mismas fuente de ventaja competitiva sostenida, su papel en el desarrollo de ventaja competitiva sostenida de los recursos humanos sigue siendo fundamental. En este sentido, no se puede obviar la doble dimensión de los recursos humanos (Kamoche, 2001). Por una parte, están constituidos por conocimiento y habilidades, cuya naturaleza intangible hace que puedan constituir la base para generar ventaja competitiva. Por otra parte, las prácticas de recursos humanos determinan la forma en que dichos recursos se combinan para crear capacidades empresariales (Ordiz y Avella, 2002). Ignorar ambas realidades supone limitar el potencial de generación de rentas de los recursos humanos.

El problema que se plantea es concretar cuáles son las prácticas necesarias, puesto que, a pesar de la abundante literatura existente hasta el momento, sigue sin estar claramente 
definida la forma en que los recursos humanos se convierten en capacidades que permiten generar rentas y competividad empresarial. En este sentido, Wright et al. (1994) proponen un modelo explicativo que ha sido ampliamente aceptado en la investigación de dirección estratégica de recursos humanos. En dicho modelo intervienen las prácticas, el comportamiento y los propios recursos humanos. Las prácticas se utilizan, por un lado, para desarrollar y controlar a los recursos humanos y, por otro, para guiar su comportamiento, el cuál media en la relación entre los recursos humanos y su contribución a la ventaja competitiva sostenida. Estas relaciones se ilustran en la Figura 1.8.

Figura 1.8. Modelo de recursos humanos como fuente de ventaja competitiva sostenible

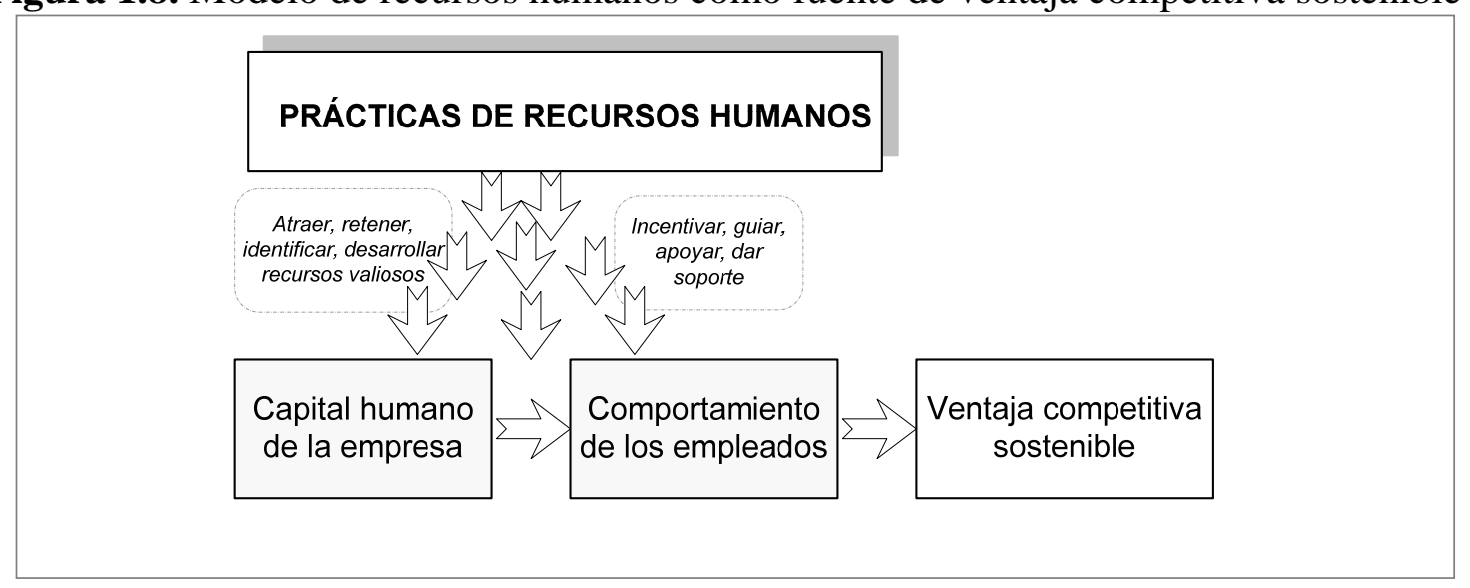

Fuente: Elaboración propia a partir de Wright et al. (1994) y de Elliot (2003)

Teniendo cuenta esta propuesta (Figura 1.8), en primer lugar, las empresas pueden desarrollar su capital humano mediante la utilización de prácticas de recursos humanos tales como el desarrollo, selección, evaluación, formación y sistemas de remuneración dirigidos a atraer, identificar y retener a los empleados de alta calidad (Wright et al., 1994). En segundo lugar, prácticas de recursos humanos tales como sistemas de reclutamiento extensivos o atractivos paquetes de remuneración, se pueden utilizar para atraer y retener a los empleados altamente cualificados y que mejor se ajusten a la organización (Wright et al., 1994). En tercer lugar, los programas de formación destinados a incrementar y desarrollar las capacidades y competencias individuales proporcionan un continuo desarrollo del conjunto del capital humano de la organización (Wright et al., 1994). 
Conscientes de la amplitud que supondría estudiar las prácticas orientadas tanto a la atracción, como al desarrollo, como a la retención de los recursos humanos, nuestro interés, en este trabajo, se centra exclusivamente en la retención (Figura 1.9). La función de retención es el proceso estratégico que engloba todas las actividades que realiza la organización que promueven y favorecen el vínculo y el compromiso de los empleados con su trabajo y organización (Chew, 2004). Nuestro interés investigador se orienta a las prácticas de recursos humanos que favorezcan la retención de los recursos humanos estratégicos de la empresa, de ese capital humano valioso, como forma de lograr mejorar los resultados organizativos, como veremos, con detalle, en el epígrafe 1.3 de este capítulo.

Figura 1.9. Área de interés investigador de este trabajo

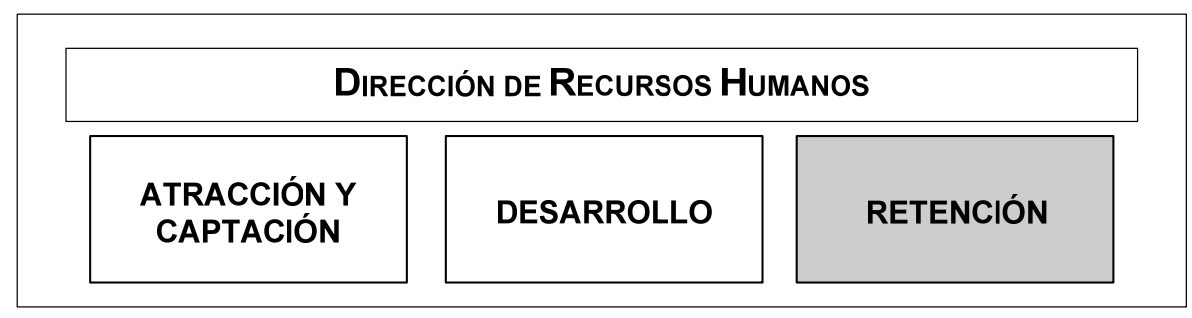

Para completar la revisión del estado del arte de la literatura de dirección estratégica de recursos humanos, debemos profundizar en los trabajos que analizan el impacto de la dirección y gestión de recursos humanos sobre el resultado organizativo y los procesos a través de los que esto sucede. Dichos procesos es lo que se ha denominado la "caja negra” de la gestión de recursos humanos (Guest y Conway, 1999). A la revisión de estos aspectos, dedicamos el siguiente epígrafe.

\subsubsection{Impacto de la gestión de recursos humanos sobre la organización: medidas} de resultados, prácticas de recursos humanos y procesos mediadores. El caso particular de la innovación

La dirección y gestión de recursos humanos persigue contribuir positivamente a los resultados y desempeño de la organización. En consecuencia, son numerosos los trabajos que han analizado, y avalan con sus resultados, la importancia de la dirección y gestión de recursos humanos y su incidencia sobre la organización (Arthur, 1994; Huselid, 1995; Huselid et al., 1997; Delery y Doty, 1996; Beckert y Gehart, 1996; 
Ichiniowsky et al., 1997, 1999; Youndt et al, 1996; Shaw, Delery, Jenkins y Gupta, 1998; Ulrich, 1997; Ferris et al., 1998; Batt, 2002; Truss 2001; Guest et al., 2003; Wright et al., 2003; Way y Johnson, 2005; Sun, Aryee y Law, 2007;Tremblay et al., 2010; entre otros). Con el fin de presentar de forma sintética las principales contribuciones, dedicamos un primer apartado a revisar las principales medidas de resultado que se utilizan en el ámbito de los estudios de gestión de recursos humanos, a continuación, dedicamos otro apartado a presentar las principales clasificaciones de prácticas de recursos humanos relacionadas con los resultados organizativos, en tercer lugar, revisamos las principales propuestas que indagan sobre los procesos intermedios por los que esta influencia sucede y, para terminar, completamos este epígrafe profundizando en la relación entre la gestión de recursos humanos y un resultado organizativo cada vez más importante: la innovación.

1.2.4.1. Impacto de la dirección estratégica de recursos humanos en los resultados organizativos: un conglomerado de medidas

Como acabamos de anticipar la influencia de la dirección y gestión de recursos humanos sobre la organización ha sido ampliamente contrastada en la literatura, sin embargo, sigue existiendo cierta controversia sobre cómo medir dicha influencia y qué variables organizativas deben utilizarse (Truss, 2001; Way y Johnson, 2005). Podemos afirmar que aún no existe consenso en la definición de resultado organizativo ni en el modo de medirlo (Dolan, Mach y Sierre, 2004). Así, por ejemplo, mientras algunos autores (Huselid, 1995) se concentran en las medidas de resultados financieros, otros, se centran en medidas como la productividad y la calidad (Arthur, 1994; McDuffie, 1995: Ichiniowski et 1997), otros, por su parte, lo miden con variables como la rotación voluntaria (Arthur, 1994) e, incluso, otros consideran el valor creado para empresa (Huselid 1995). Las anteriores medidas de resultados son las más habituales en las investigaciones de gestión de recursos humanos (Wan Ismail, Omar y Bidmeshgipour, 2010)

Con el objetivo de clasificar la diversidad de medidas de resultado utilizadas en la literatura de dirección estratégica de recursos humanos, Dyer y Reeves (1995) proponen cuatro dimensiones para clasificar las medidas de eficacia organizativa: medidas 
relativas a los recursos humanos, medidas organizativas, medidas financieras y medidas de mercado. Estos autores señalan que el ratio de rotación voluntaria-retención, la productividad y los ratios financieros son las medidas de eficacia organizativa más utilizadas para evaluar el efecto que la gestión de recursos humanos puede ejercer en los resultados de la organización. Estos resultados se resumen en la Tabla 1.2.

Tabla 1.2. Principales medidas de resultado en estudios empíricos de dirección y gestión de recursos humanos

\begin{tabular}{|c|c|c|c|c|}
\hline & \multicolumn{3}{|c|}{ MEDIDAS } & \multirow[b]{2}{*}{ Mercado } \\
\hline $\begin{array}{c}\text { TRABAJOS } \\
\text { RELEVANTES }\end{array}$ & $\begin{array}{l}\text { Recursos } \\
\text { Humanos } \\
\end{array}$ & Organizativas & Financieras & \\
\hline Arthur, 1994 & Rotacion Vol. & $\begin{array}{c}\text { Productividad, } \\
\text { Calidad }\end{array}$ & & \\
\hline Batt, 2002 & Abandonos & & $\begin{array}{l}\text { Crecimiento, } \\
\text { Ventas }\end{array}$ & \\
\hline Batt et al ., 2002 & Abandonos & & & \\
\hline Delery y Doty, 1996 & & & ROAa; ROEb & \\
\hline Guthrie, 2001 & Retención & Productividad & & \\
\hline Huselid, 1995 & Rotación Vol. & Productividad & GRATEc & Tobin's q \\
\hline \begin{tabular}{lll|} 
Ichniowski, & y & Shaw, \\
1999 & & \\
\end{tabular} & & $\begin{array}{c}\text { Productividad, } \\
\text { Calidad }\end{array}$ & & \\
\hline Ichniowski et al ., 1997 & & Productividad & & \\
\hline Shaw, et al ., 1998 & Rotación Vol. & & & \\
\hline Way, 2002 & Rotación Vol. & Productividad & & \\
\hline
\end{tabular}

Fuente: adaptado Dyer y Reeves (1995: 661) cit. en Way y Johnson (2005)

Simplificando la anterior clasificación, Paawe y Boselie (2005) aglutinan las principales medidas de resultado empresarial en tres categorías:1) resultados financieros, como por ejemplo, beneficios, ventas, q de Tobin, GRATE, acciones; 2) resultados organizativos, como por ejemplo, medidas de productividad, de calidad o de eficiencia); y 3) resultados de recursos humanos, medidas que aluden a las actitudes y comportamiento de los empleados como la satisfacción, el compromiso y la intención de abandono o de permanencia.

En definitiva, la literatura estratégica de recursos humanos utiliza tanto factores financieros como no financieros (p.e. la rotación voluntaria, beneficios, precio de acciones, posición competitiva, etc.) para medir el impacto de la gestión de recursos humanos. Sin embargo, el foco de atención ha evolucionado y, cada vez, se orienta más hacia la renovación tecnológica y nuevas formas de crecimiento. En este nuevo contexto 
se consideran la capacidad de innovación y la innovación, así como, la medida de la competitividad, como factores pertinentes para medir el resultado organizativo (Wan Ismail et al., 2010). Además, estudios recientes señalan que la gestión de recursos humanos influye sobre el desarrollo de la innovación (Chew y Huang, 2009) y ponen de manifiesto la necesidad de investigar en dicha relación. En consecuencia, dedicaremos un epígrafe posterior (1.2.4.4.) a profundizar en esta cuestión.

\subsubsection{Prácticas de recursos humanos y resultados organizativos: los sistemas de prácticas}

Las prácticas de recursos humanos son el principal medio mediante el que las empresas pueden influir, estructurar y orientar las habilidades, conocimientos, actitudes, afectos y comportamientos de los empleados para que realicen correctamente su trabajo y, de este modo, se alcancen los objetivos organizativos (Collins y Clark, 2003; Wan Ismail, 2010). El abanico de prácticas que pueden utilizar las empresas es muy amplio; desde las prácticas de análisis y diseño de puesto de trabajo, reclutamiento y selección, formación, desarrollo, promoción, evaluación del desempeño, retribución, organización del trabajo, etc., hasta prácticas orientas a una dimensión más relacional, como el liderazgo, la participación del empleado, la comunicación interna y las políticas de motivación del empleado, entre otras ${ }^{18}$.

La investigación en gestión de recursos humanos pone de manifiesto la importancia de las prácticas de recursos humanos para la organización. En concreto, Guest et al. (2003) argumentan que la asociación entre la dirección de recursos humanos y el resultado organizativo se justifica, primero, debido a que la utilización de los recursos humanos es una de las bases más potentes para generar ventajas competitivas (Barney, 1995) y, segundo, debido a que el despliegue y uso efectivo de los recursos humanos depende de la aplicación conjunta de diversas prácticas, formando sistemas de prácticas (McDuffie, 1995; Beckert y Huselid, 1998). No obstante, no ha sido posible identificar una composición única ni una terminología común para denominar a estos sistemas de prácticas. Dependiendo del tipo de prácticas incluidas, se utiliza el término "sistemas de

\footnotetext{
${ }^{18}$ Para revisar el amplio abanico de prácticas de recursos humanos posibles véase, por ejemplo, Dolan, Schuler y Valle (1998); Gómez, Mejía et al.,.(2001); Dolan et al., (2007); DeNisi y Griffin (2008) o Valero et al., (2008).
} 
trabajo de alto desempeño" (Appelbaum et al., 2000), otros autores las describen como “sistemas de alto compromiso” (Arthur, 1994; Pfeffer, 1998; Wood y Menezes, 1998) o, también, se han propuesto prácticas bajo la denominación de prácticas de "gestión de alta implicación” (Guthrie, 2001).

La literatura de dirección estratégica de recursos humanos trata de identificar aquellos sistemas de prácticas de recursos humanos que logren altos niveles de desempeño en los empleados, pudiendo contribuir, de este modo, a la mejora del resultado organizativo. Sin embargo, como acabamos de comentar, ni los trabajos prescriptivos/conceptuales ni los trabajos empíricos ofrecen una definición precisa sobre la composición de estos sistemas de prácticas. No obstante, podemos identificar que en su gran mayoría, incluyen prácticas como los procedimientos rigurosos de selección, la promoción interna basada en el mérito, los mecanismos de participación y comunicación interna, las recompensas basadas en el desempeño grupal e individual, la fórmula de equipos de trabajo multifuncionales y/o una amplia formación para los empleados.

Muchos autores han tratado de indagar sobre los criterios que permitan clasificar los sistemas de prácticas de recursos humanos, proponiendo su propio criterio para clasificar la investigación en este ámbito. Tras la revisión de la literatura realizada, hemos constatado la multitud de trabajos relevantes que clasifican las prácticas y sistemas de prácticas de recursos humanos según diferentes criterios. Para presentarlo de forma sintética y ordenada, los vamos a presentar en dos grupos, que denominamos trabajos de clasificación “tradicionales” y “emergentes”. Los primeros -tradicionalesson los trabajos que utilizan taxonomías ampliamente aceptadas y utilizadas en la investigación en recursos humanos. Los segundos -emergentes- son trabajos más recientes que utilizan nuevos criterios para clasificar las prácticas de recursos humanos y que, bajo nuestro punto de vista, están empezando a conformar una interesante corriente de investigación en recursos humanos.

\subsection{Trabajos tradicionales de clasificación de prácticas de recursos humanos}

Existen multitud de trabajos que proponen su propio criterio para clasificar los sistemas de recursos humanos. Destacamos, en primer lugar, el trabajo de McDuffie (1995) que propone diferenciar entre tres categorías de sistemas de gestión de recursos humanos: 
aquellos focalizados en desarrollar las habilidades y conocimientos necesarios en los empleados; aquellos centrados en las motivaciones para llevar a cabo un buen trabajo y, por último, los sistemas que ofrecen oportunidades a los trabajadores. Este criterio de clasificación se conoce como sistema $\mathrm{AMO}^{19}$. En la misma línea, otros autores diferencian entre sistemas de prácticas orientados a las habilidades, motivación y empowerment (Delery, Gupta y Shaw, 1997; Gardner, Moynihan, Park y Wright, 2000).

En segundo lugar, queremos señalar el trabajo de Wright y Boswell (2002) que proponen tres criterios para agrupar el amplio abanico de sistemas de prácticas presentes en la literatura de dirección de recursos humanos: conceptual, analítico y cluster. El criterio conceptual se basa en clasificar las prácticas que forman el sistema según el objetivo al que se orienten. Así, bajo este criterio se puede citar a Lawler (1986) que propone los conceptos de: compartir información, conocimientos y habilidades, poder y recompensas, prácticas para gestionar en un entorno de alto desempeño versus alto compromiso, como categorías útiles para clasificar las prácticas de recursos humanos. También, bajo este criterio se engloban los trabajos que clasifican las prácticas bajo la estructura AMO (Delery et al., 1997; Gardner et al., 2000). Por su parte, el criterio analítico se basa en el análisis estadístico, principalmente a través de análisis factoriales que indiquen qué factores (categorías) se confirman. Así, Lee y Chee (1996), estudiando la clasificación propuesta por Lawler (1986), validan tres categorías: compartir información, conocimientos y habilidades, poder y recompensas. Por su parte, Huselid (1995) agrupa las prácticas de recursos humanos en dos categorías: habilidades del empleado y estructura organizativa, por un lado y, motivación del empleado, por otro. Y, por último, el criterio cluster. A través de la metodología del análisis cluster se identifican diferentes sistemas de prácticas de recursos humanos según el tipo de empresas, industrias, etc. Cabe destacar el trabajo de Arthur (1992) que permitió clasificar los sistemas de prácticas de recursos humanos en sistemas de compromiso y sistemas de control; clasificación que ha sido muy utilizada en estudios posteriores. Posteriormente, Becker y Huselid (1996) identifican cuatro cluster de empresas asociados a diferentes sistemas de dirección estratégica de recursos humanos que

\footnotetext{
${ }^{19}$ Por sus siglas en inglés ability, motivation y opportunity.
} 
denominaron: personales, de alineación, de compensación y de alto rendimiento. Y, también, cabe destacar la aportación de Ostroff (2000), quien identifica cuatro sistemas de dirección de recursos humanos: sistemas de implicación, que ponen el énfasis en prácticas que incrementan las habilidades e implicación de los empleados; sistemas tradicionales, que incluyen prácticas ligadas a monitorizar y controlar el trabajo; sistemas de identificación que utilizan poco la dirección de recursos humanos, sólo incluyen algunas prácticas dirigidas a desarrollar el compromiso y la identificación del empleado con la organización; y, por último, los sistemas nulos, aquellos sistemas que casi no utilizan las prácticas de dirección de recursos humanos.

Y, en tercer lugar, otro grupo de trabajos proponen un nuevo criterio para clasificar los trabajos que relacionan los sistemas de prácticas y el resultado organizativo. Son aquellos que ponen el foco de atención en el concepto de ajuste entre los sistemas de prácticas de recursos humanos y la estrategia empresarial. De este modo, en base a los diferentes enfoques del "ajuste" estratégico se pueden identifican tres corrientes de trabajos que estudian las prácticas y sistemas de prácticas de recursos humanos: universalista, contingente y configuracional (Delery y Doty, 1996; Youndt et al., 1996). Los trabajos del enfoque universalista (Huselid, 1995) tratan de identificar qué prácticas son universalmente buenas y contribuyen al resultado empresarial y, por tanto, a la consecución de los objetivos estratégicos de la empresa. Delaney et al. (1989), identifica diez prácticas: selección, evaluación de desempeño, incentivos, diseño de puesto, sistema de trámite de quejas, compartir conocimiento, evaluación de actitud y participación. Por su parte, Huselid (1995) añadió, a las anteriores, el reclutamiento intensivo, horas de formación/año y los criterios utilizados para la promoción. Otro trabajo relevante es el de Pfeffer (1994) que señala dieciséis prácticas para lograr incrementar la productividad y los beneficios. Y, posteriormente, Delery y Doty (1996) identifican siete prácticas que consideran estratégicas: oportunidad de promoción, sistemas formales de formación, evaluación del desempeño, reparto de beneficios, seguridad en el empleo, comunicación interna y definición del puesto de trabajo.

Otros autores prefieren un enfoque contingente. En este caso, se estudia cuál es el sistema de prácticas de recursos humanos más apropiado para una empresa en 
particular, según sean sus estrategias y características propias (Dyer, 1985; Dyer et al., 1988; Lengnick-Hall y Lengnick-Hall, 1988; Milkovich, 1988; Jackson y Schuler, 1995, entre otros). De este modo, se trata de vincular los sistemas de dirección de recursos humanos a la complementariedad de las prácticas de dirección de recursos humanos según la estrategia de la empresa (Arthur, 1994; Youndt et al, 1996). Bajo esta corriente destacan los trabajos orientados a identificar cuáles son los sistemas de prácticas más adecuados a cada estrategia de la empresa, principalmente, analizando la estrategia make o buy (Miles y Snow, 1984) o la estrategia de liderazgo en costes o diferenciación (Porter, 1980).

Y, por último, destaca el enfoque configuracional de dirección estratégica de recursos humanos (Wright y McMahan, 1992). Los trabajos de esta categoría plantean el ajuste de las prácticas de recursos humanos con la estrategia organizativa como factor vital en la relación dirección entre la dirección estratégica de recursos humanos y el desempeño organizativo. Estos trabajos dan un paso más allá que el enfoque contingente, al considerar que existen “tipos ideales” de sistemas de prácticas de recursos humanos que se ajustan, tanto horizontal como verticalmente, a los objetivos y a la organización (Ferris et al., 1999). Además, otorgan una gran importancia al concepto de ajuste. Dolan et al. (2004) señalan que para lograr el impacto óptimo es necesario que exista ajuste o consistencia interna entre las distintas prácticas que forman el sistema de prácticas de recursos humanos ${ }^{20}$. Numerosos trabajos lo evidencian (Huselid, 1995; MacDuffie, 1995; Arthur, 1992; Ichniowski, Shaw y Prennushi, 1997). Por otro lado, el ajuste vertical (o ajuste externo) se refiere a la congruencia que debe existir entre el sistema de prácticas de recursos humanos y otras características organizativas como, por ejemplo, la estrategia. Bajo esta perspectiva, las organizaciones deben desarrollar sistemas de prácticas de recursos humanos que cumplan tanto con el ajuste interno como con el externo (Beckert y Gerhar, 1996).

Con el objetivo de resumir las clasificaciones y trabajos revisados, presentamos la Tabla 1.3 .

\footnotetext{
${ }^{20}$ También denominado ajuste horizontal. Alude a la coordinación entre las diversas prácticas de recursos humanos implantadas en la organización, consiguiendo una coherencia interna entre ellas.
} 
Tabla 1.3. Principales métodos de clasificación de los sistemas de prácticas de recursos humanos

\begin{tabular}{|c|c|c|}
\hline $\begin{array}{l}\text { Método de clasificación de } \\
\text { sistemas }\end{array}$ & $\begin{array}{c}\text { Propuesta de clasificación de sistemas y de } \\
\text { prácticas de recursos humanos }\end{array}$ & Trabajos relevantes \\
\hline \multirow{3}{*}{$\begin{array}{l}\text { Objetivo de las prácticas del } \\
\text { sistema }\end{array}$} & $\begin{array}{l}\text { Sistema AMO, habilidades-motivación y } \\
\text { oportunidades. Y sistema AME, habilidades- } \\
\text { motivación y empowerment }\end{array}$ & $\begin{array}{l}\text { McDuffie (1995), Delery, Gupta y } \\
\text { Shaw (1997), Gardner, Moynihan, Park } \\
\text { y Wright (2000) }\end{array}$ \\
\hline & $\begin{array}{l}\text { Según las prácticas se orienten a: 1) compartir } \\
\text { información, 2) conocimientos y habilidades, 3) } \\
\text { poder y recompensas }\end{array}$ & Lawler, 1986; Lee y Chee, 1996 \\
\hline & $\begin{array}{l}\text { 1) habilidades del empleado y estructura } \\
\text { organizativa; 2) motivación del empleado }\end{array}$ & Huselid, 1995 \\
\hline \multirow{3}{*}{ Análisis cluster } & Sistemas de compromiso o sistemas de control & Arthur, 1992 \\
\hline & $\begin{array}{l}\text { Sistemas de implicación, sistemas tradicionales, } \\
\text { sistemas de identificación y sistemas nulos }\end{array}$ & Ostroff, 2000 \\
\hline & $\begin{array}{l}\text { Sistemas personales, de alineación, de } \\
\text { compensación y de alto rendimiento }\end{array}$ & Becker y Huselid (1996) \\
\hline \multirow{3}{*}{$\begin{array}{c}\text { Ajuste entre los sistemas de } \\
\text { prácticas de recursos } \\
\text { humanos y la estrategia } \\
\text { empresarial }\end{array}$} & $\begin{array}{l}\text { Universalistas: existe un único sistema } \\
\text { universalmente óptimo }\end{array}$ & $\begin{array}{l}\text { Delaney et al., 1989; Huselid, 1995; } \\
\text { Pfeffer, 1994; Delery y Doty, } 1996\end{array}$ \\
\hline & $\begin{array}{l}\text { Contingentes: el sistema más adecuado depende } \\
\text { de la estrategia y contingencia de la empresa }\end{array}$ & $\begin{array}{l}\text { Dyer, 1985; Dyer et al, 1988; 1995; } \\
\text { Lengnick-Hall y Lengnick-Hall, 1988; } \\
\text { Milkovich, 1988; Arthur, 1994; Youndt } \\
\text { et al, 1996; Jackson y Schuler, 1995; }\end{array}$ \\
\hline & $\begin{array}{l}\text { Configuracionales: el sistema depende de la } \\
\text { contingencia de la empresa y del ajuste horizontal } \\
\text { y vertical }\end{array}$ & $\begin{array}{l}\text { Wright y McMahan, 1992; Arthur, } \\
\text { 1992; Huselid, 1995; MacDuffie, 1995; } \\
\text { Beckert y Gerhar, 1996; Ichniowski, } \\
\text { Shaw y Prennushi, 1997; Chew y } \\
\text { Horwitz, } 2004 \\
\end{array}$ \\
\hline
\end{tabular}

\subsection{Trabajos emergentes de clasificación de prácticas de recursos humanos}

Debido al creciente interés por el conocimiento y su gestión dentro de la organización, la investigación en recursos humanos incorpora nuevas propuestas de clasificación de los sistemas de prácticas de recursos humanos. Desde finales de la década de los noventa hasta la actualidad, diversos trabajos incorporan nuevos criterios para clasificar las prácticas y sistemas de prácticas de recursos humanos y consideran los términos “configuraciones” o “arquetipos” para denominar a estos sistemas de prácticas.

Así, en primer lugar, podemos destacar los trabajos que se acercan al enfoque de conocimiento e incorporan, expresamente, variables de la gestión del conocimiento. En este sentido, cabe destacar el trabajo de Morris et al. (2005) quienes distinguen entre 
prácticas de recursos humanos orientadas al desarrollo del stock de conocimiento y aquéllas prácticas orientadas a favorecer los flujos de conocimiento dentro de la organización. En esta línea, Kang, Morris y Snell (2007) distinguen entre configuraciones de prácticas orientas a favorecer comportamientos emprendedores y configuraciones orientadas a favorecer comportamientos cooperativos de los empleados, según las formas de transferir, compartir y hacer fluir el conocimiento.

En segundo lugar, identificamos otro grupo de trabajos que incorporan variables relativas al capital humano (capital intelectual, social y afectivo) para clasificar las prácticas de recursos humanos. En este ámbito, destaca el trabajo de Youndt y Snell (2004) quienes proponen seis configuraciones de prácticas de recursos humanos en función del tipo de capital sobre el que se quiera influir y cómo influir (orientada a adquirir, a crear, que sea igualitaria, colaborativa, documentativa y de tecnologías de la información).

En tercer lugar, podemos distinguir un grupo de trabajos que clasifican las configuraciones o arquetipos de prácticas en función de las peculiaridades del colectivo de empleados al que se dirijan, principalmente, si son o no son estratégicos o de alto valor para la empresa, y en función de la tipología de su relación contractual y de empleo. Dentro de este tipo de propuestas debemos destacar los trabajos de Tsui, Pearce, Porter y Hite (1995); Tsui, Pearce, Porter y Tripoli (1997); Lepack y Snell (1999; 2002); Hitt, Bierman, Shimizu y Kochlar (2001); Wang, Tsui, Zhang y Ma (2003); Lepak, Taekuchi y Snell (2003) y, especialmente, el trabajo de Tsui y Wu (2005). Debido a la implicación que dos de estos trabajos van a tener en nuestra investigación, creemos necesario detenernos y comentarlos brevemente. Son los trabajos de Lepack y Snell (1999; 2002) y el trabajo de Tsui y Wu (2005). Primero, Lepack y Snell (1999; 2002) proponen diferenciar entre cuatro configuraciones de prácticas de recursos humanos. Para ello, tienen en cuenta por un lado, lo valiosos que sean los recursos humanos (según su valor y escasez), por otro, el modo de empleo (internalizados o externalizados) y, por último, la relación de empleo que desarrollen (transaccional o relacional). Estas dimensiones permiten diferenciar cuatro configuraciones de prácticas de recursos humanos según se orienten a: la colaboración, 
al compromiso, a la conformidad y a la productividad. La figura A1.2 del Anexo I sintetiza estas ideas. Y, segundo, también debemos detenernos en el trabajo de Tsui y Wu (2005). Estos autores argumentan la necesidad de considerar un nuevo tipo de relación de empleo que supere a la relación tradicional de empleo, puesto que dichas relaciones condicionan las prácticas a desarrollar con los empleados. Así, teniendo en cuenta los incentivos ofrecidos a los empleados y las contribuciones esperadas de ellos, Tsui y Wu definen cuatro situaciones: dos situaciones de relación de empleo en la que está en equilibrio (bajos incentivos-bajas contribuciones y, otra, de altos incentivos-altas contribuciones; esta última es la denominada "relación de inversión mutua"-se considerada la situación óptima-) y dos situaciones de desequilibrio (una, de sobreinversión y, otra, de infra-inversión). La Figura A1.3 del Anexo I de esta tesis representa esta propuesta. Lo más relevante de estos trabajos es que justifican y señalan la importancia de diferenciar al colectivo de empleados estratégicos junto a la necesidad de desarrollar relaciones especiales de empleo con ellos y, a la par, diseñar prácticas de gestión y retención adecuadas a cada uno de los colectivos.

Y, por último, en cuarto lugar, diferenciamos otro grupo de trabajos de dirección de recursos humanos, muy relacionados con el grupo anterior, que proponen clasificar las configuraciones de prácticas de recursos humanos en función de su orientación, hacia la dimensión transaccional o hacia la dimensión relacional de la relación de empleo. Tras el trabajo de Tsui y Wu (2005) queda constancia de la multidimensionalidad de las motivaciones de los empleados, los cambios sucedidos en la fuerza laboral y la necesidad de "actualizar” la relación de empleo, otorgando una mayor importancia a la faceta social-relacional. De hecho, Hislop (2005) destaca la necesidad de diferenciar entre dos tipos de contrato o relación de empleo: contrato transaccional y relacional ${ }^{21}$. Estas consideraciones han conducido a los investigadores a diferenciar entre dos tipos de prácticas de recursos humanos coherentes con la relación de empleo que las

\footnotetext{
${ }^{21}$ La distinción entre transaccional y relacional (Rousseau, 1990; McDonald y Makin, 2000; Morrison y Robinson, 1997) es recurrente en la literatura (Hislop 2005, Galunic y Anderson, 2000) y se apoya en la teoría del contrato psicológico. Los contratos transaccionales son aquellos en los que el nivel de lealtad y compromiso del empleado es limitado y la relación de empleo se analiza, básicamente, en términos económicos. En cambio, los contratos relacionales, existen cuando se da un sentido de ajuste a la organización; la lealtad y el compromiso están presentes de forma significativa en los empleados, existiendo, además, una fuerte componente emocional en la relación de empleo.
} 
organizaciones desarrollan con sus empleados: las prácticas transaccionales y las prácticas relaciones. Las transaccionales son aquellas prácticas que satisfacen la dimensión clásica, recogida en la relación de empleo tradicional (p.e. retribución, tipo de contrato, condiciones laborales, diseño del puesto, formación, promoción, etc.) y, por su parte, las prácticas relacionales, son aquellas orientadas a satisfacer la dimensión social-relacional del empleado (p.e. sistemas de participación del empleado, comunicación interna, relaciones con pares, subordinados y compañeros, prácticas que favorezcan la motivación y la implicación, etc.). Esta clasificación subyace en diversos estudios de recursos humanos (Coff, 1997; Alvesson, 2000; Lengnick-Hall y LengnickHall, 2003; Morris, Snell y Lepack, 2005; Kang, Morris y Snell, 2007).

Esta clasificación -transaccional-relacional- también está presente en otras investigaciones bajo diferentes denominaciones. Así, por ejemplo algunos autores utilizan la denominación de prácticas “hard” y prácticas “soft” (Gould-Williams y Davies, 2005; Tremblay et al.,2010). Las prácticas con una orientación "hard” pueden ser equiparables a la categoría transaccional y son aquellas orientadas a las incrementar la eficiencia y el control de los empleados. Las prácticas “soft”, pueden ser equiparables a la dimensión relacional, son aquellas que favorecen la participación, la confianza o la colaboración de los empleados. Otros autores proponen otras denominaciones, como Wan Ismail et al., (2010), que distinguen entre (1) prácticas administrativas, aquellas prácticas que forman parte de la implementación de la gestión y dirección de recursos humanos; formarían la parte transaccional (p.e. reclutamiento/selección, formación, diseño del puesto, gestión de retribución, condiciones de trabajos, etc.); y (2) prácticas instrumentales, aquéllas que permiten a la organización alcanzar su misión y visión estratégica (Lado y Wilson, 1994) como, por ejemplo, la gestión del conocimiento, las relaciones internas, el rol de los mandos o el liderazgo, entre otras; es decir, aquéllas que centran su atención en la dimensión relacional de la relación de empleo.

En definitiva, esta reciente taxonomía, que distingue entre prácticas recursos humanos de dimensión transaccional y relacional, será la que seguiremos en nuestra investigación, puesto que permite aglutinar las prácticas de recursos humanos clave para 
lograr la retención de empleados estratégicos, como desarrollaremos en epígrafes posteriores.

Como resumen de este apartado, queremos señalar que a pesar del amplio número de estudios que han evidenciado la relación positiva entre diferentes sistemas de prácticas de recursos humanos y los resultados organizativos (Arthur, 1994; Huselid, 1995; Ichniowski, Shaw y Prennushi, 1997; McDuffie, 1995; Guthrie, 2001, entre otros), la literatura empírica no ha revelado, todavía, una forma única y universal de clasificar las prácticas y sistemas de prácticas de recursos humanos. La literatura de dirección estratégica de recursos humanos sugiere diferentes orientaciones estratégicas a la hora de diseñar los sistemas o configuraciones de prácticas de recursos humanos y diferentes opciones en relación a la composición de los mismos. En definitiva, se confirma la inexistencia de un consenso claro en ambos aspectos y aún es una incógnita saber con certeza qué prácticas de recursos humanos deben ser incluidas por ser más eficaces o si existe un sistema de dirección de recursos humanos ideal y universalmente efectivo o si depende de la estrategia y contingencia de la empresa. Éstas son algunas de las cuestiones sin resolver en el ámbito de la dirección estratégica de recursos humanos y, por tanto, en las que interesa seguir profundizando con nuevos estudios.

Además del problema de identificación de las medidas de resultados organizativos a utilizar y de la elección de las prácticas de recursos humanos adecuadas, otra de las cuestiones que requiere mayor investigación es la identificación de los procesos y elementos mediadores a través de los que la dirección y gestión de recursos humanos influye en el resultado organizativo, es decir, descubrir qué hay en la “caja negra” de la dirección y gestión de recursos humanos (Boselie et al., 2005). A esta cuestión, en particular, dedicamos el siguiente epígrafe.

1.2.4.3. Procesos mediadores de la influencia de la gestión de recursos humanos en los resultados organizativos: la "caja negra” de recursos humanos

Como ya hemos comentado de forma reiterada, la relación entre la gestión de recursos humanos y los resultados de la organización es una cuestión ampliamente contrastada 
empíricamente. Sin embargo, en la actualidad, aún no se tiene un conocimiento detallado sobre los procesos por los que esto ocurre. Por ello, la tendencia actual de muchas investigaciones, en el campo de los recursos humanos, es analizar dichos procesos, es decir, indagar sobre cómo se produce dicho impacto y qué variables o procesos mediadores suceden, abriendo, lo que se ha denominado la “caja negra” de recursos humanos.

Sin embargo, es a partir de finales de los años noventa cuando podemos identificar las primeras propuestas que señalan la existencia de una serie de pasos o procesos mediadores, entre las prácticas de recursos humanos y su impacto sobre el resultado empresarial. Estas propuestas, generalmente, parten de la idea de que las variables de resultado directo de las prácticas de recursos humanos son variables relativas a las actitudes y comportamientos de los empleados que, en etapas posteriores, influyen sobre las variables de resultado empresarial. Destacamos a continuación las propuestas más relevantes y utilizadas en la literatura específica de dirección de recursos humanos.

Una de las primeras propuestas relevantes es el modelo conceptual de Guest (1997) que incorpora diversas etapas y elementos mediadores en la relación entre la gestión de recursos humanos y los resultados empresariales, en concreto, los financieros. Este autor propone tres elementos mediadores: variables resultado de la gestión de recursos humanos, variables de comportamiento de los empleados y variables que recogen el resultado de desempeño. Así, distingue cuatro etapas entre las prácticas de recursos humanos y los resultados financieros, como puede observarse en la Figura 1.10.

Figura 1.10. Modelo Conceptual de Guest (1997)

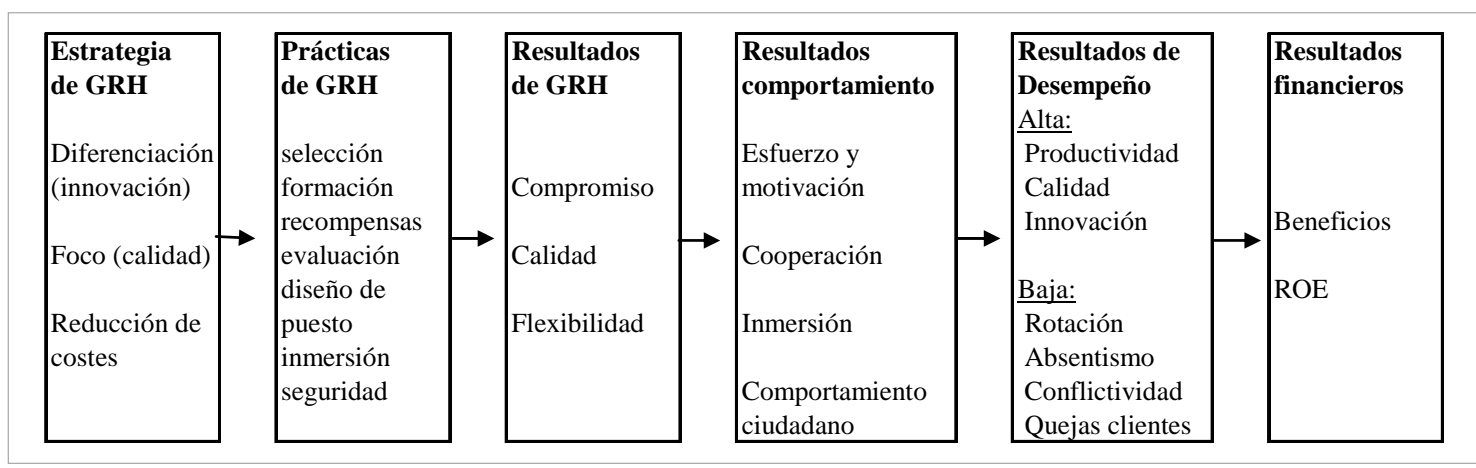

Fuente: adaptado de Guest (1997) 
Contemporáneo a Guest, también destaca la propuesta de Paauwe y Richardson (1997), quienes diferencian una única etapa intermedia. Su propuesta recoge las variables de resultado de la gestión de recursos humanos (actitudes y comportamientos relativos a los empleados) como elementos mediadores que impactan, directamente, sobre el resultado de desempeño organizativo. Como peculiaridad a otras propuestas, estos autores son los primeros que incorporan la relación de causalidad inversa, identificando un ciclo de influencia desde los resultados organizativos hacia las actividades que la empresa desarrolla en materia de recursos humanos, retroalimentando todo el proceso. La Figura 1.11 recoge estas ideas.

Figura 1.11. Modelo de Paauwe y Richardson (1997)

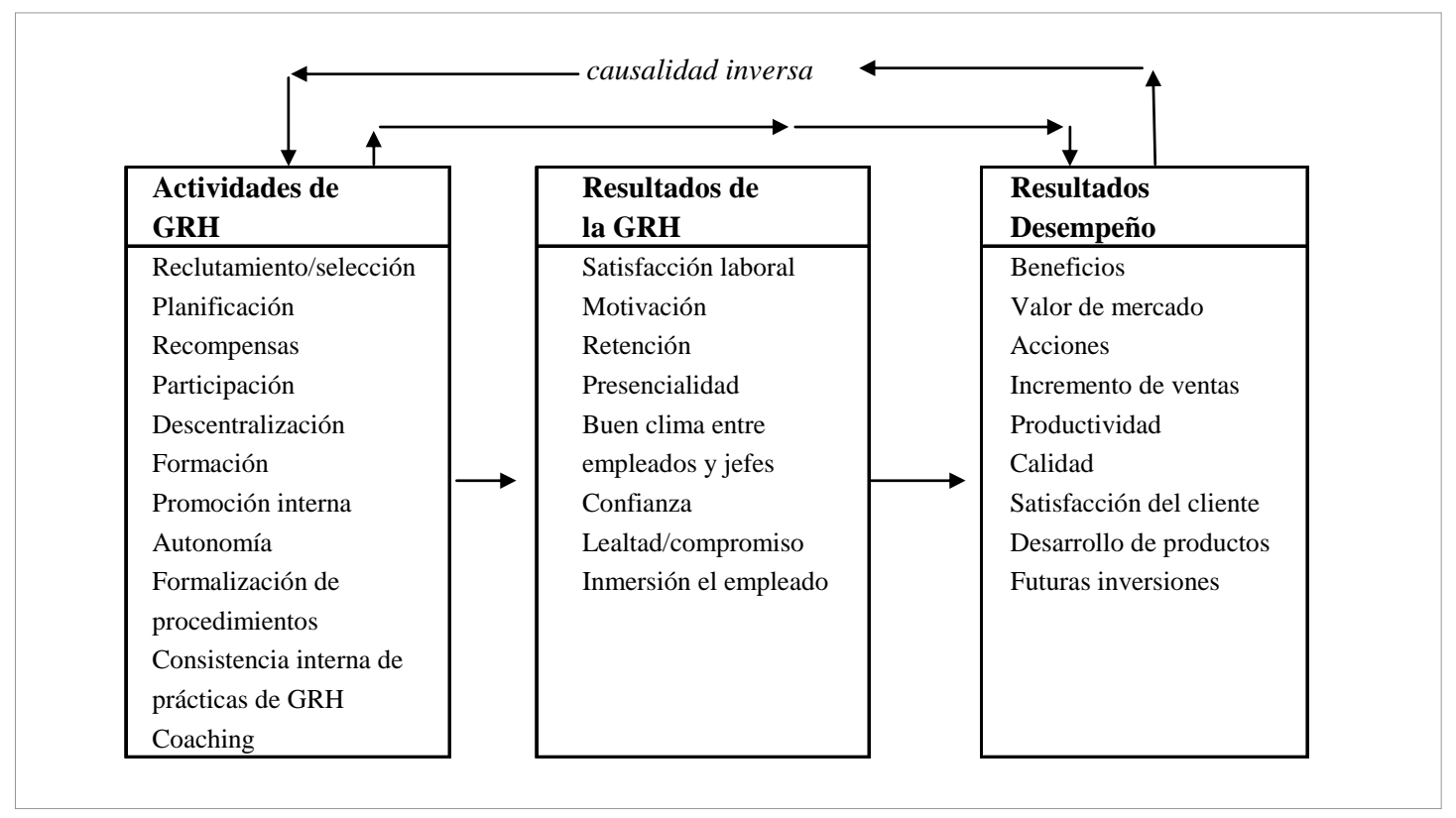

Fuente: adaptado de Paauwe y Richardson (1997) en Boselie et al.(2005)

Posteriormente, Appelbaum, Bailcy, Berg y Kalleberg (2000) también proponen un modelo en el que identifican una única etapa intermedia como elemento mediador: el esfuerzo discrecional de los trabajadores, es decir, el esfuerzo que los trabajadores realizan más allá del esperado por su relación contractual. Además, su propuesta se centra en una categoría concreta de prácticas de recursos humanos (los sistemas de prácticas de alto desempeño) y su efecto sobre el resultado empresarial. La Figura 1.12 sintetiza estas ideas. 
Figura 1.12. Modelo de Appellbaum, Bailey, Berg y Kalleberg (2000)

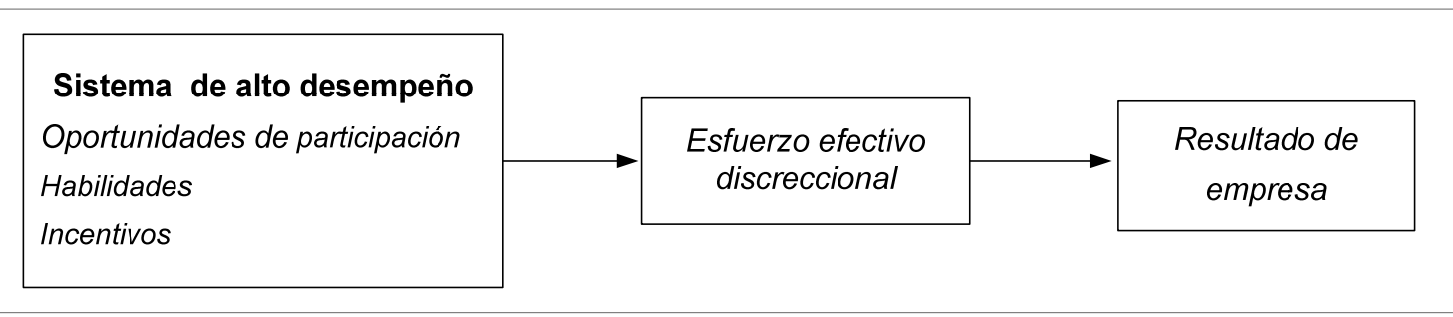

Fuente: adaptado de Appelbaum et al. (2000)

Más recientemente, tomando como referencia los trabajos de Guest (1997) y Paauwe y Richardson (1997), debemos destacar el trabajo de Boselie et al., (2005), quienes ponen de manifiesto la existencia de una serie de procesos mediadores, la existencia de causalidad inversa y plantean la posibilidad de que, también, exista una relación directa entre las prácticas de recursos humanos y ciertos ${ }^{22}$ resultados “internos”. De forma resumida, la Figura 1.13 recoge el modelo planteado por estos autores.

Figura 1.13. Modelo de Boselie et al. (2005)

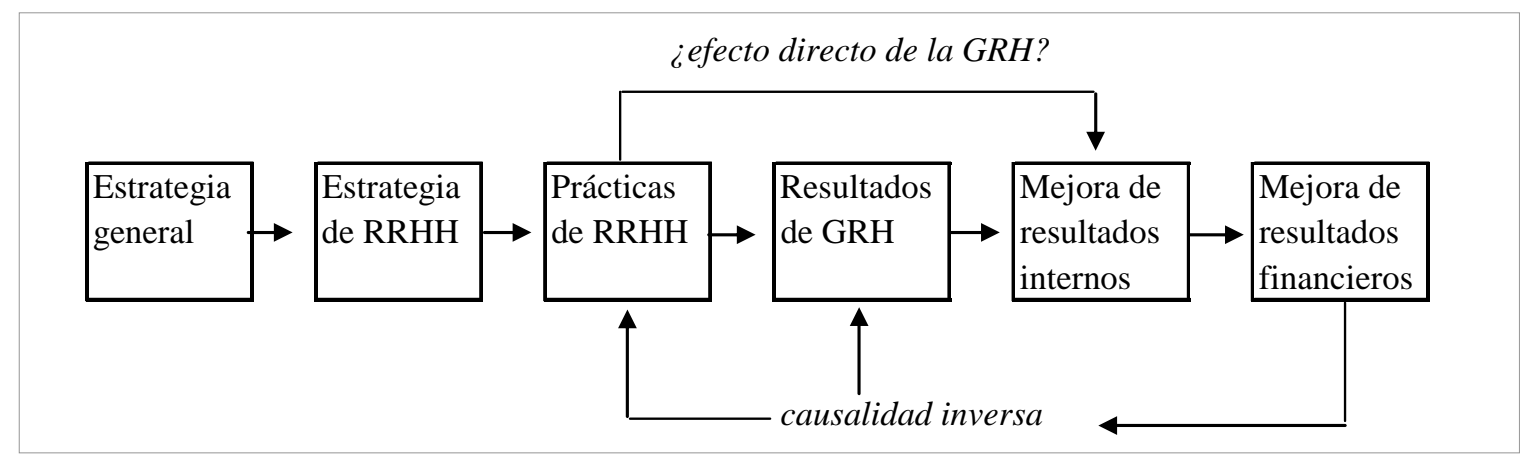

Fuente: Boselie et al. (2005)

En línea con los anteriores trabajos, destacan los modelos teóricos de Way y Johnson (2005) y de Delery y Shaw (2001) apoyando la tesis de que las prácticas de recursos humanos tienen sólo un efecto indirecto sobre el resultado empresarial. Su influencia se produce a través del efecto sobre otras variables intermedias, como son el clima organizativo o los comportamientos y actitudes de los empleados (Tremblay, Cloutier, Simard, Chêneverta y Vandenberghe, 2010). Estos modelos son consistentes con

${ }^{22}$ Estos resultados internos se conciben en términos de medida del comportamiento y actitudes desarrolladas por los empleados como consecuencia de las actividades de gestión de recursos humanos desarrolladas. Se denominan intermedios porque median la relación causal existente entre la gestión de recursos humanos y el desempeño organizativo (Boselie et al., 2005). 
algunos trabajos que demuestran que los resultados de la dirección de recursos humanos, por ejemplo: clima organizativo, retención, comportamientos positivos, colaboración con otros empleados, compromiso, confianza, estabilidad laboral, etc., median en la relación entre las prácticas de dirección de recursos humanos y la eficacia organizativa (Way y Johnson 2005; Sun, Aryee y Law 2007; Tremblay et al., 2010).

Lo cierto es que, cada vez más autores, apuestan por la estudiar la caja negra de la dirección estratégica de recursos humanos y distinguir diferentes etapas intermedias y variables mediadoras. Prueba de ello, es la reciente propuesta de Boxal y Macky (2009). Estos autores postulan que las prácticas de recursos humanos de alta implicación influyen, directamente, sobre variables vinculadas a las personas (p.e. su grado de implicación, su percepción de la retribución, incremento de habilidades, etc.) que, a su vez, influyen sobre los resultados de dos modos: por un lado, directamente mediante un camino cognitivo $\mathrm{y}$, por otro lado, indirectamente, a través de la dimensión motivacional de los empleados (por ejemplo, a través de la confianza organizativa, satisfacción laboral, compromiso organizativo). En definitiva, por un lado, cognitivamente, se favorece el "poder hacer" del empleado incrementando su cualificación, favoreciendo la colaboración y comunicación con otros empleados de forma que pueda llevar a cabo mejor su trabajo, etc. Por otro lado, motivacionalmente, a través de prácticas de empowerment, incentivos, etc., que repercuten de forma positiva en el compromiso, satisfacción laboral y confianza organizativa, se busca mejorar el “querer” hacer del empleado. De este modo, a través de ambos caminos se explica la mejora de los resultados de la organización (Véase la Figura 1.14). 
Figura 1.14. Modelo de Boxal y Macky (2009)

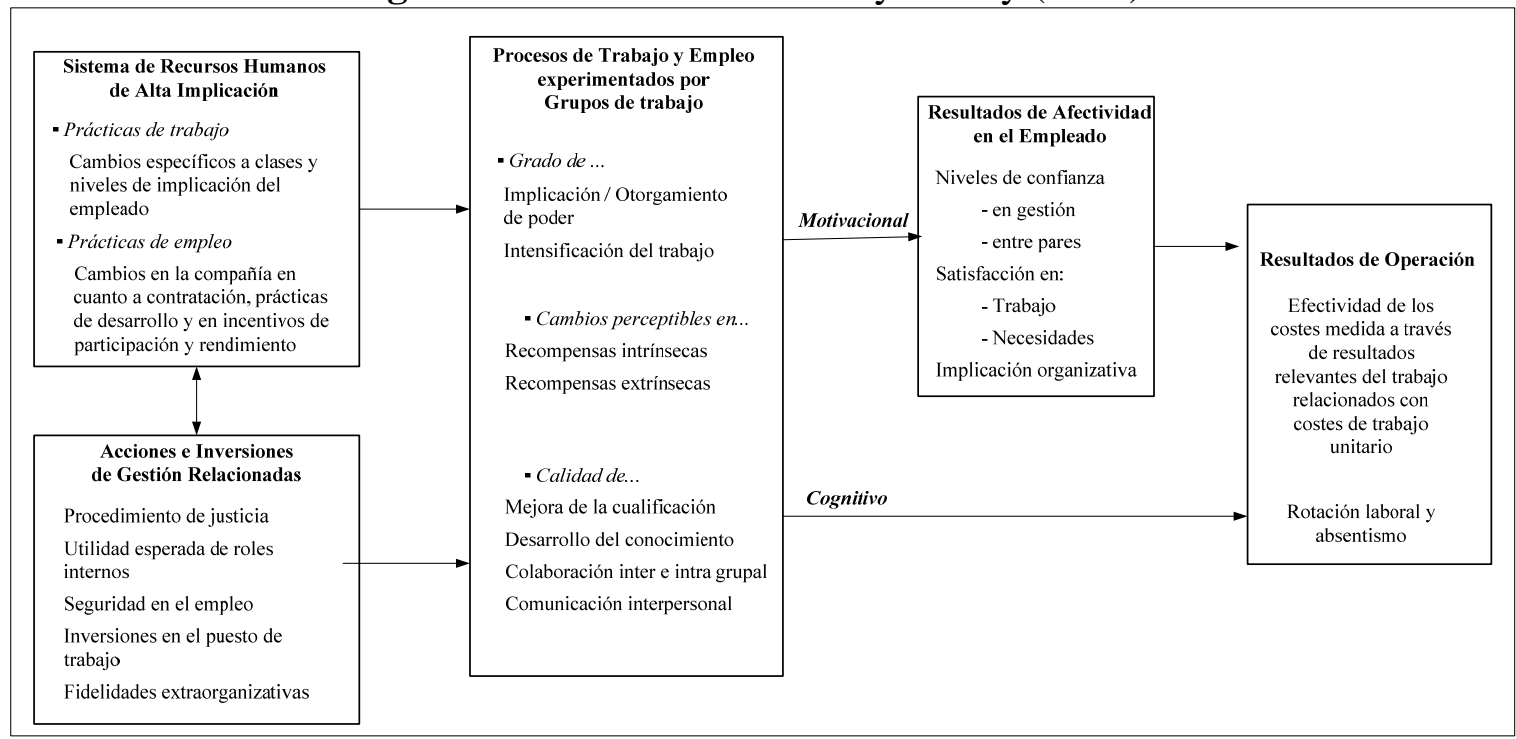

Fuente: adaptado de Boxal y Macky (2009)

Uno de los aspectos que más destaca de la anterior propuesta de Boxal y Macky (2009) es que las etapas intermedias incluyen variables de recursos humanos equiparables con las dimensiones de capital humano. Según Boxal y Macky (2009), las prácticas de recursos humanos influyen, por un lado, sobre el capital intelectual, por cuanto potencian y desarrollan las habilidades y los conocimientos de los empleados; por otro lado, influyen sobre el capital social, por cuanto mejoran la calidad de la colaboración inter e intra grupos y la comunicación interna, factores que contribuyen positivamente al desarrollo del capital social; y, por último, influyen sobre el capital afectivo, por cuanto afectan (indirectamente, según estos autores) a la dimensión motivacional y afectiva, al condicionar su nivel de confianza, satisfacción laboral y compromiso organizativo. Este será uno de los trabajos claves que apoyan el modelo que describiremos en el siguiente capítulo.

Teniendo en cuenta la revisión que hemos realizado para este trabajo, hemos encontrado que una de las características comunes, en gran parte de los trabajos consultados, es la inclusión del efecto mediador de variables que recogen los comportamientos y las actitudes de los empleados. En este sentido, podemos señalar algunos, como, por ejemplo, el de Guzzo, Noonan y Elron (1994) quienes estudiaron la influencia de las prácticas de recursos humanos sobre la intención de abandono contrastando el papel mediador del compromiso organizativo y la percepción del soporte organizativo. 
Wayne, Shore y Liden (1997) evaluaron el efecto de las prácticas de recursos humanos sobre el resultado empresarial, examinando el papel mediador del soporte organizativo y la calidad de la relación de intercambio con el líder. Posteriormente, Meyer y Smith (2000) estudiaron el impacto que las prácticas de recursos humanos ejercían sobre el compromiso organizativo y analizaron el efecto mediador de la justicia de procedimiento y el soporte organizativo. En esa misma línea, Whitener (2001) exploró la influencia del soporte organizativo sobre el compromiso el papel mediador de la confianza y el papel moderador de las prácticas de recursos humanos. Además, Allen, Shore y Griffeth (2003) evaluaron el efecto de las prácticas de recursos humanos sobre la rotación voluntaria y el efecto mediador del compromiso y soporte organizativo. Por su parte, Gould-Williams (2003) confirmó la influencia directa de las prácticas de recursos humanos sobre varias variables de resultado de recursos humanos (como la retención, intención de permanencia y esfuerzo del empleado) y el papel mediador del compromiso, la satisfacción y la confianza. Posteriormente, Paré y Tremblay (2007) examinaron el efecto de las prácticas de recursos humanos sobre la intención de abandono y el papel mediador de la justicia, el compromiso y comportamientos ciudadanos "extras".

Los trabajos que acabamos de señalar pertenecen al cuerpo de trabajos que analizan variables mediadoras relacionadas con los comportamientos y actitudes de los empleados. De hecho, también queremos destacar el trabajo de Gould-Williams (2007) y el de Tremblay et al. (2010). Estos autores señalan que el estudio del impacto de las prácticas de recursos humanos sobre las actitudes y comportamientos de los empleados está captando, cada vez, mayor atención en la literatura de recursos humanos; así como, también, destacan la tendencia a estudiar estos mecanismos mediadores desde diversos enfoques teóricos como, por ejemplo, la teoría del intercambio social, la teoría del comportamiento, la teoría de contrato psicológico, entre las más relevantes. De hecho, Tremblay et al. (2010) afirman que, a pesar del reconocimiento de la relevancia de la faceta psicológico-actitudinal de los empleados, el papel que la gestión de recursos humanos juega en relación a esos factores mediadores ha sido inexplorado. Por ello, existe una tendencia actual, en los estudios de dirección estratégica de recursos humanos, a dar entrada teórica a otras disciplinas, como la teoría del comportamiento, el 
intercambio social o el contrato psicológico que pueden complementar al enfoque de recursos y capacidades, puesto que permiten explicar cómo variables organizativas (p.e. sistemas de prácticas de recursos humanos) influyen sobre los comportamientos, actitudes y afectos del empleado que, posteriormente, se traduce en mejoras de resultado de la organización.

En este trabajo, también utilizaremos esta visión ecléctica, pues como veremos en el capítulo dos, nuestra propuesta incluye una serie de efectos mediadores en la influencia de la dirección y gestión de recursos humanos sobre el resultado empresarial. Por tanto, aunque el soporte teórico fundamental del presente trabajo es el enfoque de recursos y capacidades, en concreto, su extensión de dirección estratégica de recursos humanos, también utilizaremos algunos de los argumentos que ofrecen otras perspectivas teóricas derivadas de la teoría del comportamiento, como son el contrato psicológico y el intercambio social. Así, de forma conjunta, pretendemos poder explicar mejor el impacto que la gestión de recursos humanos puede ejercer sobre el resultado empresarial, a través del capital humano estratégico de la organización.

Como síntesis de este epígrafe, y hasta donde alcanza nuestro conocimiento en esta materia, podemos señalar que todavía no se tiene certeza sobre cuántas y cuáles son las etapas intermedias o elementos mediadores que permiten explicar el impacto de la dirección de recursos humanos sobre el resultado empresarial. Ésta sigue siendo una cuestión abierta y, por tanto, de gran interés para nuevas investigaciones.

Además, por otro lado y en relación a los resultados organizativos sobre los que la gestión de recursos humanos puede influir, directa o indirectamente, debemos señalar que debido a los cambios tan turbulentos y rápidos que caracterizan a los mercado actuales, las organizaciones se ven avocadas a competir, no sólo en términos de calidad y coste, sino también, en términos de tiempo en el mercado y, sobre todo, en grado de innovación de sus productos (Wan Ismail et al., 2010:407). En este nuevo contexto se considera la capacidad de innovación y la innovación como factores pertinentes para medir el resultado organizativo (Wan Ismail et al., 2010). En este escenario, recientes estudios manifiestan que la gestión de recursos humanos puede jugar un papel clave e 
influir sobre el desarrollo de la innovación (Chew y Huang, 2009). Por ello, nos interesa profundizar en la innovación como una medida de resultado empresarial y prestar una especial atención al papel que la gestión de recursos humanos y los propios recursos humanos pueden jugar en el desarrollo de la capacidad de innovación y en el logro de innovaciones en la organización. En consecuencia, dedicamos el siguiente epígrafe a analizar esta cuestión, centrándonos en este tipo particular de resultado organizativo que reclama de nuevos estudios que profundicen en el mismo.

\subsubsection{Gestión de recursos humanos e innovación}

Los mercados están cada vez más globalizados, son más competitivos y el ritmo del cambio tecnológico se acelera. En este escenario tan cambiante, las organizaciones deben competir, no sólo en términos de calidad y coste sino, también, en términos de innovación (Wan Ismail et al., 2010). En este contexto, surge con fuerza un nuevo criterio para hacer frente a la competencia: la innovación. La innovación y, por ende, la capacidad de innovación (como antecedente de la innovación), son factores clave para alcanzar ventajas competitivas sostenibles en el tiempo. Por ello, a continuación, una vez que reconozcamos su valor estratégico y definamos, tanto la innovación como la capacidad de innovación, nos detendremos en analizar la influencia que la gestión de recursos humanos, a través del capital humano (intelectual, social y afectivo) y de las prácticas de recursos humanos, puede ejercer para favorecer el desarrollo innovador de la empresa. A estas cuestiones dedicamos las siguientes páginas.

No obstante, de forma previa a abordar las mencionadas cuestiones queremos destacar el carácter estratégico de la innovación, puesto que la capacidad de innovación se ha consolidado como una de las fuentes críticas para genera las ventajas competitivas (Galende y Suárez, 1999; Galende, 2006). Este carácter estratégico de la innovación, ya fue puesto de manifiesto por autores pioneros en la materia. Cabe destacar a Schumpeter (1939), quien señalaba a la innovación como una variable crucial para la supervivencia y crecimiento a largo plazo de la empresa (Naranjo et al., 2008).

El enfoque de recursos y capacidades enfatiza la importancia de la innovación como una de las fuentes de ventajas competitivas (Hall, 1993; Carmeli, 2001; Gopalakrishnan y Bierly, 2001). Para Prahalad y Hamel (1990) la competitividad en el largo plazo se 
deriva de la posibilidad de crear, a menor coste y más rápidamente que los competidores, tecnologías y habilidades esenciales que den lugar a productos absolutamente innovadores. Asimismo, Martínez, Charterina y Araujo (2010) identifican este enfoque como el más apropiado para analizar el impacto de otros recursos intangibles (de tipo humano, comercial u organizativo) sobre la innovación (Galende y Suárez, 1999) y para analizar el proceso de innovación desde el punto de vista interno (Leornard-Barton, 1992; Helfat, 1994, 1997).

En esta línea, Tether (2003) señala que la innovación está asociada con una actitud y un conjunto de prácticas y comportamientos asociados a esa actitud. Por tanto, la innovación se considera una capacidad dinámica (Zollo y Winter, 2002) en la que los recursos humanos, con sus conocimientos, comportamientos y actitudes, juegan un importante papel. También, Saa-Pérez y Díaz-Díaz (2007) consideran la innovación como una capacidad dinámica de conocimiento tecnológico que comprende la aplicación y materialización del conocimiento adquirido y generado en la obtención de nuevos productos y/o procesos. Es decir, la innovación refleja la capacidad para transformar y explotar el conocimiento tecnológico (Zahra y George, 2002).

Dotando de un carácter más global al concepto de innovación, Perdomo, González y Galende (2006) la consideran un resultado de diversos aspectos de la empresa (planificación y compromiso de la dirección, comportamiento e integración, proyectos, conocimientos y habilidades, información y comunicación y entorno externo) poniendo de manifiesto la dificultad para poder definirlo.

\subsection{Concepto de innovación}

El estudio de la innovación ha dado lugar a un extenso número de trabajos. Sin embargo, hasta donde alcanza nuestro conocimiento, todavía no existe ni un marco teórico único ni una forma de análisis universal desde la que abordar su estudio, ni tampoco existe un consenso sobre su concepto (Gopalakrishnan y Damanpour, 1997; Jiménez Jiménez y Sanz Valle, 2007). En lo que sí parece haber un mayor acuerdo en considerar que todas las conceptualizaciones de innovación aluden al concepto de novedad (Zaltman et al., 1973; Damanpour, 1991; Nohria y Gulati, 1996; Johannessen et al., 2001). La innovación puede tener diferentes significados o definiciones 
dependiendo del contexto y objetivo de estudio (García-Mulero, 2007), sin embargo, de forma general, se entiende que la innovación va asociada a la capacidad de una empresa para adoptar algo nuevo. Tras la revisión de la literatura, queremos hacer notar cuatro aspectos claves que caracterizan la innovación: supone la introducción de algo nuevo, es un proceso, supone el desarrollo de algún avance o cambio y tiene la intención deliberada de generar ventajas para la organización (Perdormo-Ortiz et al., 2006; Naranjo, Sanz y Jiménez, 2008; Huang et al., 2009a; Benítez- Amado et al., 2010).

La innovación en la organización puede ser muy diversa. Esto ha dado lugar a diferentes tipos o clasificaciones de innovación. Por ejemplo, Lynn (1998) propone diferenciar entre innovaciones tecnológicas (se realizan a través del uso de nuevas tecnologías) e innovaciones de mercado (productos/servicios existentes son vendidos en nuevos mercados). Por su lado, Tidd, Bessant y Pavitt (1997) distinguen entre innovaciones de producto, servicio y proceso, mientras que Boer y During (2001) diferencian entre innovación de producto (desarrollo de nuevos productos o servicios), innovación de proceso (introducción de nuevos sistemas de producción o técnicas de servicio) e innovación organizativa (creación de nuevas formas de organización o prácticas de gestión o dirección). Posteriormente, Hislop (2005) apuesta por diferenciar entre innovación incremental o radical (si el cambio es a través de una secuencia de pequeños cambios o supone cambios fundamentales), e innovación orientada a producto o a servicio (si se diseña un nuevo producto/servicio o se modifican los existentes).

Debemos señalar que, puesto que la capacidad de innovación se identifica como la que provee a la empresa del potencial necesario para lograr desarrollar de forma efectiva la innovación (Terziovski, 2007), numerosos estudios utilizan, indistintamente, los conceptos de capacidad de innovación y de innovación e, incluso, miden la capacidad de innovación a través de los indicadores que miden la innovación (Tidd et al., 1997; Tang, 1998; Calentone et al., 2002; Pavitt, 2003; Perdomo-Ortiz, et al., 2006; Terziovski, 2007; Sáez, Aramburu y Rivera, 2009). Sin embargo, otros autores (Teece, 1997; Wan Ismail et al., 2010) manifiestan la necesidad de diferenciar entre ambos conceptos, al considerar que pertenecen a diferentes niveles del proceso de innovación en la empresa. Así, consideran que la capacidad de innovación es una variable de 
resultado intermedio que influye, directamente, sobre la innovación, a la que definen como variable de resultado final. En este trabajo también seguiremos esta línea argumental, considerándola una antecedente de la innovación final.

La capacidad de innovación es un constructo complejo, lo que ha derivado en que numerosos autores, más que ofrecer una definición concreta, hayan dedicado sus esfuerzos a estudiar e identificar los procesos y factores críticos de su éxito con el fin de descubrir cómo se desarrolla en las empresas (Tidd et al., 1997; Tang, 1998; Pavitt, 2003; Perdomo-Ortiz et al., 2006, entre otros). Así, algunas de las definiciones más relevantes entienden la capacidad de innovación como la capacidad que permite a la empresa crear, ampliar o modificar su recurso básico, el conocimiento (Helfat et al., 2007). Otros autores, definen la capacidad de innovación como la predisposición cultural de la empresa para innovar, considerando que surge de una cultura organizacional que estimula a los empleados a ser innovadores en el desarrollo de nuevos productos o procesos (Santos Vijande y Álvarez-González, 2007). Otros la definen en base a su potencial para poder innovar (Terzouvski, 2007). En definitiva, al igual que ocurre con la innovación, no existe una definición universal sobre la capacidad de innovación. En la Tabla 1.4 se recogen algunas de las principales definiciones revisadas sobre capacidad de innovación e innovación.

Tabla 1.4. Principales definiciones de capacidad de innovación y de innovación

\section{CAPACIDAD DE INNOVACIÓN}

\begin{tabular}{|l|l|}
\hline Lall (1992) & $\begin{array}{l}\text { Las habilidades y conocimientos necesarios para absorber, dominar y } \\
\text { mejorar tecnologías existentes y crear otras nuevas }\end{array}$ \\
\hline $\begin{array}{l}\text { Lawson y Samson } \\
\text { (2002) }\end{array}$ & $\begin{array}{l}\text { La habilidad de transformar conocimiento e ideas en nuevos productos, } \\
\text { procesos o sistemas para el beneficio de la empresa y sus stakeholders. }\end{array}$ \\
\hline Terziovski (2007) & $\begin{array}{l}\text { Aquella capacidad que provee a la organización del potencial para poder } \\
\text { innovar de forma efectiva }\end{array}$ \\
\hline Helfat et al.(2007) & $\begin{array}{l}\text { Aquella capacidad que permite a la organización crear, ampliar o } \\
\text { modificar su recurso básico: el conocimiento }\end{array}$ \\
\hline Santos et al. (2007) & $\begin{array}{l}\text { La predisposición cultural de la empresa para innovar, considerando que } \\
\text { surge de una cultura organizacional que estimula a los empleados a ser } \\
\text { innovadores en el desarrollo de nuevos productos o procesos }\end{array}$ \\
\hline
\end{tabular}




\begin{tabular}{|c|c|}
\hline \multicolumn{2}{|l|}{ INNOVACIÓN } \\
\hline $\begin{array}{l}\text { Damanpour y } \\
\text { Gopalakrishnan } \\
\text { (1998) }\end{array}$ & La adopción de una idea o comportamiento nuevo para la organización \\
\hline $\begin{array}{l}\text { Boer y During } \\
(2001)\end{array}$ & $\begin{array}{l}\text { Diferencian entre innovación 1) de producto-nuevos productos o } \\
\text { servicios-, 2) de proceso-nuevos sistemas de producción o técnicas de } \\
\text { servicio- y 3) organizativa -nuevas formas de organización o prácticas de } \\
\text { gestión o dirección-. }\end{array}$ \\
\hline $\begin{array}{l}\text { Zollo y Winter } \\
\text { (2002) }\end{array}$ & $\begin{array}{l}\text { Definición desde una perspectiva dinámica. Es el modelo aprendido y } \\
\text { estable de actividad colectiva a través del que la organización, de forma } \\
\text { sistematizada, genera y modifica sus rutinas operativas con el propósito } \\
\text { de incrementar su efectividad” }\end{array}$ \\
\hline $\begin{array}{l}\text { Zahra y George, } \\
\text { (2002) }\end{array}$ & $\begin{array}{l}\text { La innovación refleja la capacidad para transformar y explotar el } \\
\text { conocimiento tecnológico }\end{array}$ \\
\hline $\begin{array}{l}\text { Manual de Oslo } \\
\text { (OCDE, 2005) }\end{array}$ & $\begin{array}{l}\text { La introducción de un nuevo, o significativamente mejorado, producto } \\
\text { (bien o servicio), proceso, método de comercialización o método } \\
\text { organizativo en las prácticas internas de la empresa, la organización del } \\
\text { lugar de trabajo o las relaciones exteriores }\end{array}$ \\
\hline Hislop (2005) & $\begin{array}{l}\text { La modificación o transformación, que de forma deliberada realiza una } \\
\text { organización, de sus productos/servicios, procesos o estructuras. }\end{array}$ \\
\hline $\begin{array}{l}\text { Leede y Looise } \\
\text { (2005) }\end{array}$ & $\begin{array}{l}\text { Un cambio deliberado y radical en los productos existentes, en los } \\
\text { procesos o en la organización, de modo que se alcance una ventaja } \\
\text { competitiva sobre los competidores }\end{array}$ \\
\hline $\begin{array}{l}\text { Saa-Pérez y Díaz- } \\
\text { Díaz (2007) }\end{array}$ & $\begin{array}{l}\text { Una capacidad dinámica de conocimiento tecnológico que reprenda la } \\
\text { aplicación y materialización del conocimiento adquirido y generado en la } \\
\text { obtención de nuevos productos y/o procesos }\end{array}$ \\
\hline
\end{tabular}

De forma complementaria a clarificar el concepto de innovación surge la necesidad de precisar cómo medirla.

\subsection{Diversidad de medidas de innovación}

Como acabamos de revisar, no existe una única definición de innovación ni de capacidad de innovación; del mismo modo ocurre con las variables, ítems y criterios tenidos en cuenta para medirlas. Uno de los trabajos más recientes que resume esta diversidad de medidas es el de Wan Ismail et al., (2010). Estos autores ofrecen una interesante clasificación de la evolución de las medidas de innovación. Distinguen una primera etapa, años cincuenta y sesenta, en la que las medidas de innovación se centran en indicadores como: inversión en I+D, personal dedicado a investigación, plantilla con 
formación universitaria, intensidad tecnológica, etc. Posteriormente, entre los años setenta y los ochenta, se van incorporado nuevos indicadores, como: número de patentes, número de publicaciones científicas, número o tipo de nuevos productos, etc. La tercera etapa de indicadores, que abarca la última década del siglo veinte, se caracteriza por la introducción de nuevos tipos de medidas basadas, por ejemplo, en índices de innovación, encuestas de innovación, etc. Por último, identifican una última etapa, a partir del año dos mil, en la que las medidas de innovación incorporan nuevas dimensiones como la internacionalización, la diversidad de empresas, la colaboración entre ellas, etc.. Además, en esta etapa también toman protagonismo ciertos indicadores de innovación vinculados al conocimiento, a la valoración de intangibles, medidas cluster, análisis de las redes de relación (composición, número de participantes), etc. En definitiva, el abanico de opciones que ofrece la literatura es muy extenso y diverso.

\subsection{La gestión estratégica de recursos humanos y la innovación}

En la relación entre la gestión de recursos humanos y los resultados empresariales, es preciso destacar, como ya hemos comentado previamente, un tipo de resultado especialmente importante en el entorno actual: la innovación y, por ende, la capacidad de innovación como su principal antecesora. La tendencia en la literatura reciente es considerar la innovación y la capacidad de innovación como variables de resultado empresarial. Ello se debe a diversas consideraciones. Primero, en el entorno actual, donde la competencia se ha ampliado a nivel mundial y existen mayores turbulencias y presiones, la habilidad de la organización para innovar se ve, cada vez más, como un factor clave para asegurar el éxito empresarial (Cohen y Levinthal, 1990; LeonardBarton, 1995; McGrath, 2001; Tsai, 2001; Shipton et al., 2006). Y, segundo, aunque la literatura ha acumulado un amplio conocimiento sobre la relación entre la gestión de recursos humanos y el resultado organizativo, principalmente medido en términos financieros (Dyer y Reeves, 1995; Huselid, 1995; McDuffie, 1995; Bae y Lawler, 2000; Hutchinson et al., 2003), el conocimiento sobre la contribución de la gestión de recursos humanos al resultado de innovación es aún escasa, por lo que se requiere mayor investigación en la relación entre la gestión de recursos humanos y la innovación (Laursen y Foss, 2003; Shipton et al., 2006). 
Sorprendentemente, hasta esta última década, no se ha comenzado a estudiar en profundidad el vínculo entre la gestión de recursos humanos y el resultado innovador de la empresa. No obstante, ya se puede identificar un incipiente grupo de trabajos relevantes al respecto (Laursen, 2002; Laursen y Foss, 2003; Lau y Ngo, 2004; Leede y Loise, 2005; Jiménez-Jiménez y Sanz-Valle, 2005, Shipton et al., 2006; Saa-Perez y Díaz-Díaz, 2007; Chen y Huang, 2009; Wan Ismail et al., 2010, entre otros).

La literatura de innovación destaca lo importante que es para la empresa poder disponer de un correcto abanico de habilidades y conocimientos (Therrien y Leornad, 2003). Una parte crítica del conocimiento y habilidades que requiere la innovación reside, precisamente, en los empleados. Los conocimientos, habilidades y competencias de los empleados se consideran, por tanto, recursos clave para el desarrollo e innovación de los productos y servicios que ofrecen las organizaciones (López-Cabrales et al., 2009). En otras palabras, existe un amplio reconocimiento de la relevancia del capital humano, principalmente, en su dimensión de capital intelectual, para la innovación (JiménezSanz y Sabater-Sánchez, 2010).

Por otro lado, algunos autores apuestan por el capital humano como variable mediadora en la relación entre la gestión de recursos humanos y la innovación, como resultado organizativo. Este papel mediador ha sido sugerido en recientes trabajos (Morris et al., 2005; Kang, Morris y Snell, 2007). En concreto, este creciente interés se relaciona con la importancia del conocimiento y la innovación en el mundo empresarial actual (Youndt y Snell, 2004), debido a que mucho del conocimiento útil para la empresa, se puede generar a través del capital intelectual, el capital social y el capital afectivo, dimensiones, todas ellas, vinculadas a los recursos humanos estratégicos.

Los trabajos de Youndt y Snell (2004), Morris et al. (2005) y Kang et al., (2007) son trabajos de referencia en la senda de las investigaciones que incorporan al capital humano como variable intermedia o mediadora. Su principal contribución a la literatura de dirección estratégica de recursos humanos es que, mientras que el valor que aportan los recursos humanos ha sido concebido, tradicionalmente, en términos de su capital intelectual y stock de conocimientos, estos trabajos incorporan, además, las relaciones sociales entre los empleados y su dimensión afectiva, como mecanismos que facilitan 
los flujos eficientes de conocimiento y el aprendizaje organizacional. De este modo, se puede crear valor para la organización y, por ende, lograr mejorar los resultados organizativos.

Diversos autores analizan la influencia directa de los propios recursos humanos en la innovación, puesto que consideran que la innovación reside en la inteligencia, la imaginación y/o el conocimiento de los individuos y en que su comportamiento favorezca el desarrollo de la misma (Kanter, 1985; Schuler et al., 1987; Amabile et al., 1996; Huang, Li y Chen, 2009; Benítez, Pérez y Tamayo, 2010). Con ello, están tratando de explicar, cómo contribuye el capital humano a la innovación en la empresa. La relación del capital humano y la capacidad de innovación deriva de la relación entre innovación y conocimiento (Nonaka y Takeuchi, 1995), tanto el relativo al que poseen los individuos -capital intelectual- como el presente en las relaciones en las que éstos participan -capital social-. El capital intelectual incide en la innovación, incluso puede llegar a considerarse requisito previo para su desarrollo (Lane, Koka y Puthak, 2006). Hay autores que lo justifican por la vinculación del conocimiento a la creatividad (Shipton et al., 2005; West et al. 2004; Amabile, 1996), otros, en cambio, se centran en el papel del capital social en la creación de nuevo conocimiento (Morris et al., 2005; Armbretch et al., 2001; Tsai y Ghoshal, 1998) y, por último, otros autores, proponen la esfera afectiva, la generación de actitudes positivas en los empleados, como factor imprescindible para poder desarrollar la capacidad de innovación en la organización (Hislop, 2005). A continuación, nos detenemos en la relación de estas tres dimensiones del capital humano con la innovación en la organización.

En cuanto a la primera dimensión, existe consenso en considerar que el capital intelectual de los recursos humanos es uno de los elementos cruciales para el desarrollo de innovación en las organizaciones (Jiménez-Jiménez y Sabater-Valle, 2010). Por un lado, es debido a que el capital intelectual se forma a través de los conocimientos de los empleados y, sabemos de la demostrada relación entre conocimiento e innovación (Nonaka y Takeuchi, 1995); y, segundo, se debe a la consideración de que la capacidad de innovación de la empresa reside en la inteligencia, imaginación y creatividad de sus empleados (Jiménez-Jiménez y Sabater-Valle, 2010). Así lo ponen de manifiesto 
diversos estudios que avalan que el capital intelectual juega un importante papel en la capacidad de innovación (Zhara y George, 2002; Laursen, 2002; Searle y Ball, 2003; Foss, 2007; Saa-Pérez y Díaz-Díaz, 2007; López-Cabrales, Pérez-Luño y Valle-Cabrera, 2009, entre otros). Sin embargo, no en todos los casos se ha logrado contrastar la influencia positiva del capital intelectual en la innovación, obteniendo resultados, a veces, contradictorios (Pérez-Cano y Quevedo-Cano, 2004).

Respecto a la segunda dimensión, es decir, al capital social, Nonaka $(1991,1994)$ y Nonaka y Takeuchi (1995) asientan las bases para explicar la influencia de esta variable sobre la innovación. Estos autores señalan que el conocimiento necesario para el desarrollo de innovación no sólo se presenta en el capital intelectual sino, también, en las interacciones sociales entre empleados de diferentes secciones de la organización. Esto se debe a que, estas interacciones permiten acceder a un abanico mayor y más rico de conocimientos y, con ello, se favorecen los procesos de compartición y transferencia de conocimiento, lo cuál resulta beneficioso para el desarrollo de nuevos productos o servicios. Así se ha puesto de manifiesto en diversos estudios (Uzzi, 1997; Tsai y Ghoshal, 1998; Armbretch et al., 2001; Cavusgil, Calantone y Zaho, 2003; De Clercq y Sapienza, 2006; De Clercq, Thongpapanl y Dimos, 2007; Chen y Huang, 2009; Lin et al, 2009; Sáenz, Aramburu y Rivera, 2009; Camelo, García y Sousa, 2010; GarcíaPintos, Caballero y Piñeiro, 2010, entre otros).

Y, en tercer lugar, en relación al capital afectivo, Tsai y Ghoshal (1998) son pioneros en evidenciar el efecto que la dimensión afectiva tiene sobre la capacidad de innovación. Posteriormente, diversos autores postulan que la contribución de los empleados a la innovación, mediante su conocimiento, depende de factores afectivos y consideran que los afectos desarrollados en los empleados son esenciales para los comportamientos creativos e innovadores de los empleados (Hislop, 2003; Cabrera y Cabrera, 2005; Thompson y Heron, 2005, Gendrom, 2007; Cabrera, Collins y Salgado, 2006). La relación positiva entre el capital afectivo y la innovación se ha reflejado en diversos trabajos. Algunos autores, consideran al capital afectivo como un motivador intrínseco (Ipe, 2003; Camelo, García y Sousa, 2010;) y, por tanto, antecedente de procesos que conducen al desarrollo de la capacidad e innovación (Cabrera y Cabrera, 2005; Camelo 
et al., 2010). Otros autores, defienden que aquellas organizaciones en las que existe un capital afectivo, los empleados están dispuestos a proporcionar un esfuerzo discrecional extra $^{23}$ que favorece el desarrollo de innovaciones (Meyer y Allen, 1997; Alvesson, 2000; Takeuchi, 2001; Storey y Quintas, 2001; Hislop, 2003; Camelo et al., 2010). Otros trabajos, proponen que genera una mayor implicación con los objetivos de la organización, ya que desarrolla un flujo constante de comunicación y una mayor interacción social, lo que redunda positivamente en la capacidad innovadora de la empresa (Van der Bij, Song y Weggeman, 2003). Por su parte, otros autores, centrando su atención en el capital afectivo de los empleados, evidencian cómo desarrollándolo a través prácticas de recursos humanos que favorezcan la confianza organizativa y el compromiso organizativo, se contribuye, de forma notable, a la mejora de la innovación (Ipe, 2003; Hislop, 2003; Cabrera y Cabrera, 2005; Thompson y Heron, 2005, 2006; Cabrera, Collins y Salgado, 2006; Wu, Hsu y Yeh, 2007; Ellonen et al., 2008; Camelo et al., 2008, 2010).

No obstante lo anterior, no sólo cabe señalar la influencia de los propios recursos humanos en la generación de innovación sino, también, cabe estudiar el papel fundamental que van a jugar las prácticas de recursos humanos. A esta cuestión dedicamos los siguientes párrafos.

\subsection{Prácticas de recursos humanos e innovación}

Como acabamos de revisar, en el caso de la innovación es especialmente importante poder identificar y gestionar el capital humano vinculado a los recursos humanos debido, principalmente, a su posesión, utilización y compartición de conocimiento. Esto se debe a que el cambio y la innovación recaen, generalmente, en un colectivo especial de empleados, formado por técnicos, especialistas, profesionales de innovación y desarrollo y, también, por aquellos empleados que poseen la mayoría del conocimiento requerido para asegurar el cumplimiento de tareas y el uso de las tecnologías necesarias (Shipton et al., 2006). Además, éstos suelen ser una de las bases competitivas de la empresa. Nos referimos a los empleados clave o recursos humanos estratégicos, los

\footnotetext{
${ }^{23}$ Este esfuerzo se concreta en desarrollar comportamientos ciudadanos, compartir conocimiento o colaborar con otros.
} 
cuales ya hemos definido en epígrafes previos. Estos empleados, distribuidos en diferentes niveles de la organización, juegan un importante papel intercambiando y realizando sugerencias de mejora para ellos mismos, o contribuyendo a que otros lo hagan, por lo que desde la dirección estratégica de recursos humanos se debe afrontar el reto de desarrollar e implementar las prácticas necesarias para facilitar estos procesos (Laursen y Foss, 2003). En consecuencia, para la investigación en dirección estratégica de recursos humanos es fundamental identificar qué prácticas de recursos humanos específicas o qué combinación de éstas, están asociadas positivamente con la innovación o la capacidad de innovación en la organización (Shipton et al., 2006).

En esta línea, Morcillo (1997) afirma que para llevar a cabo la innovación con éxito es imprescindible crear las condiciones necesarias para catalizar y dirigir las aptitudes, capacidades y actitudes de los empleados. En este sentido, las prácticas de recursos humanos conforman una de las herramientas básicas por las que las empresas pueden influir y guiar las habilidades, los conocimientos y los comportamientos de lo empleados (Collins y Clark, 2003; Chen y Huang, 2009). Por tanto, las prácticas de recursos humanos se consideran elementos primordiales para el desarrollo de las actividades de innovación (Jiménez-Jiménez y Sanz-Valle, 2007). Como ya hemos manifestado, los recursos humanos y, en particular, la dirección y gestión de recursos humanos, son claves para el éxito de la innovación (Laursen y Foss, 2003; Searle y Ball, 2003; Jiménez-Jiménez y Sanz-Valle, 2003, 2007; Jiménez-Sanz y Sabater-Sánchez, 2010). De hecho, incluso, desde la propia literatura específica de innovación (Cohen y Levinthal, 1989, 1990, 1994), se señala la importancia de los procesos internos que desarrollan los empleados, puesto que, a través de ellos, las empresas adquieren, asimilan, transforman y explotan conocimiento, con la intención de crear capacidades dinámicas que permitan desarrollar su capacidad de innovación y lograr innovaciones (Zhara y George, 2002) ${ }^{24}$. Así, se considera que algunas capacidades que desarrollan los

\footnotetext{
${ }^{24}$ Nos estamos refiriendo a la literatura existente sobre capacidad de absorción. Zhara y George (2002) distinguen dos capacidades que forman la capacidad de absorción: capacidad de absorción potencial (dimensión de adquisición y asimilación) y capacidad de absorción realizada (formada por la transformación y la explotación). Además, contemplan la existencia de diferentes contingencias externas e internas que afectan a la capacidad de absorción.
} 
recursos humanos, como la capacidad de aprendizaje, son capacidades fundamentales para el desarrollo de innovaciones (Tsai, 2001).

Diversos estudios empíricos evidencian la influencia positiva que las prácticas de recursos humanos pueden ejercer, directamente, sobre la innovación o indirectamente mediado por su influencia en procesos de creación de conocimiento (Cabrera y Cabrera, 2005; Camelo et al., 2010; García-Pintos et al., 2010). Así, las prácticas de recursos humanos favorecen el desarrollo la capacidad de innovación y el logro de resultados innovativos de la empresa, por ejemplo, informando a los empleados de que la actividad innovadora será reconocida y recompensada (Laursen y Foss, 2003; Minbaeva et al., 2003, 2005; Shipton et al., 2006; Cabrera y Cabrera, 2005; Jiménez-Jiménez y SanzValle, 2005; Chen y Huang, 2009; Ling et al., 2010; Camelo et al., 2010; García-Pintos et al., 2010), facilitando las habilidades y conocimientos necesarios para llevarla a cabo (Cabrera y Cabrera, 2005; Camelo et al., 2010; Jiménez-Jiménez y Sanz-Valle, 2005; Lau y Ngo, 2004; Leede y Loise, 2005), facilitando la colaboración entre empleados a través del trabajo en equipo, procesos de participación y comunicación interna (entre otros, Laursen y Foss, 2003; Thierre y Leonard, 2003; Lau y Ngo, 2004; Cabrera y Cabrera, 2005; Perdomo Ortiz et al., 2006; Pérez-Cano y Quevedo-Cano, 2006; Shipton et al., 2006; Camelo et al., 2010). En consecuencia, estas prácticas son consideradas como una de las vías que tienen las empresas para poder mejorar su capacidad de innovación y/o los procesos que la desarrollan. La Tabla 1.5. recoge las principales prácticas, contrastadas en estudios empíricos, que vinculan la gestión de recursos humanos y la innovación.

A pesar de todo lo expuesto, el conocimiento sobre la contribución y el papel que juega la gestión de recursos humanos sobre la innovación organizativa es aún escasa, exceptuando los estudios que consideran la innovación como estrategia organizativa (Leede y Looise, 2005). Se hace necesario, pues, seguir profundizando en esta cuestión (Jiménez-Jiménez y Sabater-Sánchez, 2010). En consecuencia, la vinculación de la gestión de recursos humanos y la innovación, a través del desarrollo de la capacidad de innovación de la empresa, será uno de los aspectos en le que nos interesará profundizar en este trabajo. 
Tabla 1.5. Prácticas de recursos humanos vinculadas a la innovación

\begin{tabular}{|c|c|c|}
\hline POLÍTICAS & PRÁCTICAS & TRABAJOS EMPÍRICOS RELEVANTES \\
\hline $\begin{array}{l}\text { DISEÑO DE } \\
\text { PUESTO }\end{array}$ & $\begin{array}{l}\text { Variedad de tareas, diseño } \\
\text { flexible, autonomía, } \\
\text { multisdisciplinar }\end{array}$ & $\begin{array}{l}\text { Cabrera y Cabrera (2005); Shipton et } \\
\text { al.,(2006);Thierre y Leonard (2003); García- } \\
\text { Pintos et al.,(2010) }\end{array}$ \\
\hline $\begin{array}{l}\text { TRABAJO EN } \\
\text { EQUIPO }\end{array}$ & $\begin{array}{l}\text { Equipos multidisciplinares, } \\
\text { equipos de resolución de } \\
\text { problemas, equipos }\end{array}$ & $\begin{array}{l}\text { Cabrera y Cabrera (2005); Camelo et al. } \\
\text { (2010); Lau y Ngo (2004); Laursen y } \\
\text { Foss(2003); Perdomo Ortiz et al., (2006); } \\
\text { Pérez-Cano y Queveo-Cano (2006); Shipton } \\
\text { et al., (2006); Thierre y Leonard(2003) }\end{array}$ \\
\hline $\begin{array}{l}\text { RECLUTAMIENT } \\
\text { O Y SELECCIÓN }\end{array}$ & $\begin{array}{l}\text { Ajuste persona-organización, } \\
\text { selección por competencias, } \\
\text { ajuste persona-cultura }\end{array}$ & $\begin{array}{l}\text { Cabrera y Cabrera (2005); Camelo et al., } \\
\text { (2010); Chen y Huang (2009); García- Pintos } \\
\text { et al., 2010; Jiménez-Jiménez y Sanz-Valle } \\
\text { (2005); Ling et al (2010); Perdomo Ortiz et } \\
\text { al., (2006); Saa-Pérez y Díaz-Díaz (2007); } \\
\text { Searle y Ball (2003) }\end{array}$ \\
\hline $\begin{array}{l}\text { ACOGIDA- } \\
\text { SOCIALIZACIÓN }\end{array}$ & $\begin{array}{l}\text { Formación de acogida y } \\
\text { socialización }\end{array}$ & $\begin{array}{l}\text { Cabrera y Cabrera (2005); Chen y Huang } \\
\text { (2009); Shipton et al (2006) }\end{array}$ \\
\hline FORMACIÓN & $\begin{array}{l}\text { Habilidades trabajo equipo y } \\
\text { habilidades sociales, formación } \\
\text { extensiva, en el puesto versus } \\
\text { en el aula, en temas de calidad }\end{array}$ & $\begin{array}{l}\text { Cabrera y Cabrera, 2005; Camelo et al } \\
\text { (2010); Chen y Huang (2009); Jiménez- } \\
\text { Jiménez y Sanz-Valle (2005); Lau y Ngo } \\
\text { (2004);Leede y Loise (2005); Ling et al } \\
\text { (2010); Minbaeva et al (2003, 2005); } \\
\text { Perdomo Ortiz et al (2006); Searle y Ball } \\
\text { (2003); Shipton et al., (2006); Thierre y } \\
\text { Leonard (2003) }\end{array}$ \\
\hline PROMOCIÓN & $\begin{array}{l}\text { Promoción según rendimiento, } \\
\text { desarrollo interno }\end{array}$ & $\begin{array}{l}\text { Camelo et al (2010); Jiménez-Jiménez y Sanz- } \\
\text { Valle (2005); Leede y Loise (2005); Ling et } \\
\text { al (2010); Minbaeva et al (2003; 2005); Saa- } \\
\text { Pérez y Díaz-Díaz (2007); }\end{array}$ \\
\hline $\begin{array}{l}\text { EVALUACIÓN } \\
\text { DESEMPEÑO }\end{array}$ & \begin{tabular}{|l|} 
Basada en rendimiento \\
individual, en rendimiento \\
grupal-equipo o en resultado de \\
empresa
\end{tabular} & $\begin{array}{l}\text { Cabrera y Cabrera, 2005; Camelo et al } \\
\text { (2010); Chen y Huang (2009); García-Pintos } \\
\text { et al (2010); Jiménez-Jiménez y Sanz-Valle } \\
(2005) ; \text { Ling et al (2010); Minbaeva et al } \\
(2003,2005) ; \text { Shipton et al., (2006) }\end{array}$ \\
\hline RETRIBUCIÓN & $\begin{array}{l}\text { Contingente, basada en } \\
\text { rendimiento, según resultados } \\
\text { de equipo o empresa, mix } \\
\text { retributivo (fijo, variable, no } \\
\text { monetario) }\end{array}$ & $\begin{array}{l}\text { Cabrera y Cabrera, 2005; Chen y Huang } \\
\text { (2009); García Pintos et al (2010); Jiménez- } \\
\text { Jiménez y Sanz-Valle (2005); Lau y Ngo } \\
\text { (2004);Laursen y Foss (2003); Leede y Loise } \\
\text { (2005); Ling et al (2010); Minbaeva et al } \\
\text { (2003, 2005); Perdomo Ortiz et al (2006); } \\
\text { Pérez Cano y Quevedo Cano (2006); Searle y } \\
\text { Ball (2003); Shipton et al., (2004); Thierre y } \\
\text { Leonard (2003) }\end{array}$ \\
\hline $\begin{array}{l}\text { IMPLICACIÓN, } \\
\text { PARTICIPACIÓN, } \\
\text { COMUNICACIÓN } \\
\text { INTERNA }\end{array}$ & $\begin{array}{l}\text { Participación en toma de } \\
\text { decisiones comunicación } \\
\text { abierta, compartición de } \\
\text { información, delegación }\end{array}$ & $\begin{array}{l}\text { Cabrera y Cabrera (2005); Camelo et al } \\
\text { (2010); Chen y Huang (2009); Jiménez- } \\
\text { Jiménez y Sanz-Valle (2005);Laursen y Foss } \\
\text { (2003); Minbaeva et al (2003); Thierre y } \\
\text { Leonard (2003) }\end{array}$ \\
\hline OTRAS & $\begin{array}{l}\text { Reconocimiento, rotación de } \\
\text { puestos, seguridad en empleo, } \\
\text { aprendizaje exploratorio, entre } \\
\text { otras }\end{array}$ & $\begin{array}{l}\text { Jiménez-Jiménez y Sanz-Valle } \\
\text { (2005);Laursen y Foss (2003); Searle y Ball } \\
\text { (2003); Shipton et al (2006) }\end{array}$ \\
\hline
\end{tabular}


A modo de cierre de este epígrafe 1.2, resumimos las principales cuestiones puestas de manifiesto. En primer lugar, hemos destacado la importancia del recurso humano para la creación de valor y la competitividad empresarial. Especialmente, el valor de los empleados clave, aquellos que forman el capital humano estratégico de la empresa, a través de su capital intelectual, social y afectivo. Y, en segundo lugar, hemos revisado el caso concreto de la innovación y su relación con el capital humano y la gestión de recursos humanos. Además, reconocemos la necesidad de profundizar en los procesos por los que los propios recursos humanos y la gestión de recursos humanos influyen sobre los resultados organizativos.

En este trabajo proponemos estudiar la retención del capital humano estratégico como proceso mediador o etapa intermedia de la “caja negra” existente entre la gestión de recursos humanos y los resultados organizativos. En consecuencia, con el fin de asentar las bases teóricas que nos permitan desarrollar esta investigación, el siguiente epígrafe recoge una revisión del estado del arte de la literatura de retención de empleados y, en particular, su relación con la gestión de recursos humanos.

\subsection{GESTIÓN DE RECURSOS HUMANOS Y RETENCIÓN DEL CAPITAL HUMANO DE LA ORGANIZACIÓN}

Desde el punto de vista empresarial, la retención de empleados altamente cualificados y poseedores de habilidades valiosas es más importante hoy en día de lo que ha sido nunca. Diversas tendencias (p.e. globalización, incremento de trabajo intensivo en conocimiento, aceleración de los cambios tecnológicos) hacen fundamental que las empresas retengan su capital humano (Holtom, Mitchell, Lee y Eberly, 2008). Es más, a pesar de las diferencias entre países, industrias o sectores de actividad, la investigación en empresas de todo el mundo señala la importancia de la retención de los empleados valiosos para el éxito empresarial. En respuesta a lo anterior, las empresas han implementado diversas prácticas de recursos humanos orientadas a evitar los abandonos voluntarios evitables y no deseados (Fulmer, Gerhart y Scott, 2003; Holtom et al., 2008). 
Cada vez todo es más efímero e imitable, excepto las personas. Bajo el enfoque de recursos y capacidades, los recursos humanos son uno de los activos de la empresa que se aprecian si la empresa prospera (Ulrich, 1998; Ordiz y Avella, 2002). Aunque los cambios tecnológicos supongan la creación de nuevos puestos de trabajo, dejando obsoletas determinadas habilidades, los programas de formación y desarrollo pueden conseguir que los trabajadores no se queden obsoletos. En consecuencia, aquellas empresas que quieran ser competitivas y tener éxito, necesitan retener en la organización los recursos que conformen la clave de su éxito competitivo, entre los que ciertos recursos humanos resultan fundamentales.

Bajo los postulados del enfoque de recursos y capacidades, como se ha explicado previamente en los epígrafes 1.1. y 1.2., los recursos humanos ofrecen una de las bases para generar ventajas competitivas de forma sostenida. En este sentido, se asume que el valor, la singularidad y la inimitabilidad se consideran las principales características de éstos que hacen que puedan conducir a la empresa hacia la consecución de ventajas competitivas (Barney, 1991; Boxal y Purcell, 2003; Holtbrugge, Friedmann y Puck, 2010). Por tanto, las empresas tienen más posibilidades de desarrollar ventajas competitivas sostenibles cuando poseen una fuerza de trabajo con conocimientos y habilidades valiosas, únicas y que no puedan ser imitadas por sus competidores (Boxall, 1996; Wright, McMahan y McWilliams, 1994). Para que esto suceda la retención de este capital humano, y de todo lo que dicho capital lleva consigo (conocimientos, habilidades, relaciones sociales, actitudes, afectos, etc.), se convierte en un requisito fundamental para el éxito empresarial. Por tanto, no es de extrañar el creciente interés por investigar las vías o modos diversos para lograr dicha retención.

Además, el interés por investigar las fórmulas de retención del capital humano estratégico, no sólo se debe al efecto positivo que puede ejercer sobre la competitividad de la empresa sino que, también, se debe a otros dos motivos. Primero, para evitar los enormes costes de reemplazamiento, directos e indirectos, que le supone a la empresa no lograr retener a sus empleados y tener que reemplazarlos (Cascio, 2006) ${ }^{25} \mathrm{y}$,

\footnotetext{
${ }^{25}$ Los costes asociados con la no retención y afrontar de nuevo el reclutamiento, selección y formación de un nuevo empleado varía entre el 90-200\% del salario anual de dicho puesto (Cascio, 2006; Mitchel, Holtom y Lee, 2001).
} 
segundo, se debe a su vinculación positiva con el resultado empresarial (Shaw, Gupta y Delery, 2005; Allen, Bryant y Vardaman, 2010). Además, debemos señalar que el interés por el estudio de la retención emerge tanto desde el ámbito académico, fundamentalmente desde las áreas psicológica, organizativa e industrial ${ }^{26}$, como muestran excelentes trabajos de revisión de esta cuestión (Abelson y Baysinger, 1984; Hom y Griffeh, 1995, 2001; Shaw et al., 2005; Holtom, Mitchel, Lee y Eberly, 2008), como también, desde el ámbito empresarial, en el que el interés y preocupación por la retención se señala como uno de los retos de la dirección de recursos humanos del futuro $^{27}$ (Allen, et al.,2010).

La retención de empleados estratégicos, reteniendo así el talento en la organización, es uno de los objetivos actuales y de futuro del área de recursos humanos que requiere de una mayor investigación (Holtom et al., 2008; Allen et al., 2010; Shaw, Dineen, Fang y Vellella, 2009; Thite, 2010). Éste es uno de los objetivos fundamentales en este trabajo que, en particular, se centra en el colectivo de los empleados estratégicos de la organización.

Sin embargo, el estudio en profundidad de este fenómeno no es tarea sencilla. Son múltiples las variables que pueden incidir en la retención de los empleados de la empresa. Por tanto, el objetivo de este epígrafe es presentar las bases teóricas y empíricas sobre retención que puedan servir de apoyo para la investigación que pretendemos abordar. En consecuencia, dedicamos las siguientes páginas a presentar los aspectos más relevantes sobre la retención de empleados y la gestión de recursos humanos. En primer lugar, revisamos la evolución del concepto de retención y sus diversas taxonomías. En segundo lugar, revisamos la literatura que ha investigado este fenómeno. Esta literatura tiene la peculiaridad de estructurarse en dos tipos de trabajos;

\footnotetext{
${ }^{26}$ Entre ellas destacan la teoría del comportamiento, la teoría del soporte organizativo y diversas teorías psicológicas de motivación y de comportamiento que se recogen en la Figura A1.10 del Anexo I de este trabajo.

${ }^{27}$ Así se pone de manifiesto en recientes informes empresariales como, por ejemplo, la sexta edición del Barómetro de Recursos Humanos de CSC y Expansión \& Empleo (2009), la encuesta "Los retos que deberán enfrentar las organizaciones y los recursos humanos en los próximo diez años", realizada por la Society for Human Resource Management (2010) o el informe "Gestión de personas en 2020", realizado por Price Water House Coopers y publicado en 2010 (Véase el apartado A.1.1. y la Figura A.1.1 del Anexo I de este trabajo en el que incluimos el detalle de estas noticias).
} 
por un lado, estudios basados en propuestas de modelos explicativos de la retención ${ }^{28}$ y, por otro lado, trabajos empíricos que contrastan prácticas organizativas y su efecto sobre la retención. En ambos tipos de trabajos se incluyen diversas prácticas de recursos humanos que señalaremos en las siguientes páginas.

\subsubsection{Concepto de retención de empleados. Algunas taxonomías de la retención}

El estudio de la retención requiere del conocimiento sobre cómo y por qué los empleados deciden abandonar la organización para, de este modo, poder diseñar medidas eficaces que logren dicha retención. Por ello, los primeros estudios que analizaron este fenómeno se centraron en el análisis de los abandonos y de la rotación voluntaria. Así, en los años sesenta y setenta surge una corriente de estudios que tratan de identificar las causas que explicaban por qué un empleado decidía abandonar la organización (March y Simon, 1958; Price, 1977; Mobley, 1982a) influyendo, negativamente, en la retención de empleados. Sin embargo, no es hasta la década de los noventa cuando, expresamente, se comienza a investigar el fenómeno retención (O’Reilly y Chatman, 1986; Meyer y Allen, 1991; White, 2001).

Lo cierto es que no podemos hablar de retención sin tener en cuenta la variable de la que se deriva: la rotación voluntaria. El estudio de la rotación voluntaria y de la retención están muy relacionados, por ello, para conceptualizar la retención, los investigadores han recurrido a estudiar la rotación voluntaria e, incluso, las conciben como “dos caras de una misma moneda”29 (White, 2001; Chawla, 2005) y, por tanto, tiene sentido estudiarlas de forma conjunta (Hulin, 1991; White, 2001). No obstante, aunque la rotación voluntaria y la retención sean dimensiones de un mismo fenómeno, bajo nuestro punto de vista, pertenecen a diferentes niveles de análisis -individuo y organización, respectivamente-. El fenómeno de rotación voluntaria se ha estudiado, principalmente, desde el punto de vista del individuo, centrándose en las causas que

\footnotetext{
${ }^{28}$ Generalmente, los modelos tratan de explicar la retención desde su otra cara: "la rotación voluntaria”. La retención y la rotación voluntaria están estrechamente vinculadas y pueden concebirse como dos caras de la misma moneda (Chawla, 2005). Por ello, numerosos trabajos abordan este fenómenos desde la perspectiva de la rotación voluntaria.

${ }^{29}$ En este sentido, por ejemplo, el Harvard Business Essencials (2002:6) define la retención como el inverso de la rotación voluntaria, siendo ésta la suma de los abandonos voluntarios e involuntarios de los empleados.
} 
influyen sobre su decisión de abandono. En cambio, el estudio de la retención de empleados se aborda, generalmente, desde una óptica organizativa, es decir, centrando el foco de atención en las acciones que lleva a cabo la organización para lograr retener a sus empleados. En nuestra opinión, la relación entre el concepto de retención y rotación voluntaria puede entenderse como complementaria, sin necesidad de concebirla como dos caras de la misma moneda, aunque tampoco son conceptos independientes sin ningún tipo de relación. Sin embargo, a pesar de estas consideraciones, debemos destacar que para revisar la investigación en retención a la vez es necesario tener presente la literatura de rotación voluntaria.

El término rotación de personal encierra mucha más complejidad de la que, a priori, podría parecer. Por un lado, se pueden utilizar diversos sinónimos que se refieren a ella: salida, abandono, separación, ruptura del vínculo contractual o turnover. Por otro, existe una prolífica literatura al respecto, aunque ha evolucionado a lo largo del tiempo, hasta llegar a nuestros días, con definiciones mucho más complejas y completas. Si hubiera que indicar un trabajo pionero sobre la retención y rotación voluntaria, sin duda, sería el trabajo de March y Simon (1958). Estos autores, a través de su teoría del equilibrio organizativo, plantean un modelo en el que analizan las contraprestaciones de la relación laboral, la satisfacción laboral y, aunque no ofrecen una definición explícita sobre rotación, aluden al término baja voluntaria, conceptuándolo como “el final de la participación del empleado en la organización, pasando a estar fuera de la nómina de la organización”. Unos años más tarde, Price (1977) ofrece una definición mucho más concreta sobre la rotación: "El movimiento individual, a través de los límites de pertenencia de un sistema social”. Y cinco años más tarde, Mobley (1982a) va perfilando el concepto anterior, utilizando una terminología más empresarial. Este autor la define como "el cese voluntario de pertenecer a una organización por un individuo que recibe compensación económica por participar en dicha organización”. Como en la definición previa, se hace referencia a que el movimiento de salida lo inicia el empleado y, además, añade el elemento económico como clave en la decisión de ruptura $^{30}$. En 1998, Maertz y Campion, propusieron la siguiente definición de rotación

\footnotetext{
${ }^{30}$ Las definiciones de Price (1977) y Mobley (1982a) son algunas de las más aceptadas y utilizadas en las investigaciones sobre rotación y retención de empleados.
} 
voluntaria: "Casos en los que la dirección y gestión de la compañía está de acuerdo en que el empleado tenía la oportunidad física de continuar empleado en la compañía en el momento de terminar su vinculación con la misma” (1998). Posteriormente, diferentes autores han propuesto otras definiciones y diversas formas de clasificación de este concepto, contribuyendo al refinamiento del concepto.

En la década de los noventa, algunos autores consideraron que las anteriores definiciones no describían la realidad de la rotación, puesto que la estudiaban de forma aislada sin considerar otros comportamientos que estaban estrechamente relacionados con ella (Hom y Griffeth, 1991). Con el ánimo de superar esta limitación, surgieron nuevas conceptualizaciones, como la de Hulin (1991), definiendo la variable “constructo de abandono” que aglutina en este concepto a la rotación voluntaria, el absentismo, los retrasos y otros comportamientos (cómo estar ausente en el trabajo, falta de concentración, sindicalización, caída del rendimiento, etc.). También surgieron otras propuestas que conciben a la rotación voluntaria y la retención como las dos caras de la misma moneda y, por tanto, proponen estudiarlas de forma simultánea y conjunta (O’Reilly y Chatman, 1986; Meyer y Allen, 1991; White, 2001). Es a partir de estas contribuciones cuando surgen los estudios que analizan, expresamente, la retención de empleados en la organización, principalmente a través del análisis de una nueva variable fundamental para la retención: el compromiso organizativo. Debido a su importante influencia sobre la retención, merece un breve apunte.

El compromiso de los empleados con la organización (junto con la satisfacción laboral) ha sido tradicionalmente la variable más relacionada con la retención de empleados. Inicialmente se definió como "un fuerte sentimiento de aceptación de los valores y objetivos de la organización como propios, una clara propensión a realizar considerables esfuerzos por el bien de la organización y un fuerte deseo de permanencia en la misma” (Mowday, Steers y Porter, 1979). Posteriormente, Meyer y Allen $(1991,1997)$ refinaron este constructo de vínculo psicológico de los empleados con la organización distinguiendo tres componentes del compromiso organizativo: afectiva, normativa y 
constitutiva o de continuidad ${ }^{31}$. La componente afectiva, referida al sentimiento de vínculo, identificación e implicación con la organización (Meyer y Allen, 1991) es una de las más estudiadas y utilizadas en los estudios de retención y ha dado lugar al desarrollo de otras variables más evolucionadas como, por ejemplo, el “employee engagement"32.

No obstante, volviendo a la revisión realizada de las definiciones de retención, las posteriores definiciones de retención no son concretas. Casi ningún trabajo propone una definición que no se apoye en definiciones previas de la rotación voluntaria. Así, la retención va quedando conceptualizada como aquel proceso que trata de mantener en plantilla a los empleados, logrando que no se marchen a la competencia; también se asimila con la intención de permanencia del empleado y, además, se asocia con el diseño de prácticas y políticas que equilibren las necesidades de los empleados y desarrollen un entorno que anime a los empleados a permanecer en la organización. Dicho de otra forma, la retención se puede entender como "mantener en la organización a los buenos empleados” (Chew, 2004; Holtom et al., 2008). En base a las aportaciones revisadas, proponemos nuestra propia definición de retención como ”el proceso voluntario de permanencia de un trabajador de la organización, con la que está vinculado contractualmente, sin que existan barreras tangibles o intangibles a su salida y pudiendo abandonar si quisiera, pero que decide permanecer en la empresa motivado por razones personales y/o profesionales”. Esta será la conceptualización que utilizaremos en el desarrollo de la presente investigación.

\footnotetext{
${ }^{31}$ El compromiso afectivo se refiere a la identificación con, involucramiento en, y vínculo emocional con la organización. Los empleados con fuerte compromiso afectivo hacia la empresa permanecen en la misma porque quieren hacerlo. El compromiso de continuidad se basa en la valoración que el empleado realiza de los costes asociados a dejar esa organización. Los empleados con fuerte compromiso de continuidad permanecen en la misma porque tienen que hacerlo. Finalmente, el compromiso normativo se refiere al sentido de obligación hacia la organización. En este caso, el empleado permanece porque siente que debe hacerlo. Los tres componentes influyen sobre la permanencia del empleado en la organización (Allen y Meyer, 1996).

${ }^{32}$ El compromiso afectivo se considera una variable precursora del desarrollo de otras como el employee engagement, que relaciona ese vínculo afectivo de los empleados y sus comportamientos (Gibbons, 2006; Richman, Civian, Shannon, Hill y Brennan, 2008). Un reciente meta-análisis define employee engagement como "la conexión emocional e intelectual que el empleado tiene hacia su trabajo, organización, jefes o compañeros, influyéndole de forma positiva en la realización de esfuerzos extra en su trabajo" (Gibbons, 2006:5).
} 
De forma complementaria a las definiciones propuestas en la literatura, otro modo para conceptualizar la retención es a través de sus diversas clasificaciones. Los principales criterios de clasificación que se han ido desarrollando en la literatura de retención y que permiten comprender mejor su concepto, son tres: voluntariedad, funcionalidad y evitabilidad (Véase Figura 1.15).

Figura 1.15. Clasificación de rotación de personal

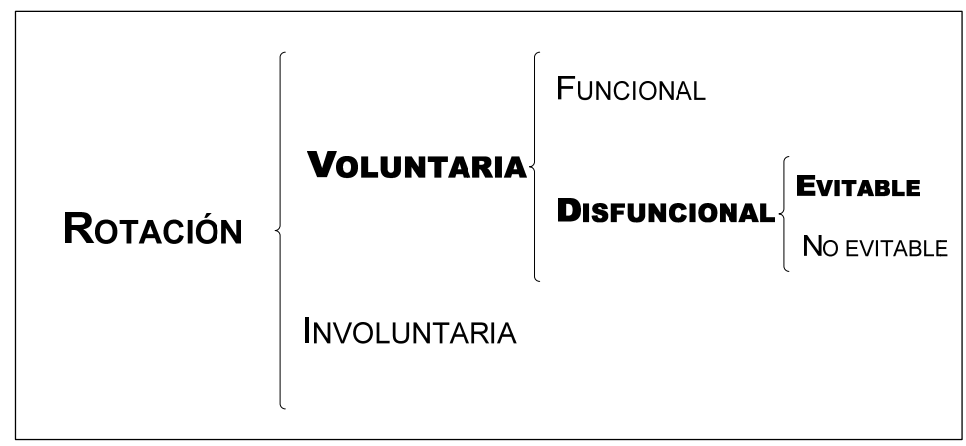

Fuente: Elaborado a partir de Hom y Griffeth (1995)

El criterio de voluntariedad clasifica la rotación en función de quien inicia el movimiento de salida de la empresa, es decir, si el trabajador se marcha de un modo voluntario -rotación voluntaria ${ }^{33}$ - o si, por el contrario, es forzado a salir desde la organización -rotación involuntaria- ${ }^{34}$. (Price, 1977; Marsh y Mannari, 1977; Maerzt y Campion, 1998). El segundo criterio, funcionalidad, fue introducido por Dalton, Krachardt y Porter (1981) y Dalton, Todor y Krackhardt (1982) que, desde una perspectiva organizativa, diferenciaban entre rotación funcional y disfuncional, en función del tipo de empleado que abandonara la organización. La primera se refiere a la salida de empleados poco valiosos o productivos y, por tanto, puede ser beneficiosa para la empresa. La rotación disfuncional es aquélla en la se marcha algún empleado muy valioso y, por tanto, las consecuencias para la organización pueden ser muy negativas, ya que en la mayoría de los casos son empleados difícilmente sustituibles. Y, por último, se añade el criterio de evitabilidad a la clasificación anterior (Dalton, Todor y

\footnotetext{
33 En lo sucesivo, cuando utilicemos el término rotación de personal nos estaremos refiriendo a la rotación voluntaria. Quedan fuera de nuestro campo de estudio los casos de rotación involuntaria donde el empleado se ve forzado a abandonar la empresa.

34 Aunque aparentemente parece una clasificación sencilla, a menudo, no es fácil etiquetar determinadas situaciones. Este es el caso de situaciones en las que el empleado se marcha, por ejemplo, por jubilaciones anticipadas, por presiones personales, por bajas por maternidad, etc.
} 
Krackhardt, 1982; Abelson, 1987), distinguiendo además de funcional-disfuncional, entre evitable y no evitable por parte de la organización, en función de la capacidad que pueda tener la organización para evitar o no la marcha de los empleados. De todas las situaciones posibles, el caso que realmente debe preocupar a las empresas es el de la rotación disfuncional controlable o evitable, puesto que en esta categoría es donde las empresas tienen margen de maniobra para utilizar prácticas y medidas que puedan favorecer la retención de estos empleados. Aglutinando estos tres criterios, Hom y Griffeth (1995) clasifican la rotación considerando la voluntariedad, la funcionalidad y la evitabilidad, definiendo cuatro situaciones posibles: a) rotación involuntaria; b) rotación voluntaria funcional; c) rotación voluntaria disfuncional no evitable; y d) rotación voluntaria disfuncional evitable. La Figura 1.16 recoge esta propuesta.

Figura 1.16. Clasificación y ejemplos de rotación

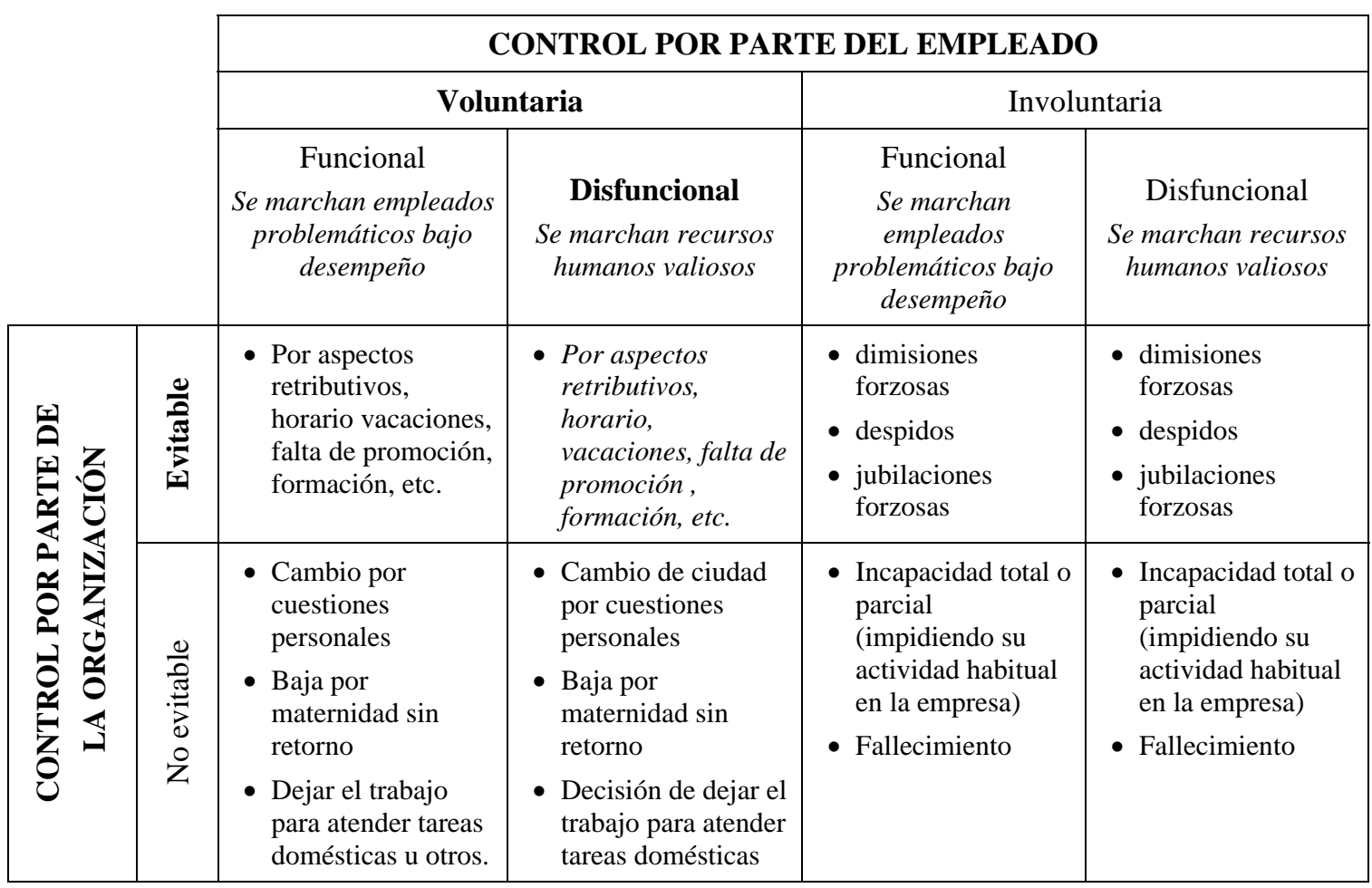

Fuente: Elaborado a partir de Maerz y Campion (1998), Hom y Griffeth (1995) y Abelson (1984).

De forma análoga a la rotación, la retención puede clasificarse como funcional o disfuncional (Johnson, Griffeth y Griffin, 2000). Cuando los empleados de bajo desempeño abandonan la organización y se logra mantener a los empleados de alto 
desempeño, estaremos ante una retención funcional, que, de hecho, mejora los resultados organizativos (Johnson et al., 2000). Por el contrario, cuando los buenos trabajadores abandonan la empresa y los trabajadores de bajo desempeño permanecen, estaremos ante una retención disfuncional, puesto que puede perjudicar tanto a la innovación como a los resultados de la organización (Abbasi y Hollman, 2000 cit. en Chew, 2004).

Desde un punto de vista estratégico, las empresas deben diseñar planes de gestión de sus personas que favorezcan la retención funcional o, en otras palabras, traten de reducir la rotación voluntaria, disfuncional y evitable. Esta categoría es la que debe preocupar a las empresas, ya que es en la que pueden intervenir directamente a través de sus prácticas de recursos humanos, tratando de mantener a sus trabajadores más valiosos y estratégicos. En definitiva, se trata de cambiar su idea de marcharse por la de quedarse, una tarea realmente compleja en la práctica empresarial.

Una vez identificada la evolución del concepto y la taxonomía de la retención de empleados, nos interesa centrar la atención en los estudios que la han investigado. Así, en primer lugar, revisaremos la principal literatura que aborda el estudio sobre retención. Como ya hemos anticipado, esta literatura se agrupa en dos tipos de trabajos, por un lado, los trabajos basados en modelos que tratan de explicar las causas, los procesos y las consecuencias de la retención (o de la rotación voluntaria, en los estadios iniciales de esta literatura). Y, por otro lado, trabajos que sin apoyarse, expresamente en modelos, estudian prácticas que puedan influir sobre la retención. En este trabajo, en concreto, nos vamos a centrar, exclusivamente, en los trabajos que incorporen prácticas de recursos humanos en sus análisis.Todo ello nos permitirá asentar las bases para proponer un sistema de prácticas de recursos humanos concreto orientado a potenciar la retención de empleados, que presentaremos en el último epígrafe de este capítulo.

\subsubsection{Revisión de la literatura de investigación en retención de empleados}

La revisión de la literatura que hemos realizado, nos ha permitido constatar que éste es un campo muy amplio de investigación que ha dado lugar a una extensa y diversa literatura. Se pueden identificar más de mil quinientos estudios académicos sobre este tópico y, no obstante, continúa siendo un vibrante campo de investigación (Holtom et 
al., 2008; Hausknecht y Trevor, 2011). Hasta donde alcanza nuestro conocimiento, la investigación en retención y rotación voluntaria se ha desarrollado analizando tres dimensiones que influyen en ella: mercado de trabajo, individuo y organización (Holtom et al., 2008(Helfat, 1997 \#156)). La Figura 1.17 esquematiza esta tridimensionalidad de la investigación en este fenómeno.

Figura 1.17. Dimensiones de análisis de la rotación voluntaria y de la retención

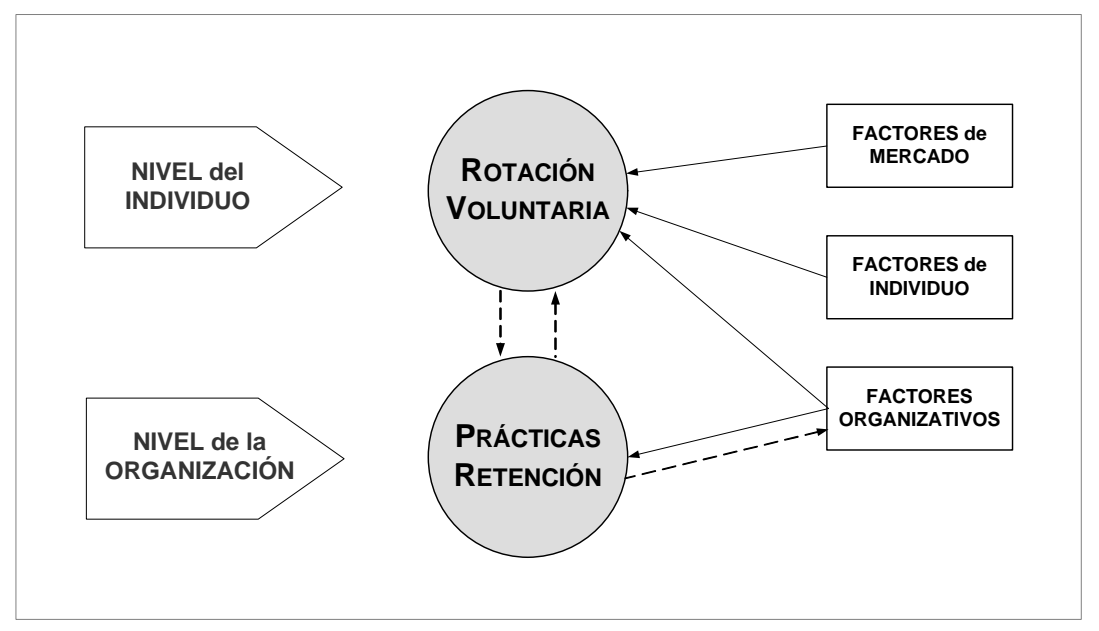

Nuestra investigación se ubica en la perspectiva organizativa y, por ello, nos centramos en la segunda y tercera de estas dimensiones. Por un lado, tratando de comprender los factores que influyen en la decisión de abandono o permanencia del empleado y, por otro, tratando de indagar en el papel que las organizaciones, a través de su gestión, pueden jugar sobre la retención de sus empleados. En concreto, elegimos la gestión desde el ámbito de la función de recursos humanos ${ }^{35}$.

Por tanto, el objetivo de este apartado de revisión es profundizar en el proceso de rotación voluntaria del individuo para, de este modo, poder contribuir al estudio e identificación de las prácticas de retención que, más eficiente y eficazmente, pueden utilizar las organizaciones actuales. De este modo, nuestra intención es poder contribuir al desarrollo de la literatura de retención, literatura más escasa que la de rotación

\footnotetext{
${ }^{35}$ Quedan fuera del ámbito de este trabajo los estudios que analizan la relación entre los factores del mercado y la retención.
} 
voluntaria $^{36}$ (Allen 2004). En particular, en el análisis de las prácticas de recursos humanos que las empresas pueden utilizar para favorecer la retención de sus empleados y en sus consecuencias. Así, para conseguir este objetivo, se hace una revisión de la perspectiva organizativa de este fenómeno.

Desde la perspectiva organizativa, son numerosos los trabajos que analizan la retención/rotación voluntaria, buscando fórmulas para predecirla, controlarla, calculando los costes y beneficios asociados a ella (Mobley, 1982; Mathiew y Zajac, 1990; Hom y Griffeth, 1995 Maertz y Campion, 1998, y Morrel et al., 2001), o tratando de identificar y buscar fórmulas para retener a sus empleados (Griffeth y Hom, 2001, 2004; Williams, 2001; Peterson, 2004; Borislavova, 2004; Chew, 2004; Buck y Watson, 2005, Chiu et al.(Cho, 2005 \#707;Chow, 2010 \#709;Clark, 1997 \#396;Clark, 2001 \#397;Coff, 1997 \#399;Cohen, 1989 \#401;Cohen, 1994 \#402), 2002; Starosta, 2007; Richman et al., 2008; Thite, 2010, entre otros).

La amplia variedad de factores de dimensión organizativa, presentes en la literatura revisada, puede ser clasificada en dos grupos: a) factores demográficos-organizativos, es decir, factores que caracterizan a la organización y su gestión, como son: el tamaño de la organización, el grado de centralización, la edad de la organización, la estructura interna, la misión, la estrategia, etc., y b) factores relativos a las prácticas de gestión de recursos humanos (directas o indirectas), como son el sistema de retribución, la formación, el diseño de puestos, la comunicación, la formación, el diseño de carreras y la posibilidad de promoción, la relaciones internas, el clima laboral, el estilo de liderazgo, etc. Esta clasificación resulta adecuada para el objeto de nuestro estudio, puesto que, en este trabajo, hemos optado por revisar los principales trabajos de la literatura de rotación voluntaria y retención, centrados en los factores y actividades desarrolladas desde la dirección de recursos humanos. Ese es nuestro ámbito de estudio en esta investigación.

\footnotetext{
${ }^{36}$ Griffeth y Hom (2004) y Allen (2004) hacen una llamada de atención y destacan cómo la mayoría de la investigación se ha centrado en estudiar el fenómeno de por qué los empleados abandonan la organización más que por qué se quedan. Además, apuntan que los directivos e investigadores deberían dedicar más esfuerzos a definir estrategias de retención que controlen los niveles de rotación voluntaria, especialmente en puestos clave y en empleados de alto valor.
} 
La investigación de retención, como ya hemos comentado con anterioridad, se caracteriza por desarrollarse bien, a través de la propuesta de modelos que tratan de recoger las causas, procesos y consecuencias de este tópico, o bien, a través de trabajos que analizan directamente la relación entre diversas prácticas organizativas (en concreto, en este trabajo nos centramos en las prácticas de recursos humanos) y la retención. Por tanto, con el ánimo de sintetizar y clarificar esta extensa literatura, en primer lugar, en el epígrafe 1.3.2.1 nos detenemos en revisar la literatura que destaca los principales modelos de retención y, a continuación, en el epígrafe 1.3.2.2., revisaremos la literatura que vincula, expresamente, prácticas de recursos humanos y retención de empleados.

\subsubsection{Los principales modelos de retención: un recorrido cronológico}

Con el fin de presentar los trabajos revisados de un modo ordenado, hemos decidimos seguir la propuesta de Holtom et el. (2008) y utilizar el criterio cronológico que ellos proponen. Así, en el desarrollo de la investigación de retención que se apoya en la definición y estudio de modelos, distinguimos una primera etapa, previa a 1984, una segunda etapa, entre 1984-1994 y, una tercera etapa, desde 1994 hasta la actualidad ${ }^{37}$. Como complemento a esta la revisión, véase la Figura A1.4 del Anexo I donde presentamos un esquema cronográfico, así como algunos de los principales modelos de estudio de este fenómeno, que introduciremos a en los siguientes párrafos..

\section{$\underline{1^{\circ} \text { etapa de investigación: previa a } 1984}$}

El periodo anterior a 1984 se caracteriza por el desarrollo de los principales modelos que han servido de base para el desarrollo posterior de este cuerpo investigador. Los trabajos que han contribuido significativamente al inicio de esta corriente de investigación científica son: March y Simon (1958), Porter y Steers (1973), Mobley (1977), Price (1977), Martín (1977, 1979), Mobley, Griffeth, Hand y Meglino (1979),

\footnotetext{
${ }^{37}$ Otro criterio de clasificación, también interesante, es el propuesto por Naggiar (2001), proponiendo tres bloques, según el foco de interés y relacionándolos cronológicamente: 1) etapa ente 1950-1970: foco de estudio centrado en situaciones de la organización y de mercado. 2) Décadas de los setenta y ochenta, foco de estudio centrado en las características del puesto de trabajo. Y 3) A partir de finales de los ochenta, década de los noventa en adelante: foco de estudio centrado en identificar las mejores prácticas para lograr la retención de empleados, entre ellas destaca el interés por estudiar las prácticas de recursos humanos (Naggiar, 2001). Recomendamos la lectura del citado trabajo y del trabajo de revisión de Weibo, Kaur y Zhi (2010) para profundizar en la investigación en retención.
} 
Bluedorn (1980), Price y Mueller (1981, 1986) Steers y Mowday (1981) y Hom, Griffeth y Sellaro (1984). Se caracterizan por centrarse en la variable rotación voluntaria y trataron de dar respuesta y explicar el proceso por el que una persona decide abandonar su organización, desde el nivel de análisis del individuo. Por ello, la atención investigadora se dirigió a la satisfacción y al compromiso laboral, así como a las diferencias entre individuos y la naturaleza del trabajo, como variables explicativas del proceso de abandono (Holtom et al., 2008). De la extensa literatura de esta etapa, en esta investigación nos centramos en los trabajos que proponen modelos que destacan por su relación expresa con variables o prácticas de recursos humanos y que presentamos a continuación.

En primer lugar, cabe señalar el modelo seminal de March y Simon (1958), de forma indirecta, incluye algunas prácticas de recursos humanos (características del trabajo, supervisión, premios y recompensas, participación y horario de trabajo compatible con otras actividades) como antecesoras de la deseabilidad percibida de dejar la organización $^{38}$. En segundo lugar, el modelo de Price (1977) es el primero en incorporar, expresamente y de forma directa, variables relativas al área de recursos humanos (la retribución o salario, el grado de integración y la comunicación) como influyentes directa y positivamente sobre la satisfacción en el trabajo, repercutiendo negativamente sobre la rotación voluntaria y, por ende, positivamente sobre la retención de empleados. Posteriormente, Mobley, Griffeth, Hand y Meglino (1979), en su “modelo expandido de rotación voluntaria”, mejoran su modelo previo, denominado “modelo de las relaciones intermedias” (Mobley, 1977). En él, Mobley y sus colegas

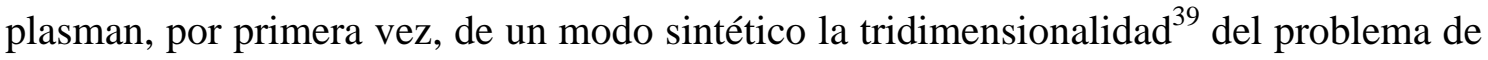
la rotación voluntaria (y de la retención), sugiriendo cuatro grupos de factores determinantes de la intención de abandono: la satisfacción laboral, la insatisfacción laboral, la utilidad esperada en otros trabajos-puestos de la propia organización y la utilidad esperada en trabajos-puestos fuera de la organización. Este modelo incorpora

\footnotetext{
${ }^{38}$ Véase Figura A1.5 del Anexo I de esta tesis.

${ }^{39}$ Es decir, existe una triada de factores que influyen y se relacionan con la retención: factores de mercado (laborales, normativos, entorno económico, etc.), de organización (prácticas y políticas de la organización, características de la organización) y de individuo (características propias de la persona, características demográficas, etc.).
} 
variables relacionadas con el ámbito de recursos humanos como son: el contenido del puesto de trabajo, las recompensas (retribución), la supervisión, el clima laboral y el trabajo en grupo e incluye, también, la importancia de la supervisión y nuevas formas de organización del trabajo. De forma similar, Martín $(1977,1979)$ propone un modelo que incluía la retribución (salario y paga de beneficios), integración de los empleados, la comunicación instrumental, la comunicación formal, el grado de centralización en la organización, la rutinización, la justicia distributiva y la promoción.

Basándose en el trabajo de Price (1977), Bluedorn (1980) propone un "modelo unificado” incorporando variables controlables por la organización (aunque no logra contrastarlas todas) como son: promoción, formalización de las tareas y la equidad interna, con influencia positiva sobre la satisfacción en el trabajo. Por último, debemos destacar en esta etapa, el modelo desarrollado por Price y Mueller (1981), puesto que incorpora diversas prácticas de recursos humanos ya utilizadas en modelos anteriores (comunicación instrumental, salario, rutinización, oportunidades de promoción, justicia distributiva) e incorpora nuevas variables como el trabajo sobredimensionado, la formación y la responsabilidad en el puesto de trabajo.

\section{$\underline{2^{a} \text { etapa de investigación:1984-1994 }}$}

Este periodo se caracteriza por un creciente interés sobre variables del contexto laboral organizativo, principalmente, por su influencia negativa sobre la retención, como, por ejemplo, el cansancio y el estrés laboral. Las variables de contexto que caracterizan los trabajos desarrollados en esta etapa se pueden agrupar en dos categorías según Holtom et al. (2008): 1) variables de nivel organizativo y de nivel macro (p.e. cultura organizativa) y 2) variables que relacionan a las personas con su contexto laboral, principalmente, las relaciones de los empleados (p.e. soporte percibido organizativo, soporte percibido del supervisor). En este periodo se avanza hacia estudios más complejos que incluyen variables organizativas como la cultura organizativa, la cohesión de grupos, los sistemas de retribución, la demografía y el género de la plantilla, etc. Además, la investigación en rotación y retención comienza a incluir variables que recogen las relaciones de los empleados con su entorno organizativo (soporte percibido del supervisor, de los compañeros, etc.) o su grado de ajuste a la 
organización. Por último, debemos hacer notar que es en este periodo cuando se desarrolla el concepto de compromiso organizativo, a través del trabajo de Meyer y Allen (1991). Este constructo es de gran relevancia para la retención y la rotación voluntaria, puesto que existe una amplia evidencia de la relación entre las tres facetas del compromiso (normativo, afectivo y de continuidad) y el comportamiento de abandono/permanencia del empleado en la organización.

Otro de los primeros trabajos relevantes en este periodo es el de Abelson y Baysinger (1984). Estos autores tratan de identificar el nivel óptimo de rotación de la organización, buscando el equilibrio entre los costes de retención y los costes de rotación. Además, incluyen una variable que denominan "política de gestión de recursos humanos” como variable clave para lograr el equilibrio entre ambos costes. Éste es uno de los primeros modelos que abarca las tres dimensiones ${ }^{40}$ (mercado, organización e individuo) e, incluye, variables y prácticas de gestión de recursos humanos como son: el grado de centralización y la participación en la toma de decisiones, la formalización de las tareas y los procedimientos, la comunicación instrumental, las oportunidades de promoción y la autonomía en el puesto.

También, destacan las contribuciones de O’Reilly, Chatman y Caldwell (1991), pioneros en introducir el concepto de ajuste persona-organización como influyente variable en la decisión de abandono. O, el trabajo de Hulin (1991) que, bajo un enfoque heurístico, propone introducir un nuevo constructo, el constructo de abandono ${ }^{41}$, en sustitución de la variable rotación voluntaria o abandono, al considerar que existen un conjunto de comportamientos interrelacionados que, de forma conjunta, explican la rotación voluntaria. También destacan, en esta etapa, los trabajos seminales de la teoría del soporte organizativo (Eisenberger et al., 1986, 1990), que han tenido una gran repercusión y aplicación en las investigaciones posteriores.

Además de lo anterior, no podemos pasar por alto el trabajo de Hom y Griffeth (1995) debido a su esfuerzo integrador. A través de su "modelo integrativo de rotación voluntaria”, tratan de aglutinar las principales contribuciones validadas hasta el

\footnotetext{
${ }^{40}$ Que son denominadas atributos del entorno, de la organización y del individuo (Abelson y Baysinger, 1984:337).

${ }^{41}$ Traducción del término en inglés withdrawal construct.
} 
momento en la literatura de rotación voluntaria/retención (véase en la Figura A1.6 del Anexo I de esta tesis). Este modelo ya incorpora numerosas variables del área de recursos humanos que habían sido contrastadas empíricamente, como la equidad y justicia del sistema de retribución, contrastado empíricamente por Miceli et al.(1991), la seguridad del empleo (Ashford et al, 1989 y Davy et al., 1991), el sistema de recompensas extras y la formación (Mobley, 1977; Rusbult y Farrel, 1983; Mathieu y Zajac, 1990), el sistema de retribución (Hulin et al., 1985; Price y Mueller, 1981, 1986; Mobley, 1982a, Cotton y Tuttle, 1986), el trabajo en equipo y el nivel de cohesión del grupo (Cotton y Tuttle, 1896; Price y Mueller, 1981,1986; Tsui et al., 1992) y, además, incorpora una variable relativa al diseño o enriquecimiento del puesto de trabajo a través de, lo que denomina, la complejidad del puesto y su alcance. Esta propuesta incluye también la satisfacción laboral y el compromiso organizativo, como variables mediadoras en la relación con la rotación voluntaria/retención.

Desde la propuesta integradora de Hom y Griffeth (1995), han disminuido enormemente los intentos por modelizar este fenómeno, debido a la gran multitud de factores que es necesario considerar, dificultando el desarrollo de un modelo ampliamente generalizable y, por ello, han surgido otro tipo de propuestas.

\section{$\underline{3^{\circ} \text { etapa de investigación: desde } 1994 \text { hasta la actualidad }}$}

Desde 1994 hasta nuestros días, la investigación en retención y rotación ha experimentado un desarrollo notable ${ }^{42}$. En concreto, este periodo se caracteriza por la relevancia que adquiere la variable retención sobre la variable rotación voluntaria y la propuesta de modelos innovadores, en relación a los modelos desarrollados en etapas anteriores. Así, podemos destacar el “modelo desplegado” (Lee y Mitchel, 1994, 1996), el "modelo de las ocho fuerzas” (Maertz, 2001; Maerzt y Campion,2004), el “modelo RETEN” (Luna Arocas y Camps Torres, 2003), el “modelo organizativo de la

\footnotetext{
${ }^{42}$ Holtom et al.,(2008) ofrecen una extensa revisión de la literatura del tema que nos ocupa y definen siete categorías para agrupar esta investigación, según el objeto de estudio: 1) Nuevas diferencias entre individuos (habilidades, rasgos de la personalidad); 2) efecto del estrés y el cambio; 3) trabajos empíricos sobre modelos emergentes, como el modelo desplegado; 4) profundización en el efecto de variables de contexto organizativo, principalmente relaciones interpersonales (p.e. comportamiento ciudadano); 5) identificación de factores y variables orientados específicamente a la retención (compromiso e inmersión en el trabajo-job embeddedness-); 6) modelo dinámicos y 7) profundización en la comprensión de relaciones identificadas previamente en la literatura.
} 
persistencia del empleado" (Peterson, 2004), los modelos basados en el soporte organizativo percibido (Eisenberger et al., 1986, 2001; Rhoades et al., 2001) y el “modelo de inmersión en el trabajo” (Mitchell et al., 2001; Lee et al., 2004). Todos ellos se comentan, brevemente, a continuación.

Un primer grupo de estos modelos siguen enfocando el análisis de la retención desde la óptica del individuo y de la rotación voluntaria, analizando las causas que conducen al empleado a abandonar la empresa. Distinguimos los dos siguiente modelos. Primero, el “modelo desplegado ${ }^{43}$ " desarrollado por Lee y Mitchel $(1994,1996)$. Es un modelo explicativo de los distintos caminos o vías a través de los que un empleado decide abandonar la organización (véase la Figura A1.7. del Anexo I de este trabajo). Estos autores incorporan la idea de que existe un suceso que inicia todo el proceso de decisión de abandono; a este suceso lo denominan $\operatorname{shock}^{44}$. A partir de este punto inicial, el modelo plantea, como si de un árbol de decisión se tratara, diferentes vías o caminos de decisión de los individuos, denominados path. Y, segundo, el "Modelo de las ocho fuerzas” de Maerzt y Campion (2004) trata de aglutinar todas las causas y antecedentes de la intención de abandono, como predecesora inmediata de la rotación voluntaria. Este modelo recoge todos los factores que pueden motivar o incitar al empleado a intentar abandonar su organización. Así, Maerzt (2001) propone ocho categorías, que denomina “fuerzas”, como antecedentes de la intención de abandono (véase Tabla 1.6.). De este modo, teniendo en cuenta las diversas fuerzas que pueden influir sobre los empleados, es más fácil poder identificar las causas de los posibles abandonos y, por tanto, se pueden diseñar estrategias y prácticas que lo impidan y potencien la retención del empleado en la organización.

\footnotetext{
${ }^{43}$ Traducción del término unfolding model (Lee y Mitchel, 1994, 1996).

${ }^{44}$ Shock: puede ser cualquier cambio esperado o inesperado, en el devenir del sistema social que sacuda, reestructure al empleado de su estado o desafíe su "status quo" con respecto a su percepción sobre su trabajo. El shock puede ser positivo, negativo o neutral (Lee y Mitchell, 1994).
} 
Tabla 1.6. Las ocho fuerzas del Modelo de Maerzt et al. (2001, 2004)

\begin{tabular}{|c|l|}
\hline Afectivas & $\begin{array}{l}\text { Dimensión relacionada con el sentimiento de pertenencia a la organización y la vinculación a la } \\
\text { misma, al puesto, a la profesión... }\end{array}$ \\
\hline Alternativas & $\begin{array}{l}\text { Percepción del empleado sobre su eficiencia y habilidades, y sobre su capacidad y certeza de } \\
\text { poder encontrar otras alternativas de trabajo. }\end{array}$ \\
\hline Comportamentales & Costes tangibles y psicológicos de abandonar la organización. \\
\hline Calculadoras & $\begin{array}{l}\text { Valoración de las expectativas de lo que se espera conseguir permaneciendo en la organización. } \\
\text { Orientación futura racional del propio interés }\end{array}$ \\
\hline Normativas & $\begin{array}{l}\text { Percepciones que el empleado tiene sobre lo que esperan de él sus familiares y amigos (externos } \\
\text { a la organización) con respecto a la rotación voluntaria.. }\end{array}$ \\
\hline Morales/éticas & Valores morales y éticos del empleado, en cuanto al comportamiento de abandono. \\
\hline Contractuales & Obligaciones percibidas, lo que debe a la organización, contrato psicológico. \\
\hline Constitutivas & $\begin{array}{l}\text { Las relaciones del empleado con los individuos y grupos de si organización. Vinculaciones con } \\
\text { los compañeros, (no a la organización). }\end{array}$ \\
\hline
\end{tabular}

Fuente: elaboración propia a partir de Maerzt et al. (2001, 2004)

Un segundo grupo de modelos desarrollados en este periodo, se han focalizado, expresamente, en la retención. Además, se centran en la perspectiva organizativa y analizan el fenómeno de la retención relacionándolo con prácticas organizativas, entre ellas, las prácticas de recursos humanos. En esta línea de trabajos destacan la propuesta de Luna y Camps (2003) y la propuesta de Peterson (2004). En el caso español, cabe señalar la contribución de Luna y Camps (2003) con su modelo de retención de personal denominado "modelo RETEN: modelo estratégico de retención de personal en la organización”. En él incluyen un conjunto de PAR (practicas de alto rendimiento), en concreto, selección objetiva, formación adecuada, el ajuste al puesto laboral, gestión de retribución y promociones adecuadas, el clima laboral relacional y la equidad responsabilidad-salario, como influyentes sobre tres variables resultado de recursos humanos (compromiso organizativo, satisfacción salarial y la propensión al abandono); siendo la propensión al abandono un claro antecedente de la rotación voluntaria y el compromiso organizativo y la satisfacción salarial, claros potenciadores de la retención del empleado (véase Figura A1.8 del Anexo I). 
El modelo que plantea Peterson (2004) ${ }^{45}$, “modelo organizativo de la persistencia del empleado”, presta especial atención al papel que juega la organización en la retención de empleados (principalmente, a través de la socialización y los procesos de integración). El modelo plantea una relación simbiótica entre variables organizativas y variables del individuo, en un planteamiento orientado al desarrollo de los recursos humanos a través de su correcta gestión, mediante lo Peterson denomina “integración”. La integración representa el ajuste persona-organización y recoge la necesidad que tienen los individuos de percibir su conexión con la organización y sentirse integrados en ella. De este modo, asumen valores y objetivos de la organización como propios, desarrollan un mayor compromiso con la organización y satisfacción laboral y, por ende, permanecen en ella. Peterson identifica diversos procesos de integración que favorecen la retención, entre los que incluye aspectos de gestión de recursos humanos como son: interacción con los superiores, conocimiento de los requerimientos del puesto, oportunidades de desarrollo profesional, información sobre el desarrollo de carrera profesional, participación en la toma de decisión sobre el desarrollo profesional y prácticas de equilibrio entre vida personal-laboral.

Un tercer grupo de trabajos desarrollados desde 1994, son aquéllos que incorporan la variable soporte organizativo percibido como variable mediadora de la influencia de prácticas organizativas sobre la rotación voluntaria o sobre la retención (Véase Figura 1.15). Estos trabajos se apoyan en la teoría del soporte organizativo (Eisenberger et al., 1986; Shore y Shore, 1995) y desarrollan un nuevo constructo denominado soporte organizativo percibido $^{46}$ (Eisenberger et al., 1986, 1990, 1997, 2001; Rhoades et al., 2001, 2002; Allen et al., 2003). La idea de que los empleados valoran el apoyo, el soporte o el trato que la empresa les dedica, y que esto afecta a su motivación y comportamiento, no es nueva, ya aparece recogida expresamente por Levinson en 1965. No obstante, esta corriente de trabajos contribuye a refinar dicha consideración, puesto que postulan que si un empleado percibe que la organización le da soporte y apoya, es decir, que se preocupa por él, es porque lo valoran positivamente; ello le genera un sentimiento de apoyo percibido y, en reciprocidad, actúa de un modo que sea positivo

\footnotetext{
${ }^{45}$ Véase Figura A1.9 del Anexo I de este trabajo.

${ }^{46}$ Habitualmente se indentifica por su siglas en inglés POS (Perceived Organizational Support).
} 
para la organización y que así sea percibido por ella. Todo ello se traduce una mejora de su desempeño, de su compromiso y de su retención (Eisenberger et al., 1986).

Figura 1.18.

Estructura general de los modelos de retención basados en el soporte organizativo

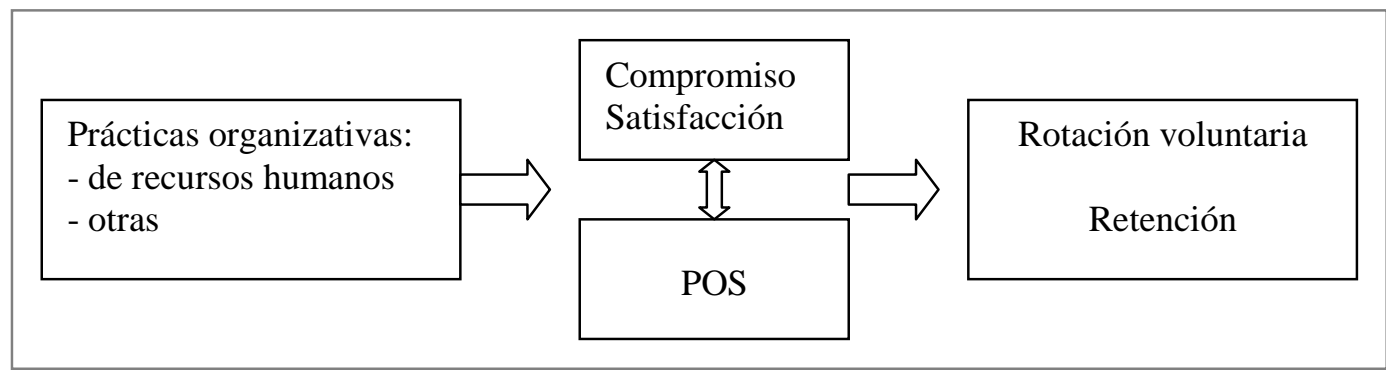

Dentro de este grupo de trabajos podemos destacar el trabajo de Rhoades, Eisenberger y Armeli (2001), que integran, expresamente, diversas prácticas de recursos humanos, como son: las recompensas, la equidad de procedimientos y el soporte del supervisor. Posteriormente, Rhoades y Eisenberger (2002), a través de un meta-análisis, confirman el impacto positivo que, sobre el soporte organizativo percibido, ejercen diversas prácticas de recursos humanos (principalmente, justicia, liderazgo, comunicación, recompensas, salario, reconocimiento, promoción). Y, en la misma línea, Allen, Shore y Griffeth (2003) evidencian el efecto de la participación en la toma de decisiones, la equidad retributiva, el sistema de recompensas y las oportunidades de desarrollo, sobre la rotación voluntaria, mediado por el soporte organizativo percibido.

Por último, identificamos una cuarta categoría de trabajos, que se caracterizan por centrarse exclusivamente en la retención, sin tener en cuenta la rotación o la intención de abandono de los empleados. Es decir, ponen el foco de atención en analizar por qué un empleado se queda en la organización, más que en identificar las razones por las que decide abandonar la organización, como había sido la tendencia en la investigación desarrollada hasta el momento. En este sentido, destaca el modelo basado en el constructo “inmersión en el trabajo "47" (Mitchell, Holtom et al., 2001). Este constructo trata de recoger todas las fuerzas que retienen o mantienen a una persona en su trabajo, en otra palabras, todas las dimensiones que contribuyen a mantener satisfecho a un

\footnotetext{
${ }^{47}$ Inmersión en el trabajo del término original job embeddness.
} 
empleado, favoreciendo así su permanencia, su compromiso, su implicación y su satisfacción. Mitchell, Holtom et al. (2001), desarrollan este nuevo constructo y lo definen como la red en la que un individuo queda atrapado en su trabajo. Un empleado queda “atrapado” en su trabajo por diferentes vínculos (Mitchell et al., 2001) unos relativos al trabajo (factores laborales) y otros externos (factores extra-laborales). Estos vínculos provienen de tres aspectos críticos: sus relaciones con otra gente y actividades -vínculos-, el grado de ajuste y compatibilidad con su trabajo, organización y comunidad en los diferentes espacios de la vida del empleado -ajuste-, y la facilidad de ruptura (el coste que le supondría al empleado dejar la organización) -sacrificio-. Estas tres dimensiones son denominadas respectivamente: vínculos, ajuste y sacrificio (Mitchell et al., 2001; Lee et al., 2004) y están asociadas a dos ámbitos: relativo al trabajo o externo a él, definidos a través de las dimensiones de “organización” o de “comunidad y entorno del individuo”, respectivamente. La Tabla 1.7 resume estas dimensiones.

Tabla 1.7. Definición de las dimensiones que forman el constructo inmersión en el trabajo

\begin{tabular}{|c|l|}
\hline $\begin{array}{c}\text { Inmersión en el } \\
\text { trabajo }\end{array}$ & $\begin{array}{l}\text { Representa un amplio abanico de factores que influyen sobre la retención del } \\
\text { empleado: (1) ajuste con el puesto, comunidad-entorno y otros aspecto } \\
\text { individuales, (2) grado de conexión con otros individuos y actividades, (3) } \\
\text { pérdidas, coste de oportunidad por dejar organización }\end{array}$ \\
\hline \hline $\begin{array}{c}\text { Ajuste- } \\
\text { Organización }\end{array}$ & $\begin{array}{l}\text { Refleja la compatibilidad con la organización y el confort percibido por los } \\
\text { empleados. Los valores del individuo, sus objetivos de carrera y desarrollo futuro se } \\
\text { deben principalmente a su ajuste con el trabajo y requerimientos laborales actuales. }\end{array}$ \\
\hline $\begin{array}{c}\text { Ajuste- } \\
\text { Comunidad }\end{array}$ & $\begin{array}{l}\text { Se refiere al grado de ajuste con la comunidad y el entorno cercano percibido por el } \\
\text { individuo. Por ejemplo: cultura, clima, instalaciones, etc. }\end{array}$ \\
\hline $\begin{array}{c}\text { Vínculos- } \\
\text { Organización }\end{array}$ & $\begin{array}{l}\text { Incluye los vínculos y relaciones formales e informales entre los empleados y otras } \\
\text { personas dentro de la organización. }\end{array}$ \\
\hline $\begin{array}{c}\text { Vínculos- } \\
\text { Comunidad }\end{array}$ & $\begin{array}{l}\text { Se refiere al vínculo entre empleados y otros grupos de personas. Recoge las } \\
\text { influencias que ejercen la familia y otros agentes sociales sobre los individuos y sus } \\
\text { decisiones. }\end{array}$ \\
\hline $\begin{array}{c}\text { Sacrificio- } \\
\text { Organización }\end{array}$ & $\begin{array}{l}\text { Se refiere a la percepción sobre la pérdida de beneficios materiales y psicológicos, si } \\
\text { abandonara el trabajo. Por ejemplo, pérdida de amigos de trabajo, de trabajar en } \\
\text { proyectos interesantes, de beneficios sociales de esa organización, etc. }\end{array}$ \\
\hline $\begin{array}{c}\text { Sacrificio- } \\
\text { Comunidad }\end{array}$ & $\begin{array}{l}\text { Se refiere al sacrificio que se tendría que hacer si abandona ese trabajo. Cambiarse de } \\
\text { ciudad, pérdida de actividades extralaborales que estuviera realizando, etc. }\end{array}$ \\
\hline
\end{tabular}

Fuente: adaptado de Holtom, Mitchell y Lee (2006)

Recientes investigaciones (Holtom, Mitchell y Lee, 2006; Lin, 2007; Zhao y Liu, 2010) han evidenciado que las prácticas de recursos humanos pueden favorecer la inmersión 
en el trabajo, en alguna de sus dimensiones. Por ejemplo, Zhao y Liu (2010), evidencian que la formación sobre desarrollo de carrera, procesos de selección selectivos, ajuste del horario, flexibilidad laboral, oportunidades de formación y procesos de socialización contribuyen a la dimensión ajuste-organización. En relación a la mejora de la dimensión vínculos-organización, identifican la autonomía, participación del empleado, oportunidades para compartir conocimiento, premios y reconocimiento, apoyo de supervisores y jefes a nuevos empleados y subordinados. Y, por último, en relación al sacrificio-organización, señalan como principales medidas: los planes de ayuda en empresa, comedor, medidas de conciliación, beneficios sociales, reparto de beneficios, privilegios para familiares como descuentos, acceso a instalaciones lúdicas de la empresa, etc.

A modo de resumen, y una vez realizada la revisión de los modelos fundamentales de retención y rotación voluntaria, podemos extraer varias conclusiones. Primero, hemos identificado que la mayoría de los trabajos que estudian la retención (y también, la rotación voluntaria) incorporan variables mediadoras. Por un lado, la satisfacción laboral y el compromiso organizativo (Mobley et al., 1979; Hom y Griffeth, 1995; Meyer y Allen, 1997; Meyer et al., 2002) y, por otro, constructos más complejos como: el soporte percibido de la organización (Eisenberger et al., 1986; Shore y Shore, 1995; Allen, Shore y Griffeth, 2003), factores relativos al intercambio con el líder (Graen et al., 1977; 1982; Graen y Scandura, 1986; Wayne et al., 1997) o el constructo de inmersión en el trabajo (Mitchell, Holtom, Lee et al.,2001; Lee, Mitchell et al., 2004). Esto es un patrón habitual en los estudios de retención y rotación voluntaria. Además, como hemos podido observar, la mayoría de los trabajos se desarrollan sobre la estructura planteada en la propuesta seminal de March y Simon (1958) o sobre alguna de las partes que lo forman (Véase Figura 1.19). 
Figura 1.19. Esquema tradicional de estudios sobre rotación voluntaria/retención

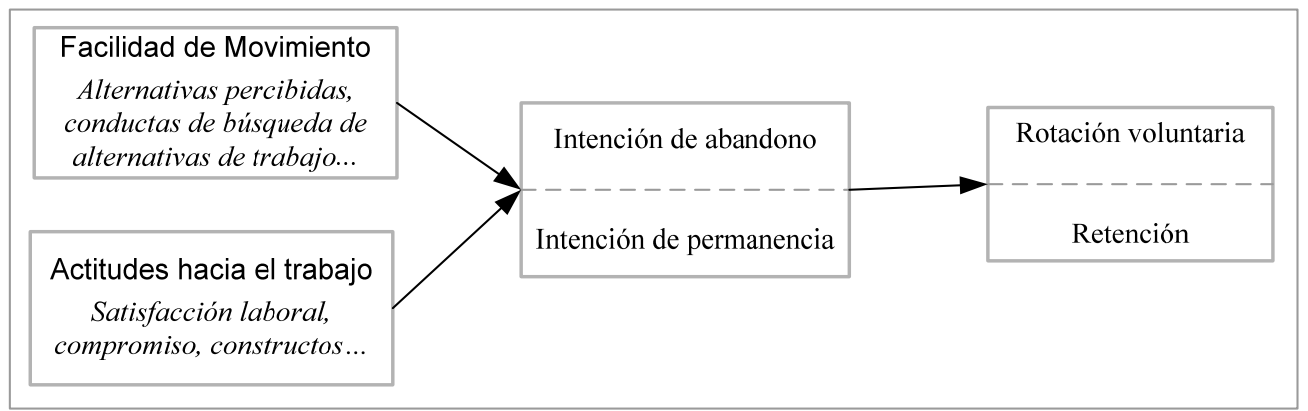

Fuente: Adaptado de Giosan (2003:7)

En este trabajo, nuestro interés se centra en aquel ámbito en el que la empresa tenga capacidad de actuación y, en concreto, en el proceso que la gestión de recursos humanos puesto que a través de él puede potenciar la retención de los empleados. La siguiente Figura 1.20 representa nuestro ámbito de estudio, dentro del esquema clásico de investigación en retención/rotación.

Figura 1.20. Ámbito de estudio de este trabajo

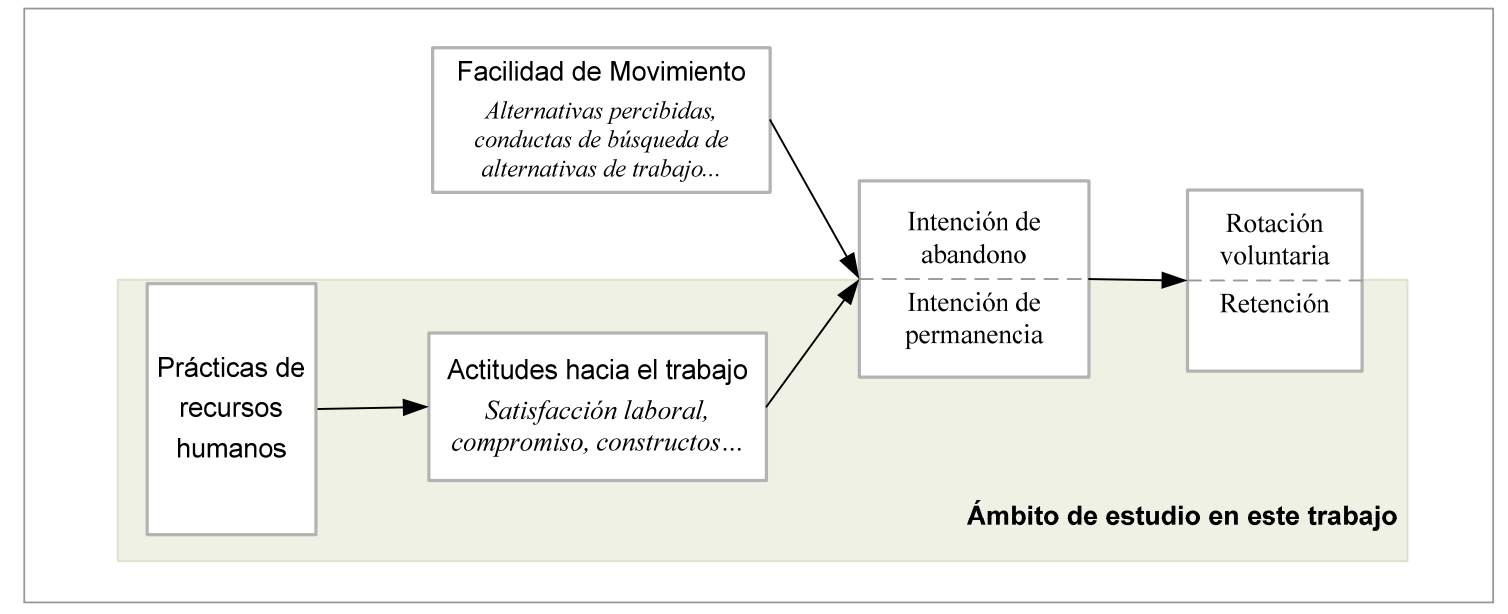

Y, segundo, tras constatar que éste es un ámbito de investigación muy extenso, hemos prestado una atención especial a identificar las prácticas de recursos humanos que se incorporan en los principales modelos de retención o de rotación voluntaria. Así, a modo de resumen, la Tabla 1.8 y la Tabla 1.9. recogen las principales prácticas y variables de recursos humanos incluidas,y su grado de utilización. 
Tabla 1.8. Principales modelos de retención que incluyen prácticas de recursos humanos

\begin{tabular}{|c|c|c|c|c|c|c|c|c|c|c|c|c|}
\hline $\begin{array}{c}\text { Principales modelos de retención y } \\
\text { prácticas de recursos humanos } \\
\text { incluidas }\end{array}$ & 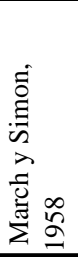 & 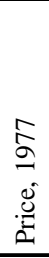 & 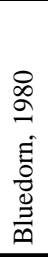 & 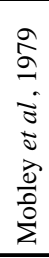 & 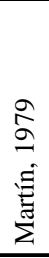 & 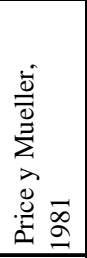 & 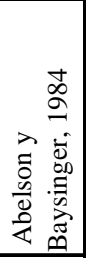 & 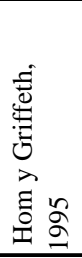 & 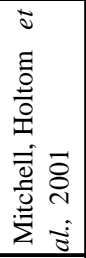 & 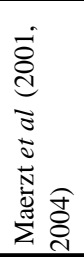 & 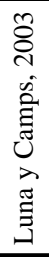 & 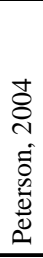 \\
\hline $\begin{array}{l}\text { Definición del puesto/trabajo: } \\
\text { autonomíal, retador, etc. }\end{array}$ & $\mathbf{x}$ & & $\mathbf{x}$ & $\mathbf{X}$ & & $\mathbf{x}$ & $\mathbf{x}$ & $\mathbf{X}$ & $\mathbf{x}$ & & & \\
\hline Retribución-salario & & $\mathbf{X}$ & $\mathbf{x}$ & $\mathbf{X}$ & $\mathbf{x}$ & $\mathbf{X}$ & & $\mathbf{x}$ & $\mathbf{x}$ & & $\mathbf{x}$ & \\
\hline Recomensas y premios & $\mathbf{X}$ & & & $\mathbf{X}$ & $\mathbf{X}$ & & & $\mathbf{X}$ & $\mathbf{X}$ & & $\mathbf{X}$ & \\
\hline Relación con jefe. Supervisión.Apoyo & $\mathbf{X}$ & & & $\mathbf{X}$ & & & & & $\mathbf{X}$ & $\mathbf{X}$ & & $\mathbf{X}$ \\
\hline Relación con compañeros & & & & & & & & & $\mathbf{X}$ & $\mathbf{X}$ & & \\
\hline Participación & $\mathbf{x}$ & & & & & & $\mathbf{x}$ & & $\mathbf{x}$ & & & $\mathbf{x}$ \\
\hline Comunicación & & $\mathbf{x}$ & $\mathbf{x}$ & & $\mathbf{x}$ & $\mathbf{x}$ & $\mathbf{x}$ & & $\mathbf{x}$ & & & $\mathbf{x}$ \\
\hline Promoción, desarrollo carrera & & & $\mathbf{x}$ & & $\mathbf{x}$ & $\mathbf{x}$ & $\mathbf{X}$ & & $\mathbf{X}$ & $\mathbf{X}$ & & $\mathbf{X}$ \\
\hline Formación & & & & & & $\mathbf{X}$ & & $\mathbf{x}$ & $\mathbf{X}$ & & & \\
\hline Clima laboral & & & & $\mathbf{X}$ & & & $\mathbf{X}$ & & $\mathbf{X}$ & & $\mathbf{X}$ & \\
\hline Equidad y justicia percibida & & & $\mathbf{X}$ & & $\mathbf{x}$ & $\mathbf{X}$ & & $\mathbf{x}$ & $\mathbf{X}$ & & $\mathbf{X}$ & \\
\hline Ajuste persona-puesto & & & & & & & & & $\mathbf{X}$ & & $\mathbf{X}$ & \\
\hline Conciliación (horario, etc.) & $\mathbf{X}$ & & & & & & & & $\mathbf{X}$ & & & $\mathbf{X}$ \\
\hline Selección & & & & & & & & & & & $\mathbf{X}$ & \\
\hline Integración, socialización & & $\mathbf{X}$ & $\mathbf{X}$ & & $\mathbf{X}$ & & & & $\mathbf{x}$ & & & \\
\hline Trabajo en equipo & & & & $\mathbf{X}$ & & & & $\mathbf{x}$ & $\mathbf{x}$ & & & \\
\hline
\end{tabular}

Tabla 1.9. Ranking de las prácticas de recursos humanos más utilizadas en los modelos de retención/rotación voluntaria

\begin{tabular}{|lll|}
\hline \multicolumn{2}{|c|}{ Ranking de las prácticas de recursos humanos más utilizadas } \\
\hline $67 \%$ & de los principales modelos incluyen & Retribución-salario \\
$58 \%$ & de los principales modelos incluyen & Definición del puesto/trabajo \\
$58 \%$ & de los principales modelos incluyen & Comunicación \\
$58 \%$ & de los principales modelos incluyen & Promoción, desarrollo carrera \\
\hline $50 \%$ & de los principales modelos incluyen & Recomensas y premios \\
$50 \%$ & de los principales modelos incluyen & Equidad y justicia percibida \\
$42 \%$ & de los principales modelos incluyen & Relación con jefe. Supervisión \\
\hline $33 \%$ & de los principales modelos incluyen & Participación \\
$33 \%$ & de los principales modelos incluyen & Clima laboral \\
$33 \%$ & de los principales modelos incluyen & Integración, socialización \\
\hline $25 \%$ & de los principales modelos incluyen & Formación \\
$25 \%$ & de los principales modelos incluyen & Conciliación (horario, etc.) \\
$25 \%$ & de los principales modelos incluyen & Trabajo en equipo \\
\hline $17 \%$ & de los principales modelos incluyen & Ajuste persona-puesto \\
$8 \%$ & de los principales modelos incluyen & Relación con compañeros \\
\hline
\end{tabular}


Como se muestra en la tablas anteriores, las prácticas de recursos humanos que se incluyen en más de la mitad de los modelos de retención fundamentales son: primero, aquellas vinculadas al sistema de retribución, no sólo estudiando el efecto de un salario competitivo sino, también, incluyendo otras formas de recompensas y premios, que permiten que el sistema de retribución sea percibido por los empleados como justo, cumpliendo, por tanto, con el principio de equidad interna. Segundo, las prácticas relacionadas con el diseño del puesto de trabajo. En concreto, analizando si la autonomía en el puesto o la diversidad de tareas influyen positivamente sobre la retención. Tercero, la posibilidad de promoción y de desarrollo de carrera profesional, también, aparecen recogidos en más de la mitad de los modelos revisados. Y, por último, prácticas ligadas a la faceta relacional del empleado como la comunicación interna y la supervisión de los mandos con sus subordinados, también se incluye en gran número de estos trabajos.

Por otro lado, entre un tercio y un cuarto de los modelos revisados incluyen prácticas que favorecen las relaciones dentro de la organización como: las medidas de participación del empleado, el trabajo en equipo o las medidas de socialización e integración del empleado. En este mismo grado porcentual podemos señalar, también, la formación y las medidas de conciliación que, curiosamente, ya aparecían recogidas en el modelo seminal de March y Simon (1958) a través del tipo de horario de trabajo, y que no vuelven a quedar recogidas en ningún modelo hasta las aportaciones más recientes de Mitchell et al., (2001) o Luna y Camps (2003).

Por último, como medidas menos habituales en los modelos revisados, podemos señalar la valoración del ajuste que exista entre persona y puesto de modo que, a mayor ajuste, mayor posibilidad de permanencia en la empresa. Del mismo modo, cabe señalar la relación entre compañeros, como variable que puede influir positivamente en la retención cuando esta relación es satisfactoria. Precisamente, esta última práctica citada se ha incorporado a los modelos más recientes, lo que podemos interpretar como un cambio en la tendencia de tipo de prácticas o variables relevantes en los modelos de retención. 
Una vez realizada la revisión de la literatura basada en los principales modelos de retención/rotación, en el siguiente epígrafe revisamos los principales estudios que, sin utilizar un apoyo expreso en estos modelos, analizan el impacto de diversas prácticas sobre la retención de empleados, en concreto, nos centramos exclusivamente en los trabajos que incorporan prácticas de recursos humanos, puesto que es nuestro ámbito de estudio particular en esta investigación.

\subsubsection{Revisión de los trabajos que relacionan las prácticas de recursos humanos y la retención de empleados en la organización}

La revisión realizada nos ha permitido identificar un cuerpo importante de trabajos que, bien desde la perspectiva organizativa, o bien, desde la perspectiva del individuo, analizan la influencia que la gestión de recursos humanos, a través de sus prácticas, puede ejercer sobre la retención de empleados. En concreto, la gestión de la retención se puede definir como un proceso estratégico y coherente que comienza por conocer las razones por las que los empleados se vinculan a la organización (Fitz-enz, 1990; Davies, 2001; Chew, 2004). Por ello, diversas investigaciones de gestión de recursos humanos han analizado, por ejemplo, cómo la formación o la retribución, entre otras, reducen la tasa de absentismo y de rotación voluntaria y, con ello, mejoran la calidad de vida en el trabajo y los resultados financieros (Arthur, 1994; Delaney y Huselid, 1996; Huselid, 1995; Ichniowski, Shaw y Prennushi, 1997; Snell y Youndt, 1995; MacDuffie, 1995; Meyer y Allan, 1991; Snell y Dean, 1992).

Tratar de retener y comprometer a los empleados con la organización implica, por tanto, comprender lo que necesitan para estar satisfechos en sus trabajos y asumir que dichos empleados responden positivamente, cuando sus empresas prestan atención a sus necesidades y tratan de motivarlos e implicarlos (Dobbs, 2001; Chew, 2004).

Como queda reflejado en el epígrafe anterior, la investigación sobre retención ha dejado una literatura muy extensa y diversa. Los principales trabajos de revisión de este tópico dan muestra de la gran variedad de prácticas y variables de gestión de recursos humanos presentes en esta literatura de retención (Hom y Griffeth, 1995; Griffeth y Hom, 2001, 2004; Holtom et al., 2008; Weibo, Kaur y Zhi, 2010). En este sentido, diversos trabajos de revisión han tratado de identificar cuáles son las mejores prácticas de retención. Así, 
por ejemplo, Fitz-enz (1990) identifica la cultura y estructura organizativa, la estrategia de reclutamiento y selección, el sistema de retribución y recompensas, los programas de apoyo y soporte al empleado y los sistemas de desarrollo de carrera como las más eficaces para lograr la retención de los empleados en la organización. Por su parte, Naggiar (2001) identifica siete áreas clave para lograr la retención a través de la gestión de recursos humanos: selección, orientación, formación, desarrollo de carrera, motivación, compensación y evaluación/feedback. Los trabajos de revisión de Griffeth y Hom (2004; 2001) señalan las siguientes prácticas: diseño de puesto, formación, promoción, entrevistas realistas de trabajo, reclutamiento y selección, orientación y socialización, tipos de contratación, medidas de conciliación vida personal-laboral, trabajo en equipo, sistema de retribución, relaciones internas (con compañeros y con superiores), estilo de liderazgo y supervisión, clima laboral, organización del trabajo y ajuste persona-puesto, organización. En el caso de sectores intensivos en conocimiento, Dockel (2003) encuentra que los factores de retención más utilizados en la literatura eran: formación y desarrollo, soporte del supervisor, conciliación vida laboral-personal, diseño enriquecido de puesto y el salario base. Otro trabajo relevante es de Chew (2004); esta autora propone distinguir entre dos grupos de factores: los factores de recursos humanos (ajuste persona-puesto, retribución, formación y desarrollo de carrera) y los factores organizativos (liderazgo, relaciones, cultura, comunicación, entorno y condiciones laborales como, por ejemplo, las medidas de conciliación). En definitiva, aunque existe un abanico muy amplio de prácticas de recursos humanos detectadas, no existe un consenso generalizado sobre cuáles son las más eficaces.

En este trabajo, una vez realizada una revisión del estado del arte sobre retención, hemos identificado una amplia diversidad de prácticas de recursos humanos utilizadas por las empresas para favorecer la retención de sus empleados. Sin embargo, nos vamos a centrar en algunas de las más efectivas y recurrentes en la literatura y, a ellas, dedicaremos las siguientes páginas. Estas prácticas serán las que formarán parte del modelo objeto de estudio de la presente investigación, que presentamos con detalle en el siguiente capítulo. Así, las prácticas seleccionadas son: diseño del puesto de trabajo, desarrollo profesional del empleado (promoción y formación), retribución, relaciones internas del empleado (con la organización y con otros miembros de la organización) y 
condiciones y organización del trabajo. No obstante, debemos señalar que la literatura de retención también incluye otras prácticas relevantes, como las vinculadas al proceso de entrada en la organización (reclutamiento, selección y socialización). Estas prácticas no van a ser objeto de nuestra investigación, puesto que hemos decidido centrar nuestro análisis en las prácticas más eficaces una vez que el empleado ya se ha incorporado a la organización.

1.3.2.2.1. Estudios que relacionan la retención del empleado y el diseño de su puesto de trabajo

Los estudios desarrollados por Hackman, Oldham, et al. (1980, 1988, 1987, 1983, 1991) demostraron la importancia que las características del puesto podían ejercer sobre la satisfacción laboral y sobre algunos comportamientos de los empleados, como su permanencia en la organización. Pese a haber transcurrido más de tres décadas, sigue siendo un modelo que goza de plena vigencia. El modelo plantea cinco "dimensiones clave del puesto” que influyen sobre la satisfacción laboral y, por ende, sobre la retención: 1) la variedad de habilidades-destrezas empleadas, 2) la identidad de la tarea, 3) el grado de impacto de su trabajo sobre otros trabajos, personas, etc., 4) grado de autonomía en su puesto y 5) la existencia de feed-back, información sobre los resultados y tareas realizadas en su trabajo (nivel de eficacia logrado). Principalmente, la autonomía y la diversidad de tareas son las dos dimensiones más frecuentemente contrastadas en los estudios de rotación voluntaria y de retención (Buck y Watson, 2002; Wooddrufee, 2006; Starosta, 2007) así como también, la descripción clara de los puestos de trabajo (Delery y Doty, 1996; Buck y Watson, 2005; Sun et al., 2007; Ng y Butts, 2009).

Dentro de este ámbito de estudio hay autores que aglutinan varias de estas características bajo lo que se ha denominado diseño enriquecido de puesto. Un puesto de trabajo enriquecido se caracteriza por motivar al empleado, ser atractivo, suponerle un reto, permitirle aprender en todo momento y ejercitarse en utilizar sus distintas capacidades y conocimientos (Hom y Griffeth, 1995). Para lograr enriquecer los puestos de trabajo y favorecer, con ello, la retención, éstos deben ser: retadores, variados y ofrecer autonomía (Griffeth y Hom, 2001; Boselie y Wiele, 2002; Horwitz et al., 2003; 
Dockel, 2003). Numerosos trabajos empíricos confirman que los empleados con puestos de trabajos complejos tienen menor probabilidad de abandono (Katerberg et al., 1979; Price y Mueller, 1981, 1986; McEvoy y Cascio, 1985), mediado por su efecto sobre la satisfacción laboral (Mobley et al, 1979; Price y Mueller, 1981, Hom y Griffeth, 1995; McEvoy y Cascio, 1985; Osca y Urien, 2001, Griffeth y Hom, 2001, entre otros) o por el compromiso (Buck y Watson, 2005). También, Boselie y Wiele (2002), Swart y Kinnie (2001, 2003b), Dockel (2003), Horwitz et al. (2003), Vaiman (2004) o Bhatnagar (2007), demuestran la influencia positiva del diseño de puesto enriquecido sobre la retención. En concreto, en el caso español, destacan los trabajos de Munduate, Fuertes y Hontangas (1993), Fuertes, Munduate y Fortea (1994), Osca y Urien (2001) o el caso reciente de García, Neira y Castro (2011) aportando evidencias positivas a dicha relación.

\subsection{Estudios que relacionan la retención del empleado y su desarrollo} profesional: formación y promoción

London (1989) concibe el desarrollo del empleado como el crecimiento personal y profesional a largo plazo de los empleados. Según Gómez-Mejía et al. (2001), se puede realizar mediante tres políticas de recursos humanos: la valoración del rendimiento, el desarrollo profesional (promoción ${ }^{48}$, principalmente) y la formación del empleado. En este trabajo nos centramos en la formación y en la promoción, puesto que son las más frecuentes y contrastadas en los modelos básicos de retención (Bluedorn, 1980; Martín, 1977, 1979; Price y Mueller, 1981; Abelson y Baysinger, 1984; Jackosky, 1984; Hom y Griffeth, 1995; Peterson, 2004; Luna y Camps, 2003).

En base a los trabajos revisados, la mayoría de los que analizan el efecto de estas prácticas sobre la retención lo hacen apoyándose en el argumento de que la promoción y

\footnotetext{
${ }^{48}$ Aunque, tradicionalmente, la promoción y desarrollo de carrera se han identificado con la movilidad vertical ascendente del empleado, hoy en día, esta interpretación resulta limitada. En este sentido, Lazarova (2004) señala: primero, que los empleados son, cada vez más, los responsables de su propio desarrollo de carrera y juegan un papel activo con sus comportamientos y actitudes; $y$, segundo, que el éxito o satisfacción que los empleados perciben del desarrollo de su carrera debe entenderse incorporando la dimensión subjetiva; es decir, el empleado se siente satisfecho con la formación que recibe, con las posibilidades de promoción o con la movilidad interna -vertical o lateral-, porque satisface sus valores, aspiraciones y objetivos intrínsecos y, no sólo, por la satisfacción del mero ascenso vertical jerárquico.
} 
la formación son percibidas por los empleados como una acción positiva de la organización, mediante la cuál envía a los empleados el mensaje de preocupación por ellos, por su bienestar y por su desarrollo, mostrando, así, la valoración positiva que la organización realiza de sus contribuciones (Nadler y Nadler, 1989); esto genera satisfacción y sentimientos de reciprocidad (Gouldner, 1960; Eisenberger et al., 1986; Robinson y Rousseau, 1994), provocando una mejora en las actitudes y comportamientos de los empleados que, en última instancia, se traduce en una mejora de la tasa de retención en la organización.

En primer lugar, puesto que la formación se considera una forma de invertir en el capital humano del empleado, mediante la que se pretende que éstos adquieran nuevos conocimientos, habilidades, los apliquen en sus trabajos y sean compartidos con otros empleados (Noe, 1996), contribuye a que los empleados puedan corregir y mejorar la realización de sus tareas (Chew, 2004), lo que se ha evidenciado que incrementa la productividad y reduce la tasa de abandono (Glance et al., 1997; Lynch y Black, 1998; Naggiar, 2001; Davies, Taylor y Savery, 2001; Mattox y Jinkerson, 2005). De hecho, diversos trabajos incluyen la formación dentro del grupo de prácticas de recursos humanos contrastadas como influyentes sobre la retención, en múltiples sectores y tipos de empresas, generalmente, a través de su efecto sobre variables intermedias como el compromiso afectivo y la satisfacción laboral (Shaw et al.,1998; Boselie y Wiele, 2002; Luna y Camps, 2003; Benson et al., 2004; Reynolds Merritt y Gladstein, 2004; Buck y Watson, 2005, Cho et al., 2005; García et al., 2011) u otros constructos, como el “intercambio jefe-subordinado” (Graen, Novak y Sommerkamp, 1982).

Según los estudios revisados, las principales prácticas de formación evidenciadas como positivas para la retención son: formación específica, polivalente, de acogida, en habilidades, de equipo o para el puesto. Por ejemplo, la formación de acogida facilita al nuevo empleado ajustarse y adaptarse a la organización a todos los niveles, reduciendo el estrés inicial de incorporación y favoreciendo, de este modo, su permanencia en la misma (Hom y Griffeth, 1995). La formación específica -orientada a dotar a los empleados de habilidades y conocimientos específicos y propios de la empresa y su puesto de trabajo- se ha demostrado favorecedora de la retención (Lams et al. (2002) cit. 
en Hemdi y Nasurdin, 2006; Benson, 2006). Y, la formación polivalente o extensiva ${ }^{49}$ -multidisciplinar- influye positivamente sobre la retención (Galunic y Anderson, 2000; López-Cabrales et al., 2008, Arthur, 2001; Sun et al., 2007). No obstante, algunos autores no han logrado evidenciar esta relación (Naggiar, 2001; Ito y Brotheridge, 2005).

Por otro lado, en relación a la promoción del empleado, Kochanski y Ledford (2001) señalan que las oportunidades de desarrollo de carrera predicen la retención de forma más significativa que otras prácticas (Dockel, 2003). La evidencia empírica muestra que las posibilidades de promoción influyen de forma positiva sobre la retención, bien directamente como parte de un sistema prácticas de recursos humanos (Delany y Huselid, 1996; Delery y Doty, 1996) o bien, a través de su efecto sobre constructos intermedios $^{50}$ (Wayne, Shore y Liden, 1997; Tansky y Cohen, 2001; Rhoades y Eisenberger, 2002; Saporta y Farjoun, 2003; Luna y Camps, 2003; Dockel, 2003; Allen, Shore y Griffeth, 2003; Vaiman, 2004; Benson et al., 2004; Cho y Woods, 2005; Peterson, 2005; Smith, 2005; Hirschfeld, 2006; Peterson, 2007). Incluso, se ha demostrado que los empleados pueden permanecer en la organización, a pesar de sentir cierta insatisfacción en el momento presente, si perciben que tienen posibilidades futuras de promoción (Hom y Griffeth, 1995). Además, diversos estudios señalan que las tareas de apoyo, asesoramiento o explicación del proceso de promoción a los empleados, influyen positivamente sobre su retención (Roehling et al., 2000, Ito y Brotheridge, 2005; Peterson, 2005). No obstante, no todos los trabajos revisados obtienen resultados positivos en la relación. Algunos de ellos alertan sobre que puesto que las promociones, generalmente, llevan asociadas formación y desarrollo de habilidades generales, esto podría provocar que los empleados puedan ser más valorados por empresas competidoras, incrementándose, por tanto, su posibilidad de abandono (Lazear 1986, 1998; Trevor et al., 1997; Huang, Lin y Chiang, 2006);

\footnotetext{
${ }^{49}$ Algunos ejemplos son: la formación en habilidades de relación, habilidades de gestión, de liderazgo, trabajo en equipo, idiomas, etc.; en general, conocimientos y habilidades que pueden ser aplicados en otros puestos, departamentos u organizaciones.

${ }^{50}$ Principalmente, la satisfacción laboral, el compromiso organizativo y el soporte percibido de la organización.
} 
logrando, justamente, el efecto contrario al que se perseguía inicialmente con esta práctica.

\subsection{Estudios que relacionan la retención del empleado y su retribución}

Resulta obvio reconocer el papel de la retribución en la relación organización-individuo o empleado-empleador. Su papel ya fue descrito por la teoría de la organización, hace más de cincuenta años, a través del concepto de recompensas recibidas (March y Simon, 1958). El sistema de retribución ${ }^{51}$ envía un mensaje a los empleados sobre su implicación, motivación y reconocimiento y, en base a él, el empleado corresponde a través del desarrollo de determinadas actitudes y comportamientos (Gouldner, 1960; Blau, 1964), que influyen sobre la retención de los mismos en la organización.

En los estudios de retención revisados, hemos identificado tres componentes en la estructura de retribución (Naggiar, 2001) que se corresponden con el foco de atención de cada trabajo. El primer componente es el método de recompensa. Es decir, la retribución debe ser distribuida de forma justa y equitativa entre los empleados y de forma acorde a sus contribuciones individuales. El segundo componente es el criterio por el que se retribuye. Las organizaciones deciden si retribuyen en base a la consecución de objetivos, al nivel de desempeño, a comportamientos que la empresa valore o a la antigüedad. Y, por último, el tercer componente es el tipo de recompensa que la empresa decide distribuir. Pueden ser económicas (salario anual, primas, comisiones, reparto de beneficios, etc.), beneficios sociales (plan de pensiones, beca para educación, vacaciones pagadas, coche de empresa, etc.) o no económicas (horario flexible, teletrabajo, reconocimiento informal, etc.). Numerosos estudios confirman la relación de estos tres componentes retributivos con la retención de empleados.

Los primeros trabajos revisados evidencian que el salario contribuye a la retención, mediado, principalmente, por la satisfacción en el puesto (Lawer, 1971,1981; Mobley,

\footnotetext{
51 El sistema de retribución ha ido evolucionando, pasando de sistemas muy simples basados, fundamentalmente, en un salario fijo (habitualmente formado por salario base, pluses, complementos y antigüedad según convenio) a fórmulas más complejas en las que se incorporan componentes de retribución variable según desempeño, retribución flexible, participación en beneficios, bonus, primas, bolsas de viaje, incentivos, retribución en especie, etc. (véase Gómez-Mejía, 1992) y, además, se ha pasado de un enfoque de retribución basada en el puesto, a una retribución basada en la persona, sus habilidades, sus competencias, sus conocimientos, sus logros, etc.
} 
1982a; Rusbult y Farrell, 1983; Hulin, Roznowski y Hachiya, 1985; Price y Mueller, 1981,1986; Cotton y Tuttle, 198; Blakemore et al., 1987; Brief y Aldag, 1989). Sin embargo, a pesar de que en muchas entrevistas y cuestionarios de salida de empleados los salarios bajos son las razones que éstos suelen esgrimir como causa principal de su abandono (Hom y Griffeth, 1995), no es hasta finales de los años ochenta cuando se presta una especial atención al sistema de retribución en los trabajos de rotación voluntaria/retención, quizás, porque hasta ese momento los investigadores provenían del ámbito psicológico y sociológico y, por tanto, prevalecía el estudio de las motivaciones intrínsecas. Es a partir de los trabajos de Brief y Aldag (1989), Hulin et al., (1985) y Price y Mueller $(1981,1986)$, cuando el sistema de retribución se reconoce como una práctica muy relevante en el campo de la retención. A partir de este momento, principalmente en la década de los noventa, se profundiza sobre la relación entre los diversos componentes del sistema de retribución y la retención de los empleados (Arthur, 1994; Hom y Griffeth $^{52}$; 1995, 2004; Shaw, 1997; Guthrie, 2000; Fay y Thompson, 2001; Thompson, 2001; Boselie y Wiele, 2002; Luna y Camps, 2003; Chew, 2004; Buck y Watson, 2005; Cho et al., 2005; Ferrat, et al, 2005).

Así, un grupo importante de trabajos evidencia la relación positiva entre la retribución variable (o contingente) y la mejora de la retención (Williams y Livingstone, 1994; Allen y Griffeth, (2001; Lazear, 2004; Chawdla, 2004, 2005; García et al., 2011). No obstante, también encontramos autores que evidencian que los programas de retribución basados en desempeño no siempre logran detener los abandonos disfuncionales (Gómez Mejía et al., 1992a; Hom y Griffeth, 1995), en otras palabras, no logran retener a los empleados más valiosos. En concreto, algunos de los trabajos revisados se centran, expresamente, en los incentivos grupales logrando evidenciar su influencia positiva sobre la retención (Blakemore et al., 1987; Buck y Watson, 2005; Cho et al., 2005) y, también, su influencia negativa (Guthrie, 2000) ${ }^{53}$.

\footnotetext{
${ }^{52}$ Hom y Griffeth (1995) integran las aportaciones previas de la literatura, proponiendo un modelo explicativo del modo en el que el sistema de retribución pueden afectar a la rotación y, por tanto, permite identificar cuáles pueden ser las vías para favorecer la retención (Véase Figura A1.11. del Anexo I).

${ }_{53}$ Guthrie (2001) constata que los incentivos grupales influyen negativamente en la retención, especialmente en el caso de empleados de alto rendimiento, efecto que se potencia con el aumento del tamaño del grupo.
} 
Otro grupo de trabajos ha validado el efecto positivo de factores no económicos (Naggiar, 2001) como los beneficios sociales (Miceli y Lane, $1991^{54}$; Milkowich y Newman, 1993; Shaw, 1997; Shaw et al., 1998; Davies et al., 2001). Y, por otro lado, otro grupo importante de investigaciones, analizan la equidad interna, la percepción de justicia del sistema de retribución y la transparencia del sistema de retribución, como factores realmente influyentes en la retención (Jones, 1991; Whitener,, 2001; Allen et al., 2003; Horwtiz et al., 2003, entre otros).

1.3.2.2.4. Estudios que relacionan la retención del empleado y sus relaciones internas con la organización, con el superior jerárquico y con los compañeros

Un grupo importante de los trabajos revisados estudian diversas prácticas que permiten influir en la dimensión social-relacional del empleado, como vía para mejorar su retención. Tras los descubrimientos de los experimentos de los talleres de Hawthorne (1924-1932), se hizo evidente el potencial motivador de la dimensión social y relacional del individuo, tal como queda recogido en la teoría psicosocial, cuyo principal representante es Elton Mayo. Satisfacer la dimensión relacional y social del individuo, mejora su motivación, lo que redunda en satisfacción laboral. Esta variable está asociada con mejores desempeños del empleado y, también, con otros comportamientos, como la retención. La importancia de la faceta relacional del empleado se basa en las aportaciones del contrato psicológico (Rousseau, 1989, 1990; Robinson y Rousseau, 1994) que postula que los empleados valoran, no sólo lo recogido formalmente en el contrato de trabajo sino, también, otros aspectos ofrecidos por la organización como pueden ser: el desarrollo de relaciones satisfactorias con la organización y sus integrantes. Estas relaciones repercuten sobre la satisfacción con la relación de empleo, incidiendo sobre sus actitudes y comportamientos, incluida su permanencia o no en la organización (Rousseau, 1989, 1990; Robinson y Rousseau, 1994).

En la revisión de la literatura que hemos realizado, hemos podido identificar diversas prácticas de recursos humanos orientadas a favorecer la dimensión relacional del empleado, como una forma de favorecer su retención y que vamos a clasificar

\footnotetext{
${ }^{54}$ Identifican la cobertura médica, como el beneficio social mejor valorado por los empleados; algo lógico en el caso de su estudio, realizado en Norteamérica, donde la cobertura de la sanidad pública es mínima.
} 
considerando el tipo de relación que desarrolla el empleado: con la organización (a través de las prácticas de comunicación interna y participación del empleado), con los superiores jerárquicos o supervisores (a través del estilo de liderazgo y del soporte recibido del supervisor) y, por último, con sus pares o compañeros de trabajo (a través de redes, trabajo en equipo, actitud de compañerismo y soporte recibido de los compañeros).

\section{Comunicación Interna}

Esta práctica comprende todas las acciones por las que la organización ofrece información a sus empleados; información relativa al propia organización como: objetivos organizativos, visión, estrategia, cambios en las políticas y procedimientos, resultados financieros, éxitos de los empleados o equipos, etc. Esta información, puede distribuirse a los empleados a través de diversos canales como son: los supervisores, la intranet, los tablones de anuncios y las revistas de empresa, las reuniones, las asambleas, etc. (Ng et al., 2006); además, también abarca canales y sistemas de comunicación que proporcionen a los empleados el acceso a información importante de la empresa, vías para comunicarse con otras secciones de la organización, así como, la oportunidad de expresarse (Gómez-Mejía et al., 1997, 2001).

La revisión de la literatura de retención nos ha permitido constatar que la comunicación interna es una de las prácticas que contribuye a la retención de empleados (Beckert y Huselid, 1998; Boselie y Wiele, 2002; Minbaeva, 2003; Choo, Woods y Mayer, 2005; Garder, Moynihan y Wright, 2007; Paré y Tremblay, 2007; Ng y Butts, 2009, entre otros). Esto se debe, principalmente, a que fortalece la identificación de los empleados con la compañía y, además, potencia la confianza organizativa (Clark, 2001; Chew, 2004) y, también, porque la comunicación interna puede percibirse como un intento de transparencia y de confianza en los empleados (acto positivo de la organización). Esto genera afectos positivos y comportamientos favorables hacia la propia organización, fomentando la intención de permanencia en la misma (Eisenberger et al., 1990; Wayne, Shore, \& Linden, 1997). Otro grupo de trabajos, lo justifican debido a que obtener información de la empresa y poder ponerse en contacto con compañeros de otras secciones o, expresarse y comunicarse con los superiores, favorece el acceso al 
conocimiento y, por tanto, facilita el poder afrontar mejor el puesto de trabajo, reduciéndose la incertidumbre, la ansiedad y el estrés laboral; de este modo, se mejora la retención de empleados en la organización (Griffeth y Hom, 2004).

\section{Participación del empleado en la organización}

Los sistemas de participación del empleado son una de las medidas que las empresas pueden utilizar para que sus empleados contribuyan con sus conocimientos y habilidades al éxito de la organización. Para ello, se les pueden hacer partícipes en la toma de decisiones, desarrollar grupos de trabajo de mejora, grupos de resolución de problemas o habilitar fórmulas para que los empleados puedan sugerir mejoras o quejarse de los aspectos que consideren relevantes (Appelbaum et al., 2000; Gardner et al., 2007). De este modo, se ofrece a los empleados el mensaje de que la empresa los valora y, por ello, se les permite participar de forma activa en el desempeño de la misma mejorando, así, su satisfacción y deseo de permanencia en la organización (Arthur, 2001).

En la revisión realizada hemos identificado numerosos trabajos que identifican esta práctica como favorecedora de la retención de empleados (Arthur 1994; Huselid, 1995; Delery y Doty, 1996; Shaw, Delery, Jenkins y Gupta, 1998; Naggiar, 2001; Guest, 2002; Buck y Watson, 2002; Boselie y Wiele, 2002; Allen et al., 2003, Ito y Brotheridge, 2005; Gardner et al., 2007; Sun, Aryee y Law, 2007; García et al., 2011).

\section{Relación con el superior jerárquico o supervisor. Estilo de liderazgo.}

El liderazgo se define como el comportamiento de un individuo que ejerce una influencia no coercitiva sobre los demás, cuando dicho individuo dirige y coordina las actividades de un grupo orientadas hacia la consecución de un objetivo común (Bryman, 1992). De forma general, hemos identificado que la mayoría de los trabajos revisados justifican la influencia de la relación con el superior y el estilo de liderazgo, en base a la idea de que los empleados personalizan la organización, es decir, conciben los actos de los agentes de la organización -como los superiores- como acciones de la propia organización (Levinson, 1965). En consecuencia, el estilo de liderazgo, el trato, el soporte, la ayuda, el apoyo y el reconocimiento que ofrezcan los mandos a sus 
subordinados, será interpretado por los subordinados como símbolo del trato que les confiere la organización según la valoración que ésta hace de sus contribuciones. En reciprocidad (Blau, 1965; Gouldner, 1960), si este trato es positivo, favorecerá que los empleados deseen corresponder de forma positiva hacia la empresa, lo que se traduce en comportamientos que la organización valore positivamente, entre otros, permanecer en la empresa (Rhoades et al., 2001; Rhoades y Eisenberger, 2002).

La importancia de la forma de actuación del superior y su influencia en la retención de empleados ha sido ampliamente validada en la literatura de retención (Rhoades y Eisenberger, 2002; Allen et al., 2003; Ito y Brotheridge, 2005; Jawahar y Hemmasi, 2006; Dockel et al., 2006; Peterson, 2007; Paré y Tremblay 2007). A partir de la revisión de la literatura que hemos realizado, podemos distinguir varias corrientes de trabajos. Por un lado, aquellos trabajos que consideran que, de este modo, se potencia el compromiso hacia la organización mejorando, con ello, la posibilidad de retención de los empleados (Podsekoff, Mackencie y Bommer, 1996; Allen 1996; Paré et al., 2001; Ferres, Travaglione y Connell, 2002; Connell, Ferres y Travaglione, 2003; Dockel, 2003; Zarraga y Bonache, 2003; Chen, Ayree y Lee, 2005; Dockel, Basson y Coetzee, 2006; Rosa-Navarro y Carmona-Lavado, 2010). Otro grupo de trabajos se apoyan en el constructo del intercambio líder-subordinado ${ }^{55}$ y lo utilizan para explicar la influencia del estilo de liderazgo sobre la rotación voluntaria (Hom y Hulin, 1981; Price y Mueller, 1981, 1986; Graen et al., 1977; 1982; Graen y Scandura, 1986; Wayne et al., 1997; Hom y Griffeth, 2001). Otro conjunto de trabajos, aunque más reducido, analizan el efecto del liderazgo desde su ineficacia. Es decir, logran evidenciar que una mala relación con su supervisor es una de las razones principales para no permanecer en la organización (Hom y Griffeth, 1995; Mobley, 1982; Bartlett, 2001; Griffeth y Gaertner, 2001; Lambert et al., 2001; Chawla, 2005). Y, por último, otro grupo importante de trabajos empíricos, contrastan la influencia positiva del liderazgo sobre la retención a

\footnotetext{
${ }^{55}$ Desde esta perspectiva teórica se plantea que cuando el superior ofrece información, da órdenes, aconseja e interacciona con el empleado, se producen intercambios entre ambos (el denominado LMX, leadership member exchange-). De este modo, si se produce un alto LMX se facilita la adaptación del trabajador a sus funciones y trabajo y, en consecuencia, el subordinado expresará mayor compromiso y asumirá mayor responsabilidad, lo que, a la postre, se traducirá en una mayor retención del empleado.
} 
través del papel mediador del constructo soporte percibido del supervisor ${ }^{56}$ (Eisenberger et al., 1986, 1990, 1997, 2001; Rhoades, Eisenberger y Armelli, 2001; Eisenberger et al., 2002; Rhoades y Eisengerger, 2002). Estos trabajos demuestran que el soporte que el trabajador percibe, le genera sentimientos que forman este constructo, influyendo positivamente sobre su compromiso con la organización y, por ende, sobre su retención (Rhoades et al., 2001, 2002; Allen, Shore y Griffeth, 2003).

\section{Relación con los compañeros}

Diversos trabajos empíricos evidencian que aquellos empleados que desarrollan fuertes relaciones con sus compañeros de trabajo tienden a permanecer mayor tiempo en sus empresas (Clark, 2001; Chew, 2004). El vínculo entre las relaciones internas de los empleados y su retención es claro. La interacción entre empleados favorece su dimensión afectiva y proporciona un apoyo emocional que ayuda a llevar a cabo las tareas, mejorando la satisfacción laboral, reduciendo el estrés y favoreciendo, por ende, la retención (Bateman, 2009).

En la revisión realizada hemos identificado dos grupos de trabajos: aquéllos centrados en la fórmula de trabajar en equipo, en proyectos y en colaboración con otros empleados y, aquéllos, centrados en estudiar el compañerismo y el soporte que unos empleados ofrecen a otros. Ambas fórmulas se evidencian como favorecedoras de la retención de empleados (Maerzt y Campion, 1998; Lambert et al., 2001; Maertz, 2001; Mitchell, Holtom, Lee et al., 2001; Friedman y Holtom, 2002; Peterson, 2004; Mossholder, Setton y Henagen, 2005; Hom, Tsui et al., 2008; Bateman, 2009).

Por un lado, algunos trabajos evidencian que las organizaciones que favorecen el trabajo en equipo, los proyectos de trabajo que aglutinen a compañeros y que faciliten las interacciones sociales informales entre empleados, tanto dentro como fuera de la organización -a través de su cultura, forma de gestión, organización de eventos o cualquier otra actividad que favorezca la interacción entre empleados- favorece la retención de sus empleados (Clark, 2001; Mossholder et al., 2005; Bateman, 2009)

\footnotetext{
56 El soporte percibido del supervisor (PSS: perceived supervisor support) se desarrolla bajo la perspectiva del soporte organizativo (Rhoades, Eisenberger y Armeli, 2001; Smith, 2005).
} 
$\mathrm{Y}$, por otro lado, las organizaciones que fomentan el compañerismo ${ }^{57}$ y que los empleados se den apoyo y soporte unos a otros, facilitan que exista cordialidad, amistad, muestras de apoyo y preocupación entre los compañeros de trabajo, de modo que pueden debatir y proponer ideas mucho más libremente, lo que se ha demostrado que influye de forma positiva sobre su satisfacción laboral (Fass, Bishop y Glissmeyer, 2007) y contribuye a crear entornos positivos de trabajo, favoreciendo la retención de empleados (Settoon y Mossholder, 2002; Hart, Miller y Johnson, 2003 cit. en Chew, 2004; Bateman, 2009). Esto se debe a que cuanto más conectado socialmente esté un empleado a nivel profesional y personal en su trabajo, se genera un mayor vínculos de éste con la organización y sus miembros, potenciando su permanencia en la organización (Friedman y Holtom, 2002).

\subsection{Estudios que relacionan la retención del empleado y las condiciones y} organización del trabajo

Otra de las categorías de prácticas relacionadas con el área de recursos humanos que pueden influir sobre la retención de empleados, son las relativas a las condiciones y organización del trabajo. Así, en la revisión realizada hemos podido identificar dos tipos de prácticas especialmente relevantes.

En primer lugar, los trabajos que analizan las características físicas del entorno de trabajo. Derivado de las aportaciones de Oldham y sus colaboradores (1988), la evidencia empírica muestra que los factores y características físicas del puesto de trabajo condicionan las actitudes laborales y el comportamiento de abandono o permanencia (Hom y Griffeth: 1995). Los estudios desarrollados por Oldham et al., (1983, 1987), demostraron que ciertos factores podían ser desaconsejables para la retención, como por ejemplo: la densidad social (el número total de personas en el trabajo puede sobre-estimular a los empleados e incrementar los conflictos interpersonales), la iluminación y colores de las paredes (pueden incrementar las sensaciones de restricción espacial y producir sobre-estimulación), los cerradores y los

\footnotetext{
${ }^{57}$ Settoon y Mossholder (2002) definen el compañerismo como el comportamiento cooperativo y de asistencia que se tiene directamente con los compañeros y confirman que es un indicador significativo del grado de vínculo que se tienen entre ellos.
} 
paneles o paredes separadoras, la distancia entre compañeros de trabajo (reduce la percepción de multitud o agobio por multitud y reduce las distracciones), etc.

Y, en segundo lugar, de mayor interés para nuestra investigación, la gestión del conflicto entre el rol desempeñado en la vida laboral y el rol desempeñado en la vida personal y cómo uno puede afectar al desarrollo del otro, y viceversa. Nos referimos, fundamentalmente, a las medidas de conciliación entre la vida personal y la laboral.

Los cambios políticos, legales, económicos, han creado nuevas condiciones y expectativas que los empleados demandan a sus organizaciones. Los cambios en el mercado laboral debido a la incorporación de la mujer al trabajo, la existencia de parejas con doble carrera y el deseo de los individuos de lograr una mayor calidad de vida mediante el disfrute del tiempo libre y actividades de ocio (Greenhaus, 2008) son, algunos de los motivos, que han impulsado a las empresas a implantar prácticas de conciliación.

El conflicto entre vida personal y laboral es una forma de conflicto entre roles en el que las presiones de los ámbitos del trabajo y de la vida personal son incompatibles en algún aspecto (Greenhaus y Beutell, 1985; Hom y Griffeth, 1995; Fisher et al., 2003). A veces aspectos de la vida personal, principalmente familiar, interfieren negativamente en el trabajo y viceversa, lo cual tiene efectos negativos sobre la calidad de la vida en el trabajo, produciendo situaciones de estrés que favorecen el deseo de abandono de los empleados en detrimento de su retención (Greenhaus, Collins, Singh y Parasuraman, 1997; Fisher et al., 2003; Griffeth y Hom, 2004; Chew, 2004; Eby et al., 2005; Branham, 2005). Por ello, las empresas han comenzado a llevar a cabo diferentes medidas y han adaptado sus condiciones de trabajo buscando disminuir este conflicto entre el rol de la vida personal y laboral de sus empleados. Para ello utilizan este tipo de medidas de conciliación de vida laboral-familiar (Crooker, Smith y Tabak, 2002).

La revisión que hemos realizado ofrece soporte empírico sobre la utilidad de estas medidas para favorecer la retención de sus empleados, principalmente, a través de medidas como los permisos laborales para atender asuntos personales, ayuda o servicio para cuidado de hijos y familiares dependientes, permisos de maternidad y paternidad, la flexibilidad horaria y el teletrabajo (Grover y Croker, 1995; Hom y Grifeth, 1995; 
Thompson, Beauvais y Lyness, 1999; Guest y Conway, 1999; Perry-Smith y Blum, 2000; Allen et al., 2000; Lambert 2000; Arthur, 2001; Griffeth y Hom, 2001; Arthur, 2001; Guest, 2002; Teo y Waters, 2002; Dockel, 2003; Lazarova, 2004; Hoonakker, Carayon y Schoepke, 2004; Thompson y Heron, 2006; Casper, Weltman y Kwesiga, 2007; Harr, 2007; Ahuja et al., 2007; Peterson, 2007; Parkes y Langford, 2008; Sánchez-Vidal et al., 2010; Pasamar y Valle, 2011). No obstante, aunque la mayoría de estos trabajos se refieren a la retención de empleados con familia, recientes estudios señalan que las medidas de conciliación, también, son eficaces en la retención de empleados sin hijos o empleados solteros (Casper et al., 2007) ${ }^{58}$. En línea con estas aportaciones, en la presente investigación optamos por el término conciliación vida laboral/personal, en vez de laboral/familiar.

Dentro de los trabajos revisados, cabe destacar la aportación de Fisher (2004) y, en especial, la de Greenhaus y Powell (2006), por cuanto evidencian que la relación vida laboral-personal no siempre tiene por qué ser negativa, sino que, ambas esferas pueden concebirse como aliadas. Es decir, puede existir un enriquecimiento personal-laboral ${ }^{59}$ bidireccional (Greenhaus y Powell, 2006). De este modo, las experiencias en un rol pueden incrementar la calidad de vida del otro rol, potenciando el desempeño del otro rol, derivando en mayor satisfacción y, por tanto, en una mayor retención de empleados.

En las páginas anteriores hemos tratado de sintetizar las principales prácticas de recursos humanos que han sido contrastadas empíricamente como variables favorecedoras de la retención de empleados en las organizaciones. A modo de resumen, presentamos la Tabla 1.10. recogiendo estas prácticas y los principales autores que las han utilizado en sus investigaciones.

\footnotetext{
${ }^{58}$ Esta consideración da lugar al término conciliación vida laboral-personal en sustitución del término conciliación laboral-familiar (Casper et al., 2007).

${ }^{59}$ Greenhaus y Powell (2006) proponen tres vías que justifican que la participación en diversos roles (laboral y personal) puede producir efectos positivos. En primer lugar, las experiencias laborales y las personales pueden tener efectos aditivos sobre el bienestar de los empleados. La satisfacción con el trabajo y con la vida personal se ha demostrado que tiene efectos aditivos sobre la felicidad y la satisfacción. Segundo, trabajar y tener vida personal puede ayudar a protegerse del agotamiento o angustia de la otra esfera. Así la esfera laboral puede ayudar a paliar las preocupaciones del ámbito laboral, y viceversa. Y tercero, las experiencias vividas en una de las esferas pueden ayudar a desempeñar mejor su rol de la otra esfera.
} 
Tanto la revisión de las prácticas de recursos humanos identificadas en los estudios basados en modelos de retención como aquellas prácticas identificadas en otro tipo de trabajos, nos sirve de base para poder seleccionar un conjunto de estas prácticas adecuadas al estudio que nos proponemos realizar en esta tesis doctoral y que presentamos en el siguiente epígrafe. 
Tabla 1.10. Resumen de las principales medidas de gestión de recursos humanos eficaces para la retención de empleados

\begin{tabular}{|c|c|c|}
\hline $\begin{array}{l}\text { Prácticas de } \\
\text { recursos humanos }\end{array}$ & Actividades clave para retener & Trabajos relevantes \\
\hline $\begin{array}{l}\text { Diseño del puesto } \\
\text { de trabajo }\end{array}$ & $\begin{array}{l}\text { Diseño enriquecido de puesto, autonomía, puesto } \\
\text { retador, requiere de diversas habilidades y } \\
\text { conocimientos, tareas no repetitivas }\end{array}$ & $\begin{array}{l}\text { Hackman y Oldham, et al., 1980; McEvoy y Cascio, 1985; Hom y Griffeth, 1995; Delery y } \\
\text { Doty,1996; Griffeth y Hom, 2001; Osca y Urien, 2001; Swart y Kinnie, 2001,2003; Boselie y } \\
\text { Wiele, 2002; Buck y Watson, 2002; Dockel, 2003; Horwitz et al.,2003; Vaiman, 2004; Buck y } \\
\text { Watson, 2005; Wooddrufee, 2006; Bhatnagar, 2007; Starosta, 2007; Sun et al., 2007; Ng y } \\
\text { Butts, 2009; García et al., 2011 }\end{array}$ \\
\hline Formación & $\begin{array}{l}\text { Formación de acogida, formación extensiva, } \\
\text { formación intensiva, mentoring }\end{array}$ & $\begin{array}{l}\text { Graen, Novak y Sommerkamp,1982 ; Hom y Griffeth,1995; Glance et al.,1997 ; Lynch y } \\
\text { Black, } 1998 \text {; Shaw et al., 1998 ; Galunic y Anderson, 2000; Naggiar, 2001; Davies, Taylor y } \\
\text { Savery, 2001; Arthur ,2001; Boselie y Wiele, 2002; Luna y Camps, 2003; Chew, 2004; } \\
\text { Benson et al., 2004; Reynolds, Merritt y Gladstein, 2004; Mattox y Jinkerson, 2005; Buck y } \\
\text { Watson, 2005; Cho et al., 2005; Ito y Brotheridge, 2005; Hemdi y Nasurdin, 2006; Benson, } \\
\text { 2006; Sun et al., 2007; López-Cabrales et al., 2008 }\end{array}$ \\
\hline $\begin{array}{l}\text { Oportunidades de } \\
\text { desarrollo } \\
\text { profesional }\end{array}$ & $\begin{array}{l}\text { Formalización del sistema de promoción, } \\
\text { comunicación del sistema de promoción, } \\
\text { existencia de promociones, promoción basada en } \\
\text { desempeño, apoyo y asesoramiento al desarrollo } \\
\text { de carrera }\end{array}$ & $\begin{array}{l}\text { Hom y Griffeth, 1995; Delany y Huselid,1996; Delery y Doty,1996, Wayne, Shore y } \\
\text { Liden,1997; Roehling et al., 2000; Tansky y Cohen,2001; Rhoades y Eisenberger,2002; } \\
\text { Dockel, 2003; Saporta et al.,2003; Luna y Camps,2003; Allen, Shore y Griffeth,2003; Vaiman, } \\
\text { 2004; Benson et al.,2004; Cho y Woods,2005; Peterson, 2005; Smith,2005; Ito y Brotheridge } \\
\text { 2005; Hirschfeld, 2006; Huang, Lin y Chiang, 2006; Peterson ,2007;García et al., } 2001\end{array}$ \\
\hline $\begin{array}{l}\text { Retribución, } \\
\text { recompensas, } \\
\text { incentivos }\end{array}$ & $\begin{array}{l}\text { Retribución variable según desempeño, } \\
\text { incentivos grupales, equidad retributiva (interna } \\
\text { y externa), beneficios sociales, salario alto, } \\
\text { transparencia del sistema de retribución }\end{array}$ & $\begin{array}{l}\text { Hulin et al., 1985; Brief y Aldag,1989 ; Miceli y Lane,1991; Jones et al., } 1991 \text {; Milkowich y } \\
\text { Newman, 1993; Arthur, 1994; Williams y Livingstone, 1994; Hom y Griffeth, 1995; Shaw, } \\
\text { 1997; Shaw et al.,1998; Guthrie, 2000, Naggiar, 2001; Fay y Thompson, 2001; Thompson, } \\
\text { 2001; Davies et al., 2001; Whitener, 2001; Allen y Griffeth, 2001; Boselie y Wiele, 2002 } \\
\text {;Luna y Camps, 2003; Allen et al.,2003; Horwtiz et al.,2003; Chew, 2004; Lazear, 2004; Cho } \\
\text { et al., 2005; Ferrat et al., 2005; Chawdla, 2005; Buck y Watson, 2005; Cho et al., 2005; García } \\
\text { et al., } 2011\end{array}$ \\
\hline
\end{tabular}




\begin{tabular}{|c|c|c|}
\hline $\begin{array}{l}\text { Prácticas de } \\
\text { recursos humanos }\end{array}$ & Actividades clave para retener & Trabajos relevantes \\
\hline $\begin{array}{l}\text { Liderazgo, soporte } \\
\text { del supervisor }\end{array}$ & $\begin{array}{l}\text { Apoyo profesional y emocional a los } \\
\text { subordinados, accesibilidad, soporte percibido } \\
\text { del supervisor, reconocimiento }\end{array}$ & $\begin{array}{l}\text { Podsekoff, Mackencie y Bommer,1996 ; Allen ,1996; Rhoades et al., 2001; Paré et al.,2001; } \\
\text { Hom y Griffeth, } 2001 \text {;Lambert et al., 2001; Rhoades y Eisenberger, 2002; Ferres, Travaglione } \\
\text { y Connell, 2002; Allen et al., } 2003 \text {;Connell, Ferres y Travaglione, 2003; Dockel, 2003; } \\
\text { Zarraga y Bonache, 2003;Celeste y Brotheridge,2005;Chen, Ayree y Lee,2005; Chawla, } \\
\text { 2005;Jawahar y Hemmasi, 2006; Dockel et al.,2006 ; Dockel, Basson y Coetzee, } 2006 \text {; } \\
\text { Peterson,2007; Paré y Tremblay, 2007; Rosa-Navarro y Carmona-Lavado, } 2010\end{array}$ \\
\hline $\begin{array}{l}\text { Comunicación } \\
\text { interna y } \\
\text { participación }\end{array}$ & $\begin{array}{l}\text { Intranet, reuniones, tablones de anuncio, } \\
\text { reuniones, asambleas, buzón de sugerencias, } \\
\text { participar en toma de decisiones, }\end{array}$ & $\begin{array}{l}\text { Arthur,1994; Huselid,1995; Delery y Doty, 1996; Beckert y Huselid,1998; Shaw, Delery, } \\
\text { Jenkins y Gupta ,1998; Clark,2001; Arthur,2001; Naggiar, 2001; Boselie y Wiele, 2002; } \\
\text { Guest,2002; Buck y Watson, 2002; Boselie y Wiele,2002; Minbaeva,2003; Allen et al., 2003; } \\
\text { Chew, 2004; Griffeth y Hom, 2004; Choo, Woods y Mayer, 2005; Ito y Brotheridge, 2005; } \\
\text { Gardner, Moynihan y Wright,2007; Paré y Tremblay, 2007; Sun, Aryee y Law, 2007; Ng y } \\
\text { Butts,2009; García et al., 2001 }\end{array}$ \\
\hline $\begin{array}{l}\text { Relaciones con } \\
\text { compañeros }\end{array}$ & $\begin{array}{l}\text { Redes de trabajo, trabajo en equipo, actividades } \\
\text { informales, lugares de ocio y reunión, favorecer } \\
\text { compañerismo y ayuda entre compañeros, dar } \\
\text { soporte a compañeros, etc. }\end{array}$ & $\begin{array}{l}\text { Maerzt y Campion, 1998; Lambert et al., 2001; Maertz, 2001; Mitchell, Holtom, Lee et al., } \\
\text { 2001; Clark, 2001; Friedman y Holtom, 2002; Friedman y Holtom, 2002; Settoon y } \\
\text { Mossholder, 2002; Peterson, 2004; Chew, 2004; Mossholder, Setton y Henagen, 2005; Fass, } \\
\text { Bishop y Glissmeyer, 2007; Hom, Tsui et al., 2008; Bateman, } 2009\end{array}$ \\
\hline $\begin{array}{c}\text { Condiciones y } \\
\text { organización del } \\
\text { trabajo }\end{array}$ & $\begin{array}{l}\text { Ergonomía, factores ambientales no estresantes, } \\
\text { flexibilidad horaria, permisos laborales para } \\
\text { atender asuntos personales y familiares, ayudas } \\
\text { económicas, teletrabajo, conciliación, etc. }\end{array}$ & $\begin{array}{l}\text { Greenhaus y Beutell, 1985; Hom y Griffeth: 1995; Greenhaus, Collins, Singh y Parasuraman, } \\
\text { 1997; Thompson, Beauvais y Lyness, 1999; Allen et al., 2000; Lambert 2000; Arthur, 2001; } \\
\text { Crooker, Smith y Tabak, 2002; Teo y Waters, 2002; Dockel, 2003, Fisher et al., 2003; Griffeth } \\
\text { y Hom, 2004; Chew, 2004; Fisher, 2004; Lazarova, 2004; Hoonakker, Carayon y Schoepke, } \\
\text { 2004; Eby et al., 2005; Branham, 2005; Thompson y Heron, 2006; Greenhaus y Powell, 2006; } \\
\text { Casper, Weltman y Kwesiga, 2007; Harr, 2007; Parkes y Langford, 2008; Ahuja et al., 2007; } \\
\text { Peterson, 2007; Casper et al., 2007; Sánchez-Vidal et al., 2010; Pasamar y Valle, } 2011\end{array}$ \\
\hline
\end{tabular}




\subsection{PROPUESTA DE UNA TAXONOMÍA DE PRÁCTICAS DE RECURSOS HUMANOS ORIENTADAS A LA RETENCIÓN DE EMPLEADOS ESTRATÉGICOS: PRÁCTICAS TRANSACCIONALES Y PRÁCTICAS RELACIONALES}

A través de la revisión presentada en los epígrafes anteriores, hemos podido constatar la importancia de los recursos humanos y del capital humano que de ellos emana, para la generación de ventajas competitivas para la empresa. Por tanto, parece obvio señalar que la retención de estos recursos puede ser vital para la organización. A este respecto, la literatura de rotación voluntaria y retención de empleados ha estudiado, en profundidad, este fenómeno tratando de identificar las mejores prácticas y fórmulas relacionadas con las prácticas de recursos humanos para lograr retener a sus empleados (Naggiar, 2001; Arthur, 2001; Griffeth y Hom, 2001,2004; Peterson, 2004; Lazarova, 2004; Vaiman, 2004; Buck y Watson, 2005; Huang, Lin y Chuang, 2006; Hausknecht et al., 2006, Whitaker, 2009; Bateman, 2009; Allen et al., 2010; entre otros). Esta cuestión es altamente compleja, como prueba la extensa literatura existente hasta el momento; literatura en la que no existe un único sistema o única clasificación de prácticas que aseguren dicha retención.

En este trabajo, como ya hemos anticipado en epígrafes anteriores, pretendemos profundizar en el estudio de la retención de empleados estratégicos para la organización. Para ello, proponemos analizar la influencia de diversas prácticas de recursos humanos, admitiendo que no es una lista exhaustiva de prácticas. Para su selección, nos basamos en la revisión realizada, tanto de la investigación sobre sistemas de prácticas de recursos humanos como en la investigación sobre retención y rotación voluntaria, las dos áreas básicas de literatura para la presente investigación.

Por un lado, la investigación reciente en gestión estratégica de recursos humanos pone de manifiesto la multidimensionalidad de las motivaciones de los empleados, los cambios en la fuerza laboral y la necesidad de "actualizar” la relación de empleo, otorgando una mayor importancia a la faceta social y relacional (Tsui y Wu, 2005), como ya hemos comentado en epígrafes anteriores. Estas consideraciones han conducido a los investigadores a diferenciar entre dos tipos de prácticas de recursos 
humanos, coherentes con la relación de empleo que desarrollan con sus empleados: las transaccionales y las relacionales (Hislop, 2005; Tremblay et al., 2010). Por un lado, las transaccionales son aquellas prácticas que satisfacen la dimensión clásica, recogida en la relación de empleo tradicional y están orientadas a las incrementar la eficiencia y el control de los empleados (p.e. retribución, tipo de contrato, condiciones laborales, diseño del puesto, formación, promoción, etc.) y, por otro, las prácticas relacionales son aquellas orientadas a satisfacer la dimensión socialrelacional del empleado y a favorecer la participación, confianza, colaboración de los empleados (p.e. sistemas de participación del empleado, comunicación interna, relaciones con pares, subordinados, prácticas que favorezcan la motivación y la implicación, etc.). Como ya hemos expuesto anteriormente ${ }^{60}$, esta clasificación subyace en diversos estudios previos (Coff, 1997; Alvesson, 2000; Lengnick-Hall y Lengnick-Hall, 2003; Morris, Snell y Lepack, 2005; Hislop, 2005; Gould-Williams y Davies, 2005; Kang, Morris y Snell, 2007; Tremblay et al., 2010; Wan Ismail et al., 2010).

Por otro lado, las investigaciones más recientes de retención apuestan por incluir nuevas dimensiones de factores que potencian la retención de sus empleados y sugieren que son múltiples las “fuerzas” que logran retener a sus empleados más valiosos (Maerzt et al., 2001, 2004; Mitchell, Holtom et al., 2001; Besich, 2003; Lee, Mitchell et al., 2004; Holtom, Mitchell y Lee, 2006; Holtom, Tsui et al., 2009). Ello apunta a que, no sólo las prácticas tradicionales, incluidas en la relación contractual, influyen sobre la retención, sino que, otras prácticas, vinculadas a la faceta más relacional del empleado, adquieren importancia como factores favorecedores de la retención.

Esta diferenciación entre prácticas transaccionales y relacionales se asienta en los postulados de varios enfoques como son la teoría del intercambio social (Blau, 1964), los desarrollos conceptuales sobre la relación empleado-organización (CoyleShapiro, Shore, Taylor, y Tetrick, 2004; Tsui, Pearce, Porter, y Hite, 1995), el enfoque del soporte organizativo (Eisenberger et al., 1986; Shore y Shore, 1995; Allen, Shore y Griffeth, 2003) y, principalmente, en la teoría del contrato psicológico

${ }^{60}$ Véase el epígrafe 1.2.3.1.2. Sistemas de prácticas de recursos humanos y resultado organizativo. 
que distingue entre contrato o relación de empleo transaccional y relacional $^{61}$ (Rousseau, 1989, 1990; Robinson y Rousseau, 1994; Morrison y Robinson, 1997; Shore et al., 1998). Bajos estos enfoques, las prácticas de recursos humanos reflejan la inversión que la organización realiza en sus empleados y los comportamientos que la organización espera de ellos ${ }^{62}$; repercutiendo en que el empleado valore su relación de empleo como completa y satisfactoria, o no. En línea con este argumento, sabemos que, hoy en día, la relación de empleo empleado-empleador tradicional ha cambiado $^{63}$ y se ha visto reemplazada por nuevas concepciones (Tsui y Wu, 2005), basadas en la idea de demandar un mayor abanico de comportamientos y mayor compromiso a los empleados, a través de ofrecerles variados incentivos como contrapartida a sus contribuciones; para ello, la organización debe tratar de desarrollar relaciones estables, a largo plazo e indefinidas con los empleados, incluyendo no sólo aspectos transaccionales sino, también, relacionales.

En resumen, fundamentalmente, la diferenciación entre estas dos dimensiones, transaccional-relacional, se asienta, como ya hemos comentado, sobre la teoría del contrato psicológico $^{64}$ (Rousseau, 1989, 1990; Robinson y Rousseau, 1994) y sobre su vinculación con la relación de empleo. Además, diversa evidencia empírica (Shore

\footnotetext{
${ }^{61}$ Las aportaciones del contrato psicológico distinguen entre contrato o relación de empleo transaccional y relacional (Rousseau, 1990; Morrison y Robinson, 1997; McDonald y Makin, 2000). Los contratos transaccionales son aquellos en los que el nivel de lealtad y compromiso del empleado es limitado y la relación de empleo se analiza básicamente en términos económicos. Por el contrario, los contratos relacionales existen cuando se da un sentido de ajuste con la organización y la lealtad y el compromiso están presentes de forma significativa en los empleados, existiendo una fuerte componente emocional en la relación de empleo.

${ }^{62} \mathrm{Si}$ un empleado percibe que la organización invierte en él, le da soporte y apoya, es porque lo valoran positivamente y, en reciprocidad (Gouldner, 1960), actuará de forma que la empresa valore positivamente, por ejemplo, mediante su comportamiento, compromiso y permanencia en la empresa (Eisenberger et al., 1986).

${ }^{63}$ En lugar de seguridad en el trabajo, el empleador ofrece un puesto de trabajo retador, interesante, retribuciones variables, u oportunidades de aprender habilidades valiosas; y, el empleado, como contraprestación, ofrece alto rendimiento en su puesto, aunque sin un alto grado de compromiso con la organización (Tsui y Wu, 2005).

${ }^{64}$ Postula que entre empleado y empleador se produce una relación que va más allá de lo recogido formalmente en el contrato de trabajo. El empleado percibe su relación de empleo como algo más amplio en lo que valora todo lo que formal, e informalmente, recibe de la organización (empleador): trato recibido, atención, confianza, formación, reconocimiento, buen clima laboral, etc. Todo ello compone lo que se ha denominado el contrato relacional. Aquél contrato que recoge los factores no contractuales pero que también forman parte de la relación de empleo. De este modo se incorporan aspectos psicológicos a la relación de empleo que el empleado percibe y valora y que, por tanto, influyen en su nivel de satisfacción con su relación de empleo, lo cuál incide sobre sus actitudes y comportamientos.
} 
et al., 1998) demuestra que los empleados con menores intenciones de abandono son los que percibe su relación de empleo como completa. Por contra, cuando el empleado percibe que el empleador está fallando en las recompensas prometidas o esperadas, es mucho más probable que busque empleo en cualquier otro lugar (Robinson y Morrison, 1995) repercutiendo negativamente, además, en las actitudes y comportamientos de los empleados $\mathrm{y}$, por ende, en la efectividad organizativa (Robinson y Rousseau, 1994; Coyle-Shapiro y Kessler, 2000; Coyle-Shapiro, 2002; Thompson y Heron, 2005, 2006).

En este trabajo proponemos utilizar este criterio para clasificar y seleccionar las prácticas de recursos humanos objeto de nuestra investigación. Así, proponemos el siguiente conjunto de prácticas de recursos humanos (véase Figura 1.21).

Figura 1.21. Taxonomía y propuesta de prácticas de recursos humanos orientas a la retención de empleados

\begin{tabular}{|c|c|}
\hline \multicolumn{2}{|c|}{$\begin{array}{c}\text { PRÁCTICAS DE RECURSOS HUMANOS } \\
\text { orientadas a la retención }\end{array}$} \\
\hline $\begin{array}{l}\quad \text { TRANSACCIONALES } \\
\text { Favorecer relaciones estables empleado-empleador } \\
\text { Satisfacción de contrato tradicional }\end{array}$ & $\begin{array}{l}\quad \text { RELACIONALES } \\
\text { Favorecer relaciones internas satisfactorias } \\
\text { Satisfacción del contrato relacional }\end{array}$ \\
\hline $\begin{array}{l}\text { Diseño del puesto de trabajo } \\
\text { Sistema de retribución } \\
\text { Desarrollo profesional } \\
\text { Medidas de conciliación laboral/personal }\end{array}$ & $\begin{array}{l}\text { Soporte del supervisor } \\
\text { Comunicación interna } \\
\text { Participación del empleado } \\
\text { Relaciones internas-apoyo compañeros }\end{array}$ \\
\hline
\end{tabular}

Así, por un lado, las prácticas transaccionales se caracterizan por orientarse a promover la estabilidad en la relación empleado-empleador, desarrollar y mantener relaciones fuertes y estables (relaciones de empleo orientadas al largo plazo) a través de satisfacer la dimensión contractual de la relación de empleo tradicional. En esta categoría incluimos: diseño del puesto de trabajo, retribución, desarrollo profesional del empleado (formación y promoción) y medidas de conciliación de la vida laboral/personal. Y, por otro lado, las prácticas relacionales se caracterizan por orientarse a crear y desarrollar relaciones internas satisfactorias con la organización y 
sus miembros (superiores y compañeros), favoreciendo así la dimensión social ${ }^{65}$ del contrato relacional (Rousseau, 1995). En esta categoría incluimos: comunicación interna, participación del empleado, soporte del supervisor y relaciones internas de apoyo con compañeros.

A modo de cierre de este capítulo, reconocemos que la necesidad de profundizar en los procesos a través de los que los propios recursos humanos y la gestión de los mismos influyen sobre los resultados organizativos es una cuestión sobradamente reconocida y aceptada, si bien no es fácil establecer la forma exacta en que se lleva a cabo. Hemos constatado la necesidad de retener el capital humano estratégico de la empresa y hemos identificado las tendencias emergentes de conceptualización del capital humano, que proponen que éste se subdivide en tres dimensiones: capital intelectual, capital social y capital afectivo. En conformidad y, sentadas estas bases conceptuales y empíricas, estamos en condiciones de iniciar nuestra propia investigación en retención de recursos humanos, para la que nos basaremos en la taxonomía de prácticas de recursos humanos propuesta en el epígrafe final de este capítulo, que diferencia entre prácticas de naturaleza transaccional y aquéllas de naturaleza relacional. Con todo lo anterior, en el segundo capítulo, proponemos un modelo original de retención de empleados que será objeto de desarrollo y de contrastación empírica en los capítulos tercero y cuarto.

\footnotetext{
${ }^{65}$ Conocemos que las motivaciones que llevan al empleado a permanecer en su puesto de trabajo son mucho más amplias que las que se derivan estrictamente de la relación transaccional. El hombre como ser social, tiene otras motivaciones de índole psicosocial y relacional.
} 
Capítulo 2 MODELO E HIPÓTESIS DE LA INVESTIGACIÓN 



\section{INTRODUCCIÓN}

El capítulo precedente nos ha permitido asentar las bases de esta investigación. Tomando como fundamentos teóricos el enfoque de recursos y capacidades (Barney, 1991, 1997; Grant, 1996), el enfoque de dirección estratégica de recursos humanos (Dyer, 1993; Pfeffer, 1994; Snell et al. 1994; Wright et al., 1994; Beckert y Gerhart, 1996) y la literatura específica sobre retención (Mobley et al., 1979; Hom y Griffeth, 1995; Griffeth y Hom, 2001; Mitchell et al., 2001; Peterson, 2004; Chew, 2004; Buck y Watson, 2005; Starosta, 2007; Chew y Chan, 2008; Avey et al., 2009; Thite, 2010; Zhao y Liu, 2010), hemos podido constatar que: (1) a pesar de que existe amplia evidencia empírica sobre la influencia positiva de la gestión de recursos humanos en los resultados organizativos, aún no se ha profundizado lo suficiente en los estadios o mecanismos intermedios mediante los cuales esto ocurre. Se hace necesario, por tanto, destapar esa "caja negra” e investigar sobre cuáles son los procesos por los que se produce dicho impacto (Ulrich (1997), Wright et al. (1999), McMahan et al. (1999), Guest (1997), Ferris et al., (1999), Guthrie (2001), Brewster, Sparrow y Harris (2005), Boselie et al. (2005), Subramony (2009), Boxal y Macky (2009); (2) una vez reconocido el gran valor que tienen las personas en el éxito y competitividad empresarial (Pfeffer, 1994; Barney, 1991,1997), la realidad es que no todos los empleados tienen la misma importancia estratégica para la organización. Existe un determinado colectivo de empleados que, como poseedores de capital humano valioso para la empresa, son estratégicos y es a ellos a quienes la empresa debe esforzarse más por retener y fidelizar (Lepack y Snell, 1999, 2002; López, Real y Valle, 2007; Chew y Chan, 2008); y (3), hoy en día, es necesario considerar nuevas dimensiones a la hora de medir resultados, dimensiones que el mundo empresarial ha ido incorporando a sus objetivos estratégicos. En particular, cabe destacar los resultados relativos al desarrollo de innovaciones, siendo necesario en este sentido analizar la contribución de la gestión de recursos humanos y del capital humano a la capacidad de innovación (Shipton et al., 2006; Jiménez-Jiménez y Sanz-Valle, 2005; Chen y Huang, 2009; Wan Ismail et al., 2010), además de su impacto en otro tipo de resultados empresariales. 
El análisis de estas consideraciones nos conduce a plantear un modelo que, siendo lo más sencillo posible ${ }^{1}$, sea capaz de explicar la forma en que un determinado conjunto de prácticas de recursos humanos puede influir sobre los resultados de la organización, siendo su pilar mediador la retención de capital humano. Con el objetivo de plantear este modelo, en el capítulo anterior hemos revisado las principales propuestas que abordan los procesos integrantes de la "caja negra” de recursos humanos. Entre ellas, seleccionamos la de Boselie et al., (2005) y la de Boxal y Macky (2009) por ser las más acordes al modelo que queremos estudiar, puesto que ambas propuestas consideran la existencia de variables de resultado intermedias en la relación entre la gestión de recursos humanos y el resultado empresarial. En concreto, en la presente investigación, proponemos un conjunto de prácticas de retención de recursos humanos que influyen sobre variables que miden el desempeño de la gestión de recursos humanos (en nuestro caso, centrado en la retención del capital humano-intelectual, social y afectivo-), que a su vez, impactan sobre resultados internos (capacidad de innovación y resultados de las personas), los cuales en última instancia, mejoran el desempeño organizativo y financiero de organización. El modelo que proponemos en este trabajo se esquematiza de forma básica en la Figura 2.1.

Figura 2.1 Estructura del modelo de este trabajo basada en Boselie et al. (2005) y Boxal y Macky (2009)

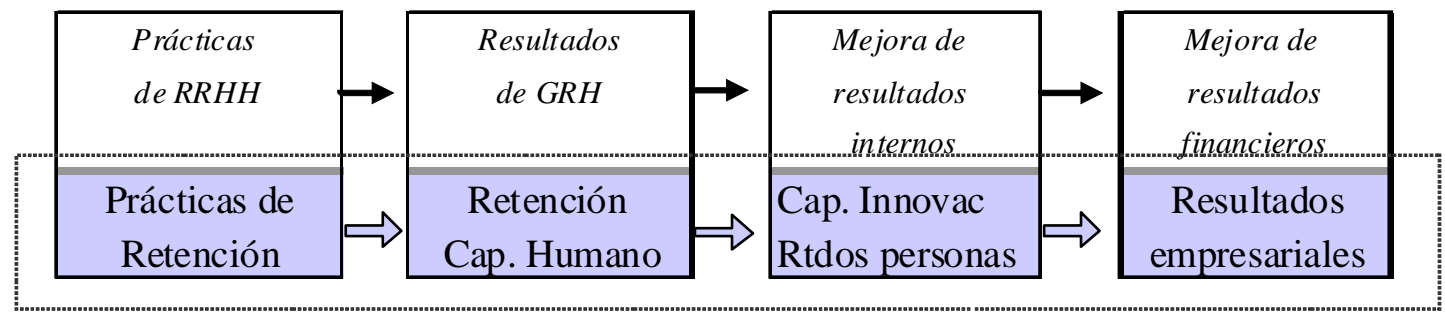

A continuación, presentamos con detalle el modelo original y enunciamos la tesis de este trabajo de investigación; seguidamente definimos las variables dependientes e independientes y, por último, presentamos las principales hipótesis y subhipótesis del modelo, que completamos, a modo de cierre, con un resumen de las mismas.

\footnotetext{
${ }^{1}$ La regla de oro de la simulación y el modelado señala que se debe tratar de diseñar lo más sencillo y simple que sea posible.
} 


\subsection{PRESENTACION GENERAL DEL MODELO PROPUESTO}

En este primer epígrafe aportamos la descripción general del modelo de tesis en el que, seguidamente, profundizaremos. Esto nos permite obtener una panorámica global del mismo, presentando sus bloques de variables y las principales relaciones susceptibles de contrastación.

El modelo que presentamos (Figura 2.2) plantea que la retención de empleados clave ${ }^{2}$ de las organizaciones, propiciada desde la gestión de recursos humanos, puede mejorar la capacidad de innovación de la organización y sus resultados organizativos.

La primera parte del modelo comprende el conjunto de prácticas de recursos humanos orientadas a la retención de los empleados. Tales prácticas se subdividen en dos grandes bloques complementarios: (1) prácticas de recursos humanos de naturaleza transaccional, entre las que se incluyen el diseño del puesto de trabajo, la retribución, el desarrollo del empleado (formación y promoción) y la conciliación entre la vida laboral/personal; y (2) prácticas de recursos humanos de naturaleza relacional, que comprenden el soporte del supervisor, la comunicación interna, la participación del empleado y las relaciones sociales de apoyo entre compañeros.

La segunda parte del modelo se centra en la retención del capital humano relativo a los empleados clave de la organización. La retención de este capital humano es esencial para asegurar el éxito competitivo y los resultados organizativos. En particular, nuestro modelo distingue tres componentes del capital humano: capital intelectual, capital social y capital afectivo (Gratton y Ghoshal, 2003; Barney y Clark, 2007). El capital intelectual alude al conjunto de conocimientos, habilidades y experiencias que posee cada empleado. El capital social hace referencia a las relaciones sociales que se establecen entre los empleados de la organización. Por último, el capital afectivo ofrece la dimensión emocional del empleado y, en concreto, recoge el afecto y vínculo del empleado para con la organización.

\footnotetext{
${ }^{2}$ Estos empleados clave, también denominados recursos humanos estratégicos, han sido definidos en el capítulo previo (p.e. Rosseau, 1995; Tsui et al., 1995; Morris et al.2005; López-Cabrales et al., 2007), siendo el objeto de estudio de la presente investigación.
} 
La tercera y última parte del modelo aborda los diversos resultados organizativos (intermedios y finales) que se derivan de la retención del capital humano. En cuanto a los resultados intermedios, consideramos necesario incorporar, por un lado, la capacidad de innovación de la organización, dado el contexto dinámico y competitivo que envuelve a las empresas en la actualidad, y, por otro lado, los resultados relativos a las personas; definimos ambas variables como antecedentes de los resultados empresariales. Finalmente, identificamos los resultados empresariales como resultado final de la organización de naturaleza económico-financiera.

Las relaciones que se producen entre las variables integrantes de cada una de las tres partes del modelo que acabamos de describir nos conducen a definir las hipótesis fundamentales que, a su vez, se subdividen en subhipótesis para recoger dichas relaciones de forma individualizada. En consecuencia, en este trabajo distinguimos tres bloques de hipótesis: (a) las que relacionan las prácticas de recursos humanos -transaccionales y relacionales- con el capital humano de la organización -intelectual, social y afectivo-, (b) las que relacionan el capital humano retenido con los resultados intermedios (capacidad de innovación y resultados de las personas) y (c) las que recogen la relación entre las variables de resultados intermedios y de resultados finales.

Este modelo propuesto responde a la tesis general que nos planteamos en esta investigación, y que enunciamos del siguiente modo:

\section{TESIS}

Las prácticas de recursos humanos -transaccionales y relacionales- afectan positivamente a la retención del capital humano- intelectual, social y afectivo- de la organización, influyendo positivamente en la capacidad de innovación y los resultados de las personas, y contribuyendo, en última instancia, a mejorar los resultados empresariales.

En la Figura 2.2., se pueden observar los distintos bloques, variables, relaciones e hipótesis del modelo que acabamos de presentar. 
Figura 2.2- Modelo de investigación e hipótesis

PRÁCTICAS DE RECURSOS HUMANOS ORIENTADAS A LA RETENCIÓN DE CAPITAL HUMANO (INTELECTUAL, SOCIAL Y AFECTIVO) Y SU IMPACTO SOBRE LA MEJORA DE LA CAPACIDAD DE INNOVACIÓN Y OTROS RESULTADOS ORGANIZATIVOS.

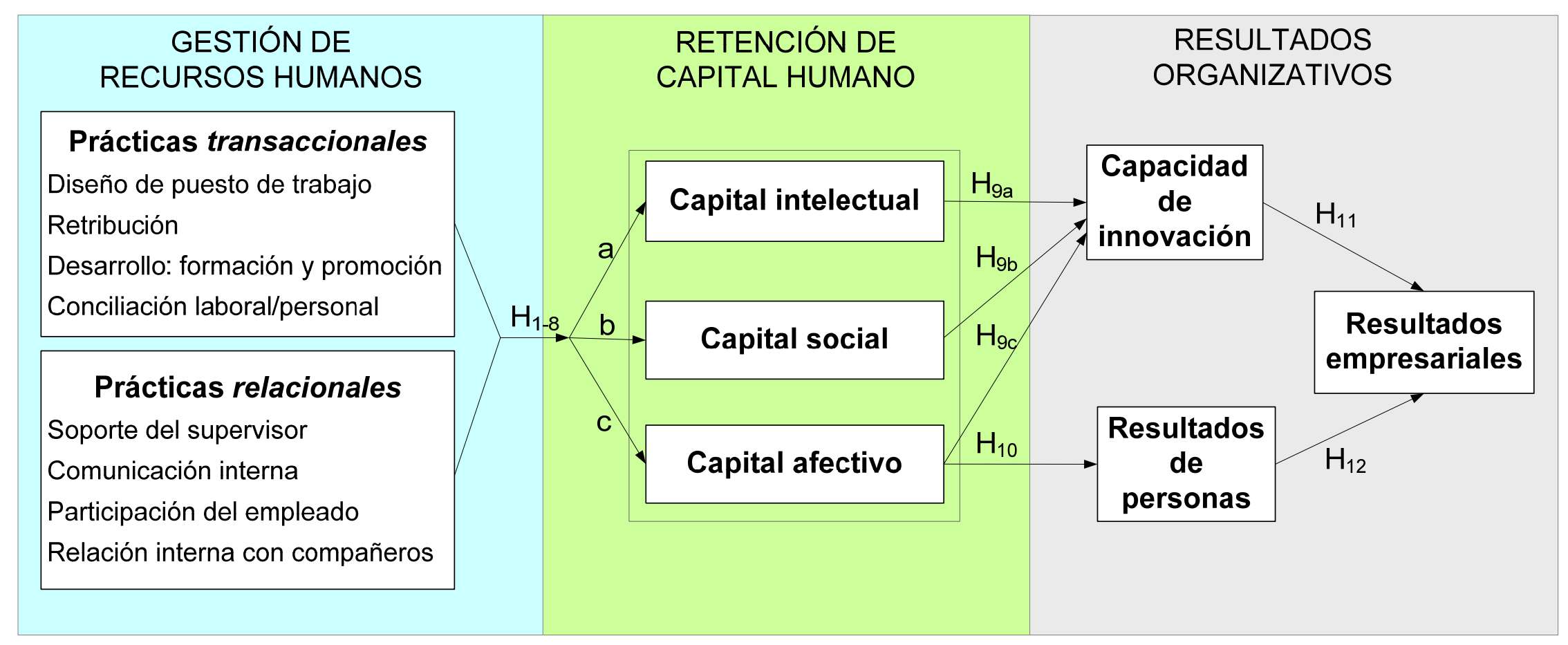

Nota: Las $\mathrm{H}_{\mathrm{i}}$ representan las hipótesis del modelo. Las hipótesis $\mathrm{H}_{1-8}$, se corresponden con las subhipótesis relativas a cada práctica de recursos humanos, donde $n=1$ es la hipótesis del diseño enriquecido del puesto, hasta $n=8$, que es la hipótesis relativa al soporte y relaciones con los compañeros. Además, cada una de estas prácticas se relaciona con el capital intelectual (hipótesis a), el capital social (hipótesis b) y el capital afectivo (hipótesis c). Por tanto, se plantean 24 subhipótesis entre las prácticas de recursos humanos y la retención de capital humano de la organización. Del mismo modo, ocurre con la influencia del capital humano sobre la capacidad de innovación que recoge la hipótesis nueve, a través de las correspondientes subhipótesis relativas a cada dimensión del capital humano (intelectual, social y afectiva). 


\subsection{DESARROLLO DEL MODELO: DEFINICIÓN DE VARIABLES}

El siguiente epígrafe aborda la presentación de las diferentes variables dependientes e independientes del modelo, así como de las relaciones entre dichas variables expresadas en las hipótesis y subhipótesis fundamentales que emanan del modelo. Comenzamos abordando la definición de las variables dependientes de este estudio; seguidamente, presentamos las variables independientes y, por último, desarrollamos y justificamos las relaciones planteadas en nuestro modelo mediante la definición de las correspondientes hipótesis y subhipótesis.

\subsubsection{Variables dependientes del modelo: capital humano y resultados organizativos}

En las siguientes páginas se conceptualizan las variables de capital humano -intelectual, social y afectivo- y las variables de resultados intermedios y finales -capacidad de innovación, resultados de las personas y resultado empresarial-, todas ellas variables dependientes de nuestro modelo.

\subsubsection{Capital Humano}

El capital humano es considerado como una capacidad de la organización que permite extraer las mejores soluciones a través del conocimiento de sus empleados (Bontis, 1998). El capital humano comprende el conocimiento, tanto tácito como explícito, que posee una organización a través de sus empleados, así como las interacciones y relaciones de las que participan los empleados, junto a las actitudes y los afectos desarrollados en el contexto laboral (Bontis et al., 2001; Bontis, 1998; Bueno, 2000; Ordóñez, 2003; Gratton y Ghoshal, 2003). Desde una perspectiva estratégica, el capital humano es un recurso único e intangible que diferencia a una organización de otras y asienta la base para su capacidad competitiva ${ }^{3}$ (Lengnick-Hall y Lengnick-Hall, 2006).

Como ya hemos señalado en el capítulo primero, son numerosas las definiciones de capital humano aportadas por los investigadores. De todas ellas, seleccionamos la de

\footnotetext{
${ }^{3}$ La capacidad competitiva se basa en la habilidad de la empresa para transformar su tecnología y sistemas operativos de modo que permitan adoptar nuevas perspectivas y llevar a cabo cambios en los sistemas sociales, favoreciendo y potenciando el capital social y el capital humano, logrando así un conocimiento superior desde el que ser más competitivos.
} 
Gratton y Ghoshal (2003) y la de Barney y Clark (2007) por ser las más acordes con nuestro modelo. Ambas propuestas coinciden en las tres componentes definidas como integrantes del capital humano. Barney y Clark (2007) diferencian entre: (1) el conocimiento, experiencias y habilidades, (2) las relaciones con compañeros, subordinados o superiores, así como con personas externas a la empresa como, por ejemplo, proveedores, clientes, etc., y (3) el compromiso de los empleados con la empresa. Por su parte, Gratton y Ghoshal (2003) distinguen entre el capital intelectual (conocimiento, habilidades y experiencias), el capital social (sociabilidad, redes y relaciones del empleado, por cuanto permite al individuo acceder a recursos que poseen otros) y, en último lugar, el capital emocional (recoge rasgos como la autoconfianza, valor, autoestima e integridad, que influyen sobre la actitud para convertir el conocimiento y las relaciones en acciones). Además, Gratton y Ghoshal (2003) consideran que estas tres componentes están muy relacionadas, ${ }^{4}$ y que son, precisamente, estas interacciones las que caracterizan al capital humano como estratégico y susceptible de generar ventajas competitivas.

Así pues, tomando como referencia las propuestas de Gratton y Ghoshal (2003) y Barney y Clark (2007), en este trabajo definimos el capital humano atendiendo a sus tres dimensiones fundamentales: capital intelectual, capital social y capital afectivo. La Figura 2.3. representa esta definición, que abordamos a continuación con mayor detalle.

Figura 2.3. Conceptualización del capital humano

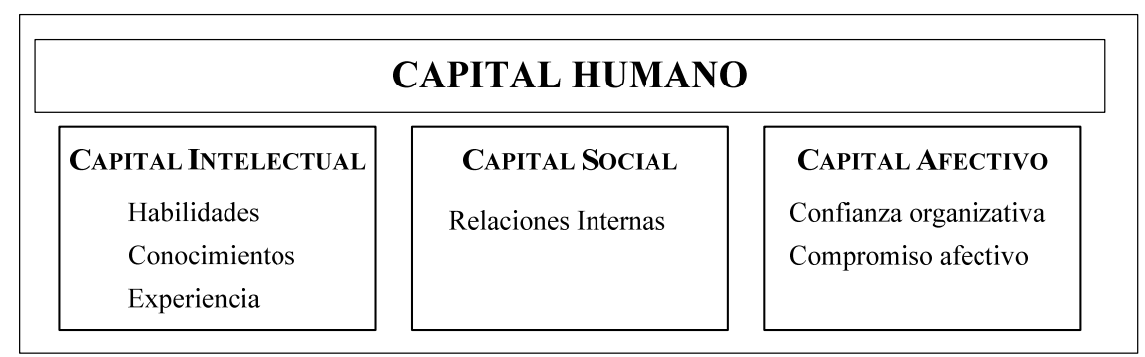

Fuente: elaboración a partir de Barney y Clark (2007) y Gratton y Ghoshal (2003)

\footnotetext{
${ }^{4}$ El capital social, en forma de relaciones recíprocas, extensas y fluidas, permite acceder al conocimiento y habilidades de otros, desarrollando así el capital intelectual. El capital emocional aporta la integridad y autoconfianza para construir relaciones abiertas y de confianza, que sustentan el capital social. La propensión al aprendizaje del capital intelectual puede conducir al autodesarrollo, mejorando la autoconfianza y, por tanto, contribuyendo al capital emocional. Y, además, a través del refuerzo de estos ciclos de retroalimentación, el autoconocimiento, desarrollado mediante relaciones valiosas y abiertas, potencia la autoconfianza y la autoestima (Graton y Ghoshal, 2003:3).
} 
De forma previa a esbozar nuestra definición tridimensional de capital humano, consideramos necesario matizar que no todo el capital humano de los empleados es un recurso homogéneo y, por tanto, conducente al logro de resultados homogéneos (LópezCabrales et al., 2007). Existen diferentes tipos de empleados, con diferentes conocimientos, habilidades y experiencias que, por tanto, aportan diferentes contribuciones a la compañía (Atchinson, 1991). Sólo algunos empleados pueden considerarse claves o especialmente valiosos, puesto que poseen el capital humano que debe ser retenido y fidelizado en la organización (Barney y Wright, 1998; Lepack y Snell, 1999, 2002; Morris et al., 2005). Nuestro estudio se centra, precisamente, en el capital humano ligado a este colectivo particular de empleados: los estratégicos.

A continuación, definimos las variables componentes del capital humano propuestas en esta investigación.

\subsection{Capital intelectual}

En el contexto que nos ocupa, definimos el capital intelectual como los conocimientos, habilidades y experiencias individuales de los empleados (Edvinsson y Malone, 1997; Stewart, 1997; Youndt y Snell, 2004; Lengnick-Hall y Lengnick-Hall, 2006), es decir, como el conocimiento que posee una organización a través de sus empleados, formado tanto por conocimiento tácito como explícito (Bontis et al., 2001; Bontis, 1998; Bueno, 2000; Ordóñez, 2003) ${ }^{5}$.

Los empleados con mayores conocimientos, habilidades y experiencia son considerados más expertos y brillantes puesto que poseen la capacidad de incrementar el resultado empresarial. A través de sus conocimientos y habilidades encuentran el modo de lograr la mejora del beneficio para los clientes o de disminuir los costes de producción o servicio, de múltiples formas. Por ejemplo, los empleados creativos tienen un mayor potencial para generar innovaciones en producto y servicio que hagan incrementar el valor de éstos para el cliente, ajustándose mejor a sus necesidades (Youndt y Snell,

\footnotetext{
${ }^{5}$ En este punto señalamos que nuestra concepción de “capital intelectual” equivale a lo que otros autores (Edvinsson y Malone, 1997; Stewart, 1997; Youndt y Snell, 2004; López-Cabrales et al, 2007) denominan simplemente "capital humano". Nuestra elección responde a la necesidad de recoger y diferenciar una subdimensión diferente de otras -social y afectiva-, la vertiente más intelectual y cognitiva del capital humano.
} 
2004). Los empleados con conocimientos, experiencias y habilidades valiosos para la organización suelen desempeñar su trabajo en las actividades clave de la misma (Lepack y Snell, 1999; López-Cabrales et al., 2007). Además, estos empleados son quienes adquieren nuevo conocimiento, el cual incrementa el capital intelectual de la organización, pudiendo contribuir, así, al desarrollo de la capacidad de aprendizaje de ésta, a la mejora organizativa y a mantener actualizada y no obsoleta a la organización (Kang, Morris y Snell, 2007).

Considerando una perspectiva estratégica, el capital intelectual puede ser un recurso único, inimitable, intangible y valioso que diferencie a una organización de otras y siente las bases de su capacidad competitiva (Lengnick-Hall y Lengnick-Hall, 2006; López-Cabrales et al., 2007). Dichos rasgos lo caracterizan como recurso estratégico y, como tal, fuente de ventaja competitiva sostenible en el tiempo (Barney, 1991; Youndt et al., 2004; Subramanian y Youndt, 2005). De hecho, nuestro estudio se centra, precisamente, en el capital intelectual ligado al colectivo de empleados considerados estratégicos. En consecuencia, y apoyándonos en las propuestas conceptuales de Lengnick-Hall y Lengnick-Hall (2006) y de Youndt y Snell (2004), en este trabajo definimos el capital intelectual como aquella variable que recoge los conocimientos, habilidades y experiencias que poseen los empleados clave de la organización, de forma que este capital pueda ser considerado un recurso único e intangible que diferencie a dicha organización de otras y la provea de las bases para su capacidad estratégica.

\subsection{Capital Social}

El capital social es un recurso intangible de la organización que se apoya en la estructura y contenido de las relaciones sociales de la misma (Adler y Kwon, 2002). Definirlo no es tarea fácil y ello ha derivado en la existencia de diferentes conceptualizaciones y ámbitos de aplicación ${ }^{6}$, no habiéndose alcanzado todavía un consenso en su definición.

\footnotetext{
${ }^{6}$ Véase Adler y Kwon (2002) para una revisión extensa del concepto de capital social.
} 
El trabajo de Nahapiet y Ghoshal (1998) es, quizás, una de las propuestas más notorias y utilizadas hasta el momento. Estos autores consideran el capital social como "la suma de los recursos potenciales y actuales inmersos dentro, a través de, y derivados de las redes de relación de un individuo o una unidad social” (1998:243) ${ }^{7}$. Estas redes de relaciones entre empleados y grupos (tanto dentro como fuera de la organización), entre otras cosas, proveen de información y ayudan a resolver problemas, añadiendo valor y potenciando la capacidad estratégica de la organización (Reagans y McEvily, 2003).

Otra propuesta importante es la de Leana y Van Buren (1999) quienes tratan de dar un paso más y definen el capital social como el recurso que refleja el carácter de las relaciones sociales entre empleados que tienen lugar dentro de la organización ${ }^{8}$. Por otro lado, desde una perspectiva organizativa, debemos señalar a Youndt y Snell (2004) quienes definen el capital social como la habilidad global de la organización para intercambiar y mover el conocimiento entre los empleados, proveedores, clientes, aliados estratégicos u otras empresas.

Éstas y otras definiciones permiten identificar tres elementos comunes del capital social: requiere de la participación de actores -individuos y/u organización-, genera flujos de conocimiento y se soporta sobre una estructura de interacciones o redes de relación. Esas interacciones o redes de relación dan soporte a procesos que mueven el conocimiento entre individuos, dentro y fuera de la organización, entre unidades de la propia organización e, incluso, entre diferentes organizaciones (Nahapiet y Ghoshal, 1998; Leana y Van Buren, 1999; Adler y Kwon, 1999,2002; Leana y Pil, 2006). Así, hay autores que diferencian ente capital social interno y capital social externo ${ }^{9}$ (Leana y

\footnotetext{
${ }^{7}$ Lo denominan capital social organizativo y distinguen tres dimensiones: estructural, relacional y cognitiva. La dimensión estructural se refiere a las conexiones entre los actores (quiénes y con qué frecuencia se comparte información), la dimensión relacional hace alusión al tipo de relación personal que los individuos han desarrollado a través de sus interacciones y, la dimensión cognitiva, se refiere a aquellos recursos que provienen de interpretaciones compartidas (lenguaje y códigos compartidos).

${ }^{8}$ Según Leana y Van Buren (1999), condicionado por dos dimensiones clave: asociabilidad y confianza.

${ }^{9}$ Esta variedad de posibilidades ha conducido a que en la perspectiva organizativa se distinga entre dos tipos de capital social: capital social interno y capital social externo (Leana y Pil, 2006). El interno alude a las interacciones entre los miembros de la organización (Coleman, 1990; Leana y Van Buren, 1999) y el externo a las interacciones entre la organización -o sus miembros- y colaboradores externos (Kale et al., 2000; Uzzi, 1997 en Leana y Pil, 2006). El capital social externo se excluye en este estudio puesto que supondría ampliar (demasiado) el campo de análisis e introducir agentes externos a la empresa sobre los que la gestión de recursos humanos no puede tener alcance.
} 
Pil, 2006). El presente estudio se centra en el ámbito del capital social interno, aquel desarrollado exclusivamente a través de la interacción entre empleados de la organización.

Las organizaciones son conscientes de que quienes poseen el conocimiento son los propios empleados $y$, puesto que los empleados son libres de abandonar la empresa en cualquier momento, existe un riesgo significativo de pérdida del capital intelectual en tanto que éste no sea transferido, compartido, transformado e institucionalizado (Youndt y Snell, 2004). Para evitar la pérdida de conocimiento, las organizaciones tratan de diseñar estructuras, redes e interacciones que protejan las inversiones realizadas en recursos de conocimiento, tratando de favorecer procesos colaborativos y relaciones entre empleados. Se construye, así, el capital social. De hecho, se considera que el capital social es uno de los mecanismos más eficientes para compartir conocimiento tácito y explícito entre individuos (Grant, 1996; Kogut y Zander, 1992; Nonaka y Takeuchi, 1995 cit. en Kang, Morris y Snell, 2007: 237). Es más, los procesos de adquisición, transferencia e integración de conocimiento valioso para la organización suelen desarrollarse en el contexto de las relaciones sociales entre empleados (Nahapiet y Ghoshal, 1998).

Teniendo en cuenta las anteriores consideraciones, y apoyándonos, fundamentalmente, en las conceptualizaciones de Leana y Van Buren (1999) y Offstein y Gnyawali (2006), en este trabajo definimos el capital social como la variable que recoge las relaciones e interacciones sociales en las que participan los empleados clave, al amparo de la propia organización, intercambiando, combinando, transfiriendo o creando conocimiento.

En base a esta definición, y desde una perspectiva organizativa, el capital social tal como lo definimos en este trabajo, tiene naturaleza estratégica. Esto es debido, en primer lugar, a que comprende la participación, no de cualquier tipo de empleado, sino de aquellos considerados estratégicos y especialmente valiosos por los conocimientos, habilidades y experiencias que poseen (Morris et al., 2005). Y, en segundo lugar, a la capacidad de las relaciones entre empleados para crear sinergias y una identidad única. Las relaciones estables y satisfactorias entre empleados, pueden marcar la diferencia 
entre una estructura técnica y rígida y una estructura en la que fluya el aprendizaje, generando un valor mayor que la suma de las contribuciones individuales (LengnickHall y Lengnick-Hall, 2003, 2006; Offstein y Gnyawali, 2006). Por otra parte, el modo concreto en que se lleven a cabo dichas relaciones, permitiendo procesos de combinación, creación, transferencia e integración de conocimiento, puede generar diferenciación y ventaja competitiva, si se produce de forma única ${ }^{10}$, inimitable $\mathrm{y}$ estructurada (Afiouni, 2007).

\subsection{Capital Afectivo}

El capital afectivo es la tercera dimensión que conforma el capital humano en este trabajo. Apoyándonos en Gratton y Ghoshal (2003), hemos optado por utilizar el término “capital afectivo” porque, por un lado, recoge semánticamente la idea de vínculo a las emociones y a los afectos $\mathrm{y}$, por el otro, mantiene coherencia terminológica con las otras dos dimensiones del capital humano: capital intelectual y capital social.

Los afectos que desarrollan las personas en sus trabajos pueden ser de dos tipos: externos o internos (Thomspon, 1998). Los externos, son los sentimientos y creencias que los clientes, proveedores, accionistas o socios desarrollan hacia la empresa y, los internos, son los afectos, creencias y sentimientos desarrollados por las personas que trabajan en la organización hacia la propia organización y sus miembros. Debemos hacer notar que, en este trabajo, sólo nos centraremos en la vertiente interna del capital afectivo, es decir, en los afectos de los empleados hacia y con la propia organización, ya que los externos están fuera del alcance de la influencia de la gestión de recursos humanos.

El capital afectivo entronca con la idea de que no es suficiente que la empresa posea un capital intelectual y social adecuados, sino que, además, necesita que los empleados desarrollen unos afectos que se traduzcan en una actitud positiva, un “querer hacer” y

\footnotetext{
${ }^{10}$ Este autor, alude a la dificultad para identificar cómo se produce, ya que si estas relaciones se realizan de un modo único, no habitual o con unas estructuras de relación que no son las típicas. Todo ello favorece la ambigüedad causal y dificulta su imitación por parte de competidores..
} 
un grado de motivación que los conduzca hacia comportamientos óptimos para alcanzar los resultados buscados y mejorar la competitividad empresarial (Gendrom, 2007).

Hoy en día es evidente el papel que los afectos y emociones juegan en la motivación y estímulo de los empleados (Goleman, 1999; Barsade y Gibson, 2007). La dirección empresarial no puede permitirse ignorar que los afectos de su fuerza de trabajo constituyen un recurso crítico (Lee et al., 2008) que debe aprender a manejar y estimular si quiere sacar el máximo potencial de las personas. Comprender cómo operan estos afectos y cómo influyen en los resultados organizativos es una pieza esencial para entender cómo se hace el trabajo y cómo poder hacerlo mejor (Barsade y Gibson, 2007). En otras palabras, la faceta afectiva del conjunto de empleados ejerce una clara influencia sobre sus actitudes, comportamientos y su nivel de desempeño, influyendo, por ende, en los resultados organizativos (Beckert et al., 1997; Guest, 1997).

Puesto que en nuestro modelo queremos incorporar esta dimensión afectiva del capital humano, debemos definir, previamente, dicha variable. Para ello nos apoyamos en las definiciones propuestas por McGrath y Van Buskirk (1999) y Thomson (1998) y, por tanto, definimos el capital afectivo como la variable que recoge el sentimiento colectivo de confianza y que promueve el compromiso afectivo de los empleados clave con la organización. En otras palabras, el capital afectivo recoge el grado de vinculación afectiva, confianza e identificación que estos empleados desarrollan hacia su organización. Estos afectos se construyen a través del compromiso afectivo y de la confianza que los empleados desarrollen hacia la misma (Figura 2.4).

Figura 2.4. Definición de capital afectivo

\begin{tabular}{|c|c|}
\hline \multicolumn{2}{|c|}{ CAPITAL AFECTIVO } \\
\hline COMPROMISO & CONFIANZA \\
AFECTIVO & ORGANIZATIVA \\
\hline
\end{tabular}

En primer lugar, sabemos que el compromiso organizativo representa el vínculo afectivo y de identificación con la organización (Kanter, 1968; Buchanan, 1974; Mowday et al., 1979). También, y de forma más completa, es considerado como un constructo multidimensional (Reichers, 1985; O’Reilly y Chatman, 1986; Meyer y 
Allen, 1991; Jaros et al., 1993 cit en Meyer y Herscovitch, 2001), distinguiendo tres dimensiones o tipos de compromiso organizativo: afectivo, de continuidad y normativo ${ }^{11}$. Para Gallardo (2008) estas tres dimensiones representan maneras diferentes de sentirse unido a la organización. Las personas permanecen comprometidas con la organización porque quieren y generan afectos positivos hacia la misma (afectivo), porque lo necesitan (de continuidad) o porque sienten que deben hacerlo (normativo). En nuestra definición de capital afectivo, incorporamos sólo el compromiso organizativo en su dimensión afectiva, aquel que recoge el vínculo emocional y afectivo del empleado con la organización, su identificación con ella y su implicación con la misma. En otras palabras, el compromiso afectivo alude al grado en que un individuo está emocionalmente vinculado a una organización, a través de sentimientos de lealtad, cariño, simpatía, identificación, implicación y deseo de pertenencia (Meyer y Allen, 1991; Jaros et al., 1993; Gallardo, 2008). Nuestra decisión de incluir sólo esta dimensión (excluyendo las componentes de continuidad y normativa) se debe a que es, precisamente, la dimensión afectiva la que ha demostrado tener una mayor influencia sobre la satisfacción laboral y el deseo de permanencia en la organización (Meyer y Allen, 2001; Meyer et al., 2002).

En segundo lugar, junto al compromiso afectivo, la confianza organizativa también conforma el capital afectivo, tal como lo definimos en esta investigación. La confianza ha sido definida de múltiples formas (Mayer, Davis, Schoorman, 1995; Rousseau, Sitkin, Burt, Camerer, 1998; Das y Teng, 2004; Dietz y Hartog, 2006 ${ }^{12}$ ), abordada desde diferentes niveles de análisis (individual, grupal, organizativa, interorganizativa) y clasificada según diversas tipologías ${ }^{13}$. Todo ello evidencia su carácter

\footnotetext{
${ }^{11}$ El compromiso afectivo recoge el vínculo emocional que los empleados sienten hacia la organización, caracterizado por su identificación e implicación con ella, así como, también, por el deseo de permanecer en la misma. El compromiso de continuidad deriva de los costes que los empleados asocian a la decisión de "abandonar la organización". El compromiso normativo, se asocia con la internalización de presiones normativas para actuar de forma acorde a los intereses organizativos y con la obligación moral de los empleados a mantenerse en la organización. (Meyer y Allen, 2001; Gallardo, 2008).

${ }^{12}$ Dietz y Hartog (2006) presentan un excelente trabajo de revisión sobre la confianza organizativa.

${ }^{13}$ Destacamos algunas de las más notables como: la de Clark y Payne (1997) que distinguen entre confianza disposicional, interpersonal y situacional o, la propuesta por Rousseau et al. (1998), quienes distinguen entre confianza relacional, calculadora e institucional. A pesar de esta diversidad de propuestas, sí parece existir consenso en considerar que alude a una cierta predisposición a ser
} 
multidimensional (p.e., Mayer et al., 1995; McAllister, 1995). De entre la diversidad de propuestas existente, en nuestro trabajo seleccionamos la confianza organizativa, por ser la dimensión más acorde con nuestro modelo y la definimos como la disposición general de los empleados valiosos a ser vulnerables a las acciones de la organización debido a las expectativas positivas que tienen en relación con las intenciones y comportamientos de la misma (Mayer et al., 1995; Rousseau et al., 1998). La confianza organizativa recoge, de esta manera, la confianza en relación a la organización y dentro de la organización (Dietz y Hartog, 2006) derivada de las estructuras, procesos y relaciones que ocurren dentro de la misma ${ }^{14}$, y se caracteriza por ser impersonal y colectiva (Bagraim y Hime, 2007). Este sentimiento de confianza se desarrolla en el empleado a través del afecto hacia sus superiores, hacia la dirección de la empresa y hacia sus compañeros (Mayer y Davis, 1999; Tzafrir et al. 2004, Mayer y Gavin, 2005).

Para cerrar nuestra definición de capital afectivo, queremos hacer notar su naturaleza estratégica, del mismo modo que sucedía con el capital intelectual y social. El capital afectivo puede ser caracterizado como un capital estratégico porque, por un lado, emana de un tipo concreto de empleados, aquellos que hemos denominado clave o estratégicos (Morris et al., 2005), y por otro lado, porque dicho capital en sí mismo, puede ser fuente de ventaja competitiva debido a su carácter único, inimitable y valioso para la organización. De hecho, la gestión de los afectos y emociones de los empleados es una competencia esencial en las empresas que quieran alcanzar el éxito en el futuro (Thomson, 1998; Ordoñez de Pablos, 2000). En este sentido, Thomson (1998) afirma que el capital afectivo contribuye a conformar la “personalidad” de la organización, marcando su carácter único y diferenciándola de los competidores. Por su parte, Tzafrir et al. (2003) consideran este capital como un activo intangible con capacidad para

vulnerable en base a las creencias positivas que se tienen de la otra parte (Mayer et al., 1995; Rousseau et al. 1998)

${ }^{14}$ Otros autores proponen distinguir entre confianza organizativa interpersonal (lateral y vertical) y confianza organizativa impersonal o, también llamada, institucional (Costigan et al.et al., 1998; Atkinson y Butcher, 2003; McKnight et al.et al., 1998, 2002; Ellonen et al., 2008). Confianza organizativa interpersonal lateral, es aquella que surge entre los empleados y sus compañeros; $y$, la vertical, es la que se da entre empleados y supervisores. La confianza organizativa impersonal o institucional es la confianza de los miembros de la organización en la visión, estrategia, tecnología y competencia comercial de la organización, así como en la equidad de los procesos y estructuras de la misma y en sus políticas de recursos humanos (Ellonen et al., 2008). 
generar ventaja competitiva sostenible. Además, existe constancia de que las organizaciones que logran mantener altos niveles de afecto y confianza en su gestión, generan mayor ventaja competitiva en relación a las que no lo logran (Barney y Hansen, 1994; Whitener et al., 1998). Así pues, teniendo en cuenta las consideraciones previas, el capital afectivo es la tercera componente estratégica del capital humano que las organizaciones deben cuidar si aspiran a ser competitivas y a alcanzar sus objetivos.

Una vez presentadas las variables dependientes relativas al capital humano, pasamos a presentar las variables dependientes relativas a los resultados organizativos.

\subsubsection{Resultados Organizativos}

Como ya se ha hecho notar, la importancia de la gestión de recursos humanos y su influencia sobre los resultados organizativos y la competitividad empresarial es hoy en día aceptada y ha sido ampliamente contrastada en la literatura (Arthur, 1994; Huselid, 1995; Huselid et al., 1997; Delery y Doty, 1996; Beckert y Gehart, 1996; Ichiniowsky et al., 1997, 1999; Youndt et al., 1996; Ulrich, 1997; Shaw, Delery, Jenkins y Gupta, 1998; Ferris et al., 1998; Truss 2001; Batt, 2002; entre otros). No obstante, debemos señalar que sigue existiendo controversia en lo relativo a la medición de los efectos de la gestión de recursos humanos en términos de resultados $\mathrm{y}$, también, sobre qué variables de resultado deben utilizarse (Truss, 2001; Way y Johnson, 2005). Diversos autores han tratado de clasificar las principales medidas de eficacia organizativa utilizadas en los estudios incluidos dentro del ámbito de recursos humanos, diferenciando entre variables de resultado de recursos humanos, organizativas, financieras, de mercado y de las personas, entre otras ${ }^{15}$ (Dyer y Reeves, 1995; Guest, 1997). Además, la investigación reciente en recursos humanos propone una relación causal entre las variables de resultado final, diferenciando entre variables de resultados internos y variables de resultados financieros o finales (Paauwe y Richardson, 1997; Boselie et al., 2005; Boxal y Macky, 2009).

Siguiendo estas consideraciones (revisadas en el capítulo primero) clasificamos los resultados que derivados de la gestión de recursos humanos en tres niveles secuenciales diferentes (Way y Johnson, 2005; Boselie et al., 2005). Por un lado, consideramos unos

\footnotetext{
${ }^{15}$ En el capítulo primero ya se han expuesto estas ideas con mayor detalle.
} 
resultados directos de la influencia de la gestión de recursos humanos; por otro lado, reconocemos una categoría de resultados organizativos intermedios como variables que recogen el impacto directo que sobre ellos ejercen el comportamiento y actitudes de los empleados y, por último, consideramos un resultado final vinculado a la dimensión económica-financiera de la organización. En concreto, en este trabajo distinguimos dos variables de resultado organizativo intermedio (capacidad de innovación y resultados de las personas) y una variable de resultado de consecución final (resultado empresarial).

A continuación, definimos cada una de esas tres variables de resultados organizativos.

\subsection{Capacidad de Innovación}

se considera que la capacidad de innovación provee a la organización del potencial para poder innovar de forma efectiva (Terziovski, 2007). La capacidad de la organización para innovar permite desarrollar mejoras y nuevos productos, ofreciendo nuevas oportunidades y una capacidad de respuesta rápida ante los cambios del entorno, generando valor empresarial y mejorando los resultados (Calantone et al., 2002). Por ello, la capacidad de innovación es considerada un factor clave para asegurar el éxito competitivo (Cohen y Levinthal, 1990; Kogut y Zander, 1992; Leonard-Barton, 1995; Grant, 1996; Decarolis y Deeds, 1999; Tsai, 2001, Shipton et al., 2006; Naranjo, Sanz y Jiménez, 2008; Huang et al., 2009a; Benítez-Amado et al., 2010). Estas consideraciones han conducido a un incremento del interés por su estudio (Argote, McEvil y Reagans, 2003; Perdomo-Ortiz, González-Benito y Galende, 2006; Jiménez Jiménez y Sanz Valle, 2007; Huang et al., 2009a; Benítez- Amado et al., 2010). Sin embargo, y a pesar del creciente y extenso número de trabajos sobre la capacidad de innovación, todavía no existe ni un marco teórico único ni una forma de análisis universal desde la que abordar su estudio, sin ni siquiera existir consenso sobre el propio concepto de innovación (Gopalakrishnan y Damanpour, 1997; Jiménez Jiménez y Sanz Valle, 2007). La innovación puede tener diferentes definiciones dependiendo del contexto y objetivo de estudio (García-Mulero, 2007). Se ha definido como proceso, como resultado, en términos de su adopción y en términos de novedad (Naranjo et al., 2008). Se puede clasificar en diferentes tipos o categorías (Gopalakrishnan y Damanpour 1997; Perdormo-Ortiz et al., 2006). Estas cuestiones han sido revisadas con mayor detalle en 
el capítulo primero. No obstante, una pauta común en todas ellas es considerar que la esencia de la innovación va asociada a su capacidad para adoptar algo nuevo.

La capacidad de innovación es un constructo complejo, por ello, numerosos autores, más que ofrecer una definición concreta de la misma, analizan cómo se desarrolla en las empresas mediante el estudio y la identificación de los antecedentes o factores críticos de su éxito (Tidd et al., 1997; Tang, 1998; Pavitt, 2003; Perdomo-Ortiz et al., 2006, entre otros). De esta forma, habitualmente, la capacidad de innovación se conceptualiza y mide a través de los indicadores y de las dimensiones de la innovación ${ }^{16}$ (Lawson y Samson, 2001; Calentone et al., 2002;; Pavit, 2003; Perdomo-Ortiz, et al., 2006; Terziovski, 2007). Si tenemos en cuenta, además, que una forma habitual definir la innovación es como la capacidad que permite a la organización crear, ampliar o modificar su recurso básico: el conocimiento (Helfat et al., 2007; Sáez, Aramburu y Rivera, 2009), podemos considerar que la relación entre innovación y capacidad de innovación es muy cercana y que a través de una se puede tener una aproximación de la realidad de la otra e, incluso, se puede evaluar el valor empresarial innovador a través de la capacidad de innovación de la organización (Li et al., 2006).

En consecuencia, apoyándonos en los trabajos de Calantone et al. (2002) y de Terziovski (2007), en este trabajo conceptualizamos la capacidad de innovación como la habilidad colectiva de una organización para transformar el conocimiento en mejoras a través del desarrollo de nuevos productos-servicios, procesos o sistemas organizativos, con el propósito de beneficiar a la empresa y a su competitividad.

Para cerrar este apartado, queremos destacar la naturaleza estratégica de la capacidad de innovación, como fuente potencial de ventaja competitiva sostenible (Calantone et al., 2002; Perdomo-Ortiz et al., 2006). Las empresas que desarrollan su capacidad de innovación podrán satisfacer las necesidades de sus clientes, ofreciendo productos adaptados a sus demandas, y serán capaces de desarrollarlos más rápido y más eficientemente que la competencia, lo que permite lograr ventaja competitiva, mejores

\footnotetext{
${ }^{16}$ La capacidad de innovación, a menudo, se mide a través del desempeño innovador de la organización y viceversa.
} 
desempeños y mejores resultados (Nonaka y Takeuchi, 1995; López-Cabrales et al., 2009, 2006).

\subsection{Resultados de las personas y resultados empresariales}

Como ya ha sido señalado, existen diversas variables de resultado que median en la relación entre la gestión de recursos humanos y los resultados empresariales (Guest, 1997; Appellbaum et al., 2000; Delery y Shaw, 2001; Paul y Anhataramn, 2003; Way y Johnson 2005; Boselie et al., 2005; Sun, Aryee y Law 2007; Tremblay et al., 2010, entre otros). Junto a la capacidad de innovación, nuestro modelo distingue otros dos tipos de variables de resultado que, además, tendrán relación causal entre ellas: una variable de carácter intermedio -los resultados de las personas- y otra variable de carácter final- los resultados empresariales-.

La variable de resultados de las personas se refiere a medidas del comportamiento laboral de los empleados desarrollado como consecuencia, directa o indirecta, de la gestión de recursos humanos llevada a cabo en dicha organización. Nos referimos a ellos como resultados intermedios puesto que condicionan el grado de consecución de objetivos y resultados financieros. Así, los resultados de las personas más habitualmente utilizados en la investigación en recursos humanos son el absentismo, la rotación voluntaria, la satisfacción laboral, la productividad, el nivel de desempeño, el buen clima laboral o la presencialidad, entre otros (Guest, 1997; Paauwe y Richardson, 1997; Guthrie, 2001; Sun et al., 2007; Tremblay et al., 2010). En concreto, en este trabajo definimos los resultados de las personas como la variable de resultado intermedio que recoge el nivel de desempeño, comportamientos laborales y satisfacción de los empleados, a través del índice de satisfacción laboral, el nivel de desempeño y de productividad, la tasa de abandono voluntario y la tasa de absentismo laboral.

Por último, los resultados empresariales indican el éxito que la organización alcanza en el mercado y recoge medidas del resultado de sus actividades medido, principalmente, en términos financieros y de mercado. Los estudios revisados en el ámbito de la gestión de recursos humanos, habitualmente, miden el impacto final de esta función a través de medidas como la rentabilidad económicas, la cuota de mercado, los beneficios, la satisfacción del cliente, el desarrollo de productos, el ratio de crecimiento de ventas, etc. 
(Dyer y Reeves, 1995; Delery y Doty, 1996; Batt, 2002; Paauwe y Richardson, 1997; Boselie et al., 2005; Shaw et al., 1998, 2005). Además, en este trabajo, la variable resultados empresariales también incluye un componente relativo al grado de innovaciones introducidas en el mercado y al esfuerzo innovador realizado por la empresa, puesto que estas medidas revelan el éxito que la empresa pueda estar alcanzando en el mercado (DeCarolis y Deeds, 1999; Smith, Collins y Clark, 2005; Chow y Gong, 2010), tal como se recoge investigaciones centradas en colectivos de empresas innovadoras o intensivas en conocimiento (Gong y Chow, 2010). Por tanto, en esta investigación definimos los resultados empresariales como la variable de resultado final que recoge el nivel de desempeño financiero y de mercado de la organización, a través de sus ventas, cuota de mercado, rentabilidad económica y resultados de su esfuerzo innovador.

Con estas definiciones, hemos presentado las seis variables dependientes del modelo de esta investigación: capital intelectual, capital social, capital afectivo, capacidad de innovación, resultados de las personas y resultados empresariales. A continuación, definimos las variables independientes (prácticas de recursos humanos orientadas a la retención de empleados clave), antes de cerrar este capítulo con la definición y justificación de las hipótesis y subhipótesis del trabajo.

\subsubsection{Variables independientes del modelo: prácticas de recursos humanos orientadas a la retención del capital humano de la organización}

El modelo que proponemos en la presente investigación incluye diversas prácticas de recursos humanos como variables independientes del mismo. Como hemos recogido en el capítulo anterior, se pueden identificar diversas clasificaciones de las prácticas de recursos humanos. Algunas de las más habituales son el criterio de alto desempeño o la diferenciación entre prácticas de control o de compromiso (Arthur, 1992; Huselid, 1995; Delery et al., 1997; Wright y Boswell, 2002). En nuestro caso, queremos identificar y clasificar aquel conjunto de prácticas de recursos humanos que permitan mejorar la retención del capital humano de la organización. Para ello, no podemos pasar por alto que la retención implica lograr estabilidad en la relación de empleo, es decir, que la 
relación de empleo se mantenga en el tiempo de forma voluntaria. Para lograrlo, ambas partes (empresa y empleado) deben sentirse satisfechas con dicha relación.

Puesto que la relación de empleo demandada en la actualidad (Tsui y Wu, 2005; Hom, Tsui et al., 2009) incluye, no sólo la faceta tradicional de intercambio de la relación de empleo (dimensión transaccional), sino también una faceta relacional que recoge la dimensión social-relacional del empleado, nuestra propuesta de prácticas de recursos humanos distingue entre dos tipos de prácticas, aquéllas de naturaleza transaccional y aquéllas de naturaleza relacional, como hemos anticipado previamente al final del capítulo primero. De este modo, continuamos en la senda abierta por otras investigaciones que sugieren, directa o indirectamente, aplicar la distinción entre prácticas de naturaleza relacional y prácticas de naturaleza transaccional (Alvesson, 2000; Lengnick-Hall y Lengnick-Hall, 2003; Hislop, 2005; Morris, Snell y Lepack, 2005; Gould-Williams y Davies, 2005; Kang, Morris y Snell, 2007; Tremblay et al., 2010; Wan Ismail et al., 2010).

Debemos señalar que el soporte teórico de esta clasificación se apoya en el enfoque del contrato psicológico, que distingue entre contrato o relación de empleo transaccional y relacional (Rousseau, 1990; McDonald y Makin, 2000; Morrison y Robinson, 1997; Guest, 1998; 2004) y su vinculación con la relación de empleo. Por un lado, sabemos que aquellos empleados que no perciben su relación de empleo como completa y que consideran que la organización no les ofrece las recompensas prometidas o esperadas, tienen una gran probabilidad de abandonar de forma voluntaria la organización (Robinson y Morrison, 1995; Shore et al., 1998). Y por otro lado, la relación de empleo actual va más allá de lo recogido formalmente en el contrato de trabajo (Tsui y Wu, 2005) e incorpora aspectos tanto transaccionales como relacionales. Así, los contratos transaccionales son aquellos en los que el nivel de lealtad y compromiso del empleado es limitado y la relación de empleo se analiza, básicamente, en términos económicos y mediante el análisis de las contribuciones que realiza cada parte según lo pactado en contrato. Por el contrario, los contratos relacionales se desarrollan cuando existe un sentido de "ajuste” a la organización y la lealtad y el compromiso estás presentes de forma significativa en los empleados. En este tipo de relación existe un fuerte 
componente emocional y el empleado manifiesta satisfacción con las relaciones que desarrolla en el seno de la organización, relaciones con sus compañeros, con sus superiores, sus subordinados e, incluso, con la propia organización.

Las consideraciones previas, junto a la revisión de la literatura específica de retención, nos permiten proponer un conjunto de prácticas de recursos humanos agrupadas, por tanto, en dos categorías. Por un lado, las prácticas de naturaleza transaccional, que son aquéllas que favorecen la estabilidad en la relación empleado-empleador, satisfaciendo la dimensión transaccional de su relación de empleo. En esta categoría incluimos aquellas ampliamente validadas en la literatura de retención: el diseño del puesto de trabajo, la retribución, el desarrollo del empleado y las medidas de conciliación de vida laboral-personal. Y, por otro lado, las prácticas de naturaleza relacional, que son aquéllas que favorecen la estabilidad de las relaciones del empleado dentro de la organización, satisfaciendo la dimensión relacional de su relación de empleo. En esta categoría incluimos: el soporte del supervisor, la comunicación interna, la participación del empleado y las relaciones internas de apoyo entre compañeros. A modo de resumen, la Tabla 2.1 recoge las prácticas de retención de recursos humanos que proponemos en este trabajo, y que definiremos con mayor detalle a continuación.

Tabla 2.1. Prácticas de recursos humanos propuestas

\begin{tabular}{|c|c|c|}
\hline $\begin{array}{c}\text { PrÁcticas } \\
\text { DE }\end{array}$ & $\begin{array}{l}\text { TRANSACCIONALES } \\
\text { Favorecer relaciones estables } \\
\text { empleado-empleador } \\
\text { Satisfacción de contrato tradicional }\end{array}$ & $\begin{array}{l}\text { Diseño del puesto de trabajo } \\
\text { Retribución } \\
\text { Desarrollo profesional (formación y } \\
\text { promoción) } \\
\text { Conciliación vida laboral-personal }\end{array}$ \\
\hline $\begin{array}{l}\text { RECURSOS } \\
\text { HUMANOS }\end{array}$ & $\begin{array}{c}\text { RELACIONALES } \\
\text { Favorecer relaciones internas } \\
\text { estables y satisfactorias } \\
\text { Satisfacción de contrato relacional }\end{array}$ & $\begin{array}{l}\text { Soporte del supervisor } \\
\text { Comunicación interna } \\
\text { Participación del empleado } \\
\text { Relaciones internas de apoyo entre } \\
\text { compañeros }\end{array}$ \\
\hline
\end{tabular}




\subsubsection{Prácticas de recursos humanos de naturaleza transaccional}

Como acabamos de anticipar, entre las prácticas de recursos humanos de naturaleza transaccional, consideramos las siguientes: diseño de puesto de trabajo, retribución, desarrollo profesional del empleado y medidas de conciliación de vida laboral-personal. Estas prácticas favorecen la estabilidad en la relación empleado-empleador mediante la satisfacción del contrato de empleo transaccional (Rousseau, 1990; Morrison y Robinson, 1997) puesto que cada parte intercambia “algo”, esperando poder satisfacer su propia función de utilidad.

La nueva relación de empleo (Tsui y Wu, 2005) apunta hacia la demanda de un mayor abanico de comportamientos por parte de la organización y de un mayor compromiso con los empleados, ofreciéndoles diversos incentivos como contrapartida a sus contribuciones más significativas (Stewart, 1998; Tsui y Wu, 2005). Para ello, las organizaciones pueden valerse de prácticas de recursos humanos que transmitan a los empleados la idea de que se invierte en su desarrollo. De este modo, los empleados se sienten valorados por su empresa, generándose en ellos el deseo de corresponder de forma recíproca a través, por ejemplo, de su permanencia y/o de altos niveles de desempeño. En consecuencia, se logra potenciar la retención y favorecer comportamientos que mejoren el resultado organizativo (Shipton et al., 2005,2006; Kang et al., 2007) lo que, en última instancia, se traduce en satisfacción para ambas partes de la relación de empleo.

Determinadas prácticas de recursos humanos como el diseño de puesto de trabajo retadores e interesantes, la retribución contingente basada en el desempeño, los incentivos, las oportunidades de aprender habilidades valiosas, el desarrollo de carrera profesional y las medidas de conciliación laboral-personal, contribuyen a desarrollar relaciones fuertes, estables y satisfactorias entre empleado y organización (Leana y Van Buren, 1999; Roehling, Cavanaugh, Moynihan y Boswell, 2000; Griffeth y Hom, 2001, 2004; Thomson y Heron, 2005). Estas prácticas atienden a lo que la organización, como empleador, puede ofrecer formalmente al empleado, quedando incluso, recogido de forma expresa en su relación contractual. Veamos, a continuación, la definición que proponemos en este trabajo para cada una de estas prácticas con mayor detalle. 


\section{Diseño del puesto de trabajo}

El diseño y características del puesto es una de las prácticas ampliamente contrastada como favorecedora de la retención (Mobley et al., 1979; Price y Mueller, 1981; Hom y Griffeth, 1995; Peterson, 2004). El trabajo en el que se soportan la mayoría de los estudios empíricos que lo evidencian es el modelo de las características del puesto de trabajo de Hackman y Oldham $(1976,1980)^{17}$, según el cuál determinadas características del puesto de trabajo hacen que el empleado se sienta más satisfecho laboralmente, favoreciéndose, así, su retención en la empresa. Una propuesta mejorada del modelo básico de Hackman y Oldham es el "enriquecimiento del puesto de trabajo", que se destaca como una de las vías más potentes para retener el capital humano (McEvoy y Cascio, 1985; Price y Mueller, 1981, 1986; Hom y Griffeth, 1995; Griffeth y Hom, 2001; Osca y Urien, 2001, Boselie y Wiele, 2002; Horwitz et al., 2003; Dockel, 2003; Vaiman, 2004; Buck y Watson, 2005; Bhatnagar, 2007; entre otros).

El enriquecimiento del puesto de trabajo (Griffeth y Hom, 2001; Boselie y Wiele, 2002; Horwitz et al., 2003; Dockel, 2003) consiste en el diseño de puestos en los que se ofrezca autonomía, requieran de la aplicación de complejas y variadas habilidades y conocimientos, supongan un reto para el empleado y se realicen tareas diversas y no repetitivas. Ésta es la práctica concreta que proponemos estudiar en este trabajo.

\section{Retribución}

Otra de las prácticas de recursos humanos que forman parte de la relación contractual entre empleado y empleador es la retribución. La retribución es considerada un elemento clave en la motivación y satisfacción laboral de los empleados, y refleja la valoración que la empresa realiza de sus empleados, influyendo en el nivel de satisfacción con la relación de empleo. Es el componente contractual básico de cualquier relación de empleo puesto que recoge la principal contraprestación que recibe un empleado por trabajar para un empleador (organización) (March y Simon, 1958).

\footnotetext{
${ }^{17}$ El Modelo de las características o dimensiones del puesto de trabajo de Hackman y Oldham (1980) identifica cinco dimensiones clave: 1) la variedad de habilidades-destrezas empleadas, 2) la identidad de la tarea, 3) el grado de impacto de su trabajo sobre otros trabajos, personas, etc., 4) grado de autonomía en su puesto y 5) la existencia de feed-back, información sobre los resultados y tareas realizadas en su trabajo. (Véase Figura A2.11 del Anexo II de este trabajo).
} 
Como se ha hecho notar en el capítulo primero, la evidencia de la influencia que la retribución puede ejercer sobre la retención de empleados, es muy notable (March y Simon,1958; Price, 1977; Mobley et al, 1979; Martin et al, 1979; Bluedorn, 1980; Price y Mueller, 1981; Hulin, et al., 1985; Hom y Griffeth, 1995; Luna y Camps, 2003, Shaw et al.,1998; Davies et al., 2001; Boselie y Wiele, 2002; Hom y Griffeth, 2004; Buck y Watson, 2005; Cho et al., 2005; entre otros). En concreto, cabe destacar la influencia, especialmente significativa, de algunas componentes de la retribución entre las que podemos destacar las siguientes: la retribución contingente o variable, es decir, aquélla que se concede en función del nivel de desempeño alcanzado por el empleado (Williams y Livingstone, 1994; Allen y Griffeth, 2001; Lazear, 2004; Chawdla, 2004, 2005); la retribución que cumple con los principios de equidad retributiva interna y externa (Hom y Griffeth, 1995; Whitener, 2001); la transparencia del sistema de retribución, cuando éste es un sistema conocido por todos los empleados (Hom y Griffeth, 1995; Horwtiz et al., 2003); la presencia de múltiples incentivos (Lazear, 2004) y la inclusión de beneficios sociales en el paquete retributivo ofrecido por la organización (Gomez-Mejia y Balkin, 1992a; Hom y Griffeth, 1995; Guthrie, 2000; Fay y Thompson, 2001; Rynes et al., 2004). Todas estas formas retributivas, que acabamos de citar, son algunas de las que cuentan con una mayor evidencia empírica en la literatura de retención y que veremos con mayor detalle en el desarrollo de las hipótesis de este trabajo.

En concreto, en esta investigación, proponemos estudiar un sistema de retribución que integre los criterios de equidad retributiva externa (salario superior a la competencia), equidad retributiva interna (retribución equitativa entre puestos similares), que incluya incentivos contingentes en función del desempeño individual, grupal y/u organizativo y que, además, incorpore alguna componente de beneficio social.

Desarrollo profesional del empleado

Como sabemos, las empresas cuentan con diversas prácticas para favorecer el desarrollo profesional del empleado (Gómez-Mejía et al., 2001). En concreto, en este trabajo decidimos profundizar en la formación y en la promoción puesto que la evidencia nos muestra que empleados insatisfechos, en el momento presente, pueden optar por no 
abandonar su organización si perciben posibilidades de desarrollo profesional en el futuro, permaneciendo, por tanto, en la organización (Hom y Griffeth, 1995). Este desarrollo futuro dependerá de las posibilidades de promoción que pueda ofrecer la empresa y de la adquisición, o mejora, de competencias y habilidades que puedan llevar a cabo los empleados mediante la formación a la que puedan acceder en su empresa. Por ello, consideramos que estas dos prácticas de desarrollo profesional (formación y promoción) pueden favorecer la satisfacción laboral y, por ende, la retención y la estabilidad de la relación laboral empleado-empleador. Además, la formación y las posibilidades de promoción son prácticas que, al realizarse de forma unilateral por la organización, pueden percibirse por los empleados como una muestra de la valoración positiva que la empresa realiza de ellos. Éstos, en reciprocidad, desarrollan un mayor compromiso organizativo, mejoran su desempeño e incrementan su deseo de permanencia en la misma.

Tanto las posibilidades de promoción como la formación han recibido una importante atención por parte de los investigadores de recursos humanos (March y Simon, 1958; Bluedorn, 1980; Price y Mueller, 1981; Abelson y Baysinger, 1984; Jackosky, 1984; Delany y Huselid, 1996; Delery y Doty, 1996; Shaw et al., 1998; Rhoades y Eisenberger, 2002; Tansky y Cohen , 2001; Saporta y Farjoun, 2003; Luna y Camps, 2003; Allen, Shore y Griffeth, 2003; Benson et al., 2004; Reynolds Merritt y Gladstein, 2004; Peterson, 2004, 2005; Cho y Woods, 2005; Celeste y Brotheridge, 2005; Mattox y Jinkerson, 2005; Hirschfeld , 2006; entre otros), quienes han logrado evidenciar su influencia positiva sobre la satisfacción laboral y sobre la retención de empleados, como veremos en el desarrollo de las hipótesis. En estos trabajos se pueden identificar un amplio abanico de tipos de formación, como son: formación específica o intensiva, polivalente, transversal, de acogida, en habilidades, de equipo o para el puesto, entre otras; y, también, diversas modalidades de promoción en la empresa: promoción basada en la antigüedad, promoción basada en el desempeño, promoción realizada a través de un sistema formal o informal, sistema de promoción conocido u oculto, etc.

En esta investigación evaluaremos la influencia de aquella formación que incorpore actividades de formación de acogida junto con una formación que incluye tanto 
formación intensiva como extensiva ${ }^{18}$. Una formación con estas características facilita que el empleado pueda adaptarse a la organización, acometa eficientemente su puesto de trabajo y adquiera competencias que lo hagan más versátil y empleable (Galunic y Anderson, 2000; Celeste y Brotheridge, 2005; Benson, 2006). En relación con la promoción, queremos estudiar el efecto de la existencia de posibilidades de promoción, caracterizadas por estar recogidas formalmente y basadas en el desempeño de los empleados.

Medidas de conciliación entre la vida laboral y personal

Otras de las prácticas que las organizaciones pueden aplicar para favorecer la satisfacción de sus empleados con la relación de empleo son aquéllas que minimicen el conflicto que pueda surgir entre los requerimientos de la vida laboral y de la vida personal de un empleado, puesto que la actividad que éste desarrolla en una de ambas esferas puede afectar negativamente al desarrollo de su actividad en la otra (Grover y Croker, 1995). En este sentido, hay que señalar que la incorporación de la mujer al trabajo ha conllevado una redistribución de tareas y reasignación de responsabilidades en las unidades familiares que, junto con el incremento de la demanda de tiempo para dedicar a la vida personal que solicitan los empleados, está fomentando el desarrollo de nuevos sistemas de organización del trabajo y de gestión de recursos humanos que se concentran en las denominadas medidas de conciliación (Hom y Griffeth, 1995; Griffeth y Hom, 2001; Arthur, 2001; Griffeth y Hom, 2001; Dockel, 2003; Lazarova, 2004; Peterson, 2007; Ahuja et al., 2007). Algunas de las medidas de conciliación más habituales son: los permisos de maternidad y paternidad, servicios de apoyo al cuidado de hijos y familiares dependientes, horarios de trabajo flexibles, teletrabajo, permisos laborales para atender asuntos personales, etc. (Grover y Croker, 1995; Arthur, 2001; Pasamar y Valle, 2011).

Queremos hacer notar que, aunque la mayoría de las medidas de conciliación se han concebido pensando en empleados con familia, nuestra propuesta de medidas de

\footnotetext{
${ }^{18}$ La formación intensiva recoge la formación orientada al desarrollo de las competencias específicas de su puesto y propias de su empresa. La formación extensiva, es aquélla orientada a la formación de habilidades, de carácter interdisciplinar y polivalente que ofrece al empleado la adquisición de conocimientos y habilidades aplicables a puestos de trabajo diferentes del suyo y a otras empresas.
} 
conciliación se referirá a medidas dirigidas a todo tipo de empleados. Por ello, utilizamos el término conciliación vida laboral-personal, y no el más restrictivo de conciliación laboral-familiar, en línea con la senda iniciada por otros autores como Casper et al. $(2007)^{19}$. En consecuencia, en este trabajo consideramos que las prácticas de conciliación entre vida laboral-personal recogen prácticas como la flexibilidad horaria, las facilidades temporales para atender asuntos personales $\mathbf{y}$ diversas ayudas económicas.

\subsubsection{Prácticas de recursos humanos de naturaleza relacional}

Entre las prácticas de recursos humanos de naturaleza relacional, en este estudio consideramos las siguientes: soporte del supervisor, comunicación interna, participación del empleado y relaciones sociales con los compañeros. Estas prácticas son coincidentes en cuanto a favorecer y dar estabilidad a las relaciones internas en las que participan los empleados, influyendo, de este modo, positivamente en la satisfacción del contrato relacional de los mismos (Rousseau, 1990; Morrison y Robinson, 1997).

Como hemos expuesto con anterioridad, la relación de empleo va más allá de lo recogido formalmente en el contrato de trabajo (Rousseau, 1989, 1990; Robinson y Rousseau, 1994). El empleado actual percibe su relación de empleo de una forma amplia, valorando un número de aspectos mayor que los recogidos formalmente en su contrato de trabajo (dimensión transaccional) como pueden ser, por ejemplo, las relaciones que desarrollan en la organización (Rousseau, 1989, 1990; Robinson y Rousseau, 1994; Tsui y Wu, 2005; Hom, Tsui et al., 2009). Esto se debe a que la persona, como ser social, tiene motivaciones de índole psicosocial y, por ende, el desarrollo de relaciones y vínculos sociales satisfactorios repercute en su satisfacción laboral afectando, en última instancia, a su intención de permanencia en la organización (Hom y Griffeth, 1995).

En base a las consideraciones previas, las relaciones de empleo actuales (Tsui y Wu, 2005; Hom, Tsui et al., 2009) evidencian la necesidad de satisfacer, no sólo la esfera

\footnotetext{
${ }^{19}$ Casper et al. (2007) evidencian la influencia positiva de las medidas de conciliación en empleados solteros sin hijos y defienden la necesidad de incluir a este colectivo de empleados en el ámbito de aplicación de las medidas de conciliación.
} 
transaccional sino, también, la esfera relacional del empleado. Con este fin, las organizaciones tratan de favorecer el desarrollo de relaciones sociales estables y satisfactorias por parte de sus empleados, tanto con la organización como con sus compañeros y con sus superiores (Leana y Van Buren, 1999). Para ello, pueden aplicarse diversas prácticas de recursos humanos, entre las que seleccionamos: la comunicación interna, la participación del empleado, el soporte del supervisor y las relaciones sociales entre compañeros. A continuación, describimos con detalle cómo conceptualizamos estas cuatro prácticas en la presente investigación.

\section{Comunicación interna}

La comunicación interna incluye aquellas acciones mediante las que las organizaciones proporcionan información a sus empleados (relativa a objetivos organizativos, a la estrategia, a los resultados financieros, a los éxitos de los empleados o equipos, etc.), les ofrecen vías para comunicarse con otras secciones de la organización y les conceden la oportunidad de expresarse; todo ello canalizado a través de diversos medios como la intranet, los tablones de anuncios, las revistas de empresa, diversos tipos de reuniones o asambleas, etc. (Gómez-Mejía et al., 1997, 2001; Ng et al., 2006). Se pueden distinguir diferentes tipos de comunicación interna. Basándonos en Gómez-Mejía et al. (2001) podemos diferenciar entre comunicación vertical -ascendente o descendente-, comunicación horizontal y comunicación informal ${ }^{20}$.

A través de las prácticas que favorecen la comunicación interna, los empleados perciben un esfuerzo de transparencia y de acercamiento hacia ellos (acto positivo por parte de la organización) quién demuestra la confianza que deposita en ellos permitiéndoles comunicarse, informándoles y ofreciéndoles el acceso a información sensible, de este modo se logra favorecer la relación entre empleados y entre empleado y organización, generando afectos positivos y comportamientos favorables hacia la propia organización

\footnotetext{
${ }^{20}$ La comunicación vertical descendente es la que permite a los directivos y mandos aplicar sus decisiones e influir sobre los empleados que están en niveles inferiores de la jerarquía. Comunicación vertical ascendente es la que permite a los empleados comunicar sus ideas y sentimientos a quienes toman las decisiones en niveles jerárquicos superiores al suyo. Comunicación horizontal es aquélla que se da entre empleados de mismo nivel jerárquico. Finalmente, la comunicación informal alude al intercambio de información, sin una agenda planificada, que se produce de modo espontáneo entre los empleados (Gómez-Mejía et al., 2001).
} 
(Eisenberger et al., 1990; Wayne et al., 1997; Chew, 2004). Todo lo cuál, favorece la satisfacción del contrato relacional y la retención de empleados (Price, 1977; Bluedorn, 1980; Price y Mueller, 1981; Abelson y Baysinger, 1984; Beckert y Huselid, 1998; Boselie y Wiele, 2002; Minbaeva, 2003; Griffeth y Hom, 2004; Choo, Woods y Mayer, 2005; Garder, Moynihan y Wright, 2007; Paré y Tremblay, 2007; Ng y Butts, 2009, entre otros), como veremos con mayor detalle en el desarrollo de las hipótesis.

En concreto, en este trabajo consideramos la comunicación interna como la práctica que desarrolla actividades conducentes a informar a los empleados sobre aspectos clave de la empresa, a facilitar canales de comunicación entre diversas secciones de la organización, como vías para que fluya la información y a facilitar, asimismo, la comunicación con los superiores.

Participación del empleado

La participación del empleado es otra de las prácticas mediante las que se fortalece la relación entre empleados y organización. Abarca diversas medidas con las que los empleados tienen la oportunidad de contribuir con sus conocimientos y habilidades al éxito de la organización, como pueden ser la participación en la toma de decisiones, el trabajo en grupos de mejora y en grupos de resolución de problemas o la participación en sistemas de sugerencias o quejas, con el fin de contribuir a la mejora de los procesos, productos o servicios de la organización a la que pertenecen (Gómez-Mejía et al., 2001).

Estas medidas trasladan a los empleados el mensaje de que la empresa los valora y los tiene en consideración, favoreciendo, en reciprocidad, una actitud y comportamiento positivo hacia la organización (Eisenberger et al., 1990; Rhoades y Eisenberger, 2002). De este modo, la relación empleado-empleador se fortalece, lo que según la evidencia empírica, favorece la retención del empleado (March y Simon, 1958; Abelson y Baysinger, 1984; Arthur 1994; Huselid, 1995; Delery y Doty, 1996; Shaw et al., 1998; Holtom et al., 2001; Naggiar, 2001; Guest, 2002; Buck y Watson, 2002; Boselie y Wiele, 2002; Peterson, 2004; Celeste y Brotheridge, 2005; Sun, Aryee y Law, 2007; Gardner et al., 2007, entre otros), como veremos, con más detalle, en el aparatado de hipótesis de este trabajo. 
En concreto, consideramos la participación del empleado como una de las prácticas de recursos humanos que satisface el contrato relacional del empleado al permitir a los empleados la toma de decisiones, facilitar que puedan realizar sugerencias en aspectos relativos al trabajo o a la organización y fomentar su participación en grupos de trabajo orientados a la mejora o a la resolución de problemas.

Soporte del supervisor o del superior jerárquico ${ }^{21}$

Una de las facetas de la relación de empleo con mayor repercusión sobre la satisfacción laboral del empleado es, sin lugar a dudas, la relación que desarrolle con sus superiores jerárquicos (Chawla, 2005). Esto se debe a que los empleados tienden a personalizar a la organización, es decir, conciben los actos de los agentes de la organización -especialmente los superiores- como acciones de la propia organización (Levinson, 1965). En consecuencia, el estilo de liderazgo, el trato, el soporte, la ayuda, el apoyo y el reconocimiento que los superiores otorguen a sus subordinados, será interpretado por éstos como símbolo del trato que les confiere la propia organización, en función de la valoración que ésta hace de sus contribuciones. Por esta razón, el establecimiento de relaciones satisfactorias con los superiores se traduce en satisfacción con la relación de empleo y, por ende, en el desarrollo de comportamientos que la organización valore positivamente (Rhoades et al., 2001; Rhoades y Eisenberger, 2002).

Como veremos en la justificación de hipótesis, numerosos trabajos ofrecen evidencia empírica de la importancia de la relación superior-subordinado ${ }^{22}$ en la retención de empleados así como en su nivel de desempeño y en su grado de implicación con la empresa (Mobley, 1982; Graen y Scandura, 1986; Graen et al., 1977; 1982; Bartlett, 2001; Griffeth y Gaertner, 2001; Lambert et al., 2001; Hom y Griffeth, 1995; Griffeth y

\footnotetext{
${ }^{21}$ En esta tesis doctoral utilizaremos indistintamente los términos supervisor o superior jerárquico para referirnos a la persona que ocupa un puesto jerárquico superior a un conjunto de empleados. Habitualmente, también se denominan mandos o jefes.

${ }^{22}$ La teoría del soporte organizativo ofrece apoyo teórico para comprender las repercusiones positivas de la relación y trato que tanto la organización como el supervisor ofrecen al empleado (Eisenberger et al, 1986; Rhoades y Eisenberger, 2002) También, la teoría del intercambio líder-empleado (Graen et al., 1977; 1982) ofrece amplio soporte para comprender las implicaciones de una buena relación entre subordinado y superior.
} 
Hom, 2001; Rhoades y Eisenberger, 2002; Chawla, 2005; Jawahar y Hemmasi, 2006; Dockel et al., 2006; Peterson, 2007; Paré y Tremblay 2007, entre otros).

Teniendo en cuenta estas consideraciones, proponemos estudiar un estilo de relación entre superiores jerárquicos y subordinados en la que los primeros ofrezcan soporte y apoyo a los segundos, garantizando, así, una relación satisfactoria entre ambos. Por ello, definimos este tipo de relación de apoyo entre líder y subordinado como aquella en la que los supervisores sean accesibles para los empleados a su cargo, muestren interés por el desarrollo de dichos empleados, atiendan sus necesidades y valoren y reconozcan el trabajo de sus subordinados.

Relaciones internas de apoyo entre compañeros

La faceta relacional del empleado no sólo se conforma a través de su relación con la organización y con los superiores, sino que, también, se desarrolla a través de las relaciones que lleve a cabo con sus compañeros. La relación con los compañeros y el trato que se confieran unos a otros influyen en la satisfacción de la faceta relacional de la relación de empleo, favoreciendo que los empleados permanezcan en sus empresas debido, en parte, a estas relaciones satisfactorias (Clark, 2001; Chew, 2004). De hecho, las organizaciones tienen la capacidad de habilitar entornos y formas de trabajo que favorezcan las relaciones, soporte y apoyo entre compañeros de trabajo, a través de su cultura, su forma de gestión, del trabajo en equipo, o de la organización de eventos formales e informales, así como, a través de las conductas en las que se manifieste apoyo y compañerismo entre empleados (Chew, 2004; Mossholder et al., 2005). Este apoyo proviene del cuidado, asistencia y consideración recibido de los compañeros, que provoca la necesidad de actuar de forma recíproca e, incrementa, el compromiso hacia ellos y hacia la organización en su conjunto (Meyer y Allen, 1997; Mossholder, Setton y Henagen, 2005). La satisfacción con las relaciones desarrolladas con los compañeros, mejora la satisfacción con la relación de empleo (Fass, Bishop y Glissmeyer, 2007) y, en consecuencia, estos empleados tienden a permanecer en la organización debido, al menos en parte, a la buena relación que han establecido con sus compañeros de trabajo (Clark, 2001; Mossholder et al., 2005). 
Como veremos en las hipótesis, diversos trabajos del ámbito de investigación de recursos humanos y de la retención, han evidenciado que aquellos empleados que desarrollan fuertes relaciones con sus compañeros de trabajo tienden a permanecer en sus empresas (Mobley et al., 1979; Hom y Griffeth, 1995; Maerzt y Campion, 1998; Mitchell et al., 2001; Lambert et al., 2001; Friedman y Holtom, 2002; Luna y Camps, 2003; Peterson, 2004; Mossholder, Setton y Henagen, 2005; Hom, Tsui et al., 2008; Bateman, 2009, entre otros).

Teniendo en consideración los argumentos previos, en este trabajo queremos estudiar la influencia de las prácticas que favorecen las relaciones internas de apoyo entre empleados mediante la realización de actividades sociales fuera del ámbito laboral, facilitando lugares de relación y favoreciendo las conductas de compañerismo entre ellos.

Llegados a este punto, y una vez definidas tanto las variables dependientes como las variables independientes de nuestro modelo, el siguiente paso responde a nuestro interés por explorar las relaciones que se dan entre ellas, a través del planteamiento y justificación de las correspondientes hipótesis y subhipótesis de nuestro modelo. 


\subsubsection{Relaciones fundamentales entre las variables del modelo: formulación de hipótesis y subhipótesis}

En este epígrafe desarrollamos y justificamos las relaciones planteadas en nuestro modelo mediante la definición de las correspondientes hipótesis y subhipótesis.

El propósito de esta investigación es analizar la influencia de la gestión de recursos humanos sobre el resultado organizativo a través de su efecto sobre la retención del capital humano estratégico de la organización. En concreto, en el modelo planteado (Figura 2.2.) consideramos que las prácticas de recursos humanos propuestas influyen positivamente sobre el capital humano, favoreciendo su retención, como consecuencia de su efecto fortalecedor de la relación de empleo y de su papel potenciador de relaciones sociales estables y satisfactorias entre los empleados. Por otro lado, la retención del capital humano favorece la capacidad de innovación y los resultados de las personas que, en última instancia, influyen sobre el resultado empresarial. Éstas son las principales relaciones que conforman nuestro modelo de estudio, y de las que derivan las correspondientes hipótesis y subhipótesis que presentamos a continuación.

Comenzamos por las hipótesis relativas a la primera parte del modelo, abordando la influencia de las prácticas de recursos humanos sobre la retención del capital humano de la organización (intelectual, social y afectivo), dentro del cuál distinguimos dos subapartados: el relativo al impacto de las prácticas de naturaleza transaccional y el relativo al impacto de las prácticas de naturaleza relacional. En segundo lugar, abordamos las hipótesis derivadas de la relación entre el capital humano y la capacidad de innovación de la organización, así como su impacto en la variable de resultado de personas. Finalmente, exponemos las hipótesis vinculadas con el impacto de la capacidad de innovación y de los resultados de las personas sobre el resultado empresarial. La estructura de los siguientes apartados se recoge en la siguiente tabla.

Figura 2.5. Organización de las hipótesis y relaciones en este trabajo

\begin{tabular}{|c|c|c|}
\hline $\begin{array}{c}\text { Prácticas de recursos } \\
\text { humanos y capital } \\
\text { humano }\end{array}$ & $\begin{array}{c}\text { Capital humano y } \\
\text { resultados intermedios }\end{array}$ & $\begin{array}{c}\text { Resultados intermedios } \\
\text { y resultado final }\end{array}$ \\
\hline Epíg. 2.2.3.1. & Epíg. 2.2.3.2. & Epíg. 2.2.3.3. \\
\hline
\end{tabular}




\subsubsection{Relación entre las prácticas de recursos humanos y la retención del capital humano de la organización}

Las prácticas de recursos humanos orientadas a la retención del capital humano que proponemos en este trabajo, como ya hemos anticipado, se clasifican en dos grupos: transaccionales y relacionales. En primer lugar, presentamos las hipótesis y subhipótesis correspondientes a las prácticas de recursos humanos que hemos considerado transaccionales y, seguidamente a éstas, abordamos las hipótesis correspondientes a las prácticas de naturaleza relacional.

\subsection{Hipótesis relativas a las prácticas transaccionales de recursos humanos y la retención de capital humano de la organización}

Las prácticas de recursos humanos de naturaleza transaccional se caracterizan por el papel que pueden jugar en la creación y desarrollo de relaciones estables entre la organización y los empleados, por cuanto pueden lograr satisfacer lo pactado o esperado contractualmente en la relación de empleo. Además, estas prácticas transmiten a los empleados la señal de que se invierte en ellos, todo lo cuál redunda en mejoras de su retención, mejoras en el nivel de desempeño y mejoras en la motivación de estos empleados (Robinson y Morrison, 1995; Shore et al., 1998).

A continuación, enunciamos y justificamos las hipótesis que relacionan las cuatro prácticas de recursos humanos transaccionales -diseño de puesto de trabajo, retribución, desarrollo profesional del empleado y conciliación laboral-personal- con la retención de capital humano de la organización, en su triple dimensión (intelectual, social y afectiva).

\subsection{Relación entre el diseño de puesto de trabajo y la retención del capital humano de la organización}

La definición del puesto de trabajo es una de las áreas de acción clave de la función de gestión de recursos humanos debido a su relación con la satisfacción laboral del empleado (Pérez y Garrido, 1998; Spector, 1997). Como ya hemos expuesto en el capítulo anterior, el diseño del puesto del trabajo ya se incluía en los estudios pioneros sobre retención de capital humano, debido a su impacto sobre la satisfacción laboral y 
sobre la intención de abandono o de permanencia del empleado en la empresa (March y Simon, 1958; Mobley et al., 1979; Price y Mueller, 1981). Posteriormente, a través de las aportaciones del modelo de Hackman y Oldham (1976, 1980) ${ }^{23}$ se desarrolla el “enriquecimiento del puesto de trabajo” como una de las actuaciones más efectivas para retener el capital humano en la empresa, tal y como demuestra la evidencia empírica (McEvoy y Cascio, 1985; Price y Mueller, 1981, 1986; Delery y Doty, 1996; Hom y Griffeth, 1995; Griffeth y Hom, 2001; Osca y Urien, 2001, Dockel, 2003; Buck y Watson, 2005; Sun et al., 2007; Ng y Butts, 2009; Rose y Gordon, 2010; Tseng, 2010; entre otros).

Así pues, en primer lugar, proponemos una hipótesis que recoja la relación del diseño enriquecido de puesto de trabajo y la retención del capital humano, atendiendo a las tres componentes del capital humano:

Hipótesis 1: El diseño enriquecido del puesto de trabajo influye positivamente en la retención del capital humano de la organización, a través de sus dimensiones de capital intelectual, social y afectivo

Puesto el capital humano está formado por el capital intelectual, el capital social y el capital afectivo, justificaremos esta primera hipótesis atendiendo a la influencia que el diseño enriquecido de puesto de trabajo puede ejercer sobre cada uno de estos tres capitales, tal como exponemos a continuación.

Como sabemos, el diseño enriquecido de los puestos de trabajo implica el desarrollo de puestos que ofrezcan un alto grado de autonomía al empleado, que supongan un reto para la persona, que requieran de la aplicación de complejas y variadas habilidades y conocimientos y que impliquen la realización de tareas diversas y no repetitivas. Estas características hacen que los empleados que ocupan este tipo de puestos se encuentren

\footnotetext{
${ }^{23}$ Según estos autores, las principales fuentes de satisfacción del empleado son intrínsecas al trabajo y se derivan del contenido y contexto inmediato en que éste se desarrolla. Diferencian cinco dimensiones clave: 1) la variedad de habilidades-destrezas empleadas, 2) la identidad de la tarea, 3) el grado de impacto de su trabajo sobre otros trabajos, personas, etc., 4) grado de autonomía en su puesto y 5) la existencia de retroalimentación, información sobre los resultados y tareas realizadas en su trabajo. Estas dimensiones estarían correlacionadas significativamente con la satisfacción y, por tanto, potencian la motivación del empleado y su retención.
} 
más motivados y más satisfechos que otros empleados (Hom y Griffeth, 1995). Varias razones lo justifican. Por un lado, se da el hecho de que los puestos de trabajo, así configurados, resultan más atractivos por cuanto suponen un reto para el empleado. Ello implica que al empleado le supone un objetivo o empeño difícil de llevar a cabo, constituyendo un estímulo y un desafío, en sí mismo. El reto puede ser más o menos complejo y, en todo caso, supondrá superarse empleando diversas habilidades y conocimientos, lo que dará lugar a que el puesto resulte más satisfactorio y a que, en consecuencia, se favorezca la retención de los empleados que ocupan estos puestos y, por ende, la retención de su capital intelectual en la organización (Katerberg, Hom y Hulin, 1979; Price y Mueller, 1981, 1986; Dockel, 2003; Vaiman, 2004; Hislop, 2005; Bhatnagar, 2007). Por otro lado, los puestos enriquecidos permiten que el empleado aprenda y se ejercite en aplicar sus distintas capacidades y sus conocimientos. De este modo, los empleados encuentran sentido a lo que hacen, se responsabilizan de sus actividades y se sienten partícipes de los logros que consiguen y con autonomía para conseguir más (Hom y Griffeth, 1995); con ello, se favorece su deseo de permanencia en la organización (Griffeth y Hom, 2001; Boselie y Wiele, 2002; Horwitz et al., 2003; Dockel, 2003) y, por tanto, podemos deducir que, también, se favorecerá la permanencia del capital intelectual que ellos poseen. Por último, un puesto enriquecido debe otorgar un alto grado de autonomía al empleado, es decir, ofrecer relativa libertad, independencia y discreción al individuo para planificar y fijar su trabajo y los procedimientos para conseguirlo (Hackman y Oldham, 1980); todo ello favorece la satisfacción de los empleados por cuanto se sienten valorados y reconocidos, potenciando su intención de permanencia en la organización (Vaiman, 2004; Bhatnagar, 2007).

Estas características, propias de los puestos de trabajo enriquecidos, adquieren especial relevancia en el caso de empleados altamente cualificados y en empresas intensivas en conocimiento (Hislop, 2005). Así lo demuestran Swart y Kinnie (2001, 2003b) y Dockel (2003) quienes evidencian que, para este tipo de empleados, los puestos de trabajo interesantes y retadores ejercen un gran impacto positivo sobre su retención y, de forma análoga, sobre su capital intelectual. De hecho, en estos trabajos, los puestos 
enriquecidos muestran un impacto sobre la retención de empleados mayor que el provocado por los salarios elevados.

Teniendo en cuenta las consideraciones previas, estamos en disposición de formular la primera de las tres subhipótesis ${ }^{24}$ que permite relacionar el diseño de puesto y la retención del capital humano, atendiendo al impacto del diseño enriquecido de puesto sobre una de las componentes del capital humano: el capital intelectual.

Subhipótesis 1a: El diseño enriquecido del puesto de trabajo influye positivamente en la retención del capital intelectual

Como hemos comentado anteriormente, el capital social se manifiesta en los procesos en los que los empleados interaccionan unos con otros, participando en actividades en las que se comparte, transfiere, combina o aplica conocimiento. En este sentido, el diseño del puesto de trabajo puede facilitar que se lleven a cabo estas interacciones.

Gagné, Senecal y Koester (1997) relacionan las características del diseño del puesto de trabajo con la mejora de la motivación y satisfacción del empleado, variables que, a su vez, potencian el desarrollo de comportamientos que respaldan el capital social. Por su parte, Keloway y Barling (2000) señalan que el diseño del puesto puede influir en las habilidades, motivaciones y oportunidades que se ofrecen a los empleados para utilizar y mover el conocimiento en la organización. También, Gagné (2009) afirma que es precisamente su impacto en la motivación lo que justifica que el diseño enriquecido de puesto favorezca el desarrollo de comportamientos de intercambio y combinación de conocimiento, procesos que, como ya sabemos, dependen en buena medida del capital social. En este trabajo Gagné (2009) propone un modelo en el que estudia diferentes prácticas de recursos humanos, entre ellas, el diseño de puesto, y analiza su efecto sobre las motivaciones $\mathrm{y}$ actitudes de los empleados hacia los comportamientos e interacciones en los que se comparte conocimiento. De hecho, la autonomía se identifica como una de las dimensiones clave del puesto de trabajo que puede favorecer el capital social. Otros estudios apoyan de forma expresa el importante efecto de la autonomía.

\footnotetext{
${ }^{24}$ En la numeración de las subhipótesis añadimos las letras "a”, "b” o "c", para indicar que se refieren al capital intelectual, al capital social o al capital afectivo, respectivamente.
} 
Por ejemplo, Park et al. (2004) demuestran que el trabajo en equipo, el apoyo a los empleados y la autonomía en el puesto de trabajo alientan el intercambio de conocimiento. Gagné y Deci (2005), por su parte, identifican la autonomía como un importante mecanismo para influir en la motivación intrínseca de los empleados (Gagné y Deci, 2005) y que repercute en su nivel de desempeño y en su participación en procesos que sustentan el capital social (Foss, Minbaeva et al., 2009). Posteriormente, Lin (2007a) evidencia que la posibilidad de disponer de autonomía en el puesto de trabajo se relaciona positivamente con el capital social. Además, podemos suponer que este tipo de puestos enriquecidos, al suponer retos y objetivos complejos, pueden requerir de la interacción con otros empleados de la organización, favoreciendo el apoyo al capital social.

De acuerdo con todo lo expuesto en las líneas precedentes, planteamos la siguiente hipótesis acerca de la influencia que el diseño enriquecido de puesto de trabajo ejerce sobre el capital social.

Subhipótesis 1b: El diseño enriquecido del puesto de trabajo influye positivamente en el capital social

Por último, nos detenemos en la relación del diseño enriquecido de puesto con el capital afectivo. El diseño enriquecido de puesto puede ser percibido por los empleados como una acción positiva que la organización realiza fruto de la valoración y consideración positiva hacia sus empleados quienes, en reciprocidad (Gouldner, 1960), desarrollan afectos positivos hacia la organización.

Los puestos de trabajo enriquecidos permiten al empleado aplicar sus conocimientos y habilidades, aprender nuevos competencias, realizar tareas no repetitivas y asumir nuevos retos, así como gozar de autonomía para su desarrollo, por lo que suelen ser internamente satisfactorios y estimulantes para los empleados, y afectan positivamente a su nivel de satisfacción y a los afectos y emociones que puedan desarrollar hacia el propio trabajo y, por ende, hacia la organización (McEvoy y Cascio, 1985; Osca y Urien, 2001, Griffeth y Hom, 2001, Buck y Watson, 2002). Sobre este particular, Ryan y Deci (2000) demuestran que aquellos trabajos en los que se goza de autonomía están positivamente relacionados con la motivación intrínseca del empleado y que ésta se 
relaciona con la mejora del afecto hacia la organización (Foss, Minbaeva et al., 2009). Por su parte, Buck y Watson (2002) evidencian que en aquellos puestos en los que se ofrece una mayor responsabilidad y discreción a los empleados, se logra mejorar su compromiso afectivo organizativo. Recientemente, otros investigadores han aportado nuevas evidencias que respaldan la relación positiva entre el diseño enriquecido de puesto -especialmente en su dimensión de autonomía- con los afectos organizativos de los empleados (Malhotra, Galleta, y Kirsch, 2008; Gagné, Chemolli, Bosque, y Koestner, 2009).

De acuerdo con todo lo anterior, proponemos la siguiente subhipótesis, que recoge la dimensión afectiva del capital humano y su relación con el diseño de puesto de trabajo.

Subhipótesis 1c: El diseño enriquecido del puesto de trabajo influye positivamente en el capital afectivo

\subsection{Relación entre la retribución y la retención del capital humano de la organización}

Una de las prácticas de recursos humanos más extendida y utilizada es, sin lugar a dudas, la retribución. El sistema de retribución juega un papel crítico a la hora retener empleados valiosos y a la hora de motivarlos para que desarrollen altos niveles de desempeño (Gómez, Mejía, 1992; Thompson, 2001; Fay y Thompson, 2001). En concreto, de entre los diversos atributos de la retribución que se han constatado como efectivos para retener a los empleados, destacamos cuatro especialmente significativos: la contingencia, la equidad interna, la equidad externa (competitividad salarial) y los beneficios sociales (Hom y Griffeth, 1995; Allen y Griffeth, 2001; Dockel, 2003).

En conformidad, proponemos una hipótesis que recoja la relación de la retribución y la retención del capital humano, enunciando la siguiente hipótesis.

Hipótesis 2: La retribución (contingente, competitiva, equitativa y que incluya beneficios sociales) influye positivamente en la retención del capital humano de la organización, a través de sus dimensiones de capital intelectual, social y afectivo 
Atendiendo a la conceptualización de capital humano que proponemos en esta investigación, justificaremos esta segunda hipótesis teniendo en cuenta la relación de la retribución con cada una las tres dimensiones definidas: intelectual, social y afectiva, tal como desarrollamos a continuación.

Aunque la retribución es una de las primeras prácticas de recursos humanos incluidas en los modelos de retención ${ }^{25}$, es en la década de los ochenta, con los trabajos de Hulin et al. (1985), Brief y Aldag (1989) y Price y Mueller (1986), cuando se reconoce plenamente su efecto sobre la retención de empleados y, por ende, sobre la retención de su capital intelectual. A partir de este momento, la evidencia empírica ha permitido validar su influencia de varias formas. Primero, a través de variables intermedias, como la satisfacción laboral o el compromiso (Shaw et al., 1998; Davies et al., 2001; Chiu et al., 2002; Boselie y Wiele, 2002; Buck y Watson, 2005; Cho et al., 2005; Hom y Griffeth, 2004). Segundo, mediante un efecto directo (Gomez-Mejia y Balkin, 1992a; Hom y Griffeth, 1995, Shaw, 1996; Guthrie, 2000; Fay y Thompson, 2001; Rynes et al., 2004). Y tercero, en conjunto con otras prácticas, formando sistemas de prácticas influyentes en la retención de empleados (Arthur, 1994; Huselid, 1995; Delery y Doty, 1996; Guthrie, 2001; Naggiar, 2001; Paul y Anantharaman, 2003; Ferrat, et al., 2005; Ng y Butts, 2009).

Como ya hemos anticipado, los atributos de la retribución que se han constatado como efectivos para retener al capital intelectual son enormemente diversos. Entre esos atributos, centramos nuestra atención en cuatro especialmente significativos: la contingencia, la equidad interna, la equidad externa (competitividad salarial) y los beneficios sociales (Hom y Griffeth, 1995; Allen y Griffeth, 2001; Dockel, 2003).

En primer lugar, las organizaciones con sistemas de retribución contingentes-aquellos en los que una parte de la remuneración se vincula al nivel de desempeño logrado por el individuo, el grupo y/o la empresa- logran favorecer la retención de sus empleados como fruto del impacto que se ejerce sobre la satisfacción del empleado y como fruto de la percepción de seguridad laboral que desarrollan (Gómez-Mejia y Balkin, 1992a,

\footnotetext{
${ }^{25}$ Como los modelos de March y Simon, 1958; Price, 1977; Mobley et al., 1979; Martin et al., 1979; Bluedorn, 1980; Price y Mueller, 1981; Hom y Griffeth, 1995; Luna y Camps, 2003, entre otros.
} 
Hom, 1992; Williams y Livingstone, 1994 ${ }^{26}$; Allen y Griffeth, 2001; Chawdla, 2004, 2005; Rynes, Gerhart y Minette, 2004). Además, el incremento de las recompensas por el trabajo desempeñado favorece el sentimiento de reciprocidad en los empleados, haciendo que éstos manifiesten mayor predisposición a permanecer en la organización contribuyendo a la consecución de los objetivos empresariales (Ng y Butts, 2009). La retribución contingente ayuda a que los empleados tengan claras las tareas que deben realizar, lo objetivos que deben alcanzar y, a mayores, les incentiva a desarrollar las habilidades y conocimientos necesarios para desarrollar estas tareas y alcanzar dichos objetivos (Shipton et al., 2006). Asimismo, existe evidencia acerca de que la fijación de metas claras y concretas contribuye a reducir la ansiedad y el estrés laboral, ambas variables muy negativas para la retención de empleados (Griffeth y Hom, 2004).

En segundo lugar, la equidad interna -retribuir en cuantía y forma similar a puestos similares- está presente en numerosos trabajos de retención. La percepción que el empleado tiene sobre lo justo, satisfactorio y transparente que sea su sistema de retribución favorece la aceptación del mismo, mejora su satisfacción laboral y respalda la retención del capital humano (Hom y Griffeeth, 1995; Byrne, 2005; Tseng, 2010). Este argumento ha sido validado en poblaciones empresariales muy heterogéneas, como muestran el trabajo de Jones (1991) en el sector de la Administración Pública, de Luna y Camps (2003) en el ámbito español, y de Allen, Shore y Griffeth (2003) en empresas norteamericanas.

En tercer lugar, y tras la revisión sobre retención realizada en el capítulo precedente, es sabido que los empleados frecuentemente achacan a los salarios no competitivos la decisión de abandonar la organización para la que trabajan (Hom y Griffeth, 1995; Griffeh y Hom, 2004). No obstante, los salarios competitivos -salarios por encima de la media del sector-, si bien, se han demostrado muy recomendables ${ }^{27}$, no son esenciales

\footnotetext{
${ }^{26}$ Williams y Livingstone (1994) a través de un trabajo de meta-análisis, evidenciaron que los sistemas de retribución contingentes favorecían la retención del capital humano más valioso.

${ }^{27}$ Las razones por las que los empleados abandonan una organización no siempre son las que detallan en sus argumentos. Rynes, Gerhart y Minette (2004) indican que existe una gran discrepancia entre lo que los empleados dicen y hacen en relación a la importancia que le dan a la retribución. No siempre las razones que los empleados explican o justifican a la empresa, son las que realmente los conducen a abandonar la organización.
} 
para la retención de empleados. Por un lado, algunos autores demuestran que una retribución superior a la retribución media del mercado ayuda a retener a los trabajadores valiosos (Horwtiz et al., 2003; Vaiman, 2004; Huang, Lin y Chiang, 2006). Pero, por otro lado, también hay indicios para pensar que la retribución competitiva juega un papel necesario aunque no suficiente en la retención de empleados ya que, superado un cierto nivel retributivo, otros factores comienzan a ser más importantes para lograr la retención de los empleados (Kochansi y Leford, 2001; Fay y Thompson, 2001; Dockel, 2003). Estas consideraciones han propiciado que las empresas conciban sus sistemas de retribución como una práctica que debe ir más allá de un simple salario (Dockel, 2003) y, por ello, las empresas han comenzado a incluir suplementos y prestaciones adicionales como los beneficios sociales. Los beneficios sociales como, por ejemplo, los planes de pensiones, los seguros médicos, las becas para estudios, servicios de guardería, etc., son medidas que influyen positivamente en la intención de permanencia de los empleados (Hulin et al., 1985; Miceli y Lane, 1991; Milkowich y Newman, 1993; Hom y Griffeth, 1995; Vaiman, 2004) y que repercuten positivamente en la retención del capital intelectual de los empleados.

Teniendo en cuenta las consideraciones previas, proponemos que la retribución con carácter contingente -que valora el desempeño individual, grupal y empresarial-, competitiva y que cumpla con el principio de equidad interna, y que incorpore algún componente de beneficio social, podrá favorecer la retención del capital intelectual presente en los empleados valiosos de la organización, como se postula en la siguiente subhipótesis:

Subhipótesis 2a: La retribución (contingente, competitiva, equitativa y que incluya beneficios sociales) influye positivamente en la retención del capital intelectual

En lo relativo al capital social, la retribución que cada organización ofrezca a sus empleados también puede jugar un papel relevante.

La retribución es una importante fuente de motivación en el trabajo (Rynes, Gerhart y Minette, 2004) y un elemento crucial de la relación de empleo actual (Tsui et al., 1997) 
pues, de alguna manera, viene a ser un indicativo de la valoración que la organización otorga a sus empleados (Eisenberger et al., 1986, 1997).

Diversos trabajos han demostrado que las organizaciones que estimulan y reconocen las contribuciones de los empleados por medio de retribuciones contingentes o variables, logran, en efecto, motivar a dichos empleados para que realicen esfuerzos “extra” en su trabajo, es decir, comportamientos más allá de los esperados con el fin de contribuir positivamente a los resultados organizativos (Forrester, 2000; Nielsen y Pedersen, 2003; Wayne, Shore, Bommer y Tetrick, 2002; cit. en Ng y Butts, 2009). En este contexto, es de esperar que estos comportamientos "extras" incluyan la realización de tareas en interacción y relación con otros empleados de la organización, en pro de la mejora organizativa, favoreciendo, por tanto, el refuerzo de su capital social.

En relación con el impacto de la retribución contingente sobre el capital social, existen evidencias divergentes. Por ejemplo, y a nivel teórico, Leana y Van Buren III (1999) argumentan que una retribución contingente grupal a nivel colectivo puede llegar a generar comportamientos oportunistas en algunos empleados que se traduzcan en una disminución de su esfuerzo individual y de su cooperación con los demás, repercutiendo negativamente en el capital social; por contra, si los empleados interiorizan los objetivos colectivos como propios, también puede potenciar el desarrollo de comportamientos de cooperación orientados a la consecución de estos objetivos colectivos nutriendo, de este modo, su capital social. En línea con este argumento, Campbell, Campbell y Chia (1998) observan que las estrategias de retribución contingente basadas en un desempeño y objetivos individuales pueden ser inapropiadas en entornos en los que se trabaja en equipo, porque fomentan que los empleados busquen su fin personal y no que cooperen con el grupo, incidiendo negativamente sobre el capital social. Por el contrario, otros autores, como Collins y Smith (2006), evidencian que la retribución favorece la creación de un capital social que promueve los comportamientos de intercambio y combinación de conocimiento, en línea con las argumentaciones de otros autores como Kogut y Zander (1992) y Nahapiet y Ghoshal (1998). 
Así pues, en base a las consideraciones previas, enunciamos la siguiente subhipótesis que relaciona la retribución con la dimensión social del capital humano.

Subhipótesis 2b: La retribución (contingente, competitiva, equitativa y que incluya beneficios sociales) influye positivamente en el capital social

Por último, nos centramos en la relación de la retribución con el capital afectivo. Como ya hemos anticipado, la retribución refleja el modo en que la organización valora y recompensa al empleado por su trabajo. Por tanto, podrá influir sobre los afectos y actitudes que los empleados desarrollan hacia la organización (Eisenberger et al., 1990; Rhoades y Eisenberger, 2002), en función del grado de satisfacción o insatisfacción que les produzca la retribución recibida.

Por un lado, la retribución contingente, al discriminar de forma positiva a los empleados de alto rendimiento y reconocer el esfuerzo realizado, genera que, en reciprocidad, estos empleados desarrollen afectos positivos y sentimiento de vínculo hacia la organización. Además, la retribución contingente, al fijar objetivos y metas claras, guía y retribuye comportamientos y resultados concretos, logrando reducir la ambigüedad de tareas e incertidumbre sobre lo que cada empleado debe desarrollar y mejorando su compromiso organizativo (Mowday, Porter y Steers, 1982; Mathieu y Zajac, 1990). Esta relación positiva entre retribución contingente y capital afectivo también ha sido puesta de manifiesto por Gardner, Moynihan y Wright (2007), quienes consideran que este tipo de retribución muestra la evaluación positiva que la empresa realiza del empleado, que, en última instancia, mejora el afecto entre empleado y empleador.

Por otro lado, los salarios competitivos se interpretan por los empleados como una muestra de la valoración positiva de su empresa hacia ellos, reconociéndoles, de este modo, mayor valor que el que les otorgan las empresas competidoras. Esto genera actitudes y afectos positivos hacia la organización que se traducen en refuerzo de su capital afectivo (Hom y Griffeth, 1995; 2004; Rhoades, Eisenberger y Armeli, 2001; Buck y Watson, 2002; Shore y Griffeth, 2003; Hemdi y Nasurdin, 2006). Del mismo modo, los beneficios sociales también pueden ser interpretados como una muestra del 
interés de la organización por el bienestar de los empleados, lo que redunda en que, en reciprocidad, se incremente el apego hacia la empresa y se favorezca, por ende, el afianzamiento de su capital afectivo (Rhoades et al., 2001; Gardner et al., 2007).

Así pues, teniendo en cuenta las consideraciones previas, enunciamos la siguiente subhipótesis que relaciona la retribución con la dimensión afectiva del capital humano.

Subhipótesis 2c: La retribución (contingente, competitiva, equitativa y que incluya beneficios sociales) influye positivamente en el capital afectivo

\subsection{Relación entre el desarrollo profesional del empleado y la retención del capital humano de la organización}

Como ya hemos anticipado, en este trabajo nos centramos en la formación y la promoción, como prácticas de desarrollo profesional del empleado, puesto que, en la actualidad, la oportunidad de poder aprender, a través de las actividades de formación, y el desarrollo de carrera profesional, se han convertido en importantes requerimientos de los empleados hacia su relación de empleo, condicionando, por tanto, sus actitudes y sus comportamientos (Ng, et al., 2006).

Las prácticas de formación y de promoción ponen de manifiesto el interés y preocupación de la organización por sus empleados y por su desarrollo (Nadler y Nadler, 1989). Por medio de estas prácticas los empleados perciben que se invierte en ellos, puesto que, tanto a través de la formación como de la promoción, se incrementa su red de contactos, sus conocimientos, sus habilidades, sus competencias y sus capacidades. Todo ello puede repercutir de forma positiva sobre su satisfacción laboral, generando en ellos el deseo de poder actuar en reciprocidad con la empresa, lo que se traduce en una mejora de sus actitudes y comportamientos (Gouldner, 1960; Rousseau, 1989, 1990; Robinson y Rousseau, 1994; Eisenberger et al., 1986, 2002). Todo ello, en última instancia, mejora la retención del capital humano (Rose y Gordon, 2009; Tseng, 2010), favorece el desarrollo de las actitudes colaborativas entre los empleados e incrementa su nivel de desempeño (Lazarova, 2004; Kang et al., 2007). 
Por tanto, como tercera hipótesis de este trabajo, proponemos relacionar el desarrollo profesional del empleado, mediante la formación y la promoción, como práctica que favorece la retención del capital humano de la organización. En consecuencia, enunciamos la siguiente hipótesis.

Hipótesis 3: El desarrollo profesional del empleado- mediante la formación y la promoción- influye positivamente en la retención del capital humano de la organización, a través de sus dimensiones de capital intelectual, social y afectivo

$\mathrm{Al}$ igual que en las anteriores hipótesis, atenderemos a las tridimensionalidad del capital humano para justificar esta hipótesis.

En primer lugar, la formación es considerada una práctica de recursos humanos muy eficaz para favorecer la retención del capital humano, más efectiva, incluso, que los incrementos salariales y el reparto de beneficios (Arthur, 2001). La formación mejora la capacidad del empleado para realizar su trabajo y le ayuda a clarificar los objetivos a alcanzar, reduciendo el estrés laboral y la incertidumbre, y mejorando, con ello, los niveles de satisfacción y de retención (Price y Mueller, 1981; Hom y Griffeth, 1995; Dockel, 2003; Sun, Aryee y Law, 2007). Así se ha puesto de manifiesto en diversos trabajos empíricos (Delery y Doty, 1996; Shaw et al., 1998; Davies, Taylor y Savery, 2001; Boselie y Wiele, 2002; Horwtiz et al., 2003; Luna y Camps, 2003; Reynolds, Merritt y Gladstein, 2004; Benson et al., 2004; Buck y Watson, 2005; Mattox y Jinkerson, 2005; Cho et al., 2005; entre otros) que demuestran la influencia positiva que la formación ejerce sobre la retención de los empleados y, por ende, sobre la retención de su capital intelectual.

Son diversos los tipos de formación que se han contrastado como efectivos para retener el capital intelectual. Entre esos tipos destacamos como especialmente significativos a la formación de acogida, la formación intensiva y la formación extensiva ${ }^{28}$.

\footnotetext{
${ }^{28}$ La formación intensiva también puede denominarse específica, y la formación extensiva también puede denominarse como polivalente o multidisciplinar.
} 
La formación de acogida facilita el proceso de adaptación del empleado a su nuevo rol laboral. Con ella se ofrece al nuevo empleado información sobre la organización, los procesos y los procedimientos de trabajo, su puesto, su entorno laboral y sus compañeros. La formación de acogida facilita la adaptación a la organización, reduciendo el estrés inicial de incorporación y favoreciendo su deseo de permanencia (Fisher, 2001; Hom y Griffeth, 1995; Griffeth y Hom, 2001). Esta formación es especialmente relevante para mejorar la retención del capital intelectual porque es, precisamente, en este colectivo de empleados -los nuevos empleados- en los que se detectan las tasas más altas de abandonos (Mobley, 1982a, Wanous, 1980, 1992; Hom y Griffeth, 1995).

La formación específica o intensiva, orientada a dotar a los empleados de habilidades y conocimientos específicos y propios de la empresa y de su puesto de trabajo, también favorece la retención del capital humano y, por ende, de su capital intelectual. Este tipo de formación mejora la cualificación del empleado para su puesto de trabajo, permitiéndole ejecutar correctamente sus tareas y obligaciones y disminuyendo, por tanto, su nivel de frustración o estrés, factores que están asociados negativamente con la retención (Lams et al. (2002) cit. en Hemdi y Nasurdin, 2006). Además, la formación específica o intensiva, dificulta la movilidad o transferencia de los empleados a otras organizaciones, en tanto que los conocimientos adquiridos en este tipo de formación no son transferibles a otros puestos u organizaciones ${ }^{29}$. De este modo, se favorece la retención del capital intelectual en la organización (Benson, 2006) contribuyendo, además, a la creación de ventajas competitivas a través del capital humano puesto que estas habilidades son escasas, valiosas y difíciles de imitar (Grant, 1996; Lado y Wilson, 1994; Barney y Wright, 1998; Jerez-Gómez, Céspedes-Llorente y ValleCabrera, 2003).

\footnotetext{
${ }^{29}$ Tradicionalmente, éste ha sido uno de los modos de favorecer la retención "forzada" de los empleados por cuanto se cualificaba al trabajador para ser empleable en esa organización pero no en otras (Benson, 2006).
} 
Por otro lado, las empresas también necesitan que sus empleados reciban una formación polivalente o extensiva $^{30}$ (aquélla que es multidisciplinar, genérica y transferible a otros ámbitos laborales) que asegure que puedan desempeñar trabajos diversos y desarrollar múltiples tareas. Ello constituye un factor importante para la obtención de ventajas competitivas basadas en los recursos humanos (Arthur, 1994; Delaney y Huselid, 1996; Lengnick-Hall y Lengnick-Hall, 1988, 2003; Jerez-Gómez, Céspedes-Llorente y ValleCabrera, 2003). Además, a través de la formación extensiva los empleados amplían sus opciones y posibilidades de desarrollo de carrera profesional y de promoción interna. Esta posibilidad de promoción futura influye positivamente en su retención en tanto que el empleado permanecerá en la organización aspirando a tal desarrollo (Arthur, 2001; Sun et al., 2007; López-Cabrales et al., 2008). Sin embargo, debemos señalar que la formación extensiva dota al empleado de nuevos conocimientos y habilidades que facilitan su posible desarrollo de carrera tanto dentro de la propia organización como en otras organizaciones (Celeste y Brotheridge, 2005). De hecho, la formación extensiva reduce la incertidumbre de los empleados respecto a la posibilidad de encontrar otro trabajo, si fuera necesario. Este aspecto puede ser valorado positivamente por los empleados, favoreciendo su retención y la de su capital intelectual (Benson, 2006; Galunic y Anderson, 2000) $)^{31}$ aunque, por otro lado, resulta paradójico puesto que también mejora la empleabilidad de los mismos, lo que incrementa la posibilidad de que puedan o decidan abandonar la organización (Naggiar, 2001; Celeste y Brotheridge, 2005).

En segundo lugar, también la promoción influye de forma positiva en la retención de empleados, y por ende, en la retención de su capital intelectual, bien, directamente

\footnotetext{
${ }^{30}$ Algunos ejemplos son: la formación en habilidades de relación, habilidades de gestión, de liderazgo, trabajo en equipo, idiomas, etc.; en general, conocimientos y habilidades que pueden ser aplicados en otros puestos, departamentos u organizaciones.

${ }^{31}$ Numerosas empresas e investigadores sugieren que la empleabilidad puede suplantar la seguridad en el trabajo a largo plazo, como una de las bases del compromiso recíproco entre empleados y empresa (Galunic y Anderson, 2000). Para las compañías que no pueden ofrecer seguridad en el empleo a largo plazo, favorecer la empleabilidad puede ser una buena solución. Ello supone incrementar las inversiones en el desarrollo de los empleados para garantizar que los empleados tengan las habilidades necesarias para recolocarse en el mercado si, inesperadamente, se quedasen sin empleo. La lógica es que la empresa puede reducir la incertidumbre del empleado de encontrar otro trabajo, lo que favorece que los empleados sean más proclives a sentir compromiso hacia la organización y, por tanto, permanezcan en la misma (London, 1989; Tansky y Cohen, 2001; Galunic y Anderson, 2000, Benson, 2006).
} 
(Delany y Huselid, 1996; Delery y Doty, 1996) o bien, a través de su efecto sobre constructos intermedios $^{32}$ (Wayne, Shore y Liden, 1997; Allen, Shore y Griffeth, 2003; Benson et al., 2004; Cho y Woods, 2005; Peterson, 2005; Saporta y Farjoun, 2003; Luna y Camps, 2003; Rhoades y Eisenberger, 2002; Smith, 2005; Tansky y Cohen, 2001; Dockel, 2003). Es más, los empleados insatisfechos en un momento dado pueden optar por no abandonar su organización si perciben posibilidades de desarrollo profesional en el futuro (Hom y Griffeth, 1995). De hecho, las oportunidades de promoción predicen la retención de forma más significativa que otras prácticas de recursos humanos, como la retribución o la relación con el supervisor (Kochanski y Ledford (2001) cit. en Dockel, 2003). Diversos estudios señalan las oportunidades de promoción como una de las prácticas de recursos humanos más eficaces para retener el capital intelectual vinculado a los empleados clave de las organizaciones (Vaiman, 2004; Morris et al., 2005; Hirschfeld, 2006; Peterson, 2007). Sin embargo, la promoción también puede suponer un riesgo de pérdida del capital intelectual; sobre todo del capital asociado a determinados empleados valiosos. En efecto, la promoción de ciertos empleados, especialmente si se produce de forma rápida, emite una fuerte señal al mercado de trabajo acerca del alto valor de tales empleados, incrementando la posibilidad de que otras empresas traten de captarlos (Huang, Lin y Chiang, 2006).

Así pues, de acuerdo con lo expuesto en las líneas precedentes planteamos la siguiente subhipótesis acerca de la influencia positiva que puede ejercer el desarrollo profesional, a través de la formación y la promoción, en la dimensión intelectual del capital humano.

Subhipótesis 3a: El desarrollo profesional del empleado - a través de la formación y las oportunidades de promoción- influye positivamente en la retención del capital intelectual

En lo relativo al capital social, las prácticas de desarrollo del empleado también juegan un papel fundamental. Cabrera y Cabrera (2005) afirman que el desarrollo del empleado, a través de la formación y de la promoción profesional, juega un importante

\footnotetext{
32 Principalmente la satisfacción laboral, el compromiso organizativo y soporte percibido de la organización (POS) (Eisenberger et al., 1986; 2002).
} 
papel en la constitución del capital social. Su argumentación se basa en que el uso de la formación y de los programas de desarrollo incrementan el nivel de autoeficacia de los empleados (Bandura, 1997). Consecuentemente, los empleados se sienten más seguros de sus habilidades $\mathrm{y}$, por tanto, se muestran más proclives a cooperar con otros, nutriendo, de este modo, su capital social.

En concreto, Jerez-Gómez, Céspedes-Llorente y Valle-Cabrera (2003) señalan que la formación debe contemplarse en sentido amplio, y no sólo en términos de construcción de habilidades y conocimientos. Así, la formación puede proporcionar un lenguaje común y una visión compartida, facilitando la comunicación entre empleados y los procesos de colaboración en los que éstos participen (Jerez et al., 2003) y, por ende, dando soporte a su capital social. Por ejemplo, la formación de acogida permite a los nuevos empleados adquirir el lenguaje, los valores y las normas de la organización, así como el esquema compartido de conocimiento (Kang et al., 2003; Cabrera y Cabrera, 2005). Además, les permite conocer su lugar de trabajo, compañeros, tareas, lugares de reunión, etc., favoreciendo un rápido desarrollo de su red de contactos internos y sustentando, de este modo, al capital social. Asimismo, la formación dota al empleado de los conocimientos y habilidades necesarios para realizar tareas en áreas diferentes al puesto asignado, contribuyendo así a la cooperación entre empleados (Osterman, 1994). Por otra parte, la formación en sí misma, mediante la propia participación en la acción formativa, aumenta las oportunidades de cooperar con otros compañeros, favorece el conocimiento entre empleados y desarrolla la confianza entre ellos y en las capacidades de los demás, no sólo durante el transcurso de la acción formativa sino, también, después, manteniéndose en el tiempo. Todo ello favorece la creación y mantenimiento de redes internas estables, influyendo de forma positiva sobre el capital social.

Por su parte, la promoción también puede facilitar la cooperación entre compañeros y, en consecuencia, dar soporte al capital social. Así, las prácticas de desarrollo profesional del empleado influyen de forma positiva sobre este capital, debido a que permiten romper las barreras que los impiden colaborar compartiendo su conocimiento (Swart y Kinnie, 2003) o bien porque influyen en la creación de un clima social que favorece la cooperación y colaboración entre empleados (Collins y Smith, 2006; Hsu, 
Chen Wang y Yu, 2007). Así pues, las medidas de desarrollo de carrera, fomentan la permanencia del empleado en la organización y favorecen su predisposición a la cooperación e interacción con otros, repercutiendo positivamente en su capital social.

Atendiendo a estos argumentos, planteamos la siguiente subhipótesis que relaciona el desarrollo profesional del empleado y la dimensión social del capital humano.

Subhipótesis 3b: El desarrollo profesional del empleado - a través de la formación y las oportunidades de promoción-, influye positivamente en el capital social

Por último, en lo que se refiere al capital afectivo existen numerosos trabajos que confirman la influencia del desarrollo profesional del empleado en este tipo de capital.

Por un lado, autores como Robinson y Rousseau (1994) postulan que el desarrollo profesional del empleado, a través de la formación y la promoción, permite asegurar la empleabilidad de los trabajadores y, además, desarrolla su afecto hacia la organización. Del mismo modo, Tzafrir et al. (2004) afirman que el capital afectivo se crea en el ámbito de las interacciones positivas entre empleados, gracias a la existencia de sentimientos positivos. Tomando estos argumentos en consideración, deducimos que las prácticas de desarrollo del empleado pueden favorecer la confianza y satisfacción laboral de los empleados, puesto que, por un lado, reflejan la inversión que la organización realiza en sus empleados demostrando así, su interés por ellos y por su desarrollo (Eisenberger et al., 1986) y, por otro lado, incrementan su empleabilidad. Todo ello es valorado de forma positiva por los empleados, quienes, en reciprocidad (Gouldner, 1960) desarrollan afectos positivos hacia la organización, contribuyendo, por tanto al sostenimiento del capital afectivo.

Por otro lado, desde un plano más teórico, Hislop (2003) justifica la relación positiva entre las prácticas de desarrollo profesional del empleado y el capital afectivo apoyándose en el modelo de contrato psicológico de Guest y Conway (1997). Este modelo plantea que los empleados desarrollan con la organización una relación que va más allá de lo recogido formalmente en el contrato de trabajo. En efecto, los empleados generan expectativas de aprendizaje, de promoción, de trabajo en un contexto y clima 
laboral determinados, etc., y estos “otros” componentes de la relación laboral conforman lo que se denomina el contrato psicológico entre empresa y empleado. En consecuencia, el ofrecimiento o no de estos componentes esperados por los empleados tendrá una serie de consecuencias actitudinales (desarrollo del compromiso organizativo, de afecto hacia la organización, de satisfacción laboral, entre otras) y comportamentales (esfuerzo realizado, intención de permanencia en la empresa, absentismo, etc.). Por tanto, bajo estas argumentaciones, la formación y la promoción, como prácticas de desarrollo profesional del empleado, pueden favorecer la retención de los empleados por cuanto dan soporte a los afectos positivos hacia la organización, es decir, nutriendo el capital afectivo de estos empleados.

Por último, podemos citar diversos trabajos que justifican empíricamente la relación positiva entre el desarrollo profesional del empleado y el capital afectivo (Meyer y Allen, 1997; Agarwal y Ferrat, 1999; Kochansky y Leford, 2001; Paré et al., 2001; Allen, Shore y Griffeth, 2003; Gardner et $a l^{33}$, 2007) ${ }^{34}$. Algunos autores justifican esta relación a través de la influencia positiva que la formación y las posibilidades de promoción ejercen en el desarrollo de un clima de apego y afinidad hacia la organización (Collins y Smith, 2006). Otros constatan cómo la promoción y la formación son las dos prácticas de recursos humanos de mayor eficacia sobre el capital afectivo, seguidas de la evaluación del desempeño (Hemdi y Nasurdin, 2006). También están aquellos autores que señalan la creciente demanda por los empleados de oportunidades de formarse en el trabajo para, así, poder desarrollar su carrera profesional, por lo que aquellas organizaciones que favorezcan el desarrollo profesional de sus empleados sustentan desarróllale capital afectivo de sus empleados (Ng, Butts, Vandenberg, DeJoy y Wilson, 2006)

\footnotetext{
${ }^{33}$ Cabe destacar este trabajo porque es de los escasos y trabajos que abordan simultáneamente la investigación tanto desde la perspectiva de los directores de recursos humanos como desde la perspectiva de los empleados (Gardner et al., 2007),

${ }^{34}$ A pesar, de estas evidencias empíricas no todos los trabajos han logrado validar la relación que nos ocupa, como ocurre con Dockel (2003).
} 
En suma, de acuerdo con lo expuesto en las líneas precedentes, planteamos la siguiente subhipótesis que relaciona las prácticas de desarrollo del empleado y el capital afectivo:

Subhipótesis 3c: El desarrollo profesional del empleado - a través de la formación y : las oportunidades de promoción-, influye positivamente en el capital afectivo

\subsection{Relación entre las medidas de conciliación laboral-personal y la retención del capital humano de la organización}

Cascio (2000) define las medidas de conciliación como “cualquier medida financiada por la empresa para beneficio del empleado o condición de trabajo que ayude a los empleados a equilibrar sus demandas laborales y no laborales”. En concreto, en este trabajo analizamos el efecto de determinadas medidas de conciliación especialmente significativas, como son: la flexibilidad horaria, las facilidades temporales para atender asuntos personales y las ayudas económicas, y proponemos estudiar su efecto positivo en la retención del capital humano. Así pues, enunciamos la siguiente hipótesis.

Hipótesis 4: Las medidas de conciliación de la vida laboral y personal influyen positivamente en la retención del capital humano de la organización, a través de sus dimensiones de capital intelectual, social y afectivo

Dado que el capital humano considerado en esta investigación se compone de capital intelectual, de capital social y de capital afectivo, justificaremos esta cuarta hipótesis atendiendo a la influencia de las medidas de conciliación sobre cada uno de estos tres componentes.

Como ya hemos comentado con anterioridad, los motivos que han impulsado a las empresas a implementar prácticas de conciliación son muy diversos. Entre los más relevantes cabe citar los cambios en el mercado laboral debidos a la incorporación de la mujer al trabajo, la existencia de parejas con doble carrera y el deseo manifestado por los individuos de lograr una mayor calidad de vida mediante el disfrute de tiempo libre y actividades de ocio (Greenhaus, 2008). En este nuevo entorno, se ha producido una 
redistribución de las tareas y reasignación de responsabilidades en las unidades familiares que puede suponer cierto conflicto para los empleados. Todo ello conlleva cambios en las demandas que, tanto empresas como empleados, realizan a la otra parte de la relación laboral. En consecuencia, las empresas tratan de responder a las nuevas demandas tomando en consideración tanto la faceta laboral como la faceta "no-laboral" de sus empleados. Con este fin, las empresas ofrecen a sus empleados medidas de conciliación que les faciliten el equilibrio entre su vida laboral y su vida personal (Crooker, Smith y Tabak, 2002; Pasamar y Valle, 2011). De este modo los empleados se encuentran más satisfechos y conformes con su relación laboral, favoreciéndose, por tanto, su retención y su compromiso organizativo (Hom y Griffeth, 1995; Griffeth y Hom, 2001; Dockel, 2003; Lazarova, 2004; Vaiman, 2004) y, por ende, influyendo positivamente en la retención del capital intelectual vinculado a estos empleados. Además, estas medidas de conciliación demuestran el interés de la empresa por el bienestar de sus empleados, contribuyendo a que éstos deseen actuar en reciprocidad, adoptando comportamientos que la empresa valore de forma positiva como puede ser la permanencia en la empresa (Rousseau 1989; 1995; Settoon, Bennett y Liden, 1996; Eisenberger et al, 1986; Lambert 2000; Parkes y Lanford, 2008; Sánchez-Vidal et al., 2010), situación que redunda positivamente en la retención del capital intelectual.

Las medidas de conciliación que utilizan las empresas son muy heterogéneas. Algunas de las que tienen más eficacia para la retención de empleados son los horarios flexibles, los permisos temporales, las excedencias para asuntos personales (principalmente para poder afrontar el cuidado de los hijos), ayudas económicas, asistencia médica o el abono de guarderías (Hom y Griffeth, 1995; Hill, 2000; Perry-Smith y Blum, 2000; Arthur, 2001; Griffeth y Hom, 2001; Guest, 2002; Teo y Waters, 2002; Dockel, 2003; Boyar, Maertz, Pearson y Keough, 2003 ${ }^{35}$; Lazarova, 2004; Hoonakker, Carayon y Schoepke, 2004; Chew, 2004; Ahuja et al., 2007; Peterson, 2007; Harr, 2007). Abundando en estos resultados, diversos trabajos confirman que, en el caso de empleados con familias, éstos

\footnotetext{
${ }^{35}$ Como sabemos, el conflicto entre la vida laboral y personal puede ser bidireccional. Es decir, el desarrollo del trabajo puede interferir en el desarrollo de la vida personal del empleado, y viceversa. En este sentido, Boyar et al. (2003) descubren que la interferencia que el trabajo ejerza sobre el correcto desarrollo de la vida personal es mucho más pernicioso para la retención de empleados, que la interferencia que la vida personal pueda ejercer en el desarrollo de la faceta laboral de empleado.
} 
registran menor conflicto en el trabajo y mayor vínculo con la organización cuando sus empresas son conciliadoras (Allen et al., 2000; Thompson, Beauvais y Lyness, 1999; Thompson y Heron, 2006; Casper, Weltman y Kwesiga, 2007; Parkes y Langford, 2008), lo cuál favorece que permanezcan en sus organizaciones, reteniéndose, por tanto, su capital intelectual en la organización.

De acuerdo con todo lo anterior, proponemos la siguiente subhipótesis que relaciona las medidas de conciliación entre la vida laboral y la vida personal con la retención del capital intelectual:

Subhipótesis 4a: Las medidas de conciliación de vida laboral-personal influyen positivamente en la retención del capital intelectual

Siguiendo con el análisis del efecto que las medidas de conciliación pueden ejercer sobre el capital humano, también es objeto de nuestro interés analizar su relación con el capital social. Aunque en la revisión realizada no hemos encontrado literatura que apoye, de forma expresa, esta hipótesis, consideramos interesante proponerla y contrastarla, puesto que sí hemos encontrado evidencia del efecto positivo de las medidas de conciliación en las actitudes y afectos de los empleados (Parkes y Lanford, 2008). Además, como sabemos, las medidas de conciliación pueden fomentar la adopción de determinados comportamientos en los empleados que la empresa valore positivamente $^{36}$. Tales comportamientos pueden consistir, entre otros, en mostrarse más colaborativos con otros empleados, participar activamente en procesos de interacción con otros empleados, etc., contribuyendo así a sostener el capital social.

En este sentido, Perry-Smith y Blum (2000) señalan que las organizaciones que adoptan prácticas de conciliación logran que sus empleados alcancen mejores niveles de desempeño y desarrollen comportamientos más allá de los esperados por su relación contractual. Además, estos autores señalan que las medidas de conciliación favorecen el

\footnotetext{
${ }^{36}$ Los empleados llevan a cabo comportamientos que la empresa valore positivamente en respuesta a acciones de la empresa en las que ésta manifieste un trato positivo hacia los empleados, como pueden ser las prestaciones sociales y medidas de conciliación (Blau, 1964; Rousseau 1989;1995; Eisenberger et al., 1986; Lambert 2000; Rhoades y Eisenberger, 2002; Parkes y Lanford, 2008).
} 
empeño de los empleados por contribuir a la consecución de los objetivos de la empresa y, dicho empeño, se traduce en comportamientos orientados a favorecer la colaboración con otros empleados y la participación en procesos en los que combinan y comparten conocimiento con los demás, puesto que, de este modo, contribuyen de forma más eficiente a la consecución de los objetivos empresariales. En línea con esta argumentación, Wright y sus colaboradores demuestran que las empresas que favorecen el bienestar en el trabajo logran mejoras en el desempeño de sus empleados (Wright, Cropanzano y Bonett, 2007; Wright y Cropanzano, 2004). En consecuencia, asumiendo que las medidas de conciliación favorecen el bienestar de los empleados, podemos deducir que estas medidas sí pueden llegar a favorecer su nivel de desempeño y que, en dicho desempeño, pueden tener cabida actividades en las que los empleados cooperen y colaboraren con otros empleados dando soporte, de este modo, al capital social.

Por otro lado, puesto que algunas medidas de conciliación facilitan la ausencia temporal de los empleados (Crooker et al., 2002), se nos antoja lógico pensar que estas situaciones requieran de una mayor cooperación y coordinación entre compañeros, especialmente, en dos momentos. En un primer momento, la necesidad de cooperación aumenta de forma previa a la ausencia temporal del empleado que utiliza la medida de conciliación, puesto que los empleados que se van a ausentar deberán coordinarse, compartir información y colaborar con aquellos compañeros que permanecen en el puesto en dicho periodo y que, incluso, podrán tener que asumir tareas de los compañeros ausentes. En un segundo momento, una vez que los empleados ausentados temporalmente se reincorporan con normalidad a su puesto de trabajo, la colaboración es necesaria porque deberán ponerse al día y recibir información laboral relativa a su periodo de ausencia. Pensamos que con este tipo de situaciones, favorecidas por ciertas medidas de conciliación, se influye positivamente y se potencia la red social y las interacciones de los empleados, sustentando, por tanto, su capital social.

En suma, de acuerdo con lo expuesto en las líneas precedentes, planteamos la siguiente subhipótesis que relaciona las medidas de conciliación laboral-personal y la dimensión social del capital humano: 
Subhipótesis 4b: La medidas de conciliación de vida laboral-personal influyen positivamente en el capital social

Por último, nos detenemos en la relación de las medidas de conciliación con el capital afectivo. Estas medidas pueden ser interpretadas por los empleados como el resultado de una actuación voluntaria realizada por la organización que valora positivamente a sus empleados, algo que los empleados perciben favorablemente, generando en ellos el desarrollo de afectos positivos hacia la organización (Eisenberger et al, 1986; Rousseau 1989; 1995; Settoon et al., 1996; Javed, Whitfield y Yousafzai, 2009³), y que sustentan el capital afectivo. Diversos estudios avalan esta relación.

Grover y Crooker (1995) demuestran que los empleados que trabajan en organizaciones que ofrecen ayudas para facilitar la conciliación a sus empleados desarrollan un mayor vínculo y afecto hacia las mismas. Además, diversos estudios (Grover y Crooker, 1995; Hom y Griffeth, 1995; Lazarova, 2004; Fisher, 2004; Greenhaus y Powell, 2006; Ahuja et al., 2007; Pasamar y Valle, 2011, entre otros) avalan que las medidas de conciliación (como por ejemplo, los horarios flexibles, los periodos de excedencia, los permisos para cuidado familiar, el seguro médico y las ayudas económicas) favorecen el desarrollo del capital afectivo, y que esta relación se constata en un amplio colectivo de empleados. Así, por ejemplo, dicha relación se ha evidenciado en empleados altamente cualificados (Dockel, 2003; Dockel, Basson y Coetzee, 2006), comprobándose que este efecto positivo se confirma, incluso, en aquellos empleados que no se benefician directamente de estas medidas, puesto que su mero ofrecimiento simboliza la preocupación y la valoración del empleado, y ello fortalece el vínculo y afecto del empleado hacia la organización, nutriendo, por tanto, su capital afectivo. Por supuesto, también encontramos evidencia empírica de la influencia positiva de las medidas de conciliación en el capital afectivo de empleados con familias (Allen et al., 2000; Thompson, Beauvais y Lyness, 1999; Thompson y Heron, 2006; Ahuja, Chudoba y Kacmar, 2007;

\footnotetext{
${ }^{37}$ Javed et al. (2009), basándose en trabajos previos de meta-análisis (como el de Kinicki et al. (2002), para la satisfacción laboral, y el de Mathieu y Zajac (1990), para el compromiso organizativo), incorpora, por primera vez en un meta-análisis, las prácticas de conciliación como factor que condiciona las actitudes y afectos de los empleados
} 
Casper, Weltman y Kwesiga, 2007; Parkes y Langford, 2008; Sánchez-Vidal, CegarraLeiva y Cegarra-Navarro, 2010), así como en empleados solteros y sin hijos (Casper et al.,2007) y también en empleados contratados tanto a tiempo parcial como a tiempo completo (Ng, Butts, Vandenberg, DeJoy y Wilson, 2006).

En relación con estos resultados, Haar y Spell (2004) señalan que no es suficiente con el mero ofrecimiento de las medidas de conciliación, sino que para que verdaderamente tengan efecto sobre los afectos de los empleados, las empresas deben, por un lado, asegurarse de que los empleados las conocen y saben cómo acceder a ellas y, por otro lado, deben conocer la valoración real que los empleados realizan de dichas medidas. Estas consideraciones son muy relevantes puesto que, tal como señalan Pasamar y Valle (2011), a menudo, las medidas de conciliación más ofertadas por las empresas no son las medidas más utilizadas ni las mejor valoradas por los empleados.

Por último, debemos señalar que no todos los trabajos revisados confirman la relación que nos ocupa. Así, contrariamente a los resultados anteriormente expuestos, Nord, Fox, Phoenix y Viano (2002) identifican que algunas medidas de conciliación, como el teletrabajo y la flexibilidad horaria, pueden llegar a tener un impacto negativo en el capital afectivo de los empleados, por el sentimiento de aislamiento y soledad que pueden implicar. No obstante, los resultados más frecuentes en la literatura revisada confirman la relación positiva entre las medidas de conciliación y el desarrollo de los afectos en los empleados, y ésta será nuestra línea argumental.

Así pues, teniendo en consideración los argumentos expuestos, enunciamos la siguiente subhipótesis que relaciona las medidas de conciliación y la dimensión afectiva del capital humano.

Subhipótesis 4c: Las medidas de conciliación de vida laboral-personal influyen positivamente en el capital afectivo

Una vez presentadas las hipótesis relativas a la relación entre las prácticas de recursos humanos transaccionales y la retención del capital humano, a continuación, centramos 
nuestro interés en presentar y justificar las hipótesis y subhipótesis correspondientes a las relaciones en las que participan las prácticas de recursos humanos relacionales.

\subsection{Hipótesis relativas a las prácticas relacionales de recursos humanos y la retención de capital humano de la organización}

Las prácticas de recursos humanos de naturaleza relacional se caracterizan por su influencia en la satisfacción del contrato relacional ${ }^{38}$ (Rousseau, 1995; Morrison y Robinson, 1997) de los empleados, favoreciendo, por tanto, el desarrollo de relaciones satisfactorias y estables entre el empleado y la organización, entre el empleado y sus superiores, y/o entre los empleados entre sí. De este modo, las prácticas relacionales influyen de forma positiva en la faceta social-relacional del empleado, faceta que, en la relación de empleo actual (Tsui y Wu, 2005; Hom, Tsui et al., 2009), debe ser considerada como elemento de retención y de motivación del empleado.

A continuación, enunciamos y justificamos las hipótesis que relacionan las cuatro prácticas de recursos humanos relacionales - soporte del supervisor, comunicación interna, participación del empleado y relaciones internas de apoyo entre con compañeros- con la retención de capital humano de la empresa (intelectual, social y afectivo).

\subsection{La relación entre el soporte del supervisor y la retención del capital humano de la organización}

Como sabemos, los empleados tienden a personalizar a la organización, es decir, conciben los actos de determinados miembros de la organización -especialmente, los

\footnotetext{
${ }^{38}$ Como ya hemos expuesto en el capítulo primero, la perspectiva del contrato relacional postula que entre empleado y empleador se produce una relación que va más allá de lo recogido formalmente en el contrato de trabajo. El empleado percibe su relación de empleo como algo más amplio en lo que valora todo lo que formal e informalmente recibe de la organización (empleador): trato recibido, atención, confianza, formación, reconocimiento, buen clima laboral, etc. Todo ello compone lo que se ha denominado el contrato relacional; este contrato relacional recoge los factores no contractuales pero que también forman parte de la relación de empleo. De este modo, se incorporan a la relación de empleo determinados aspectos psicológicos y sociales que el empleado percibe y valora y que, por tanto, influyen en su satisfacción, incidiendo sobre sus actitudes y sus comportamientos.
} 
mandos y superiores- como acciones que realiza la propia organización (Levinson, 1965). Por tanto, el comportamiento que los supervisores desarrollen con los empleados a su cargo será percibido por éstos como el trato que les otorga la propia organización. En consecuencia, el apoyo y soporte que ofrecen los superiores a sus subordinados, influye en la retención de dichos empleados y, por ende, en la retención del capital humano de la organización (Wayne et al., 1997; Rhoades y Eisenberger, 2002; Allen et al., 2003). Diversos enfoques ${ }^{39}$ justifican esta relación, argumentando que cuando los superiores ofrecen ayuda, apoyo y reconocimiento a sus subordinados, éstos consideran dicho trato como símbolo del trato que les otorga la organización conforme a la valoración que ésta realiza de sus contribuciones. Por tanto, si esta valoración es positiva, en base a las normas de reciprocidad (Blau, 1965; Gouldner, 1960), favorecerá que los empleados deseen corresponder a la empresa. Esta correspondencia se traduce en comportamientos tales como un mayor vínculo hacia la empresa, un mejor nivel de desempeño, una mayor permanencia en la empresa, y una mejor actitud del empleado (Rhoades et al., 2001; Rhoades y Eisenberger, 2002). De hecho, uno de los mecanismos con los que cuentan los empleados para corresponder al buen trato que reciben de su empresa es, precisamente, permanecer en ella (Eisenberger et al., 1990). De este modo, a mayor soporte por parte del supervisor percibido por los empleados, mayor deseo de permanencia, lo que deriva en una mayor retención de los empleados y, por tanto, de su capital humano en la organización (Rhoades y Eisenberger, 2002; Eisenberger et al., 2002; Allen et al., 2003; Jawahar y Hemmasi, 2006; Dockel et al., 2006; Peterson, 2007). En consecuencia, formulamos la siguiente hipótesis.

\section{Hipótesis 5: El soporte del supervisor influye positivamente en la retención del capital humano de la organización, a través de sus dimensiones de capital intelectual, social y afectivo}

39 La Teoría del Soporte Organizativo (Eisenberger et al., 1986), a través de los postulados del intercambio social (Blau, 1964) y las normas de reciprocidad (Gouldner, 1960), ha permitido desarrollar constructos y corrientes de estudio muy utilizados en la literatura de retención y rotación voluntaria como son el apoyo organizativo percibido -POS-Perceived Organizacional Support- (Eisenberger et al.et al., 1986), el apoyo percibido del supervisor -PSS-Perceived Supervisor Support (Rhoades y Eisenberger, 2002) y la relación de intercambio con el líder -LMX-Leader Member Exchange- (Graen y Scandura, 1987); precisamente estos dos últimos enfoques se centran en analizar la influencia positiva que el soporte y la relación de supervisor-empleado pueden ejercer sobre la retención y sobre el compromiso y confianza de los empleados. 
Nuevamente, al igual que en las anteriores hipótesis, abordamos la justificación de esta hipótesis a través de la relación con cada una de las tres dimensiones que componen el capital humano: capital intelectual, capital social y capital afectivo.

Como ya hemos expuesto en apartados anteriores, en el presente estudio, el soporte del supervisor se concibe como el comportamiento que el supervisor desarrolla para con sus empleados subordinados, mostrándose accesible, interesándose por ellos y por su trabajo y reconociendo sus logros. En otras palabras, el soporte del supervisor supone que éste desarrolle comportamientos de apoyo, de ayuda y de reconocimiento del valor de los empleados a su cargo, los cuales se ha demostrado que favorecen el bienestar de los empleados ${ }^{40}$, facilitan que éstos adquieran los conocimientos y la autoconfianza necesarios para ser eficaces en su trabajo, todo lo cuál, en reciprocidad, potencia el vínculo entre empleados y organización, la retención de éstos y, por ende, la retención de su capital intelectual (Hom y Hulin, 1981; Price y Mueller, 1981, 1986; Graen y Scandura, 1986; Wayne et al., 1997; Griffeth y Hom, 2001; Mitchell et al., 2001; Mitchell, Holtom y Lee, 2001; Lee et al., 2004; Celeste y Brotheridge, 2005; Paré y Tremblay, 2007).

Desde la otra cara de la misma moneda ${ }^{41}$, las repercusiones de una mala supervisión sobre el abandono voluntario son innegables (Chawla, 2005). Muchos empleados señalan la mala relación con su supervisor como aspecto determinante de su abandono de la organización (Mobley, 1982; Hom y Griffeth, 1995; Chawla, 2005). Es más, los superiores, a través de sus comportamientos, tienen una influencia directa sobre la decisión de abandono de los empleados (Bartlett, 2001; Griffeth y Gaertner, 2001; Lambert et al., 2001).

En base a las consideraciones previas, enunciamos la siguiente subhipótesis que relaciona el soporte que el superior ofrece a sus subordinados y la retención del capital intelectual.

\footnotetext{
${ }^{40}$ Para amplia estas ideas, consultar los trabajos realizados bajo la teoría del intercambio líder-empleado (Graen et al.et al., 1977; 1982).

${ }^{41}$ La retención y la rotación voluntaria pueden ser identificadas como las dos caras de una misma moneda.
} 
Subhipótesis 5a: El soporte del supervisor influye positivamente en la retención del capital intelectual

En lo que se refiere al capital social, también es de esperar que aquellas organizaciones en las que los superiores ofrecen apoyo a sus empleados mediante su asesoramiento, mostrándose accesibles, manifestando preocupación por su bienestar y/o reconociendo el trabajo de los empleados a su cargo, puedan lograr impactos positivos en el capital social debido, en gran parte, a dos mecanismos. En primer lugar, el apoyo del supervisor ejerce un efecto positivo sobre las actuaciones y comportamientos de los empleados en sus puestos de trabajos (Rhoades et al., 2001; Rhoades y Eisenberger, 2002), actuaciones que, a menudo, requieren de la colaboración de otros compañeros, así como, compartir y transferir conocimiento a otros puestos y empleados. Todo ello se relaciona positivamente con el capital social, puesto que dichas actuaciones pueden requerir la interacción con otros empleados, sustentando, así, el capital social. En segundo lugar, el trato y apoyo que los supervisores ofrecen a sus subordinados, favorece la interacción entre superior y subordinado, desarrollando y estabilizando la relación entre ambos, relación que también se pueden vincular positivamente al sustento de su capital social.

Diversos trabajos avalan la relación entre el soporte del supervisor y el capital social. Así, por ejemplo, el trabajo de Dockel (2003) evidencia que el soporte del supervisor favorece el desarrollo de comportamientos que conducen a la innovación. Teniendo en cuenta que la innovación requiere del intercambio e interacción de conocimiento (con otro conocimiento), y que gran parte del conocimiento de la organización reside en las personas, podemos deducir que entre los comportamientos que favorece el apoyo del supervisor se encuentran aquéllos de cooperación y colaboración entre empleados los cuales, como sabemos, se vinculan directamente con el capital social. Por otro lado, Zarraga y Bonache (2003), en su estudio sobre equipos de trabajo, encuentran resultados significativos sobre el impacto positivo del apoyo del líder sobre el capital social, por cuanto favorece determinados procesos de creación y transferencia de conocimiento. Más recientemente, Lin, Lee y Wang (2009), analizando los factores favorecedores de 
los flujos de conocimiento, evidencian que el soporte percibido del supervisor se relaciona positivamente con el mantenimiento del capital social, a través de los procesos de cooperación que favorece.

Así pues, las anteriores consideraciones nos ofrecen indicios para pensar que, efectivamente, el apoyo del supervisor puede dar soporte y nutrir la dimensión social del capital humano; relación que recogemos en la siguiente subhipótesis:

Subhipótesis 5b: El soporte del supervisor influye positivamente en el capital social

Por último, el soporte del supervisor también puede incidir sobre los afectos del empleado hacia la organización, esto es, en el capital afectivo.

Sabemos que el buen trato recibido por el supervisor mejora la percepción que los empleados tienen del soporte recibido de la propia organización, puesto que los empleados interpretan que dicho apoyo se debe a la política y cultura de la organización (Levinson, 1965), y no a la conducta discrecional del supervisor. Estas apreciaciones favorecen el vínculo afectivo de los empleados hacia la organización (Hutchison, 1997). En otras palabras, el soporte percibido de la organización, a través del soporte percibido de los superiores, nutre y sustenta el capital afectivo (Rhoades, Eisenberger y Armeli, 2001; Rhoades y Eisenberger, 2002; Peterson, 2007).

En este sentido, algunos trabajos, como los de Whitener et al.(1998) y Whitener (2001), demuestran que aquellos superiores que son consistentes e íntegros en sus comportamientos, que delegan, comunican abiertamente y demuestran interés por sus subordinados, favorecen el desarrollo del capital afectivo. Del mismo modo, otros estudios evidencian que en aquellas organizaciones en las que los mandos ofrecen soporte a sus empleados se genera confianza hacia los propios mandos, lo cuál repercute favorablemente en el afecto y el apego de los empleados hacia la organización (Connell, Ferres y Travaglione, 2003; Zarraga y Bonache, 2003; Chen, Ayree y Lee, 2005). Esta relación, también se ha evidenciado en el caso particular de los sectores tecnológicos por Paré et al. (2001), quienes demuestran que el reconocimiento que los empleados reciben de sus superiores está correlacionado fuertemente con su afecto hacia la 
organización. Curiosamente, este tipo de empleados es especialmente sensible al reconocimiento y apoyo recibido de sus superiores, por cuanto los hace sentir más importantes (componente clave de motivación intrínseca). La relación analizada también se ha comprobado en el caso de empleados clave (Dockel, 2003; Dockel, Basson y Coetzee, 2006). En otras palabras, cuando el jefe y el subordinado mantienen una relación de calidad, el empleado genera un mayor afecto y un mayor vínculo con su organización (Rosa-Navarro y Carmona-Lavado, 2010).

Así pues, teniendo en consideración los argumentos expuestos, enunciamos la siguiente subhipótesis que relaciona el soporte del supervisor y la dimensión afectiva del capital humano.

Subhipótesis 5c: El soporte del supervisor influye positivamente en el capital afectivo

\subsection{La relación entre la comunicación interna y retención del capital humano de la organización}

La comunicación interna comprende todos los mensajes que se emiten en el interior de la organización, así como los sistemas y canales a través de los que se desarrolla (Valero et al., 2005; Ng et al., 2006). La comunicación interna constituye un acto de transparencia para los empleados (acto positivo de la organización), generando afectos positivos y comportamientos favorables hacia la propia organización y fomentando la intención de permanencia en la misma (Eisenberger et al., 1990; Wayne et al., 1997). Diversos estudios avalan la influencia positiva de la comunicación interna sobre la retención del capital humano (Hom y Griffeth, 1995; Beckert y Huselid, 1998; Boselie y Wiele, 2002; Minbaeva, 2003; Choo et al., 2005; Paré y Tremblay, 2007; Ng y Butts, 2009; entre otros) y, en consecuencia formulamos la siguiente hipótesis.

\section{Hipótesis 6: La comunicación interna influye positivamente en la retención del capital humano de la organización, a través de sus dimensiones de capital intelectual, social y afectivo}

Al igual que en las hipótesis anteriores, dado que el capital humano se compone de capital intelectual, de capital social y de capital afectivo, justificaremos esta sexta 
hipótesis atendiendo a la influencia de la comunicación interna sobre cada uno de estos tres componentes.

A través de la comunicación interna los empleados obtienen información relativa a la empresa, a la estrategia, a su puesto de trabajo, establecen contacto con compañeros, se comunican con los superiores, etc., todo lo cuál, facilita su acceso al conocimiento necesario para afrontar mejor su trabajo y conocer con mayor exactitud sus objetivos y cómo alcanzarlos. Ello permite reducir la incertidumbre, la ansiedad y el estrés laboral, lo que se ha demostrado que influye positivamente sobre la retención del empleado y, por tanto, sobre la retención de su capital intelectual (Kolowsky y Marom (2004) cit. en Griffeth y Hom, 2004). Además, como hemos anticipado, algunas prácticas de comunicación interna permiten informar a los empleados sobre aspectos organizativos y estratégicos y facilitan la comunicación con los superiores así como con miembros de otros departamentos, lo cuál se percibe como muestra de una gestión transparente y como señal de consideración hacia los empleados, repercutiendo positivamente en su retención y, por ende, en la de su capital intelectual (Price, 1977; Bluedorn, 1980; Martín, 1979; Price y Mueller, 1981; Abelson y Baysinger, 1984; Beckert y Huselid, 1998; Boselie y Wiele, 2002; Minbaeva, 2003; Choo, Woods y Mayer, 2005, Gardner et al.,2007. Paré y Tremblay, 2007; Ng y Butts, 2009, entre otros). La comunicación interna puede percibirse como una de las acciones que la empresa realiza en beneficio de los empleados, lo que, en cierto modo, refuerza el sentimiento de la creencia de de que la empresa valora a sus empleados, reforzando su intención de permanencia y, por ende, contribuyendo al mantenimiento de su capital intelectual (Paré y Tremblay, 2007; Ng y Butts, 2009). De hecho, Rousseau (1998) sugiere que comunicar a los empleados aspectos empresariales de la organización fortalece la percepción de sí mismos como agentes importantes de la empresa y necesarios para la consecución de los objetivos organizativos, todo lo cuál refuerza su intención de permanencia en la empresa, favoreciendo su retención y, por ende la de su capital intelectual.

Por tanto, en base a las consideraciones previas, enunciamos la siguiente subhipótesis que relaciona la comunicación interna y la retención del capital intelectual. 
Subhipótesis 6a: La comunicación interna influye positivamente en la retención del capital intelectual

Por otro lado, puesto que conocemos que el capital social se vincula a las redes e interacción entre empleados, resulta lógico pensar que aquellas organizaciones que desarrollan actividades de desarrollo de la comunicación interna, están logrando habilitar los medios necesarios para mantener y nutrir su capital social. Diversos trabajos han logrado evidenciar la relación positiva entre la comunicación interna y el capital social.

En concreto, Minbaeva et al. (2003) comprueban que determinadas prácticas de comunicación interna, como las que permiten informar a los empleados sobre la estrategia y el rendimiento empresarial y aquéllas que favorecen la conexión entre diferentes departamentos, jefes y/o subordinados, dan soporte al capital social, por cuanto potencian la cooperación y colaboración entre los empleados. De hecho, la comunicación interna, al facilitar el desarrollo de vías de relación entre los empleados, logra favorecer los procesos de interacción en los que fluye información respaldando, por tanto, al desarrollo del capital social (Minbaeva, 2005). Además, otros autores, como Collins y Smith (2006) y Sun, Aryee y Law (2007), también han confirmado que la comunicación interna, al favorecer un clima de colaboración, influye de forma positiva en el capital social de la organización.

Así pues, las anteriores consideraciones nos ofrecen indicios para pensar que, efectivamente, la comunicación interna puede influir positivamente en la dimensión social del capital humano; relación que recogemos en la siguiente subhipótesis:

Subhipótesis 6b: La comunicación interna influye positivamente en el capital social

Por último, consideramos la influencia de la comunicación interna en la dimensión afectiva del capital humano. 
La motivación de los empleados es mayor cuando son informados sobre las cuestiones relevantes que afectan a su empresa, a la estrategia, a los objetivos empresariales, etc., puesto que ello se percibe como una prueba de confianza que la organización deposita en los empleados (Minbaeva et al., 2003). Ello fomenta, a su vez, afectos positivos de los empleados hacia la organización, en correspondencia con el trato recibido (Gouldner, 1960; Eisenberger et al., 1990). De hecho, Whitener (1997) destaca la eficacia de los procesos de comunicación interna para favorecer el capital afectivo, especialmente, si se canalizan a través de los mandos y superiores.

Diversos estudios avalan que la comunicación interna potencia el vínculo psicológico y el apego que los empleados sienten hacia su empresa debido a que la existencia de medidas de comunicación interna favorece que los empleados se perciban como partes importantes para la organización y la consecución de sus objetivos (Rousseau, 1998; Soupata, 2005; Ng y Butts, 2009). Además, determinadas prácticas de comunicación interna como pueden ser la de informar sobre la estrategia y el rendimiento empresarial o la de favorecer la comunicación interna entre departamentos y con la alta dirección de la empresa, transmiten confianza a los empleados, nutriendo, de este modo, su capital afectivo (Minbaeva et al., 2003; Tzafrir, Harel, Baruch y Dolan, 2004; Searle, Hartog, Weibel, 2007). En este sentido, diversos estudios han confirmando la relación positiva entre la comunicación interna y el capital afectivo, tanto en el caso de empleados contratados a tiempo parcial como a tiempo completo (Ng et al.,2006) y tanto desde la perspectiva del empleado como desde el punto de vista de la dirección de recursos humanos (Gardner, Moynihan y Wright, 2007).

Así pues, teniendo en consideración los argumentos expuestos, enunciamos la siguiente subhipótesis que relaciona la comunicación interna y la dimensión afectiva del capital humano.

Subhipótesis 6c: La comunicación interna influye positivamente en el capital afectivo 


\subsection{La relación entre la participación del empleado y la retención del capital humano de la organización}

La participación del empleado abarca aquellas medidas que permiten al empleado contribuir con sus conocimientos y habilidades al éxito de la organización (Gardner et al., 2007; Appelbaum et al., 2000) mediante, por ejemplo, su implicación en la toma de decisiones, el trabajo en grupos de mejora y en grupos de resolución de problemas o mediante la sugerencia de mejoras o quejas acerca de los aspectos que consideren relevantes. Estas medidas expresan el reconocimiento que la organización realiza de la valía de los empleados, quienes, en correspondencia, mejoran su actitud y comportamiento laboral, permaneciendo en ella (Eisenberger et al., 1990; Rhoades y Eisenberger, 2002). Así, proponemos estudiar el efecto positivo de las medidas de participación de los empleados en la retención del capital humano y, por tanto, formulamos la siguiente hipótesis.

Hipótesis 7: La participación del empleado en la empresa influye positivamente en la retención del capital humano de la organización, a través de su influencia en el capital intelectual, social y afectivo de los empleados

Del mismo modo que hemos realizado en las hipótesis anteriores, justificaremos esta séptima hipótesis atendiendo a la influencia de la participación del empleado en cada uno de estos tres componentes del capital humano definidos en este trabajo.

En concreto, algunas medidas de participación del empleado como su implicación en procesos de toma de decisión se muestra como una de las más eficaces para mejorar la motivación, la satisfacción y el deseo de permanencia de los empleados considerados estratégicos y, por ende, para retener su capital intelectual (Arthur, 2001; Naggiar, 2001). Es más, muchos de estos empleados estratégicos, manifiestan gran desagrado por trabajar en organizaciones que restringen sus oportunidades de participación en la toma de decisiones, pudiendo ello condicionar su permanencia en la organización (Naggiar, 2001). Por su parte, Arthur (2001) señala que las medidas de participación ofrecen a los empleados el mensaje de que la empresa los valora y confía en su valía y, por esa razón, 
los permite participar de forma activa en el desempeño de la misma; todo ello repercute de forma positiva en la motivación del empleado y en su deseo de permanencia. De este modo, esta autora destaca la enorme importancia que para los empleados tiene el sentimiento de aprecio y valoración que las organización les ofrece a través de las medidas de participación, favoreciendo que se sientan parte de la empresa. De hecho, Arthur (2001) señala la participación de los empleados, como una de las mejores prácticas para retener el capital intelectual ligado a los empleados más valiosos.

Asimismo, diversos trabajos han validado empíricamente la relación que nos ocupa (Abelson y Baysinger, 1984; Huselid, 1995; Delery y Doty, 1996; Shaw et al., 1998; Holtom et al., 2001; Arthur, 2001; Naggiar, 2001; Guest, 2002; Buck y Watson, 2002; Boselie y Wiele, 2002; Allen, 2003; Peterson, 2004; Celeste y Brotheridge, 2005; Sun, Aryee y Law, 2007; Gardner et al., 2007, entre otros).

Así pues, en base a las consideraciones previas, enunciamos la siguiente subhipótesis que relaciona la participación del empleado y la retención del capital intelectual.

Subhipótesis 7a: La participación del empleado en la empresa influye positivamente en la retención del capital intelectual

La participación del empleado no sólo afecta a la retención del capital intelectual sino, también, al capital social. Leana y Van Buren (1999) argumentan que las prácticas de recursos humanos que favorecen el desarrollo de relaciones satisfactorias dentro de la organización ${ }^{42}$ inducen a los empleados a asumir nuevos roles y desempeños más allá de lo esperado. A través de las medidas de participación los individuos tienen la oportunidad de colaborar directamente con los objetivos organizativos y de contribuir con sus esfuerzos al logro de objetivos de orden superior, aquéllos que van más allá de los vinculados a su puesto de trabajo. Por tanto, serán más proclives a dedicar tiempo y esfuerzo a la realización de tareas que sean útiles para la empresa, como por ejemplo, su implicación en grupos de mejora, en grupos de resolución de problemas, en sistemas de

\footnotetext{
${ }^{42}$ La participación del empleado es uno de los mecanismos de relación entre empleado y organización.
} 
sugerencias, etc., tareas, éstas, que requieren de la interacción con otros compañeros, nutriendo de este modo, su capital social.

Diversos estudios que avalan la relación que nos ocupa. Así, Sun, Aryee y Law (2007) evidencian que las empresas que animan y facilitan la participación activa de sus empleados, favorecen la cooperación y colaboración entre ellos y con la propia organización, beneficiando, de este modo, el mantenimiento e, incluso, desarrollo de su capital social. Por otro lado, las medidas de participación pueden intensificar la percepción que el empleado tiene de congruencia entre sus propios valores y los de la organización, puesto que al poder participar en la toma de decisiones se potencia que el empleado asuma como propios los objetivos y valores de la organización, por lo que se incrementando su identificación con la empresa y se promueve su colaboración con otros miembros de la misma (Arthur, 1994; Meyer y Hercovitch, 2001; Garder, Moynihan y Wright, 2007), todo lo cuál, da soporte al capital social. En el caso español, López-Cabrales, Leal-Fernández y Valle-Cabrera (2007) señalan la delegación y la participación en procesos de toma de decisión como medidas motivadoras de la adquisición de conocimientos específicos y valiosos para la compañía, así como favorecedoras de la creación del capital social, por cuanto exigen de la colaboración, interacción y compartición de conocimiento entre distintos empleados.

En suma, de acuerdo con lo expuesto en las líneas precedentes, planteamos la siguiente subhipótesis que relaciona las medidas de participación del empleado y la dimensión social del capital humano.

Subhipótesis 7b: La participación del empleado en la empresa influye positivamente en el capital social

Por último, las medidas de participación del empleado también pueden influir en el capital afectivo. Shaw, Delery, Jenkins y Gupta (1998) contrastan que algunas prácticas de recursos humanos, como la participación del empleado, pueden reducir los ratios de abandono por su efecto mediador sobre el capital afectivo. Como en el caso de otras medidas comentadas con anterioridad, los empleados valoran la posibilidad de 
participación como un reconocimiento a su valía y a su capacidad para contribuir con los resultados de la empresa $y$, en correspondencia, genera el desarrollo de afectos positivos hacia la misma.

Podemos añadir que las medidas de participación del empleado ayudan a satisfacer las necesidades de orden superior (autoconfianza, seguridad en uno mismo, autorrealización, logro) al permitir el ejercicio de habilidades y conocimientos valiosos que el empleado posee y al ofrecerle la posibilidad de influir en decisiones relacionadas con su propio trabajo. Además, puesto que estas medidas favorecen las relaciones con otros empleados, pueden contribuir a clarificar objetivos y procedimientos, facilitando el cumplimiento de los objetivos personales. Todo ello refuerza el vínculo y apego del empleado hacia la organización fortaleciendo, de este modo, su capital afectivo (Nagiar, 2001; Buck y Watson; 2002; Allen et al., 2003; Celeste y Brotheridge, 2005).

En el caso español, Escrig, Roca y Bou (2003) defienden que la participación del empleado en procesos de toma de decisión genera una mayor responsabilidad en los empleados que éstos realicen elecciones en base a reflexiones personales. Ello provoca una mayor implicación en cuestiones relativas a su trabajo favoreciendo que los empleados estén más integrados y apegados afectivamente a la organización.

Así pues, de acuerdo con lo expuesto en las líneas precedentes, planteamos la siguiente hipótesis que relaciona las medidas de participación del empleado y la dimensión afectiva del capital humano, del siguiente modo:

Subhipótesis 7c: La participación del empleado en la organización influye positivamente en el capital afectivo

\subsection{La relación entre las relaciones de apoyo entre compañeros y la retención del capital humano de la organización}

Las organizaciones tienen la capacidad de habilitar entornos y formas de trabajo que favorezcan las relaciones internas y el apoyo entre compañeros. Por ejemplo, el trabajo en equipo es una forma de interaccionar con otros empleados, el trabajo en colaboración con otros compañeros o llevar a cabo eventos informales entre empleados (tanto dentro 
como fuera de la organización), de modo que favorecen el vínculo y reciprocidad entre los empleados, lo que repercute de forma positiva en su deseo de permanencia en la organización, contribuyendo a la retención del capital humano. En consecuencia, formulamos la siguiente hipótesis.

\section{Hipótesis 8: Las relaciones internas de apoyo entre compañeros influyen positivamente en la retención del capital humano de la organización, a través de su influencia en el capital intelectual, social y afectivo de los empleados}

Al igual que en las hipótesis anteriores, dado que el capital humano se compone de capital intelectual, de capital social y de capital afectivo, justificaremos esta octava hipótesis atendiendo a la influencia de las medidas de conciliación en cada uno de estos tres componentes.

El comportamiento de apoyo entre compañeros al que nos referimos en este trabajo, alude al cuidado, asistencia, muestras de amistad y consideración recibido de los compañeros, y a la necesidad de actuar de forma recíproca, (Chew, 2004; Mossholder, Setton y Henagen, 2005), y es indicativo del grado de compromiso que los empleados desarrollan con sus pares (Settoon y Mossholder, 2002). Así, cuando un empleado recibe apoyo de otros empleados, genera un sentimiento de compromiso y reciprocidad hacia esos compañeros, y hacia la propia organización, lo cuál fortalece su relación con dichos compañeros, influyendo de forma positiva en su deseo de permanencia en la misma, incluso, aunque sienta cierta insatisfacción con otros aspectos de la organización (Maerzt y Campion, 1998). De este modo, se logra favorecer su retención y, por ende, la del capital intelectual (Mobley et al., 1979; Hom y Griffeth, 1995; Maerzt y Campion, 1998; Lee et al., 1999; Mitchell et al., 2001; Luna y Camps, 2003; Mossholder et al., 2005).

Por otra parte, son especialmente relevantes las actividades organizadas por la empresa, tanto formales como informales, en las que los empleados puedan sentirse libres para hablar, apoyar y ayudar a otros compañeros, porque, por un lado, ello redunda en una mayor satisfacción laboral y, por ende, en la mejora de su retención (Lambert et al., 2001; Friedman y Holtom, 2002) y, por otro lado, porque dicho apoyo también puede contribuir a la reducción del estrés, lo que, en última instancia, sabemos que favorece la 
retención del empleado (Fass, Bishop y Glissmeyer, 2007; Bateman, 2009); por lo que , de un modo otro, se logra favorecer la retención de su capital intelectual.

En base a las consideraciones previas, enunciamos la siguiente subhipótesis entre las relaciones internas de apoyo entre empleados y la retención del capital intelectual.

Subhipótesis 8a: Las relaciones internas de apoyo entre compañeros influyen positivamente en la retención del capital intelectual

En lo que se refiere al capital social, las relaciones internas de apoyo entre compañeros también pueden ser relevantes, puesto que, como hemos comentado con anterioridad, fortalecen la relación entre los empleados y, por tanto, su interacción social, influyendo de forma positiva sobre el capital social.

Así, por ejemplo, las situaciones en las que los empleados participan en eventos organizativos en los que se comunican cara a cara, favorecen los procesos en los que los empleados cooperan y se relacionan, conformándose así su capital social (Zárraga y Bonache, 2003; Swart y Kinnie, 2003b; Lengnick-Hall y Lengnick-Hall, 2006). Randel y Ranft (2007) evidencian que aquellas organizaciones en las que los empleados mantienen relaciones estables con otros compañeros, indirectamente facilitan y promueven su desempeño y favorecen la cooperación con otros empleados que, en última instancia, influye en el desarrollo del capital social. Por su parte, Lilius (2006) ${ }^{43}$ ofrece evidencia empírica sobre los efectos positivos del apoyo entre compañeros y propone un doble beneficio. Por un lado, las relaciones internas de apoyo entre compañeros ofrecen un soporte emocional que favorece la reafirmación positiva de los empleados que, a su vez, facilita a éstos enfrentar y perseverar ante dificultades laborales. Por otro lado, estas relaciones de apoyo ofrecen un soporte instrumental a través de ayuda directa, de la colaboración en la resolución de problemas, de ofrecer consejos, de facilitar el acceso a conocimientos y experiencias de otros, etc. Ambas

\footnotetext{
${ }^{43}$ Lilius (2006) trata de dar soporte empírico a la "teoría de organización cuidadora” desarrollada por Kahn (1993, 2005), que sugiere que las interacciones entre compañeros pueden generar recursos emocionales, sociales y psicológicos beneficiosos para la organización
} 
consecuencias se puede traducir en: primero, generar sensación de auto-eficacia ${ }^{44}$, es decir, mayor confianza en las propias habilidades. De este modo los empleados se muestran más proclives a la cooperación con otros empleados (Cabrera, Colins y Salgado, 2006). Y, segundo, generar gratitud y deseo de corresponder por el apoyo recibido, ofreciendo su ayuda y su apoyo a otros compañeros. En este sentido, según Lin (2001), este apoyo recíproco entre empleados es un proceso colectivo que requiere de recursos sociales como son los flujos de información entre empleados y los procesos de coordinación entre ellos, procesos que se relacionan positivamente con el capital social.

Más recientemente, Lin, Lee y Wang (2009) ${ }^{45}$ también avalan la relación positiva entre el capital social y la posibilidad de ayudar a otros compañeros. En su investigación, estos autores tratan de identificar los factores que más influyen en la relación entre la ayuda entre compañeros y el capital social. Sus resultados señalan tres factores que, efectivamente, se generan mediante las relaciones sociales de apoyo entre compañeros; y son: la confianza entre compañeros, el poder ayudarse y disfrutar con ello y, por último, la posibilidad de participar en encuentros y reuniones informales.

En suma, de acuerdo con todo lo expuesto en las líneas precedentes, planteamos la siguiente hipótesis que relaciona las relaciones internas de apoyo entre compañeros y la dimensión social del capital humano.

Subhipótesis 8b: Las relaciones internas de apoyo entre compañeros influyen positivamente en el capital social

Por último, las relaciones internas de apoyo entre compañeros, también, tienen efectos significativos en el capital afectivo. Como hemos comentado en repetidas ocasiones, los empleados valoran positivamente el soporte y apoyo que la organización les ofrece,

\footnotetext{
${ }^{44}$ Se refiere a la creencia de un individuo en sus propias habilidades y capacidades para poder alcanzar determinados objetivos, afectando a sus decisiones, al esfuerzo que realizará y a la perseverancia con que enfrentará obstáculos y dificultades (Bandura, 1977).

${ }^{45}$ Estos autores utilizan la lógica difusa. Esta vertiente de la matemática permite abordar la imprecisión intrínseca de las escalas de medición utilizadas, habitualmente, en los estudios organizativos, en los que la subjetividad del respondente es una limitación común (Nguyen y Walter, 2001).
} 
influyendo de forma significativa sobre su compromiso y afecto organizativos (Allen, Shore y Griffeth, 2003). Por tanto, aquellas medidas facilitadoras del apoyo entre empleados, son consideradas por los empleados como un acto positivo de la organización contribuyendo, así, a mejorar el capital afectivo de sus empleados (Rhoades y Eisenberger, 2002; Lilius, 2006). Además, el compañerismo y las muestras de apoyo entre empleados, crean confianza entre los empleados y ofrece un apoyo emocional a los empleados que se ha demostrado que repercute de forma positiva en el vínculo y afecto de los empleados hacia la organización (Ferres, Connell y Travaglione, 2004; Fass et al., 2007; Baeman, 2009).

Por su parte, Peterson (2007) comprueba empíricamente que favorecer los encuentros sociales y el apoyo entre empleados, por ejemplo, organizando actividades lúdicas fuera del trabajo, facilitando que los empleados se ayuden y preocupen unos de otros o favoreciendo un clima de camaradería, mejora el capital afectivo de los empleados. Recientemente, Wright (2009) avala la relevancia que el soporte y apoyo de los compañeros tiene para reducir el estrés de éstos y mejorar, así, su afecto hacia la organización. Por su parte, Ng y Sorensen (2008) confirman una alta correlación ${ }^{46}$, tanto del apoyo del supervisor como del apoyo de los compañeros, con el desarrollo de capital afectivo. Y, en la misma línea, Rousseau y Aubé (2010) evidencian que ambos tipos de apoyo (del supervisor y de los compañeros) manifiestan un impacto positivo y aditivo sobre los afectos organizativos de los empleados.

Así pues, estos argumentos nos permiten plantear la siguiente subhipótesis que vincula las relaciones internas de apoyo entre compañeros y la dimensión afectiva del capital humano.

Subhipótesis 8c: Las relaciones internas de apoyo entre compañeros influyen positivamente sobre el capital afectivo

\footnotetext{
${ }^{46}$ Cabe destacar que, en este trabajo, el soporte del supervisor muestra impacto, sobre el capital afectivo, levemente mayor al que ejerce el soporte y apoyo de los empleados.
} 


\subsubsection{La relación entre el capital humano retenido y los resultados intermedios de} la organización: la capacidad de innovación y los resultados de las personas

Este apartado se estructura en dos partes. La primera parte plantea las hipótesis de la relación del capital humano, en sus tres facetas -capital intelectual, social y afectivo-, con la capacidad de innovación. Y la segunda parte aborda la relación entre el capital afectivo y los resultados de las personas.

\subsection{La relación entre el capital humano y la capacidad de innovación de la organización}

Zhara y Nielsen (2002) destacan la necesidad de desarrollar, de motivar y de retener a los empleados. El objetivo es preservar su conocimiento en la organización, contribuyendo, de este modo, a la generación de un nuevo conocimiento que permita mejorar su capacidad de innovación. Es más, poder mantener en la organización un capital humano vinculado a un colectivo de empleados lo suficientemente formados y motivados, se ha demostrado que favorece el mantenimiento de la capacidad de innovación en la empresa (González-Álvarez y Nieto-Antolín, 2007).

La relación entre el capital humano y la capacidad de innovación de la organización deriva de la relación entre innovación y conocimiento, tanto el relativo al que poseen los individuos -capital intelectual- como el vinculado a las relaciones entre ellos-capital social-. De hecho, el capital intelectual es considerando un requisito previo para el desarrollo de la innovación (Lane, Koka y Puthak, 2006), principalmente, debido a la vinculación existente entre el conocimiento y la creatividad (Shipton et al., 2005; West et al. 2004; Amabile, 1996), y en tanto que ambos favorecen la innovación. Por otro lado, el capital social desempeña un importante papel en la creación de nuevo conocimiento (Morris et al., 2005; Armbretch et al., 2001; Tsai y Ghoshal, 1998) y consecuentemente puede contribuir a la mejora de la capacidad de innovación. Por último, la esfera afectiva del capital humano es decir, el capital afectivo también es relevante para el desarrollo de la capacidad de innovación en la organización (Hislop, 2005). En consecuencia, podemos formular la siguiente hipótesis 
Hipótesis 9: La retención del capital humano, a través de sus dimensiones de capital intelectual, capital social y capital afectivo, influye positivamente en la capacidad de innovación de la organización

En consecuencia, en este trabajo planteamos que las tres componentes del capital humano -capital intelectual, capital social y capital afectivo- pueden tener influencia en la capacidad de innovación, y estas relaciones son las que proponemos en las siguientes subhipótesis ${ }^{47}$.

2.2.3.2.1.1. La relación entre la retención de capital intelectual y la capacidad de innovación de la organización

El capital intelectual abarca los conocimientos, habilidades y capacidades de los empleados estratégicos de la empresa. De forma general, se considera que la habilidad de la empresa para innovar está relacionada intrínsecamente con el conocimiento de sus recursos humanos (Foss, 2007; Laursen, 2002), es decir, con el capital intelectual. Por tanto, este capital juega un importante papel en el desarrollo de su capacidad de innovación (Galunic y Rodan, 1998; Lopez-Cabrales et al., 2009). Es más, existe consenso en considerar que el capital intelectual de los recursos humanos es uno de los elementos cruciales para el desarrollo de la innovación en las organizaciones actuales (Jiménez-Jiménez y Sabater-Valle, 2010).

Lane, Koka y Puthak (2006) señalan como requisitos para el desarrollo de la innovación la existencia y el mantenimiento del conocimiento en la organización. Este argumento se justifica porque, considerando que la innovación tiene su origen en una idea creativa (West et al. 2004; Shipton et al., 2005), para que estas ideas creativas puedan surgir es necesario, por un lado, que previamente exista conocimiento -capital intelectual- que permita generarlas, $\mathrm{y}$, por otro lado, que transcurra tiempo suficiente para el desarrollo de esas nuevas ideas. Para lograr este mantenimiento de conocimiento en las

\footnotetext{
${ }^{47} \mathrm{Al}$ igual que en el caso de la nomenclatura para las subhipótesis relativas a las prácticas de recursos humanos y el capital humano, utilizaremos los subíndices "a," "b” y "c", para referirnos a las relaciones con el capital intelectual, social y afectivo, respectivamente.
} 
organizaciones, éstas tratan de retener a su capital humano más valioso, asegurando, así, la retención de capital intelectual valioso -por ende, los conocimientos, habilidades y experiencias- que permita mejorar su capacidad de innovación. De hecho, Collins y Smith (2006) señalan la retención del capital intelectual como un requerimiento previo a los procesos de aprendizaje organizativo que conducen a mejorar la capacidad de innovación de la organización.

Por su parte, Searle y Ball (2003) y Saa-Pérez y Díaz-Díaz (2007), sobre la base del potencial innovador de los empleados, destacan la importancia del capital intelectual en la capacidad de innovación. Delgado, Navas et al. (2008), siguiendo a Pizarro et al. (2007) argumenta que el capital intelectual influye positivamente en la capacidad de lograr innovaciones de producto, en base a los conocimientos de alto valor que pueden tener los empleados puesto que favorecen un mejor tratamiento de la información, un aprendizaje rápido y una aplicación eficaz de lo aprendido, potenciando la capacidad de innovación de la organización. Por tanto, la retención de empleados poseedores de un alto nivel de capital intelectual permite el fortalecimiento de dicho potencial innovador, mejorando la capacidad innovativa de la organización. Por su parte, también LópezCabrales, Pérez-Luño y Valle-Cabrera (2009), Martín de Castro, Alama, Navas y López (2009) y Jiménez-Jiménez y Sabater-Valle (2010) validan empíricamente que el capital intelectual potencia la capacidad de innovación ${ }^{48}$. Teniendo en consideración los anteriores argumentos, planteamos la siguiente subhipótesis que vincula la retención del capital intelectual y la capacidad de innovación.

Subhipótesis 9a: La retención del capital intelectual influye positivamente en la capacidad de innovación de la organización

\footnotetext{
${ }^{48}$ Profundizando en esta cuestión, Jiménez-Jiménez y Sabater-Valle (2010) identifican que los empleados cuyo capital intelectual se forma por conocimientos y habilidades capaces de generar competencias de exploración y explotación, son los empleados que más contribuyen al desarrollo innovativo organizativo.
} 


\subsection{La relación entre el capital social y la capacidad de innovación de la} organización

La innovación requiere, no sólo del capital intelectual, sino también de procesos de cooperación y colaboración de empleados -capital social- en los que se promuevan los flujos de conocimiento que dan soporte a la generación de nuevo conocimiento y, por ende, favorezcan la capacidad de innovación de la organización (Armbrecht et al., 2004; Morris et al., 2005).

Los trabajos de Nonaka (1991) y de Nonaka y Takeuchi (1995) destacan la importancia de los individuos y de los procesos de interacción entre ellos en la creación y compartición de conocimiento y como vías para el desarrollado de la innovación. Así, estos autores consideran que tanto el individuo y sus conocimientos (capital intelectual) como el capital social son básicos para el desarrollo de la capacidad innovadora de la organización. En sentido, aunque la literatura revisada nos muestra que tanto el capital intelectual como el capital social pueden influir sobre la capacidad de innovación (Morris et al., 2005 ${ }^{49}$ ) es, precisamente, el capital social quien recoge gran parte del conocimiento más crítico y significativo en el desarrollo de la capacidad de innovación (Cavusgil, Calantone y Zaho, 2003; Kang, Morris y Snell, 2007). Esto se debe a que las interacciones sociales, principalmente las interfuncionales, favorecen el intercambio de nuevas ideas que, normalmente, no surgen mediante los mecanismos formales (Ghoshal, Korine y Szulanski 1994) y facilitan, además, la colaboración de diferentes áreas funcionales, todo lo cual permite la combinación de conocimiento heterogéneo que favorece el desarrollo de innovaciones (De Clercq, Thongpapanl y Dimos, 2007, Chen y Huang , 2009; Lin et al., 2009; Rivera, 2009; Camelo, García y Sousa, 2010; GarcíaPintos, Caballero y Piñeiro, 2010).

El capital social, sustentado en las redes de interacción entre empleados, favorece el desarrollo de procesos que permiten la transferencia de conocimiento y que favorecen el acceso a un amplio y diverso abanico de conocimientos por los empleados; esta situación mejora la habilidad de la organización para desarrollar nuevos productos o servicios, es decir, para innovar (Ghoshal, Korine, y Szulanski 1994; Nonaka, 1994;

\footnotetext{
${ }^{49}$ Morris et al. (2005) aluden a ellos como stocks y flujos de conocimiento, respectivamente.
} 
Powell, Koput, y Smith-Doerr 1996; Uzzi, 1997; De Clercq y Sapienza, 2006). Abundando en estos argumentos, Armbretch et al. (2001) demuestran que las interacciones y procesos de cooperación entre empleados son críticos para favorecer la innovación en la empresa. Sus resultados evidencian que, aunque la capacidad de innovación suela depender de la habilidad de los empleados para generar nuevas ideas ${ }^{50}$, son los procesos de interacción entre empleados los que resultan catalizadores críticos de la creatividad y, consecuentemente, de la capacidad de innovación. De hecho, estas interacciones sociales, en otras palabras, el capital social, constituye una de las vías por las que las ideas creativas pueden ser capturadas y compartidas, todo lo cual, mejora la capacidad de innovación de la empresa (Tsai y Ghoshal, 1998; Armbretch et al., 2001; Hislop, 2005; Morris et al. 2005). También, Muñoz y Nieto (2006), en el ámbito español, demuestran que las empresas en las que se desarrollan el capital social a través de relaciones de intercambio de alta calidad (en este caso, relaciones de los empleados con su superior inmediato y con su grupo de trabajo) se ejercía una influencia positiva y significativa en su comportamiento creativo, que redunda en mejora de la innovación.

En suma, de acuerdo con lo expuesto en las líneas precedentes, planteamos la siguiente subhipótesis que relaciona el capital social y la capacidad de innovación.

Subhipótesis 9b: El capital social influye positivamente en la capacidad de innovación de la organización

2.2.3.1.3. La relación entre el capital afectivo y la capacidad de innovación de la organización

Por último, no podemos olvidar el tercer componente del capital humano que puede influir en la capacidad de innovación: el capital afectivo.

Shipton et al. (2005, 2006) consideran que el desarrollo de la innovación está ligado tanto a atributos individuales como a atributos colectivos y requiere de la actitud positiva y disposición proactiva de los empleados a participar en procesos de

\footnotetext{
${ }^{50}$ Estos autores consideran que de esta forma se contribuye a mejorar los productos, servicios o procesos de la organización.
} 
conocimiento. Con este objetivo, las organizaciones tratan de desarrollar un capital afectivo en sus empleados (Huselid, 1995). Así, algunos trabajos han demostrado que factores afectivos como el compromiso organizativo, la confianza organizativa o el sentimiento de vínculo con la organización, es decir, el capital afectivo, son esenciales en los comportamientos creativos e innovativos de los empleados (Tsai y Ghoshal, 1998; Hislop, 2003; Cabrera y Cabrera, 2005; Thompson y Heron, 2005; Gendrom, 2007).

Otros trabajos evidencian que en las organizaciones que se preocupan por nutrir el capital afectivo de sus empleados, gozan de su disposición a realizar esfuerzos discrecionales “extra” que pueden favorecer la capacidad de innovación, por ejemplo, a través de mostrarse más proclives a utilizar y compartir su conocimiento (Meyer y Allen, 1997; Alvesson, 2000; Takeuchi, 2001; Storey y Quintas, 2001; Hislop, 2003; Camelo et al., 2010), o demostrando una mayor implicación con los objetivos de la organización (Van der Bij, Song y Weggeman, 2003). También, trabajos como los de Lin (2007) y Camelo et al. (2010) basan sus argumentaciones en las motivaciones del individuo. Así, estos autores demuestran que la motivación intrínseca facilita el desarrollo de comportamientos que mejoran la capacidad de innovación, de forma más efectiva que la motivación extrínseca. En consecuencia, y puesto que el capital afectivo es considerado un motivador intrínseco (Camelo, García y Sousa, 2010; Ipe, 2003), se relaciona positivamente con la mejora de la capacidad de innovación (Camelo et al., 2010; Cabrera y Cabrera, 2005). Y ya, en el ámbito español, Camelo et al. (2010) evidencian la relación positiva del capital afectivo con el grado en el que los empleados contribuyen a mejorar la capacidad innovadora de la empresa, analizando esta relación desde el nivel del empleado ${ }^{51}$.

Así pues, de acuerdo con lo expuesto en las líneas precedentes, planteamos la siguiente subhipótesis que relaciona el capital afectivo y la capacidad de innovación.

Subhipótesis 9c: El capital afectivo influye positivamente en la capacidad de innovación de la organización

\footnotetext{
${ }^{51}$ Son escasos los trabajos de este ámbito desarrollados a nivel del individuo.
} 
Las subhipótesis anteriores nos han permitido justificar el impacto de las variables que forman el capital humano sobre la capacidad de innovación. No obstante, el capital afectivo también influye sobre la satisfacción del empleado con la organización, condicionando tanto sus actitudes como sus comportamientos. Todo ello repercute en la variable de resultado intermedio que hemos denominado "resultado de las personas"52. A esta relación dedicamos la siguiente hipótesis.

\subsection{La relación entre el capital afectivo y los resultados de las personas}

Existe evidencia empírica acerca de la influencia del vínculo afectivo organizativo de los empleados y su nivel de desempeño, su productividad, su satisfacción y su absentismo, entre otros ratios, que en este estudio recogemos en la variable resultados de las personas (Guest, 1997; Paauwe y Richardson, 1997; Paauwe y Boselie, 2005; Dyer y Reeves, 1995; Beckert et al., 1997; Guest, 1997; Ferris et al., 1998; Huselid y Beckert, 2000; Wright y Gardner, 2003). En este sentido, Boselie, Diezt y Boon (2005) revisan la investigación en recursos humanos del periodo 1994-2003 confirmando la amplia y significativa evidencia de la influencia que las prácticas de recursos humanos pueden ejercer el capital afectivo y éste, a su vez, sobre los resultados de las personas.

Aquellos empleados que desarrollan cierto vínculo y apego hacia la organización (capital afectivo) y una mayor motivación suelen demostrar una mayor satisfacción laboral que los conduce a desarrollar una actitud positiva hacia la organización y hacia su propio trabajo, un mayor nivel de desempeño y un mayor nivel de contribución con los objetivos organizativos (Martín, Martín y Trevilla, 2009), a la par que estos empleados muestran menores tasas de absentismo y de rotación voluntaria y son facilitadores de un mejor ambiente laboral (Reichers, 1985; Mathieu y Zajac, 1990; Iverson y Buttigieg, 1999; Meyer et al., 2002; Escrig, Roca y Bou, 2003; Paul y Anantharaman, 2003). Recientemente, García-Cruz et al. (2008) señalan algunas de las

\footnotetext{
${ }^{52}$ Como ya se ha justificado en el epígrafe 2.2.1.2, en este trabajo distinguimos entre resultados de las personas y resultados financieros, dimensiones que en muchos trabajos aparecen recogidas conjuntamente a través de los "resultados organizativos". Nuestra propuesta obedece a la corriente que identifica los resultados de las personas como antecedente del resultado empresarial, siendo, ésta última, la variable de resultado final (Paauwe y Richardson, 1997; Paul y Anhataramn, 2003; Boselie et al., 2005, entre otros)
} 
consecuencias más relevantes del desarrollo del capital afectivo en la organización, como son el desarrollo del compromiso organizativo (Costa, 2002; Ferres, Connell y Travaglione, 2003), la mejora del desempeño (Costa, 2002; Searle y Wilson, 2002) y la mejora de la satisfacción laboral de los empleados y de la satisfacción con relaciones en las que participan en el seno de la organización (Costa, 2002; Atkinson y Butcher, 2003). Además, sus resultados confirman la influencia positiva del capital afectivo en el desarrollo de comportamientos ciudadanos (García-Cruz y Valle-Cabrera, 2008) que conducen a la mejora de las variables que, en este estudio, recogemos la través de "los resultados de las personas”.

Así pues, en base a las consideraciones previas, planteamos la siguiente hipótesis que recoge la relación del capital afectivo y los resultados de las personas en la organización.

Hipótesis 10: El capital afectivo influye positivamente sobre los resultados de las personas en la organización

Por último, debemos analizar las relaciones de impacto en el resultado final planteado en esta investigación: el resultado empresarial.

\subsubsection{3.- La relación de la capacidad de innovación y de los resultados de las personas con el resultado empresarial}

Con las dos siguientes hipótesis abordamos la parte final de las relaciones propuestas en este trabajo, analizando el impacto que, tanto la capacidad de innovación como los resultados de las personas, pueden ejercer sobre los resultados empresariales de la organización. Los resultados empresariales analizados en este trabajo se definen a través de medidas financieras ${ }^{53}$ como la rentabilidad económica, la cifra de ventas o la cuota de mercado, entre otras, puesto que las medidas financieras se reconocen de forma tácita como los mejores indicadores del éxito de organización e, incluso, pueden ser considerados los únicos indicadores válidos, habida cuenta de su valor para los ejecutivos de la compañía, los accionistas y "el mercado" (Ichniowski et al., 1996).

\footnotetext{
${ }^{53}$ Las medidas financieras se reconocen de forma tácita como los mejores indicadores del éxito de organización, incluso pueden ser considerados los únicos indicadores válidos, habida cuenta de su valor para los ejecutivos de la compañía, los accionistas y "el mercado" (Ichniowski et al., 1996).
} 


\subsection{La relación de la capacidad de innovación y el resultado empresarial}

La innovación es, hoy en día, una de las principales fuentes de ventaja competitiva para las empresa (López et al., 2009). Por tanto, las empresas que logran satisfacer las necesidades de sus clientes, ofreciendo productos adaptados a sus demandas, y que son capaces de desarrollarlos más rápido y más eficientemente que sus competidores, estarán en una mejor posición para obtener mayores desempeños y mejores resultados (Nonaka y Takeuchi, 1995; Calantone et al., 2002; López-Cabrales et al., 2009).

Sabemos que existe un estrecho vínculo entre determinadas capacidades organizativas, como la capacidad de innovación, la ventaja competitiva y los resultados organizativos (López-Cabrales et al., 2006). De hecho, está demostrado que las empresas con mayor capacidad para aprender e innovar son más sensibles a los cambios, más flexibles y responden más rápido que sus competidores (Jiménez-Jiménez y Sanz-Valle, 2006). En concreto, la capacidad de innovación favorece la capacidad de la empresa para adaptar y cambiar sus productos, sus procesos y sus sistemas de gestión más rápidamente que la competencia, logrando, así, una situación de ventaja competitiva que les permite alcanzar mayor rentabilidad y mejores resultados financieros. Incluso, algunos autores, como Cavusgil, Calantone y Zhao (2003), señalan la capacidad de innovación como el factor más determinante del resultado empresarial.

Por otro lado, la capacidad de innovación mejora el desempeño organizativo (Damanpour, 1991; Pérez-Luño et al., 2007; García y Navas, 2007) y potencia la creación de nuevos productos, el acceso a nuevos mercados y la adecuación a las necesidades de los clientes, generando mayores beneficios, mayor crecimiento y mayores resultados financieros que se concretan en una mayor cuota de mercado, un incremento de la cifra de ventas superior a la de los competidores o una mejor rentabilidad económica (Damanpour et al., 1989; Brown y Eisenhard, 1995; Gnyawali et al., 1997; Hansen et al., 1999; Damanpour y Gopalakrishnan, 2001; Bontis et al., 2002; Nieto y Navas, 2003; Jimenez-Jimenez y Sanz-Valle, 2006; López-Cabrales, Pérez-Luño y Valle-Cabrera, 2009; entre otros). En esta misma línea, otros autores como, por ejemplo, Flor, Camisón y Oltra (2004) demuestran la influencia positiva de la 
capacidad de innovación sobre el desempeño alcanzado por empresas que trabajan en mercados internacionales y González-Álvarez y Nieto-Antolín (2005), apoyándose en el enfoque de recursos y capacidades, argumentan que la capacidad de innovación de la organización, debido a la ambigüedad causal que la caracteriza, respalda el mantenimiento de la ventaja competitiva innovadora de la empresa permitiendo que ésta alcance mejores resultados empresariales que sus competidores.

En suma, de acuerdo con lo expuesto en las líneas precedentes, planteamos la siguiente hipótesis que relaciona la capacidad de innovación y los resultados empresariales.

Hipótesis 11: La capacidad de innovación influye positivamente en los resultados empresariales de la organización

\subsection{La relación de los resultados de las personas y el resultado empresarial}

Tradicionalmente, se considera que las prácticas de recursos humanos influyen sobre las actitudes y comportamientos de los empleados con el fin de mejorar su nivel de desempeño, su productividad, su satisfacción laboral o su retención; variables que, en última instancia, condicionan el resultado empresarial (Huselid, 1995; Beckert et al., 1997; Guest, 1997; Wright y Gardner, 2003). Excelentes trabajos de revisión así lo han confirmado (Wright y McMahan, 1992; Dyer y Reeves, 1995; Guest, 1997; Ferris et al., 1999, Wright y Boswell, 2002; Bowen y Ostroff, 2004; Ferris et al., 2004, Brewster et al., 2005; Pauwe y Boselie, 2005; Boselie et al., 2005; Lepack et al., 2006; Takeuchi et al., 2009; Pauwee, 2009). No obstante, a pesar de esta amplia evidencia empírica, la dirección de la causalidad entre las variables resultado de las personas y las variables de resultado empresarial aún no está del todo clara y podemos encontrar evidencias en ambos sentidos (Wright, Gardner, Moynihan y Allen, 2004, 2005). En cualquier caso, la mayoría de los trabajos avalan la influencia positiva de los resultados de las personas en resultado empresarial.

Variables como la satisfacción laboral, la productividad del empleado o la rotación voluntaria y el absentismo (en sentido inverso) reflejan la predisposición de los empleados a realizar un mayor esfuerzo en su trabajo contribuyendo, de este modo, a la 
consecución de los objetivos empresariales; por tanto, cuando estas variables son positivas se logra que los empleados contribuyan más y mejor en las tareas y actividades que realizan, contribuyendo así a que la empresa, por su parte, también pueda alcanzar un mejor desempeño organizativo que se plasma en sus ratios de rentabilidad económica, de crecimiento, de medidas financieras, etc., en otras palabras, en mejores resultados empresariales (Ostroff, 1992; Paauwe y Ricardson, 1997; Shaw et al., 1997; Guest, 1999; Batt, 2002; Schneider, Hanges, Smith y Salvaggio, 2003; Paul y Anantharaman, 2003; Wright et al., 2004; Guthrie, Datta y Wright, 2004; Boselie, Dietz y Boon, 2005; Takeuchi et al., 2009).

Por tanto, en base a los argumentos expuestos en este apartado, planteamos la siguiente hipótesis.

Hipótesis 12: Los resultados de las personas influyen positivamente en los resultados empresariales de la organización

\subsubsection{RESUMEN DE LAS HIPÓTESIS PROPUESTAS.}

A modo de resumen, a continuación presentamos varias tablas que recogen las hipótesis y subhipótesis de este trabajo. En primer lugar, incluimos las hipótesis relativas al impacto de las prácticas de recursos humanos propuestas sobre capital humanointelectual, social y afectivo-, seguidamente, recogemos las hipótesis relativas a la relación de capital humano de la organización con las variables de resultados “intermedios” (capacidad de innovación y resultados de las personas) y, por último, las hipótesis que recogen las relaciones de impacto sobre el resultado empresarial. Todas estas hipótesis constituyen los objetivos de la posterior contrastación empírica. 
Tabla 2.2. Hipótesis que recogen la relación de las prácticas de recursos humanos transaccionales con la retención del capital humano

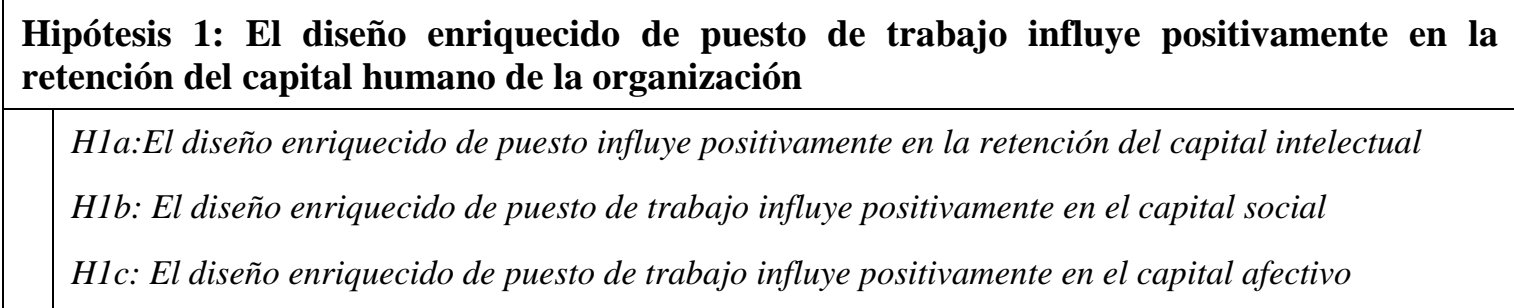

Hipótesis 2: La retribución (contingente, competitiva, equitativa y que incluya beneficios sociales) influye positivamente en la retención del capital humano de la organización

H2a: La retribución (contingente, competitiva, equitativa y que incluya beneficios sociales) influye positivamente en la retención del capital intelectual

$H 2 b$ : La retribución (contingente, competitiva, equitativa y que incluya beneficios sociales) influye positivamente en el capital social

H2c: La retribución (contingente, competitiva, equitativa y que incluya beneficios sociales) influye positivamente en el capital afectivo

Hipótesis 3: El desarrollo profesional del empleado influye positivamente en la retención del capital humano de la organización

HЗa: El desarrollo profesional del empleado influye positivamente en la retención del capital intelect.

H3b: El desarrollo profesional del empleado influye positivamente en el capital social

H3c: El desarrollo profesional del empleado influye positivamente en el capital afectivo

Hipótesis 4: Las medidas conciliación de vida laboral-personal influyen positivamente en la retención del capital humano de la organización

H4a: Las medidas de conciliación de vida laboral-personal influyen positivamente en la retención del capital intelectual

H4b: Las medidas conciliación de vida laboral-personal influyen positivamente en el capital social

H4c Las medidas conciliación laboral-personal influyen positivamente en el capital afectivo

Tabla 2.3. Hipótesis que recogen la relación de las prácticas de recursos humanos relacionales con la retención del capital humano

Hipótesis 5: El soporte del supervisor influye positivamente en la retención del capital humano de la organización

H5a: El soporte del supervisor influye positivamente en la retención del capital intelectual

H5b: El soporte del supervisor influye positivamente en el capital social

H5c: El soporte del supervisor influye positivamente en el capital afectivo

Hipótesis 6: La comunicación interna influye positivamente en la retención del capital humano de la organización

H6a: La comunicación interna influye positivamente en la retención del capital intelectual

H6b: La comunicación interna influye positivamente en el capital social 
H6c: La comunicación interna influye positivamente en el capital afectivo

Hipótesis 7: La participación del empleado influye positivamente en la retención del capital humano de la organización

H7a: La participación del empleado en la empresa influye positivamente en la retención del capital intelectual

H7b: La participación del empleado en la empresa influye positivamente en el capital social

H7c: La participación del empleado en la empresa influye positivamente en el capital afectivo

Hipótesis 8: Las relaciones internas de apoyo entre compañeros influyen positivamente en la retención del capital humano de la organización

H8a:Las relaciones internas de apoyo entre compañeros influyen positivamente en la retención del capital intelectual

H8b: Las relaciones internas de apoyo entre compañeros influyen positivamente en el capital social

H8c.Las relaciones internas de apoyo entre compañeros influyen positivamente en el capital afectivo

Tabla 2.4. Hipótesis que recogen la relación del capital humano con las variables intermedias de resultados organizativos (capacidad de innovación y resultados de personas)

Hipótesis 9: El capital humano retenido influye positivamente en la capacidad de innovación de la organización

H9a: La retención del capital intelectual influye positivamente sobre la capacidad de innovación de la organización

H9b: El capital social influye positivamente sobre la capacidad de innovación de la organización

H9c.El capital afectivo influye positivamente sobre la capacidad de innovación de la organización

Hipótesis 10: El capital afectivo influye positivamente sobre los resultados de las personas en la organización

Tabla 2.5. Hipótesis que recogen la relación de las variables intermedias de resultado con el resultado empresarial

Hipótesis 11: La capacidad de innovación influye positivamente en los resultados empresariales de la organización

Hipótesis 12: Los resultados de las personas influyen positivamente en los resultados empresariales de la organización 
Una vez definidas las hipótesis y subhipótesis de nuestro modelo de investigación, pasamos a contrastarlas en los siguientes capítulos. En el capítulo tercero describimos el diseño de la parte empírica: variables, metodología y muestra, con las que contrastaremos las hipótesis planteadas. A continuación, en el capítulo cuarto, presentamos el análisis estadístico llevado a cabo. Posteriormente, en el capítulo V, señalamos las conclusiones y principales aportaciones de esta investigación así como sus limitaciones. Finalmente, cerramos el presente trabajo detallando la bibliografía utilizada e incorporando un apartado de anexos que recoge información relevante de todo el trabajo realizado. 
Sección II

\section{DESARROLLO EMPÍRICO}





\section{Capítulo 3}

\section{DISEÑO DE LA}

\section{INVESTIGACIÓN EMPÍRICA}





\section{INTRODUCCIÓN}

En el presente capítulo exponemos las cuestiones relativas al diseño de la investigación empírica, lo que implica el seguimiento de una serie de pasos para operativizar los conceptos teóricos de la investigación y contrastar las hipótesis del modelo propuesto en el capítulo anterior.

Los pasos para el diseño de la investigación empírica suponen: primero, describir la muestra, explicar cómo se ha confeccionado el cuestionario y cuáles son las escalas e ítems que componen el mismo; posteriormente, revisar cómo se lleva a cabo la recogida de información; y, por último, justificar y presentar las técnicas de análisis de datos que se aplican en esta investigación para la contrastación de las hipótesis.

En primer lugar, dedicamos un apartado a describir el diseño de la muestra, lo que supone determinar la unidad objeto de análisis, así como las características de la misma. En particular, tomamos como población objeto de estudio empresas de más de 30 empleados que hayan recibido financiación del $\mathrm{CDTI}^{1}$ para innovación entre los años 2001 y 2007, empresas para las que el desarrollo de innovaciones constituye una de sus actividades estratégicas. Una vez delimitado el ámbito de esta investigación, describimos las características esenciales de la muestra. En segundo lugar, explicamos las partes fundamentales del cuestionario utilizado para este estudio, así como los diferentes ítems y escalas de medición utilizados para cada una de las variables que lo componen. Posteriormente, describimos el proceso de recogida de información. En esta investigación se ha optado por la utilización de envío postal del cuestionario complementándolo con el envío por correo electrónico del mismo (ambas son fuentes secundarias de información). En la última parte del capítulo, describimos las principales técnicas de análisis de datos que se van utilizar, justificando su adecuación a los diferentes objetivos y tareas necesarias para la validación de las escalas de medida y la contrastación empírica de las hipótesis del modelo: ecuaciones estructurales a través del análisis por mínimos cuadrados parciales (PLS- Partial Least Squares).

\footnotetext{
${ }^{1}$ Centro para el Desarrollo Tecnológico Industrial; entidad perteneciente al Ministerio de Ciencia e Innovación.
} 


\subsection{DISEÑO DE LA MUESTRA}

El primer paso necesario para iniciar la contrastación empírica de las hipótesis objeto de estudio es diseñar adecuadamente la muestra que servirá para obtener los datos. Para ello, se necesita delimitar las unidades de observación de la muestra seleccionada justificando el interés de la misma para la presente investigación.

La delimitación de las unidades de observación implica determinar cuáles son las realidades que se desean observar y qué datos debemos obtener de las mismas para desarrollar la investigación empírica. El principal criterio para la elección de las unidades de observación es que exista consonancia entre las unidades de observación y los objetivos e hipótesis planteadas en la investigación. El objetivo principal de esta investigación es analizar en qué medida un conjunto adecuado de prácticas de recursos humanos permite retener a los empleados estratégicos de la organización y, por ende, su capital humano-intelectual, social y afectivo-, favoreciendo, por tanto, la capacidad de innovación y los resultados de la organización.

Atendiendo a este propósito, el ámbito de estudio elegido comprende empresas con carácter innovador y con un tamaño mínimo. Los criterios de selección se detallan a continuación.

En primer lugar, para medir el tamaño de empresa, dado que este trabajo se enmarca dentro del ámbito de la Dirección de Recursos Humanos, hemos optado por elegir el número de empleados como indicador del mismo. Este criterio es el más habitual en las investigaciones de campo de la dirección estratégica de recursos humanos vinculadas a la innovación (Bae y Lawler, 2000; Céspedes, Jerez y Cabrera, 2005; Laursen y Foss, 2003; Ordoñez de Pablos, 2003; entre otros). Hemos fijado como tamaño mínimo el de empresas de más de 30 empleados, para asegurar que exista una función suficiente de recursos humanos, tal y como también proponen otras investigaciones del campo de la gestión de recursos humanos (Peña García-Pardo et al., 2010). Peña García-Pardo et al. (2010) fijan el umbral mínimo en 20 empleados, mínimo que establecen tras desarrollar 
un test piloto para garantizar la existencia de un departamento de recursos humanos con funciones claramente definidas ${ }^{2}$.

En segundo lugar, y para asegurar el carácter innovador y de desarrollo de la capacidad innovadora de las empresas de la muestra, hemos seleccionado empresas que hayan recibido, empleado y justificado financiación de fondos públicos para innovación durante el periodo comprendido entre los años 2000-2007. Esta información se ha obtenido del Centro para el Desarrollo Tecnológico Industrial (CDTI). El CDTI es una entidad pública empresarial, dependiente del Ministerio de Ciencia e Innovación, que tiene como objetivo ayudar a las empresas españolas a elevar su nivel tecnológico mediante la financiación de proyectos de $\mathrm{I}+\mathrm{D}$, la gestión y promoción de su participación en programas internacionales de cooperación tecnológica, el apoyo a la transferencia de tecnología en el ámbito empresarial y el apoyo a la creación de empresas de base tecnológica. En la actualidad el CDTI se ha consolidado como una de las entidades clave en la promoción de la innovación y el desarrollo tecnológico empresarial español. La información procedente de este organismo ya ha sido utilizada en estudios previos sobre innovación demostrando su validez (Montoro, Mora y Guerras, 2006; Segarra Ciprés, 2006; Mora Valentín, 2002). Por último, otro de los motivos de la elección de este tipo de empresas es que permite asegurar, con ciertas limitaciones, un tipo de empresa innovadora en la se pueda identificar la presencia de empleados clave y demandantes de adecuadas políticas de gestión.

Como se ha detallado en el capítulo anterior, existe un gran número de referencias que señalan que no todo el capital humano es un recurso homogéneo ni ofrece el mismo nivel de resultados y desempeño a la organización. Algunos individuos constituyen el grupo de los empleados clave o estratégicos cuyo trabajo es esencial para las actividades clave de la organización -innovación, en este caso- y este grupo es considerado, a menudo, como el verdadero capital que debe ser retenido y fidelizado (Lepack y Snell, 1999; Lopez-Cabrales et al., 2007). Este capital tiene un elevado valor estratégico (Barney y Wright, 1998), por lo que requiere ser tratado y gestionado de un modo adecuado (Lepack y Snell, 1999).

\footnotetext{
${ }^{2}$ Otros estudios del ámbito español fijan el umbral mínimo en 40-50 empleados (López-Cabrales et al., 2009; Jiménez-Jiménez y Sabater - Sánchez, 2010).
} 
Se puede afirmar que, en general, las tareas orientadas a la innovación recaen en un tipo de empleado formado, principalmente, por técnicos, especialistas, profesionales de la I+D y, también, en aquellos empleados que tienen el conocimiento requerido para asegurar el cumplimiento de tareas y tecnologías necesarias (Shipton et al., 2006). Estos empleados, distribuidos en diferentes niveles de la organización, juegan un papel importante dentro de la misma, intercambiando y realizando sugerencias de mejora para sí o contribuyendo a que otros lo hagan. De este modo se mejora el conocimiento, la innovación y los resultados de la organización (Subramanian y Youndt, 2005; Youndt et al., 2004). Por tanto, el área de recursos humanos se enfrenta al reto de desarrollar e implementar las prácticas necesarias para facilitar este proceso e influir, de forma positiva, sobre la innovación (Laursen y Foss, 2003; Shipton et al., 2006; García-Pintos, García y Piñeiro; 2010), que cual constituye, precisamente, uno de los objetos de estudio de este trabajo.

Por tanto, la unidad de observación de esta investigación es la empresa y, concretamente, aquellas empresas de más de 30 empleados que hayan recibido financiación para innovación entre el 2000-2007, según las bases de datos del CDTI. Este conjunto de empresas están muy comprometidas con el desarrollo de innovaciones para competir, de un modo sostenible, en un mercado cambiante y complejo como el actual. Esta selección responde a nuestro interés investigador porque: 1) asegura una función suficiente de recursos humanos; 2) ofrece una población de empresas para las que el desarrollo de la capacidad de innovación es importante y forma parte de sus objetivos; y 3) permite asegurar la existencia de un grupo de empleados clave, sobre los que queremos estudiar el impacto que determinadas prácticas de recursos humanos ejercen sobre ellos, sus relaciones y sus afectos respecto a la organización, lo que se ha denominado en el capítulo anterior, capital intelectual, capital social y capital afectivo.

Como se ha indicado, la población observada se delimitó mediante la utilización de un directorio de empresas españolas facilitado por el Centro para el Desarrollo Tecnológico Industrial (CDTI). Dicho directorio fue solicitado durante el verano del 2008 al CDTI. Este directorio constaba únicamente del nombre de las empresas y su dirección web. El directorio se completó mediante la búsqueda de direcciones postales, nombre del responsable de empresa y/o de recursos humanos y mail de contacto, durante los meses 
de septiembre, octubre y noviembre de 2008. Como resultado, se elaboró un directorio de $1556(\mathrm{~N})$ empresas con los criterios indicados en el epígrafe anterior.

\subsection{DISEÑO DEL CUESTIONARIO Y OBTENCIÓN DE DATOS}

Una vez seleccionada la base de empresas objeto de estudio, el siguiente paso consistió en elaborar un cuestionario que recogiera las escalas de medida de las variables del modelo propuesto para la investigación. Posteriormente, se llevó a cabo el proceso de recogida de información para la obtención de datos de las empresas objeto de estudio.

\subsubsection{Diseño del cuestionario}

Como pasos previos al desarrollo del cuestionario final, realizamos una amplia revisión de la literatura específica que permitió seleccionar los ítems más adecuados para la medición de las variables propuestas en este estudio. En base a ello, elaboramos un primer cuestionario con el que se realizó una fase exploratoria (pre-test), contando con la colaboración, mediante la realización de entrevistas en profundidad, de un panel de expertos formado por distintos profesionales del ámbito institucional, empresarial y académico que revisaron y contribuyeron a mejorar y depurar el cuestionario, tanto en cuestiones de fondo como de forma.

El panel de expertos se compuso por responsables de recursos humanos y de gestión de conocimiento de diferentes empresas con una fuerte componente innovadora (Grupo Siro, Peguform S.L., Grupo Antolín, Telefónica I+D), por consultores de recursos humanos, expertos en cuestionarios de la Dirección General de Estadística de la Junta de Castilla y León y por expertos académicos en técnicas de investigación y expertos en organización de empresas. Teniendo en cuenta toda la información y matizaciones recabadas, este proceso de mejora culminó en la propuesta del cuestionario definitivo, con un formato operativo adecuado para su difusión. Veáse el apartado A3.3 del Anexo III que recoge la versión definitiva del mismo.

El cuestionario desarrollado está compuesto por cuatro bloques de cuestiones, que representan los distintos ítems asociados a cada una de las variables del modelo, a saber: datos generales, prácticas de recursos humanos de retención, capital humano estratégico 
de la organización -intelectual, social y afectivo- y resultados organizativos. A continuación, se explica, con más detalle, cada uno de estos bloques.

En primer lugar, en la portada previa al cuestionario, se aclaran al lector potencial tres aspectos importantes para la posterior cumplimentación del mismo. Primero, se señala el objetivo principal y motivación de la investigación: analizar el impacto de las prácticas de recursos humanos en la retención de empleados clave, así como, sobre la capacidad de innovación de la organización; segundo, se especifica a quien va dirigido el cuestionario y, por tanto, debe ser el responsable de responder: al director de recursos humanos de la empresa o, en su defecto, al director general de la misma. Y, por último, cuáles son los empleados de interés para el estudio y en los que se debe pensar al responder el cuestionario: empleados valiosos, estratégicos, altamente cualificados. Este último aspecto era de vital importancia para el estudio, ya que toda la investigación se orienta a un colectivo concreto de empleados, aquellos que la empresa considera claves y especialmente valiosos, por lo que las medidas encaminadas a su retención tienen un mayor sentido. Por ello, a lo largo del cuestionario, también se recordó, en varias ocasiones, el tipo de empleados al que se refería el mismo.

En el primer bloque de cuestiones se incluyen los datos generales de la empresa, que servirán como variables de control del estudio y variables descriptivas de la muestra. En particular, se pregunta por el sector de actividad, los años de actividad empresarial del centro de trabajo, el número de trabajadores medio, la edad media de sus empleados, la antigüedad media de sus empleados, si la empresa pertenece a un grupo corporativo y, por último, si es nacional o internacional. A continuación, en el segundo bloque, se abordan las prácticas de recursos humanos orientadas a la retención de empleados. En concreto, se valoran aspectos sobre: diseño de puesto de trabajo, retribución, desarrollo del empleado, conciliación vida laboral/personal, soporte del supervisor, comunicación interna, participación del empleado y relaciones internas entre compañeros.

El Cuadro 3.1 resume los ítems que se han utilizado para medir cada una de dichas prácticas y las referencias en las que nos hemos basado. Para su medición se utilizó siempre una escala Likert de 5 puntos (siendo el valor 1 total desacuerdo/nunca y 5 total acuerdo/siempre). 
Cuadro 3.1. Escalas de medición de las prácticas de recursos humanos de retención

\begin{tabular}{|l|l}
\hline ÍTEMS DEL CUESTIONARIO & AUTORES CLAVE \\
\hline
\end{tabular}

Diseño de puesto enriquecido

Los PUESTOS DE TRABAJO, en esta empresa:

Plantean retos a los empleados

Ofrecen libertad y autonomía al empleado para planificar su trabajo

Contienen tareas y actividades heterogéneas (no repetitivas)

Requieren que el empleado utilice habilidades y conocimientos

complejos y cualificados

\section{Retribución}

EI SISTEMA DE COMPENSACIÓN, en esta empresa:

Ofrece un nivel retributivo superior al de la competencia

Mantiene la equidad retributiva entre puestos o categorías similares

Incluye incentivo basado en el desempeño individual

Incluye incentivo basado en el desempeño del grupo de trabajo

Incluye incentivo basada en el resultado anual de la empresa

Incluye una componente de incentivo a largo plazo

Incluye un paquete de beneficios sociales para los empleados
Hackman y Oldham, 1980; Thomson y Heron, 2006, Guest, 2002; Vaiman, 2004; Dockel, 2003; Shipton et al., 2004

\section{Desarrollo: Formación y Promoción}

\section{Esta empresa ofrece:}

Un programa de acogida y formación para los nuevos empleados Actividades de formación orientadas al desarrollo de conocimientos y habilidades específicos de esta empresa

Formación amplia e interdisciplinar

Formación de trabajo en equipo y de relaciones interpersonales

Formación orientada al desarrollo de carrera profesional

Oportunidades de promoción

Un sistema de promoción basado en el desempeño

Un sistema formal de desarrollo de carrera profesional
Youndt y Snell, 2004; Lepack y Snell, 2002; Pfeffer, 1994,1998; Collins y Smith, 2006, Hsu et al., 2007; Shaw et al., 1999; Shaw, 1996; Shipton et al., 2004; Choo et al., 2005; Minbaeva et al., 2003; Thomson y Heron, 2006

\section{Conciliación vida laboral-personal}

Esta empresa ofrece:

Flexibilidad a los empleados para que elijan y distribuyan su horario Facilidades para atender las necesidades familiares o personales (reducción de jornada, teletrabajo, excedencias, permisos, )

Ayudas económicas para las necesidades personales de sus empleados (préstamos, ayudas para guardería, etc.)

Un plan específico formal de conciliación de vida laboral-personal
Lopez Cabrales et al., 2008;

Sun et al., 2007; Lepack y Snell, 2002; Minbaeva, 2005; Delery y Doty, 1996; Cho e tal., 2005; Thomson y Heron, 2006; Youndt y Snell, 004; Hsu et al., 2007

\section{Soporte del supervisor o superior jerárquico}

Los mandos de esta empresa

Son generalmente accesibles para los empleados

Muestran interés por el desarrollo y crecimiento profesional de los

empleados a su cargo

Atienden los problemas y necesidades de sus empleados

Reconocen los méritos y logros de los empleados a su cargo
Lazarova, 2004; Vaiman, 2004; White at al., 2003; Guest,2002; Peterson, 2007; Parker, 2007; Thomson y Heron, 2006; Parkes y Langford,2008;Fisher, 2001. 
Cuadro 3.1bis. Escalas de medición de las prácticas de recursos humanos de retención

\begin{tabular}{|c|c|}
\hline ÍTEMS DEL CUESTIONARIO & AUTORES CLAVE \\
\hline \multicolumn{2}{|c|}{ Comunicación Interna } \\
\hline $\begin{array}{l}\text { Los empleados de esta empresa: } \\
\text { Reciben regularmente información sobre aspectos clave de empresa. } \\
\text { Disponen de canales de comunicación entre distintos departamentos, } \\
\text { unidades o secciones para resolver problemas y buscar soluciones } \\
\text { Disponen de medios diversos de comunicación interna (intranet, } \\
\text { revista de empresa, tablones de anuncios, etc.) } \\
\text { Disponen de facilidades para comunicarse con sus superiores }\end{array}$ & $\begin{array}{l}\text { Minbaeva, 2003; Choo et al, } \\
\text { 2005; Garder et al, } 2007\end{array}$ \\
\hline \multicolumn{2}{|l|}{ Participación del empleado } \\
\hline $\begin{array}{l}\text { Los empleados de esta empresa: } \\
\text { Son requeridos y se valora su opinión para tomar algunas decisiones } \\
\text { Tienen la posibilidad de sugerir mejoras relacionadas con su trabajo } \\
\text { Pueden sugerir mejoras relacionadas con su empresa, por ejemplo, a } \\
\text { través de un sistema de sugerencias y reclamaciones } \\
\text { Participan formalmente en grupos de mejora de calidad, grupos de } \\
\text { resolución de problemas, etc. }\end{array}$ & $\begin{array}{l}\text { Hsu, Lin et al. 2007, Bae y } \\
\text { lawler, 2000; Garder et al, } \\
\text { 2007, Hsu, Lin et al. 2007, } \\
\text { Guest, } 2002 \text {; Sun et al., } \\
\text { 2007; Delery y Doty, 1996; } \\
\text { Jiménez y Sanz, } 2005\end{array}$ \\
\hline \multicolumn{2}{|l|}{ Relaciones internas de apoyo entre compañeros } \\
\hline $\begin{array}{l}\text { En esta empresa: } \\
\text { Se promueven actividades fuera del trabajo en las que los empleados } \\
\text { pueden relacionarse } \\
\text { Se dispone de lugares donde los empleados pueden relacionarse (sala } \\
\text { de café, salas de estar, etc.) y/o de instalaciones de ocio } \\
\text { (instalaciones deportivas, etc.) } \\
\text { Los empleados saben que pueden dedicar tiempo, atención y ayuda a } \\
\text { sus compañeros } \\
\text { Se fomentan acciones que favorezcan el compañerismo }\end{array}$ & $\begin{array}{l}\text { Peterson, 2007; Mossholder } \\
\text { et al, 2005; Minbaeva, } 2005\end{array}$ \\
\hline
\end{tabular}

Por otra parte, el tercer bloque de preguntas recopila información relativa al capital humano. En particular, se formulan cuestiones sobre las componentes del capital humano: capital intelectual, capital social y capital afectivo. La definición conceptual de estas variables dependientes ya ha sido presentada en el capítulo anterior. Véase el Cuadro 3.2, a continuación, para conocer los ítems utilizados y los trabajos utilizados como referencia para seleccionarlos. Para su medición se utilizó, como en el caso anterior, una escala Likert de 5 puntos (siendo el valor 1 total desacuerdo y 5 total acuerdo). 
Cuadro 3.2. Escalas de medición del capital humano -intelectual, social y afectivo- de los empleados estratégicos de la organización

\begin{tabular}{|c|c|}
\hline ÍTEMS DEL CUESTIONARIO & AUTORES CLAVE \\
\hline \multicolumn{2}{|l|}{ Capital intelectual } \\
\hline $\begin{array}{l}\text { Esta empresa logra mantener de forma estable a los empleados: } \\
\text { Altamente cualificados, } \\
\text { Considerados como "los mejores" en nuestro sector } \\
\text { Creativos y brillantes } \\
\text { Expertos y/o competentes en sus trabajos y funciones } \\
\text { Que desarrollan nuevas ideas y conocimiento }\end{array}$ & Youndt y Snell, 2004 \\
\hline \multicolumn{2}{|l|}{ Capital social } \\
\hline $\begin{array}{l}\text { En esta empresa es habitual que los empleados: } \\
\text { Combinen e intercambien conocimiento para resolver problemas o } \\
\text { crear oportunidades } \\
\text { Compartan sus propias ideas para presentar o proponer nuevas ideas, } \\
\text { productos o servicios } \\
\text { Colaboren entre ellos para diagnosticar y resolver problemas } \\
\text { Compartan información y aprendan unos de otros } \\
\text { Interaccionen e intercambien ideas con personal de otras áreas } \\
\text { Apliquen el conocimiento de un área de la empresa para resolver } \\
\text { problemas que surjan en otras }\end{array}$ & $\begin{array}{l}\text { Youndt y Snell, 2004; } \\
\text { Collins y Smith (2006) }\end{array}$ \\
\hline \multicolumn{2}{|l|}{ Capital afectivo } \\
\hline $\begin{array}{l}\text { Los empleados de esta empresa: } \\
\text { Tienen un fuerte sentimiento de pertenencia a esta empresa } \\
\text { Consideran que la empresa tiene un gran sentido y valor personal } \\
\text { para ellos } \\
\text { Consideran como propios los problemas de la empresa } \\
\text { Consideran que la empresa los trata de forma justa } \\
\text { Consideran que la empresa es honesta, sincera y confian en ella } \\
\text { Consideran que hay coherencia entre lo que empresa "dice” y "hace" }\end{array}$ & $\begin{array}{l}\text { Meyer y Allen, (1996), } \\
\text { Thomson y Heron (2006), } \\
\text { Rhoades et al. (2001), } \\
\text { Robinson\&Rousseau(1994), } \\
\text { Mayer y Davis (1995), } \\
\text { Tzafrir y Dolan (2004), } \\
\text { Collins y Smith (2006) }\end{array}$ \\
\hline
\end{tabular}

El cuarto y, último bloque de preguntas del cuestionario, se orienta a los resultados, que como hemos expuesto en la presentación del modelo, en el capítulo anterior, se estructuran en dos tipos: resultados internos (capacidad de innovación y resultados relativos a las personas) y resultados finales (resultados empresariales). Las definiciones de estas tres variables ya han sido expuestas previamente en el capítulo segundo. En el Cuadro 3.3, se resumen los principales ítems utilizados para medir las variables de resultados del modelo propuesto en esta investigación y los trabajos correspondientes revisados a tal efecto. Al igual que en los dos bloques anteriores, para su medición, se utilizó una escala Likert de 5 puntos (siendo el valor 1 total desacuerdo y 5 total 
acuerdo), con la peculiaridad de que las variables de resultados (empresarial y de personas), se definían en términos relativos, esto es, en comparación con las empresas competidoras del sector.

Cuadro 3.3. Escalas de medición de las variables de resultados organizativos

\begin{tabular}{|l|l|}
\hline ÍTEMS DEL CUESTIONARIO & AUTORES CLAVE \\
\hline
\end{tabular}

\section{Capacidad de Innovación}

\begin{tabular}{|l|l} 
Esta empresa: & Calantone et al, 2002 \\
Pone en práctica nuevas ideas frecuentemente & \\
Busca nuevas formas de hacer las cosas & \\
Es creativa en los métodos y procesos de trabajo & \\
Suele ser pionera en lanzar nuevos productos y servicios al mercado & \\
Percibe la innovación como arriesgada y tiende a la evitarla (rev) & \\
Ha incrementado la introducción en el mercado de nuevos & \\
productos/servicios en los últimos 5 años &
\end{tabular}

Resultados de las Personas

En relación a la competencia, en los últimos 5 años, la empresa Ha incrementado el grado de satisfacción laboral (resultados de encuesta de clima, etc.)

Ha incrementado el grado medio de desempeño de los empleados (productividad, etc.)

Ha disminuido la tasa de abandono voluntario de los empleados Ha disminuido la tasa de absentismo laboral

\section{Resultados empresariales}

En relación a la competencia, en los últimos 5 años, la empresa Ha incrementado sus ventas Ha mejorado su posición competitiva (cuota de mercado) Ha mejorado su rentabilidad (económica)

Ha incrementado el número de innovaciones llevadas a cabo

Ha incrementado el esfuerzo que hace por innovar (gastos, horas/persona y equipo, formación, etc.)

\subsubsection{Obtención de datos}

\subsubsection{Envío del cuestionario}

Para la obtención de la información necesaria para el contraste de las hipótesis y subhipótesis formuladas se han utilizado varios métodos con el fin de intensificar el ratio de respuesta. 
En primer lugar, se buscó el apoyo institucional como vía para reforzar y dar credibilidad y seguridad sobre el objetivo del estudio y de quiénes lo realizaban. Para ello, se acudió al Parque Científico de la Universidad de Valladolid ${ }^{3}$ y al Vicerrectorado de Desarrollo e Innovación de la misma Universidad, quienes manifestaron el deseo firme de apoyar este estudio. Con ese fin, el Sr. Vicerrector de Desarrollo e Innovación y Director General del Parque Científico de la Universidad de Valladolid, redactó una carta de apoyo para que la pudiéramos adjuntar con el cuestionario. En el apartado A3.1. del Anexo III puede consultarse dicha carta.

En segundo lugar, al tratarse de una muestra de empresas innovadoras, consideramos que la vía electrónica podía ser un buen canal para el envío del cuestionario. Por ello, el primer envío de carta y cuestionario, se hizo a través del correo electrónico. La carta/email que se utilizó como presentación al cuestionario se ha recogido en el apartado A3.2. del Anexo III. En este mail se presentaba brevemente la investigación, se adjuntaba el cuestionario y se señalaba una dirección web diseñada para su cumplimentación automática. Posteriormente, una vez descontadas las respuestas recibidas por e-mail, se envió por correo postal al resto de las empresas de la muestra. Este envío se componía de la carta de de apoyo del Parque Científico de la UVA, el cuestionario y un sobre franqueado con nuestra dirección, para facilitar al máximo el envío del cuestionario.

Debemos señalar que, sorprendentemente, la tasa de respuesta electrónica fue muy baja $^{4}$. Analizando este hecho, hemos llegado a la conclusión de que puede deberse a dos motivos principales: 1) la seguridad informática de las empresas “devolvía” el cuestionario enviado y, 2) aún no existe cultura de respuesta electrónica por lo que sigue siendo más eficaz, el método tradicional de envío postal adjuntando un sobre sellado para la respuesta.

\footnotetext{
${ }^{3}$ El Parque Científico de la Universidad de Valladolid es un organismo cuya misión es configurar un espacio que potencie la interacción entre el mundo científico y las empresas, ayudando a orientar los resultados de la investigación universitaria hacia las demandas y necesidades más apremiantes del entorno. Esto facilita la transferencia de conocimientos y tecnología, apoyando la creación de nuevas empresas y promoviendo campos el desarrollo de una cultura orientada a la innovación tecnológica y la gestión del conocimiento. Colabora, así, con el desarrollo de investigación pública de excelencia.

${ }^{4}$ Solo el $12 \%$ del total de los cuestionarios recibidos se recibieron a través de mail o el enlace web que se habilitó para su difusión.
} 
El lanzamiento del cuestionario se realizó en la semana del 20-26 de noviembre del 2008. A partir de ese momento, y durante los meses comprendidos entre diciembre del 2008 y marzo-abril del 2009 se recibieron los cuestionarios.

\subsubsection{Recepción del cuestionario}

El total de cuestionarios recibidos fue de 246. Una vez eliminados 7 cuestionarios incompletos, el total de cuestionarios válidos sometidos a estudio ha sido de 239. Por tanto, la tasa de respuesta obtenida es del $15 \%$, con un error muestral máximo de $\pm 6 \%$. Esta tasa puede considerarse muy adecuada, si se compara con las tasas de otros estudios de similar naturaleza, especialmente en el campo de los recursos humanos. El Cuadro 3.4 contiene la ficha técnica de la investigación empírica.

Cuadro 3.4. Ficha técnica de la investigación empírica

\begin{tabular}{|l|l|}
\hline $\begin{array}{l}\text { UNIVERSO Y ÁMBITO DE LA } \\
\text { INVESTIGACIÓN }\end{array}$ & $\begin{array}{l}1556 \text { empresas innovadoras ubicadas } \\
\text { en territorio español }\end{array}$ \\
\hline \hline TAMAÑO DE LA MUESTRA FINAL & 239 empresas \\
\hline \hline TASA DE RESPUESTA & $15 \%$ \\
\hline \hline ERROR MUESTRAL & $+/-6 \%$ \\
\hline \hline $\begin{array}{l}\text { METODO DE OBTENCIÓN DE LA } \\
\text { INFORMACIÓN }\end{array}$ & $\begin{array}{l}\text { Cuestionario postal o cuestionario } \\
\text { electrónico }\end{array}$ \\
\hline \hline PROCEDIMIENTO DE MUESTREO & $\begin{array}{l}\text { El cuestionario fue enviado a todas } \\
\text { las empresas que constituían la } \\
\text { población }\end{array}$ \\
\hline \hline PERIODO DE TRABAJO DE CAMPO & Noviembre 2008-abril 2009 \\
\hline
\end{tabular}

\subsubsection{Test de factor único de Harman}

Asímismo, puesto que en cada empresa sólo una persona respondía al cuestionario, es importante controlar que no haya un sesgo en la forma de contestar a las diversas preguntas que pudiera dar lugar a relaciones espurias. Por ello, se realizó el test del factor único de Harman (Podsakoff y Organ, 1986), que indica que no hay evidencias de 
que exista un factor común substancial en los datos recogidos. Al efectuar un análisis factorial con todos los ítems del modelo, se extrajeron 17 factores con un autovalor superior a la unidad, que explicaban un $72 \%$ de la varianza. El primer factor explicaba sólo un $29 \%$. Este test nos sirve como señal de que el sesgo del método común no es un problema en esta investigación ${ }^{5}$.

\subsubsection{Perfil de la muestra}

Una vez expuesto el contenido y estructura del cuestionario, procedemos a caracterizar la muestra obtenida con los 239 cuestionarios válidos recibidos.

\subsubsection{Sector de actividad}

La muestra obtenida representa una variedad de sectores de actividad. No obstante, a pesar del predominio de las empresas del sector industrial (79.1\%,), también existe un porcentaje destacable de empresas del sector servicios (12.8\%) y de otras actividades (8.1\%), como puede verse en la Figura 3.1.

Figura 3.1. Sectores principales de actividad de la muestra

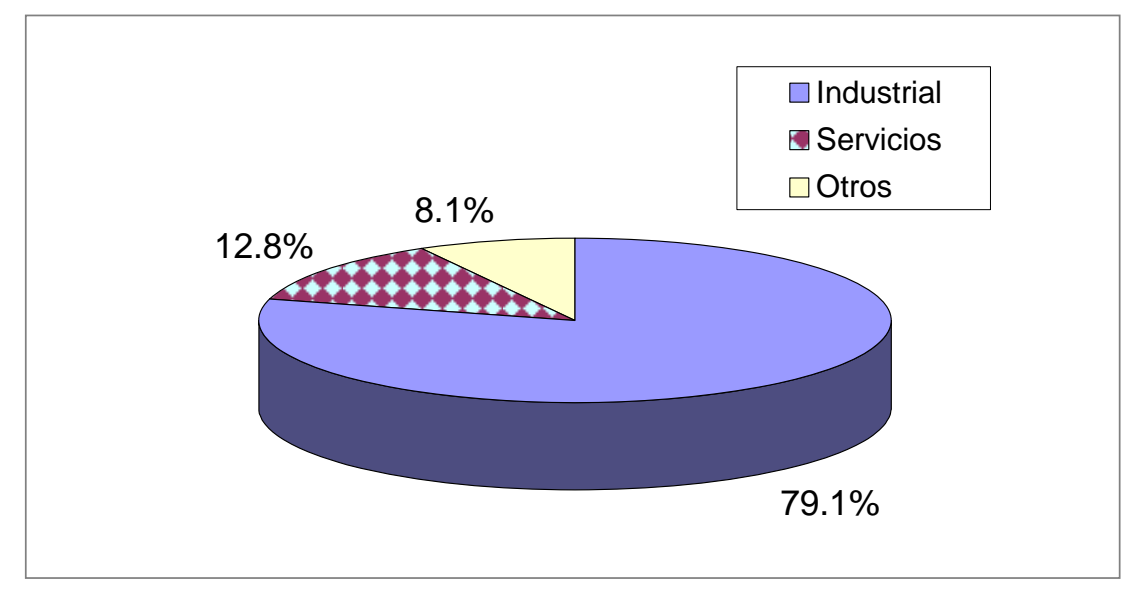

\footnotetext{
${ }^{5}$ El hecho utilizar medidas subjetivas únicamente puede dar lugar a un sesgo de método común. El sesgo de método común se puede producir cuando tanto la variable dependiente como las independientes provienen de la misma fuente, como es el caso de este estudio. Para valorar el sesgo de método común hemos utilizado el análisis de un factor de Harman. Se introdujeron todas las variables del estudio en un análisis factorial exploratorio y se examinó la solución no rotada para determinar el número de factores que son necesarios para explicar la varianza de la variable. La asunción básica de esta técnica es que si existe una sustancial varianza de método común: a) el análisis factorial extraerá un único factor o b) un único factor acumulará la mayoría de la covarianza de las medidas. Analizando los resultados obtenidos en este estudio estos hechos no ocurren.
} 


\subsubsection{Tamaño de empresa}

En cuanto al tamaño de las empresas, medido a través del número de empleados ${ }^{6}$ (Arthur, 1994; Huselid, 1995; Delaney y Huselid, 1996; Guthrie, 2001; Youndt y Snell, 2004; Wright et al., 2004; López-Cabrales et al, 2009, etc.), sólo un pequeño porcentaje son empresas muy grandes (10.0\%) con más de 1000 empleados, o pequeñas $(17.4 \%)$ con una plantilla de entre 30-50 empleados. El porcentaje mayoritario de empresas (72.6\% de la muestra) tiene una plantilla de entre 50 y 1000 empleados, lo que asegura que, un porcentaje muy elevado de empresa de la muestra estudiada, tiene un tamaño suficiente como para contar con una sección o departamento de recursos humanos.

Figura 3.2. Tamaño de las empresas por número de empleados

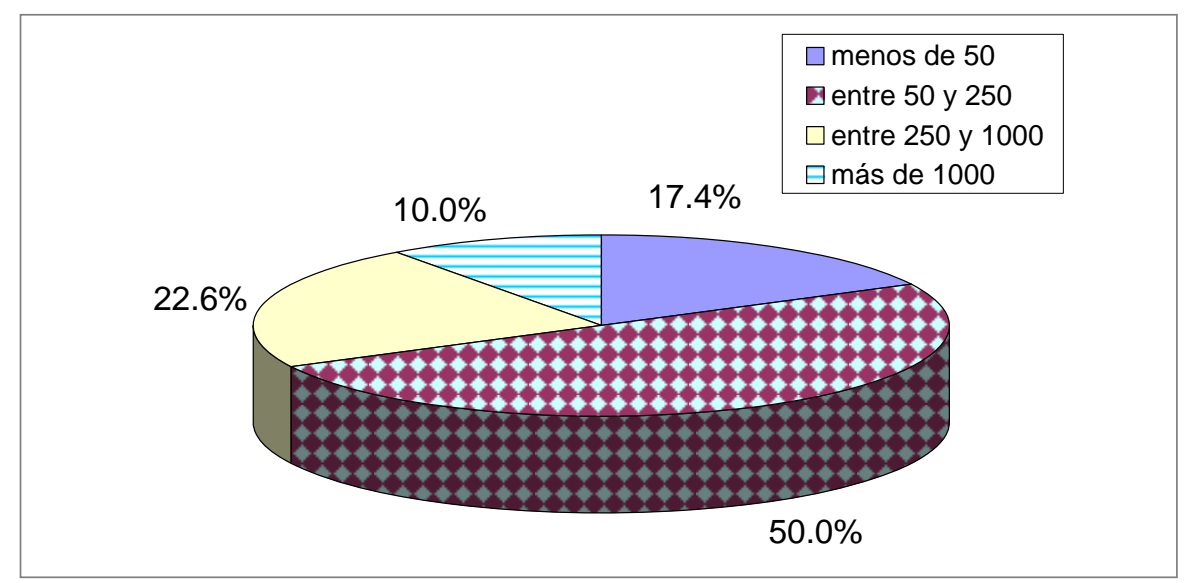

\subsubsection{Edad media de la plantilla}

Con respecto a la edad media de los empleados, el $72.8 \%$ de las empresas que respondieron al cuestionario poseen una plantilla cuya edad media no supera los 40 años, por lo que, de forma mayoritaria, estamos estudiando empresas en las que los

\footnotetext{
${ }^{6}$ En la literatura de recursos humanos es muy habitual definir el tamaño de la empresa en función del número empleados a través de su logaritmo neperiano, reescalando los valores a una escala de menor dispersión.
} 
empleados son jóvenes, tal como se muestra en la Figura 3.2. Sólo un 1.3\% de la muestra presentaba una edad media de la plantilla superior a 50 años.

Figura 3.3. Edad media de las plantillas de empleados

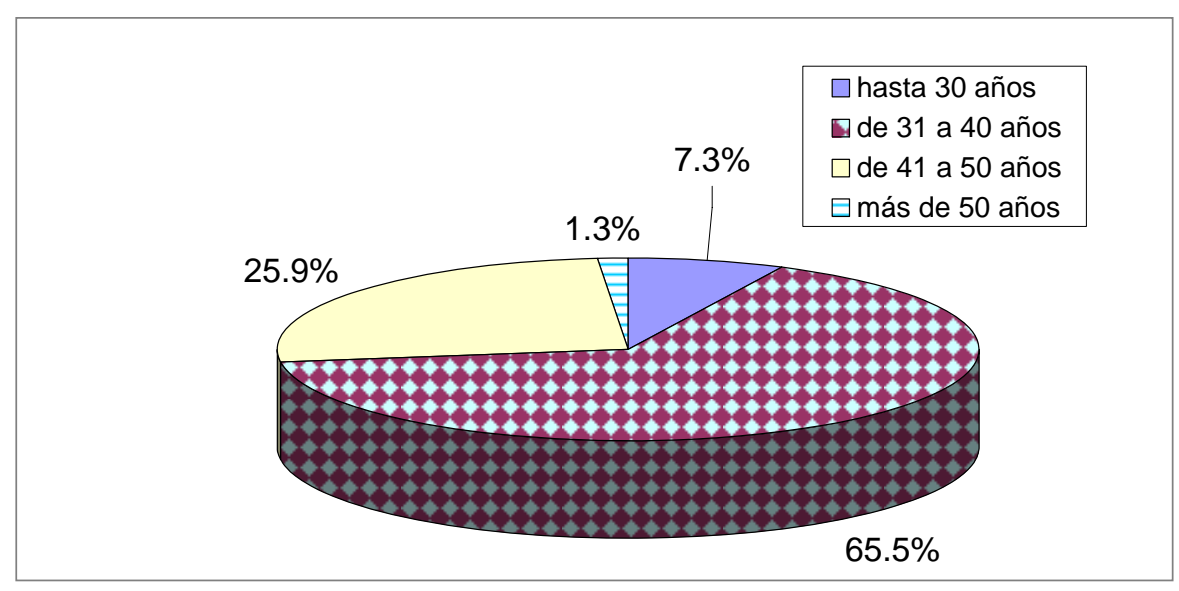

\subsubsection{Antigüedad de los empleados}

En relación a la antigüedad media de los empleados, el 68.1\% de las empresas cuenta con empleados que, por término medio, han permanecido en la empresa más de 5 años (ver Fig. 3.4). Por el contrario, solo el 5.3\% de las empresas manifiestan que sus empleados llevan menos de 3 años en la misma, y un $26.1 \%$ tienen empleados que llevan en la empresa entre 3 y 5 años. De forma mayoritaria, los empleados presentan una trayectoria mínima de 3 años en la empresa.

Figura 3.4. Antigüedad media de los empleados

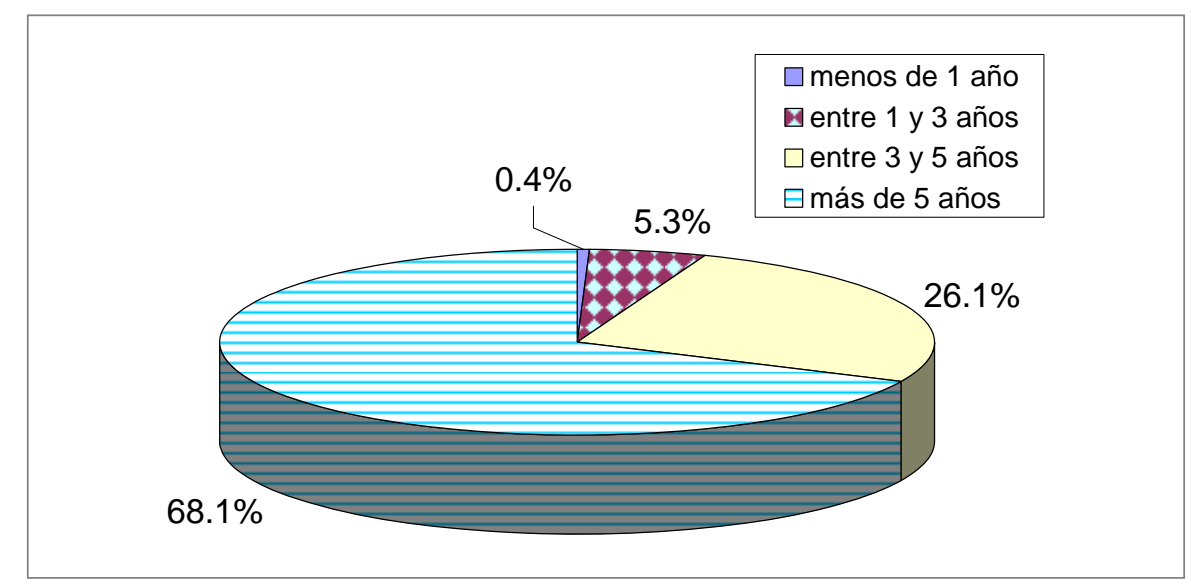




\subsubsection{Pertenencia a grupo multinacional.}

En este estudio, el $60.4 \%$ de las empresas que respondieron al cuestionario pertenecía a un grupo empresarial (con un total de respuestas de 227 empresas sobre las 239 de la muestra final). De este porcentaje de empresas, el 78\% pertenecían a grupos de origen nacional y el 22\% a grupos de origen internacional.

Figura 3.5. Pertenencia a grupo corporativo y nacionalidad

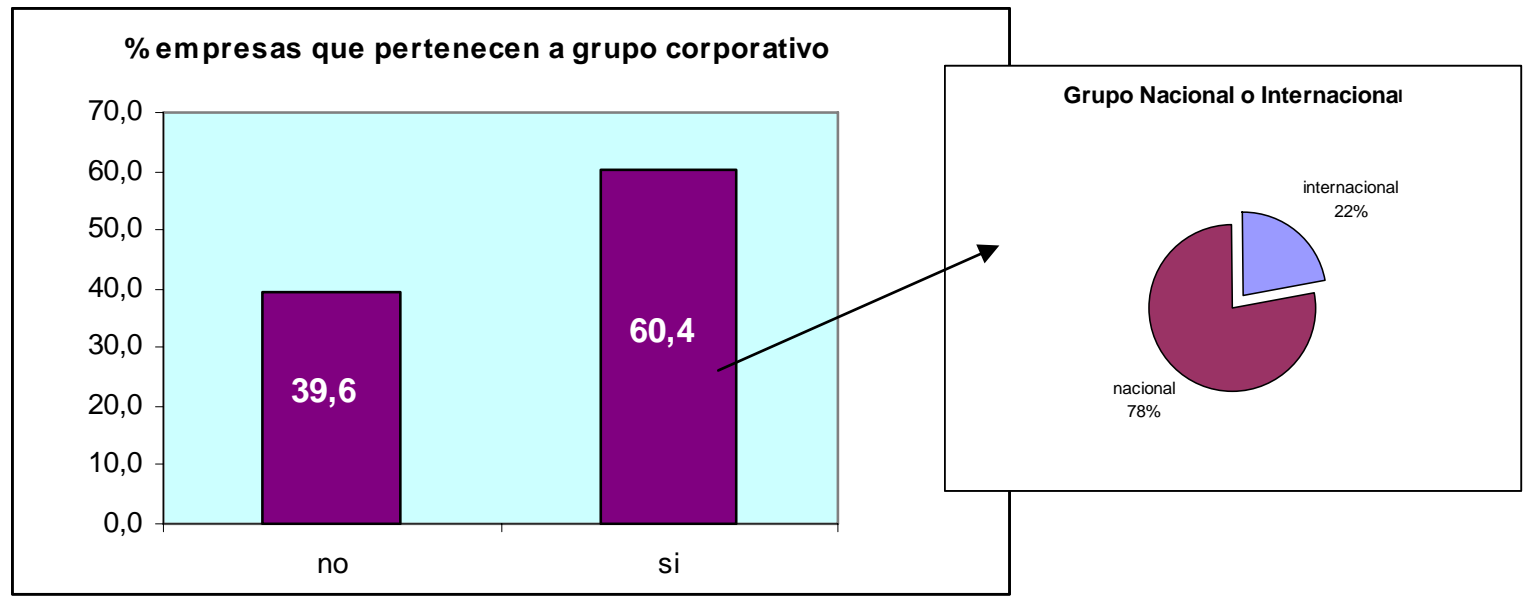

\subsection{METODOLOGÍA DE ANÁLISIS}

El análisis de modelos de ecuaciones estructurales (SEM) es la técnica que utilizamos para validar las hipótesis enunciadas. Esta metodología es adecuada para estimar modelos que incluyen variables complejas y abstractas, no directamente observables y/o para modelos que plantean múltiples relaciones (causales) entre una o más variables independientes y una o más variables dependientes (Rodríguez-Pinto et al., 2008). Este tipo de análisis también se ha denominado modelización causal, aunque en este estudio se utilizará la denotación (SEM) ya que, como señalan Baumgartner y Homburg (1996), la denominación modelización causal no siempre resulta adecuada debido a la dificultad para inferir relaciones causales a partir de los resultados obtenidos con datos de corte transversal, como son lo que utiliza este estudio.

Esta metodología ha demostrado ser enormemente útil en la investigación en el campo de las ciencias sociales, en las que es habitual la definición de modelos en los que 
interactúan diferentes tipos de variables observables y no observables. Buzzell (2004) destaca que el análisis SEM es apropiado para identificar las relaciones estratégicas y aportar una representación mucho más realista de los factores que determinan las diferencias observadas en los resultados y en los niveles de éxito o fracaso de las empresas (Rodríguez-Pinto, 2008).

Entre las virtudes de esta metodología destacan su capacidad para tratar de manera integrada y sistemática:

1. Los problemas de medición de conceptos teóricos que se hacen operativos a través de variables complejas y abstractas, que con frecuencia no son directamente observables.

2. La estimación de las relaciones existentes entre estos constructos. En otras palabras, los modelos de ecuaciones estructurales permiten analizar globalmente el conjunto de las relaciones existentes entre múltiples variables teóricas independientes y dependientes, teniendo en cuenta explícitamente los posibles errores de medición de estas variables que no siempre pueden ser observadas de manera directa (Bagozzi, 1994; Rodríguez-Pinto, 2008).

Dentro de las técnicas de modelos de ecuaciones estructurales (SEM), se identifican dos grandes enfoques complementarios. Por un lado, el análisis de la estructura de covarianzas, en adelante CBSEM, Covariance-Based Structural Equation Modeling (Bollen, 1989; Jöreskog, 1970), enfoque que ha gozado de una amplia aceptación y ha sido aplicado en el campo de las ciencias sociales, en parte, debido al desarrollo de numeroso programas informáticos que facilitan la estimación de este tipo de modelos, como son LISREL, EQS o AMOS, entre otros. Y, por otro lado, el análisis por mínimos cuadrados parciales, en adelante PLS, en alusión a sus siglas en inglés, Partial Least Squares (Chin, 1998; Fornell y Cha, 1994; Hulland, 1999), como técnica menos extendida (Rodríguez-Pinto, 2008), debido a que su desarrollo es más reciente.

Existen diferencias substanciales entre ambas metodologías, como puede verse de forma resumida en el Cuadro 3.5, con una explicación más detallada en el siguiente apartado. Rodríguez-Pinto (2008) señala las diferencias en los supuestos estadísticos relativas a la 
distribución de las variables observadas, los requisitos de tamaño de la muestra, la finalidad predictiva o explicativa-causal, los tipos de escalas utilizados, la relación entre las variables observables y no observables y, por último, la naturaleza de los estadísticos que se utilizan para evaluar la calidad del ajuste del modelo objeto de estudio (Gefen et al., 2000; Chin y Newsted, 1999; Rodríguez-Pinto, 2008).

Cuadro 3.5. Principales diferencias entre los modelos de ecuaciones estructurales basados en covarianzas y los basados en el enfoque de mínimos cuadrados parciales

\begin{tabular}{|c|c|c|}
\hline Criterio & CBSEM & PLS \\
\hline Objetivo & $\begin{array}{l}\text { Enfoque orientado a la estimación de } \\
\text { los parámetros del modelo, basado en } \\
\text { las covarianzas entre las variables } \\
\text { observadas. }\end{array}$ & $\begin{array}{l}\text { Enfoque orientado a la predicción, } \\
\text { basado en la varianza de las variables } \\
\text { dependientes. }\end{array}$ \\
\hline $\begin{array}{l}\text { Requisitos de las } \\
\text { variables }\end{array}$ & $\begin{array}{l}\text { Normalmente se requiere trabajar con } \\
\text { datos medidos con escalas continuas y } \\
\text { que sigan una distribución } \\
\text { multivariante. }\end{array}$ & $\begin{array}{l}\text { Admite cualquier tipo de escalas y no } \\
\text { asume ninguna distribución concreta. }\end{array}$ \\
\hline $\begin{array}{l}\text { Tipos de } \\
\text { constructos }\end{array}$ & $\begin{array}{l}\text { En general solo admite constructos } \\
\text { medidos con indicadores reflexivos. }\end{array}$ & $\begin{array}{l}\text { Admite constructos medidos tanto con } \\
\text { indicadores reflexivos como } \\
\text { formativos. }\end{array}$ \\
\hline $\begin{array}{l}\text { Puntuaciones de } \\
\text { las variables } \\
\text { latentes }\end{array}$ & Indeterminadas. & Se estiman explícitamente. \\
\hline $\begin{array}{l}\text { Estimación de los } \\
\text { parámetros }\end{array}$ & $\begin{array}{l}\begin{array}{l}\text { Énfasis en la precisión de los } \\
\text { parámetros estimados, que son } \\
\text { consistentes. }\end{array} \\
\end{array}$ & $\begin{array}{l}\text { Escaso énfasis en los parámetros } \\
\text { individuales. Su consistencia aumenta } \\
\text { a medida que se incrementan el } \\
\text { número de indicadores y el tamaño de } \\
\text { la muestra. La estabilidad de los } \\
\text { parámetros se determina mediante } \\
\text { procedimientos de remuestreo. }\end{array}$ \\
\hline Tamaño muestral & $\begin{array}{l}\text { La estimación con muestras pequeñas } \\
\text { es problemática. El tamaño muestral } \\
\text { necesario aumenta con la complejidad } \\
\text { del modelo y si los datos no se } \\
\text { distribuyen normalmente. }\end{array}$ & $\begin{array}{l}\text { Puede estimar modelos con muestras } \\
\text { muy pequeñas. El tamaño mínimo } \\
\text { depende del número de variables que } \\
\text { contenga la ecuación de medida o la } \\
\text { ecuación estructural más compleja. }\end{array}$ \\
\hline $\begin{array}{l}\text { Complejidad del } \\
\text { modelo }\end{array}$ & $\begin{array}{l}\text { La estimación de modelos muy } \\
\text { complejos plantea problemas por la } \\
\text { ausencia de grados de libertad y por su } \\
\text { posible sobreajuste. }\end{array}$ & $\begin{array}{l}\text { Por definición, no hay índices de } \\
\text { ajuste. La bondad del modelo se } \\
\text { determina en función de su capacidad } \\
\text { para explicar las variables } \\
\text { dependientes. }\end{array}$ \\
\hline
\end{tabular}

Fuente: Rodríguez-Pinto, 2008. 


\subsubsection{Comparativa CBSEM versus PLS}

\subsubsection{Distribución de las variables.}

El análisis CBSEM requiere que las variables observadas sigan una distribución multivariante específica (normalidad en el caso de máxima verosimilitud) y requiere un amplio tamaño muestral que, a menudo, puede estar más allá del alcance de los investigadores, sobre todo si los modelos planteados son muy complejos (Hair et al., 1999). Para solucionarlo se puede recurrir a métodos alternativos a la estimación por máxima verosimilitud que pueden permitir trabajar con datos de muestras no-normales, aunque entonces se requerirán muestras aún mayores (Rodríguez-Pinto et al., 2008). Otras soluciones para llevar a cabo la estimación de estos modelos de forma viable pueden ser: la imposición de restricciones a los parámetros, no tener en cuenta determinadas variables del modelo o disminuir el número de indicadores para algunas variables latentes; pero ninguna de ellas resulta muy aconsejable (Raykov \& Widaman, 1995).

En este sentido, una alternativa es llevar a cabo la estimación a través de PLS, ya que esta metodología no requiere una distribución de frecuencias determinada y permite trabajar con variables observadas que no sigan una distribución normal, estimando las mediciones y los parámetros estructurales mediante un procedimiento iterativo que combina la regresión simple y múltiple tradicionales por mínimos cuadrados ordinarios (MCO). El análisis PLS trabaja segmentando los modelos y analizando cada bloque de variables por separado, de este modo se ve menos afectado por el tamaño de la muestra o la distribución de frecuencias de las variables (Barclay et al., 1995; Gefen et al.,2000).

Por tanto, debido a la naturaleza de esta metodología, en donde los parámetros del modelo se estiman por bloques, el tamaño de muestra requerido en PLS es mucho menor $^{7}$ que en CBSEM.

\footnotetext{
${ }^{7}$ Rodríguez-Pinto (2008) expone con detalle las recomendaciones que autores como Barclay et al. (1995); Chin (1998b) o Chin y Newsted (1999) ofrecen en relación al tamaño de muestra para operar con PLS. Éste debe ser al menos 10 veces superior al valor más alto de entre los dos siguientes: (a) el número de indicadores formativos que definen el constructo más complejo, es decir, el número de variables observadas que contiene la ecuación más larga del modelo de medida; o (b) el número de antecedentes
} 


\subsubsection{Finalidad y objetivo de la metodología}

Los análisis CBSEM y PLS tienen diferente finalidad. El objetivo de los modelos CBSEM está orientado a explicar causas, ya que permite contrastar si un modelo teórico especificado a priori puede reproducir -con la máxima convergencia posible- la estructura real de varianzas-covarianza, en base a los datos de que se disponga. Por ello, este enfoque permite confirmar teorías examinando si el modelo propuesto se ajusta estadísticamente a lo que ocurre en la realidad (Byrne, 1998 y 2001; Hair et al., 1999). Por el contrario, el análisis PLS está más orientado a predecir. Trata de maximizar la capacidad para explicar la varianza de las variables dependientes o endógenas del modelo, como si de una regresión lineal se tratara, lo que equivale a minimizar el error de predicción de estas variables, razón por la que esta metodología aplica una estimación por mínimos cuadrados ordinarios (Rodríguez-Pinto, 2008). Se trata, por tanto, de un enfoque orientado a la predicción y, también, muy útil para el desarrollo de nuevas teorías en las que no se conocen con exactitud todas las variables relevantes y sus interrelaciones, ya que permite identificar la existencia de relaciones aún no incluidas. En este sentido, PLS se ve menos afectado por el problema de falta de especificación o de omisión de alguna variable relevante, ya que esto tiene una menor influencia en los parámetros estimados en otras partes del modelo (Chin, 1998 a y b; Chin y Newsted, 1999; Gefen et al., 2000).

\subsubsection{Escalas}

Una diferencia importante entre los enfoques basados en covarianzas y los de mínimos cuadrados parciales radica en el tipo de escalas admitidas por uno y otro. Estrechamente relacionado con las exigencias de normalidad que CBSEM impone a las variables observadas, requiere que éstas se midan mediante escalas continuas. PLS es más flexible en cuanto a la escala de medición permitida, ya que se pueden utilizar variables medidas con escalas ordinales e incluso categóricas (Falk y Miller, 1992).

que apuntan a la variable latente dependiente en la ecuación estructural más compleja. La muestra observada $(\mathrm{N}=239)$ cumple este requisito con claridad. 


\subsubsection{Relaciones entre variables y modelos de medida: reflectivos versus formativos}

Otra de las grandes diferencias entre ambos análisis deriva del tipo de relaciones entre las variables observadas y las no observadas que pueden manejarse o, dicho de otro modo, de los tipos de modelos de medida que pueden ser analizados en cada método. El CBSEM requiere que todos los constructos se midan a través de indicadores reflectivos (es decir, las variables observadas con las que se trata de medir cada concepto teórico son una manifestación o efecto del mismo, lo que explica su interrelación). Esta manera de medir, claramente inspirada en la noción de unidimensionalidad, ha dominado las investigaciones empíricas de las ciencias sociales. En este sentido, Blesa, Ripollés y Monferrer, (2008), basándose en Diamantopoulos y Winklhofer (2001), afirman que la mayor parte de investigadores en ciencias sociales asumen que los indicadores de una escala miden el efecto del constructo medido, por lo que los ítems (p.ej., variables observadas) que componen dicha escala son percibidos como indicadores reflectivos de los constructos subyacentes (p.ej., la variable latente). Sin embargo, los indicadores causales parecen más apropiados cuando estos pueden ser considerados más como la causa que como el efecto del la variable latente medida. Esta perspectiva de medida alternativa implica la creación de un índice más bien que de una escala (Bollen y Lennox, 1991). En consecuencia, una alternativa en el proceso de medición es el uso de indicadores formativos o causales, lo que supone la creación de índices compuestos, más que el desarrollo de escalas ${ }^{8}$ (Fornell y Bookstein, 1982; Bollen y Lennox, 1991; Law y Wong, 1999; Edwards y Bagozzi, 2000; Diamantopoulos y Winklhofer, 2001; Jarvis, MacKenzie y Podsakoff,, 2003; Diamantopoulus, Riefler y Roth, 2008). En este caso, una variación en alguna de las variables observadas provoca cambios en el constructo -que es inherentemente multidimensional-, y no al revés. En otras palabras, el indicador es una de las causas o antecedentes de la variable latente con la que se

\footnotetext{
${ }^{8}$ Rodríguez-Pinto (2008) alerta sobre el incremento de voces que destacan los riesgos de aceptar el procedimiento convencional de medición de variables latentes automáticamente como indicadores reflectivos, sin tener en cuenta la verdadera naturaleza de la relación entre los conceptos que se tratan de medir y sus variables observadas. Según Edwards y Bagozzi (2000), los investigadores parecen haber puesto mucho énfasis en explicar las relaciones causales entre constructos, pero no han prestado la misma atención a la identificación del tipo de relaciones que se dan entre estos constructos y sus medidas. El estudio de Jarvis et al. (2003), así lo pone de manifiesto, señalando que numerosos constructos fueron erróneamente tratados como reflectivos cuando, en realidad, los indicadores correspondientes eran formativos.
} 
relaciona. Bajo esta perspectiva, el significado conceptual y empírico de una variable latente formativa queda determinado (formado) por el conjunto de variables observadas empleadas (indicadores), que no tienen que estar necesariamente correlacionadas entre sí (Jarvis et al., 2003; Diamantopoulus et al., 2008). El Cuadro 3.6 y la Figura 3.6 resumen algunos de los principales criterios que caracterizan y diferencian a los constructos formativos y reflectivos.

Cuadro 3.6. Diferencias entre constructos reflectivos y formativos

\begin{tabular}{|l|l|}
\hline \multicolumn{1}{|c|}{ Constructos reflectivos } & \multicolumn{1}{|c|}{ Constructos formativos } \\
\hline $\begin{array}{l}\text { La dirección de la causalidad va del constructo a } \\
\text { sus indicadores. El constructo es la causa de los } \\
\text { indicadores. }\end{array}$ & $\begin{array}{l}\text { La dirección de la causalidad va de los } \\
\text { indicadores al constructor. Son la causa del } \\
\text { constructo. }\end{array}$ \\
\hline $\begin{array}{l}\text { Los indicadores son manifestaciones del } \\
\text { concepto que se quiere medir }\end{array}$ & $\begin{array}{l}\text { Los indicadores constituyen dimensiones del } \\
\text { concepto en cuestión }\end{array}$ \\
\hline $\begin{array}{l}\text { Los indicadores covarían entre sí } \\
\text { La eliminación de un indicador no altera el } \\
\text { significado conceptual del constructo }\end{array}$ & $\begin{array}{l}\text { Los indicadores no están necesariamente } \\
\text { correlacionados } \\
\text { modificar la definición del constructo }\end{array}$ \\
\hline $\begin{array}{l}\text { Los indicadores son intercambiables, “dicen” lo } \\
\text { mismo de forma diferente }\end{array}$ & $\begin{array}{l}\text { Los indicadores no son intercambiables, } \\
\text { aportan diferente contenido al constructo }\end{array}$ \\
\hline El error de medida se produce en los indicadores & Error de medida se produce en el constructo \\
\hline
\end{tabular}

Basado en: Jarvis, MacKenzie y Podsakoff (2003) y en Rodríguez-Pinto (2008).

Figura 3.6. Escalas reflectivas versus Índices formativos ${ }^{9}$

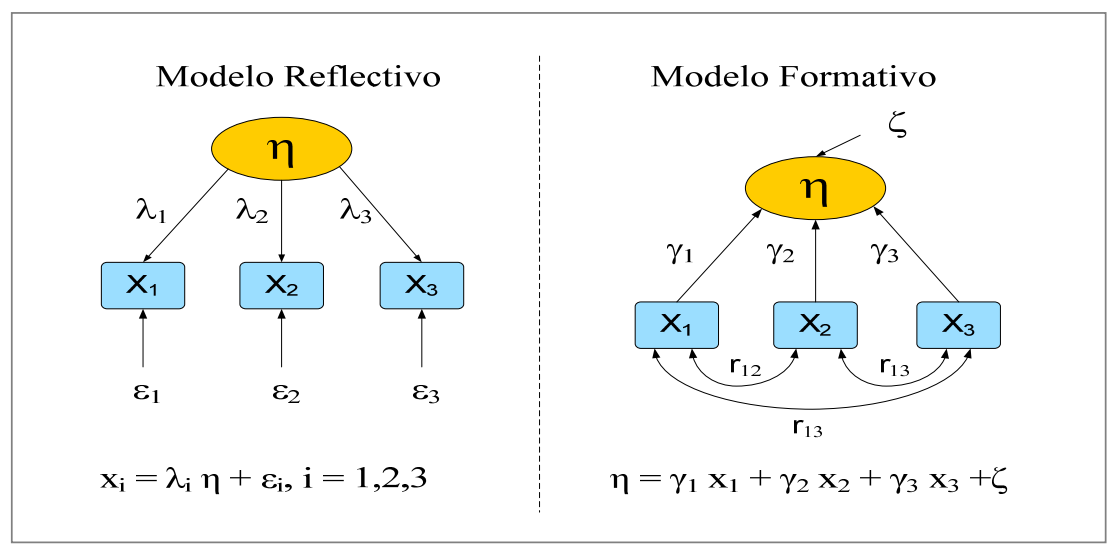

Fuente: Diamantopoulus et al. (2008)

\footnotetext{
${ }^{9}$ En el modelo reflectivo, cada ítem componente de la escala (Xi) es resultado de una función de la variable $(\eta)$ más un error $(\varepsilon)$. En cambio, en los modelos formativos, la variable $(\eta)$ es resultado de la suma de lo que aporta cada uno de los factores (Xi) más un error $(\zeta$ ) del significado que nos queda recogido a través de los factores.
} 
Cuatro de los constructos del modelo propuesto en este trabajo son de carácter formativo: el diseño de puesto de trabajo, la retribución, el desarrollo del empleado y las medidas de conciliación entre vida laboral/personal. En estas cuatro variables la dirección causal va de los indicadores al constructo. Los indicadores (ítems) constituyen dimensiones diferentes que forman cada constructo, de modo que si eliminamos uno de estos indicadores, se pierde parte del contenido conceptual definido en este trabajo para dicha variable. Los indicadores de cada variable no son intercambiables entre sí, sino que cada uno aporta significado conceptual diferenciador. Y, por último, los indicadores no están excesivamente correlacionados entre sí (esta cuestión se aborda con mayor detalle en el siguiente capítulo).

Así, en primer lugar, con respecto a la práctica de diseño enriquecido de puesto de trabajo, el constructo relativo a esta práctica se forma través de diversos atributos que de forma conjunta conforman este tipo de puestos. Estos componentes son: suponer un reto para el empleado, ofrecer autonomía, implicar la realización de tareas heterogéneas y requerir del uso de habilidades y conocimientos complejos. En segundo lugar, en relación con la retribución, la variable que recoge el sistema de retribución propuesto en este trabajo abarca las principales dimensiones de un sistema de retribución: la equidad interna y externa, la contingencia con el resultado individual, grupal o de empresa, e incluye incentivos a largo plazo y beneficios sociales. Estas componentes del sistema retributivo difieren unas de otras y de forma conjunta logran crear la retribución propuesta en este trabajo por su potencial para retener al capital humano estratégico. En tercer lugar, nos referimos al desarrollo del empleado. Esta variable abarca tres dimensiones principales que aportan diferente contenido conceptual a la variable y que, en la práctica, son actividades diferenciadas, que se pueden dar unas sin las otras y no son intercambiables. De hecho es de forma conjunta, a través de la presencia de todas ellas, como se logra establecer un sistema de desarrollo del empleado mucho más potente que pueda favorecer en mayor grado la retención de empleados valiosos. En nuestro estudio identificamos varias componentes: la formación de acogida, la formación en competencias específicas del puesto o la empresa, la formación en competencias transversales o en habilidades para trabajo en equipo y las oportunidades de promoción indicando si ésta se apoya en los resultados de rendimiento y desempeño 
de los empleados. Por último, en cuarto lugar, la variable de conciliación entre vida laboral y personal propuesta se genera a través de diversas medidas que consideramos está perfectamente diferenciadas, aportando, cada una d ellas, un dominico conceptual diferente: por un lado, aquellas medidas que favorecen la cantidad de tiempo y franja temporal para de las necesidades de las vidas personales, y por otro lado, aquellas medidas que en términos económicos ofrecen alguna ayuda para el desarrollo de la vida personal de los empleados.

El resto de las variables propuestas en esta investigación se miden a través de escalas reflectivas. De forma general, en todas ellas, los ítems o indicadores utilizados son consecuencia de las variables que miden, reflejan comportamientos, ratios o actitudes consecuencia de la existencia de dicha variable. Además, los ítems de cada variable son intercambiables entre sí, están fuertemente correlacionados en la mayoría de los casos y la pérdida o eliminación de algún indicador no resta dominio conceptual al índice (a la variable, en cuestión) (Véase Cuadro 3.1 y Cuadro 3.2.). Por tanto, las variables: soporte de supervisor, comunicación interna, participación del empleado, relaciones internas entre compañeros, las tres variables de capital humano (capital intelectual, capital social y capital afectivo), la capacidad de innovación, los resultados de las personas y los resultados empresariales, son variables de naturaleza reflectiva.

\subsubsection{Estadísticos de la bondad de ajuste del modelo}

Una última diferencia entre CBSEM y PLS se encuentra en el tipo de estadísticos que las aplicaciones informáticas suministran para efectuar el diagnóstico sobre la bondad del modelo contrastado (Gefen et al., 2000).

Los programas estadísticos de ecuaciones estructurales más conocidos (basados en covarianzas- CBSEM) generan tres tipos de estadísticos. Por una parte, obtienen las estimaciones de todos los parámetros individuales de los modelos de medición y estructural (cargas factoriales, errores de medida, coeficientes path, correlaciones, etc.), así se obtienen los niveles de significación de estos parámetros y la varianza explicada de los constructos endógenos. Por otra parte, proporcionan una batería de estadísticos para evaluar el ajuste global del modelo (Baumgartner y Homburg, 1996). El más importante es el de la $\chi^{2}$ y su probabilidad asociada, que mide la distancia entre la 
matriz de datos inicial y la estimada por el modelo, pero que es dependiente del tamaño muestral, por lo que diversos autores han propuesto numerosos estadísticos alternativos para juzgar el ajuste absoluto, incremental y de parsimonia (GFI, AGFI, RMR, RMSEA, ECVI, NFI, CFI, AIC, CAIC, CN, etc. $)^{10}$. Por último, también es posible obtener los denominados índices de modificación, que facilitan la tarea del investigador en la identificación de las posibles causas de desajustes en el modelo y la reespecificación del mismo.

PLS no puede suministrar estadísticos sobre el grado de ajuste del modelo (Chin, 1998 a y b) ${ }^{11}$, dado que no trata de reproducir la matriz de datos original sino de maximizar la varianza explicada de los constructos endógenos. Aplicando esta metodología se obtienen las estimaciones de los pesos y cargas factoriales, de las covarianzas residuales del modelo de medición, de los coeficientes que miden las relaciones estructurales, de las correlaciones entre las variables latentes, así como del valor del $\mathrm{R}^{2}$ y de la varianza media extraída (AVE, Average Variance Extracted) para cada constructo. La significación de los parámetros estimados se calcula empleando un proceso de remuestreo -bootstrapping o jacknifing-. Ante la ausencia de índices de ajuste global en PLS, la bondad de un modelo se evalúa analizando la significación de los parámetros estimados, la capacidad para predecir las variables dependientes -los valores de la $\mathrm{R}^{2}$-, así como la consistencia interna y la validez convergente y discriminante de los constructos reflectivos.

\subsubsection{Selección de la metodología para esta investigación}

Para el contraste empírico de las hipótesis vamos a utilizar el análisis de mínimos cuadrados parciales. Esta elección se justifica por diversas razones.

Primero, PLS tiene como objetivo fundamental minimizar el error de predicción -esto es, maximizar la varianza explicada- de las variables dependientes del modelo aplicando, para ello, una estimación iterativa mediante mínimos cuadrados ordinarios de los distintos parámetros agrupados en bloques (Chin y Newsted, 1999; Tenenhaus et al.,

\footnotetext{
${ }^{10}$ Para profundizar en estos aspectos se pueden consultar manuales como el de Hair et al., (1999).

${ }^{11}$ Tenenhaus et al. (2005) han propuesto recientemente una solución operativa que sirva como índice para evaluar globalmente un modelo PLS. Sin embargo, faltan referencias sobre qué valores puedan ser considerados aceptables para este índice, denominado "criterio global de bondad del ajuste" (GoF).
} 
2005). Uno de los objetivos de esta investigación es identificar cuáles son las variables que más contribuyen a la retención del capital humano de la empresa y a la capacidad de de innovación de la misma, por lo que esta metodología parece apropiada para explicar la influencia sobre las variables dependientes propuestas en el modelo.

Segundo, otra ventaja operativa de PLS es que, además de su flexibilidad en cuanto a la métrica de las variables recogidas, no presupone una distribución de frecuencias concreta. La mayoría de las variables del estudio, medidas con una escala tipo Likert de cinco puntos, no pueden ser consideradas en sentido estricto como continuas; y no todos los datos superan las pruebas de normalidad multivariante. Realizar un análisis basado en covarianzas es problemático en este contexto, máxime si tenemos en cuenta la complejidad del modelo.

En tercer lugar, y como principal razón para elegir PLS, se destaca su capacidad para analizar modelos que incluyan tanto constructos formativos como reflectivos. Nuestra investigación contiene variables formativas y reflectivas, y sólo PLS puede trabajar con ambos tipos. Concretamente, las variables relativas a las cuatro prácticas transaccionales de recursos humanos -diseño enriquecido de puesto, retribución, desarrollo y conciliación- se construyen a partir de índices formativos; el resto de variables son medidas a través de escalas reflectivas, como se indica en el Cuadro 3.7.

Cuadro 3.7. Tipología de las variables de estudio

Total número de variables del modelo: 13 (100\%)

DEPENDENCIA

8 independientes (62\%)

5 dependientes (38\%)

REFLECTIVAS-FORMATIVAS

4 son Índices Formativos (31\%)

9 son Escalas Reflectivas (69\%)

Finalmente, el carácter exploratorio de este estudio también parece apuntar al uso de PLS, frente al enfoque CBSEM, que es válido cuando se trata de confirmar teorías. 
Cuando la teoría subyacente en la especificación del modelo a contrastar ha alcanzado un elevado grado de desarrollo es preferible -y quizás más factible- la utilización de medidas reflectivas (Chin, 1998b); pero cuando los modelos tienen un carácter exploratorio el empleo de variables formativas puede solventar los problemas de medición ante la ausencia de escalas válidas y fiables; además, este tipo de indicadores puede adecuarse mejor a la realidad de algunos campos de investigación ${ }^{12}$. Por último, debido a que los modelos de ecuaciones estructurales tipo AMOS utilizan las covarianzas entre sus medidas, la inclusión de indicadores formativos es problemática (Chin, 1998b). PLS, en cambio, permite el análisis de modelos con indicadores tanto formativos como reflectivos (Barclay et al., 1995; Chin, 1998a y 1998b; Gefen et al., 2000).

El modelo propuesto en este trabajo trata de avanzar sobre los precedentes de la retención del capital humano y los resultados de innovación de la empresa. En este sentido, el presente trabajo es un primer paso de una investigación. Pretendemos continuar, profundizando en la medición de los conceptos de recursos humanos y en la formulación de hipótesis concernientes a la compleja red de relaciones que puede darse entre las prácticas de recursos humanos y los tres tipos de capital humano incluidos en el modelo, así como en su efecto sobre variables de resultado empresarial. PLS es, por tanto, útil para sugerir posibles relaciones entre bloques de variables cuya medición necesita ser desarrollada (Chin y Newsted, 1999).

Sin embargo, la elección de PLS no está exenta de inconvenientes. El principal está relacionado con la imposibilidad de tener en cuenta el posible error de medida de los indicadores. En general, en la estimación a través de mínimos cuadrados parciales se agregan variables observadas que pueden contener errores de medida, lo que puede producir estimadores inconsistentes ${ }^{13}$ (Chin y Newsted, 1999). Otro de los

\footnotetext{
12 Esto no significa que la naturaleza reflectiva o formativa de los indicadores pueda establecerse a posteriori, por razones técnicas o como pretexto fácil para justificar una baja consistencia interna, sino que la elección entre un tipo u otro de especificación debe realizarse antes, apoyándose en argumentos teóricos sobre la relación entre el concepto que se trata de medir y el conjunto de ítems que se utilizan para ello (Rodríguez-Pinto, 2008).

${ }^{13}$ El sesgo suele manifestarse en unas cargas factoriales estimadas más altas en el modelo de medida y en unos coeficientes estructurales relativamente más bajos. No obstante, los valores estimados tienden a
} 
inconvenientes es que, a diferencia de CBSEM que proporciona información rica para evaluar el ajuste del modelo, en PLS el diagnóstico debe basarse en apreciaciones subjetivas sobre la magnitud de los coeficientes estimados y el nivel de explicación que se logra de las variables dependientes. En cualquier caso, los procedimientos basados en CBSEM y en PLS deben contemplarse como complementarios y no como alternativas mutuamente excluyentes ${ }^{14}$.

Además, en el caso de los estudios de Organización de Empresas, la utilización de esta metodología aún es incipiente, como muestran los escasos trabajos españoles identificados (López-Cabrales et al., 2007; Dolz, C.; Iborra, M.; Aldás, J., 2009; Benítez-Amado, et al., 2010), aunque no ocurre lo mismo en otros campos donde es ampliamente utilizado, como es el caso del marketing (Jarvis et al., 2003).

No existen demasiadas aplicaciones informáticas que permitan estimar modelos a través de mínimos cuadrados parciales y, algunas de ellas son bastante recientes, por lo que están en pleno desarrollo y proceso de mejora. Uno de los primeros programas y más conocido es LVPLS (véase Lohmoller, 1984). Recientemente han comenzado a aparecer aplicaciones basadas en LVPLS que la mejoran sensiblemente incorporando una interfaz gráfica que facilita las tareas de especificación de las ecuaciones del modelo. Esto puede ser interpretado como una prueba del creciente interés que los investigadores en el ámbito de las ciencias sociales están demostrando por este tipo de metodología. De acuerdo con Temme, Kreis y Hildebrandt (2006), en la actualidad, además de LVPLS, se puede recurrir a programas como PLS-GUI, VisualPLS, PLS-Graph, SPAD-PLS o SmartPLS. El software PLS-Graph 3.00 (Chin, 2003) ha desarrollado una interfaz gráfica que facilita su utilización y se ha difundido bastante hasta el momento y, además, según comprueban Temme et al. (2006), incorpora de manera correcta los procesos de remuestreo y tratamiento de los valores perdidos. A partir de PLS-Graph 3.00, se ha desarrollado Smart-PLS. Para el análisis de datos por mínimos cuadrados parciales (PLS) en este estudio hemos utilizado el software Smart-PLS versión 2.0 M3

acercarse a su 'verdadero" valor en la medida que aumenten el número de indicadores utilizados para cada variable latente y el tamaño muestra1 (Chin y Newsted, 1999).

14 Por estas razones, como una de las posibles extensiones futuras de este trabajo, consideramos interesante la posibilidad de aplicar CBSEM, a través de AMOS, a una parte de las relaciones del modelo propuesto. 
desarrollado por Ringle, Wende y Will (2005). La utilización de la metodología PLS implica un enfoque desarrollado en dos etapas (Barclay, Higgins y Thompson, 1995); en primer lugar, se aborda el modelo de medición y, en segundo lugar, el modelo estructural, como analizamos con detalle en el siguiente capítulo. 

Capítulo 4 RESULTADOS DE LA INVESTIGACIÓN 



\section{INTRODUCCIÓN}

Tras haber expuesto en el capítulo anterior los aspectos más importantes de la metodología empleada, en este capítulo abordamos el análisis estadístico de la investigación con el fin de validar tanto las medidas utilizadas como las hipótesis planteadas en el modelo del capítulo dos. Ello implica el seguimiento de una serie de pasos para operativizar los conceptos teóricos de la investigación y contrastar dichas hipótesis.

La metodología utilizada es la de mínimos cuadrados parciales (PLS- Partial Least Squares). Debemos señalar que, aunque PLS estima en el mismo proceso los parámetros del modelo de medida y del modelo estructural, Anderson y Gerbing (1988) recomiendan que los resultados de este tipo de modelos se analicen e interpreten en dos etapas: primero, abordando la fiabilidad de las escalas de medida y, segundo, evaluando el modelo estructural. En consecuencia, nuestro análisis también se estructura en dos fases. En la primera realizamos la evaluación de la fiabilidad y de la validez del modelo de medida $\mathrm{y}$, en la segunda, llevamos a cabo la evaluación del modelo estructural (Hulland, 1999: 198). Con respecto a las escalas de medida, y como ya se anticipó en el capítulo anterior, el estudio presenta dos tipos de modelos de medida: reflectivo y formativo. Esta distinción es importante porque los procedimientos de validación son diferentes. Los métodos tradicionales para validar las escalas reflectivas (unidimensionalidad, consistencia, validez convergente y discriminante) no son apropiados para evaluar índices formativos y viceversa (Dimantopoulus et al., 2008).

A continuación en el epígrafe 4.1., empezaremos por examinar las cuestiones relativas a la evaluación del modelo de medida $\mathrm{y}$, en el siguiente epígrafe, describimos los resultados del análisis y evaluación del modelo estructural, identificando las hipótesis que se verifican, así como, las que son refutadas. Posteriormente, para completar el análisis empírico, en el epígrafe 4.3 llevamos a cabo una evaluación global del modelo propuesto, lo que permite evaluar la capacidad predictora del modelo. 


\subsection{ESTIMACIÓN DEL MODELO DE MEDIDA}

Recordamos que el modelo final que ha sido objeto de contraste empírico en la presente tesis consta de trece constructos agrupados en tres grandes bloques claramente identificables: prácticas transaccionales y relaciones de recursos humanos orientadas a retención, capital humano y resultados organizativos. Asimismo, recordamos también que, si bien las prácticas de recursos humanos transaccionales se miden utilizando indicadores reflectivos, el resto de variables han sido especificadas como constructos formativos. El Cuadro 4.1. resume, de forma breve, las principales diferencias de validación (criterios e indicadores), entre ambos tipos de escalas.

\begin{tabular}{|c|c|}
\hline \multicolumn{2}{|c|}{$\begin{array}{c}\text { Cuadro } 4.1 \\
\text { CRITERIOS PARA LA VALIDACIÓN DE ESCALAS DE MEDIDA }\end{array}$} \\
\hline \multicolumn{2}{|c|}{ ÍNDICES FORMATIVOS } \\
\hline Variables del modelo & Diseño de Puesto, Retribución, Desarrollo y Conciliación. \\
\hline Indicadores y análisis & $\begin{array}{l}\text { - Validez de contenido (validez conceptual) y especificidad de indicadores } \\
\text { - Analizar los pesos (weights) y su nivel de contribución al índice } \\
\text { - Multicolinealidad: revisar la correlación entre pares indicadores. Se desea que } \\
\text { el estadístico Factor de Inflación de la Varianza (FIV }<5 \text { ) y Tolerancia }>0,2 \text {. } \\
\text { También que el Índice de Condición no sea superior a } 30 \text {, a } 15 \text { siendo más } \\
\text { restrictivos (entre } 5 \text { y } 10 \text { ya indica posible multicolinealidad). }\end{array}$ \\
\hline \multicolumn{2}{|c|}{ ESCALAS REFLECTIVAS } \\
\hline Variables del modelo & $\begin{array}{l}\text { - Capital intelectual, capital social, capital afectivo, soporte del líder, } \\
\text { comunicación interna, participación, relaciones internas, capacidad de } \\
\text { innovación, resultados de las personas y resultados empresariales. }\end{array}$ \\
\hline Indicadores y análisis & $\begin{array}{l}\text { - Fiabilidad: Signo, magnitud y significación de las cargas (loadings }>0,7) \text {. } \\
\text { - Validez convergente: Fiabilidad Compuesta }(\mathrm{Pc}>0,7) \text { y Varianza Extraída } \\
\text { media (AVE }>0,5) \text { : } \\
\rho_{c}=\frac{\left(\sum \lambda_{i}\right)^{2}}{\left(\sum \lambda_{i}\right)^{2}+\sum \operatorname{Var}\left(\varepsilon_{i}\right)} \quad A V E=\frac{\sum \lambda_{i}^{2}}{\sum \lambda_{i}^{2}+\sum \operatorname{Var}\left(\varepsilon_{i}\right)} \\
\text { - Validez discriminante: } \sqrt{\mathrm{AVE}}>\text { Correlaciones con otros constructos y análisis } \\
\text { de las correlaciones cruzadas (cross-loadings). }\end{array}$ \\
\hline
\end{tabular}

Fuente: Diamantopoulus et al $(2001,2008)$. 
Para llevar a cabo la estimación del modelo de medida y la validación del modelo estructural se ha utilizando el programa Smart-PLS versión 2.0 M3 (Ringle, Wende y Will, 2005). Para el análisis de la multicolinealidad se ha utilizado el programa SPSS versión 15.0. A continuación, describimos los pasos que hemos seguido para realizar la validación de los constructos del modelo: primero la validación de los constructos formativos (índices) y, segundo, la validación de los constructos reflectivos (escalas).

\subsubsection{VALIDACIÓN DE LOS ÍNDICES FORMATIVOS}

Para la validación de los constructos formativos ${ }^{1}$, Diamantopoulos et al. (2001, 2008) sugieren analizar la validez de contenido, la especificidad de los indicadores y la colinealidad de los indicadores.

El análisis de la validez de contenido ${ }^{2}$ asegura que el índice formativo recoge todo el dominio conceptual de la variable latente. Éste debe incluir todas las dimensiones que lo forman. El análisis de la especificidad de los indicadores supone identificar un conjunto de indicadores que recojan todo el significado del concepto en los términos descritos en la validez de contenido. Ambas quedan justificadas con la revisión de los estudios y la literatura analizada, y con el examen de los pesos (weights), pues lo que se trata de interpretar es la contribución que cada indicador tiene en la formación de la correspondiente variable (Chin, 1998b). Smart-PLS proporciona estimaciones tanto de los pesos como de las cargas, con independencia de si el ítem concreto es formativo o reflectivo. En el caso de los índices formativos, nos debemos fijar en los pesos para analizar la contribución de cada ítem. En este sentido, se debe tener en cuenta el tipo de relación epistemológica entre las variables latentes y las observadas, pues ello afecta a la validación del índice. Puesto que en la definición de los constructos formativos no se requiere que la escala sea internamente consistente, los procedimientos tradicionales de análisis de la fiabilidad y validez de las escalas reflectivas no son adecuados (Bagozzi, 1994). Consecuentemente, unos pesos reducidos no son motivo suficiente para depurar un ítem formativo, pues no se espera que todas las causas o posibles medidas empleadas

\footnotetext{
${ }^{1}$ Recordamos que un índice formativo es un constructo latente compuesto por sus indicadores de medida o lo que es lo mismo por una combinación lineal de ellos. Tales indicadores son causas o antecedentes de la variable latente, características que definen el concepto en cuestión; no son manifestaciones del concepto como ocurre con los constructos (Diamantopoulos y Winklhofer, 2001).

${ }^{2}$ Es el equivalente a la validez de contenido de las escalas reflectivas (Rodríguez y Hernández, 2008).
} 
para construir un índice tengan la misma importancia ni que sean internamente consistentes (Law y Wong, 1999). Es más, bajo este esquema de medición, la eliminación de un indicador de esta clase supone alterar el dominio conceptual de la variable en cuestión (Bollen y Lennox, 1991) y, por tanto, su validez de contenido; por lo que siempre habrá que tratar de no alterar el dominio conceptual del índice.

Además de la validez de contenido y la especificidad de los indicadores, también se debe tener en cuenta la multicolinealidad entre los indicadores; un rasgo deseable en un modelo de medición reflectivo que, sin embargo, se convierte en un problema en un modelo formativo (Bollen y Lennox, 1991; Diamantopoulos y Winklhofer, 2001; Diamantopoulus et al., 2008), ya que podrá generar problemas en los cálculos posteriores. Por ello, se debe evitar. En consecuencia, para los índices formativos se debe llevar a cabo un diagnóstico de multicolinealidad, que en este trabajo realizamos, primero, mediante el examen de la correlación entre cada par de indicadores y, segundo, mediante el análisis de los estadísticos de colinealidad, a saber, Tolerancia (T), su inverso (el Factor de Inflación de la Varianza (FIV o VIF, en inglés)) y el Índice de Condición (IC). Estas medidas nos dan el grado en que cada variable independiente se explica por otras variables independientes del modelo propuesto (Hair et al., 1999).

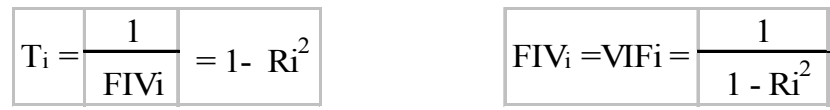

La Tolerancia $(\mathrm{T})$ refleja el porcentaje de la varianza de la variable que no queda explicada por las otras variables. Por tanto, una Tolerancia baja (y elevados valores de FIV) significa que esa variable queda muy explicada por las demás, denotando la existencia de colinealidad y, por ende, contribuyendo poco a la explicación de la variable dependiente. Se asume que ratios de Tolerancia menores de 0.1 , que corresponden con valores de FIV mayores de $10 \mathrm{y} \mathrm{R}^{2}=0.9$, son muy problemáticos y evidencian la existencia de multicolinealidad. Valores de FIV por encima del 5 y de Tolerancia menores de 0,2 ó 0,3 comienzan a ser problemáticos (Kleinbaum, Kupper y Muller, 1988) e indican que puede empezar a haber problemas de multicolinealidad. Además, también se recomienda revisar el índice de condición (Hair et al., 1999). Valores del número o índice de condición $(\mathrm{CN})$ entre 5 y 10 están asociados con 
colinealidad débil, mientras que índices de condición superiores a 30 señalan una colinealidad de moderada a fuerte (Belsey, 1991). En nuestro trabajo se fijará el umbral mínimo en 15, indicando la posible existencia de multicolinealidad.

Teniendo en cuenta los tres aspectos revisados: la lógica conceptual del constructo, los pesos y los indicadores de colinealidad, ya estaremos en disposición de abordar la validación los índices formativos del modelo de investigación. Así pues, para llevar a cabo la validación de los índices formativos analizaremos los pesos, completando nuestro análisis con el estudio de la multicolinealidad de las variables de cada índice y buscando, en todo momento, asegurar la validez de contenido. Ello permite mantener el dominio conceptual de los índices correspondientes a las variables de este trabajo.

A través del algoritmo de Smart-PLS, se pueden obtener los pesos (weights) de los ítems que forman cada índice formativo de nuestro modelo: Diseño de Puesto de trabajo, Retribución, Desarrollo y Conciliación.

Tabla 4.1. Pesos (weights) de los ítems de los índices formativos

\begin{tabular}{lcccc}
\hline & $\begin{array}{c}\text { Diseño } \\
\text { Puesto }\end{array}$ & Retribución & Desarrollo & Conciliación \\
\hline Ptrab1 & 0,744 & & & \\
Ptrab2 & 0,240 & & & \\
Ptrab3 & $-0,003$ & & & \\
Ptrab4 & 0,303 & & & \\
\hline Retrib1 & & 0,446 & & \\
Retrib2 & & 0,595 & & \\
Retrib3 & & $-0,181$ & & \\
Retrib4 & & 0,166 & & \\
Retrib5 & & 0,208 & & \\
Retrib6 & & $-0,213$ & & \\
Retrib7 & 0,277 & & \\
\hline Desarr1 & & & 0,042 & \\
Desarr2 & & & 0,203 & \\
Desarr3 & & & 0,142 & \\
Desarr4 & & & 0,054 & \\
Desarr5 & & & 0,199 & 0,206 \\
Desarr6 & & & 0,427 & 0,683 \\
Desarr7 & & & 0,229 & \\
Desarr8 & & & $-0,014$ & \\
\hline Conci1 & & & \\
Conci2 & & & & \\
Conci3 & & & & \\
Conci4 & & & & \\
\hline
\end{tabular}




\section{Diseño enriquecido de puesto de trabajo}

El análisis de los pesos de este índice, nos indica que las variables reto, autonomía y aplicación de habilidades y competencias complejas, son las dimensiones que más contribuyen en la definición del diseño enriquecido del puesto, ya que sus pesos son los más elevados $(0,744,0,240$ y 0,303 respectivamente), especialmente el que el puesto suponga un reto interesante para el empleado. Los signos son positivos, por lo que cuanto más se incorporen de forma expresa estas dimensiones a la definición de los puestos de trabajo, más enriquecidos se podrán considerar éstos. La dimensión relativa a la realización de actividades diversas y heterogéneas, presenta una carga insignificante y negativa. Además, puesto que es el ítem de mayor correlación con otras variables (en concreto con Ptrab4), valoramos la posibilidad de eliminar este indicador del constructo.

Tabla 4.2.

Correlaciones de los factores de la variable Diseño de puesto de trabajo

\begin{tabular}{|ll|c|c|c|c|}
\hline & & $\begin{array}{c}\text { Ptrab1 } \\
\text { retador }\end{array}$ & $\begin{array}{c}\text { Ptrab2 } \\
\text { autonomia }\end{array}$ & $\begin{array}{c}\text { Ptrab3 } \\
\text { actividades } \\
\text { diversas }\end{array}$ & $\begin{array}{c}\text { Ptrab4 cualifc } \\
\text { variada y } \\
\text { amplia }\end{array}$ \\
\hline Ptrab1 retador & Correlación de Pearson & 1 &, $281(* *)$ &, $432(* *)$ &, $346(* *)$ \\
\hline Ptrab2 autonomia & Correlación de Pearson &, $281(* *)$ & 1 &, $395(* *)$ &, $312(* *)$ \\
\hline $\begin{array}{l}\text { Ptrab3 actividades } \\
\text { diversas }\end{array}$ & Correlación de Pearson &, $432(* *)$ &, $395(* *)$ & 1 &, $467(* *)$ \\
\hline $\begin{array}{l}\text { Ptrab4 cualifc } \\
\text { variada y amplia }\end{array}$ & Correlación de Pearson &, $346(* *)$ &, $312(* *)$ &, $467(* *)$ & 1 \\
\hline
\end{tabular}

** La correlación es significativa al nivel 0,01 (bilateral). $\mathrm{N}=239$

La eliminación de este indicador no afecta al dominio conceptual del mismo, puesto que si el puesto es retador y requiere de la aplicación y uso de conocimientos y habilidades complejos, es de esperar que implique la realización de actividades diversas y no repetitivas. Antes de proceder a la eliminación de este indicador, también hemos analizado la multicolinealidad entre estos indicadores, que aunque no fuera severa, apuntaba a la existencia de indicios de multicolinealidad (IC es levemente mayor de 15). En consecuencia optamos por eliminar el indicador Ptrab3 del constructo diseño de puesto (enriquecido) y comprobamos que no existe ningún problema de multicolinealidad en el nuevo índice: el mayor FIV es 1,2 y el Índice de Condición alcanza el valor de 14 (Véase Tabla 4.3) 
Tabla 4.3.

FIV y Colinenalidad de los factores de la variable Diseño de puesto de trabajo

Coeficientes $^{\mathrm{a}}$

\begin{tabular}{|c|c|c|c|c|c|c|c|c|}
\hline \multirow{2}{*}{\multicolumn{2}{|c|}{ Modelo }} & \multicolumn{2}{|c|}{$\begin{array}{l}\text { Coeficientes no } \\
\text { estandarizados }\end{array}$} & \multirow{2}{*}{ 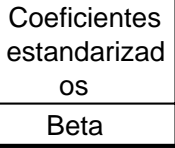 } & \multirow[b]{2}{*}{$\mathrm{t}$} & \multirow[b]{2}{*}{ Sig. } & \multicolumn{2}{|c|}{$\begin{array}{l}\text { Estadísticos de } \\
\text { colinealidad }\end{array}$} \\
\hline & & B & Error típ. & & & & Tolerancia & FIV \\
\hline \multirow[t]{4}{*}{1} & (Constante) & 2,137 & ,346 & & 6,172 & ,000 & & \\
\hline & Ptrab1 retador & ,223 & ,072 & ,208 & 3,089 & ,002 & ,847 & 1,181 \\
\hline & Ptrab2 autonomia &,- 003 & ,072 &,- 003 &,- 040 & ,968 & ,869 & 1,151 \\
\hline & $\begin{array}{l}\text { Ptrab4 cualifc } \\
\text { variada y amplia }\end{array}$ & ,188 & 071 & ,180 & 2,644 & ,009 & ,830 & 1,205 \\
\hline
\end{tabular}

a. Variable dependiente: RetCapInt2 mantener a los mejores de sector

Diagnósticos de colinealidad ${ }^{\mathrm{a}}$

\begin{tabular}{|c|c|c|c|c|c|c|c|}
\hline \multirow[b]{2}{*}{ Modelo } & \multirow[b]{2}{*}{ Dimensión } & \multirow[b]{2}{*}{ Autovalor } & \multirow[b]{2}{*}{$\begin{array}{l}\text { Indice de } \\
\text { condición }\end{array}$} & \multicolumn{4}{|c|}{ Proporciones de la varianza } \\
\hline & & & & (Constante) & $\begin{array}{l}\text { Ptrab1 } \\
\text { retador }\end{array}$ & $\begin{array}{c}\text { Ptrab2 } \\
\text { autonomia }\end{array}$ & $\begin{array}{c}\text { Ptrab4 cualifc } \\
\text { variada y } \\
\text { amplia }\end{array}$ \\
\hline \multirow[t]{4}{*}{1} & 1 & 3,914 & 1,000 &, 00 &, 00 & ,00 &, 00 \\
\hline & 2 & ,034 & 10,656 & ,00 & ,38 & ,72 & ,08 \\
\hline & 3 & ,032 & 11,119 & ,00 & ,44 & ,03 & ,81 \\
\hline & 4 & ,020 & 14,032 & ,99 & 18 & ,25 & ,10 \\
\hline
\end{tabular}

a. Variable dependiente: RetCapInt2 mantener a los mejores de sector

\section{$\underline{\text { Retribución }}$}

La retribución es una de las variables que más ha influido tradicionalmente en los comportamientos y actitudes de los empleados, y son diversas las componentes que la intergran. En nuestro caso dos ítems destacan por su importante contribución al índice: Ptrab1 y Ptrab2, puesto que denotan pesos superiores a los demás indicadores, concretamente, la competividad salarial y la equidad interna retributiva son importantes aspectos que forman la variable retribución. Respecto a las dimensiones de retribución contingente en sus facetas individual, grupal o de empresa; la aportación de la variable contingente con el desempeño individual (Retrib3) presenta uno de los menores valores en la construcción del índice y, además, con signo negativo, aunque no significativo. También el indicador Retrib6, muestra signo negativo; es decir los incentivos a largo plazo como la opción de compra de acciones, etc. no parece tener influencia en la construcción del índice. Por otro lado, los factores Retrib4 y Retrib5 presentan 
aportaciones pequeñas a la construcción del índice. Ambos se refieren a la dimensión de contingencia de la retribución.

Completando el análisis de los pesos, creemos interesante analizar las correlaciones entre estos indicadores y la posible existencia de multicolinealidad. El análisis de la correlación entre los ítems que componen la variable Retribución muestra que existe relación significativa entre algunos ítems, especialmente de Retrib4 con Retrib 3 y Retrib5, así como una alta correlación entre Retrib6 y Retrib7 (Véase Tabla 4.4.). Este análisis nos sugiere la existencia de algunos problemas de multicolinealidad puesto que obtenemos un índice de condición que supera el valor 16, aunque la Tolerancia se mantiene en valores prudentes.

Tabla 4.4.

Correlaciones de los factores de la variable Retribución

\begin{tabular}{|c|c|c|c|c|c|c|c|}
\hline Correlación de Pearson & $\begin{array}{c}\text { Retrib1 sal } \\
\text { superior } \\
\text { competencia }\end{array}$ & $\begin{array}{c}\text { Retrib2 } \\
\text { equidad retrib } \\
\text { interna }\end{array}$ & $\begin{array}{c}\text { Retrib3 } \\
\text { incentivo } \\
\text { desemp indiv }\end{array}$ & $\begin{array}{c}\text { Retrib4 } \\
\text { incentivo } \\
\text { desemp grupo }\end{array}$ & $\begin{array}{c}\text { Retrib5 } \\
\text { incentivo } \\
\text { rtado empresa }\end{array}$ & $\begin{array}{c}\text { Retrib6 } \\
\text { incentivo } 1 / \mathrm{p} \\
\text { acciones... }\end{array}$ & $\begin{array}{c}\text { Retrib7 } \\
\text { beneficios } \\
\text { sociales } \\
\end{array}$ \\
\hline $\begin{array}{l}\text { Retrib1 sal superior } \\
\text { competencia }\end{array}$ & 1 &, $248(* *)$ & ,221(**) &, $204(* *)$ &, $138(*)$ & $-0,003$ &, $196(* *)$ \\
\hline $\begin{array}{l}\text { Retrib2 equidad retrib } \\
\text { interna }\end{array}$ &, $248(* *)$ & 1 &, $211(* *)$ &, $228(* *)$ &, $210(* *)$ &, $162(*)$ &, $220(* *)$ \\
\hline $\begin{array}{l}\text { Retrib3 incentivo desemp } \\
\text { indiv }\end{array}$ &, $221(* *)$ &, $211(* *)$ & 1 &, $499(* *)$ &, $359(* *)$ &, $238(* *)$ &, $173(* *)$ \\
\hline $\begin{array}{l}\text { Retrib4 incentivo desemp } \\
\text { grupo }\end{array}$ & ,204(**) &, $228(* *)$ & ,499(**) & 1 &, $477(* *)$ &, $327(* *)$ & ,265(**) \\
\hline $\begin{array}{l}\text { Retrib5 incentivo rtado } \\
\text { empresa }\end{array}$ &, $138(*)$ &, $210(* *)$ &, $359(* *)$ &, $477(* *)$ & 1 &, $309(* *)$ &, $322(* *)$ \\
\hline Retrib7 beneficios sociales &, $196(* *)$ &, $220(* *)$ &, $173(* *)$ &, $265(* *)$ &, $322(* *)$ &, $434(* *)$ & 1 \\
\hline
\end{tabular}

** 'La correlación es significativa al nivel 0,01 (bilateral).

* :La correlación es significante al nivel 0,05 (bilateral).

A tenor de estas consideraciones y buscando, en todo momento, mantener el dominio conceptual de la variable retribución propuesta en este trabajo, proponemos eliminar los indicadores Retrib3, Retrib5 y Retrib6. Ello no altera las dimensiones que forman esta variable: equidad externa, equidad interna, retribución contingente y retribución en beneficios sociales, a través de Retrib1, Retrib2, Retrib4 y Retrib7, respectivamente. Para finalizar comprobamos que este nuevo índice no presenta problemas de multicolinealidad puesto que el Índice Condición es 13 y los valores de Tolerancia y 
FIV se mantienen en los niveles adecuados (Ver Tabla 4.6.). Además, no identificamos ninguna correlación alta entre los indicadores del índice validado (Ver Tabla 4.5.)

Tabla 4.5.

Correlaciones de los factores depurados de la variable Retribución

\begin{tabular}{|l|c|c|c|c|}
\hline \multicolumn{1}{|c|}{ Correlación de Pearson } & $\begin{array}{c}\text { Retrib1 sal } \\
\text { superior } \\
\text { competencia }\end{array}$ & $\begin{array}{c}\text { Retrib2 } \\
\text { equidad retrib } \\
\text { interna }\end{array}$ & $\begin{array}{c}\text { Retrib4 } \\
\text { incentivo } \\
\text { desemp grupo }\end{array}$ & $\begin{array}{c}\text { Retrib7 } \\
\text { beneficios } \\
\text { sociales }\end{array}$ \\
\hline Retrib1 salario superior a competencia & 1 &, $248(* *)$ &, $204(* *)$ &, $196(* *)$ \\
\hline Retrib2 equidad interna en retribución &, $248(* *)$ & 1 &, $228(* *)$ &, $220(* *)$ \\
\hline Retrib4 incentivo desempeño grupo &, $204(* *)$ &, $228(* *)$ & 1 &, $265(* *)$ \\
\hline Retrib7 beneficios sociales &, $196(* *)$ &, $220(* *)$ &, $265(* *)$ & 1 \\
\hline
\end{tabular}

**La correlación es significativa al nivel 0,01 (bilateral).

Tabla 4.6.

FIV y Colinenalidad de los factores de la variable Retribución

Coeficientes $^{\mathrm{a}}$

\begin{tabular}{|c|c|c|c|c|c|c|c|c|}
\hline \multirow{2}{*}{\multicolumn{2}{|c|}{ Modelo }} & \multicolumn{2}{|c|}{$\begin{array}{l}\text { Coeficientes no } \\
\text { estandarizados }\end{array}$} & \multirow{2}{*}{$\begin{array}{c}\text { Coeficientes } \\
\text { estandarizad } \\
\text { os }\end{array}$} & \multirow[b]{2}{*}{$\mathrm{t}$} & \multirow[b]{2}{*}{ Sig. } & \multicolumn{2}{|c|}{$\begin{array}{l}\text { Estadísticos de } \\
\text { colinealidad }\end{array}$} \\
\hline & & B & Error típ. & & & & Tolerancia & FIV \\
\hline \multirow[t]{5}{*}{1} & (Constante) & 2,598 &, 254 & & 10,227 &, 000 & & \\
\hline & $\begin{array}{l}\text { Retrib1 sal superior } \\
\text { competencia }\end{array}$ & 141 & ,057 & 159 & 2,460 & ,015 & ,904 & 1,106 \\
\hline & $\begin{array}{l}\text { Retrib2 equidad } \\
\text { retrib interna }\end{array}$ & ,236 & ,057 & ,270 & 4,148 & ,000 & ,887 & 1,128 \\
\hline & $\begin{array}{l}\text { Retrib4 incentivo } \\
\text { desemp grupo }\end{array}$ & $-4,1 E-005$ & ,039 & ,000 &,- 001 & ,999 & ,886 & 1,128 \\
\hline & $\begin{array}{l}\text { Retrib7 beneficios } \\
\text { sociales }\end{array}$ & ,014 & ,037 & ,024 & ,374 & ,709 & ,891 & 1,123 \\
\hline
\end{tabular}

a. Variable dependiente: RetCaplnt1 mantener a los muy cualificados

Diagnósticos de colinealidad ${ }^{\mathrm{a}}$

\begin{tabular}{|c|c|c|c|c|c|c|c|c|}
\hline \multirow[b]{2}{*}{ Modelo } & \multirow[b]{2}{*}{ Dimensión } & \multirow[b]{2}{*}{ Autovalor } & \multirow[b]{2}{*}{$\begin{array}{l}\text { Indice de } \\
\text { condición }\end{array}$} & \multicolumn{5}{|c|}{ Proporciones de la varianza } \\
\hline & & & & (Constante) & $\begin{array}{l}\text { Retrib1 sal } \\
\text { superior } \\
\text { competencia }\end{array}$ & $\begin{array}{c}\text { Retrib2 } \\
\text { equidad } \\
\text { retrib interna }\end{array}$ & $\begin{array}{l}\text { Retrib4 } \\
\text { incentivo } \\
\text { desemp } \\
\text { grupo }\end{array}$ & $\begin{array}{c}\text { Retrib7 } \\
\text { beneficios } \\
\text { sociales }\end{array}$ \\
\hline \multirow[t]{5}{*}{1} & 1 & 4,633 & 1,000 & ,00 & ,00 & ,00 & ,01 & ,01 \\
\hline & 2 & , 169 & 5,237 & ,01 & ,02 & ,01 & ,03 & ,99 \\
\hline & 3 & ,124 & 6,121 & ,02 & ,05 & ,03 & ,96 & ,00 \\
\hline & 4 & ,048 & 9,796 & ,02 &, 74 & ,43 &, 00 & ,00 \\
\hline & 5 & ,026 & 13,253 & ,95 & 19 &, 53 & ,00 & ,00 \\
\hline
\end{tabular}

a. Variable dependiente: RetCaplnt1 mantener a los muy cualificados 


\section{Desarrollo del empleado}

El desarrollo del empleado abarca las prácticas que permiten el crecimiento personal y profesional a largo plazo de los empleados (London, 1989). Para ello, la formación y la promoción resultan muy significativas y relevantes (Gómez Mejía et al., 2001). Por ello, esta variable incorpora varias dimensiones que de forma conjunta definen el constructo desarrollo profesional del empleado: formación de acogida, formación en competencias específicas de la empresa y/o puesto, formación interdisciplinar y en habilidades de trabajo en equipo, formación para el desarrollo de carrera y la promoción basada en el desempeño.

El análisis de las cargas que componen este constructo (Véase Tabla 4.1.) indica que la formación de acogida (Desarr1), la formación en habilidades sociales (Desarr4) y la existencia de un programa formal de promoción (Desarr8), son los tres indicadores que menor peso tienen. En cambio, la existencia real de posibilidades de promoción y la promoción basada en el desempeño son los indicadores con un mayor peso $(0,427 \mathrm{y}$ 0,229) en este constructo. A priori, podríamos pensar en eliminar los ítems que ofrecen un peso mínimo a este constructo (Desarr1, Desarr4 y Desarr8), pero para ello debemos analizar, previamente, la existencia o no de problemas de multicolinealidad en este constructo; para ello, nos fijaremos en las correlaciones entre los indicadores y en las pruebas de multicolinealidad que nos permite realizar el programa SPSS versión 15.

El análisis de la correlación entre los ítems que componen el índice de la variable desarrollo del empleado_nos muestra correlaciones relativamente altas $(>0,450)$ entre la mayoría de los ítems, lo que nos da una idea de la necesidad de realizar un ajuste en esta escala (Véase Tabla 4.7.). Además, las pruebas de multicolinealidad de este constructo ofrecen un índice de condición de 26 y valores de FIV que superan el umbral de 5, lo cuál alerta sobre la existencia de cierta multicolinealidad. En consecuencia, decidimos depurar este índice tratando de minorar el problema de multicolinealidad pero sin perder de vista el dominio conceptual del constructo que debe mantener las grandes dimensiones conceptuales que lo componen: formación de acogida, formación y promoción. 
Tabla 4.7. Correlaciones de los factores de la variable Desarrollo del empleado

\begin{tabular}{|c|c|c|c|c|c|c|c|c|}
\hline Correlación de Pearson & $\begin{array}{c}\text { Desarr1 } \\
\text { formac } \\
\text { acogida }\end{array}$ & $\begin{array}{c}\text { Desarr2 } \\
\text { formación } \\
\text { específica } \\
\text { empresa }\end{array}$ & $\begin{array}{c}\text { Desarr3 } \\
\text { formación } \\
\text { interdisciplin } \\
\text { ar }\end{array}$ & $\begin{array}{c}\text { Desarr4 } \\
\text { formación } \\
\text { equipo, hab } \\
\text { sociales }\end{array}$ & $\begin{array}{c}\text { Desarr5 } \\
\text { formac para } \\
\text { desarrollo } \\
\text { carrera }\end{array}$ & $\begin{array}{c}\text { Desarr6 } \\
\text { oportunidade } \\
\text { s promoción }\end{array}$ & $\begin{array}{c}\text { Desarr7 } \\
\text { promoción } \\
\text { basada } \\
\text { desempeño }\end{array}$ & $\begin{array}{c}\text { Desarr8 } \\
\text { sistem formal } \\
\text { desarr carrera }\end{array}$ \\
\hline Desarr1 formac acogida & 1 &, $599(* *)$ &, $496(* *)$ &, $371(* *)$ &, $416(* *)$ &, $316(* *)$ &, $241(* *)$ &, $260(* *)$ \\
\hline $\begin{array}{c}\text { Desarr2 formación } \\
\text { específica empresa }\end{array}$ &, $599(* *)$ & 1 &, $673(* *)$ &, $617(* *)$ &, $646(* *)$ &, $468(* *)$ &, $332(* *)$ &, $379(* *)$ \\
\hline $\begin{array}{c}\text { Desarr3 formación } \\
\text { interdisciplinar }\end{array}$ &, $496(* *)$ &, $673(* *)$ & 1 &, $642(* *)$ &, $610(* *)$ &, $466(* *)$ &, $383(* *)$ &, $426(* *)$ \\
\hline $\begin{array}{c}\text { Desarr4 formación } \\
\text { equipo, hab sociales }\end{array}$ &, $371(* *)$ &, $617(* *)$ &, $642(* *)$ & 1 &, $654(* *)$ &, $417(* *)$ &, $327(* *)$ &, $439(* *)$ \\
\hline $\begin{array}{c}\text { Desarr5 formac para } \\
\text { desarrollo carrera }\end{array}$ &, $416(* *)$ &, $646(* *)$ &, $610(* *)$ &, $654(* *)$ & 1 &, $472(* *)$ &, $413(* *)$ &, $517(* *)$ \\
\hline $\begin{array}{c}\text { Desarr6 oportunidades } \\
\text { promoción }\end{array}$ &, $316(* *)$ &, $468(* *)$ &, $466(* *)$ &, $417(* *)$ &, $472(* *)$ & 1 &, $685(* *)$ &, $440(* *)$ \\
\hline $\begin{array}{c}\text { Desarr7 promoción } \\
\text { basada desempeño }\end{array}$ &, $241(* *)$ &, $332(* *)$ &, $383(* *)$ &, $327(* *)$ &, $413(* *)$ &, $685(* *)$ & 1 &, $512(* *)$ \\
\hline $\begin{array}{c}\text { Desarr8 sistem formal } \\
\text { desarr carrera }\end{array}$ &, $260(* *)$ &, $379(* *)$ &, $426(* *)$ &, $439(* *)$ &, $517(* *)$ &, $440(* *)$ &, $512(* *)$ & 1 \\
\hline
\end{tabular}

** La correlación es significativa al nivel 0,01 (bilateral).

El análisis de las correlaciones nos ofrece indicios para identificar indicadores que puedan estar demasiado relacionados con otros y que, por tanto, no estén añadiendo un valor conceptual al constructo. Por ejemplo, se constata interacción entre la formación de acogida y la formación intensiva y extensiva (Desarr1, Desarr2 y Desarr3). También entre los distintos tipos de formación y la formación para el desarrollo de la carrera, lo cuál puede resultar lógico pues los conocimientos y habilidades, tanto inderdisciplinares como específicos del puesto, pueden resultar beneficiosos para el desarrollo de carrera del empleado. Y, en tercer lugar, también encontramos una moderada correlación entre los indicadores relativos a la promoción (existencia de oportunidades de promoción, promoción basada en el desempeño y existencia de un plan formal de promoción o de carrera profesional, Desarr6, Desarr7 y Desarr8 respectivamente).

Para depurar este índice, y buscando en todo momento poder mantener el dominio conceptual del constructo, se realizaron varias pruebas de correlación y análisis de multicolinealidad entre diversas variables. Finalmente, optamos por reducir la escala a tres ítems: Desarr1, Desarr3+Dsarr4 y Dsarr7, para de este modo mantener las tres dimensiones que aportan significado diferencial a la variable. El ítem Desarr1 recoge la formación de acogida, el ítem media aritmética de Desarrollo3 y Desarrollo4 (altamente 
correlacionados) se refiere a la formación multidisciplinar y, en tercer lugar, el ítem Desarr7 recoge las oportunidades de promoción basadas en el desempeño. De este modo, las correlaciones entre estos tres ítems se encuentran en valores admisibles y cumplen con los ratios de no colinealidad (Véase la Tablas 4.8 y Tabla 4.9.)

Tabla 4.8.

Correlaciones de los factores depurados de la variable Desarrollo del empleado

\begin{tabular}{|c|c|c|c|}
\hline Correlación de Pearson & $\begin{array}{c}\text { Desarr1 formac } \\
\text { acogida }\end{array}$ & D3masD4 & $\begin{array}{c}\text { Desarr7 promoción } \\
\text { basada desempeño }\end{array}$ \\
\hline Desarr1 formac acogida & 1 &, $476(* *)$ &, $241(* *)$ \\
\hline D3masD4 &, $476(* *)$ & 1 &, $390(* *)$ \\
\hline $\begin{array}{c}\text { Desarr7 promoción } \\
\text { basada desempeño }\end{array}$ &, $241(* *)$ &, $390(* *)$ & 1 \\
\hline
\end{tabular}

**La correlación es significativa al nivel 0,01 (bilateral).

Tabla 4.9.

FIV y Colinealidad de los factores depurados de la variable Desarrollo del empleado

\begin{tabular}{|c|c|c|c|c|c|c|c|}
\hline & & & gnósticos & colinealida & & & \\
\hline \multirow[b]{2}{*}{ Modelo } & \multirow[b]{2}{*}{ Dimensión } & \multirow[b]{2}{*}{ Autovalor } & \multirow[b]{2}{*}{$\begin{array}{l}\text { Indice de } \\
\text { condición }\end{array}$} & \multicolumn{4}{|c|}{ Proporciones de la varianza } \\
\hline & & & & (Constante) & $\begin{array}{c}\text { Desarr1 } \\
\text { formac } \\
\text { acogida }\end{array}$ & D3masD4 & $\begin{array}{c}\text { Desarr7 } \\
\text { promoción } \\
\text { basada } \\
\text { desempeño }\end{array}$ \\
\hline \multirow[t]{4}{*}{1} & 1 & 3,867 & 1,000 & ,00 &, 00 & ,00 & ,00 \\
\hline & 2 & 061 & 7,966 &, 00 & , 40 & ,02 & ,63 \\
\hline & 3 & 038 & 10,124 & 13 & ,24 & ,97 & ,03 \\
\hline & 4 & 034 & 10,689 & ,87 & ,35 & ,00 & ,33 \\
\hline
\end{tabular}

a. Variable dependiente: RetCaplnt2mantener a los mejores de sector

\begin{tabular}{|c|c|c|c|c|c|c|c|c|}
\hline \multicolumn{9}{|c|}{ Coeficientesิ } \\
\hline \multirow[b]{2}{*}{ Modelo } & & \multicolumn{2}{|c|}{$\begin{array}{l}\text { Coeficientes no } \\
\text { estandarizados }\end{array}$} & \multirow{2}{*}{$\begin{array}{c}\begin{array}{c}\text { Coeficientes } \\
\text { estandarizad } \\
\text { os }\end{array} \\
\text { Beta } \\
\end{array}$} & \multirow[b]{2}{*}{$\mathrm{t}$} & \multirow[b]{2}{*}{ Sig. } & \multicolumn{2}{|c|}{$\begin{array}{l}\text { Estadísticos de } \\
\text { colinealidad }\end{array}$} \\
\hline & & $\mathrm{B}$ & Error típ. & & & & Tolerancia & FIV \\
\hline \multirow[t]{4}{*}{1} & (Constante) & 2,062 & ,256 & & 8,052 &, 000 & & \\
\hline & Desarr1 formac acogida & ,137 & ,056 & 166 & 2,430 & ,016 & ,774 & 1,292 \\
\hline & D3masD4 & ,239 & ,068 & ,252 & 3,507 & ,001 & ,699 & 1,431 \\
\hline & $\begin{array}{l}\text { Desarr7 promoción } \\
\text { basada desempeño }\end{array}$ & ,082 & ,059 & ,092 & 1,408 & , 160 & ,846 & 1,181 \\
\hline
\end{tabular}

a. Variable dependiente: RetCaplnt2 mantener a los mejores de sector 


\section{Conciliación entre la vida laboral y personal}

Las empresas, en respuesta a las demandas de sus empleados, han comenzado a desarrollar prácticas que permitan a sus empleados conciliar mejor los requerimientos de su vida laboral y de su vida personal, favoreciendo que una esfera no interfiera en el desarrollo de la otra. El análisis de los pesos de este indicador señala que las medidas que facilitan el poder atender temas personales, es el indicador que presenta un mayor peso $(0,682)$ en el índice de este constructo; en segundo lugar las medidas orientadas a ofrecer ayudas económicas que faciliten la conciliación también ofrece un peso bastante elevado (0,510); en tercer lugar, las medidas de flexibilidad horaria ofrecen un peso moderado $(0,206) \mathrm{y}$, por último, el reconocimiento de que la empresa tenga un plan formal de conciliación hace una contribución ínfima al índice. Por otro lado, el análisis de la correlación entre los ítems que componen el índice relativo a la conciliación entre la vida laboral y personal (véase la Tabla 4.10.) indica que existe una significativa correlación entre los ítems de flexibilidad horaria (Conci1) y facilidad para atender temas personales (Conci2), que analizado conceptualmente, no carece de lógica, puesto que si la empresa ofrece medidas de flexibilidad horaria, indirectamente está facilitando a sus empleados el poder atender temas personales. Por tanto, consideramos que conceptualmente estos dos indicadores podrían aglutinarse en uno, ya que recogen un dominio conceptual muy similar.

Tabla 4.10. Correlaciones de los factores de la variable Conciliación

\begin{tabular}{|l|c|c|c|c|}
\hline \multicolumn{1}{|c|}{ Correlación de Pearson } & $\begin{array}{c}\text { Conci1 } \\
\text { flexibilidad } \\
\text { horaria }\end{array}$ & $\begin{array}{c}\text { Conci2 facilidad } \\
\text { atender temas } \\
\text { personales }\end{array}$ & $\begin{array}{c}\text { Conci3 } \\
\text { ayudas } \\
\text { económicas }\end{array}$ & $\begin{array}{c}\text { Conci4 tiene } \\
\text { plan de } \\
\text { conciliación }\end{array}$ \\
\hline Conci1 flexibilidad horaria & 1 &, $567(* *)$ &, $134(*)$ &, $327(* *)$ \\
\hline $\begin{array}{l}\text { Conci2 facilidad atender temas } \\
\text { personales }\end{array}$ &, $567(* *)$ & 1 &, $167(* *)$ &, $366(* *)$ \\
\hline Conci3 ayudas económicas &, $134(*)$ &, $167(* *)$ & 1 &, $415(* *)$ \\
\hline Conci4 tiene plan de conciliación &, $327(* *)$ &, $366(* *)$ &, $415(* *)$ & 1 \\
\hline
\end{tabular}

** La correlación es significativa al nivel 0,01 (bilateral).

* La correlación es significativa al nivel 0,05 (bilateral). 
Por otro lado, y aunque las pruebas que hemos realizado no denotan problemas severos de multicolinealidad, teniendo en cuenta los análisis previos, decidimos aglutinar en media aritmética los indicadores Conci1 y Conci2, y eliminar el índice que parece aportar un significado irrelevante al constructo (Conci4). De esta forma, el índice final queda compuesto por dos dimensiones: una recoge la facilidad para atender aspectos personales, como por ejemplo a través de medidas de flexibilidad horaria, etc., y, la otra versa sobre la existencia de ayudas económicas para potenciar la conciliación. Las correlaciones entre estas variables se encuentran dentro de valores no problemáticos y las pruebas de multicolinealidad confirman su no existencia (Véase Tablas 4.11 y 4.12).

Tabla 4.11. Correlaciones de los factores depurados de la variable Conciliación

\begin{tabular}{|ll|c|c|}
\hline & & $\begin{array}{c}\text { Conci1MASC } \\
\text { onci2 }\end{array}$ & $\begin{array}{c}\text { Conci3 } \\
\text { ayud econ }\end{array}$ \\
\hline Conci1MASConci2 & Correlación de Pearson & 1 &, $169(* *)$ \\
& Sig. (bilateral) & &, 009 \\
& $\mathrm{~N}$ & 239 & 239 \\
Conci3 ayudas & Correlación de Pearson &, $169(* *)$ & 1 \\
económicas & Sig. (bilateral) &, 009 & 239 \\
\hline \multirow{2}{*}{ La correlación es significativa al nivel 0,01 (bilateral). } \\
\end{tabular}

Tabla 4.12. FIV y Colinealidad de los factores depurados de la variable Conciliación

\begin{tabular}{|c|c|c|c|c|c|c|c|c|}
\hline \multicolumn{9}{|c|}{ Coeficientes $^{a}$} \\
\hline & & \multicolumn{2}{|c|}{$\begin{array}{l}\text { Coeficientes no } \\
\text { estandarizados }\end{array}$} & \multirow{2}{*}{$\begin{array}{c}\begin{array}{c}\text { Coeficientes } \\
\text { estandarizad } \\
\text { os }\end{array} \\
\text { Beta }\end{array}$} & \multirow[b]{2}{*}{$\mathrm{t}$} & \multirow[b]{2}{*}{ Sig. } & \multicolumn{2}{|c|}{$\begin{array}{l}\text { Estadísticos de } \\
\text { colinealidad }\end{array}$} \\
\hline \multicolumn{2}{|c|}{ Modelo } & B & Error típ. & & & & Tolerancia & FIV \\
\hline \multirow[t]{3}{*}{1} & (Constante) & 2,922 & ,214 & & 13,653 &, 000 & & \\
\hline & $\begin{array}{l}\text { Conci3 ayudas } \\
\text { económicas }\end{array}$ & 132 & ,046 & ,184 & 2,877 & ,004 & ,971 & 1,029 \\
\hline & Conci1MASConcia & 130 & 057 & , 146 & 2,282 & ,023 & ,971 & 1,029 \\
\hline
\end{tabular}

a. Variable dependiente: RetCaplnt2 mantener a los mejores de sector

Diagnósticos de colinealidad(a)

\begin{tabular}{|c|c|c|c|c|c|c|}
\hline \multirow[t]{2}{*}{ Modelo } & \multirow[t]{2}{*}{$\begin{array}{l}\text { Dimensi } \\
\text { ón }\end{array}$} & \multirow{2}{*}{$\begin{array}{l}\text { Autovalor } \\
\text { (Constante) }\end{array}$} & \multirow{2}{*}{ 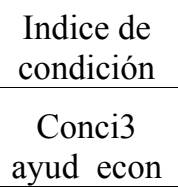 } & \multicolumn{3}{|c|}{ Proporciones de la varianza } \\
\hline & & & & $\begin{array}{c}\text { Conci1MASC } \\
\text { onci2 }\end{array}$ & (Constante) & $\begin{array}{c}\text { Conci3 ayud } \\
\text { econ }\end{array}$ \\
\hline 1 & $\begin{array}{l}1 \\
2 \\
3\end{array}$ & $\begin{array}{r}2,817 \\
, 141 \\
, 042\end{array}$ & $\begin{array}{r}1,000 \\
4,475 \\
8,150\end{array}$ & $\begin{array}{r}, 01 \\
, 06 \\
, 94\end{array}$ & $\begin{array}{r}, 02 \\
, 95 \\
, 03\end{array}$ & $\begin{array}{r}, 01 \\
, 13 \\
, 86\end{array}$ \\
\hline
\end{tabular}

a Variable dependiente: RetCapInt2 mantener a los mejores de sector 
A modo de resumen, la Tabla 4.13 recoge la propuesta de ítems inicial y los índices formativos validados finalmente. Como se puede observar, varios ítems han sido eliminados y, otros, han sido transformados con el fin de depurar las escalas de medida de estos constructos. Con ello buscábamos evitar la existencia de multicolinealidad y, al mismo tiempo, asegurar la validez de contenido de los constructos. Estos serán los índices que utilicemos para la evaluación del modelo estructural (contraste de hipótesis), que abordaremos en el epígrafe 4.2. Además, aplicando el algoritmo que Smart-PLS versión 2.0 M3 nos permite utilizar, podemos obtener los pesos (weights) de estos nuevos índices “depurados", que recogemos en la Tabla 4.13, así como su significatividad.

Podemos comprobar que estos nuevos índices mantienen las dimensiones conceptuales definidas para cada constructo propuesto en esta investigación. Así, por ejemplo, en el caso del diseño enriquecido de puesto de trabajo, cabe destacar el peso elevado de la dimensión ser retador. En la retribución, siguen destacando por su elevado peso, las dimensiones de salarios competitivos (superiores a la competencia) y equidad interna. En cuanto al desarrollo profesional del empleado, la formación de acogida y la promoción se muestran como los indicadores de mayor peso en la construcción del índice. Y, por último, en cuanto al constructo de conciliación entre la vida laboral y personal, el peso de las dos dimensiones, que finalmente dan lugar a esta práctica en la empresa (facilitar el poder atender temas personales y ayudas económicas que favorezcan la conciliación), se muestran con un peso estimado considerablemente alto, en ambos casos mayor de 0.5 . 
Tabla 4.13. Resumen de la validación de índices formativos. Modelo de medida de los índices formativos depurados*

\begin{tabular}{|c|c|c|c|c|}
\hline \multicolumn{2}{|r|}{ ÍTEMS INICIALES } & ÍNDICE VALIDADO & $\begin{array}{l}\text { PESOS } \\
\text { (weights) }\end{array}$ & $\begin{array}{l}\text { t- } \\
\text { student }\end{array}$ \\
\hline \multicolumn{5}{|c|}{ DISEÑO DE PUESTO (máx. corr. = 0,346; máx FIV=1,205 (T=0,86); máx CN=14) } \\
\hline Ptrab1 & Retador & Ptrab1: retador & 0,743 & 6,993 \\
\hline Ptrab2 & Autonomía & Ptrab2: autonomía & 0,238 & 1,577 \\
\hline Ptrab3 & Actividades diversas & ---- & & \\
\hline Ptrab4 & Cualificación variada y amplia & Ptrab4: cualificación variada & 0,301 & 1,883 \\
\hline \multicolumn{5}{|c|}{ RETRIBUCIÓN (máx. corr. =0,265; máx FIV=1,128 (T= 0,9); máx CN=13) } \\
\hline Retrib1 & Salario superior a competencia & Retrib1: equidad externa & 0,475 & 4,443 \\
\hline Retrib2 & Equidad interna en retribución & Retrib2: equidad interna & 0,610 & 6,945 \\
\hline Retrib3 & Incentivo s/desempeño individual & 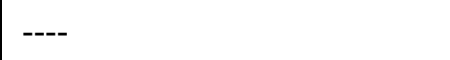 & & \\
\hline Retrib4 & Incentivo s/desempeño grupo & $\begin{array}{l}\text { Retrib4: contingente con } \\
\text { los resultados del }\end{array}$ & 0,121 & 0,987 \\
\hline Retrib5 & Incentivo s/resultado empresa & trabajo del grupo & & \\
\hline Retrib6 & Incentivo $1 / p$ acciones... & ---- & & \\
\hline Retrib7 & Beneficios sociales & Retrib7: beneficios sociales & 0,246 & 2,072 \\
\hline \multicolumn{5}{|c|}{ DESARROLLO (máx. corr. =0,476; máx FiV=1,431 (T= 0,84); máx CN = 10) } \\
\hline Desarr1 & Formación de acogida & Desarr1: formación acogida & 0,538 & 4,683 \\
\hline Desarr2 & Formación específica empresa & ---- & & \\
\hline Desarr3 & Formación interdisciplinar & Desarr3+Desarr4: formación & 0,179 & 1,295 \\
\hline Desarr4 & $\begin{array}{l}\text { Formación equipo, habilidades } \\
\text { sociales }\end{array}$ & $\begin{array}{l}\text { multidisciplinar, habilidades, } \\
\text { trabajo en equipo, etc. }\end{array}$ & & \\
\hline Desarr5 & Formación para desarrollo carrera & ---- & & \\
\hline Desarr6 & Oportunidades promoción & ---- & & \\
\hline Desarr7 & Promoción basada en desempeño & $\begin{array}{l}\text { Desarr7: promoción } \\
\text { s/desempeño }\end{array}$ & 0,555 & 4,999 \\
\hline Desarr8 & Sistema formal desarrollo carrera & --- & & \\
\hline \multicolumn{5}{|c|}{ CONCILIACIÓN (máx. corr. = 0,169; máx FIV=1,029 (T= 0,97); máx CN =8) } \\
\hline Conci1 & Flexibilidad horaria & $\begin{array}{l}\text { Conci1+Conci2: facilidades } \\
\text { para atender temas }\end{array}$ & 0,782 & 8,405 \\
\hline Conci2 & Facilidad atender temas person. & personales, flexib. horaria & & \\
\hline Conci3 & Ayudas económicas & Conci 3: ayudas económicas & 0,504 & 4,177 \\
\hline Conci4 & Tiene plan formal de conciliación & ---- & & \\
\hline
\end{tabular}

* Junto a cada constructo se recogen: la correlación de Pearson más elevada de entre todos los pares de indicadores de ese bloque, así como el factor de inflación de la varianza (FIV), la Tolerancia (T) y el índice o número o índice de condición $(\mathrm{CN})$ más elevados. Un valor del estadístico t superior a 1'64 implica que el peso del indicador correspondiente es significativamente distinto de cero al nivel de $95 \%$, para el test de t-student de una cola 


\subsubsection{VALIDACIÓN DE ESCALAS REFLECTIVAS}

Siguiendo la metodología de análisis en dos etapas propuesta por Anderson y Gerbing (1988), antes de la prueba y evaluación del modelo estructural se debe completar la evaluación del modelo de medida. En el caso de las escalas reflectivas ${ }^{3}$, dicha evaluación consiste en analizar la fiabilidad de los ítems reflectivos y de sus correspondientes constructos, así como la validez convergente y validez discriminante de las medidas propuestas.

Para analizar la fiabilidad de la escala, se observa la fiabilidad de sus correspondientes items, que SmartPLS permite comprobar mediante el análisis de las cargas (loadings): atendiendo a su signo, magnitud y significación. Para ello, se analiza si cada uno de los indicadores reflectivos mide, efectivamente, la variable latente a la que ha sido ligado. Si esto es así, la varianza compartida entre el constructo y el indicador analizado deberá ser alta. Para que lo anterior se cumpla, el valor de la carga del indicador analizado deberá ser mayor o igual a 0,7 (Chin, 1998), lo que significa que más del cincuenta por ciento de la varianza de la variable observada es compartida por el constructo.

Además de examinar la fiabilidad individual de cada indicador reflectivo, es necesario comprobar la validez convergente y discriminante de los correspondientes constructos (Barclay y otros, 1995). Las investigaciones basadas en PLS evalúan la validez convergente puesto que ésta ayuda a determinar si diversos indicadores de un constructo miden lo mismo, para lo cuál se requiere que estén altamente correlacionados. De este modo, para determinar la validez convergente, se utilizan la medida de consistencia interna (Pc,) desarrollada por Fornell y Larcker (1981) y la varianza extraída media ${ }^{4}$ (AVE). Siguiendo las recomendaciones de Nunnally (1978), la consistencia interna debe estar por encima de 0,7, para considerar aceptable la fiabilidad de un constructo (Barclay et al., 1995; Chin, 1998; Hair el al., 1999) y la varianza extraída media (AVE) debe situarse por encima de 0,5. Si se cumplen los requisitos previos, se puede

\footnotetext{
${ }^{3}$ Una escala reflectiva es un constructo latente compuesto por varios indicadores que reflejan un mismo concepto. Tales indicadores son consecuencias o manifestaciones de la variable en cuestión.

${ }^{4}$ La varianza extraída media (AVE) expresa la cantidad de la varianza que un constructo obtiene de sus indicadores en relación a la cantidad de varianza debida al error. Valores por encima de 0.5 denotan que más del 50 por ciento de la varianza del constructo es debida a sus indicadores (Cepeda y Roldán, 2005).
} 
considerar que los indicadores son confiables y que el modelo de medida reflectivo es aceptable.

El último elemento de validación de los constructos reflectivos es la validez discriminante, que permite comprobar si las escalas reflectivas del modelo están realmente midiendo conceptos diferentes y pueden distinguirse en la práctica; es decir, indica en qué medida un constructo dado es diferente de los otros constructos del modelo. Esta condición se cumple si cada variable latente comparte más varianza con sus respectivos indicadores que con otras variables del modelo. Para que exista validez discriminante debe verificarse que la raíz cuadrada de la varianza extraída media ( $\sqrt{ }$ VVE) de cada constructo es superior a la correlación que tiene con el resto de constructos (Tabla 4.15). Una forma complementaria de comprobar la validez discriminante, se logra a través del cálculo de las cargas cruzadas (crossloadings), que son los coeficientes de correlación entre cada constructo y los ítems correspondientes al resto de variables latentes. La carga estandarizada de cada indicador reflectivo, en el constructo que pretende medir, debe ser superior a la carga cruzada con el resto de constructos. Igualmente, debe cumplirse que cada variable latente se relacione más con sus propios indicadores que con las variables observadas que miden otros constructos (para ello hay que comparar cada elemento de la diagonal de la Tabla 4.16 crossloadings- con todos los elementos que están en la misma fila y en la misma columna).

A continuación, procedemos a aplicar estos criterios de validación a las escalas de medida de los constructos reflectivos del modelo que se agrupan en los tres bloques que forman la estructura del modelo: Prácticas de retención de recursos humanos (sólo las reflectivas, es decir, las relacionales: Soporte del supervisor, Comunicación interna, Participación del empleado y Relaciones internas entre compañeros), Capital humano (intelectual, social y afectivo) y las Variables de Resultado (capacidad de innovación, resultado de personas y resultado empresarial).

\section{Prácticas de recursos humanos relacionales}

Como se puede comprobar en la Tabla 4.14., todos los indicadores manifiestan un peso superior a 0,7 (Chin, 1998), excepto Relac2 (la empresa disponga de lugares de ocio y 
de relación), que, por tanto, eliminaremos de la escala final de la variable relaciones internas de apoyo entre compañeros. Además, todos las cargas de los indicadores de cada escala tienen un peso estimado muy similar, como cabía esperar por tratarse de escalas reflectivas.

Tabla 4.14. Cargas de los ítems de las prácticas de recursos humanos relacionales

\begin{tabular}{cc}
\hline Soporte del Supervisor & Pc $(0,898)$ y AVE $(0,687)$ \\
\hline Lider1 & 0,737 \\
\hline Lider2 & 0,865 \\
\hline Lider3 & 0,852 \\
\hline Lider4 & 0,855 \\
\hline Comunicación Interna & Pc $(0,862)$ y AVE $(0,609)$ \\
\hline Comunic1 & 0,746 \\
\hline Comunic2 & 0,832 \\
\hline Comunic3 & 0,750 \\
\hline Comunic4 & 0,792 \\
\hline Participación & Pc $(0,870)$ y AVE $(0,626)$ \\
\hline Partic1 & 0,810 \\
\hline Partic2 & 0,856 \\
\hline Partic3 & 0,729 \\
\hline Partic4 & 0,765 \\
\hline Relaciones Internas & Pc $(0,858)$ y AVE $(0,608)$ \\
\hline Relac1 & 0,752 \\
\hline Relac2 & $\mathbf{0 , 5 8 7}$ \\
\hline Relac3 & 0,856 \\
\hline Relac4 & 0,887 \\
\hline
\end{tabular}

Además, estas escalas cumplen con el criterio de validez convergente, puesto que obtiene unos índices de consistencia interna (Pc) superiores a 0,7 , por lo que podemos considerar aceptable la fiabilidad de estos cuatro constructos (Barclay et al., 1995; Chin, 1998; Hair et al., 1999). También cumplen con el criterio de validez convergente puesto que las cuatro prácticas alcanzan valores de la varianza extraída media (AVE) situados entre 0.608 y 0.687 , todos ellos por encima del umbral de 0.5 .

Por último, las cuatro variables también cumplen con el criterio de validez discriminante $^{5}$, es decir, cada constructo reflectivo comparte más varianza con sus

\footnotetext{
${ }^{5}$ Se analiza mediante la comparación de la raíz cuadrada del AVE (la diagonal de la Tabla 4.15) con sus correlaciones con las demás variables latentes (elementos fuera de la diagonal de la Tabla 4.15). Para cada constructo reflectivo, la raíz cuadrada de su AVE (diagonal) debería ser mayor que su correlación con cualquier otro constructo
} 
propias medidas que con otros constructos del modelo. Esta condición se cumple en todos los casos. Además, también se analizó el cálculo de las correlaciones cruzadas (crossloadings), otra de las pruebas para comprobar la validez discriminante, verificándose que,cada indicador reflectivo se relaciona más con el constructo que trata de medir que con cualquier otro constructo o variable del modelo y que cada variable latente se relaciona más con sus propios indicadores que con los indicadores de otros constructos. Los resultados de esta comprobación también son satisfactorios como puede verse en la Tabla 4.16.

Tabla 4.15-

Análisis de la validez discriminante de los constructos reflectivos

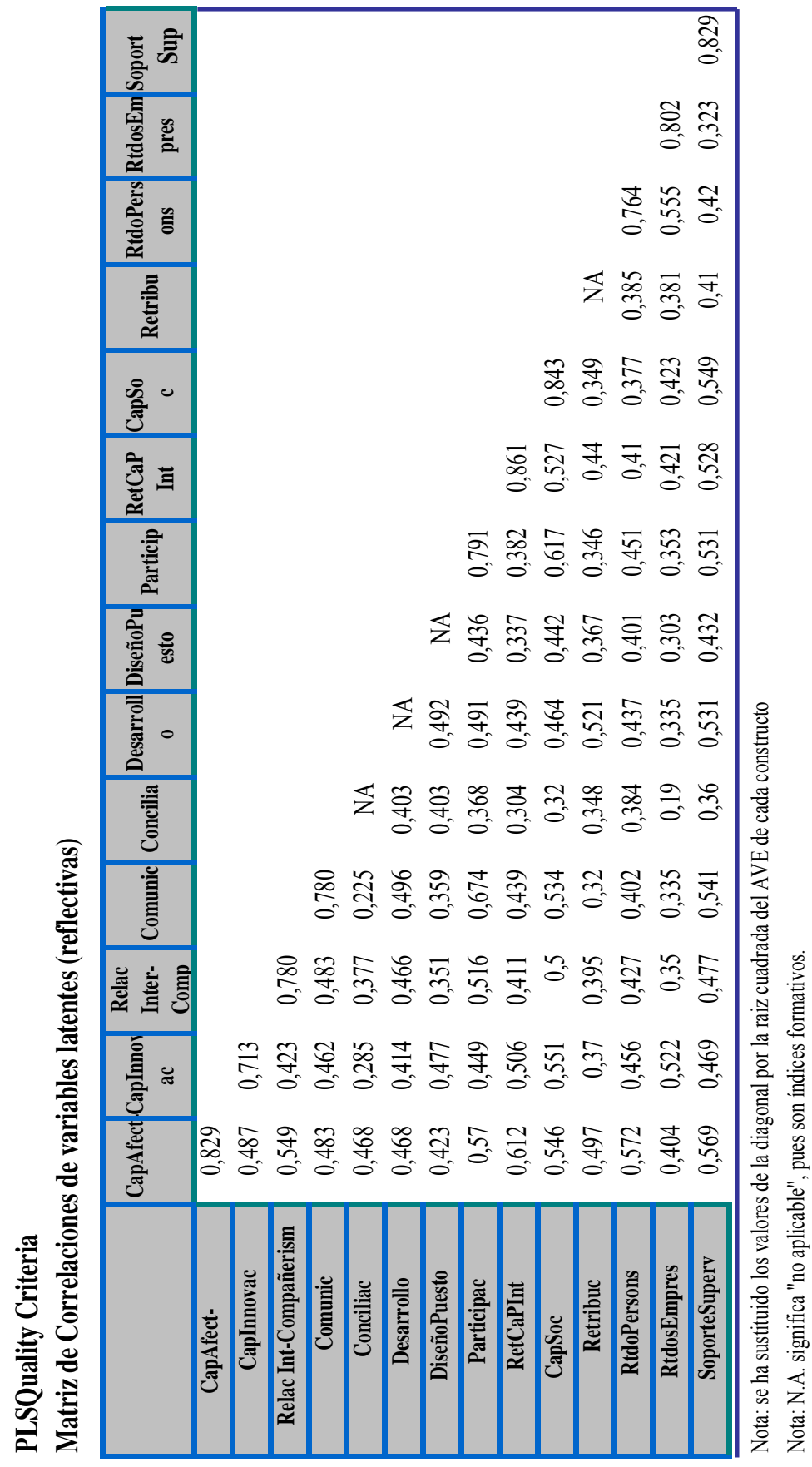


Tabla 4.16. Correlaciones cruzadas (Crossloadings) de las escalas reflectivas

\begin{tabular}{|c|c|c|c|c|c|c|c|c|c|c|}
\hline & $\begin{array}{l}\text { Soporte } \\
\text { Superv }\end{array}$ & Comunic & Participac & $\begin{array}{c}\text { Relac } \\
\text { Internas }\end{array}$ & $\begin{array}{l}\text { RetCap } \\
\text { Intelec }\end{array}$ & Cap Soc & Cap Afect & $\begin{array}{c}\text { Cap } \\
\text { Innovac }\end{array}$ & $\begin{array}{c}\text { Rtdos } \\
\text { Empres }\end{array}$ & $\begin{array}{l}\text { Rtdo } \\
\text { Persons }\end{array}$ \\
\hline Lider1 & 0,737 & 0,424 & 0,416 & 0,316 & 0,300 & 0,359 & 0,329 & 0,251 & 0,182 & 0,330 \\
\hline Lider2 & 0,865 & 0,496 & 0,510 & 0,455 & 0,515 & 0,498 & 0,503 & 0,443 & 0,313 & 0,374 \\
\hline Lider3 & 0,852 & 0,500 & 0,421 & 0,375 & 0,404 & 0,479 & 0,465 & 0,389 & 0,315 & 0,394 \\
\hline Lider4 & 0,855 & 0,383 & 0,416 & 0,417 & 0,492 & 0,468 & 0,553 & 0,436 & 0,243 & 0,304 \\
\hline Comunic1 & 0,296 & 0,746 & 0,536 & 0,371 & 0,333 & 0,362 & 0,400 & 0,270 & 0,208 & 0,294 \\
\hline Comunic2 & 0,456 & 0,832 & 0,579 & 0,359 & 0,306 & 0,453 & 0,368 & 0,405 & 0,243 & 0,339 \\
\hline Comunic3 & 0,276 & 0,750 & 0,416 & 0,372 & 0,354 & 0,349 & 0,288 & 0,382 & 0,297 & 0,233 \\
\hline Comunic4 & 0,612 & 0,792 & 0,557 & 0,403 & 0,377 & 0,483 & 0,435 & 0,384 & 0,298 & 0,371 \\
\hline Partic1 & 0,533 & 0,523 & 0,810 & 0,416 & 0,378 & 0,519 & 0,511 & 0,409 & 0,298 & 0,409 \\
\hline Partic2 & 0,466 & 0,593 & 0,856 & 0,444 & 0,303 & 0,554 & 0,481 & 0,366 & 0,288 & 0,334 \\
\hline Partic3 & 0,300 & 0,523 & 0,729 & 0,369 & 0,246 & 0,396 & 0,366 & 0,270 & 0,265 & 0,302 \\
\hline Partic4 & 0,345 & 0,497 & 0,765 & 0,400 & 0,267 & 0,464 & 0,425 & 0,359 & 0,265 & 0,375 \\
\hline Relac1 & 0,297 & 0,354 & 0,370 & 0,752 & 0,243 & 0,363 & 0,354 & 0,316 & 0,243 & 0,331 \\
\hline Relac2 & 0,193 & 0,258 & 0,209 & 0,587 & 0,217 & 0,173 & 0,232 & 0,232 & 0,184 & 0,198 \\
\hline Relac3 & 0,442 & 0,401 & 0,454 & 0,856 & 0,346 & 0,501 & 0,493 & 0,359 & 0,244 & 0,300 \\
\hline Relac4 & 0,472 & 0,457 & 0,500 & 0,887 & 0,427 & 0,435 & 0,544 & 0,388 & 0,387 & 0,459 \\
\hline RetCapInt1 & 0,441 & 0,373 & 0,312 & 0,287 & 0,836 & 0,423 & 0,516 & 0,419 & 0,354 & 0,324 \\
\hline RetCapInt2 & 0,388 & 0,333 & 0,283 & 0,332 & 0,830 & 0,373 & 0,519 & 0,436 & 0,408 & 0,379 \\
\hline RetCapInt3 & 0,446 & 0,365 & 0,318 & 0,373 & 0,874 & 0,427 & 0,491 & 0,431 & 0,337 & 0,320 \\
\hline RetCapInt4 & 0,493 & 0,408 & 0,358 & 0,399 & 0,878 & 0,507 & 0,567 & 0,420 & 0,334 & 0,370 \\
\hline RetCapInt5 & 0,497 & 0,407 & 0,369 & 0,375 & 0,883 & 0,526 & 0,539 & 0,470 & 0,378 & 0,371 \\
\hline CapSoc1 & 0,469 & 0,423 & 0,450 & 0,379 & 0,475 & 0,837 & 0,420 & 0,449 & 0,378 & 0,314 \\
\hline CapSoc2 & 0,485 & 0,462 & 0,529 & 0,442 & 0,455 & 0,845 & 0,460 & 0,520 & 0,334 & 0,350 \\
\hline CapSoc3 & 0,500 & 0,478 & 0,592 & 0,427 & 0,454 & 0,864 & 0,518 & 0,463 & 0,337 & 0,329 \\
\hline CapSoc4 & 0,447 & 0,379 & 0,451 & 0,397 & 0,470 & 0,851 & 0,498 & 0,488 & 0,389 & 0,331 \\
\hline CapSoc5 & 0,441 & 0,488 & 0,545 & 0,434 & 0,354 & 0,828 & 0,425 & 0,431 & 0,333 & 0,305 \\
\hline CapSoc6 & 0,436 & 0,465 & 0,546 & 0,446 & 0,458 & 0,835 & 0,436 & 0,430 & 0,377 & 0,277 \\
\hline CE1Compro1 & 0,423 & 0,396 & 0,458 & 0,414 & 0,526 & 0,461 & 0,791 & 0,371 & 0,248 & 0,345 \\
\hline CE2compro2 & 0,465 & 0,425 & 0,467 & 0,453 & 0,582 & 0,482 & 0,835 & 0,423 & 0,349 & 0,422 \\
\hline CE3compro3 & 0,349 & 0,377 & 0,506 & 0,437 & 0,387 & 0,381 & 0,781 & 0,359 & 0,207 & 0,400 \\
\hline CE4confi1 & 0,493 & 0,371 & 0,410 & 0,506 & 0,506 & 0,433 & 0,825 & 0,383 & 0,378 & 0,545 \\
\hline CE5confi2 & 0,520 & 0,412 & 0,526 & 0,456 & 0,499 & 0,472 & 0,875 & 0,435 & 0,369 & 0,544 \\
\hline CE6confi3 & 0,555 & 0,425 & 0,475 & 0,459 & 0,542 & 0,485 & 0,864 & 0,444 & 0,422 & 0,551 \\
\hline CapInnov1 & 0,358 & 0,399 & 0,399 & 0,317 & 0,354 & 0,433 & 0,331 & 0,833 & 0,365 & 0,359 \\
\hline CapInnov2 & 0,410 & 0,443 & 0,480 & 0,304 & 0,403 & 0,518 & 0,410 & 0,823 & 0,389 & 0,392 \\
\hline CapInnov3 & 0,459 & 0,414 & 0,422 & 0,377 & 0,445 & 0,495 & 0,451 & 0,805 & 0,388 & 0,333 \\
\hline CapInnov4 & 0,324 & 0,314 & 0,268 & 0,382 & 0,412 & 0,396 & 0,435 & 0,801 & 0,420 & 0,376 \\
\hline $\begin{array}{r}\text { Caplnnov5- } \\
\text { Codif inv }\end{array}$ & & & & & & & & & & \\
\hline CapInnov6 & $\begin{array}{l}-0,024 \\
0,265\end{array}$ & $\begin{array}{c}-0,082 \\
0,222\end{array}$ & $\begin{array}{l}0,019 \\
0,160\end{array}$ & $\begin{array}{c}-0,005 \\
0,264\end{array}$ & $\begin{array}{l}0,034 \\
0,349\end{array}$ & $\begin{array}{l}0,015 \\
0,287\end{array}$ & $\begin{array}{l}0,036 \\
0,250\end{array}$ & $\begin{array}{l}0,035 \\
0,628\end{array}$ & $\begin{array}{l}0,015 \\
0,482\end{array}$ & $\begin{array}{l}0,046 \\
0,314\end{array}$ \\
\hline RP1satisfacc & 0,405 & 0,415 & 0,438 & 0,446 & 0,367 & 0,343 & 0,519 & 0,390 & 0,474 & 0,824 \\
\hline RP2productivid & 0,394 & 0,474 & 0,447 & 0,394 & 0,306 & 0,362 & 0,470 & 0,421 & 0,487 & 0,815 \\
\hline RP3rotacVol & 0,241 & 0,124 & 0,274 & 0,240 & 0,346 & 0,227 & 0,435 & 0,322 & 0,398 & 0,757 \\
\hline RP4absentismo & 0,197 & 0,132 & 0,141 & 0,158 & 0,210 & 0,182 & 0,277 & 0,220 & 0,302 & 0,643 \\
\hline \begin{tabular}{r|} 
RE1ventas \\
RE2posi
\end{tabular} & 0,163 & 0,163 & 0,145 & 0,153 & 0,235 & 0,169 & 0,207 & 0,250 & 0,781 & 0,375 \\
\hline Competitiva & 0,282 & 0,274 & 0,307 & 0,270 & 0,368 & 0,303 & 0,331 & 0,363 & 0,864 & 0,495 \\
\hline RE3rentabilidad & 0,179 & 0,325 & 0,258 & 0,275 & 0,256 & 0,290 & 0,279 & 0,290 & 0,780 & 0,470 \\
\hline RE4n ${ }^{\circ}$ Innovacio & 0,256 & 0,289 & 0,303 & 0,294 & 0,341 & 0,402 & 0,324 & 0,564 & 0,796 & 0,414 \\
\hline $\begin{array}{r}\text { RE5esfuerzo } \\
\text { Innov }\end{array}$ & 0,366 & 0,270 & 0,352 & 0,363 & 0,437 & 0,460 & 0,428 & 0,537 & 0,786 & 0,459 \\
\hline
\end{tabular}




\section{Variables de capital humano de la organización}

En el caso del análisis de la validez de las escalas relativas a las tres variables que componen la retención del capital humano en nuestro modelo: capital intelectual, capital social y capital afectivo, las tres cumplen con los requisitos de fiabilidad (el valor de la carga del indicador analizado deberá ser mayor o igual a 0,7 ) y de validez convergente (consistencia interna $(\mathrm{Pc})$ está por encima de 0,7 y varianza extraída media (AVE) por encima de 0,5), como muestra la Tabla 4.17.

Tabla 4.17.

Cargas de los ítems de las variables de capital humano estratégico

\begin{tabular}{cc}
\hline \multicolumn{2}{c}{ Reten Cap Intelectual Pc $(0,935)$ y AVE $(0,741)$} \\
\hline RetCapInt1 & 0,836 \\
\hline RetCapInt2 & 0,830 \\
\hline RetCapInt3 & 0,874 \\
\hline RetCapInt4 & 0,878 \\
\hline RetCapInt5 & 0,883 \\
\hline Capital Social Pc $(0,937)$ y AVE $(0,711)$ \\
\hline CapSoc1 & 0,837 \\
\hline CapSoc2 & 0,845 \\
\hline CapSoc3 & 0,864 \\
\hline CapSoc4 & 0,851 \\
\hline CapSoc5 & 0,828 \\
\hline CapSoc6 & 0,835 \\
\hline Capital Afectivo Pc $(0,930)$ y AVE $(0,688)$ \\
\hline CE1Compro1 & 0,791 \\
\hline CE2compro2 & 0,835 \\
\hline CE3compro3 & 0,781 \\
\hline CE4confi1 & 0,825 \\
\hline CE5confi2 & 0,875 \\
\hline CE6confi3 & 0,864 \\
\hline
\end{tabular}

El último elemento de validación que analizamos es la validez discriminante, que se cumple en el caso de las escalas de estas tres variables, como se puede comprobar en la Tabla 4.15. anterior. Además, para completar este análisis, se analizaron las cargas cruzadas o crossloadings, otra de las pruebas para comprobar la validez discriminante, verificándose que cada indicador reflectivo se relaciona más con el constructo que trata de medir que con cualquier otro constructo o variable del modelo y, también, que cada variable latente se relaciona más con sus indicadores que con los indicadores de otros 
constructos. Los resultados de esta comprobación son, también, satisfactorios como puede comprobarse en la Tabla 4.16, ya presentada. Por tanto, también queda validado el requisito de validez discriminante de estas tres escalas.

\section{$\underline{\text { Resultados Organizativos }}$}

Las variables que forman los resultados organizativos en nuestro estudio, se agrupan en dos niveles: variables de resultado organizativo intermedio (capacidad de innovación y resultados de las personas) y variable de resultado final (resultados empresariales).

La escala de la variable capacidad de innovación, presenta unos indicadores cuyos pesos estimados cumplen con el requisito de fiabilidad, excepto en el caso de indicador CapInnov5 y del indicador CapInnov6, cuyos pesos estimados no superan el umbral de 0,7 (Chin, 1998), por lo que decidimos eliminarlos de sus respectivas escalas.

Tabla 4.18. Cargas de los ítems de las variables de resultados

\begin{tabular}{cc}
\hline Capacidad de Innovación & Pc $(0,840)$ y AVE $(0,509)$ \\
\hline CapInnov1 & 0,833 \\
\hline CapInnov2 & 0,823 \\
\hline CapInnov3 & 0,805 \\
\hline CapInnov4 & 0,801 \\
\hline CapInnov5-Codif inv ${ }^{6}$ & $\mathbf{0 , 0 3 5}$ \\
\hline CapInnov6 & $\mathbf{0 , 6 2 8}$ \\
\hline Resultados de Personas & Pc $(0,847)$ y AVE $(0,583)$ \\
\hline RP1satisfacc & 0,824 \\
\hline RP2productividad & 0,815 \\
\hline RP3rotacVol & 0,757 \\
\hline RP4absentismo & $\mathbf{0 , 6 4 3}$ \\
\hline Resultados Empresariales Pc $(0,900)$ y AVE $(0,644)$ \\
\hline RE1ventas & 0,781 \\
\hline RE2posiCompetitiva & 0,864 \\
\hline RE3rentabilidad & 0,78 \\
\hline RE4n'Innovaciones & 0,796 \\
\hline RE5esfuerzoInnov & 0,786 \\
\hline
\end{tabular}

Del mismo modo, para las escalas de la variable resultados de las personas y la variable resultados empresariales, todos sus indicadores cumplen con el criterio de fiabilidad, excepto el indicador RP4, que recoge la tasa de absentismo de los empleados y que, por tanto, será eliminado del índice.

\footnotetext{
${ }^{6}$ La variable CapInnov5 estaba codificada de forma inversa en el cuestionario.
} 
Con respecto a los requisitos de fiabilidad y validez convergente, las tres variables de resultados cumplen con estos requerimientos (Véase Tabla 4.18). Y, por último, el análisis de la validez discriminante también es satisfactoria en las escalas de las tres variables que nos ocupan, como se extrae del análisis de la Tabla 4.15., expuesta anteriormente. Y, además, el análisis de las cargas cruzadas o crossloadings, también es satisfactorio para las tres escalas, excepto en el ítem CapInnov5 (véase Tabla 4.16, ya presentada).

A modo de resumen del resultado de la validación de las escalas reflectivas, se presenta la Tabla 4.19 que recoge la propuesta de ítems que se utilizó en el cuestionario y las escalas definitivas, tras el proceso de validación que acabamos de realizar.

Tabla 4.19.

Resumen de la validación de las escalas reflectivas

\begin{tabular}{|c|c|c|c|}
\hline INDICE & & ÍTEMS INICIALES & $\begin{array}{c}\text { ESCALA } \\
\text { VALIDADA }\end{array}$ \\
\hline $\begin{array}{l}\text { Soporte del } \\
\text { supervisor }\end{array}$ & $\begin{array}{l}\text { Lider1 } \\
\text { Lider2 } \\
\text { Lider3 } \\
\text { Lider4 }\end{array}$ & $\begin{array}{l}\text { jefes accesibles } \\
\text { jefes interesan por empleados } \\
\text { jefes atienden problemas de empleados } \\
\text { jefes reconocen logros y méritos }\end{array}$ & $\begin{array}{l}\text { Lider1 } \\
\text { Lider2 } \\
\text { Lider3 } \\
\text { Lider4 } \\
\end{array}$ \\
\hline $\begin{array}{l}\text { Comunicación } \\
\text { Interna }\end{array}$ & $\begin{array}{l}\text { Comunic1 } \\
\text { Comunic2 } \\
\text { Comunic3 } \\
\text { Comunic4 } \\
\end{array}$ & $\begin{array}{l}\text { recibir información general de la empresa } \\
\text { canales comunicación entre departamentos } \\
\text { medios para comunicación interna } \\
\text { facilidades para comunicación ascendente }\end{array}$ & $\begin{array}{l}\text { Comunic1 } \\
\text { Comunic2 } \\
\text { Comunic3 } \\
\text { Comunic4 } \\
\end{array}$ \\
\hline $\begin{array}{l}\text { Participación } \\
\text { del Empleado }\end{array}$ & \begin{tabular}{|l|} 
Partic1 \\
Partic2 \\
Partic3 \\
Partic4 \\
\end{tabular} & $\begin{array}{l}\text { empleados son requeridos, se valora su opinión } \\
\text { se pueden sugerir mejoras del trabajo } \\
\text { se pueden sugerir mejoras de empresa } \\
\text { participan en grupos de mejora }\end{array}$ & $\begin{array}{l}\text { Partic1 } \\
\text { Partic2 } \\
\text { Partic3 } \\
\text { Partic4 } \\
\end{array}$ \\
\hline $\begin{array}{l}\text { Relaciones } \\
\text { internas- } \\
\text { compañerismo }\end{array}$ & $\begin{array}{l}\text { Relac1 } \\
\text { Relac2 } \\
\text { Relac3 } \\
\text { Relac4 } \\
\end{array}$ & $\begin{array}{l}\text { se promueven actividades fuera } \\
\text { disponer de lugares de relación y ocio } \\
\text { pueden dedicar tiempo a compañeros } \\
\text { se favorece el compañerismo }\end{array}$ & $\begin{array}{c}\text { Relac1 } \\
\text { Relac3 } \\
\text { Relac4 } \\
\end{array}$ \\
\hline $\begin{array}{l}\text { Retención de } \\
\text { Capital } \\
\text { Intelectual }\end{array}$ & $\begin{array}{l}\text { RetCapInt1 } \\
\text { RetCapInt2 } \\
\text { RetCapInt3 } \\
\text { RetCapInt4 } \\
\text { RetCapInt5 } \\
\end{array}$ & $\begin{array}{l}\text { mantener a los muy cualificados } \\
\text { mantener a los mejores de sector } \\
\text { mantener a los creativos-brillantes } \\
\text { mantener a los expertos } \\
\text { mantener a los que crean ideas } \\
\end{array}$ & $\begin{array}{l}\text { RetCapInt1 } \\
\text { RetCapInt2 } \\
\text { RetCapInt3 } \\
\text { RetCapInt4 } \\
\text { RetCapInt5 } \\
\end{array}$ \\
\hline Capital Social & $\begin{array}{l}\text { CapSoc1 } \\
\text { CapSoc2 } \\
\text { CapSoc3 } \\
\text { CapSoc4 } \\
\text { CapSoc5 } \\
\text { CapSoc6 }\end{array}$ & $\begin{array}{l}\text { es habitual intercambien conocimiento } \\
\text { habitual compartan ideas para crear nuevas } \\
\text { es habitual que colaboren para resolver problemas } \\
\text { es habitual que compartan informac. y aprendan } \\
\text { es habitual interacción entre áreas } \\
\text { es habitual apliquen conoc. de un área a otras }\end{array}$ & $\begin{array}{l}\text { RetCapSoc1 } \\
\text { RetCapSoc2 } \\
\text { RetCapSoc3 } \\
\text { RetCapSoc4 } \\
\text { RetCapSoc5 } \\
\text { RetCapSoc6 }\end{array}$ \\
\hline
\end{tabular}




\begin{tabular}{|c|c|c|c|}
\hline $\begin{array}{l}\text { Capital } \\
\text { afectivo }\end{array}$ & $\begin{array}{l}\text { CE1Compro1 } \\
\text { CE2 compro2 } \\
\text { CE3compro3 } \\
\text { CE4confi1 } \\
\text { CE5confi2 } \\
\text { CE6confi3 }\end{array}$ & $\begin{array}{l}\text { tienen fuerte sentimiento de pertenencia } \\
\text { la empresa tiene gran sentido personal para ellos } \\
\text { consideran propios los problemas de la empresa } \\
\text { consideran q empresa trata de forma justa } \\
\text { consideran empresa es honesta y sincera } \\
\text { considera empresa es coherente: dice-hace }\end{array}$ & $\begin{array}{l}\text { CE1Compro1 } \\
\text { CE2compro2 } \\
\text { CE3compro3 } \\
\text { CE4confi1 } \\
\text { CE5confi2 } \\
\text { CE6confi3 } \\
\end{array}$ \\
\hline $\begin{array}{l}\text { Capacidad de } \\
\text { innovación }\end{array}$ & $\begin{array}{l}\text { CapInnov1 } \\
\text { CapInnov2 } \\
\text { CapInnov3 } \\
\text { CapInnov4 } \\
\text { CapInnov5 } \\
\text { CapInnov6 } \\
\end{array}$ & $\begin{array}{l}\text { poner en práctica nuevas ideas } \\
\text { buscar nuevas formas hacer cosas } \\
\text { ser creativa en métodos trabajo } \\
\text { ser pionera lanzar nuevos productos } \\
\text { percibir innovación como riesgo-evitarla } \\
\text { incrementado nuevos prdtos en mercado-5 años }\end{array}$ & $\begin{array}{l}\text { CapInnov1 } \\
\text { CapInnov2 } \\
\text { CapInnov3 } \\
\text { CapInnov4 } \\
---------- \\
-------- \\
\end{array}$ \\
\hline $\begin{array}{l}\text { Resultados de } \\
\text { las personas }\end{array}$ & $\begin{array}{l}\text { RP1satisfacc } \\
\text { RP2productivid } \\
\text { RP3rotacVol } \\
\text { RP4absentismo } \\
\end{array}$ & $\begin{array}{l}\text { incrementado satisfacción laboral-5años } \\
\text { incrementado productividad-desempeño-5 años } \\
\text { disminuido rotación voluntaria-5 años } \\
\text { disminuido absentismo laboral-5 años }\end{array}$ & $\begin{array}{c}\text { RP1satisfacc } \\
\text { RP2productivid } \\
\text { RP3rotacVol } \\
\text {--------- } \\
\end{array}$ \\
\hline $\begin{array}{l}\text { Resultados } \\
\text { empresariales }\end{array}$ & $\begin{array}{l}\text { RE1ventas } \\
\text { RE2posiCompetit } \\
\text { RE3rentabilidad } \\
\text { RE4nº'Innovacins } \\
\text { RE5esfuerzoInnv } \\
\end{array}$ & $\begin{array}{l}\text { incrementado las ventas en los últimos } 5 \text { años } \\
\text { mejorado posición competitiva- } 5 \text { años } \\
\text { mejorado rentabilidad-5 años } \\
\text { incrementado }{ }^{\circ} \text { innovaciones- } 5 \text { años } \\
\text { incrementado esfuerzo innovador- } 5 \text { años }\end{array}$ & $\begin{array}{l}\text { RE1ventas } \\
\text { RE2posiCompetit } \\
\text { RE3rentabilidad } \\
\text { RE4n }{ }^{\circ} \text { Innovacions } \\
\text { RE5esfuerzoInnov }\end{array}$ \\
\hline
\end{tabular}

Para finalizar, y antes de analizar el modelo estructural, se deben tener en cuenta las pequeñas modificaciones que se ha decidido realizar en las escalas de medida, tanto de los índices formativos como reflectivos, y validar este "modelo de medida corregido". Como se puede observar en las dos siguientes Tablas (Tabla 4.20. y Tabla 4.21.), en el caso de los índices formativos, los indicadores, en su mayoría, son estadísticamente significativos y, además, los cuatro índices formativos cumplen los requisitos de no multicolinealidad. Por su parte, las escalas reflectivas depuradas cumplen con los criterios de fiabilidad, validez convergente y discriminante, y todos sus indicadores resultan estadísticamente significativos. En consecuencia, podemos afirmar que el modelo de medición propuesto es estadísticamente robusto. 
Tabla 4.20

Modelo de medida de los índices formativos depurados*

\begin{tabular}{lcccr}
\hline \multicolumn{1}{c}{ Constructos e indicadores } & $\begin{array}{c}\text { Valor } \\
\text { original }\end{array}$ & $\begin{array}{c}\text { Error } \\
\text { estandar }\end{array}$ & $\begin{array}{c}\text { Pesos } \\
\text { (weights) }\end{array}$ & t-student \\
\hline DISEÑO DE PUESTO (máx. corr. = 0,346; máx VIF=1,205 (T=0,86); máx CN=14) & \\
Ptrab1: retador & 0,743 & 0,106 & 0,743 & 6,993 \\
Ptrab2: autonomía & 0,238 & 0,151 & 0,238 & 1,577 \\
Ptrab4: cualificación variada & 0,301 & 0,16 & 0,301 & 1,883 \\
\hline RETRIBUCIÓN (máx. corr. =0,265; máx VIF=1,128 (T= 0,9); máx CN=13) & \\
Retrib1: equidad externa & 0,475 & 0,107 & 0,475 & 4,443 \\
Retrib2: equidad interna & 0,61 & 0,088 & 0,61 & 6,945 \\
Retrib4: contingente con grupo & 0,121 & 0,123 & 0,121 & 0,987 \\
Retrib7: beneficios sociales & 0,246 & 0,119 & 0,246 & 2,072 \\
\hline DESARROLLO (máx. corr. =0,476; máx VIF=1,431 (T= 0,84); máx CN = 10) & \\
Desarr1: formación acogida & 0,538 & 0,115 & 0,538 & 4,683 \\
Desarr3+Desarr4: form.Multidiscp & 0,179 & 0,139 & 0,179 & 1,295 \\
Desarr7: promoción & 0,555 & 0,111 & 0,555 & 4,999 \\
\hline CONCILIACIÓN (máx. corr. = 0,169; máx VIF=1,029 (T= 0,97); máx CN =8) & \\
Conci1+Conci2: facilidades, flex hor & 0,782 & 0,093 & 0,782 & 8,405 \\
Conci3: ayudas económicas & 0,504 & 0,121 & 0,504 & 4,177 \\
\hline
\end{tabular}

* Junto a cada constructo se recogen: la correlación de Pearson más elevada de entre todos los pares de indicadores de ese bloque, así como el factor de inflación de la varianza (FIV), la Tolerancia $(\mathrm{T})$ y el índice o número o índice de condición $(\mathrm{CN})$ más elevados. Un valor del estadístico $\mathrm{t}$ superior a 1'64 implica que el peso del indicador correspondiente es significativamente distinto de cero al $95 \%$, para t-student de una cola 
Tabla 4.21. Modelo de Medida de las escalas reflectivas depuradas*

\begin{tabular}{|c|c|c|c|c|c|}
\hline \multicolumn{2}{|c|}{ Constructos e indicadores } & \multirow[t]{2}{*}{$\begin{array}{c}\begin{array}{c}\text { valor } \\
\text { original }\end{array} \\
\end{array}$} & \multirow[t]{2}{*}{$\begin{array}{c}\begin{array}{c}\text { Error } \\
\text { estandar }\end{array} \\
\end{array}$} & \multirow[t]{2}{*}{$\begin{array}{c}\text { Cargas } \\
\text { (loadings) }\end{array}$} & \multirow[t]{2}{*}{ t-student } \\
\hline Soporte del líder 0 & $(\mathrm{pc}=0,898 ; \mathrm{AVE}=0687)$ & & & & \\
\hline Lider1 & jefes accesibles & 0,737 & 0,048 & 0,737 & 15,284 \\
\hline Lider2 & jefes interesan por empleados & 0,865 & 0,021 & 0,865 & 42,040 \\
\hline Lider3 & jefes atienden problemas de empleados & 0,853 & 0,025 & 0,853 & 34,740 \\
\hline Lider4 & jefes reconocen logros y méritos & 0,855 & 0,019 & 0,855 & 45,004 \\
\hline \multicolumn{6}{|c|}{ Comunicación interna $\quad(\mathrm{pc}=0,862 ;$ AVE $=0,609)$} \\
\hline Comunic1 & recibir informacion gral d empresa & 0,745 & 0,034 & 0,745 & 21,901 \\
\hline Comunic2 & canales comunic entre departam & 0,832 & 0,025 & 0,832 & 33,474 \\
\hline Comunic3 & medios para comunic interna & 0,75 & 0,038 & 0,75 & 19,984 \\
\hline Comunic4 & facilidades para comunc ascendente & 0,792 & 0,031 & 0,792 & 25,76 \\
\hline \multicolumn{6}{|c|}{ Participación del empleado $\quad(\mathrm{pc}=0,870 ;$ AVE=0,626 $)$} \\
\hline Partic1 & empleados son requeridos,valoran su opinion & 0,81 & 0,021 & 0,81 & 38,133 \\
\hline Partic2 & se pueden sugerir mejoras del trabajo & 0,855 & 0,022 & 0,855 & 39,29 \\
\hline Partic3 & se pueden sugerir mejoras de empresa & 0,729 & 0,046 & 0,729 & 15,692 \\
\hline Partic4 & participan en grupos de mejora & 0,765 & 0,029 & 0,765 & 26,426 \\
\hline \multicolumn{6}{|c|}{ Relaciones internas-compañerismo $\quad(\mathrm{pc}=0,881 ; \mathrm{AVE}=\mathbf{0 , 7 1 3})$} \\
\hline Relac1 & se promueven actividades fuera & 0,759 & 0,036 & 0,759 & 21,043 \\
\hline Relac3 & pueden dedicar tiempo a compañeros & 0,869 & 0,019 & 0,869 & 44,674 \\
\hline Relac4 & se favorece el compañerismo & 0,898 & 0,015 & 0,898 & 58,69 \\
\hline \multicolumn{6}{|c|}{$\begin{array}{ll}\text { Retención de Capital Intelectual } \quad(p c=0,935 ; \text { AVE }=0,741)\end{array}$} \\
\hline RetCapH1 & mantener a los muy cualificados & 0,835 & 0,03 & 0,835 & 28,151 \\
\hline RetCapH2 & mantener a los mejores de sector & 0,83 & 0,034 & 0,83 & 24,583 \\
\hline RetCpaH3 & mantener a los creativos-brillantes & 0,874 & 0,024 & 0,874 & 37,133 \\
\hline RetCapH4 & mantener a los expertos & 0,879 & 0,019 & 0,879 & 46,756 \\
\hline RetCapH5 & mantener a los que crean ideas & 0,885 & 0,018 & 0,885 & 48,783 \\
\hline Capital Social & $(\mathrm{pc}=0,937 ;$ AVE $=0,711)$ & & & & \\
\hline RetCapSoc1 & es habitual intercambien conocimiento & 0,836 & 0,024 & 0,836 & 35,221 \\
\hline RetCapSoc2 & habitual compartan ideas para crear nuevas & 0,844 & 0,021 & 0,844 & 40,898 \\
\hline RetCapSoc3 & es habitual que colaboren resolver problemas & 0,864 & 0,018 & 0,864 & 46,836 \\
\hline RetCapSoc4 & es habitual que compartan informac, aprendan & 0,851 & 0,021 & 0,851 & 41,339 \\
\hline RetCapSoc5 & es habitual interacción entre áreas & 0,829 & 0,023 & 0,829 & 35,586 \\
\hline RetCapSoc6 & es habitual apliquen conoc de un área a otras & 0,836 & 0,022 & 0,836 & 37,848 \\
\hline \multicolumn{6}{|c|}{ Capital afectivo $\quad(p c=0,930 ; \mathrm{AVE}=0,688)$} \\
\hline CE1Compro1 & tienen fuerte sentimiento de pertenencia & 0,791 & 0,031 & 0,791 & 25,217 \\
\hline CE2compro2 & la empresa tiene gran sentido personal & 0,835 & 0,024 & 0,835 & 34,373 \\
\hline CE3compro3 & consideran propios los problemas de empresa & 0,781 & 0,029 & 0,781 & 27,356 \\
\hline CE4confi1 & consideran q empresa trata de forma justa & 0,824 & 0,033 & 0,824 & 24,645 \\
\hline CE5confi2 & consideran empresa es honesta y sincera & 0,875 & 0,016 & 0,875 & 53,138 \\
\hline CE6confi3 & considera empresa es coherente: dice-hace & 0,864 & 0,02 & 0,864 & 42,897 \\
\hline \multicolumn{6}{|c|}{$\begin{array}{ll}\text { Capacidad de Innovación } & (\mathrm{pc}=0,902 ; \quad \text { AVE= 0,698) }\end{array}$} \\
\hline CapInnov1 & poner en práctic a nuevas ideas & 0,864 & 0,021 & 0,864 & 41,539 \\
\hline CapInnov2 & buscar nuevas formas hacer cosas & 0,869 & 0,02 & 0,869 & 42,393 \\
\hline CapInnov3 & ser creativa en métodos trabajo & 0,844 & 0,023 & 0,844 & 36,542 \\
\hline CapInnov4 & ser pionera lanzar nuevos pdtos & 0,76 & 0,03 & 0,76 & 25,046 \\
\hline \multicolumn{6}{|c|}{ Resultados de personas $\quad(\mathrm{pc}=0,855 ;$ AVE $=0,66$ ? } \\
\hline RP1satisfacc & incrementado satisfac laboral 5años & 0,867 & 0,019 & 0,867 & 44,778 \\
\hline RP2productivid & incrementado productividad 5 años & 0,848 & 0,027 & 0,848 & 31,694 \\
\hline RP3rotacVol & disminuido rotación voluntaria 5 años & 0,72 & 0,054 & 0,72 & 13,418 \\
\hline \multicolumn{6}{|c|}{ 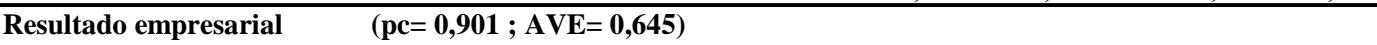 } \\
\hline RE1ventas & incrementado Ventas 5 años & 0,789 & 0,039 & 0,789 & 20,027 \\
\hline RE2posiCompetit & mejorado posic competitiva 5 años & 0,871 & 0,022 & 0,871 & 39,19 \\
\hline RE3rentabilidad & mejorado rentabilidad 5 años & 0,79 & 0,033 & 0,79 & 23,988 \\
\hline RE4n Innovacions & incrementado $\mathrm{n}^{\circ}$ innovaciones 5 años & 0,786 & 0,036 & 0,786 & 22,041 \\
\hline RE5esfuerzoInnov & incrementado esfuerzo innovador 5 años & 0,778 & 0,041 & 0,778 & 19,129 \\
\hline
\end{tabular}

* Junto a cada constructo se recogen el índice de fiabilidad compuesta (pc) y la varianza extraida media (AVE).

Se presentan las cargas y el valor del estadístico t, que si superior a 1'96 implica que la carga del indicador

correspondiente es significativamente distinta de cero al $95 \%$. 


\subsection{ANÁLISIS Y EVALUACIÓN DEL MODELO ESTRUCTURAL}

Con la evaluación del modelo estructural (Luna-Reyes et al., 2009) se pretende dar respuesta a dos cuestiones: primero, ¿en qué medida las variables predictoras contribuyen a la varianza explicada de las variables endógenas? y, segundo, ¿qué cantidad de la varianza de las variables endógenas se explica por los constructos que las predicen?

Para responder a la primera pregunta, se contrastan las relaciones causales entre los constructos del modelo, lo que permite contrastar las hipótesis del trabajo. Para ello, se examinarán el signo, el tamaño y la significación de los $\beta$ o coeficientes path estandarizados que resultan de la estimación del modelo mediante el enfoque de mínimos cuadrados parciales (PLS). Los coeficientes path se encuentran asociados a cada una de las relaciones causales y representan el mayor o menor efecto de cada una de las variables independientes sobre las variables dependientes en el modelo. El nivel de significación se determina a partir del valor de la $t$ de Student que se deriva de un proceso de remuestreo (denominado bootstrapping), que nos permite calcular SmartPLS, por el cual se generan aleatoriamente una serie de submuestras -2000 en este trabajo- a partir de la muestra original para, a continuación, estimar el modelo con cada una de ellas ${ }^{7}$. De esta forma, se puede calcular la media y el error estándar de cada parámetro del modelo en cada submuestra, además de obtener una distribución empírica de frecuencias que permite evaluar si los parámetros resultantes son o no significativamente distintos de cero.

En cuanto al segundo interrogante, para poder valorar la cantidad de varianza de las variables endógenas que se explica por las variables que las predicen, se analiza el coeficiente de determinación $\left(\mathrm{R}^{2}\right)$, que ha de ser interpretado de la misma forma que los $\mathrm{R}^{2}$ obtenidos en un análisis de regresión múltiple. Asimismo, se evalúa la capacidad de

\footnotetext{
${ }^{7}$ Siguiendo las recomendaciones de Chin (1998b) y Tenenhaus et al. (2005), dentro de las opciones del proceso de remuestreo del programa Smart-PLSPLS, se escogió la opción "construct level change", que tiene en cuenta los posibles cambios de signo que ocurran al nivel de constructo. Se debe realizar así, ya que durante el proceso de estimación es posible que en alguna de las muestras se inviertan los signos de los pesos de todos los indicadores asociados a un determinado constructo, lo que afectaría a las relaciones estructurales en las que dicho constructo está incluido. Si estos posibles cambios de signo no fueran tenidos en cuenta, se estarían inflando los errores estándar de los parámetros que miden las correspondientes relaciones estructurales (Rodríguez-Pinto, 2008).
} 
predicción, teniendo en cuenta el coeficiente de relevancia predictiva $\left(\mathrm{Q}^{2}\right)$, tal y como sugiere Chin (1998b).

A efectos del contraste de las hipótesis planteadas en el capítulo segundo y en base a la metodología utilizada, el contraste de las ocho hipótesis que relacionan las prácticas de recursos humanos propuestas y la retención de capital humano, implica la contrastación de veinticuatro subhipótesis correspondientes a la relación de cada una de estas ocho prácticas con cada una de las tres dimensiones del capital humano: capital intelectual, capital social y capital afectivo. Y, del mismo modo, el contraste de la relación planteada entre el capital humano y la capacidad de innovación supone la contrastación de sus tres correspondientes subhipótesis. La Figura 4.1. representa gráficamente las principales hipótesis propuestas en nuestro modelo y la Figura 4.1bis representa el detalle de las relaciones causales de nuestro modelo a través de las correspondientes subhipótesis que contrastamos a continuación.

Figura 4.1. Modelo con las principales hipótesis planteadas

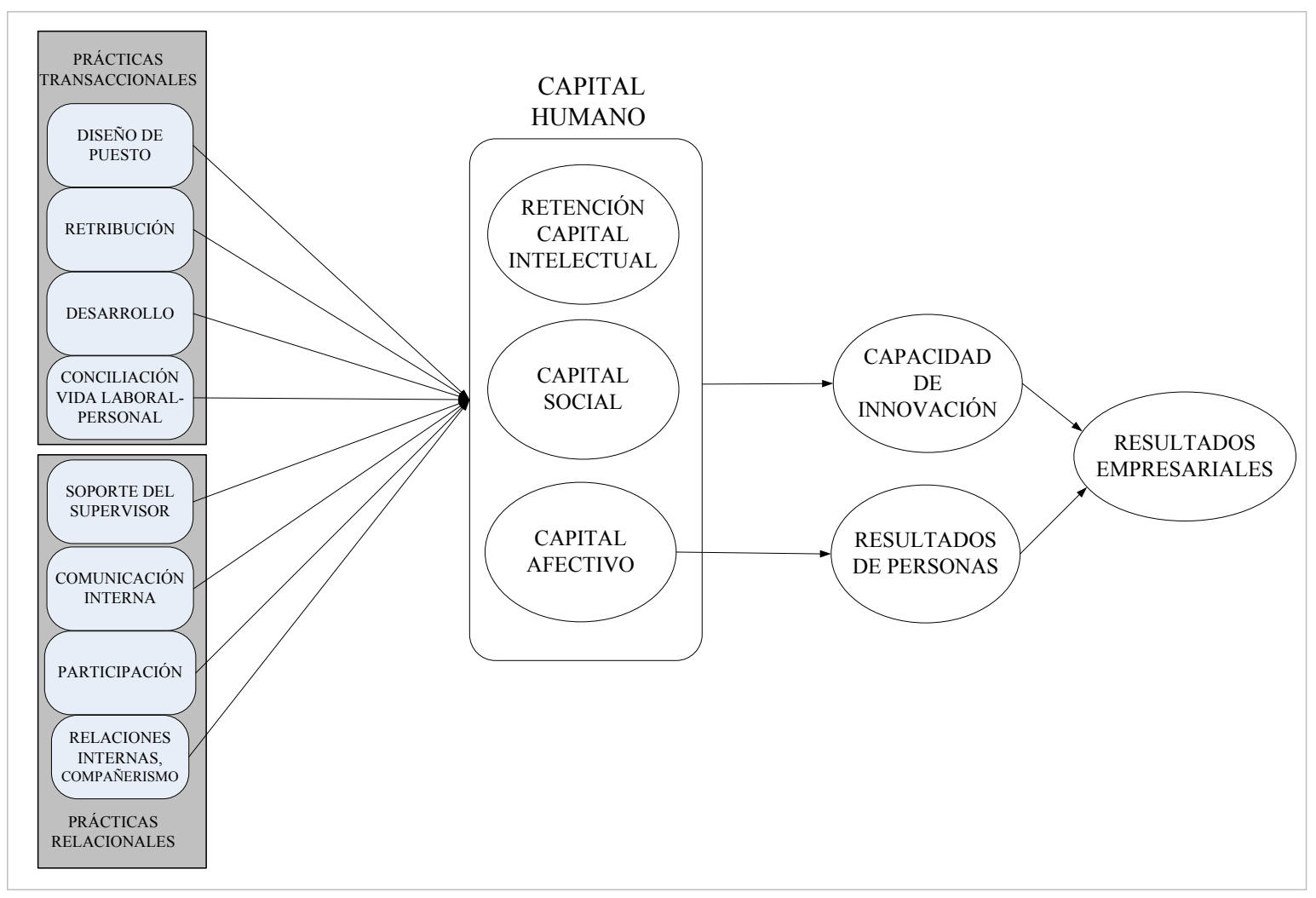


Figura 4.1bis.

Modelo con subhipótesis objeto de contraste empírico estimado con Smart-PLS

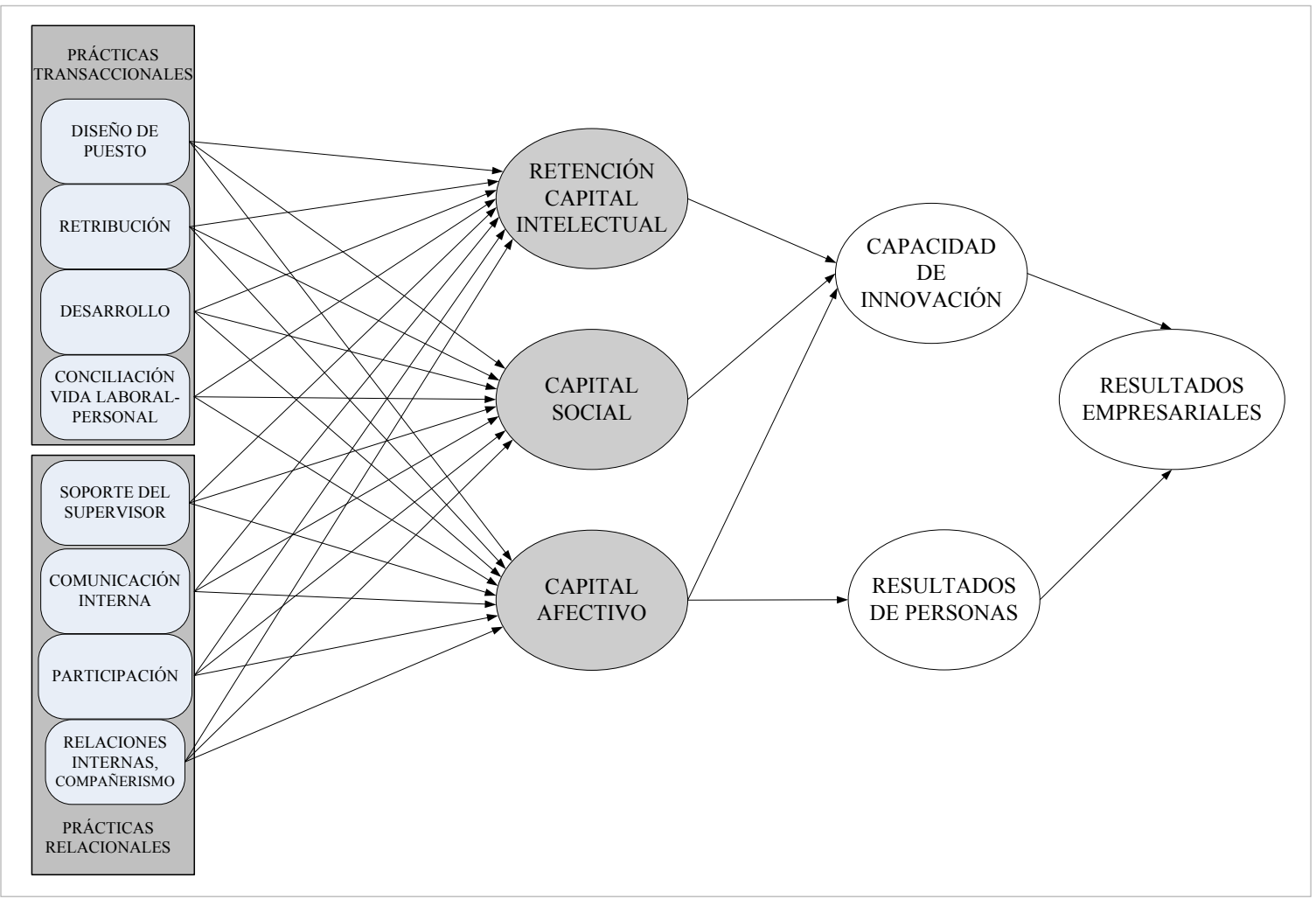

A continuación, presentamos los resultados más destacados que se revelan del contraste a través de mínimos cuadrados parciales del modelo teórico. Para una mayor claridad, se dedica una sección a cada uno de los tres grandes bloques de hipótesis y subhipótesis que conforman el modelo teórico propuesto: influencia de las prácticas de recursos humanos sobre el capital humano (intelectual, social y afectivo), influencia del capital humano sobre la capacidad de innovación y la influencia e impacto final sobre las variables de resultado (epígrafes 4.2.1, 4.2.2 y 4.2.3, respectivamente).

En consecuencia, para facilitar la visualización de los resultados, en cada apartado presentaremos las figuras correspondientes a las relaciones que se analicen aunque, lógicamente, se obtienen de la estimación del modelo global objeto de esta investigación. 


\subsubsection{Prácticas de retención de recursos humanos y capital humano de la organización. Contraste de hipótesis y subhipótesis.}

En este primer bloque se presentan los resultados del contraste de un total de veinticuatro subhipótesis. Las ocho primeras $\left(H_{1 a-8 a}\right)$ estudian la influencia que las prácticas de recursos humanos propuestas ejercen sobre la retención de capital intelectual (Figura 4.2.), las ocho segundas $\left(H_{l b-8 b}\right)$ versan sobre su efecto en el capital social (Figura 4.3.) y, las ocho terceras $\left(H_{l c-8 c}\right)$, abordan la influencia sobre el capital afectivo de la empresa (Figura 4.4). Presentaremos de este modo el contraste de subhipótesis para poder identificar de una forma clara cuáles son las prácticas de recursos humanos que tienen un mayor efecto sobre cada una de las dimensiones del capital humano.

4.2.1.1. Prácticas de recursos humanos y retención de capital intelectual. Contraste de subhipótesis $H_{1 a-8 a}$

En este apartado, contrastamos el efecto de las prácticas de recursos humanos propuestas en la retención de capital intelectual recogido a través de las subhipótesis $\mathrm{H}_{1 \mathrm{a}-8 \mathrm{a}}$. Como puede observarse en la Tabla 4.22. y en la Figura 4.2., en nuestro estudio empírico no todas las prácticas de recursos humanos propuestas logran los efectos esperados.

Tabla 4.22. Contraste de las subhipótesis del efecto de las prácticas de recursos humanos sobre la retención del capital intelectual

\begin{tabular}{|c|c|c|c|c|}
\hline & $\beta$ & $\mathrm{t}$ & Resultado & hipótesis \\
\hline DiseñoPuesto -> RetCapInt & 0,023 & 0,325 & signo esperado $(+)$, no significativa & $\mathrm{H} 1 \mathrm{a}$ \\
\hline Retribuc -> RetCapInt & 0,133 & 1,677 & Validada & $\mathrm{H} 2 \mathrm{a}$ \\
\hline Desarrollo -> RetCapInt & 0,106 & 1,56 & Signo esperado, marginalmente signf & $\mathrm{H} 3 \mathrm{a}$ \\
\hline Conciliac -> RetCapInt & 0,029 & 0,432 & signo esperado $(+)$, no significativa & $\mathrm{H} 4 \mathrm{a}$ \\
\hline SoporteSupv -> RetCapInt & 0,294 & 4,171 & Validada & $\mathrm{H} 5 \mathrm{a}$ \\
\hline Comunic -> RetCapInt & 0,17 & 2,044 & Validada & H6a \\
\hline Participac -> RetCapInt & $-0,055$ & 0,573 & signo no esperado (-), no significativa & $\mathrm{H} 7 \mathrm{a}$ \\
\hline Compañerismo -> RetCapInt & 0,096 & 1,475 & signo esperado $(+)$, no significativa & $\mathrm{H} 8 \mathrm{a}$ \\
\hline
\end{tabular}


Figura 4.2. Contraste de subhipótesis $H_{1 a-8 a}$

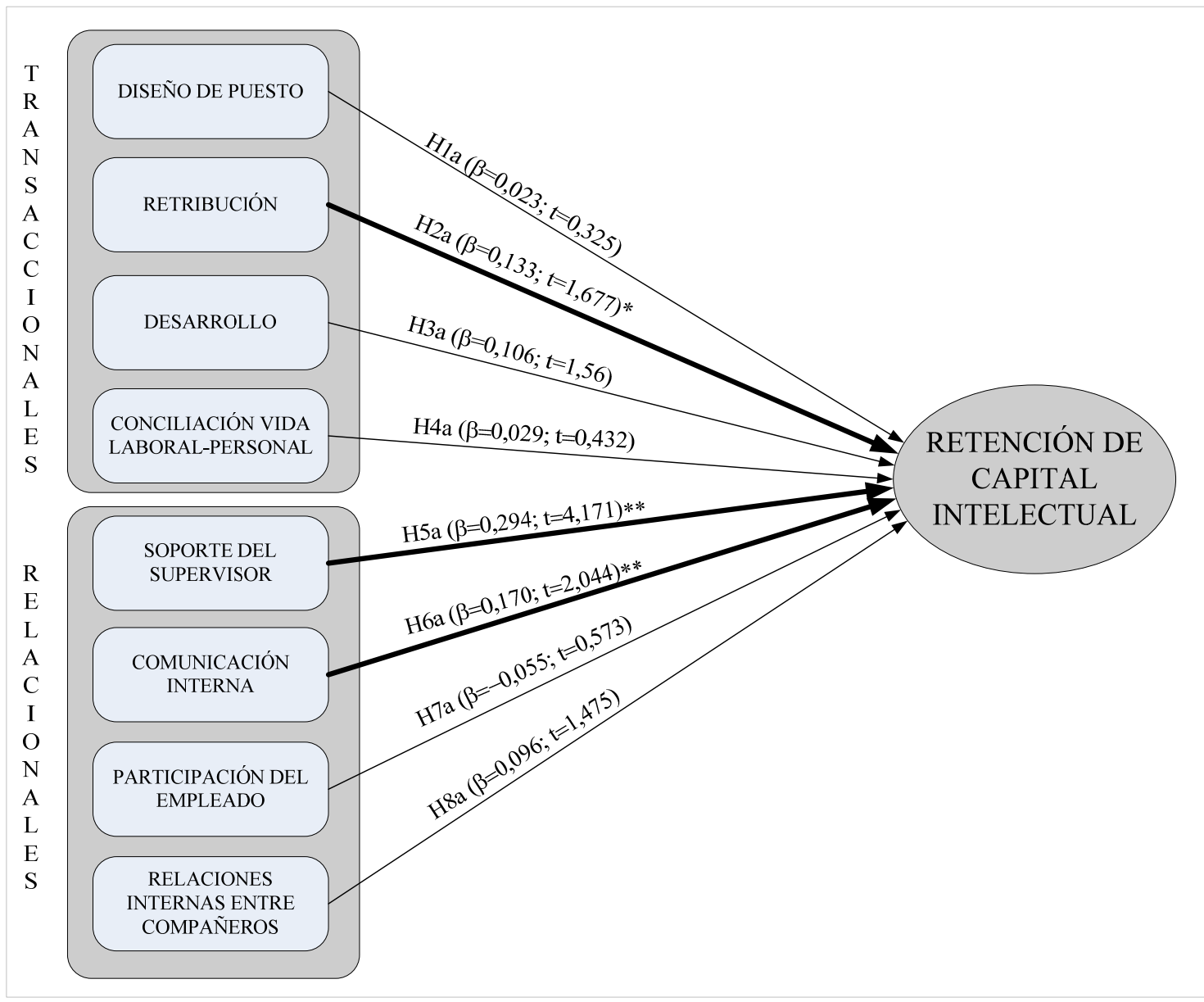

Nota: las hipótesis validadas y significativas se señalan con flecha en negrita, significativas al $* \mathrm{p}<0.05$, ${ }^{* *} \mathrm{p}<0.01$ y ${ }^{* * *} \mathrm{p}<0.001$ (al $5 \%, 1 \%$ y $0,1 \%$, es decir, al nivel de confianza del 95 , del 99 y del $99.9 \%$, respectivamente, para el test t-student de una cola).

El análisis de estos resultados conducen a rechazar la subhipótesis H1a, es decir, no se aprecia una relación significativa entre el diseño del puesto y la retención de capital intelectual. El coeficiente estimado es, como se esperaba, positivo aunque muy pequeño y no significativo $(\beta=0.023 ; \mathrm{t}=0.325)$. En principio, la interpretación de los resultados señala que los puestos de trabajo diseñados de forma que sean retadores, dotados de autonomía y que requieran una cualificación amplia y variada, no supone un factor que motive a los empleados clave a permanecer en la empresa, contrariamente a lo esperado según la literatura de retención de recursos humanos. Creemos que puede deberse a que quizás para algunos empleados pueda resultar estresante este nivel de reto y de 
exigencia o a que estos empleados valoren aspectos menos relacionados con lo pactado contractualmente como el salario, puesto de trabajo y condiciones de trabajo cuestiones habitualmente protegidas y negociadas en los convenios- y tiendan a otorgar mayor importancia a aspectos vinculados a la faceta relacional y social en el trabajo. Dicha faceta no supone una obligación contractual para la empresa, sino que ésta la toma en consideración en virtud de la valoración y apuesta por sus empleados.

En contraste con la anterior subhipótesis, se observa una asociación positiva y significativa entre la retribución y la retención de capital intelectual estratégico $(\beta=0.133 ; \mathrm{t}=1.677)$. Es decir, se verifica la subhipótesis $\mathrm{H} 2 \mathrm{a}$, lo que significa que las empresas que utilicen sistemas de retribución que incluyan la equidad interna y externa, incentivos vinculados al desempeño grupal y la posibilidad de beneficios sociales, favorecerán la retención de sus empleados más valiosos.

En cuanto al desarrollo del empleado, se observa una asociación positiva $(\beta=0.106)$, que resulta marginalmente significativa al $10 \%(\mathrm{p}<0.1 ; \mathrm{t}=1,56)$ en relación a su efecto sobre la retención del capital intelectual, por lo que, siendo estrictos, debemos considerar H3a como rechazada. Este resultado no concuerda con mucha de la literatura revisada. Quizás este tipo de empleados, debido a su alta cualificación, no valoren tanto la formación que les pueda ofrecer la empresa. Y, por otra parte, las posibilidades de promoción no siempre son factibles o conocidas por los empleados, por lo que puede que estas medidas no favorezcan la retención de estos empleados estratégicos.

La subhipótesis H4a debe ser rechazada, puesto que se observa un efecto mínimo positivo $(\beta=0.029)$ y no significativo. Sin negar que las medidas de conciliación de vida laboral y personal son bien valoradas por los empleados, parecen no tener el suficiente impacto como para retener a los empleados y, por tanto, su capital intelectual. Quizás, en este factor en concreto sería interesante analizar el sexo mayoritario de los empleados clave, así como la edad y la situación familiar, algo que en nuestro estudio no se ha podido llevar a cabo.

En cuanto a las políticas relativas a la dimensión social y relacional de la relación laboral, dos subhipótesis son validadas y dos de ellas son refutadas. 
La subhipótesis relativa a la influencia del soporte y apoyo del supervisor sobre la retención de empleados (H5a) queda validada y además ejerce un fuerte impacto sobre la misma $(\beta=0.294 ; \mathrm{t}=4.171, * * * \mathrm{p}<0.001)$. Este resultado ahonda en las contribuciones de la literatura sobre soporte organizativo y soporte del líder. Los supervisores o superiores jerárquicos, con su hacer diario y estilo de liderazgo, representan el trato que la organización confiere a sus empleados. Así, en base a las normas de reciprocidad, si los superiores apoyan y dan soporte a sus subordinados, éstos, personalizando la empresa en su superior, tratarán de devolver el buen trato recibido $\mathrm{y}$, en correspondencia, actuarán de modo satisfactorio para la empresa permaneciendo en ella y desarrollando altos niveles de desempeño.

Los resultados confirman el efecto significativo de las medidas de comunicación interna sobre la retención de empleados estratégicos, y por tanto, de su capital intelectual ( $\beta=$ $0.170 ; \mathrm{t}=2.044)$, lo que conduce a aceptar la subhipótesis H6a. Por el contrario, la subhipótesis relativa a los efectos de las medidas de participación del empleado no muestran el signo esperado -tiene un efecto negativo sobre la retención de capital intelectual- y no resulta significativa, por lo que se rechaza la subhipótesis H7a.

En último lugar, y en relación a la influencia positiva de las relaciones internas de apoyo entre compañeros, no se logra evidencia empírica que demuestre que la existencia de lugares de ocio donde los empleados puedan interaccionar y las medidas que facilitan el compañerismo, tengan impacto significativo en la retención de capital intelectual. Sólo se encuentra un impacto muy pequeño y no significativo $(\beta=0.096 ; \mathrm{t}=1.475)$, por lo que debemos rechazar H8a.

\subsubsection{Prácticas de recursos humanos y capital social. Contraste de Subhipótesis $H_{l b-8 b}$}

En este bloque se presentan los resultados del contraste de las subhipótesis $H_{1 b-8 b}$ como puede observarse en la Figura 4.3 y en la Tabla 4.23. Las cuatro primeras subhipótesis versan sobre la capacidad que tienen las prácticas de recursos humanos, denominadas transaccionales, para favorecer el capital social de la empresa. Las cuatro segundas analizan el impacto que tienen ciertas prácticas de recursos humanos, consideradas relacionales, sobre el capital social. Nuestros resultados nos conducen a refutar tres de las cuatro prácticas transaccionales y a validar tres de las cuatro prácticas relacionales. 
Estos resultados no carecen de cierta lógica puesto que las prácticas relacionales promueven los flujos de conocimiento e interacción entre los empleados y, ambas, son dimensiones que soportan el capital social definido en este trabajo, por lo que era esperable que se validaran en mayor medida las prácticas relaciones que las transaccionales. Estos resultados se muestran en la Figura 4.3. y en la Tabla 4.23.

Figura 4.3.- Contraste de subhipótesis $H_{1 b-8 b}$

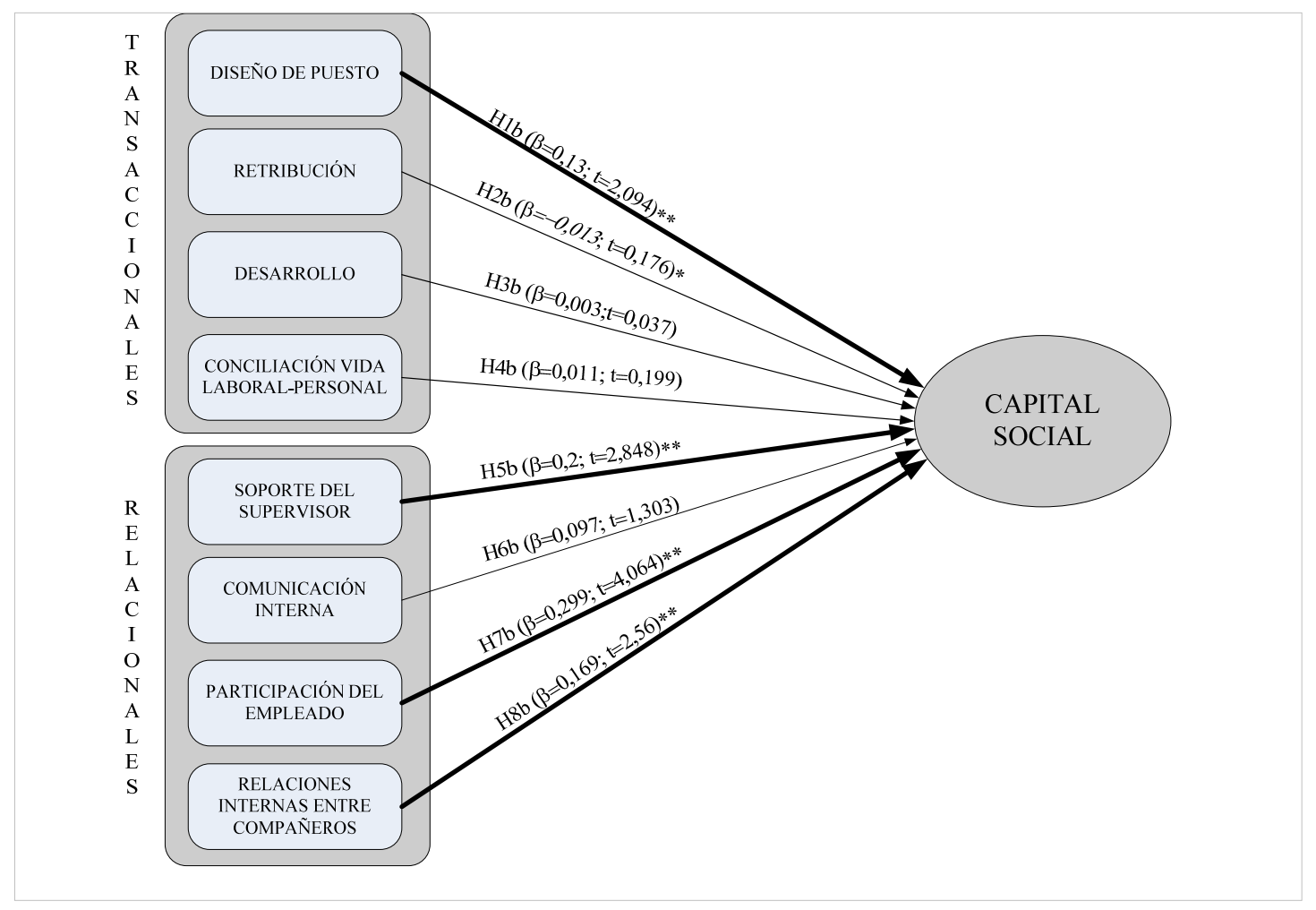

Nota: las hipótesis validadas y significativas se señalan con flecha en negrita, significativas al $* \mathrm{p}<0.05$, ${ }^{* *} \mathrm{p}<0.01 \mathrm{y} * * * \mathrm{p}<0.001$ (al $5 \%$, al $1 \%$ y al $0.1 \%$, respectivamente, para test $\mathrm{t}$-student de una cola).

Tabla 4.23. Constraste de las subhipótesis del efecto de las prácticas de recursos humanos sobre el capital social

\begin{tabular}{|ccc|c|c|}
\cline { 3 - 4 } \multicolumn{1}{c|}{} & & Resultado & hipótesis \\
\hline DiseñoPuesto -> CapSoc & 0,13 & 2,094 & Validada & H1b \\
Retribuc -> CapSoc & $-0,013$ & 0,176 & signo no esperado (-), no significativa & H2b \\
Desarrollo - $>$ CapSoc & 0,003 & 0,037 & signo esperado (+), no significativa & H3b \\
Conciliac -> CapSoc & 0,011 & 0,199 & signo esperado (+), no significativa & H4b \\
SoporteSup -> CapSoc & 0,2 & 2,848 & Validada & H5b \\
Comunic -> CapSoc & 0,097 & 1,303 & signo esperado (+), no significativa & H6b \\
Participac -> CapSoc & 0,299 & 4,064 & Validada & H7b \\
Compañerismo -> CapSoc & 0,169 & 2,56 & Validada & H8b \\
\hline
\end{tabular}


Respecto a las prácticas de recursos humanos que hemos agrupado en la categoría transaccional -diseño de puesto, retribución, desarrollo y medidas de conciliación- sólo en la primera, se han logrado resultados significativos, como explicamos, con mayor detalle, a continuación.

El diseño del puesto enriquecido se muestra, en estos resultados, como una práctica que ejerce un efecto positivo y significativo sobre el capital social $(\beta=0.13 ; t=2.094)$. Esto es lógico dado que este tipo de puestos requieren de la colaboración e interacción entre empleados, lo que favorece el mantenimiento y desarrollo del capital social. En base a ello, podemos aceptar la subhipótesis H1b.

Respecto a la retribución, observamos una asociación negativa (contraria a lo formulado en la hipótesis $)$ pero significativa $(\beta=-0.013 ; \mathrm{t}=0.176)$. Por tanto, no podemos dar por contrastada la hipótesis H2b. Este resultado nos sorprende. Puede que el sistema de retribución de la organización no apoye la consecución de objetivos comunes o de colaboración entre empleados $\mathrm{y}$, por el contrario, esté favoreciendo la competividad interna y el desempeño individualista, influyendo negativamente en el capital social. En contraste, no se observa una asociación significativa ni de la formación multidisciplinar y posibilidades de promoción $(\beta=0.003 ; \mathrm{t}=0.037)$, ni de las medidas de conciliación entre la vida laboral-personal $(\beta=0.013 ; \mathrm{t}=0.199)$ con el capital social vinculado a los recursos humanos estratégicos, por lo que debemos rechazar las subhipótesis H3b y H4b. Además, la refutación de las tres hipótesis que acabamos de mencionar es evidente ya que en todos los casos el coeficiente correspondiente es muy reducido.

En nuestros resultados, el sistema de retribución propuesto (aquél que cumple la equidad retributiva interna y externa, es contingente con el desempeño del grupo e incluye algún tipo de compensación extra) presenta un coeficiente tan pequeño y poco significativo que indica que la retribución, en contra de lo esperado, no parece favorecer un mayor capital social. Además, los resultados señalan que las prácticas de desarrollo del empleado -formación interdisciplinar y posibilidades de promoción- tampoco tienen un efecto significativo sobre el capital social. Y, en tercer lugar, las medidas de conciliación de la vida laboral-personal que ofrece la empresa a sus empleados ejerce una influencia mínima y no significativa sobre el capital social. Del mismo modo que la 
retribución, las prácticas de desarrollo y la conciliación no se muestran como prácticas que puedan tener una influencia significativa sobre el capital social.

No ocurre lo mismo para el contraste de prácticas de recursos humanos relacionales; puesto que los resultados del contraste realizado, validan tres de las cuatro subhipótesis planteadas.

El soporte y apoyo del superior se muestra como una práctica significativa y de impacto considerable sobre el capital social $(\beta=0.2 ; \mathrm{t}=2.848)$; los mismos resultados son alcanzados por las prácticas de participación $(\beta=0.299 ; \mathrm{t}=4.054)$ y por las medidas que favorecen el compañerismo entre empleados $(\beta=0.169 ; \mathrm{t}=2.56)$. En consecuencia, podemos aceptar las subhipótesis $\mathrm{H} 5 \mathrm{~b}, \mathrm{H} 7 \mathrm{~b}$ y $\mathrm{H} 8 \mathrm{~b}$, respectivamente. Es decir, favorecer el apoyo que los superiores ofrecen a los subordinados, dinamizar la participación del empleado y potenciar el desarrollo de relaciones internas entre compañeros, influye de forma significativa sobre el capital social.

Por el contrario, la comunicación interna $(\beta=0.097 ; \mathrm{t}=1.303)$ ejerce un impacto mínimo y no significativo sobre el capital social estratégico, por lo que la subhipótesis H6b debe ser rechazada. Este resultado resulta, cuanto menos curioso, puesto que en el caso de las subhipótesis H6a y H7a hemos obtenido resultados similares, es decir, todo apunta a que si la comunicación interna logra resultados significativos, no los logra la participación del empleado, y viceversa. Esto nos ofrece indicios para pensar que pueda existir cierta relación entre estas variables, que no habíamos detectado. La literatura da muestras de que en numerosas ocasiones se plantean estas prácticas indistintamente, por lo que creemos que una explicación a la refutación de esta subhipótesis es que el efecto de ambas pueda quedar recogido en una sola de ellas, en este caso la participación que, según nuestros resultados, ejerce un efecto importante (0.299). De hecho, es la práctica que recoge el mayor efecto sobre la variabilidad del capital social, lo que puede ser debido, en parte, a que recoge no sólo su impacto, sino, también, el de la comunicación interna pudiendo haber un efecto de mediación de la comunicación interna, que no habíamos planteado en el modelo objeto de esta investigación. 
4.2.1.3. Prácticas de recursos humanos y capital afectivo. Constraste de subhipótesis $H_{1 c-8 c}$.

Las prácticas de recursos humanos se muestran como una de los medios que tienen las organizaciones para promover la confianza en la organización y el compromiso de los empleados, dando lugar al capital afectivo de los empleados. En esta sección el interés se centra en analizar los resultados del contraste de las subhipótesis $H_{1 c-8 c}$. Las cuatro primeras subhipótesis versan sobre el impacto de cada una de las prácticas de recursos humanos transaccionales sobre el capital afectivo. Las cuatro segundas analizan el impacto de cada práctica relacional sobre el capital afectivo. Los resultados conducen a refutar dos de las cuatro subhipótesis de las prácticas transaccionales y a validar tres de las cuatro subhipótesis de las prácticas relacionales, como se muestra, a continuación, en la Figura 4.4 y en la Tabla 4.24.

Figura 4.4.

Contraste de las subhipótesis $H_{l c-8 c}$

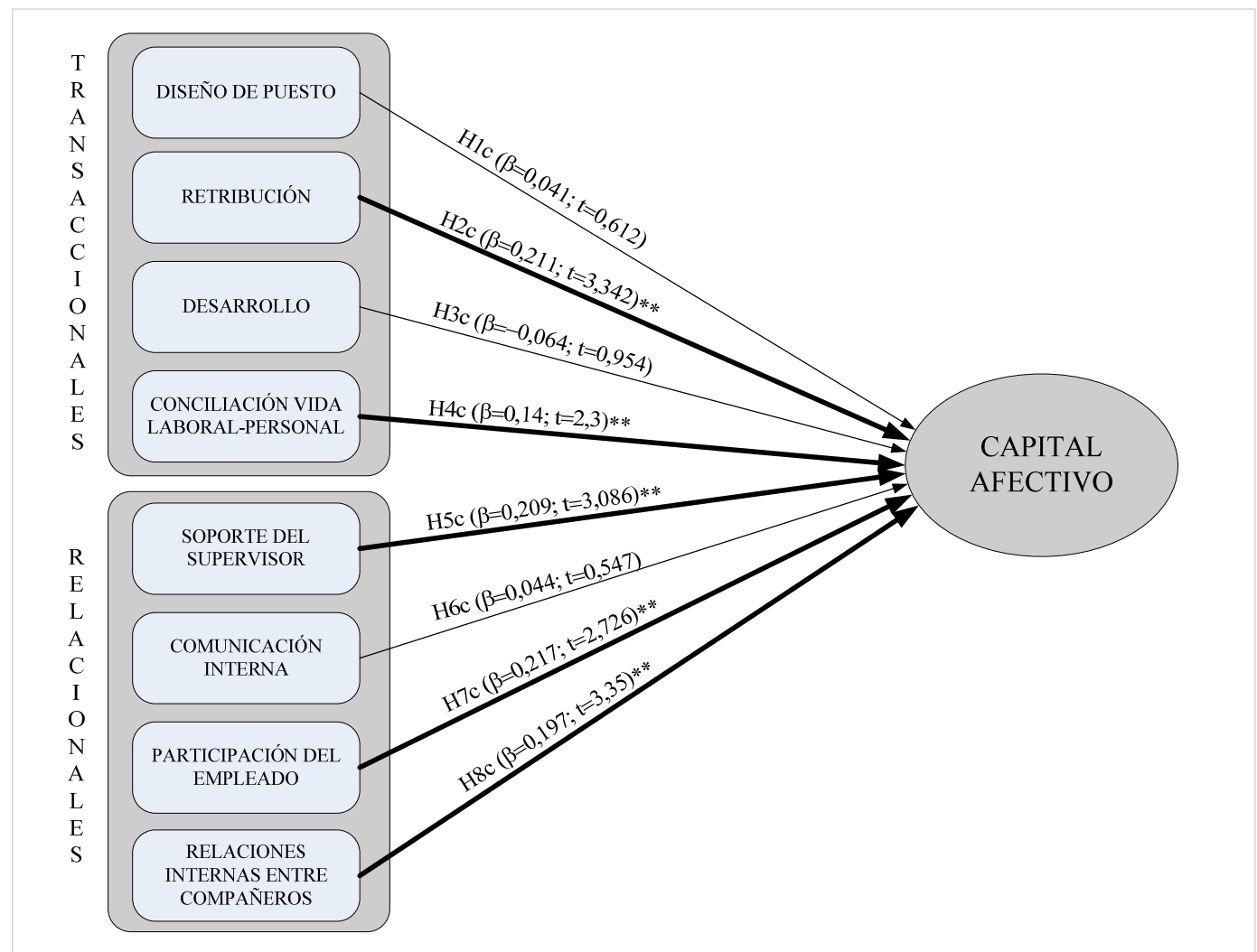

Nota: las hipótesis validadas y significativas se señalan con flecha en negrita, significativas al $* \mathrm{p}<0.05, * * \mathrm{p}<0.01 \mathrm{y} * * * \mathrm{p}<0.001$ (al 5\%, al 1\% y al $0.1 \%$, respectivamente, para test $\mathrm{t}$-student de una cola). 
Tabla 4.24.

Subhipótesis de influencia de las prácticas de recursos humanos sobre el capital afectivo

\begin{tabular}{|c|c|c|c|c|}
\hline & $\beta$ & $\mathbf{t}$ & Resultado & hipótesis \\
\hline DiseñoPuesto -> CapAfectivo & 0,041 & 0,612 & \multirow{8}{*}{$\begin{array}{r}\text { signo esperado }(+), \text { no significativa } \\
\text { validada } \\
\text { signo no esperado }(-) \text {, no significativa } \\
\text { validada } \\
\text { validada } \\
\text { signo esperado }(+) \text {, no significativa } \\
\text { validada } \\
\text { validada }\end{array}$} & $\mathrm{H} 1 \mathrm{c}$ \\
\hline Retribuc -> CapAfectivo & 0,211 & 3,342 & & $\mathrm{H} 2 \mathrm{c}$ \\
\hline Desarrollo -> CapAfectivo & $-0,064$ & 0,954 & & $\mathrm{H} 3 \mathrm{c}$ \\
\hline Conciliac $->$ CapAfectivo & 0,14 & 2,3 & & $\mathrm{H} 4 \mathrm{c}$ \\
\hline SoporteSupv -> CapAfectivo & 0,209 & 3,086 & & $\mathrm{H} 5 \mathrm{c}$ \\
\hline Comunic $->$ CapAfectivo & 0,044 & 0,547 & & H6c \\
\hline Participac -> CapAfectivo & 0,217 & 2,726 & & $\mathrm{H} 7 \mathrm{c}$ \\
\hline Compañerismo -> CapAfectivo & 0,197 & 3,35 & & $\mathrm{H} 8 \mathrm{c}$ \\
\hline
\end{tabular}

El diseño del puesto de trabajo enriquecido no parece tener ningún efecto significativo sobre el capital afectivo $(\beta=0.041 ; \mathrm{t}=0.612)$, por lo que se rechaza la subhipótesis H1c. Lo mismo ocurre con la política de desarrollo, es decir, con la formación de acogida, formación multidisciplinar y oportunidades de promoción que, sorprendentemente, presentan signo negativo, aunque muy pequeño y no significativo $(\beta=-0.064 ; \mathrm{t}=0.954)$. Así pues, también debemos rechazar H3c. Estos resultados serán comentados con mayor detalle en el capítulo de conclusiones, puesto que parecen indicar que los empleados no valoran tan positivamente la formación y promoción, como cabría esperar.

Por el contrario, la retribución influye de forma positiva y significativa sobre el capital afectivo $(\beta=0.211 ; \mathrm{t}=3.342)$, por lo que se puede aceptar la hipótesis H2c. Del mismo modo, la existencia de flexibilidad horaria y otras facilidades a la conciliación, también ejercen influencia positiva y significativa sobre el capital afectivo $(\beta=0.14 ; \mathrm{t}=2.3)$, por lo que queda validada la subhipótesis H4c. Ambas prácticas pueden ser contempladas como medidas que la empresa lleva a cabo de forma unilateral si valora y aprecia a los empleados, lo que desarrolla la confianza y compromiso de éstos con la organización.

En relación a las prácticas de recursos humanos consideradas relacionales, todas menos la comunicación interna presentan efectos positivos y significativos sobre el capitalafectivo. Tal como se esperaba, el soporte del supervisor tiene un fuerte impacto significativo sobre el capital afectivo $(\beta=0.209 ; \mathrm{t}=3.086)$. Esto concuerda con los enfoques que postulan que el supervisor o superior es la cara visible de la empresa para el empleado, por lo que si apoya técnica y afectivamente a sus emplados y tienen un 
trato correcto con los mimos, éstos actuarán de modo recíproco, lo que contribuye a generar sentimientos de afecto basados en la confianza y compromiso, que sustentan el capital afectivo. Por tanto, aceptamos como validada la subhipótesis H5c.

En esta línea de argumentos se justifican, también, los resultados alcanzados para la participación del empleado, que al lanzar un mensaje de confianza y valoración positiva de él, lo conducen a querer actuar con reciprocidad. Los resultados confirman el importante efecto positivo y significativo de esta práctica $(\beta=0.217 ; \mathrm{t}=2.726)$, por lo que se acepta la subhipótesis $\mathrm{H7c}$. Por el contrario, no ocurre lo mismo con la comunicación interna en la empresa. Los resultados $(\beta=0.044 ; \mathrm{t}=0.547)$ señalan la existencia de un efecto positivo pero muy pequeño y no significativo, por lo que debemos rechazar la subhipótesis H6c.

Nuevamente, al igual que ha ocurrido con las subhipótesis relativas a la comunicación interna y a la participación y su efecto en las otras dos variables de capital estratégico, sólo una de las dos se muestra como significativa, lo que nos hace pensar, cada vez con mayor firmeza, que estas dos políticas pueden interferir la una en la otra. Quizás a través de la mediación, una de ellas está recogiendo el efecto de las dos.

Para finalizar, también la existencia de medidas que favorezcan el compañerismo y la relación con los compañeros tiene un efecto positivo y significativo $(\beta=0.197 ; \mathrm{t}=3.35)$ sobre el capital afectivo, por lo que, en base a los resultados, la subhipótesis H8c queda, también, validada.

Una vez analizado el contraste de las subhipótesis que relacionan cada práctica de recursos humanos y la retención del capital humano, a través de sus tres componentes, estamos ya en disposición de analizar la validación parcial o total o, por el contrario, la refutación, de la relación de cada una de las ocho prácticas propuestas y la retención del capital humano. Así, en base a los resultados previos, podemos concluir que ninguna de las cuatro prácticas de naturaleza transaccional es validada de forma plena. El diseño de puesto $(\mathrm{H} 1)$, la retribución (H2) y las medidas de conciliación (H3) son validadas parcialmente puesto que sólo logramos resultados significativos en alguna de las tres dimensiones del capital humano: en el capital social (H1b) con respecto a la hipótesis del diseño de puesto; en el capital intelectual y afectivo (H2a y H2c), en el caso de la 
retribución; y en el caso de las medidas de conciliación, sólo obtenemos resultados significativos para su dimensión intelectual (H4a). Además, la hipótesis tercera, aquélla que relaciona el desarrollo profesional de empleado con la retención del capital humano, es rechazada puesto que sólo hemos identificado una validez marginal en una de sus tres dimensiones (capital intelectual, subhipótesis H3a) y ninguna significatividad en las restantes dimensiones del capital humano (social y afectiva).

En el caso de las hipótesis relativas a las prácticas de recursos humanos de naturaleza relacional y su capacidad para retener el capital humano de la organización, las cuatro prácticas propuestas son validadas: tres de ellas de modo parcial, puesto que logran resultados significativos en dos de las tres dimensiones del capital humano y una de ellas de forma absoluta. Así, la práctica relacional que se valida en sus tres dimensiones del capital humano es el soporte del supervisor (H5), lo que nos permite validar plenamente esta hipótesis. La participación del empleado $(\mathrm{H} 7)$ y las relaciones internas de apoyo entre compañeros (H8) se validan en sus dimensiones de capital social y afectivo, y la hipótesis relativa a la comunicación interna (H6) se valida en su dimensión de capital intelectual, en consecuencia, consideramos una validez parcial a estas hipótesis. Estos resultados se recogen en la Tabla 4.26 y en la Tabla 4.27 que se presentan tras el análisis de los resultados del contraste de las restantes hipótesis de nuestro modelo, que abordamos a continuación.

Sin embargo, para ofrecer mayor solidez a estos resultados, creemos recomendable completar este análisis de dos modos. Primero, realizando un análisis de multicolinealidad entre las variables de las prácticas de recursos humanos (teniendo en cuenta la validación del modelo de medida realizado). Esta prueba es importante porque si hubiera problemas severos de multicolinealidad entre ellas, podría afectar a la validez de nuestros resultados de validación de hipótesis. Y, segundo, profundizando en la relación entre la comunicación interna y la participación del empleado, para lo cuál realizaremos nuevas estimaciones del modelo que nos permitan comprobar si existe alguna relación de complementariedad o mediación entre ambas variables.

En primer lugar, procedemos al análisis de la multicolinealidad entre las prácticas de recursos humanos, para ello utilizamos el programa SPSS versión 15, y analizamos los 
resultados en la regresión con la variable de retención de capital intelectual, con la variable capital social y con la variable capital afectivo. Los resultados obtenidos en los tres casos son satisfactorios, el valor máximo de FIV es de 2,249, el valor mínimo de la Tolerancia es 0,445 y el índice de condición máximo es 27 . Por tanto, en todos los casos las prácticas de recursos humanos presentan FIV menores de 5 y valores superiores a 0,2 para la Tolerancia. Además, el índice de condición no supera el valor de 30, considerado como el valor umbral que indica problemas severos de multicolinealidad (Diamantopoulus et al., 2001, 2008). Por lo tanto, no hemos identificado problemas de multicolinealidad severos que pudieran afectar a la validación de las hipótesis relativas a las prácticas de recursos humanos (véase las Tablas A4.1 del Anexo IV).

En segundo lugar, nos parece interesante tratar de profundizar en la relación entre las variables de comunicación interna y participación, puesto que a pesar de no haber detectado problemas de multicolinealidad entre las prácticas de recursos humanos, estas dos prácticas presentan una correlación destacable (véase Tabla 4.15.) y en el proceso de validación de hipótesis, nuestros resultados no logran validar más que una de ellas, en detrimento de la otra. Todo ello nos hace sospechar que una de las variables pueda estar recogiendo información de la otra o que pueda existir cierta relación de mediación o complementariedad entre ellas. Para ello, vamos a realizar una estimación del modelo sin la variable comunicación interna $\mathrm{y}$ de un segundo modelo sin la variable participación, para, de este modo, poder comparar ambos resultados entre sí que, a su vez, podremos comparar con los resultados de la estimación del modelo completo. El análisis de los datos obtenidos es comentado a continuación (véase la Tabla 4.25).

Como ya se ha visto con anterioridad la estimación del modelo completo muestra una relación significativa de la comunicación interna con la retención del capital intelectual, y de la participación del empleado con el capital social y con el capital afectivo, siendo no significativas el resto de las relaciones en la que participan estas dos variables de recursos humanos. En el caso de la estimación del modelo sin la variable comunicación interna, no se aprecian cambios significativos en la estimación de las relaciones en las que participa esta variable y se identifica una mínima reducción de la explicabilidad de la variabilidad de las variables de capital humano, recogidas a través de sus $\mathrm{R}^{2}$. Cuando 
estimamos el modelo eliminando la variable participación del empleado, las tres relaciones de la comunicación interna con el capital humano muestran una relación significativa y positiva, $\mathrm{y}$, además, los coeficientes $\mathrm{R}^{2}$ de las tres variables de capital humano disminuyen ligeramente unas centésimas. En último lugar, también hemos estimado un modelo en el que la participación del empleado mediara parcialmente en la relación de la comunicación interna con el capital humano. En este caso, obtenemos una estimación con las mismas significaciones que la estimación del modelo completo así como los mismos valores de los $\mathrm{R}^{2}$ de las variables de capital humano. Así pues, estos resultados nos ofrecen indicios para considerar que ambas variables tienen cierta influencia individual sobre el capital humano. No obstante, no podemos descartar la existencia de cierta relación entre estas dos variables, que podría ser objeto de un análisis mas profundo que ahondara en las relaciones de interacción, complementariedad y/o mediación entre ambas.

Tabla 4.25. Estimación de modelos alternado las variables comunicación interna y participación del empleado

\begin{tabular}{|c|c|c|c|}
\hline Variables & Retención Cap Intelec & Capital Social & Capital Afectivo \\
\hline \multicolumn{4}{|c|}{ MODELO COMPLETO } \\
\hline Comunicación interna & $(\beta=0.170 ; \mathrm{t}=2,11)^{*}$ & $(\beta=0.09 ; \mathrm{t}=1.35)$ & $(\beta=0.044 ; \mathrm{t}=0.52)$ \\
\hline Participación & $(\beta=-0.055 ; \mathrm{t}=0.58)$ & $(\beta=0.29 ; \mathrm{t}=4.05)^{* * *}$ & $(\beta=0.21 ; t=2.59)^{* *}$ \\
\hline $\mathrm{R}^{2}$ & 0.362 & 0.491 & 0.531 \\
\hline \multicolumn{4}{|c|}{ MODELO SIN LA VARIABLE COMUNICACIÓN INTERNA } \\
\hline Participación & $(\beta=0.028 ; \mathrm{t}=0.33)$ & $(\beta=0.346 ; t=5.63)^{* * *}$ & $(\beta=0.23 ; \mathrm{t}=3.55)^{* * *}$ \\
\hline $\mathrm{R}^{2}$ & 0.349 & 0.486 & 0.530 \\
\hline \multicolumn{4}{|c|}{ MODELO SIN LA VARIABLE PARTICIPACIÓN } \\
\hline Comunicación interna & $(\beta=0.14 ; \mathrm{t}=1.9)^{*}$ & $(\beta=0.23 ; \mathrm{t}=3.32)^{* * *}$ & $(\beta=0.14 ; \mathrm{t}=2.09)^{*}$ \\
\hline $\mathrm{R}^{2}$ & 0.361 & 0.451 & 0.511 \\
\hline \multicolumn{4}{|c|}{ MODELO CON MEDIACIÓN PARCIAL } \\
\hline Comunicación interna & $(\beta=0.16 ; \mathrm{t}=1.97)^{*}$ & $(\beta=0.095 ; \mathrm{t}=1.26)$ & $(\beta=0.043 ; \mathrm{t}=0.53)$ \\
\hline Participación & $(\beta=-0.055 ; \mathrm{t}=0.56)$ & $(\beta=0.299 ; \mathrm{t}=4.5)^{* * *}$ & $(\beta=0.21 ; \mathrm{t}=2.68)^{* *}$ \\
\hline Com Inter $\rightarrow$ Partic & \multicolumn{3}{|c|}{$(\beta=0.67 ; \mathrm{t}=18.84)^{* * *}$} \\
\hline $\mathrm{R}^{2}$ & 0.362 & 0.490 & 0.531 \\
\hline
\end{tabular}

Nota: Valores estimados con Smart-PLS y para un bootstraping de 1000. Los valores significativos se señalan con asteriscos (significativo al $* \mathrm{p}<0.05, * * \mathrm{p}<0.01 \mathrm{y} * * * \mathrm{p}<0.001$, al nivel de confianza del $95 \%$, del $99 \%$ y del $99.9 \%$, respectivamente, para test t-student de una cola). 
En base a las consideraciones previas, estos análisis nos permiten afianzar la validez del contraste de hipótesis realizado y, aunque no se han identificado problemas severos de multicolinealidad entre las variables independientes del modelo, creemos que una interesante vía de extensión de este trabajo podría enfocarse hacia el análisis de la complementariedad e interacción entre algunas de las prácticas de recursos humanos propuestas.

\subsubsection{Capital humano-intelectual, social y afectivo- y capacidad de innovación.}

\section{Contraste de las subhipótesis H9a,b,c.}

Los resultados del contraste de este segundo bloque de hipótesis formado, por las subhipótesis H9a, H9b y H9c, se presentan, a continuación, en la Figura 4.5. Estas hipótesis tratan de profundizar en el estudio de la importancia de la retención del capital humano de la empresa sobre la capacidad de innovación. Concretamente, se trata de identificar si, en concreto, el capital intelectual, el capital social y el capital de afectivo influyen positivamente o no en la mejora de la capacidad de innovación de la organización.

Figura 4.5. Contraste de las hipótesis H9a, H9b y H9c

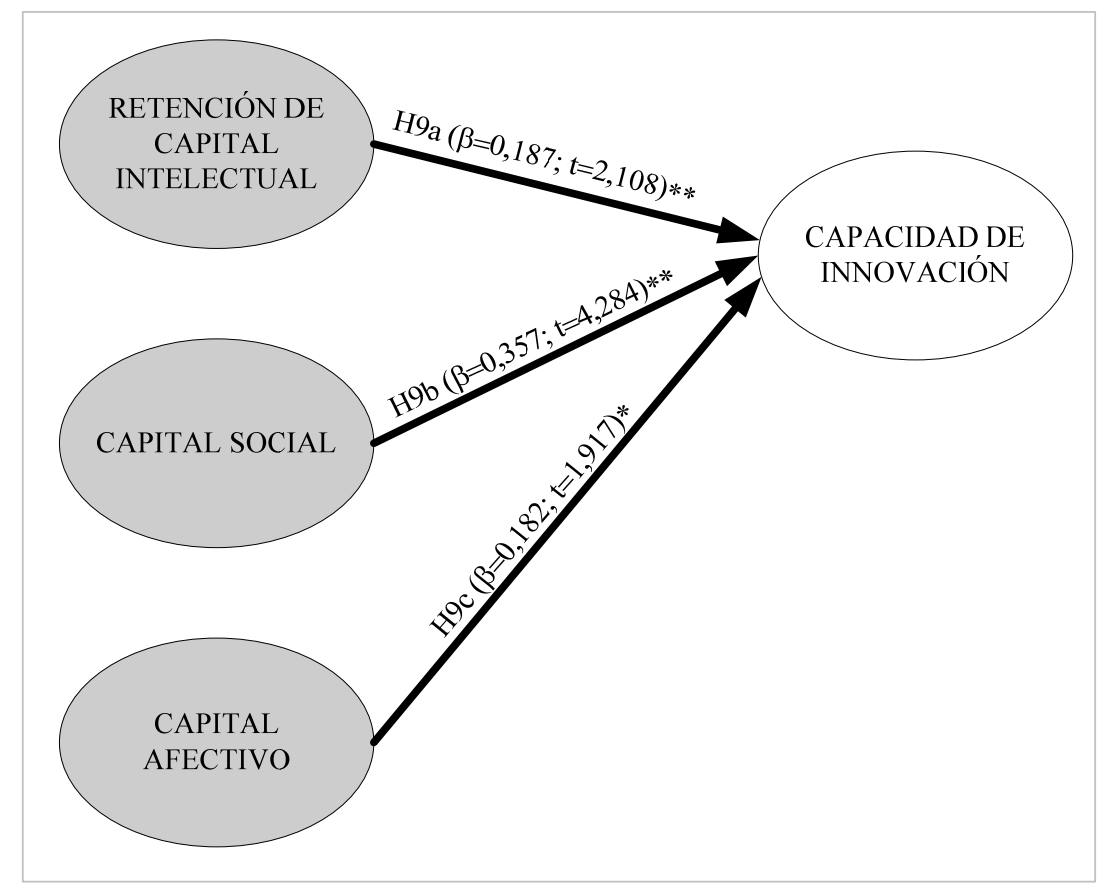

Nota: las hipótesis validadas y significativas se señalan con flecha en negrita, significativas al $* \mathrm{p}<0.05, * * \mathrm{p}<0.01$ y $* * * \mathrm{p}<0.001$ (al $5 \%$, al $1 \%$ y al $0.1 \%$, respectivamente, para test t-student de una cola). 
Los resultados muestran que la retención de capital intelectual, reteniendo a los empleados más valiosos, tiene un impacto positivo y significativo sobre la capacidad de innovación ( $\beta=0.187$; $\mathrm{t}=2.108)$; por tanto aceptamos la validez de la subhipótesis H9a.

Además, el capital social también parece ser crítico para el desarrollo de la capacidad de innovación de la empresa, ya que es la variable que ejerce un mayor impacto, positivo y significativo, sobre la capacidad de innovación $(\beta=0.357 ; \mathrm{t}=4.284)$. Por tanto, la subhipótesis $\mathrm{H} 9 \mathrm{~b}$ queda validada. Por último, también se confirma el efecto positivo y significativo $(\beta=0.182 ; \mathrm{t}=1.917)$ del capital afectivo sobre la capacidad de innovación. Lo que permite validar la hipótesis H9c.

Por tanto, cerramos esta sección reconociendo que los resultados logrados en este apartado son muy satisfactorios, puesto que se validan las tres subhipótesis propuestas. Estos resultados reafirman nuestro planteamiento de un capital humano estratégico tridimensional y su influencia en el desarrollo innovativo de la organización. Para mejorar la capacidad de innovación empresarial, no sólo es crítico mantener los conocimientos y habilidades estratégicos (capital intelectual), sino también, movilizarlos, favorecer los procesos en los que los individuos colaboran, intercambian y combinan conocimientos (capital social), así como desarrollar un actitud positiva en los empleados estratégicos que permita que todo lo anterior ocurra, favoreciendo su confianza y compromiso (capital afectivo). En consecuencia, en base a los resultados obtenidos, podemos confirmar la validación total de la novena hipótesis propuesta en este trabajo.

\subsubsection{Impacto sobre los resultados de la empresa. Contraste de Hipótesis H10, H11 у H12.}

Por último, este tercer bloque se refiere a las hipótesis H10, H11 y H12, que analizan la influencia que la capacidad de innovación y el capital afectivo pueden ejercer sobre los resultados de la empresa, tanto en su dimensión financiera-empresarial como en su dimensión personal (variable de resultado interno, antecesora causal de los resultados empresariales). Los resultados logrados en este estudio empírico pueden observarse en la Figura 4.6. 
Figura 4.6. Contraste de las hipótesis $\mathrm{H} 10, \mathrm{H} 11$ y H12

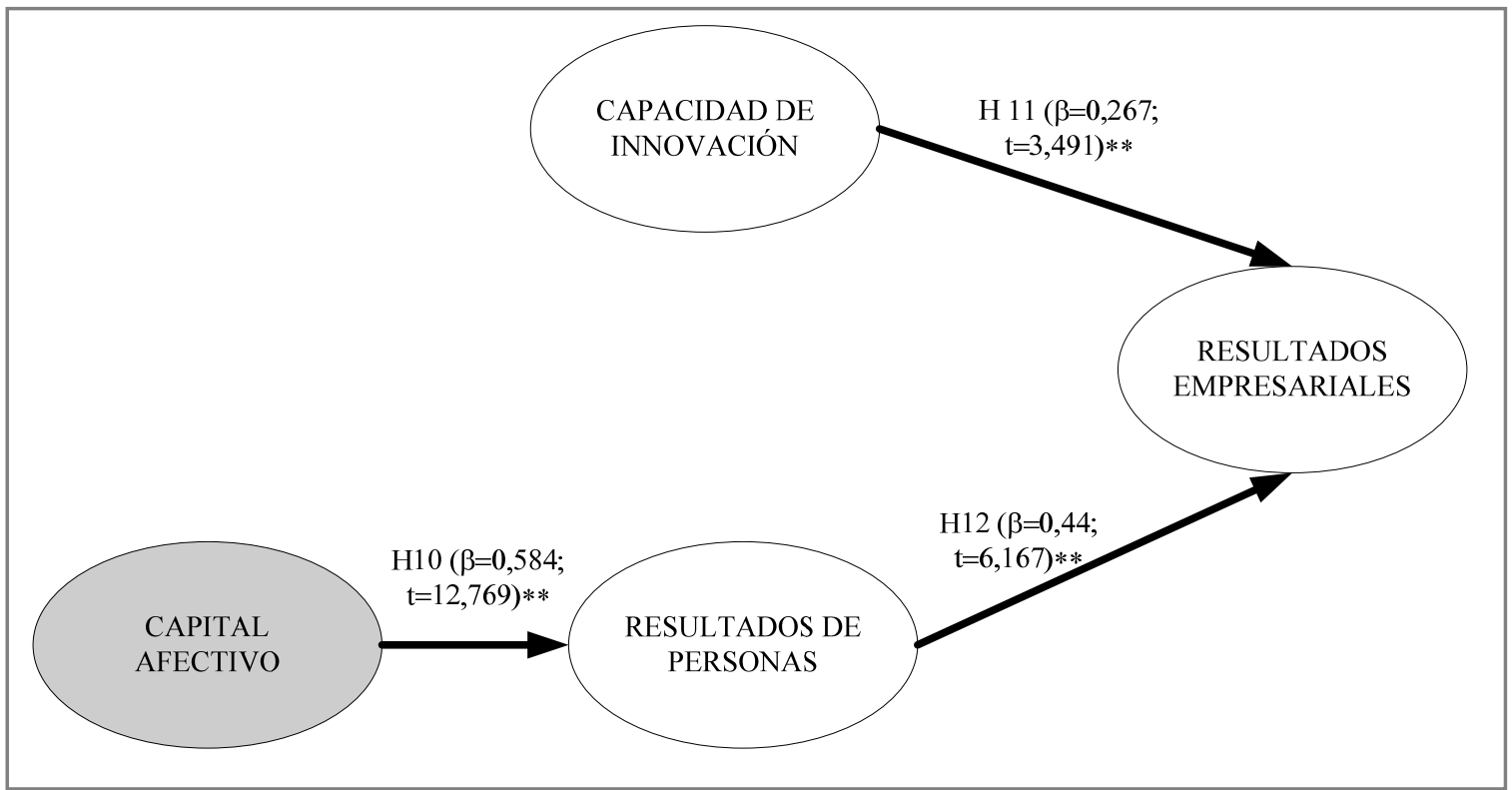

Nota: las hipótesis validadas y significativas se señalan con flecha en negrita, significativas al $* \mathrm{p}<0.05$, ${ }^{* *} \mathrm{p}<0.01 \mathrm{y} * * * \mathrm{p}<0.001$ (al $5 \%$, al 1\% y al $0.1 \%$, respectivamente, para test $\mathrm{t}$-student de una cola).

El capital afectivo se confirma como un elemento crítico para el resultado de las personas, presentando el coeficiente path más elevado de todos los obtenidos en el estudio empírico $(\beta=0.584 ; \mathrm{t}=12.769)$. En consecuencia, estos resultados nos permiten validar la hipótesis H10. La confianza y compromiso organizativo, componentes del capital afectivo, se constatan como determinantes de la satisfacción y la productividad de los empleados clave, así como, de su menor rotación voluntaria, en concordancia con lo señalado por la literatura de retención de recursos humanos.

El efecto de la capacidad de innovación sobre los resultados empresariales también se confirma como positivo y significativo $(\beta=0.267 ; \mathrm{t}=3.491)$, por lo que aceptamos como válida la hipótesis H11. No se debe olvidar que la muestra objeto de estudio está compuesta por empresas innovadoras, por lo que la capacidad de innovación puede interpretarse como antecesor de los resultados de la empresa, que dependen del logro de innovaciones y de la mejora de la posición competitiva y la rentabilidad.

Por último, los resultados, también ofrecen evidencia de la influencia positiva y significativa de los resultados de las personas $(\beta=0.440 ; t=6.167)$ sobre los resultados 
empresariales de las empresas de este estudio. Por tanto, aceptamos la validez de la hipótesis H12.

Nuevamente, los resultados que alcanzamos en esta sección son muy satisfactorios, puesto que las tres hipótesis propuestas quedan validadas.

A modo de cierre de este epígrafe 4.2, presentamos las Tabla 4.26., Tabla 4.27. y la Figura 4.7. como resumen de la validación de las hipótesis y subhipótesis de este trabajo. El balance global es muy satisfactorio. Se logran validar el sesenta por ciento de las relaciones propuestas. En cuanto al análisis de la influencia individual de cada una de las prácticas de retención de recursos humanos de carácter transaccional y relacional sobre las variables de capital humano de la organización, la mitad (doce) de las subhipótesis son validadas, y las doce restantes son refutadas $\mathrm{Y}$, por último, con respecto al efecto del capital humano sobre las variables de resultado e innovación, se logran validar todas las relaciones propuestas en el modelo. 
Tabla 4.26.

Resumen del contraste empírico de las hipótesis del modelo con Smart PLS (Bootstraping 2000 submuestras)

\begin{tabular}{|c|c|c|c|c|}
\hline & & & $\begin{array}{c}\text { Original } \\
\text { Sample }\end{array}$ & T Statistics \\
\hline HIPÓTESIS & RELACIÓN ESTUDIADA & RESULTADO & $\beta$ & $\mathbf{t}$ \\
\hline H1a & DiseñoPuesto -> RetCapInt & Signo esperado $(+)$, no significativa & 0,023 & 0,325 \\
\hline H2a & Retribuc -> RetCapInt & Validada & 0,133 & 1,677 \\
\hline $\mathrm{H} 3 \mathrm{a}$ & Desarrollo -> RetCapInt & Signo esperado, margin significativa & 0,106 & 1,56 \\
\hline $\mathrm{H} 4 \mathrm{a}$ & Conciliac $->$ RetCapInt & Signo esperado $(+)$, no significativa & 0,029 & 0,432 \\
\hline H5a & SoporteSupv -> RetCapInt & Validada & 0,294 & 4,171 \\
\hline H6a & Comunic -> RetCapInt & Validada & 0,17 & 2,044 \\
\hline $\mathrm{H} 7 \mathrm{a}$ & Participac -> RetCapInt & Signo no esperado (-), no significativa & $-0,055$ & 0,573 \\
\hline $\mathrm{H} 8 \mathrm{a}$ & Compañerismo -> RetCapInt & Signo esperado $(+)$, no significativa & 0,096 & 1,475 \\
\hline H1b & DiseñoPuesto -> CapSoc & Validada & 0,13 & 2,094 \\
\hline $\mathrm{H} 2 \mathrm{~b}$ & Retribuc $->$ CapSoc & Signo no esperado (-), significativa & $-0,013$ & 0,176 \\
\hline $\mathrm{H} 3 \mathrm{~b}$ & Desarrollo -> CapSoc & Signo esperado $(+)$, no significativa & 0,003 & 0,037 \\
\hline $\mathrm{H} 4 \mathrm{~b}$ & Conciliac $->$ CapSoc & Signo esperado $(+)$, no significativa & 0,011 & 0,199 \\
\hline H5b & SoporteSupv -> CapSoc & Validada & 0,2 & 2,848 \\
\hline $\mathrm{H} 6 \mathrm{~b}$ & Comunic -> CapSoc & Signo esperado $(+)$, no significativa & 0,097 & 1,303 \\
\hline H7b & Participac -> CapSoc & Validada & 0,299 & 4,064 \\
\hline H8b & Compañerismo -> CapSoc & Validada & 0,169 & 2,56 \\
\hline H1c & DiseñoPuesto -> CapAfectivo & Signo esperado $(+)$, no significativa & 0,041 & 0,612 \\
\hline H2c & Retribuc -> CapAfectivo & Validada & 0,211 & 3,342 \\
\hline $\mathrm{H} 3 \mathrm{c}$ & Desarrollo -> CapAfectivo & Signo no esperado (-), no significativa & $-0,064$ & 0,954 \\
\hline H4c & Conciliac -> CapAfectivo & Validada & 0,14 & 2,3 \\
\hline H5c & SoporteSupv -> CapAfectivo & Validada & 0,209 & 3,086 \\
\hline H6c & Comunic $->$ CapAfectivo & Signo esperado $(+)$, no significativa & 0,044 & 0,547 \\
\hline H7c & Participac -> CapAfectivo & Validada & 0,217 & 2,726 \\
\hline H8c & Compañerismo -> CapAfectivo & Validada & 0,197 & 3,35 \\
\hline H9a & RetCapInt -> CapInnovac & Validada & 0,187 & 2,108 \\
\hline H9b & CapSoc -> CapInnovac & Validada & 0,357 & 4,284 \\
\hline H9c & CapAfectivo -> CapInnovac & Validada & 0,182 & 1,917 \\
\hline H10 & CapAfectivo -> RtdoPersons & Validada & 0,584 & 12,769 \\
\hline H11 & CapInnovac -> RtdosEmpres & Validada & 0,267 & 3,491 \\
\hline H12 & RtdoPersons -> RtdosEmpres & Validada & 0,44 & 6,167 \\
\hline
\end{tabular}


Tabla 4.27.

Resumen de la validación de hipótesis y subhipótesis por dimensiones del capital humano

HIPOTESIS A: H1a- H8a

Las prácticas de recursos humanos orientadas a la retención influyen positivamente en la retención de capital intelectual

H1a:El diseño del puesto (autonomía, retador y variado) influye positivamente en la retención del cap. intelectual

H2a: La retribución competitiva y contingente influye positivamente en la retención del capital intelectual

H3a: El desarrollo del empleado influye positivamente retención de capital intelectual

H4a: Las medidas de conciliación laboral-personal influye positivamente en la retención del capital intelectual

H5a: El soporte y apoyo del supervisor influye positivamente en la retención del capital intelectual

H6a: La comunicación interna influye positivamente en la retención del capital intelectual

H7a: La participación del empleado influye positivamente en la retención del capital intelectual

H8a:La relaciones informales de apoyo entre los empleados influyen positivamente en la retención del cap. Intelec

HIPÓTESIS B: H1b-H8b

Las prácticas de recursos humanos orientadas a la retención influyen positivamente en el capital social estratégico.

H1b: El diseño del puesto (autonomía, retador y variado) influye positivamente en el capital social

$\mathrm{H} 2 \mathrm{~b}$ : La retribución competitiva y contingente influye positivamente en el capital social

H3b: El desarrollo del empleado influye positivamente en el capital social

H4b: La medidas de conciliación laboral-personal influye positivamente en el capital social

H5b: El soporte del supervisor influye positivamente en el capital social

H6b: La comunicación interna influye positivamente en el capital social

H7b: La participación del empleado influye positivamente en el capital social

H8b: Las relaciones informales de apoyo entre los empleados influyen positivamente en el capital social

HIPÓTESIS C: H1c-H8c

Las prácticas de recursos humanos orientadas a la retención influyen positivamente en el capital afectivo

H1c: El diseño del puesto influye positivamente en el capital afectivo

H2c: La retribución competitiva y contingente influye positivamente en el capital afectivo

H3c: El desarrollo del empleado influye positivamente en capital afectivo

H4c La existencia de medidas conciliación de vida laboral-personal influye positivamente en el capital afectivo

H5c: El soporte del supervisor influye positivamente en el capital afectivo

H6c: La comunicación interna influye positivamente en el capital afectivo

H7c: La participación del empleado influye positivamente en el capital afectivo

H8c.Las relaciones informales de apoyo entre los empleados influyen positivamente en el capital afectivo HIPÓTESIS H9

H9a: La retención del capital intelectual influye positivamente sobre la capacidad de innovación

H9b: El capital social influye positivamente sobre la capacidad de innovación

H9c: El capital afectivo influye positivamente sobre la capacidad de innovación

HIPÓTESIS 10: El capital afectivo influye positivamente sobre los resultados de las personas

HIPÓTESIS 11: La capacidad de innovación influye positivamente en los resultados empresariales de la organización

HIPÓTESIS 12: Los resultados de las personas influyen positivamente en los resultados empresariales de la organiz.

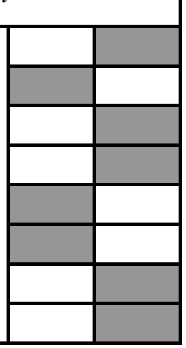


Tabla 4.27 bis

Resumen de la validación de las hipótesis globales del modelo

\begin{tabular}{|c|c|c|c|c|c|c|}
\hline HIPÓTESIS DE LAS RELACIONES GLOBALES DEL MODELO PROPUESTO & 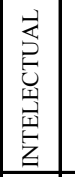 & 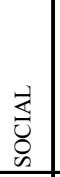 & 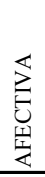 & 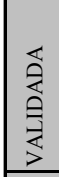 & 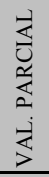 & 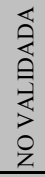 \\
\hline $\begin{array}{l}\text { H1: El diseño enriquecido de puesto de trabajo influye positivamente en la } \\
\text { retención del capital humano de la organización }\end{array}$ & & $X$ & & & $\mathbf{X}$ & \\
\hline $\begin{array}{l}\text { H2: La retribución influye positivamente en la retención del capital humano } \\
\text { de la organización }\end{array}$ & $X$ & & $\mathrm{X}$ & & $\mathbf{X}$ & \\
\hline $\begin{array}{l}\text { H3: El desarrollo profesional del empleado influye positivamente en la } \\
\text { retención del capital humano de la organización }\end{array}$ & & & & & & $\mathbf{X}$ \\
\hline $\begin{array}{l}\text { H4: Las medidas conciliación de vida laboral-personal influyen } \\
\text { positivamente en la retención del capital humano de la organización }\end{array}$ & & & $\mathrm{X}$ & & $\mathbf{X}$ & \\
\hline $\begin{array}{l}\text { H5: El soporte del supervisor influye positivamente en la retención del } \\
\text { capital humano de la organización }\end{array}$ & $\mathrm{x}$ & $\mathrm{X}$ & $X$ & $X$ & & \\
\hline $\begin{array}{l}\text { H6: La comunicación interna influye positivamente en la retención del } \\
\text { capital humano de la organización }\end{array}$ & $\mathrm{X}$ & & & & $\mathbf{X}$ & \\
\hline $\begin{array}{l}\text { H7: La partipación del empleado influye positivamente en la retención del } \\
\text { capital humano de la organización }\end{array}$ & & $\mathrm{X}$ & $\mathrm{x}$ & & $\mathbf{X}$ & \\
\hline $\begin{array}{l}\text { H8: Las relaciones internas de apoyo entre compañeros influyen } \\
\text { positivamente en la retención del capital humano de la organización }\end{array}$ & & $X$ & $\mathrm{X}$ & & $\mathbf{X}$ & \\
\hline $\begin{array}{l}\text { H9: El capital humano retenido influye positivamente en la capacidad de } \\
\text { innovación de la organización }\end{array}$ & $\mathrm{X}$ & $\mathrm{X}$ & $X$ & $\mathbf{X}$ & & \\
\hline $\begin{array}{l}\text { H10: El capital afectivo influye positivamente sobre los resultados de las } \\
\text { personas }\end{array}$ & & & & $\mathbf{X}$ & & \\
\hline $\begin{array}{l}\text { H11: La capacidad de innovación influye positivamente en los resultados } \\
\text { empresariales de la organización }\end{array}$ & & & & $\mathbf{X}$ & & \\
\hline $\begin{array}{l}\text { H12: Los resultados de las personas influyen positivamente en los resultados } \\
\text { empresariales de la organización }\end{array}$ & & & & $\mathbf{X}$ & & \\
\hline
\end{tabular}

Como se extrae de la anterior tabla, del total de las doce relaciones generales planteadas en nuestro modelo, once de ellas son validadas, cinco de las cuales se validan totalmente y las seis restantes de forma parcial (puesto que sólo obtenemos resultados significativos para alguna o algunas de las tres dimensiones del capital humano) y sólo una de las doce relaciones propuestas es refutada, como es el caso particular de la influencia del desarrollo del empleado en la retención del capital humano. Estos resultados y sus implicaciones académicas y empresariales serán abordados con mayor detalle en el capítulo siguiente. 
El contraste empírico del modelo propuesto engloba no sólo la contrastación de sus hipótesis sino, también, la evaluación global del mismo. A esta evaluación dedicamos el siguiente epígrafe; en él llevamos a cabo los análisis que permiten identificar qué cantidad de varianza de las variables endógenas queda explicada por sus variables predictoras y, además, puesto que Smart- PLS también lo permite, realizamos un diagnóstico de la capacidad predictiva del modelo propuesto.

\subsection{EVALUACIÓN GLOBAL DEL MODELO PROPUESTO}

En el presente capítulo, hemos presentado los resultados del contraste empírico de las hipótesis de trabajo, realizado a través de la metodología de mínimos cuadrados parciales (PLS). Como explicamos en el capítulo tercero, el enfoque PLS no pretende reproducir la matriz de varianzas/covarianzas observada, por lo que los programas que estiman este tipo de modelos no pueden proporcionar índices de ajuste como los que se calculan en los programas de ecuaciones estructurales tradicionales, basados en las covarianzas. En PLS se pone el énfasis en maximizar la capacidad para predecir las variables dependientes, por lo que la calidad de un modelo se establece de forma más subjetiva, examinando, además de la magnitud y significación de las relaciones estructurales (ya discutido en el epígrafe anterior), los coeficientes de determinación de dichas variables. Como puede comprobarse en la Tabla 4.28., el modelo propuesto tiene una notable capacidad de explicación tanto de la varianza de las distintas dimensiones del capital humano como de las dimensiones de resultado organizativo.

Tabla 4.28.

Coeficientes de determinación y de relevancia predictiva de las variables dependientes

\begin{tabular}{|l|c|c|}
\hline \multicolumn{1}{|c|}{ Variable dependiente } & $\mathbf{R}^{2}$ & $\mathbf{Q}^{\mathbf{2}}$ \\
\hline Retención de Capital Intelectual & 0,363 & 0,265 \\
\hline Capital Social & 0,491 & 0,347 \\
\hline Capital Afectivo & 0,531 & 0,353 \\
\hline Capacidad de Innovación & 0,378 & 0,257 \\
\hline Resultados de las personas & 0,341 & 0,222 \\
\hline Resultados empresariales & 0,370 & 0,231 \\
\hline
\end{tabular}


Todos los coeficientes de determinación $\left(R^{2}\right)$ correspondientes a estas variables superan holgadamente el $10 \%$, lo que cabe interpretar como una suficiente capacidad predictiva (Falk y Miller, 1992). Las variables incluidas en el modelo logran explicar el 36,6\% de la varianza de la retención de capital intelectual (superior a ratios de referencia, como el $20 \%$ alcanzado por Shaw et al.(1998)), explican el 49,1\% de la varianza del capital social y más de la mitad $(53,1 \%)$ de la varianza del capital afectivo. Además y, en cuanto a las variables de resultado, explican porcentajes que están en la horquilla entre el 30 y el $40 \%$, tanto de la capacidad de innovación como de los resultados empresariales y de los resultados de personas. Porcentajes, éstos, que podemos considerar más que aceptables en la literatura de recursos humanos (p.e. Huselid, Jackson y Schuler, 1997; Bae y Lawer, 2000; Calantone et al., 2002; Bae et al., 2003; Saa Pérez y Díaz-Díaz, 2007).

La Figura 4.7., recoge la evaluación del modelo y el contraste de hipótesis, lo que permite visualizar los principales resultados de este trabajo. 
Figura 4.7. Contraste empírico del modelo con Smart-PLS: contraste de subhipótesis y evaluación del modelo

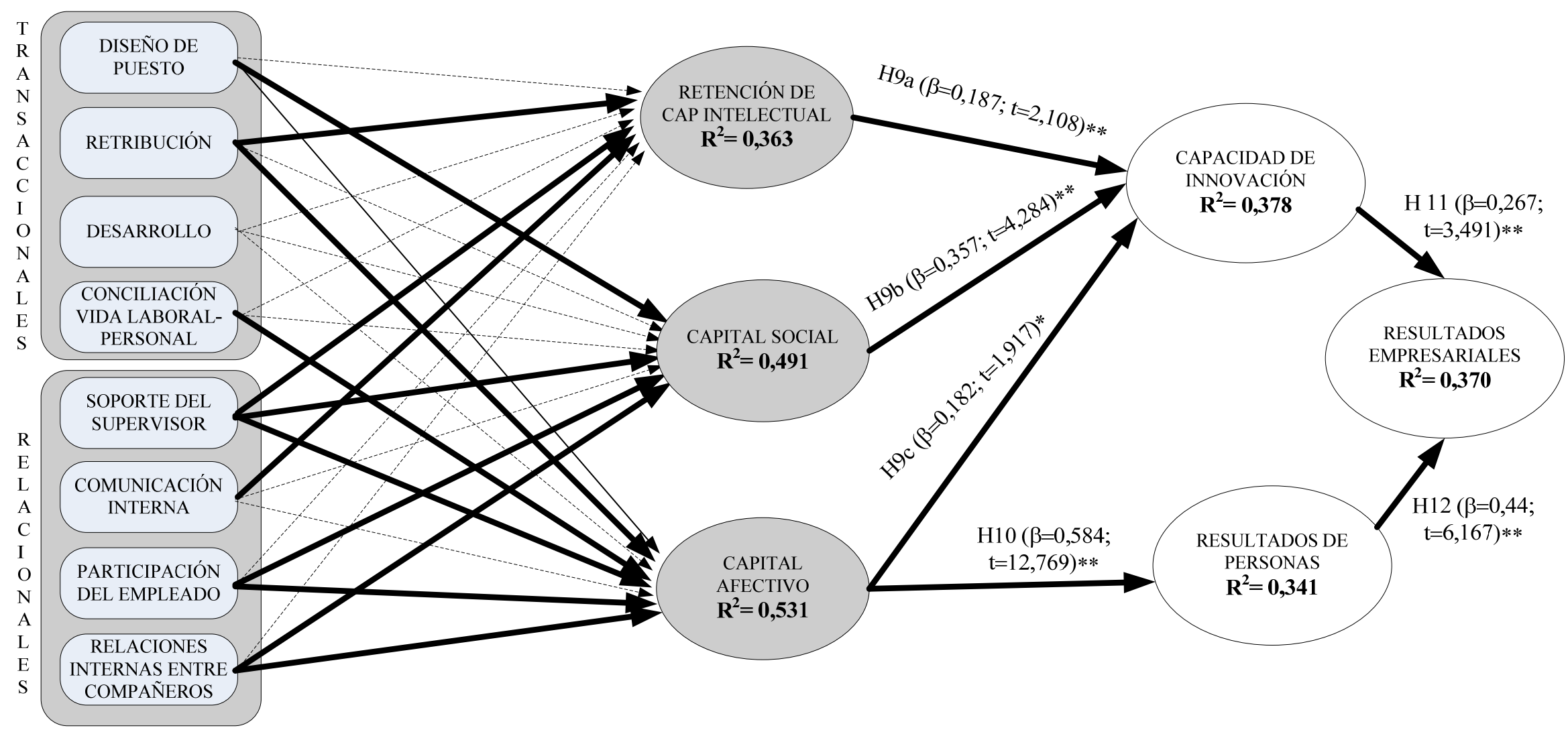

Nota: las hipótesis validadas y significativas se señalan con flecha en negrita, significativas al * $\mathrm{p}<0.05, * * \mathrm{p}<0.01$ y $* * * \mathrm{p}<0.001$ (al $5 \%$, al $1 \%$ y al $0.1 \%$, respectivamente, para test t-student de una cola). Las relaciones señaladas con flecha discontinua no se validan en nuestro trabajo. 
En línea con lo que proponen Chin (1998b) y Tenenhaus et al., (2005), además de examinar la capacidad del modelo para explicar los constructos endógenos del mismo, se puede realizar una validación cruzada del modelo evaluando en qué medida los parámetros estimados son útiles para predecir las variables observadas correspondientes a estos constructos. Esto se hace calculando el coeficiente $Q^{2}$ de relevancia predictiva ${ }^{8}$ (Stone, 1974; Geisser, 1975) para cada una de las variables, cuyo valor también recoge la Tabla 4.28., anteriormente presentada. Como puede comprobarse, todas las variables presentan un coeficiente superior a cero, lo que implica que estas variables quedan bien explicadas por el modelo propuesto y, además, el modelo tiene relevancia predictiva. Para el cálculo de este índice Smart-PLS permite calcularlo a través del procedimiento denominado Blindfoling que, en este caso, hemos realizado de forma individual para cada una de las variables dependientes del modelo.

Para concluir esta evaluación global del modelo, y centrando de nuevo la atención en las relaciones estructurales del mismo, conviene insistir en que la metodología utilizada permite abordar el contraste empírico de una serie de hipótesis referidas a las relaciones directas y lineales entre las variables del estudio ${ }^{9}$. Como se ha explicado en el anterior epígrafe, para el contraste de las hipótesis hemos considerado el tamaño y la significación de los coeficientes path estandarizados, encontrando diversas relaciones significativas a un nivel de confianza de, como mínimo, un 94\%.

Adicionalmente, Falk y Miller (1992) proponen una regla empírica para evaluar en qué medida una variable contribuye a explicar la varianza de otra variable. Según estos autores, una variable es relevante a la hora de predecir otra si explica, al menos, un $1,5 \%$ de la varianza de la última $y$, un índice razonable de esta capacidad explicativa, vendría dado por el producto del correspondiente coeficiente beta por el coeficiente de

\footnotetext{
${ }^{8}$ Según Chin (1998b), este coeficiente surge de la aplicación de una técnica de reutilización de la muestra con fines predictivos desarrollada por Stone (1974) y Geisser (1975). La adaptación para PLS de esta técnica consiste en un procedimiento de ocultación u omisión (blindfolding) de una parte de la matriz de datos correspondiente a un determinado bloque de variables observadas reflectivas -esta técnica no es aplicable para los constructos formativos-. Se estiman los datos omitidos utilizando los parámetros obtenidos con anterioridad. Este procedimiento se repite hasta que cada dato observado de ese bloque ha sido omitido y estimado. Como resultado de esta técnica se calcula una medida de validación cruzada $\left(Q^{2}\right)$, cuya fórmula es la siguiente: $Q^{2}=1-(\mathrm{SSE} / \mathrm{SSO})$; donde SSE representa la suma de los cuadrados de los errores de predicción cometidos cuando los datos omitidos se estiman utilizando los parámetros del modelo y SS0 representa la suma de cuadrados de los errores de predicción cometidos cuando los datos omitidos se reemplazan por la media de la correspondiente variable. Este coeficiente nos indica si las predicciones realizadas con los parámetros del modelo son mejores (tienen un error de predicción menor) que las resultantes de sustituir los valores omitidos por la media de la variable correspondiente, en cuyo caso el coeficiente $\mathrm{Q}^{2}$ seria mayor que cero, lo que implicaría que el modelo tiene relevancia predictiva. Para más detalles sobre esta técnica, véase Chin (1998b: 317-8).

${ }^{9}$ La consideración de otro tipo de relaciones, por ejemplo no lineales, es problemática en PLS.
} 
correlación entre ambas variables. Esta condición se cumple para todos los efectos directos y significativos y, todos ellos, como mínimo, superan el 7\%.

$* * *$

En resumen, y teniendo en cuenta los análisis previos, podemos concluir que el modelo propuesto permite explicar y predecir, de una forma bastante aceptable, los procesos por los que las prácticas orientadas a la retención de recursos humanos influyen de forma positiva sobre el resultado empresarial y la capacidad de innovación de la empresa. Dicha influencia se logra a través del efecto que las prácticas propuestas ejercen sobre la retención del capital humano (intelectual, social y afectivo), que hemos definido como vinculado a los recursos humanos estratégicos. En concreto, en los resultados de nuestro análisis destaca la significación de las prácticas relacionales. Todos estos resultados y sus principales implicaciones son comentadas con mayor detalle en el siguiente capítulo; en él presentamos las conclusiones de este trabajo y se reconocen las principales limitaciones del estudio empírico realizado, así como algunas posibles extensiones del mismo. 

Capítulo 5

\section{CONCLUSIONES}





\section{INTRODUCCIÓN}

El propósito general de esta investigación es examinar la influencia de la gestión de recursos humanos en los resultados organizativos, considerando la retención de empleados como elemento mediador de esta posible influencia. En concreto, nos plantemos analizar la retención de empleados diferenciando tres componentes de su capital humano -intelectual, social y afectivo- y su repercusión sobre la capacidad de innovación entre otros resultados organizativos. Para ello, esbozamos un modelo que pone el foco de atención en las prácticas de recursos humanos dirigidas a aquellos empleados considerados valiosos en las empresas de la muestra utilizada en esta investigación (239 empresas innovadoras españolas). La revisión teórica realizada en este trabajo, la aplicación de modelos de ecuaciones estructurales para la contrastación del modelo propuesto, el análisis a través de mínimos cuadrados parciales y la aplicación del software Smart-PLS a los datos recogidos, permiten alcanzar diversas conclusiones referidas a los objetivos planteados inicialmente en la presente investigación.

En primer lugar, hemos revisado y comprobado la influencia de la gestión de recursos humanos sobre los resultados organizativos, constatando tanto la necesidad de incluir nuevas medidas de resultados que no sean sólo financieras (Bae y Lawler, 2000), como la necesidad de profundizar en las etapas intermedias por las que esta influencia tiene lugar (Boselie et al., 2005). Las medidas ligadas al desarrollo de innovaciones, como la capacidad de innovación, y la consideración de variables de resultados intermedios y finales forman parte de la tendencia actual de la investigación en recursos humanos (Boselie et al., 2005; Boxal y Macky, 2009). No obstante, hasta el momento no existe consenso ni sobre cuáles deben ser estas medidas de resultados y ni sobre cuales deben ser estas etapas intermedias (Takeuchi, Chen y Lepack, 2009). En conformidad, en este trabajo planteamos la retención de capital humano como etapa intermedia del impacto de la gestión de recursos humanos en los resultados organizativos, proponiendo además dos niveles en las variables de resultados: resultados intermedios (capacidad de innovación y resultados de las personas) y resultados finales (resultados empresariales, de naturaleza financiera); los primeros actúan como antecedentes de los segundos. 
En segundo lugar, hemos estudiado la retención de los empleados valiosos centrándonos en su capital humano. La literatura sobre retención de empleados es muy extensa. No obstante, aún admite una mayor investigación al objeto de alcanzar consenso sobre cuales son las mejores prácticas de recursos humanos para retener a los empleados, especialmente, a los más valiosos. Diversos autores ponen de manifiesto la importancia de, por un lado, tener en cuenta los modelos emergentes de retención de empleados (Maertz et al., 2001, 2004; Mitchell et al., 2001) y, por otro lado, de considerar la actualización de la relación de empleo (Tsui y Wu, 2005; Hom, Tsui et al., 2009). Ambos aspectos nos conducen a definir dos categorías de prácticas de recursos humanos que pueden favorecer la retención de empleados: unas de naturaleza transaccional y otras de naturaleza relacional. En esta investigación hemos aplicado esta taxonomía al conjunto de las prácticas de retención seleccionadas y, por tanto, estudiamos, por un lado, prácticas de recursos humanos de naturaleza transaccional, entre las que incluimos el diseño de puesto de trabajo, la retribución, el desarrollo profesional del empleado y la conciliación vida laboral/personal; y, por otro lado, estudiamos prácticas de recursos humanos de naturaleza relacional, entre las que incluimos el soporte del supervisor, la comunicación interna, la participación del empleado y las relaciones internas de apoyo entre compañeros.

En tercer lugar, también hemos tenido la oportunidad de examinar otros tres aspectos. Concretamente, al centrar nuestro interés en un determinado colectivo de empleados: los empleados valiosos o recursos humanos estratégicos, seguimos la línea de trabajos que apunta la necesidad de utilizar diferentes tipos de prácticas para diferentes colectivos de empleados. De este modo, identificamos las prácticas de retención más adecuadas para este colectivo particular de empleados (Lepack y Snell, 1999; 2002; Morris et al., 2004). Además, hemos analizado la retención de empleados de la organización a través del concepto de capital humano. De este modo, para recoger toda la complejidad y amplitud del capital humano, incorporamos como subdimensiones del mismo el capital intelectual, el capital social y el capital afectivo (Gratton y Ghoshal, 2003; Barney y Clark, 2007). Así también contribuimos, aunque de forma indirecta, al acercamiento entre conceptos propios de la perspectiva de empresa basada en el conocimiento y los particulares del ámbito de la dirección estratégica de recursos humanos (Oltra, 2005; 
Gloet, 2006; Afiouni, 2007; Pérez, Prieto y Martín, 2009). Por último, hemos investigado en un ámbito que es vital para la competitividad actual de las empresas: la innovación. En este sentido, nuestra intención es la de ofrecer algunas recomendaciones a la práctica empresarial sobre la base de nuestros resultados.

A continuación, explicamos las conclusiones de este trabajo con mayor detalle. Esto nos permite identificar una serie de implicaciones para la práctica empresarial. También presentamos las principales limitaciones del estudio, junto con algunas líneas de desarrollo futuro de la presente investigación.

\subsection{PRINCIPALES CONCLUSIONES DE ESTA INVESTIGACIÓN}

En este epígrafe discutimos los resultados de nuestro estudio y ponemos de relieve sus principales implicaciones en el plano académico. En concreto, nuestras contribuciones se centran en el análisis de las prácticas de recursos humanos más influyentes en la retención de empleados estratégicos y en el análisis de los procesos intermedios por los que la gestión de recursos humanos influye en los resultados organizativos.

\subsubsection{Efecto de las prácticas de recursos humanos propuestas sobre la retención del capital humano vinculado a los empleados estratégicos de la organización}

La revisión de la investigación en retención nos ha permitido constatar el amplio abanico de posibilidades que tienen las organizaciones para tratar de retener a sus empleados, en general, y cuáles son aplicables a los empleados estratégicos, en particular. En concreto, seleccionamos ocho prácticas que gozan de una elevada contrastación empírica en el ámbito de la retención y que clasificamos en dos categorías, según su naturaleza transaccional o relacional. Esta distinción responde a la nueva tendencia en la conceptualización de la relación de empleo (Hom, Tsui et al., 2009). Esta nueva concepción de la relación de empleo apuesta por la incorporación expresa de la faceta relacional-social del empleado como complemento a la faceta puramente transaccional. De este modo, se completa la relación de empleo tradicional que, generalmente, ha incluido prácticas como la retribución, el diseño del puesto, la formación u otras prácticas de corte transaccional. 
A continuación exponemos las principales conclusiones derivadas del análisis que hemos realizado en relación a la capacidad de retención del capital humano de la organización de las distintas prácticas de recursos humanos propuestas.

\subsubsection{Prácticas de recursos humanos de naturaleza transaccional y su impacto en la}

\section{retención del capital humano de la organización}

Por lo que se refiere a cada una de las prácticas de recursos humanos de naturaleza transaccional incluidas en nuestro modelo, podemos concluir lo siguiente:

En primer lugar, y en lo que se refiere al diseño enriquecido del puesto de trabajo esto es, el diseño de puestos con un alto nivel de autonomía, alto nivel de reto y alta heterogeneidad de conocimientos requeridos-, nuestros resultados confirman su capacidad para influir positivamente en el capital social de los empleados estratégicos. La propia definición de este tipo de puestos, generalmente complejos y en los que se asumen retos importantes, induce pues a pensar que los empleados que los ocupan se planteen su trabajo en términos de cooperación y colaboración con otros miembros de la organización a fin de alcanzar los objetivos del puesto con eficacia, todo lo cuál fortalece su capital social. Sin embargo, contrariamente a lo esperado, el diseño enriquecido del puesto de trabajo no obtiene efectos significativamente relevantes en la retención del capital intelectual ni en el capital afectivo de los empleados. Estos resultados ofrecen indicios del cambio que se está produciendo en la valoración que los empleados hacen de ciertas prácticas de recursos humanos llevadas a cabo por la su organización. En este sentido, los empleados estratégicos no hacen depender su permanencia en la empresa de las características de su puesto de trabajo, considerando el diseño de su puesto de trabajo como una condición básica de su relación de empleo que no supone un incentivo extra para su retención ni para su implicación afectiva con la organización. Igualmente, tampoco podemos pasar por alto la complejidad que encierra el diseño de este tipo de puestos. Las organizaciones corren el riesgo de definir puestos que conlleven actividades y tareas excesivamente retadoras, que en vez de suponer un estímulo motivador para el empleado, impliquen un incremento de su estrés y de su ansiedad laboral, lo cual afecta negativamente a la capacidad de retención de su capital intelectual y de su capital afectivo. 
En segundo lugar, hemos estudiado la retribución, concluyendo que, en efecto, las empresas deben cuidar la definición de su sistema de retribución si quieren retener a su capital humano estratégico. En este sentido, las empresas deben contemplar la aplicación de diversas herramientas retributivas, ya revisadas en el capítulo primero ${ }^{1}$. De entre el amplio abanico de atributos de la retribución, en este trabajo nos hemos centrado en el análisis de aquellos sistemas de retribución que, siempre basados en la equidad retributiva externa e interna, incluyan componentes variables en función del resultado del grupo y, también, incluyan beneficios sociales. Nuestros resultados son concluyentes al demostrar la influencia positiva de este tipo de retribución sobre la retención del capital intelectual y sobre el capital afectivo de los empleados estratégicos y sugieren una relación significativa, aunque negativa, con el capital social. Todo ello nos permite plantear las siguientes reflexiones. En primer lugar, que la retribución sigue siendo un factor muy útil para la retención del capital intelectual de los empleados estratégicos, principalmente si se plantea en términos de equidad externa (salarios competitivos) y equidad interna (diseño equitativo de salarios según puesto de trabajo), que son aspectos cuyos ítems tienen el mayor peso en el constructo de retribución analizado en este trabajo. Estos resultados han sido ampliamente validados en la literatura específica de retención y mantienen su validez en la actualidad (Brief y Aldag, 1989; Hom y Griffeth, 1995; Lazear, 2004; Chawdla 2004,2005; Cho et al., 2005, entre otros). Del mismo modo, nuestros resultados también son concluyentes en la relación positiva entre la retribución y el capital afectivo de los empleados. Este resultado permite ratificar a la retribución como una de las vías por las que los empleados perciben la forma en que son valorados por su propia organización, lo que a su vez repercute en sus afectos hacia la misma (Rhoades et al., 2001; Buck y Watson, 2002; Allen, Shore y Griffeth, 2003; Hemdi y Nasurdin, 2006; Gardner et al., 2007); en

\footnotetext{
${ }^{1}$ Como por ejemplo, la individualización o contingencia (ha de tener en cuenta los resultados alcanzados por el empleado, para ello se puede incluir una parte variable), ser coherente con la empresa, su cultura y objetivos; ser persistente en el tiempo; ser simple y fácilmente comprensible por los empleados; debe cumplir el principio de equidad interna y de equidad externa o competitividad (para fomentar la atracción y retención); debería permitir cierta participación o implicación de los empleados en su diseño y además, ser comunicada, ya que mediante la transparencia se consigue generar confianza en los empleados. Todas estas cuestiones son algunas de las que, según la literatura de retención, permitirán a los empleados percibir el sistema de retribución como justo y satisfactorio, características necesarias si se quiere retener y satisfacer a los empleados (Hom y Griffeth, 1995).
} 
segundo lugar, y contrariamente a lo esperado, nuestros resultados muestran una influencia significativa y negativa de la retribución sobre el capital social. El sistema de retribución analizado no parece favorecer la cooperación y colaboración entre empleados, a pesar de incluir una componente de retribución variable contingente con el resultado del grupo. Este resultado puede deberse al diseño concreto del componente retributivo contingente en nuestra variable $y$, especialmente, al hecho de que este aspecto era el de menor peso de entre los que componían esta variable. Por ello puede no llegar a ejercer un impacto suficiente como para incentivar los comportamientos de interacción social de los empleados. Este resultado nos conduce a cuestionar si la propia definición y construcción del índice formativo de retribución pueda no ser tan completa como pensábamos y, por tanto, deba refinarse en futuras investigaciones. En cualquier caso, nuestros resultados nos permiten concluir que la retribución no es necesariamente un aspecto determinante del capital social de la organización. Evidentemente, la retribución sigue siendo un factor de gran atractivo para los empleados, aunque su influencia en las actitudes de los empleados estratégicos no es tan definitiva como cabría esperar (Whitaker, 2009; Thite, 2010, Allen et al., 2010).

En tercer lugar, también hemos analizado el desarrollo profesional del empleado, a través de la formación y de la promoción. De forma general, las prácticas de desarrollo profesional del empleado suponen una inversión en los empleados y, por tanto, tales prácticas deberían ser percibidas por los empleados como un reflejo del interés de la organización por su desarrollo y evolución profesional y/o personal. En consecuencia, cabe esperar que los empleados muestren una reciprocidad en su actitud y comportamientos, incrementando su nivel de compromiso, su nivel de rendimiento o su nivel de cooperación (Robinson y Rousseau, 1994; Wayne et al., 1997; Jerez et al., 2003; Hislop, 2003; Benson et al., 2004; Tzafrir et al., 2003, 2004; Vaiman, 2004; Cabrera y Cabrera, 2005; Morris et al., 2005; Peterson, 2007; Gardner et al., 2007, entre otros). Sin embargo, contrariamente a lo que cabría esperar conforme a las apreciaciones previas, nuestros resultados no constatan influencia alguna de las prácticas orientadas al desarrollo del empleado -formación y oportunidades de promoción- sobre los tres componentes del capital humano vinculado a los empleados estratégicos. Estos resultados, indudablemente sorprendentes nos inducen a pensar que 
si el colectivo de empleados estratégicos no hace depender su retención, cooperación y compromiso para con su empresa de las oportunidades de formación y promoción recibidos de ésta es porque las organizaciones no ofrecen unas posibilidades de formación y/o promoción verdaderamente adaptadas a las necesidades y/o expectativas de estos empleados. Los empleados estratégicos pueden no percibir la formación como una muestra del interés de la organización hacia su capital humano en tanto que, en la última década, no son pocas las empresas que se han limitado a aprovechar subvenciones del Estado y de la Unión Europea para justificar cualquier tipo de acción formativa, no necesariamente adecuada a las necesidades reales de sus empleados. Por tanto, es posible que la formación ofrecida por la organización no se haya orientado al desarrollo de conocimientos y habilidades multidisciplinares, específicos o diferenciadores, que pueden resultar verdaderamente atractivos y enriquecedores para este colectivo de empleado. Por otro lado, en relación a la promoción, es importante tener presente que no todas las organizaciones pueden ofrecer las mismas posibilidades de promoción a sus empleados. Precisamente, las características propias de los empleados considerados en este trabajo (personal estratégico y/o altamente cualificado) hace que sus expectativas profesionales no puedan ser fácilmente satisfechas por cualquier organización. En definitiva, los resultados obtenidos nos permiten concluir que la formación de acogida, la formación interdisciplinar y la promoción basada en el desempeño no son aspectos significativos en la retención de ninguno de los tres componentes del capital humano de la organización ni, por ende, en la retención de los empleados estratégicos.

En cuarto lugar, la última práctica transaccional analizada comprende las medidas de conciliación entre la vida personal y laboral. Nuestros resultados confirman el efecto positivo y significativo de este tipo de medidas sobre el capital afectivo de los empleados estratégicos, tal y como ya se muestra en estudios precedentes (Allen et al., 2000; Thompson y Heron, 2006; Ahuja, Chudoba y Kacmar, 2007; Casper et al., 2007; Parkes y Langford, 2008; Sánchez-Vida et al., 2010; Pasamar y Valle, 2011). Las medidas de conciliación persiguen el bienestar de los empleados de la organización y, al ser percibidas de esta forma por los empleados, inducen comportamientos y sentimientos positivos hacia la organización (Eisenberger et al., 1986; Rousseau 1989; 
1995). Sin embargo, y contrariamente a lo esperado, nuestros resultados no confirman la influencia significativa de las medidas de conciliación ni sobre la retención del capital intelectual ni sobre el capital social. Aunque, a priori, estos resultados nos sorprenden, es necesario reflexionar acerca de sus motivos. Sin duda, la práctica empresarial demuestra que las mujeres son el colectivo de empleados más sensible a las medidas de conciliación, por lo que el análisis de los efectos de esta práctica podría verse condicionado por el género de los empleados estratégicos de las empresas encuestadas. Por otra parte, tal y como señalan Haar y Spell (2004), puede no ser suficiente con que las empresas ofrezcan medidas de conciliación a sus empleados, sino que, para asegurar su impacto, es necesario valorar en qué medida son conocidas y utilizadas por sus empleados o, lo que es más importante, en qué medida estas prácticas ofertadas se adaptan a las verdaderas necesidades de sus empleados. En resumen, nuestros resultados nos llevan a concluir que las medidas de conciliación influyen sobre el vínculo afectivo de los empleados estratégicos hacia su organización, pero no aseguran su retención ni su implicación en procesos de interacción con otros empleados que potencien su capital social. Estos resultado nos induce a cuestionar cual es la eficacia real de oferta real de las medidas de conciliación, tales como la flexibilidad horaria, las facilidades para atender asuntos personales y las ayudas económicas a la familia.

Junto al análisis de estas cuatro prácticas de recursos humanos de naturaleza transaccional, nuestro trabajo incluye, además, el análisis de cuatro prácticas de recursos humanos de naturaleza relacional, cuyos principales resultados comentamos a continuación.

\subsubsection{Prácticas de recursos humanos de naturaleza relacional y su impacto en la} retención del capital humano de la organización

Por lo que se refiere a las prácticas de recursos humanos de naturaleza relacional incluidas en nuestro modelo, podemos concluir lo siguiente:

Nuestros resultados han sido especialmente concluyentes con las implicaciones de la primera de las prácticas analizada dentro de este grupo: el soporte del supervisor. Esta práctica influye positiva y significativamente sobre los tres componentes del capital humano: intelectual, social y afectivo. De hecho, es la única práctica de recursos 
humanos, de las ocho propuestas en esta investigación, que se muestra significativa para las tres dimensiones del capital humano. Nuestros resultados reafirman la necesidad de potenciar la faceta relacional del empleado como vía para crear una relación de empleo satisfactoria y, así, potenciar la permanencia de los empleados estratégicos en la organización, reteniendo su capital intelectual y, por ende, contribuyendo a establecer el capital social y el capital afectivo asociado a este tipo de empleados (Graen y Scandura, 1986; Wayne et al., 1997; Rhoades y Eisenberger, 2002; Allen et al., 2003; Chawla, 2005; Celeste y Brotheridge, 2005; Jawahar y Hemmasi, 2006; Dockel et al., 2006; Peterson, 2007; Paré y Tremblay 2007; Atwater y Carmeli, 2009; Rosa-Navarro y Carmona-Lavado, 2010). Los superiores jerárquicos representan la personificación de la propia organización (Levinson, 1965) y, por ello, es lógico que el modo en estos superiores se relacionan con sus subordinados sea percibido por los empleados como el trato que reciben de la propia organización. Aquellos superiores que se muestran accesibles, que reconocen el trabajo de sus empleados y ofrecen soporte a su desempeño, obtendrán de sus empleados actitudes recíprocas que favorecen su permanencia en la organización, su predisposición a la cooperación y su vínculo afectivo para con la organización. En definitiva, y conforme a nuestros resultados, la relación satisfactoria con el supervisor es la práctica que ha resultado más eficaz para retener a los empleados estratégicos y al capital humano asociado a ellos.

Por lo que se refiere a la segunda y a la tercera de las prácticas relacionales analizadas, la comunicación interna y la participación del empleado, presentamos sus resultados de forma conjunta en tanto que ambas prácticas recogen aspectos interconectados que reflejan las oportunidades que recibe el empleado para implicarse con su organización. Las oportunidades de comunicación y participación suelen ser prácticas acogidas positivamente por los empleados estratégicos y que repercuten positivamente en su satisfacción, sus comportamientos y sus sentimientos de afecto hacia la organización (Naggiar, 2001; Buck y Watson, 2002; López-Cabrales et al., 2007; Sun et al., 2007; entre otros). En este sentido, debemos señalar que los resultados obtenidos presentan cierta complementariedad a este respecto puesto que, por un lado, demuestran que la comunicación interna influye significativamente en la retención de capital intelectual, mientras que la participación del empleado influye positivamente en el capital social y 
en el capital afectivo de los empleados. Así pues, y si bien nuestros resultados no confirman la influencia significativa de ambas prácticas sobre todos los componentes del capital humano, consideramos que si confirman la necesidad de valorar la importancia de la comunicación y la participación como aspectos determinantes de la retención del capital humano. De hecho, la comunicación interna constituye un acto de transparencia de la organización que facilita a los empleados el acceso a información relevante para mejorar su desempeño, que mejora su nivel de implicación con los asuntos que conciernen a la organización y que, por tanto, establece un vínculo intelectual con el empleado que fortalece su relación de empleo. Asimismo, las medidas de participación del empleado frecuentemente requieren de la cooperación e interacción con otros miembros de la organización - a través, por ejemplo, del trabajo en equipopotenciando, de este modo, el fortalecimiento de su capital social. La participación del empleado también constituye, aunque de forma implícita, un reconocimiento y un voto de confianza a la valía de los empleados, en tanto que se les permite tomar decisiones sobre aspectos relevantes para el éxito organizativo. Ello es interpretado en reciprocidad por el empleado, afianzando su capital afectivo hacia la organización. Por lo que se refiere a las relaciones no validadas en relación a estas variables (por un lado, la influencia de la comunicación interna sobre el capital social y sobre el capital afectivo y, por otro lado, la influencia de la participación del empleado en la retención del capital intelectual), su justificación apunta a la existencia de una cierta complementariedad entre ambas prácticas que, aunque sean bien distintas, frecuentemente se utilizan indistintamente en la literatura especializada.

Por último, la cuarta práctica relacional analizada es la relación interna de apoyo entre compañeros. Sobre la base de los resultados obtenidos, podemos concluir que las relaciones de apoyo entre compañeros influyen de forma positiva sobre el capital social y sobre el capital afectivo; sin embargo, nuestros resultados no permiten extraer ninguna influencia significativa en relación a la retención del capital intelectual. Indudablemente, los comportamientos de compañerismo y de apoyo entre los empleados estratégicos favorecen el desarrollo de nexos y relaciones cooperativas entre ellos, por las que se sostiene un capital social. Además, el afecto recibido de los compañeros desarrolla un deseo de correspondencia que incrementa el capital afectivo 
de los empleados. Sin embargo, nuestros resultados indican que esta práctica no es determinante en la retención de los empleados estratégicos y de su capital intelectual. Este resultado no apoya recientes estudios que evidencian que, a menudo, los empleados no diferencian claramente entre las directrices de la organización y el comportamiento de los compañeros, de modo que si existe un ambiente de compañerismo y apoyo ente compañeros es porque el clima laboral lo favorece. Por tanto, cuando se analice si una organización ofrece apoyo y soporte a sus empleados, el compañerismo deba ser tenido en cuenta como un atributo del entorno laboral definido por la organización (Ng y Sorensen, 2008). De nuestro análisis no podemos extraer conclusiones que confirmen esta tendencia. Quizás, en las empresas de la muestra, el compañerismo no sea percibido por lo empleados como una consecuencia del entorno laboral que promueve la organización y, por ello, no presente relevancia alguna para la retención de estos empleados estratégicos y de su capital intelectual.

\subsubsection{Retención del capital humano y variables intermedias de resultado} organizativo como mecanismos por los que las prácticas de recursos humanos contribuyen a mejorar el resultado empresarial

La literatura de gestión de recursos humanos señala, expresamente, la necesidad de investigar los procesos intermedios por los que la gestión de recursos humanos influye en el resultado empresarial (Boselie et al., 2005; Takeuchi et al., 2009). Por ello, en este trabajo hemos propuesto dos etapas intermedias en el efecto de las prácticas de recursos humanos sobre el resultado empresarial: una primera etapa considera el papel intermediario de la retención de capital humano de la organización y, la segunda etapa, subsecuente a la anterior, considera la importancia de dos variables que se comportan como antecedentes del resultado organizativo: la capacidad de innovación y los resultados de las personas. La Figura 5.1. representa la secuencia causal propuesta en este trabajo y, si en el apartado anterior hemos expuesto las principales conclusiones del análisis del impacto de las prácticas de recursos humanos sobre el capital humano de la organización, en este apartado nos detenemos en extraer las conclusiones del 
análisis del impacto de la retención del capital humano sobre diversos resultados de la organización.

Figura 5.1. Secuencia causal analizada en este trabajo

\begin{tabular}{|c|c|c|}
\hline $\begin{array}{c}\text { Prácticas de } \\
\text { recursos } \\
\text { humanos }\end{array} \rightarrow \begin{array}{c}\text { Retención de } \\
\text { capital } \\
\text { humano }\end{array}$
\end{tabular}$\rightarrow \begin{gathered}\text { Capac. Innovac } \\
\text { Result. Personas }\end{gathered} \rightarrow \begin{gathered}\text { Resultados } \\
\text { empresariales } \\
\text { (financieros) }\end{gathered}$

5.1.2.1. Retención de capital humano de la organización y su impacto en las variables intermedias de resultado organizativo: capacidad de innovación y resultados de las personas

El conocimiento existente acerca de la contribución de la gestión de recursos humanos a la innovación en la organización es aún escaso (Leede y Loise, 2005; JiménezJiménez y Sabater-Sánchez, 2010) y, por ello, los resultados de este trabajo pueden ofrecer algunas aportaciones interesantes a este respecto. La relación de los recursos humanos y, por ende, del capital humano, con la capacidad de innovación ha sido tradicionalmente justificada por medio de la aportación proveniente del capital intelectual a través de los conocimientos, habilidades y creatividad de los empleados (West et al., 2004; Shipton et al., 2004). Sin embargo, las tendencias de investigación más recientes invitan a tener también en cuenta la posible influencia positiva del capital social y del capital afectivo sobre la innovación (Morris et al., 2005; De Clerq et al., 2007; Lin, 2007; Camelo et al., 2010). Los resultados obtenidos en esta investigación avalan esta tendencia en tanto que confirman la influencia positiva y significativa del capital intelectual, el capital social y el capital afectivo de los empleados estratégicos sobre la capacidad de innovación de la organización. Más concretamente, de los tres componentes del capital humano analizados, el capital social es el parece ejercer una mayor influencia en la capacidad de innovación. Indudablemente, el capital social fortalece la interacción entre empleados de diferentes áreas de la organización, facilitando, con ello, los procesos de intercambio y 
combinación de los conocimientos y experiencias heterogéneos de estos empleados. Estos procesos, a su vez, estimulan la creación de nuevo conocimiento y, por ende, el desarrollo de la capacidad de innovación de la organización. Así pues, estamos en condiciones de afirmar que, conforme a nuestros resultados, el desarrollo de la capacidad de innovación de una organización requiere de empleados con un alto capital intelectual y, además, requiere que dichos empleados interaccionen en procesos de cooperación y colaboración y se muestren vinculados afectivamente con su organización. En resumen, el capital humano en sus tres dimensiones: capital intelectual, social y afectivo, se muestran eficaces para favorecer la capacidad de innovación de la organización, como cabía esperar.

Asimismo, y junto a los resultados relativos a la relación entre el capital humano y la capacidad de innovación, nuestro trabajo también nos permite ofrecer conclusiones relativas a la relación entre el capital humano y una segunda variable intermedia de resultados, que hemos denominado resultados de las personas, y que recoge el nivel de desempeño y de satisfacción de los empleados para con su organización. Más concretamente, nuestro análisis plantea la relación positiva entre el capital afectivo de los empleados estratégicos y los resultados de las personas, confirmando que este vínculo afectivo de los empleados estratégicos hacia la organización favorece aspectos tales como el nivel de productividad y la satisfacción laboral de dichos empleados. De este modo, nuestros resultados abundan en la extensa evidencia empírica que avala la importancia de la faceta afectiva de los empleados en relación con la mejora de su actitud y comportamientos respecto a la organización.

5.1.2.2. Variables intermedias de resultado organizativo y su impacto sobre el resultado empresarial final

Los estudios de recursos humanos que proponen relaciones de causalidad entre las diferentes variables de resultado organizativo (Paauwe y Richardson, 1997; Guest, 1999; Ferris et al., 1999; Wright et al., 2005; Lepack et al., 2006, entre otros) incluyen tanto la capacidad de innovación como los "resultados de las personas" como antecedentes causales del resultado empresarial de la organización, que habitualmente se ha definido en términos financieros o de mercado. Los resultados de esta 
investigación constatan la influencia positiva y significativa de las dos variables propuestas de resultado intermedio -capacidad de innovación y resultados de las personas- sobre los resultados empresariales finales, en este caso, de naturaleza económica-financiera. Estos resultados permiten extraer dos conclusiones fundamentales: en primer lugar, que, en efecto, la actitud, satisfacción y nivel de desempeño de los empleados condiciona el éxito financiero y competitivo de las organizaciones; en segundo lugar, que el desarrollo de la capacidad de innovación es relevante para mejorar la rentabilidad y la competitividad empresarial (Chow y Gong, 2010).

Estos resultados concuerdan con las voces que, tanto desde el ámbito académico como desde la práctica empresarial, remarcan la importancia de la capacidad innovadora de las empresas como aspecto clave para competir con éxito en el presente y en el futuro. Asimismo, nuestros resultados permiten constatar la existencia de causalidad entre las variables intermedias de resultado organizativo y la variable de resultado final. Indudablemente, la identificación exacta de los procesos y variables que intervienen en la relación entre gestión de recursos humanos y los resultados organizativos es aún un campo en el que merece la pena seguir profundizando, si bien nuestros resultados permiten aportar un poco luz a esta “caja negra” de los recursos humanos.

En definitiva, podemos concluir que: 1) la consideración de etapas intermedias en la relación entre la gestión de recursos humanos y resultados organizativos tiene su significado; 2) la retención del capital humano de la organización es un proceso intermedio relevante en dicha relación; 3) es posible identificar dos niveles de variables de resultado organizativo, uno antecedente del otro, de tal forma que el primer nivel recoge tanto la capacidad de innovación como los comportamientos, actitudes, nivel de desempeño de los empleados y el segundo nivel contiene el resultado económicofinanciero de la organización.

Como complemento a la discusión de resultados previa, a continuación, destacamos diversas puntualizaciones que, a modo de resumen, dan respuesta a la cuestión de 
investigación inicialmente planteada así como a los diversos aspectos que se han tratado de estudiar con cierta profundidad.

En primer lugar, nuestros resultados ofrecen evidencia respecto a que, entre todas las prácticas de recursos humanos consideradas, tan sólo el soporte del supervisor logra un impacto positivo sobre los tres componentes del capital humano de la organización. Este resultado ofrece una serie de implicaciones interesantes. En primer lugar, consideramos que este resultado pone de manifiesto la importancia que, en el caso de los empleados estratégicos, puede tener la relación entre empleado y supervisor para la retención de estos empleados. Tal relación es el aspecto más eficaz para retener a este colectivo de empleados o, en su defecto, para hacerle abandonar la empresa (Chew, 2004). Como se concluye de nuestros resultados, no todas las prácticas analizadas logran influir significativamente sobre los tres componentes del capital humano. En consecuencia, es aconsejable diseñar sistemas de prácticas de recursos humanos que incluyan prácticas complementarias para, de este modo, lograr un mayor impacto sobre todas las dimensiones del capital humano. No son pocos los trabajos recientes que señalan esta necesidad (Thite, 2010; Allen et al., 2010), por lo que nuestras conclusiones se muestran coherentes con las últimas tendencias en los estudios sobre retención, en los que se analiza un abanico de fuerzas diversas que justifican la retención e implicación de los empleados con la organización, derivadas de los desarrollos del modelo de las ocho fuerzas de Maertz (2001) y del modelo de inmersión en el trabajo de Mitchell et al. (2001).

En segundo lugar, nuestros resultados ofrecen evidencia sobre la importancia de la faceta relacional de la relación de empleo. Como hemos expuesto en las páginas precedentes, nuestros resultados muestran que las prácticas de recursos humanos de naturaleza relacional resultan ser más significativas para la retención del capital humano que las prácticas de naturaleza transaccional. Presumimos que este resultado puede deberse a que, habitualmente, la regulación de las condiciones de trabajo en los respectivos convenios sectoriales o de empresa ya incluyen y garantizan una correcta aplicación de las prácticas que hemos denominado "transaccionales", pero no ocurre lo mismo con las prácticas relacionales, que al ser de naturaleza menos tangible, no han 
podido ser reguladas hasta el momento. Las prácticas relacionales, en consecuencia, son percibidas por los empleados como acciones discrecionales de su organización y que, por tanto, valoran positivamente en la relación de empleo. Por tanto, creemos recomendable analizar la influencia de la gestión de recursos humanos incorporando de forma expresa medidas de naturaleza relacional que satisfagan la faceta social-relacional de la relación de empleo (Alvesson, 2000; Tsui y Wu, 2005; Hom, Tsui et al., 2009; Valle-Cabrera y López-Cabrales, 2009).

En tercer lugar, el análisis de los resultados de esta investigación confirma la necesidad de estudiar las peculiaridades propias del colectivo de empleados especialmente valiosos para su organización, analizando cuáles son las prácticas más adecuadas para su gestión. Nuestros resultados confirman que aquellas prácticas de recursos humanos, ampliamente contrastadas como eficaces en empleados comunes, no muestran la misma eficacia en el colectivo de empleados estratégicos. Este resultado abunda en las propuestas de otros trabajos que señalan la necesidad de buscar arquetipos o agrupaciones de prácticas de gestión adecuadas a diferentes colectivos de empleados (Lepack y Snell, 2002; Morris et al., 2005; Kang et al., 2007; Rose y Gordon, 2010).

Finalmente, en esta investigación hemos procurado acercar aspectos provenientes del ámbito de la dirección estratégica de recursos humanos (Wright et al., 1994) y de otros enfoques teóricos como el enfoque de empresa basado en el conocimiento (Grant, 1996), con el objetivo de permitirnos explicar con mayor profundidad la influencia de la gestión de recursos humanos en los resultados organizativos (Carter y Scarbrough, 2001; Afiouni, 2007). En este sentido, el trabajo desarrollado en esta investigación nos ha permitido comprobar la utilidad de acercar estos dos ámbitos de estudio, por ejemplo, introduciendo el concepto tridimensional del recurso humano apoyado en la definición de capital humano (Gratton y Ghoshal, 2003; Barney y Clark, 2007) o, también, pudiendo abordar, el análisis del capital social como variable relevante en la explicación del fenómeno que nos ocupa. Además, la evidente relación del conocimiento con la innovación y del conocimiento con el capital humano y con los propios recursos humanos, demuestran el interés de considerar de forma conjunta 
aspectos del enfoque de empresa basada en el conocimiento como del enfoque estratégico de recursos humanos.

A continuación abordamos las contribuciones que podemos extraer, en esta investigación, para la práctica empresarial, especialmente, para el ámbito de la dirección de recursos humanos de las organizaciones.

\subsection{CONTRIBUCIONES PARA LA PRÁCTICA EMPRESARIAL}

El análisis que hemos realizado ofrece unos resultados interesantes, no sólo desde el punto de vista académico, sino también desde el punto de vista de la práctica empresarial. En este sentido, uno de los objetivos de esta investigación es el de poder extraer conclusiones útiles para el ámbito de la práctica empresarial de la gestión de recursos humanos con el fin de mejorar su contribución a la competitividad y al éxito empresarial. Desde nuestro punto de vista, las implicaciones para la gestión de recursos humanos que se derivan de las relaciones significativas observadas en el análisis llevado a cabo son, aunque modestas, diversas. Estas implicaciones integran las siguientes recomendaciones.

La dirección empresarial debe valorar el concepto del capital humano de la organización en toda su amplitud, valorando, por tanto, la potencialidad empresarial que tiene, no sólo el capital intelectual sino, también, el capital social y el capital afectivo de sus empleados.

Tras el análisis empírico realizado, nos sumamos a la opinión de otros autores, como Barney y Wright (2007) y Gratton y Ghoshal (2003), de que el valor que los empleados aportan a la organización, en virtud de su capital humano, no se deriva únicamente de sus conocimientos y habilidades -capital intelectual- sino, también, de su capital social y de su capital afectivo.

Indudablemente, el capital intelectual de los empleados constituye un recurso estratégico en muchas organizaciones. Sin embargo, las contribuciones positivas de los empleados al desempeño organizativo también provienen de la interacción, cooperación y colaboración entre dichos empleados. Concretamente, a través de su 
capital social se genera un conocimiento colectivo que puede redundar positivamente en los resultados organizativos. En consecuencia, las empresas deberían favorecer el desarrollo de capital social de sus empleados, por ejemplo, a través de estructuras de trabajo cooperativas que fomenten la interacción entre diversos empleados, que fomenten la confianza basada en el sentimiento de grupo y que fomenten unos objetivos y un lenguaje común a esos empleados. Además, no es suficiente con poseer una plantilla altamente cualificada y establecer formas de trabajo cooperativas, sino que también es necesario desarrollar un capital afectivo que esté basado en el compromiso y el vínculo afectivo de los empleados hacia su organización. Es decir, las organizaciones necesitan contar con el “querer hacer" de sus empleados como complemento y refuerzo del su capital intelectual y de su capital social. En suma, la dirección de las empresas y, en particular, el área de recursos humanos, debería valorar al recurso humano en una dimensión más completa -intelectual, social y afectiva- con el objetivo de aplicar las prácticas y políticas que puedan potenciar cada una de estas dimensiones del capital humano de sus empleados. Todas ellas son necesarias para maximizar el valor que puedan aportar los empleados a la organización a través de un capital humano multidimensional.

\section{Las empresas deberían insistir en el desarrollo de su capacidad de innovación como vía para lograr el éxito empresarial y comprender el papel del capital humano en dicho desarrollo.}

La crisis actual ha puesto de manifiesto las carencias de nuestro modelo productivo empresarial y ha obligado a replantear sus bases para fortalecer el crecimiento y la competitividad empresarial. En este escenario, la capacidad de innovación es un factor clave; por un lado, debido a su influencia para generar innovaciones y, por otro lado, porque aquellas organizaciones que desarrollan su capacidad de innovación muestran una clara propensión a incrementar su cuota de mercado, su productividad e, incluso, su capacidad exportadora y grado de internacionalización (Monzón de Cáceres, 2010). Los resultados de este trabajo también avalan dichas apreciaciones. Por tanto, las empresas deben poner énfasis en el desarrollo de la capacidad de innovación como vía para la mejora de sus resultados empresariales y competitividad. Apostar por la innovación es 
una inversión con retorno asegurado que constituye una vía sostenible para las economías avanzadas. En relación a la capacidad de innovación, nuestro análisis pone de manifiesto la significativa influencia del capital humano en su desarrollo, en especial, la dimensión del capital social. Por tanto, es aconsejable diseñar e implantar prácticas de recursos humanos que favorezcan la retención y el desarrollo del capital intelectual y afectivo de los empleados y, sobre todo, que potencien el fortalecimiento de un capital social. Todo ello asegura una mejora de la capacidad innovadora de la organización.

Las empresas deben conocer cuáles son las prácticas más efectivas para retener a sus empleados y valorar la necesidad de diseñar baterías de prácticas apropiadas para el colectivo formado por sus empleados más valiosos

Nuestro análisis pone de relieve la divergencia que existe en la influencia que logra cada práctica de recursos humanos propuesta en nuestro modelo. Así, algunas prácticas se constatan como más eficaces para favorecer la retención del capital intelectual, otras para influir positivamente en el desarrollo del capital social y otras destacan por su actuación sobre el capital afectivo de los empleados. Por tanto, puesto que no todas las prácticas de recursos humanos influyen del mismo modo sobre cada uno de los componentes del capital humano, es recomendable diseñar sistemas de prácticas complementarias y coherentes entre sí (Thite, 2010; Allen et al., 2010). Además, por otro lado, sabemos que los empleados otorgan diferentes valoraciones a las prácticas de recursos humanos de sus empresas en función de su edad, situación personalfamiliar, estatus, expectativas, etc., y en concreto, del colectivo de empleados al que pertenezcan. En consecuencia, como ya viene siendo sugerido en la literatura especializada (Morris et al., 2005; Kang et al., 2007; Rose y Gordon, 2010), las empresas no deberían aplicar las mismas prácticas a todos sus empleados. A priori, parece adecuado diferenciar las prácticas dirigidas a los empleados comunes y las prácticas dirigidas a empleados estratégicos, cuyo capital humano es especialmente valioso. En conformidad, en base a nuestros resultados, y al objeto de retener a los empleados más valiosos, recomendamos diseñar un sistema de prácticas de recursos humanos que incorporen las siguientes consideraciones: 
- Un diseño de puesto de trabajo que plantee al empleado un alto nivel de reto, así como la necesidad de aplicar conocimientos heterogéneos y/o especializados, a ser posible, en colaboración con compañeros. Conforme a nuestros resultados, esta práctica fortalece el capital social de los empleados aunque en sí misma es insuficiente para retener al colectivo de empleados estratégicos.

- Los sistemas de retribución deben asegurar el cumplimiento de los principios de equidad externa e interna retributiva. Estos atributos mantienen el protagonismo en la satisfacción de los empleados. En un segundo lugar, las empresas pueden analizar la posibilidad de completarlos con retribuciones de naturaleza variable y utilizar diversos beneficios sociales.

- Unas políticas de formación adecuadas a las necesidades reales de los empleados estratégicos y, por ello, los planes de formación deben estar orientados bien a proporcionar una formación altamente específica o bien a proporcionar una formación interdisciplinar. Es más, incluso se podría considerar la opción de participación de estos empleados como formadores internos, siempre de forma voluntaria y/o remunerada, en tanto que es una forma de reconocer y valorar positivamente su valía.

- Las medidas de conciliación entre la vida personal y laboral deben ser acordes a las necesidades reales de los empleados, siendo incluso adecuado distinguir entre diferentes prácticas de conciliación según el tipo de empleado y sus necesidades particulares.

- Una actitud de directivos, supervisores y mandos orientados para dar apoyo al empleado y al establecimiento de relaciones satisfactorias con sus subordinados. Según nuestros resultados, ésta es la práctica que alcanza una mayor influencia sobre las tres dimensiones del capital humano, lo que pone de relieve la importancia que adquieren las habilidades sociales de las personas que ocupen los puestos de mando en las organizaciones.

- Las prácticas de comunicación interna y participación del empleado deben implementarse de forma conjunta y complementaria para lograr un mayor efecto en 
la retención de empleados. Para ello, las empresas pueden habilitar los canales necesarios para el desarrollo de la comunicación interna y ofrecer la posibilidad de comunicar sucesos y sentimientos al empleado y, asimismo, de forma paralela, incorporar sistemas formalizados de participación de los empleados que premien y/o reconozcan explícitamente las aportaciones de éstos a la organización.

- La creación de un contexto laboral que potencie el compañerismo como un valor organizativo, favoreciendo los encuentros sociales informales entre empleados como práctica habitual, especialmente, fuera de la organización.

Por último, apuntamos la siguiente recomendación para la práctica empresarial derivada del análisis de nuestros resultados.

Las empresas deben asumir los cambios que conlleva la actualización que se está produciendo en la relación de empleo. En dicha relación, la faceta relacional ha adquirido un gran protagonismo para los empleados estratégicos, en detrimento de la faceta transaccional.

Este trabajo nos ha permitido verificar algunas facetas de cambio en la relación de empleo (Tsui y $\mathrm{Wu}, 2005)$. Los empleados estratégicos tienden a valorar de forma creciente la dimensión social de su relación laboral, otorgando especialmente un mayor valor a la relación que mantienen con sus superiores, a la relación con sus compañeros e, incluso, a la relación con la propia organización a través de los sistemas de comunicación interna y de participación del empleado. La función de recursos humanos debe ser consciente de esta realidad y diseñar medidas que favorezcan la satisfacción de esta dimensión relacional sin, por supuesto, descuidar la faceta más tradicional de la relación de empleado (basada en aspectos como la retribución, diseño de puesto, formación, conciliación). Para ello, consideramos recomendable insistir en la formación de los mandos o superiores jerárquicos en habilidades sociales, en las fórmulas de trabajo basadas en la cooperación, en la necesidad de perfeccionar comunicación interna, en la necesidad de dar voz y voto al empleado y en la conveniencia de favorecer el compañerismo en vez de valorar positivamente el comportamiento competitivo entre empleados. Las empresas deben comenzar a reflexionar acerca de la conveniencia y 
existencia de estos valores en su quehacer diario y decidir cómo desean que se desarrolle el trabajo en sus organizaciones.

\subsection{LIMITACIONES DE LA INVESTIGACIÓN}

Una apreciación objetiva de los resultados de esta investigación no debe estar libre de críticas. Así pues, comentamos algunas limitaciones detectadas a lo largo de este estudio y que sirven de acicate para superarlas o mejorarlas en extensiones futuras del mismo.

Una primera limitación proviene de la selección de prácticas de recursos humanos orientadas a la retención que hemos incluido en nuestro estudio. Cabría la posibilidad de incorporar otras prácticas, no consideradas, como la selección de personal, por ejemplo, a través del ajuste persona-organización (Thite, 2010) o quizás, también, la evaluación del desempeño de los empleados.

Una segunda limitación surge en relación a la medición de las variables. A pesar del esfuerzo realizado por definir nuestros constructos tan precisamente como nos ha sido posible y medirlos por medio de un cuidadoso proceso de elaboración de ítems, algunos de ellos podrían ser mejorados, como por ejemplo, los índices formativos relativos a la retribución y al desarrollo profesional del empleado. También es posible profundizar en el análisis de la unificación de las escalas de las variables de participación del empleado y comunicación interna, ya que parecen tener efectos complementarios.

Otra limitación surge de no haber considerado el análisis de los efectos mediadores y moderadores que pueden ejercer las tres variables componentes del capital humano.

Asimismo, puesto que nuestro estudio se ha centrado únicamente en organizaciones con un especial interés por la innovación, los resultados obtenidos pueden no ser perfectamente extrapolables a otras poblaciones de empresas. No obstante, debemos hacer notar que la muestra analizada es muy heterogénea y diversa, lo que favorece la extrapolación de los resultados obtenidos.

Otra de las limitaciones de nuestro estudio surge del hecho de que nuestros datos provienen de un único informante por empresa encuestada. A pesar de haber realizado 
las pruebas necesarias para confirmar la no existencia de sesgo por respuesta única, somos concientes de que podría haber sido muy útil contar con respuestas a nivel de los empleados para poder valorar, con mayor exactitud, sus percepciones sobre las prácticas de recursos humanos y compararlas con las que ofrece la dirección del área. Es bien sabido que la realización de encuestas a una única fuente, en nuestro caso han sido dirigidas al director de recursos humanos o al director gerente, supone el riesgo de existencia de posibles sesgos en las respuestas. Además, nuestro estudio se ha centrado en las prácticas de recursos humanos aplicadas a los empleados estratégicos de la organización, dejando a otros colectivos de empleados fuera de nuestro ámbito de análisis, lo que abre nuevas oportunidades de investigación en el futuro.

Por último, otra limitación de este trabajo se refiere a la metodología utilizada en la investigación empírica. La consideración de escalas formativas nos ha impedido la aplicación de análisis de estructura de covarianzas (CBSEM) a través de paquetes informáticos ampliamente utilizados en la investigación en organización de empresas, como AMOS. En consecuencia, para poder analizar escalas formativas y reflectivas al mismo tiempo, hemos utilizado el análisis por mínimos cuadrados parciales (PLS) a través del software Smart-PLS, siendo aún escasas las aplicaciones del mismo al campo de los recursos humanos, por lo que asumimos las limitaciones de PLS expuestas previamente en el capítulo tercero. En cuanto a las escalas formativas, para poder depurarlas con mayor profundidad se podría aplicar el procedimiento fijado por Diamantopoulus et al. (2001, 2008) a través de modelos MIMIC aunque, para ello, necesitaríamos nuevas variables e ítems diferentes de los derivados del cuestionario utilizado.

\subsection{FUTURAS LÍNEAS DE INVESTIGACIÓN}

Una visión constructiva de las limitaciones señaladas de esta investigación así como el trabajo desarrollado a lo largo de la misma nos permiten esbozar algunas de las líneas futuras de investigación con las que es posible dar continuidad al presente trabajo: 
1) En esta investigación hemos analizado la influencia de la gestión de recursos humanos en la retención de empleados y de ésta en los resultados organizativos. No obstante, diversos autores sugieren considerar una posible causalidad inversa (Boselie et al., 2005), relación que bien podría ser una interesante línea de extensión de nuestro trabajo. Asimismo, nuestro estudio también se podría ampliar con el fin de comparar el efecto directo y el efecto indirecto de la gestión de recursos humanos sobre los resultados internos: ¿existe algún efecto directo o todo el impacto de la gestión de recursos humanos sobre los resultados organizativos es indirecto?

2) También es posible extender nuestra investigación analizando el papel moderador y/o mediador de las tres dimensiones del capital humano sobre algunas de las variables y relaciones propuestas en nuestro modelo. En concreto, consideramos particularmente interesante estudiar el papel moderador que pueda ejercer el capital afectivo en la relación del capital intelectual y del capital social con la capacidad de innovación de la organización.

3) El estudio aquí ofrecido también puede ampliarse realizando una valoración más detallada y rigurosa del impacto conjunto de los tres componentes del capital humano. A este respecto, por un lado, consideramos posible desarrollar una única variable de capital humano que aglutine sus tres componentes a través de la creación de un constructo fiable, con objeto de analizar el efecto mediador de dicho constructo entre la gestión de recursos humanos y los resultados organizativos. Por otro lado, nos planteamos el análisis de las posibles interrelaciones entre el capital intelectual, el capital social y el capital afectivo, en línea con la propuesta de Gratton y Ghoshal (2003) quienes plantean la existencia de interrelaciones positivas entre ellas.

4) Aún cuando en esta tesis hemos procurado analizar la influencia individual de cada una de las prácticas de recursos humanos propuestas, es posible analizar la forma en que influyen, de forma agrupada, el conjunto de las prácticas de naturaleza transaccional en comparación con el conjunto de las prácticas de naturaleza relacional. Con este fin, sería posible dar continuidad a nuestro trabajo mediante la formulación de variables de segundo orden formadas, por un lado, por las prácticas de recursos humanos transaccionales y, por otro lado, por las prácticas de recursos humanos 
relacionales. Es más, puesto que los resultados obtenidos resaltan la mayor eficacia de las prácticas de recursos humanos de naturaleza relacional, el análisis podría ampliarse profundizando única y exclusivamente en esta categoría de prácticas y de variables. Ello nos permitiría analizar, con mayor profundidad, el papel del capital social en el éxito empresarial pudiendo, incluso, incorporar el capital social externo (aquel que recoge las interacciones entre la organización -o sus miembros- y colaboradores externos (Leana y Pil, 2006)).

5) Indudablemente, otra línea de extensión lógica de este trabajo es la de seguir investigando sobre las prácticas de recursos humanos que favorecen la retención de empleados. Teniendo en cuenta los resultados de nuestra investigación, creemos interesante, por ejemplo, analizar diferentes estilos de liderazgo y características de los supervisores que permitan identificar los atributos del soporte del supervisor que potencian la retención de empleados. Además, otra línea de extensión que nos planteamos en este sentido es la relativa al estudio de la diversidad de medidas de conciliación que ofrecen las empresas, comparando su impacto entre diferentes colectivos de empleados, puesto que diferentes tipos de empleados pueden requerir de diferentes medidas de conciliación. Asimismo, este trabajo puede ampliarse mediante la incorporación y/o modificación de las prácticas de recursos humanos analizadas. Nos referimos, por ejemplo, a unificar en una sola práctica la comunicación interna y la participación del empleado, modificar sustancialmente la práctica desarrollo profesional del empleado o incorporar la práctica de selección de personal estudiando el ajuste persona-organización.

6) Aún cuando en esta tesis hemos procurado analizar la influencia de las prácticas de recursos humanos sobre la retención de empleados estratégicos, la fuente de información utilizada ocasiona que nuestros resultados se deriven únicamente de la percepción del director de recursos humanos o, en su defecto, del director gerente. Sabemos que las respuestas directivas pueden variar significativamente de las percepciones de los empleados con respecto a las prácticas de recursos humanos (García, Neira y Castro, 2011; Liao et al., 2009). En consecuencia, una interesante ampliación de esta investigación reside en analizar la retención de empleados desde el 
punto de vista del empleado. Este nivel de análisis permite indagar en la percepción exacta que los empleados desarrollan sobre las prácticas de recursos humanos de sus empresas y sobre el impacto en sus comportamientos y actitudes. Además, ello permitiría comparar los resultados obtenidos desde la perspectiva del director de recursos humanos (nivel organizativo) con la perspectiva del empleado (nivel del individuo), lo que constituye un análisis multinivel que responde a la demanda creciente de este tipo de trabajos en la investigación de gestión de recursos humanos (Kehoe y Wright, 2010; Paauwe, 2009; Brewster, Sparrow y Harris, 2005).

7) Nuestro estudio se ha centrado en las prácticas de retención de recursos humanos aplicadas a los empleados estratégicos de la organización, pero también puede ser interesante ampliar el ámbito de estudio a otros colectivos de empleados, indagando en la posible divergencia de la eficacia de las prácticas de retención orientadas a cada colectivo. El avance del conocimiento de arquitecturas de prácticas de recursos humanos adecuadas a grupos concretos de empleados y el conocimiento de los factores mejor valorados y/o más satisfactorios para cada colectivo puede ser una interesante extensión de este trabajo, en línea con las recomendaciones de Lepack y Snell (2002) y con los postulados de la nueva relación de empleo (Tsui y Wu, 2005). Asimismo, podría ser interesante analizar en profundidad el caso concreto de los sistemas de retribución y de las prácticas de desarrollo del empleado, en tanto que nuestros resultados ofrecen indicios para pensar que ambas prácticas difieren en el impacto que logran en empleados estratégicos y en empleados comunes.

8) Puesto que el trabajo empírico que hemos realizado es de naturaleza transversal, otra interesante extensión del mismo viene dada por la realización de un estudio de corte longitudinal en el poder analizar el efecto que las prácticas de recursos humanos ejercen sobre los empleados y su capital humanos, a través del tiempo.

9) Tampoco debemos olvidar la posibilidad de analizar la influencia del tamaño de la organización y la que puedan ejercer otras variables de control, tales como el sector de actividad al que pertenece la organización, la antigüedad o la edad de los trabajadores, la propiedad del capital, etc., profundizando en su influencia sobre la retención del capital humano. 
10) Por último, $y$ asumiendo que en el mundo empresarial actual todas las organizaciones necesitan una cierta capacidad de innovación, también sería posible reproducir este estudio en empresas que no sean altamente innovadoras, a fin de analizar si los resultados son similares o si la capacidad de innovación resulta igualmente vinculante para el resultado empresarial de otro tipo de organizaciones.

Teniendo en cuenta la investigación desarrollada en los capítulos precedentes y la discusión de resultados previa, estamos en disposición de poder discutir sobre la validación de la tesis propuesta en trabajo, sirviendo de colofón a la misma.

Esta investigación permite validar la influencia que las prácticas de recursos humanos pueden ejercer sobre los resultados organizativos a través de la retención del capital humano vinculado a los empleados estratégicos de la organización. Las prácticas de recursos humanos propuestas -transaccionales y relacionales- no muestran una misma eficacia, siendo superior el impacto que ejercen las prácticas de naturaleza relacional sobre el capital humano -en sus tres dimensiones de capital intelectual, capital social y capital afectivo-. Por otra parte, el capital humano vinculado a los empleados estratégicos se valida como influencia positiva en la capacidad de innovación de la organización y en los resultados de las personas, todo lo cual conduce a un impacto final positivo en el resultado empresarial, de naturaleza económica-financiera. Por tanto, podemos dar por validada la tesis propuesta en este trabajo.

Llegados a este punto final del trabajo de investigación sólo nos cabe esperar que estas páginas puedan resultar útiles, tanto a los investigadores de los fenómenos organizativos -en concreto del área de recursos humanos- como a los responsables de la práctica empresarial -en especial al departamento de recursos humanos-. En concreto, esperamos que nuestro trabajo pueda ser de utilidad en el ámbito de la gestión empresarial, en tanto que es necesario asumir el reto de gestionar, motivar, retener y desarrollar a colectivos de empleados, cada vez más diversos y exigentes, en entornos altamente cambiantes y competitivos. Esa es la mejor recompensa que podríamos obtener del empeño puesto en la elaboración del presente estudio. 
ANEXOS 

ANEXO I 



\section{A.1.1. Noticias que manifiestan el interés por la retención en el mundo empresarial}

La sexta edición del Barómetro de Recursos Humanos de CSC y Expansión \& Empleo, publicada en 2009, en el que han participado 150 directores de Recursos Humanos de grandes empresas europeas (la mayoría con más de 1.000 empleados), identificaba la retención y la atracción de los mejores empleados como primera prioridad de mejora de las políticas de recursos humanos; le siguen la mejora de la gestión de competencias clave, apoyar las reestructuraciones de la empresa y el desarrollo internacional, e incrementar el compromiso de los empleados.

La encuesta "Los retos que deberán enfrentar las organizaciones y los recursos humanos en los próximo diez años”, realizada por la Society for Human Resource Management (2010) pone de manifiesto que la mitad de las organizaciones encuestadas señalan que el mayor reto será obtener capital humano brillante y optimizar la inversión realizada en dicho capital (Figura A1.1). Para alcanzar estos desafíos, según los profesionales de recursos humanos, una de las estrategias más efectivas será la retención y recompensa de los mejores empleados. En este sentido apuestan por las medidas de flexibilidad laboral que favorezcan la conciliación trabajo-vida personal, como una de las medidas más eficaces en el futuro.

Price Water House Coopers, en su nota de prensa de 24 de mayo de 2010, alerta a las compañías sobre la necesidad de anticiparse y planificar cómo retener el talento de cara a la recuperación económica. Esta es una de las conclusiones extraídas de la encuesta realizada por PWHC a partir del informe de Gestión de personas en 2020. Dicha encuesta se elaboró a principios del año 2010 basándose en las aspiraciones y expectativas laborales de más de 5.000 profesionales de todo el mundo.

En la misma línea apuntaban las afirmaciones de la Cámara de Comercio de Madrid en 2008, tras los resultados de la encuesta realizada por The Boston Consulting Group (BCG) y la asociación Europea de Gestión de Personas (EAPM) a 1.350 ejecutivos de 27 países europeos, durante 2007-08, puesto que identifican la gestión y retención del talento y del capital humano como uno de los mayores retos en los próximos años, para los departamentos de recursos humanos de las empresas europeas. 
Figura A1.1. Resultados de la encuesta

De acuerdo con los profesionales de RH, las medidas más efectivas para

lograr retener y recompensar a los empleados estratégicos así como atraer a

los mejores, son:

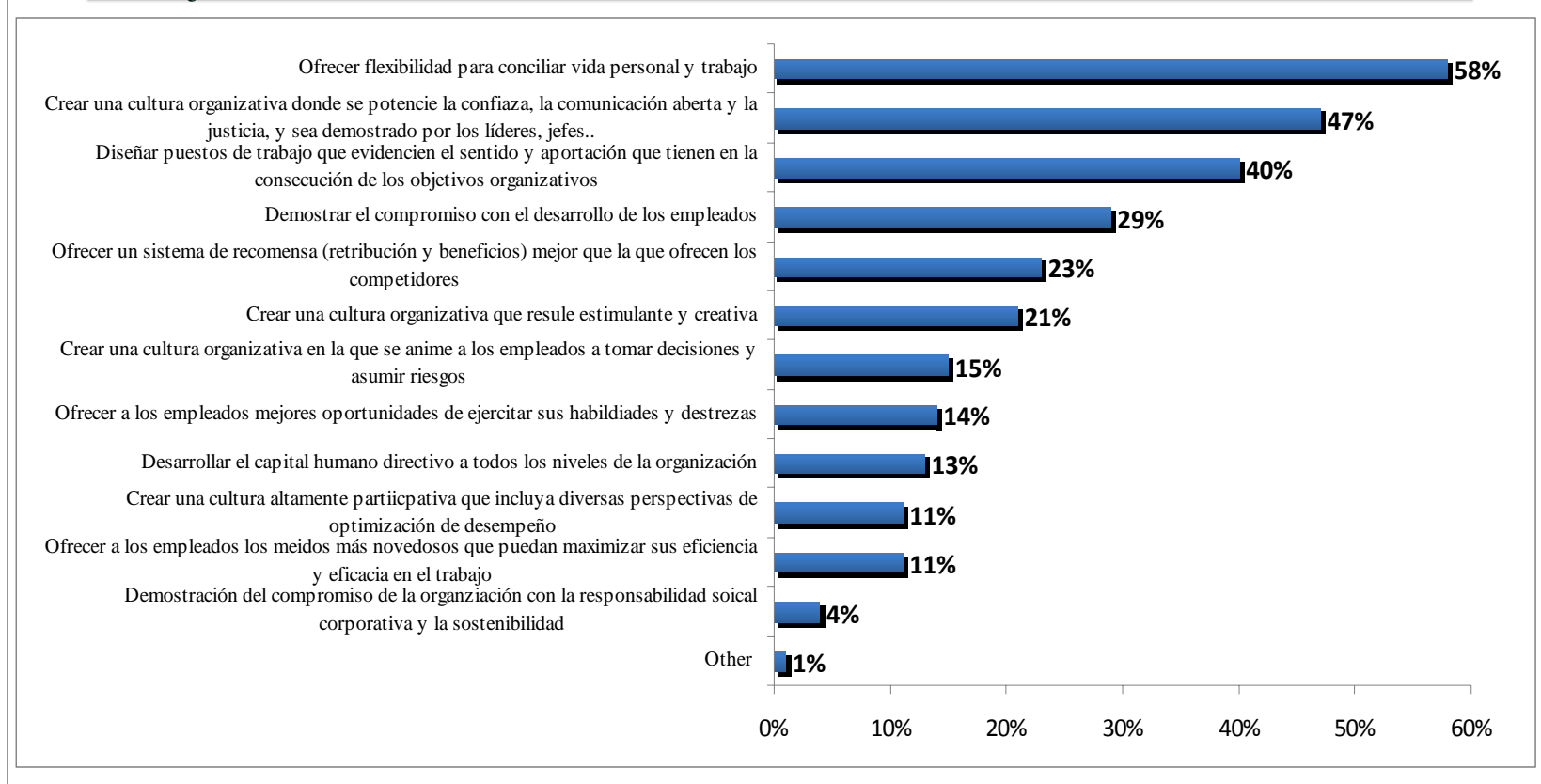

Nota: $n=449$. Los porcentajes no suman en total 100\% ya que se permitían múltiples respuestas. Los encuestados debían seleccionar tres medidas. 
Figura A1.2. Propuesta de las configuraciones de prácticas de recursos según Lepack y Snell

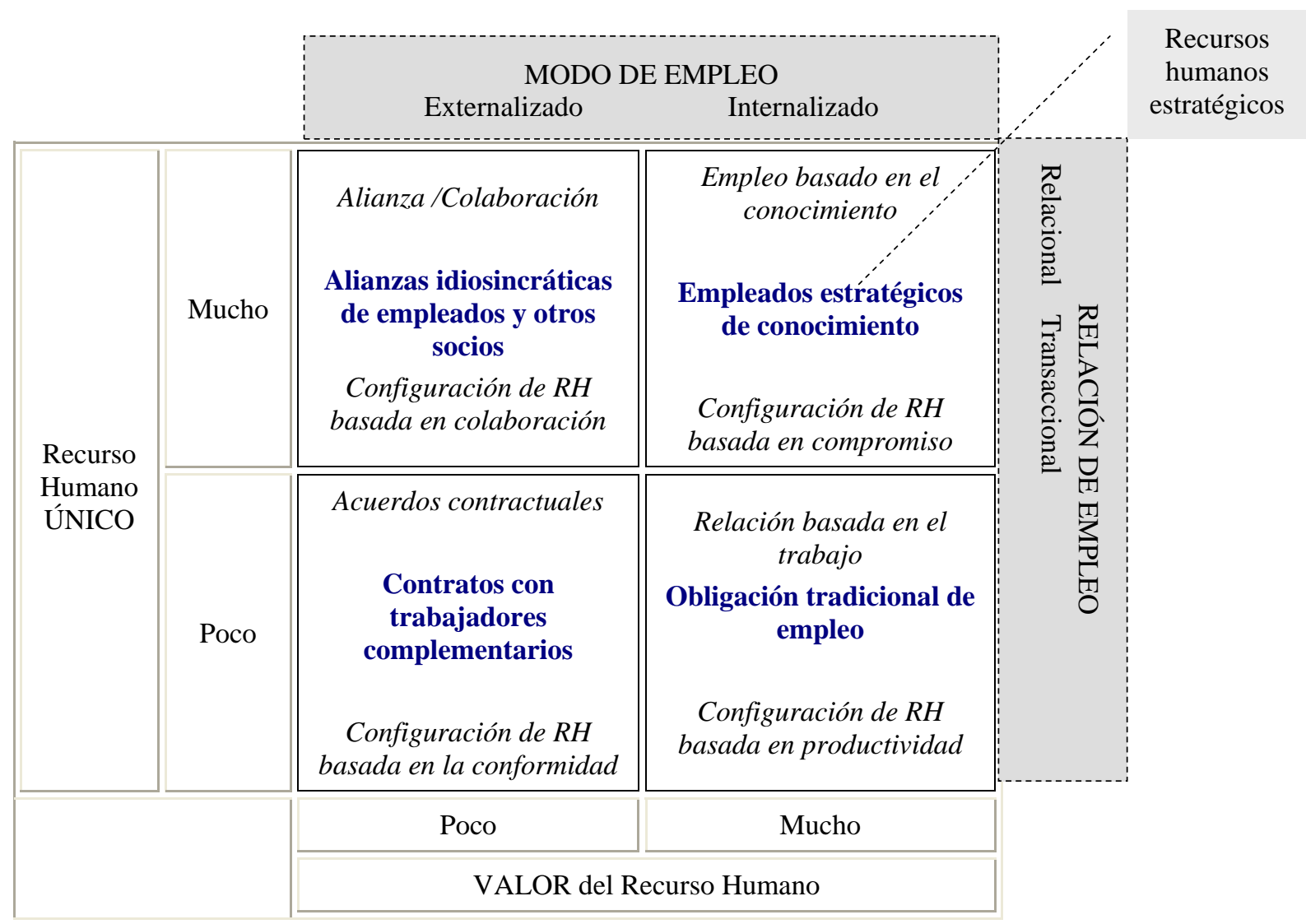

Fuente: Adaptado de Lepack y Snell $(1999,2002)$

Figura A1.3. Modelo de relación de empleo de Tsui y Wu (2005)

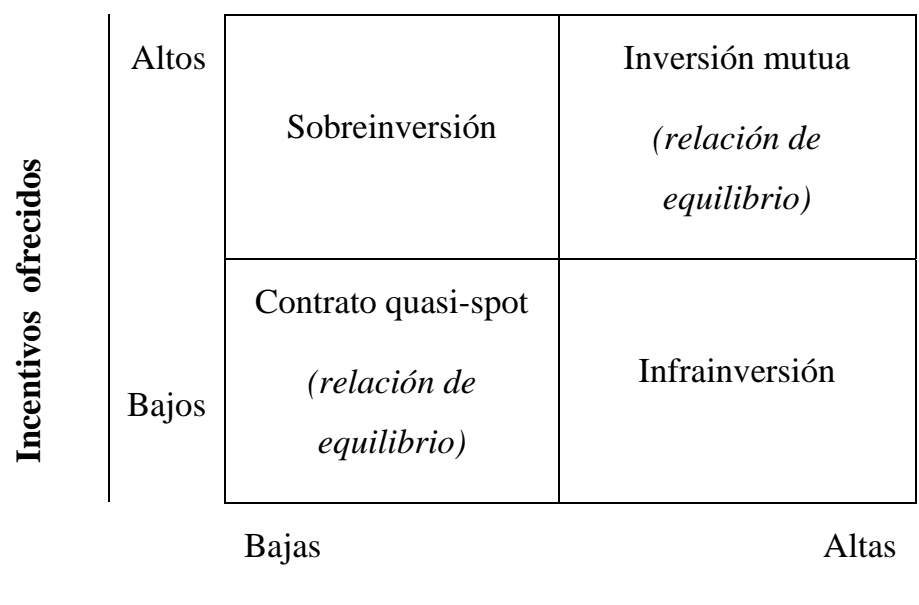

Contribuciones esperadas 
Figura A1.4. Esquema cronográfico de los principales modelos de rotación voluntaria y retención de empleados en la organización

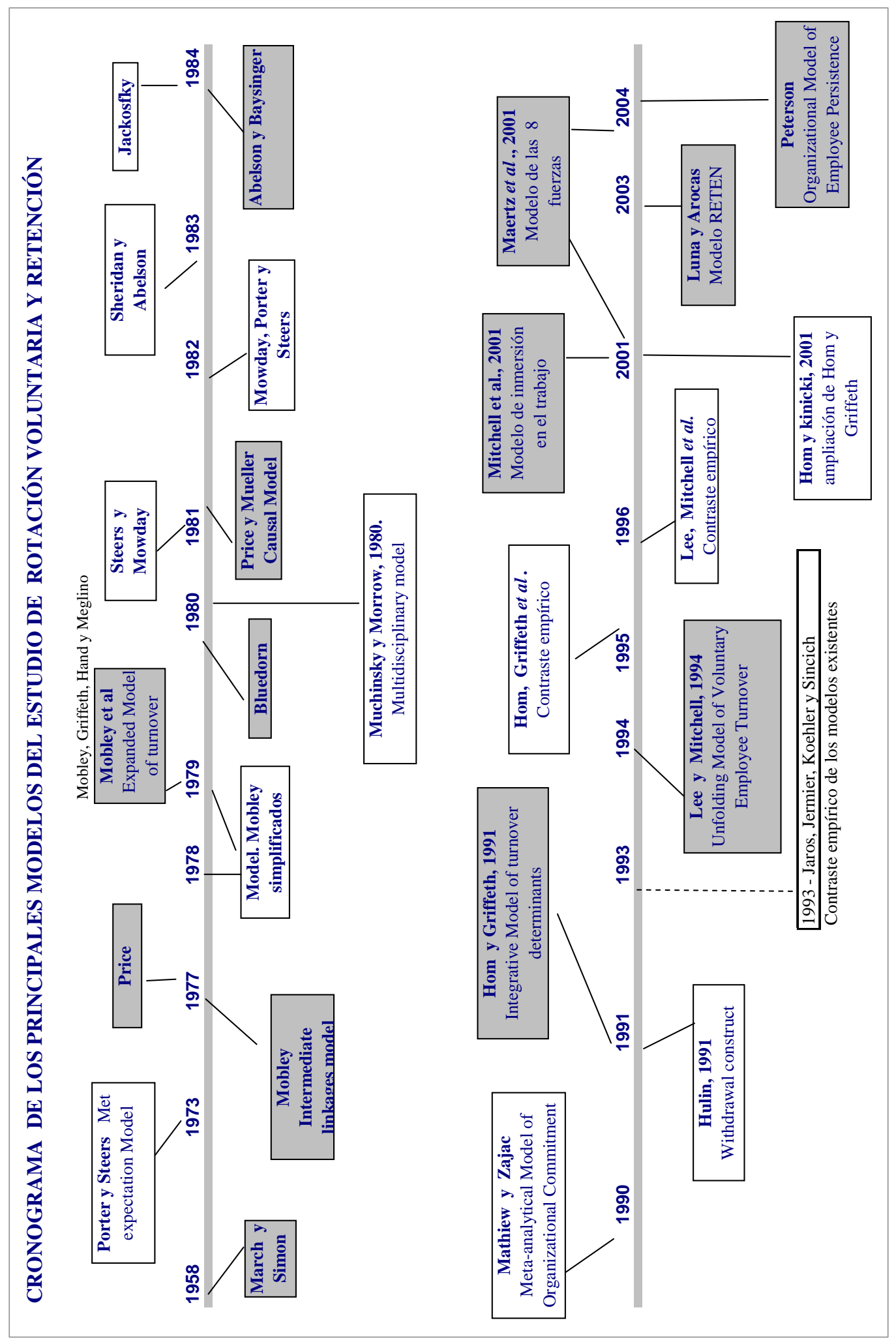


Figura A1.5. Modelo de March y Simon (1958)

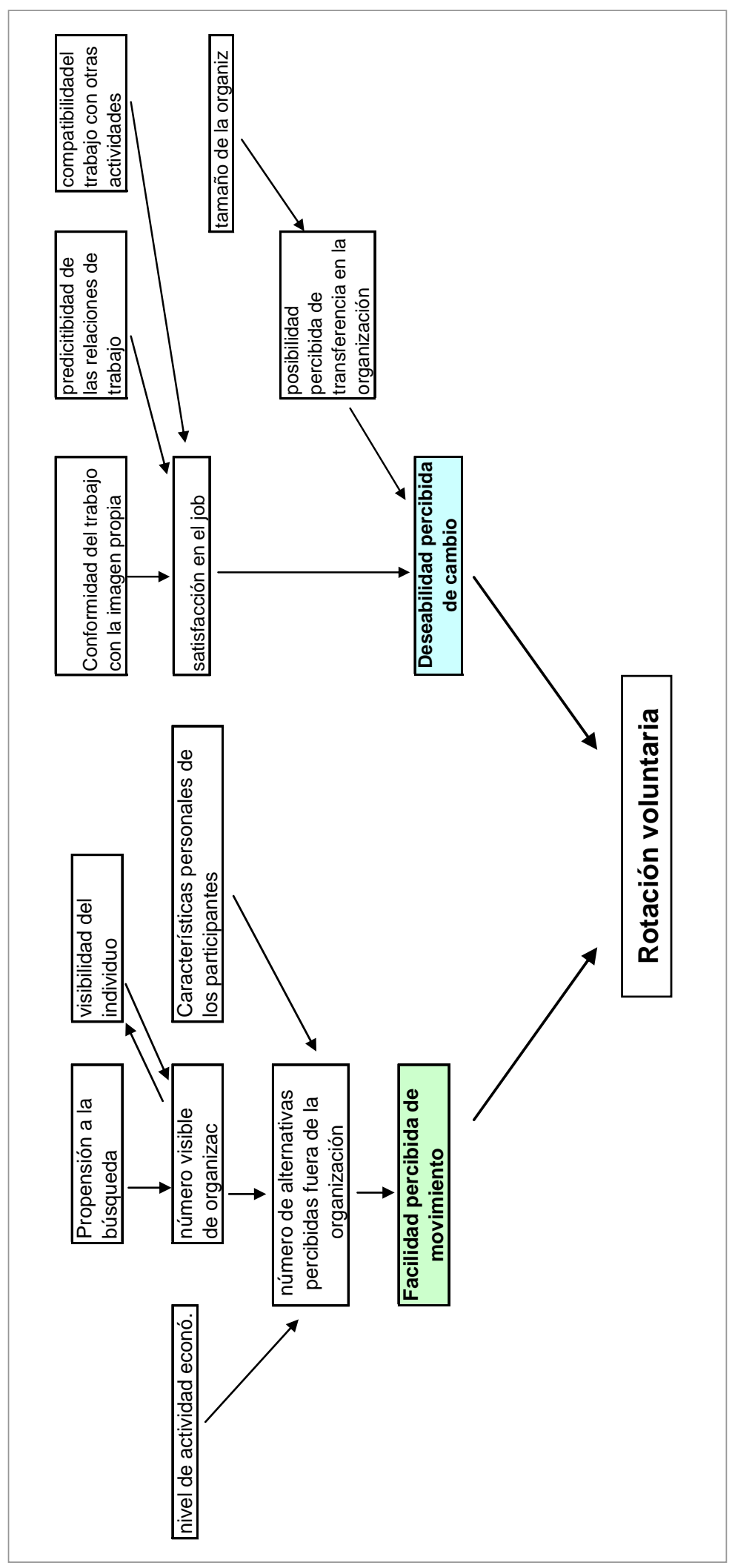


Figura A1.6. Modelo Integrativo de Rotación voluntaria (Hom y Griffeth , 1995)

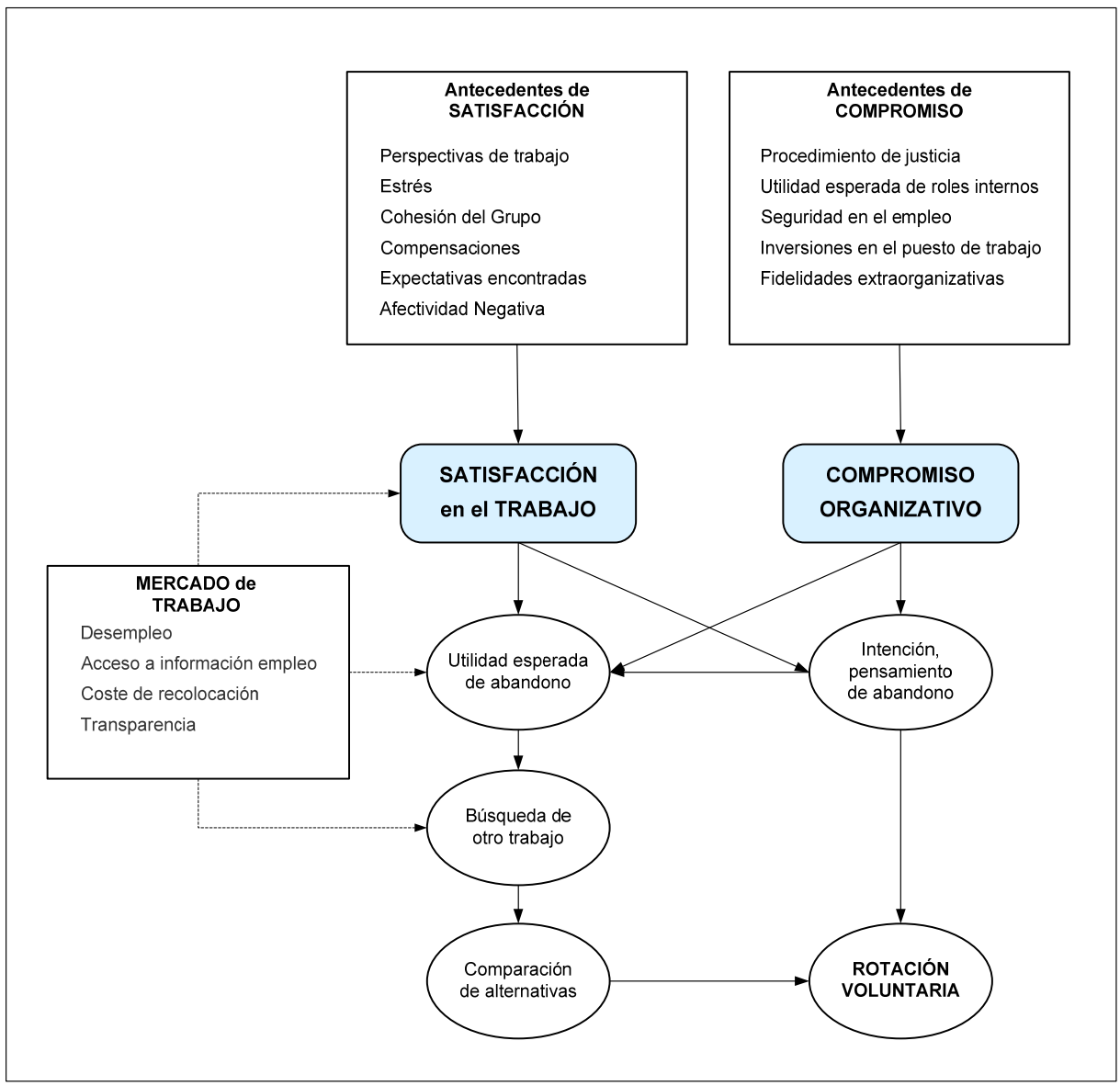

Fuente: adaptado de Hom y Griffeth (1995:108)

Figura A1.7. Modelo desplegado de rotación voluntaria. Lee y Mitchell (1994, 1996)

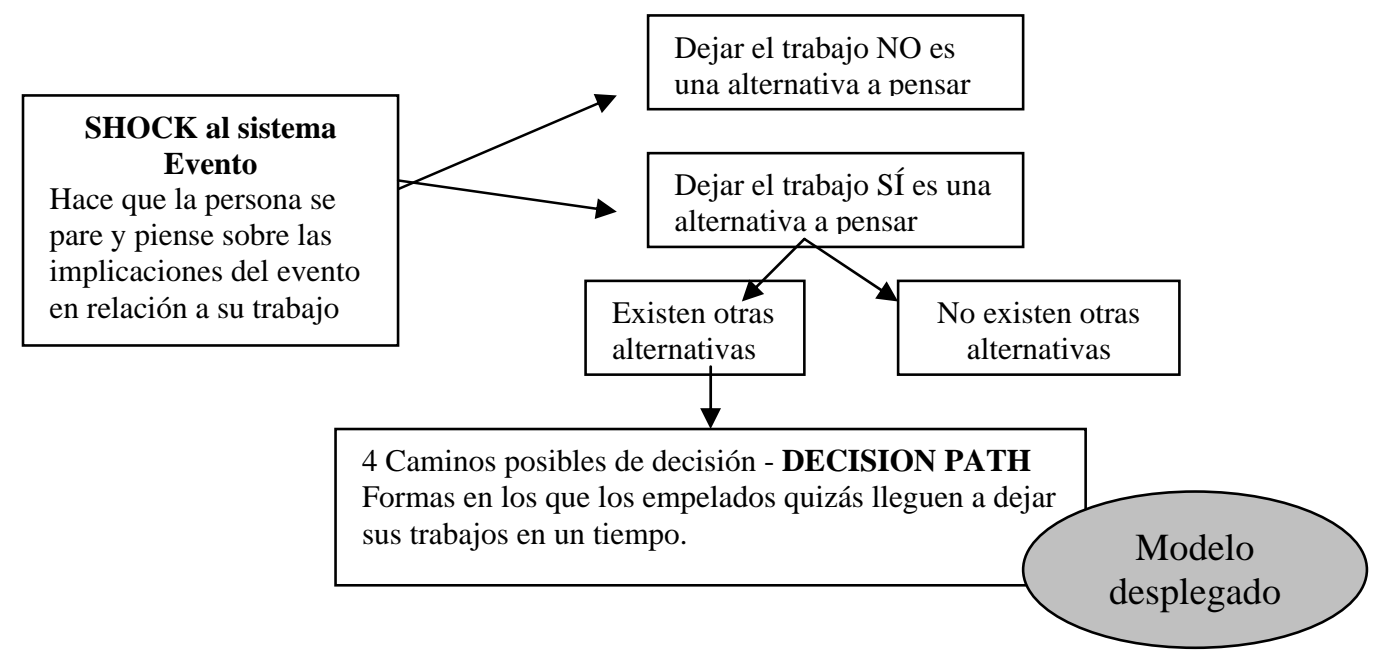




\section{PATHS O CAMINOS DE DECISIÓN PARA ABANDONAR VOLUNTARIAMENTE LA ORGANIZACIÓN}

\section{Decisión camino 1}

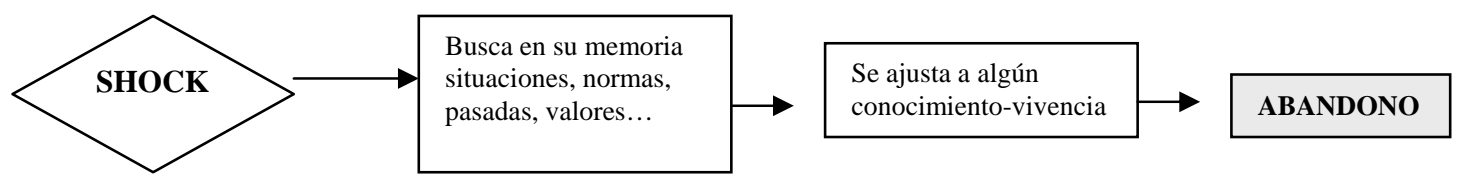

\section{Decisión camino 2}

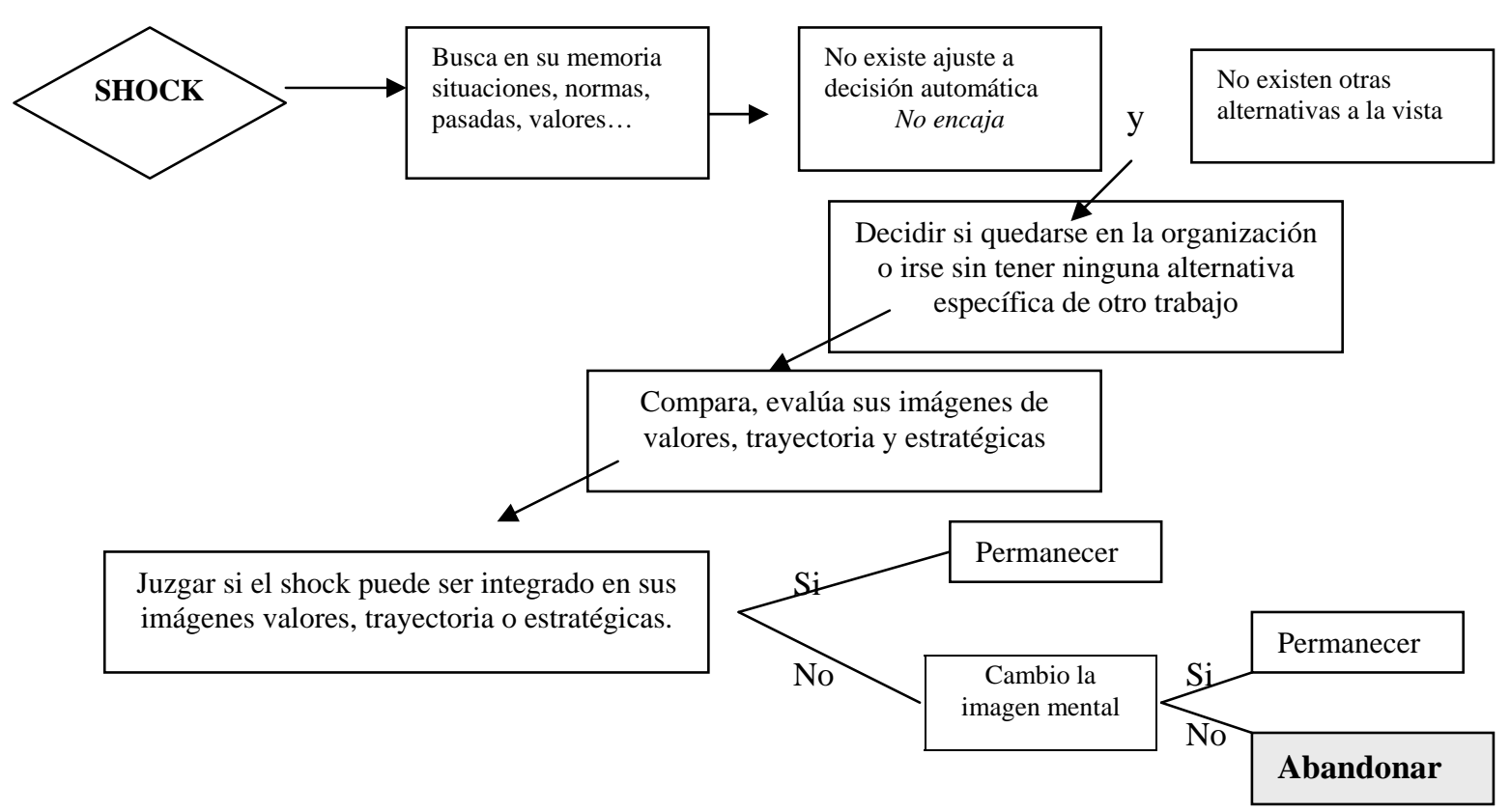

\section{Decisión camino 3:}

Elegir ¿quedarse en la compañía o irse a una alternativa de trabajo específica??

Se juzga si el shock escompatible con las

Imágenę de valores, trayectoria y estrategia
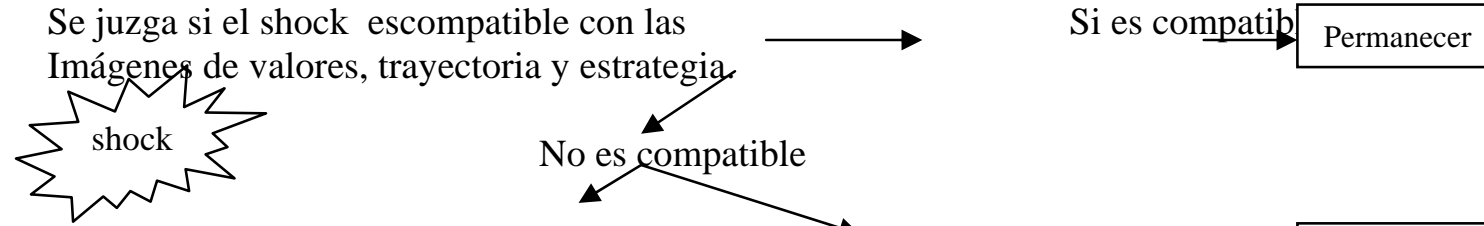

No campio la imagen<smiles></smiles>

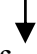

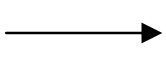

Si es compatib Permanecer

Insatisfacción laboral

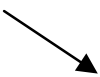


Búsqueda de alternativas laborales

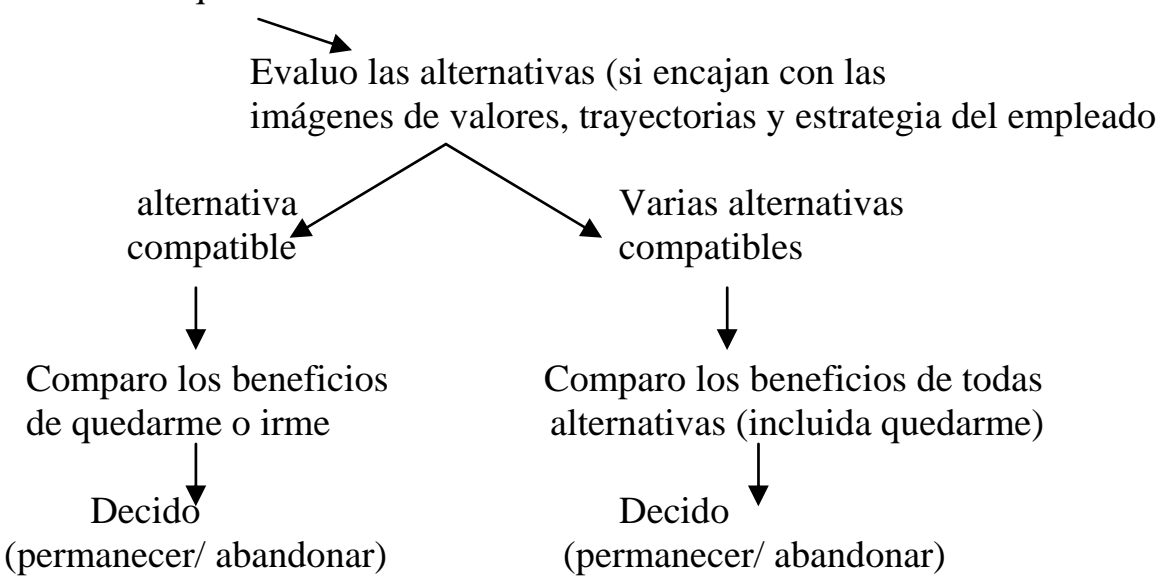

\section{Decisión camino 4:}

No existe ningún shock. Existen dos modos de comenzar:

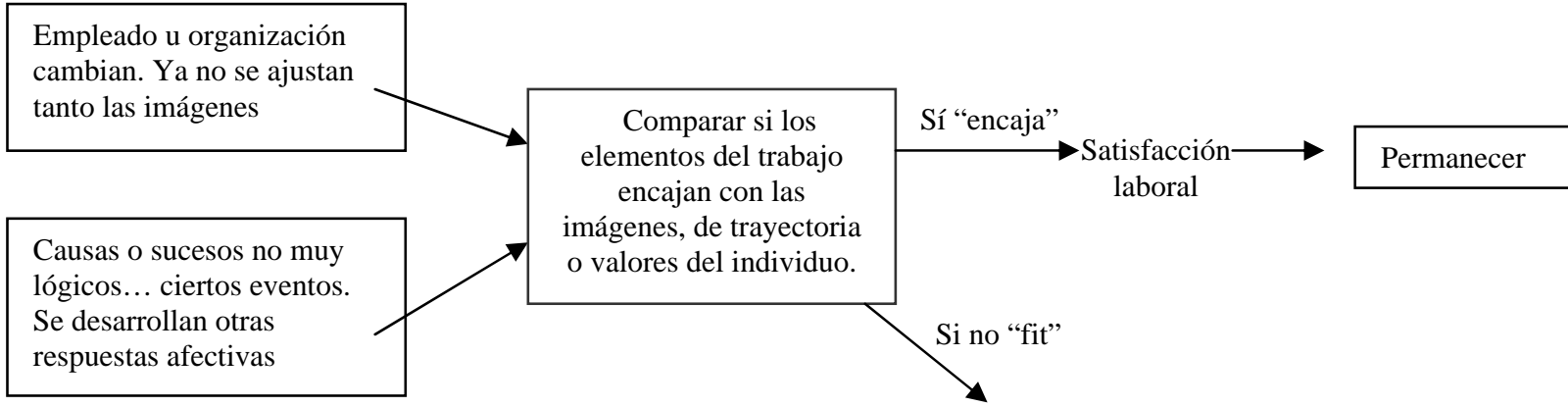

Insatisfacción laboral

Aplicar los Modelos de Mobley y Hom

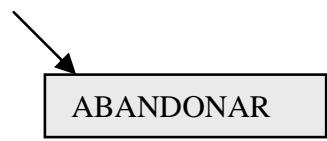


Figura A1.8. Modelo RETEN

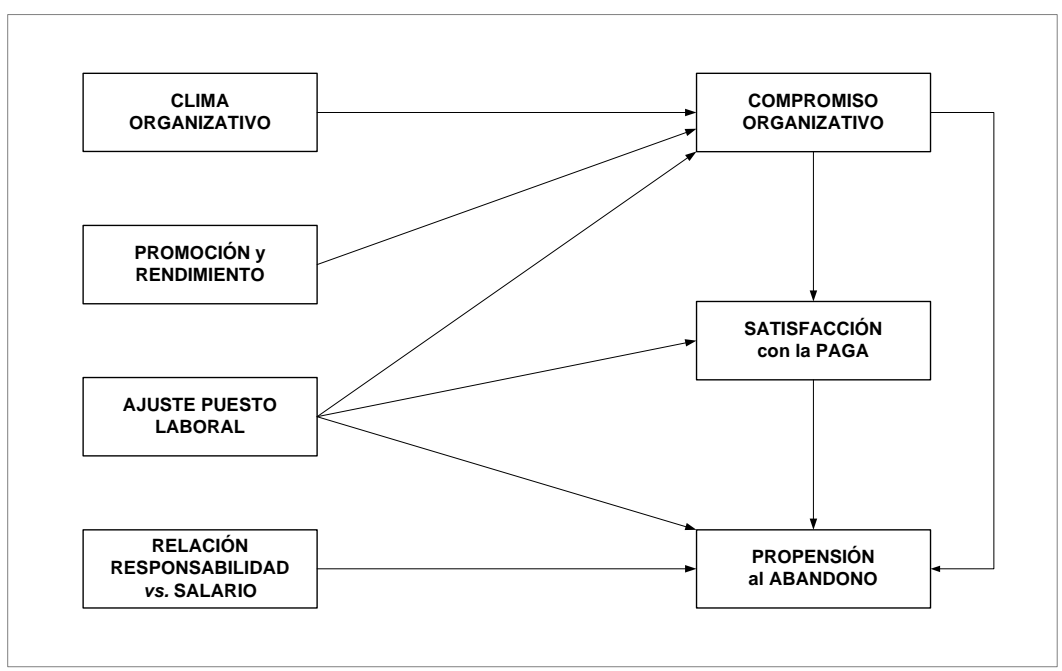

Fuente: Luna Arocas y Camps Torres (2003:14)

Figura A1.9

Modelo organizativo de persistencia del empleado de Peterson (2004)

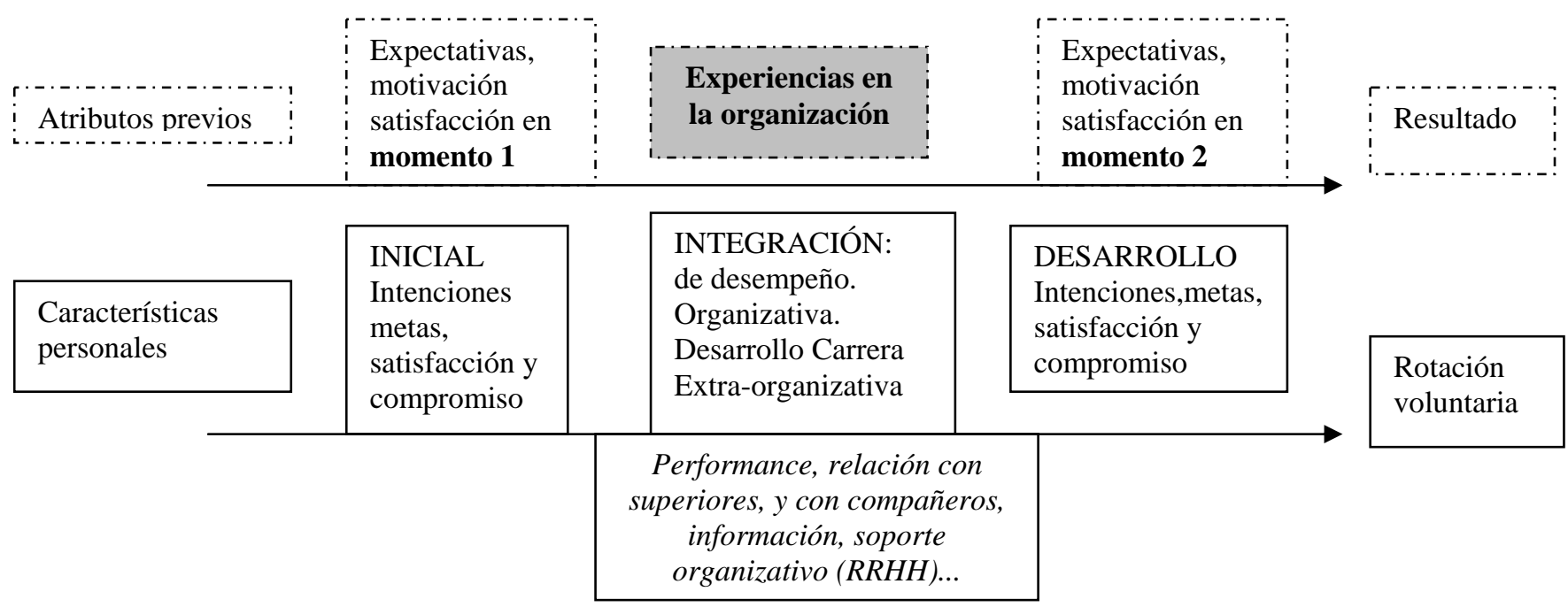

Fuente: Elaboración propia 
Figura A 1.10. Modelo básico de POS de Allen, Shore y Griffeth (2003)

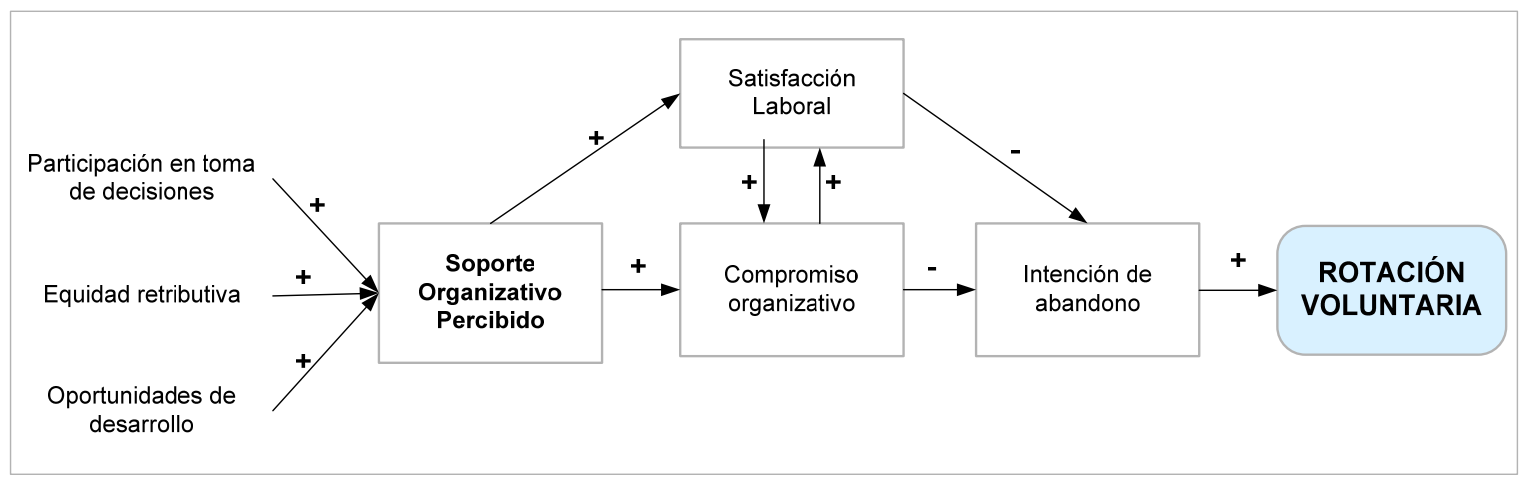

Fuente: Adaptado de Allen et al. (2003:101)

Figura A1.11. Modelo del sistema de retribución de Hom y Griffeth (1995)

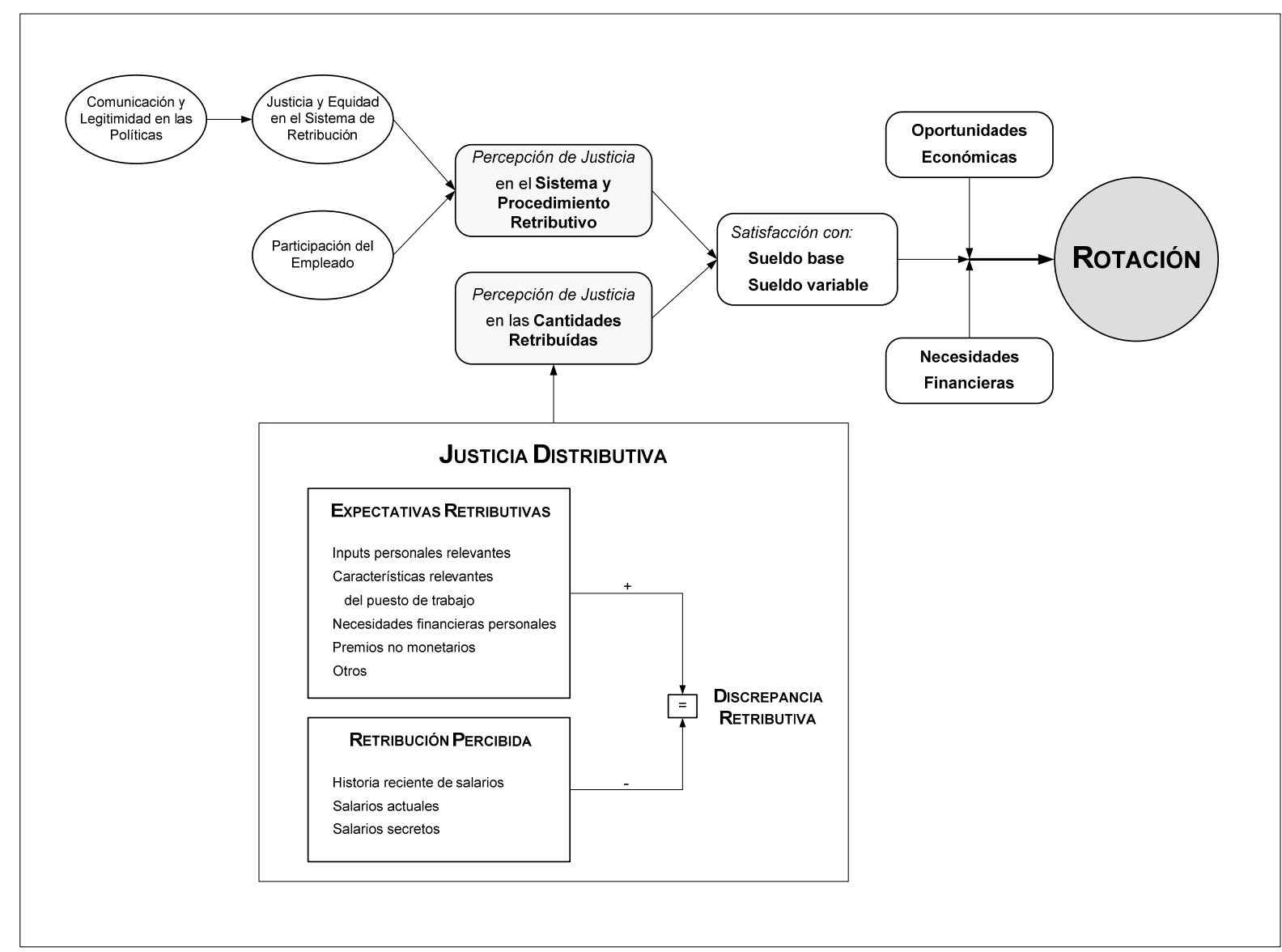

Fuente: adaptado de Hom y Griffeth (1995:224). 
Figura A1.12. Principales teorías psicológicas que contribuyen al estudio de la retención y de la rotación voluntaria

\begin{tabular}{|c|}
\hline Teorías psicológicas de motivación \\
\hline De contenido \\
\hline $\begin{array}{l}\text { Clásicas: Taylor, Relaciones Humanas de E. Mayo. } \\
\text { De Necesidades: McClelland (1962), White(1959), Maslow (1943), Herzberg (1968) }\end{array}$ \\
\hline De proceso \\
\hline $\begin{array}{l}\text { Teoría dela Equidad (Adams, 1963) } \\
\text { Teoría de las Expectativas (Vroom, 1964; Atkinson, 1964) } \\
\text { Teoría de la finalidad (Locke, 1968) } \\
\text { Teoría social cognitiva (Bandura, 1977) }\end{array}$ \\
\hline Teorías psicológicas de comportamiento \\
\hline $\begin{array}{l}\text { Teoría de la acción razonada (Fishbein y Ajzen, 1975, 1980) } \\
\text { Teoría del comportamiento planeado (Ajzen, 1991) } \\
\text { Teoría de la imagen (Beach, 1990) }\end{array}$ \\
\hline
\end{tabular}


ANEXO II 

Figura A2.1:

\section{Modelo de las Características del Puesto ${ }^{1}$ (MCP) de Hackman y Oldham (1980)}

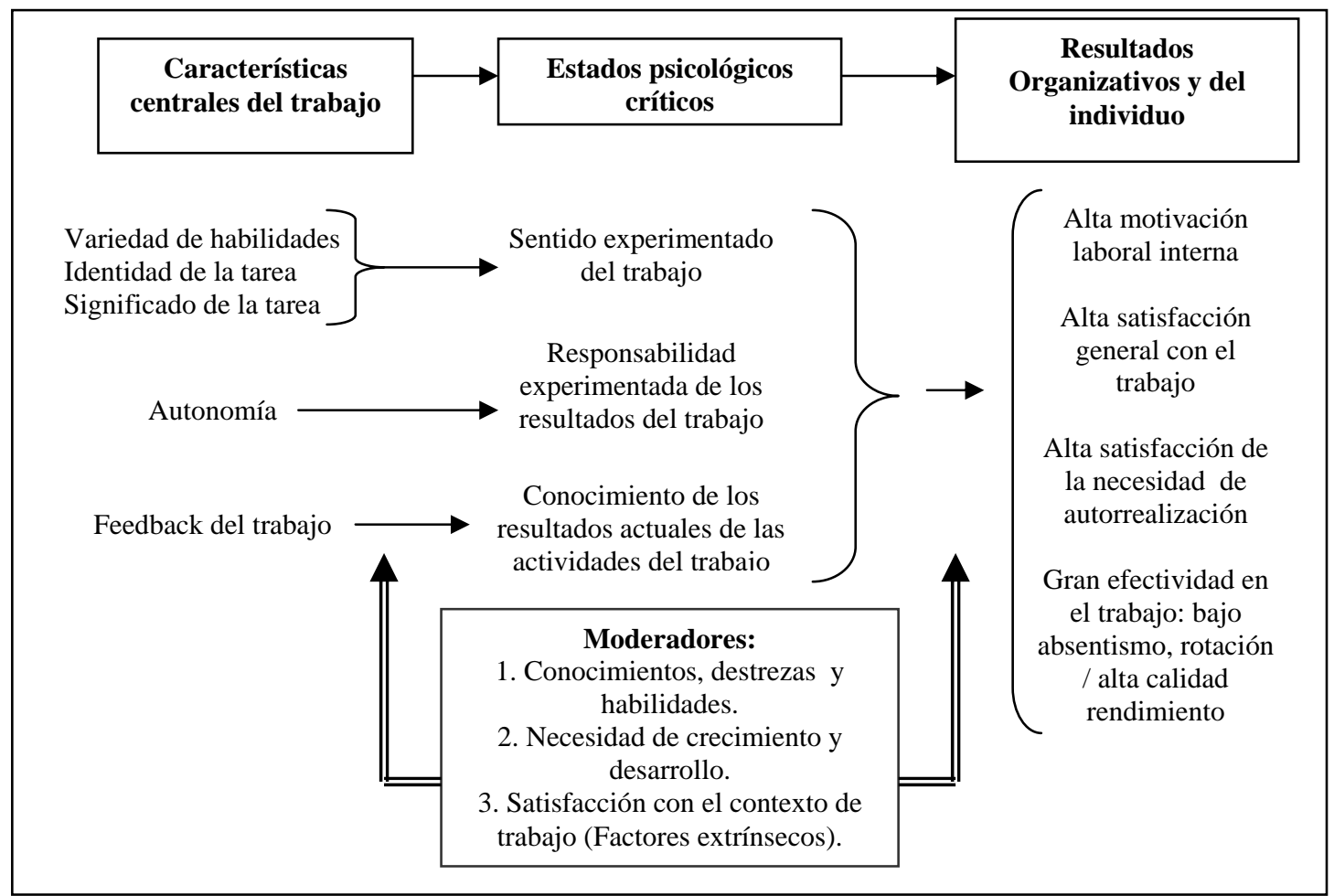

Fuente: adaptado de Hackman y Oldham (1980:92) y Fortea, Fuentes y Agost (1994:3)

${ }^{1}$ Job Characteristics Model. 
ANEXO III 



\section{A3.1. Carta de apoyo institucional a esta investigación}

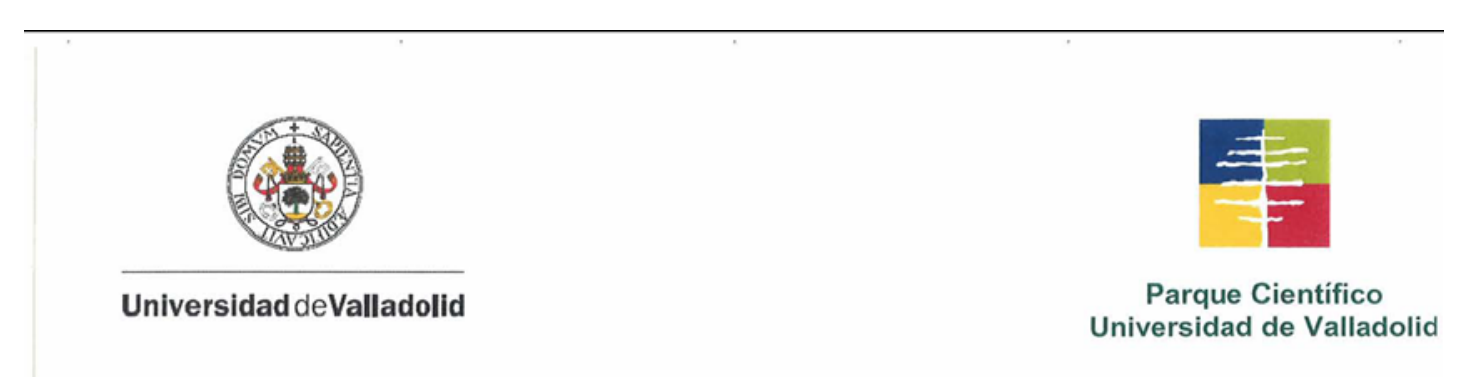

Por la presente, D. DANIEL MIGUEL SAN JOSE, Vicerrector de Desarrollo e Innovación de la Universidad de Valladolid y Director General de la Fundación Parque Científico Universidad de Valladolid, quiere comunicar que tiene constancia del trabajo de Tesis Doctoral de $D^{a}$ Celia Martín Sierra, en calidad de profesora ayudante del Departamento de Organización de Empresas y Comercialización e Investigación de Mercados, de la Facultad de Ciencias del Trabajo, perteneciente al Campus "La Yutera" de Palencia.

Dicho trabajo de Tesis Doctoral requiere el lanzamiento de un cuestionario, dirigido a empresas innovadoras con el objeto de analizar la retención y gestión del conocimiento en empresas altamente innovadoras y cómo favorecer la retención del capital humano estratégico de este tipo de empresas.

El trabajo está claramente alineado con las competencias que tiene concedidas mi Vicerrectorado, así como las atribuciones reservadas específicamente la Fundación Parque Científico Universidad de Valladolid que dirijo, y cuya misión principal es "potenciar la interacción entre la universidad y la sociedad, representada a través de las empresas, entidades públicas y privadas, y administraciones públicas...", esto es, ahondar en las potencialidades de la sociedad basada en la economía del conocimiento.

En consecuencia, se comunica que el Vicerrectorado de Desarrollo e Innovación de la Universidad de Valladolid, así como la Fundación Parque Científico UVA, tiene la voluntad de respaldar las actividades que se desempeñarán en este trabajo de Tesis Doctoral, especialmente en el lanzamiento del cuestionario dirigido a empresas innovadoras.

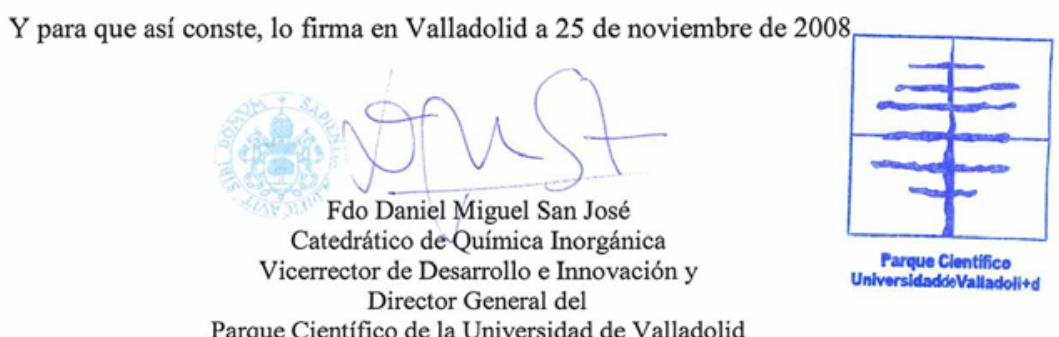




\section{A3.2. E-mail de envío del cuestionario}

\section{Att./Director de Recursos Humanos o Director Gerente}

Estimados Sres.:

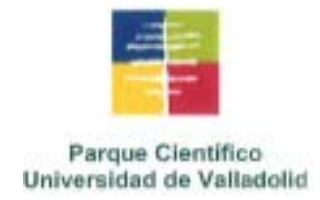

Les escribimos desde la Universidad de Valladolid, donde estamos realizando una investigación cuyo principal fin es estudiar cómo, a través de determinadas prácticas de recursos humanos, se puede favorecer la retención de conocimiento y empleados estratégicos en empresas innovadoras. Dicha investigación está avalada por el Vicerrectorado de Desarrollo e Innovación y la Fundación Parque Científico UVA. La mencionada investigación, que no tiene fines lucrativos o comerciales, se plasmará en la tesis doctoral de la profesora Celia Martín Sierra, miembro del Departamento de Organización de Empresas y CIM.

Como parte fundamental de la investigación hemos seleccionado su empresa, por ser altamente innovadora y haber recibido financiación para la innovación del CDTI en los últimos años. Esto nos lleva a solicitar su colaboración en la cumplimentación de un cuestionario que le requerirá poco tiempo (de 8 a 10 minutos) y que pueden contestar de uno de los dos modos siguientes, según les sea más cómodo:

- Vía web, en la siguiente dirección: http://uva.net63.net

- Por correo postal, pues también recibirá por esta vía el cuestionario junto con un sobre y sello para facilitar el envío, en los próximos días.

Confiamos en que su ayuda nos permita identificar las prácticas que las empresas innovadoras están aplicando en esta temática y, con ello, contribuir a mejorar la competitividad empresarial. Agradeciéndole de antemano su colaboración, nos ofrecemos para aclarar cualquier cuestión relacionada con la investigación y nos comprometemos a enviarle un informe con los principales resultados del estudio, si así lo desea.

Reciba un cordial y afectuoso saludo,

Celia Martín Sierra

Prof. Ayudante

Dpto. Organización de Empresas y CIM

Facultad de Ciencias del Trabajo

Campus La Yutera - Palencia 34004

Universidad de Valladolid

tfno. 979.108114 - 983.184560

celiams@eco.uva.es 


\section{A3.3. Cuestionario de esta investigación.}

Dpto. Organización de Empresas y Comercialización e Investigación de Mercados

\section{RETENCIÓN DE EMPLEADOS ESTRÁTEGICOS}

\section{CONSIDERACIONES PREVIAS PARA RESPONDER AL CUESTIONARIO}

\section{Contexto de la} investigación

Objetivo de la Investigación

¿Quién debería cumplimentar este cuestionario?

¿A qué tipo de empleados se refiere el cuestionario?
Este cuestionario forma parte de una tesis doctoral que investiga la retención de empleados estratégicos en empresas innovadoras. Con este fin, se busca esta colaboración empresa-universidad.

Analizar la influencia de diversas prácticas de recursos humanos en la retención de empleados estratégicos, junto con su impacto en los resultados empresariales, en particular, sobre la capacidad de innovación.

La persona Responsable de Recursos Humanos o, en su defecto, el Director Gerente de la empresa.

Todas las preguntas se refieren exclusivamente a empleados considerados estratégicos y valiosos para la empresa.

Toda la información proporcionada tiene carácter anónimo.

El equipo de investigación garantiza su compromiso de total confidencialidad.

Se entregará un informe con los principales resultados a las empresas colaboradoras que lo indiquen.

\section{Celia Martín Sierra}

Departamento de Organización de Empresas y C.I.M.

Contacto del equipo Facultad de Ciencias del Trabajo (Universidad de Valladolid) investigador

Avda. Madrid, 4434004 Palencia

Tlfn. 983.184560 ó 979.108114/ Fax 983.423899

celiams@eco.uva.es
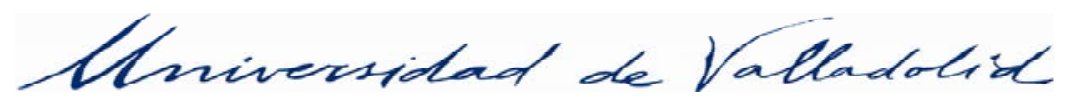
I. DATOS GENERALES DE LA EMPRESA

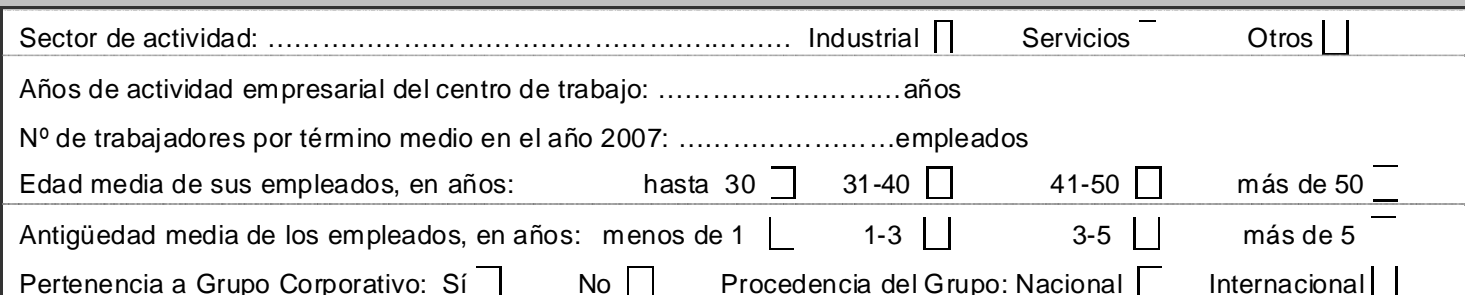

\section{PRÁCTICAS DE DIRECCIÓN DE RECURSOS HUMANOS}

Todas las preguntas se refieren a los empleados considerados estratégicos para su empresa. Valore las siguientes proposiciones marcando el valor apropiado según la escala propuesta, donde 1 refleja el valor mínimo y 5 refleja el valor máximo.

Respecto a los PUESTOS DE TRABAJO, en esta empresa: 1:Total desacuerdo/nunca, 5:Total acuerdo/siempre

\begin{tabular}{|c|c|c|c|c|}
\hline Plantean retos a los empleados & 12 & 3 & 4 & 5 \\
\hline Ofrecen libertad y autonomía al empleado para planificar su trabajo y actividades & 1 & 3 & 4 & 5 \\
\hline Contienen tareas y actividades heterogéneas (no repetitivas) & 12 & 3 & 4 & 5 \\
\hline Requieren que el empleado utilice habilidades y conocimientos complejos y cualificados & 12 & 3 & 4 & 5 \\
\hline
\end{tabular}

Respecto al SISTEMA DE COMPENSACIÓN, esta empresa:

\begin{tabular}{|c|c|c|c|c|c|}
\hline Ofrece un nivel retributivo superior al de la competencia & 1 & & 3 & 4 & 5 \\
\hline Mantiene la equidad retributiva entre puestos o categorías similares & 1 & 2 & 3 & 4 & 5 \\
\hline Incluye una componente de incentivo basada en el desempeño individual de los empleados & 1 & 2 & 3 & 4 & 5 \\
\hline Incluye una componente de incentivo basada en el desempeño del grupo de trabajo & 1 & 2 & 3 & 4 & 5 \\
\hline $\begin{array}{l}\text { Incluye una componente de incentivo basada en el resultado anual de la empresa (reparto de } \\
\text { beneficios, etc.) }\end{array}$ & 1 & 2 & 3 & 4 & 5 \\
\hline $\begin{array}{l}\text { Incluye una componente de incentivo a largo plazo (compra de acciones, reparto de bonus sobre } \\
\text { una base plurianual, etc.) }\end{array}$ & 1 & 2 & 3 & 4 & 5 \\
\hline Incluye un paquete de beneficios sociales para los empleados (s & & 2 & 3 & 4 & 5 \\
\hline
\end{tabular}

Respecto al DESARROLLO de los empleados, esta empresa:

\begin{tabular}{|l|l|l|l|l|l|l|l|l|}
\hline Ofrece un programa de acogida que incluye formación inicial para los nuevos empleados & $\mathbf{2}$ & $\mathbf{3}$ & $\mathbf{5}$ \\
\hline $\begin{array}{l}\text { Ofrece actividades de formación orientadas al desarrollo de conocimientos y habilidades específicos } \\
\text { de esta em presa }\end{array}$ & $\mathbf{1}$ & $\mathbf{2}$ & $\mathbf{4}$ & $\mathbf{5}$ \\
Ofrece una formación amplia e interdisciplinar & $\mathbf{1}$ & $\mathbf{2}$ & $\mathbf{4}$ & $\mathbf{5}$ \\
\hline Ofrece formación para adquirir habilidades de trabajo en equipo y de relaciones interpersonales & $\mathbf{1}$ & $\mathbf{2}$ & $\mathbf{3}$ & $\mathbf{4}$ \\
\hline Ofrece formación orientada al desarrollo de carrera profesional & $\mathbf{1}$ & $\mathbf{2}$ & $\mathbf{3}$ & $\mathbf{4}$ & $\mathbf{5}$ \\
\hline $\begin{array}{l}\text { Ofrece a sus empleados oportunidades de promoción } \\
\text { Ofrece un sistema de promoción basado en el desempeño }\end{array}$ & $\mathbf{1}$ & $\mathbf{2}$ & $\mathbf{3}$ & $\mathbf{4}$ \\
Tiene definido un sistema formal de desarrollo de carrera profesional & $\mathbf{1}$ & $\mathbf{2}$ & $\mathbf{3}$ & $\mathbf{4}$ & $\mathbf{5}$ \\
\hline
\end{tabular}

Respecto a la CONCILIACIÓN DE LA VIDA LABORAL-PERSONAL, esta empresa:

Ofrece flexibilidad a los empleados para que elijan y distribuyan su horario de trabajo

Ofrece facilidades para atender las necesidades de la familia u otros asuntos personales (reducción de jornada, teletrabajo, excedencias, permisos para formación, etc.)

Ofrece ayudas económicas para las necesidades personales de sus empleados (préstamos, ayudas para guardería, etc.)

Tiene un plan específico de conciliación de la vida laboral-personal

\begin{tabular}{|ll|l|l|l|}
1 & 2 & 3 & 4 & 5 \\
1 & 2 & 3 & 4 & 5 \\
1 & 2 & 3 & 4 & 5 \\
1 & 2 & 3 & 4 & 5
\end{tabular}


Respecto al LIDERAZGO, los mandos de esta empresa:

1: Total desacuerdo, 5: Total acuerdo

Son generalmente accesibles para los empleados

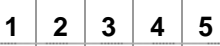

Muestran interés por el desarrollo y crecimiento profesional de los empleados a su cargo

$\begin{array}{llllll}1 & 2 & 3 & 4 & 5\end{array}$

Atienden los problemas y necesidades de sus empleados

Reconocen los méritos y logros de los empleados que tienen a su cargo

Respecto a la COMUNICACIÓN INTERNA, los empleados de esta empresa:

Reciben regularmente información sobre aspectos clave de la empresa (objetivos, estrategias, resultados financieros, etc.)

$\begin{array}{llllll}1 & 2 & 3 & 4 & 5\end{array}$

Disponen de canales de comunicación entre distintos departamentos, unidades o secciones para resolver problemas y buscar soluciones

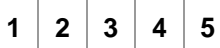

Disponen de medios diversos de comunicación interna (intranet, revista de empresa, tablones de anuncios, etc.)

Disponen de facilidades para comunicarse con sus superiores y/o directores

Respecto a la PARTICIPACIÓN, los empleados de esta empresa:

Son requeridos y se valora su opinión para tomar algunas decisiones

Tienen la posibilidad de sugerir mejoras relacionadas con su trabajo

Pueden sugerir mejoras relacionadas con su empresa, por ejemplo, a través de un sistema de sugerencias y reclamaciones

Participan formalmente en grupos de mejora de calidad, grupos de resolución de problemas, etc.

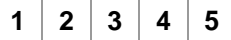

\begin{tabular}{l|l|l|l|l|}
1 & 2 & 3 & 4 & 5
\end{tabular}

$\begin{array}{llllll}1 & 2 & 3 & 4 & 5\end{array}$

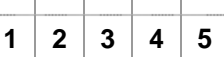

Respecto a las RELACIONES ENTRE COMPAÑEROS, en esta empresa:

Se promueven actividades fuera del trabajo en las que los empleados pueden relacionarse

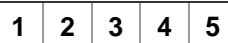

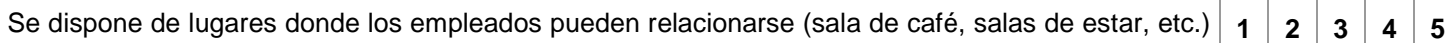
y/o de instalaciones de ocio (instalaciones deportivas, etc.)

Los empleados saben que pueden dedicar tiempo, atención y ayuda a sus compañeros

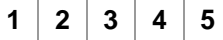

Se fomentan acciones que favorezcan el compañerismo

\begin{tabular}{l|l|l|l|l}
1 & 2 & 3 & 4 & 5
\end{tabular}

\section{RETENCIÓN Y DESARROLLO DEL CAPITAL ESTRATÉGICO}

Nuevamente, en relación con los empleados considerados estratégicos para su empresa, valore el grado de acuerdo o desacuerdo con las siguientes proposiciones en una escala de 1 a 5.

Esta empresa logra mantener de forma estable a los empleados:

1: Total desacuerdo, 5: Total acuerdo

\begin{tabular}{|l}
\hline Altamente cualificados \\
\hline Considerados como "los mejores" en nuestro sector \\
\hline Creativos y brillantes \\
\hline Expertos y/o competentes en sus trabajos y funciones \\
\hline Que desarrollan nuevas ideas y conocimiento
\end{tabular}

\begin{tabular}{l|l|l|l|l|}
1 & 2 & 3 & 4 & 5
\end{tabular}

$\begin{array}{llllll}1 & 2 & 3 & 4 & 5\end{array}$

$\begin{array}{llllll}1 & 2 & 3 & 4 & 5\end{array}$

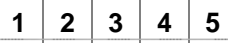

En esta empresa es habitual que los empleados:

Combinen e intercambien conocimiento para resolver problemas o crear oportunidades

$\begin{array}{lllll}1 & 2 & 3 & 4 & 5\end{array}$

Compartan sus propias ideas para presentar o proponer nuevas ideas, productos o servicios

Colaboren entre ellos para diagnosticar y resolver problemas

Compartan información y aprendan unos de otros

Interaccionen e intercambien ideas con personal de otras áreas de la empresa

\begin{tabular}{l|l|l|l|l|}
1 & 2 & 3 & 4 & 5
\end{tabular}

Apliquen el conocimiento de un área de la empresa para resolver problemas que surjan en otras

\begin{tabular}{lll|l|l|}
1 & 2 & 3 & 4 & 5
\end{tabular}

\begin{tabular}{l|l|l|l|l|}
1 & 2 & 3 & 4 & 5
\end{tabular}

\begin{tabular}{l|l|l|l|l|}
1 & 2 & 3 & 4 & 5
\end{tabular}

\begin{tabular}{|l|l|l|l|l|}
1 & 2 & 3 & 4 & 5
\end{tabular}

\begin{tabular}{l|l|l|l|l|}
1 & 2 & 3 & 4 & 5
\end{tabular} 
Respecto a la AFECTIVIDAD, los empleados de esta empresa:

1: Total desacuerdo, 5: Total acuerdo Tienen un fuerte sentimiento de pertenencia a esta empresa

Consideran que la empresa tiene un gran sentido y valor personal para ellos

Consideran como propios los problemas de la empresa

Consideran que la empresa los trata de forma justa

Consideran que la empresa es honesta y sincera con ellos y pueden confiar en ella

\begin{tabular}{lll|l|l|}
1 & 2 & 3 & 4 & 5
\end{tabular}

$\begin{array}{llllll}1 & 2 & 3 & 4 & 5\end{array}$

Consideran que hay coherencia entre lo que la empresa "dice" y "hace"

\section{RESULTADOS}

Este último bloque se refiere a los resultados de la EMPRESA. Indique su grado de acuerdo o desacuerdo con las siguientes proposiciones según la escala de 1 a 5.

Respecto a la CAPACIDAD DE INNOVACIÓN, esta EMPRESA:

1: Total desacuerdo, 5: Total acuerdo

Pone en práctica nuevas ideas frecuentemente

Busca nuevas formas de hacer las cosas

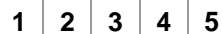

Es creativa en los métodos y procesos de trabajo

$\begin{array}{llllll}1 & 2 & 3 & 4 & 5\end{array}$

Suele ser pionera en lanzar nuevos productos y servicios al mercado

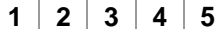

Percibe la innovación como arriesgada y tiende a la evitarla

Ha incrementado la introducción en el mercado de nuevos productos/servicios en los últimos 5 años

Respecto a los RESULTADOS de las PERSONAS, en los ÚLTIMOS 5 AÑOS esta empresa:

Ha incrementado el grado de satisfacción laboral (resultados de encuesta de clima, etc.)

Ha incrementado el grado medio de desempeño de los empleados (productividad, etc.)

Ha disminuido la tasa de abandono voluntario de los empleados

$\begin{array}{llllll}1 & 2 & 3 & 4 & 5\end{array}$

$\begin{array}{lllll}1 & 2 & 3 & 4 & 5\end{array}$

\begin{tabular}{lll|l|l}
1 & 2 & 3 & 4 & 5
\end{tabular}

Ha disminuido la tasa de absentismo labora

\begin{tabular}{|l|l|l|l|l|}
\hline 1 & 2 & 3 & 4 & 5 \\
\hline 1 & 2 & 3 & 4 & 5 \\
\hline 1 & 2 & 3 & 4 & 5 \\
\hline 1 & 2 & 3 & 4 & 5 \\
\hline
\end{tabular}

A continuación valore la posición de su empresa en relación con resto de empresas de su sector, según la escala: 1: Muy por debajo del valor medio de la competencia, 5: Muy por encima del valor medio de la competencia.

Respecto a los RESULTADOS EMPRESARIALES, en los ÚLTIMOS 5 AÑOS esta empresa:

\begin{tabular}{|c|c|c|c|c|c|}
\hline Ha incrementado sus ventas & 1 & 2 & 3 & 4 & 5 \\
\hline Ha mejorado su posición competitiva (cuota de mercado) & 1 & 2 & 3 & 4 & 5 \\
\hline Ha mejorado su rentabilidad (económica) & 1 & 2 & 3 & 4 & 5 \\
\hline Ha incrementado el número de innovaciones llevadas a cabo & 1 & 2 & 3 & 4 & 5 \\
\hline Ha incrementado el esfuerzo que hace por innovar (gastos, horas/persona y equipo, formació & 1 & 2 & 3 & 4 & 5 \\
\hline
\end{tabular}

\section{GRACIAS POR SU COLABORACIÓN !}

Si considera que los resultados de esta investigación pueden ser de interés para su empresa, por favor rellene los siguientes datos y le será remitido un informe-resumen con los principales resultados alcanzados.

Nombre de la empresa

E-mail de contacto

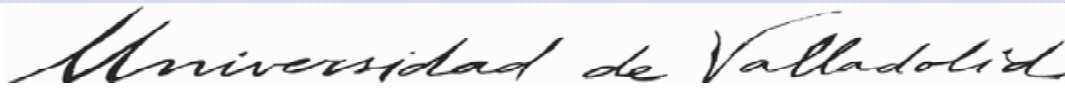


ANEXO IV 



\section{A4.1.- Tablas de análisis de multicolinealidad de los índices formativos depurados}

Tablas A4.1.1.- Diseño de puesto

\begin{tabular}{|c|c|c|c|c|}
\hline \multicolumn{2}{|c|}{$\begin{array}{c}\text { DISEÑO DE PUESTO } \\
\text { correlaciones }\end{array}$} & $\begin{array}{l}\text { Ptrab2 } \\
\text { autonomia }\end{array}$ & $\begin{array}{l}\text { Ptrab1 } \\
\text { retador }\end{array}$ & $\begin{array}{c}\text { Ptrab4 cualifc } \\
\text { variada y amplia }\end{array}$ \\
\hline Ptrab2 autonomia & $\begin{array}{l}\text { Correlación de Pearson } \\
\text { Sig. (bilateral) } \\
\mathrm{N}\end{array}$ & 239 & $\begin{array}{r}, 281(* *) \\
, 000 \\
239\end{array}$ & $\begin{array}{r}, 312(* *) \\
, 000 \\
239\end{array}$ \\
\hline Ptrab1 retador & $\begin{array}{l}\text { Correlación de Pearson } \\
\text { Sig. (bilateral) } \\
\text { N }\end{array}$ & $\begin{array}{r}, 281(* *) \\
, 000 \\
239\end{array}$ & 239 & $\begin{array}{r}, 346(* *) \\
, 000 \\
239\end{array}$ \\
\hline $\begin{array}{l}\text { Ptrab4 cualifc variada } \\
\text { y amplia }\end{array}$ & $\begin{array}{l}\text { Correlación de Pearson } \\
\text { Sig. (bilateral) } \\
\mathrm{N}\end{array}$ & $\begin{array}{r}, 312(* *) \\
, 000 \\
239\end{array}$ & $\begin{array}{r}, 346(* *) \\
, 000 \\
239\end{array}$ & 1 \\
\hline
\end{tabular}

** La correlación es significativa al nivel 0,01 (bilateral).

Coeficientes $^{\mathrm{a}}$

\begin{tabular}{|c|c|c|c|c|c|c|c|c|}
\hline \multirow{2}{*}{\multicolumn{2}{|c|}{ Modelo }} & \multicolumn{2}{|c|}{$\begin{array}{l}\text { Coeficientes no } \\
\text { estandarizados }\end{array}$} & \multirow{2}{*}{$\begin{array}{c}\text { Coeficientes } \\
\text { estandarizad } \\
\text { os }\end{array}$} & \multirow[b]{2}{*}{$\mathrm{t}$} & \multirow[b]{2}{*}{ Sig. } & \multicolumn{2}{|c|}{$\begin{array}{l}\text { Estadísticos de } \\
\text { colinealidad }\end{array}$} \\
\hline & & $\mathrm{B}$ & Error típ. & & & & Tolerancia & FIV \\
\hline & (Constante) & 2,137 & ,346 & & 6,172 & ,000 & & \\
\hline & Ptrab1 retador & ,223 & ,072 & ,208 & 3,089 & ,002 & ,847 & 1,181 \\
\hline & Ptrab2 autonomia &,- 003 & ,072 &,- 003 &,- 040 & ,968 & ,869 & 1,151 \\
\hline & $\begin{array}{l}\text { Ptrab4 cualifc } \\
\text { variada y amplia }\end{array}$ & ,188 & 071 & ,180 & 2,644 & ,009 & ,830 & 1,205 \\
\hline
\end{tabular}

a. Variable dependiente: RetCapH2 mantener a los mejores de sector

\section{Diagnósticos de colinealidad}

\begin{tabular}{|c|c|c|c|c|c|c|}
\hline \multirow[b]{2}{*}{ Modelo } & \multirow[b]{2}{*}{ Dimensión } & \multirow[b]{2}{*}{ Autovalor } & \multirow[b]{2}{*}{$\begin{array}{l}\text { Indice de } \\
\text { condición }\end{array}$} & \multicolumn{3}{|c|}{ Proporciones de la varianza } \\
\hline & & & & (Constante) & $\begin{array}{c}\text { Conci3 } \\
\text { ayudas } \\
\text { económicas }\end{array}$ & $\begin{array}{c}\text { Conci1 } \\
\text { MASConci2 }\end{array}$ \\
\hline 1 & 1 & 2,817 & 1,000 & ,01 & ,02 & ,01 \\
\hline & 2 & 141 & 4,475 & ,06 & ,95 & 13 \\
\hline & 3 & ,042 & 8,150 & ,94 & ,03 & ,86 \\
\hline
\end{tabular}

a. Variable dependiente: RetCapH2 mantener a los mejores de sector 
Tablas A4.1.2.- Retribución

\begin{tabular}{|c|c|c|c|c|c|}
\hline \multicolumn{2}{|c|}{$\begin{array}{c}\text { SISTEMA DE } \\
\text { RETRIBUCIÓN Correlaciones }\end{array}$} & \multirow{2}{*}{$\begin{array}{c}\begin{array}{c}\text { Retrib1 sal } \\
\text { superior } \\
\text { competencia }\end{array} \\
\end{array}$} & \multirow{2}{*}{$\begin{array}{l}\begin{array}{l}\text { Retrib2 } \\
\text { equidad } \\
\text { retrib } \\
\text { interna }\end{array} \\
, 248(* *)\end{array}$} & \multirow{2}{*}{$\begin{array}{c}\begin{array}{c}\text { Retrib4 } \\
\text { incentivo } \\
\text { desemp } \\
\text { grupo }\end{array} \\
, 204(* *)\end{array}$} & \multirow{2}{*}{$\begin{array}{c}\begin{array}{c}\text { Retrib7 } \\
\text { beneficios } \\
\text { sociales }\end{array} \\
, 196(* *)\end{array}$} \\
\hline $\begin{array}{l}\text { Retrib1 sal } \\
\text { superior } \\
\text { competencia }\end{array}$ & $\begin{array}{l}\text { Correlación de } \\
\text { Pearson } \\
\text { Sig. (bilateral) } \\
\text { N }\end{array}$ & & & & \\
\hline $\begin{array}{l}\text { Retrib2 equidad } \\
\text { retrib interna }\end{array}$ & $\begin{array}{l}\text { Correlación de } \\
\text { Pearson } \\
\text { Sig. (bilateral) } \\
\text { N }\end{array}$ & $\begin{array}{r}, 248(* *) \\
, 000 \\
238\end{array}$ & 238 & $\begin{array}{r}, 228(* *) \\
, 000 \\
238\end{array}$ & $\begin{array}{r}, 220(* *) \\
, 001 \\
238\end{array}$ \\
\hline $\begin{array}{l}\text { Retrib4 } \\
\text { incentivo } \\
\text { desemp grupo }\end{array}$ & $\begin{array}{l}\text { Correlación de } \\
\text { Pearson } \\
\text { Sig. (bilateral) } \\
\text { N }\end{array}$ & $\begin{array}{r}, 204(* *) \\
, 002 \\
239\end{array}$ & $\begin{array}{r}, 228(* *) \\
, 000 \\
238\end{array}$ & 239 & $\begin{array}{r}, 265(* *) \\
, 000 \\
239\end{array}$ \\
\hline $\begin{array}{l}\text { Retrib7 } \\
\text { benefic. Sociales }\end{array}$ & $\begin{array}{l}\text { Correlación de } \\
\text { Pearson } \\
\text { Sig. (bilateral) } \\
\text { N }\end{array}$ & $\begin{array}{r}, 196(* *) \\
, 002 \\
239\end{array}$ & $\begin{array}{r}, 220(* *) \\
, 001 \\
238\end{array}$ & $\begin{array}{r}, 265(* *) \\
, 000 \\
239\end{array}$ & 239 \\
\hline
\end{tabular}

** La correlación es significativa al nivel 0,01 (bilateral).

\begin{tabular}{|c|c|c|c|c|c|c|c|c|}
\hline \multicolumn{9}{|c|}{ Coeficientes $^{a}$} \\
\hline \multirow{2}{*}{$\begin{array}{l}\text { Mo } \\
\text { de } \\
\text { lo }\end{array}$} & & \multicolumn{2}{|c|}{$\begin{array}{l}\text { Coeficientes no } \\
\text { estandarizados }\end{array}$} & \multirow{2}{*}{$\begin{array}{c}\begin{array}{c}\text { Coeficien } \\
\text { tes } \\
\text { estandari } \\
\text { zados }\end{array} \\
\text { Beta }\end{array}$} & \multirow[b]{2}{*}{$\mathrm{t}$} & \multirow[b]{2}{*}{ Sig. } & \multicolumn{2}{|c|}{$\begin{array}{c}\text { Estadísticos de } \\
\text { colinealidad }\end{array}$} \\
\hline & & B & Error típ. & & & & $\begin{array}{c}\text { Tolera } \\
\text { ncia }\end{array}$ & FIV \\
\hline \multirow[t]{5}{*}{1} & (Constante) & 2,598 &, 254 & & 10,227 &, 000 & & \\
\hline & $\begin{array}{l}\text { Retrib1 sal } \\
\text { superior } \\
\text { competencia }\end{array}$ & 141 & 057 & 159 & 2,460 & 015 & ,904 & 1,106 \\
\hline & $\begin{array}{l}\text { Retrib2 equidad } \\
\text { retrib interna }\end{array}$ & ,236 & ,057 & ,270 & 4,148 & ,000 & ,887 & 1,128 \\
\hline & $\begin{array}{l}\text { Retrib4 incentivo } \\
\text { desemp grupo }\end{array}$ & $-4 E-005$ & ,039 & ,000 &,- 001 & ,999 & ,886 & 1,128 \\
\hline & $\begin{array}{l}\text { Retrib7 } \\
\text { beneficios } \\
\text { sociales }\end{array}$ & ,014 & ,037 & , 024 & ,374 & ,709 & ,891 & 1,123 \\
\hline
\end{tabular}

a. Variable dependiente: RetCapH1 mantener a los muy cualificados

Diagnósticos de colinealidad ${ }^{\mathrm{a}}$

\begin{tabular}{|c|c|c|c|c|c|c|c|c|}
\hline \multirow[b]{2}{*}{ Modelo } & \multirow[b]{2}{*}{$\begin{array}{l}\text { Dim } \\
\text { ensi } \\
\text { ón }\end{array}$} & \multirow[b]{2}{*}{$\begin{array}{c}\text { Autova } \\
\text { lor }\end{array}$} & \multirow[b]{2}{*}{$\begin{array}{l}\text { Indice de } \\
\text { condición }\end{array}$} & \multicolumn{5}{|c|}{ Proporciones de la varianza } \\
\hline & & & & $\begin{array}{l}\text { (Const } \\
\text { ante) }\end{array}$ & $\begin{array}{l}\text { Retrib1 } \\
\text { sal } \\
\text { superior } \\
\text { compete } \\
\text { ncia }\end{array}$ & $\begin{array}{l}\text { Retrib2 } \\
\text { equidad } \\
\text { retrib } \\
\text { interna }\end{array}$ & $\begin{array}{l}\text { Retrib4 } \\
\text { incentivo } \\
\text { desemp } \\
\text { grupo }\end{array}$ & $\begin{array}{c}\text { Retrib7 } \\
\text { beneficios } \\
\text { sociales }\end{array}$ \\
\hline \multirow[t]{5}{*}{1} & 1 & 4,633 & 1,000 &, 00 &, 00 & ,00 & , 01 & ,01 \\
\hline & 2 & ,169 & 5,237 & 01 & 02 & 01 & ,03 & ,99 \\
\hline & 3 & 124 & 6,121 & ,02 & ,05 & ,03 & ,96 &, 00 \\
\hline & 4 & ,048 & 9,796 & ,02 & ,74 & ,43 &, 00 &, 00 \\
\hline & 5 & ,026 & 13,253 &, 95 & ,19 &, 53 & ,00 & 00 \\
\hline
\end{tabular}

a. Variable dependiente: RetCapH1 mantener a los muy cualificados 
Tablas A4.1.3.- Desarrollo del empleado

\begin{tabular}{|c|c|c|c|c|}
\hline \multicolumn{2}{|c|}{$\begin{array}{c}\text { DESARROLLO } \\
\text { correlaciones }\end{array}$} & \multirow{2}{*}{$\begin{array}{r}\begin{array}{l}\text { Desarr1 } \\
\text { formac } \\
\text { acogida }\end{array} \\
1\end{array}$} & \multirow{2}{*}{$\begin{array}{c}\begin{array}{c}\text { Desarr7 } \\
\text { promoción } \\
\text { basada } \\
\text { desempeño }\end{array} \\
, 241\left(^{* *}\right)\end{array}$} & \multirow{2}{*}{$\begin{array}{c}\text { D3masD4 } \\
, 476\left(^{* *}\right)\end{array}$} \\
\hline Desarr1 formac acogida & Correlación de Pearson & & & \\
\hline & Sig. (bilateral) & &, 000 & ,000 \\
\hline & $\mathrm{N}$ & 238 & 236 & 238 \\
\hline \multirow{3}{*}{$\begin{array}{l}\text { Desarr7 promoción basada } \\
\text { desempeño }\end{array}$} & Correlación de Pearson &, $241(* *)$ & 1 & ,390(**) \\
\hline & Sig. (bilateral) &, 000 & &, 000 \\
\hline & $\mathrm{N}$ & 236 & 237 & 237 \\
\hline \multirow[t]{3}{*}{ D3masD4 } & Correlación de Pearson &, $476(* *)$ &, $390(* *)$ & 1 \\
\hline & Sig. (bilateral) & ,000 & ,000 & \\
\hline & $\mathrm{N}$ & 238 & 237 & 239 \\
\hline
\end{tabular}

** La correlación es significativa al nivel 0,01 (bilateral).

Coeficientes $^{a}$

\begin{tabular}{|c|c|c|c|c|c|c|c|c|}
\hline \multirow{2}{*}{\multicolumn{2}{|c|}{ Modelo }} & \multicolumn{2}{|c|}{$\begin{array}{l}\text { Coeficientes no } \\
\text { estandarizados }\end{array}$} & \multirow{2}{*}{$\begin{array}{c}\begin{array}{c}\text { Coeficientes } \\
\text { estandarizad } \\
\text { os }\end{array} \\
\text { Beta }\end{array}$} & \multirow[b]{2}{*}{$\mathrm{t}$} & \multirow[b]{2}{*}{ Sig. } & \multicolumn{2}{|c|}{$\begin{array}{l}\text { Estadísticos de } \\
\text { colinealidad }\end{array}$} \\
\hline & & $\mathrm{B}$ & Error típ. & & & & Tolerancia & FIV \\
\hline \multirow[t]{4}{*}{1} & (Constante) & 2,062 &, 256 & & 8,052 &, 000 & & \\
\hline & Desarr1 formac acogida &, 137 & ,056 & , 166 & 2,430 & ,016 & ,774 & 1,292 \\
\hline & D3masD4 & ,239 & ,068 & ,252 & 3,507 & 001 & ,699 & 1,431 \\
\hline & $\begin{array}{l}\text { Desarr7 promoción } \\
\text { basada desempeño }\end{array}$ & ,082 & ,059 & ,092 & 1,408 & , 160 & ,846 & 1,181 \\
\hline
\end{tabular}

a. Variable dependiente: RetCapH2 mantener a los mejores de sector

Diagnósticos de colinealidaa

\begin{tabular}{|c|c|c|c|c|c|c|c|}
\hline \multirow[b]{2}{*}{ Modelo } & \multirow[b]{2}{*}{ Dimensión } & \multirow[b]{2}{*}{ Autovalor } & \multirow[b]{2}{*}{$\begin{array}{l}\text { Indice de } \\
\text { condición }\end{array}$} & \multicolumn{4}{|c|}{ Proporciones de la varianza } \\
\hline & & & & (Constante) & $\begin{array}{c}\text { Desarr1 } \\
\text { formac } \\
\text { acogida }\end{array}$ & D3masD4 & $\begin{array}{c}\text { Desarr7 } \\
\text { promoción } \\
\text { basada } \\
\text { desempeño }\end{array}$ \\
\hline \multirow[t]{4}{*}{1} & 1 & 3,867 & 1,000 & ,00 & ,00 & ,00 & ,00 \\
\hline & 2 & ,061 & 7,966 & ,00 & ,40 & ,02 & ,63 \\
\hline & 3 & 038 & 10,124 & ,13 & ,24 &, 97 & ,03 \\
\hline & 4 & ,034 & 10,689 & ,87 & ,35 & ,00 & ,33 \\
\hline
\end{tabular}

a. Variable dependiente: RetCapH2 mantener a los mejores de sector 
Tablas A4.1.4.- Conciliación vida laboral-personal

\begin{tabular}{|c|c|c|c|}
\hline \multicolumn{2}{|c|}{$\begin{array}{l}\text { CONCILIACIÓN VIDA } \\
\text { LABORAL-PERSONAL } \\
\text { correlaciones }\end{array}$} & $\begin{array}{c}\text { Conci1MASCo } \\
\text { nci2 }\end{array}$ & $\begin{array}{l}\text { Conci3 } \\
\text { ayudas } \\
\text { económicas }\end{array}$ \\
\hline Conci1MASConci2 & $\begin{array}{l}\text { Correlación de Pearson } \\
\text { Sig. (bilateral) } \\
\mathrm{N}\end{array}$ & 239 & $\begin{array}{r}, 169(* *) \\
, 009 \\
239\end{array}$ \\
\hline $\begin{array}{l}\text { Conci3 ayudas } \\
\text { económicas }\end{array}$ & $\begin{array}{l}\text { Correlación de Pearson } \\
\text { Sig. (bilateral) } \\
\text { N }\end{array}$ & $\begin{array}{r}, 169(* *) \\
009 \\
239\end{array}$ & 239 \\
\hline
\end{tabular}

** La correlación es significativa al nivel 0,01 (bilateral).

Coeficientes $^{\mathrm{a}}$

\begin{tabular}{|c|c|c|c|c|c|c|c|c|}
\hline \multirow{2}{*}{\multicolumn{2}{|c|}{ Modelo }} & \multicolumn{2}{|c|}{$\begin{array}{l}\text { Coeficientes no } \\
\text { estandarizados }\end{array}$} & \multirow{2}{*}{$\begin{array}{c}\text { Coeficientes } \\
\text { estandarizad } \\
\text { os }\end{array}$} & \multirow[b]{2}{*}{$\mathrm{t}$} & \multirow[b]{2}{*}{ Sig. } & \multicolumn{2}{|c|}{$\begin{array}{l}\text { Estadísticos de } \\
\text { colinealidad }\end{array}$} \\
\hline & & $\mathrm{B}$ & Error típ. & & & & Tolerancia & FIV \\
\hline \multirow[t]{3}{*}{1} & (Constante) & 2,922 & ,214 & & 13,653 &, 000 & & \\
\hline & $\begin{array}{l}\text { Conci3 ayudas } \\
\text { económicas }\end{array}$ & ,132 & ,046 & , 184 & 2,877 & ,004 & ,971 & 1,029 \\
\hline & Conci1MASConci2 & ,130 & ,057 & ,146 & 2,282 & ,023 & ,971 & 1,029 \\
\hline
\end{tabular}

a. Variable dependiente: RetCapH2 mantener a los mejores de sector

Diagnósticos de colinealidad

\begin{tabular}{|c|c|c|c|c|c|c|}
\hline \multirow[b]{2}{*}{ Modelo } & \multirow[b]{2}{*}{ Dimensión } & \multirow[b]{2}{*}{ Autovalor } & \multirow[b]{2}{*}{$\begin{array}{l}\text { Indice de } \\
\text { condición }\end{array}$} & \multicolumn{3}{|c|}{ Proporciones de la varianza } \\
\hline & & & & (Constante) & $\begin{array}{c}\text { Conci3 } \\
\text { ayudas } \\
\text { económicas }\end{array}$ & $\begin{array}{c}\text { Conci1 } \\
\text { MASConci2 }\end{array}$ \\
\hline 1 & 1 & 2,817 & 1,000 & ,01 & ,02 & ,01 \\
\hline & 2 & 141 & 4,475 & ,06 & ,95 & 13 \\
\hline & 3 & ,042 & 8,150 & ,94 & ,03 & ,86 \\
\hline
\end{tabular}

a. Variable dependiente: RetCapH2 mantener a los mejores de sector 


\section{REFERENCIAS}

\section{BIBLIOGRÁFICAS}



Abelson, M. A. (1987). Examination of avoidable and unavoidable turnover. Journal of Applied Psychology, 72(3), 382-386.

Abelson, M. A., \& Baysinger, B. D. (1984). Optimal and dysfunctional turnover: Toward an organizational level model. Academy of Management Review, 9(2), 331-341.

Adler, P. S., \& Kwon, S. W. (2000). Social capital: the good, the bad, and the ugly. Knowledge and social capita, 89-115.

Adler, P. S., \& Kwon, S. W. (2002). Social capital: Prospects for a new concept. Academy of Management Review, 27(1), 17-40.

Afiouni, F. (2007). Human resource management and knowledge management: a road map toward improving organizational performance. Journal of American Academy of Business, 11(2), 124-130.

Ahuja, M. K., Chudoba, K. M., Kacmar, C. J., McKnight, D. H., \& George, J. F. (2007). IT Road Warriors: Balancing Work Family Conflict, Job Autonomy, and Work Overload to mitigate Turnover Intentions. Mis Quarterly, 31(1), 1-17.

Alarcón, V. F. (2004).Relaciones encontradas entre las dimensiones de las estructuras organizativas y los componentes del constructo capacidad de absorción: el caso de empresas ubicadas en el territorio español. Universitat Politècnica de Catalunya. Departament d'Organització d'Empreses.

Allen, D. G., \& Griffeth, R. W. (1999). Job performance and turnover: A review and integrative multi-route model. Human Resource Management Review, 9(4), 525-548.

Allen, D. G., \& Griffeth, R. W. (2001). Test of a mediated performance-turnover relationship highlighting the moderating roles of visibility and reward contingency. The Journal of applied psychology, 86(5), 1014-1021.

Allen, D. G., Bryant, P. C., \& Vardaman, J. M. (2010). Retaining Talent: Replacing Misconceptions With Evidence-Based Strategies. The Academy of Management Perspectives (formerly The Academy of Management Executive)(AMP), 24(2), 48-64.

Allen, D. G., Shore, L. M., \& Griffeth, R. W. (2003). The role of perceived organizational support and supportive human resource practices in the turnover process. Journal of Management, 29(1), 99.

Allen, D. G., Weeks, K. P., \& Moffitt, K. R. (2005). Turnover Intentions and Voluntary Turnover: The Moderating Roles of Self-Monitoring, Locus of Control, Proactive Personality, and Risk Aversion. Journal of Applied Psychology, 90(5), 980.

Allen, N. J., \& Meyer, J. P. (1993). Organizational commitment: Evidence of career stage effects?* 1. Journal of Business Research, 26(1), 49-61.

Allen, N. J., \& Meyer, J. P. (1996). Affective, continuance, and normative commitment to the organization: An examination of construct validity. Journal of vocational behavior, 49(3), 252-276.

Allen, N. J., \& Meyer, J. P. (2000). Construct validation in organizational behavior research: The case of organizational commitment.

Alvesson, M. (2000). Social Indentity And The Problem of Loyalty In Knowledge Intensive Companies. Journal of Management Studies, 37(8), 1101-1124.

Alvesson, M., \& Kärreman, D. (2000a). Taking the linguistic turn in organizational research. The Journal of Applied Behavioral Science, 36(2), 136.

Alvesson, M., \& Karreman, D. (2000b). Varieties of discourse: On the study of organizations through discourse analysis. Human Relations, 53(9), 1125.

Amabile, T. (1996). Creativity in context: Westview Press. 
Amabile, T. M., Conti, R., Coon, H., Lazenby, J., \& Herron, M. (1996). Assessing the work environment for creativity. Academy of management journal, 39(5), 1154-1184.

Amit, R., \& Schoemaker, P. J. H. (1993). Strategic assets and organizational rent. Strategic Management Journal, 14(1), 33-46.

Anderson, J. C., \& Gerbing, D. W. (1988). Structural equation modeling in practice: A review and recommended two-step approach. Psychological bulletin, 103(3), 411-423.

Appelbaum, E., Bailey, T., Berg, P., \& Kalleberg, A. (2000). Manufacturing advantage. Why High-Performance Work Systems Pay Off.: Cornell University Press Ithaca, NY/London.

Argarwal, R., \& Ferrat, T. (1999). Coping with labour scarcity in Information Technology: Strategies and Practices for Effective Recruitment and Retention. Cincinnati: Pinnalfex Educational Resources.

Argote, L., McEvily, B., \& Reagans, R. (2003). Introduction to the special issue on managing knowledge in organizations: Creating, retaining, and transferring knowledge. Management Science, 49(4), 5-8.

Argyle, M. (1992). ¿Trabajan más los trabajadores felices? El efecto de la satisfacción en el puesto en la realización del trabajo.http://www.fun-humanismociencia.es/felicidad/empresa/empresa16.htm

Armbrecht, F., Chapas, R. B., Chappelow, C. C., Farris, G. F., Friga, P. N., Hartz, C. A., et al. (2001). Knowledge management in research and development. Research-Technology Management, 44(4), 28-48.

Arthur, D. (2001). The employee recruitment and retention handbook: Amacom Books.

Arthur, J. B. (1992). The link between business strategy and industrial relations systems in American steel minimills. Industrial \& Labor Relations Review, 45(3), 488-506.

Arthur, J. B. (1994). Effects of human resource systems on manufacturing performance and turnover. Academy of management journal, 37(3), 670-687.

Arthur, J. B., \& Boyles, T. (2007). Validating the human resource system structure: a levelsbased strategic HRM approach. Human Resource Management Review, 17(1), 77-92.

Ashford, S. J., Lee, C., \& Bobko, P. (1989). Content, causes, and consequences of job insecurity: A theory-based measure and substantive test. Academy of management journal, 32(4), 803-829.

Atkinson, A. B., \& Micklewright, J. (1991). Unemployment compensation and labor market transitions: a critical review. Journal of economic literature, 29(4), 1679-1727.

Atkinson, C. (2007). Trust and the psychological contract. Employee Relations, 29(3), 227-246.

Atkinson, S., \& Butcher, D. (2003). Trust in managerial relationships. Journal of Managerial Psychology, 18(4), 282-304.

Atkinson, W. (1985). Home/Work. Personnel Journal, 64(11), 104-109.

Atwater, L., \& Carmeli, A. (2009). Leader-member exchange, feelings of energy, and involvement in creative work. The Leadership Quarterly, 20(3), 264-275.

Avey, J. B., Luthans, F., \& Jensen, S. M. (2009). Psychological capital: A positive resource for combating employee stress and turnover. Human Resource Management, 48(5), 677-693.

Bae, J., \& Lawler, J. J. (2000). Organizational and HRM strategies in Korea: Impact on firm performance in an emerging economy. Academy of management journal, 43(3), 502-517.

Bae, J., Chen, S., Wan, T. W. D., Lawler, J. J., \& Walumbwa, F. O. (2003). Human resource strategy and firm performance in Pacific Rim countries. The International Journal of Human Resource Management, 14(8), 1308-1332. 
Bagozzi, R. P. (1994). Structural equation models in marketing research: basic principles. Principles of marketing research, 3(1), 7-385.

Bagozzi, R. P., \& Fornell, C. (1982). Theoretical concepts, measurements, and meaning. A second generation of multivariate analysis, 2, 24-38.

Bagraim, J. J., \& Hime, P. (2007). The dimensionality of workplace interpersonal trust and its relationship to workplace affective commitment. SA Journal of Industrial Psychology, 33(3), 43.

Bandura, A. (1997). Self-efficacy: The exercise of control: Worth Publishers.

Barak, M. E., Travis, D. J., Pyun, H., \& Xie, B. (2009). The impact of supervision on worker outcomes: A meta-analysis. Social Service Review, 83(1), 3-32.

Barclay, D., Higgins, C., \& Thompson, R. (1995). The partial least squares (PLS) approach to causal modeling: Personal computer adoption and use as an illustration. Technology studies, 2(2), 285-309.

Barnett, W. P., Greve, H. R., \& Park, D. Y. (1994). An evolutionary model of organizational performance. Strategic Management Journal, 15(S1), 11-28.

Barney, B. C. (1997): Gaining and Sustaining Competitive Advantage: Addison-Wesley Publishing Company. Davis, FR.

Barney, J. B. (1986). Strategic factor markets: expectations, luck, and business strategy. Management Science, 32(10), 1231-1241.

Barney, J. B. (1991). Firm resources and sustained competitive advantage. Journal of Management, 17(1), 99-120.

Barney, J. B. (1995). Looking inside for competitive advantage. The Academy of Management Executive (1993-2005), 9(4), 49-61.

Barney, J. B. (1996). The resource-based theory of the firm. Organization Science, 7(5), 469.

Barney, J. B. (2001a). Is the resource-based" view" a useful perspective for strategic management research? Yes. Academy of Management Review, 26(1), 41-56.

Barney, J. B. (2001b). Resource-based theories of competitive advantage: A ten-year retrospective on the resource-based view. Journal of Management, 27(6), 643.

Barney, J. B. (2002). Gaining and sustaining competitive advantage: Prentice Hall Upper Saddle River, NJ.

Barney, J. B., \& Clark, D. N. (2007). Resource-based theory: Creating and sustaining competitive advantage: Oxford University Press, USA.

Barney, J. B., \& Hansen, M. H. (1994). Trustworthiness as a source of competitive advantage. Strategic Management Journal, 15(S1), 175-190.

Barney, J. B., \& Wright, P. M. (1998). On becoming a strategic partner: The role of human resources in gaining competitive advantage. Human Resource Management, 37(1), 31-46.

Barney, J., Wright, M., \& Ketchen, D. J. (2001). The resource-based view of the firm: Ten years after 1991. Journal of Management, 27(6), 625.

Barrick, M. R., \& Zimmerman, R. D. (2005). Reducing voluntary, avoidable turnover through selection. Journal of Applied Psychology, 90(1), 159-166.

Barsade, S. G., \& Gibson, D. E. (2007). Why does affect matter in organizations? The Academy of Management Perspectives.

Bartlett, K. R. (2001). The relationship between training and organizational commitment: A study in the health care field. Human Resource Development Quarterly, 12(4), 335-352. 
Barton, D. L. (1992). Core capabilities and core rigidities: a paradox in managing new product development. Strategic Management Journal, 13(2), 111-125.

Bateman, G. (2009). Employee perceptions of co-worker support and its effect on job satisfaction, work stress and intention to quit.

Batt, R. (2002). Managing customer services: Human resource practices, quit rates, and sales growth. Academy of Management Journal, 45(3), 587-597.

Batt, R. (2008). Why Good Employees Quit and What You Can Do to Stop Them. hrSPECTRUM-Cornell Center for Advancen Human Resource Studies.

Baumgartner, H., \& Homburg, C. (1996). Applications of structural equation modeling in marketing and consumer research: a review. International Journal of Research in Marketing, 13(2), 139-161.

Becker, B. E., \& Huselid, M. A. (1997). Human resources strategies, complementarities, and firm performance.

Becker, B. E., \& Huselid, M. A. (1998). High performance work systems and firm performance: A synthesis of research and managerial implications. Research in personnel and human resources management, 16, 53-102.

Becker, B. E., \& Huselid, M. A. (2006). Strategic human resources management: where do we go from here? Journal of Management, 32(6), 898.

Becker, B. E., Huselid, M. A., Pickus, P. S., \& Spratt, M. F. (1997). HR as a source of shareholder value: Research and recommendations. Human Resource Management, 36(1), 39-47.

Becker, B., \& Gerhart, B. (1996). The impact of human resource management on organizational performance: Progress and prospects. Academy of Management Journal, 39(4), 779-801.

Becket, G. S. (1964). Human capital.

Belsey, D. A. (Ed.). (1991). Conditioning diagnostics, collinearity and weak data in regression. (John Wiley \& Sons Inc., New York. ed.).

Benitez-Amado, J., Llorens-Montes, F. J., \& Perez-Arostegui, M. N. (2010). Information technology-enabled intrapreneurship culture and firm performance. Industrial Management \& Data Systems, 110(4), 550-566.

Benitez-Amado, J., Perez-Arostegui, M., \& Tamayo-Torres, J. (2010). Information technologyenabled innovativeness and green management capabilities. Paper presented at the XX Congreso Nacional de ACEDE, Granada.

Benson, G. S. (2006). Employee development, commitment and intention to turnover: a test of 'employability'policies in action. Human Resource Management Journal, 16(2), 173-192.

Benson, G. S., Finegold, D., \& Mohrman, S. A. (2004). You paid for the skills, now keep them: Tuition reimbursement and voluntary turnover. The Academy of Management Journal, 47(3), 315-331.

Berg, P., Kalleberg, A. L., \& Appelbaum, E. (2003). Balancing Work and Family: The Role of High Commitment Environments. Industrial Relations: A Journal of Economy and Society, 42(2), 168-188.

Besich, J. S. (2003). Job Embeddedness as a Predictor of Voluntary Turnover: Validation of a New Instrument. University of North Texas.

Bhatnagar, J. (2007). Talent management strategy of employee engagement in Indian ITES employees: key to retention. Employee Relations, 29(6), 640-663.

Blakemore, A. E., Low, S. A., \& Ormiston, M. B. (1987). Employment bonuses and labor turnover. Journal of Labor Economics, 5(4), 124-135. 
Blau, P. (1964). Exchange and Power in social Life.

Blesa, A., Ripollés, M., \& Monferrer, D. (2008). » La orientación al mercado como determinante de la internacionalización de las nuevas empresas». Instituto Valenciano de Investigaciones Económicas, SA, 2-39.

Bluedorn, A. C. (1980). A unified model of turnover from organizations. Human Relations, 35(2), 135.

Bock, G. W., Zmud, R. W., Kim, Y. G., \& Lee, J. N. (2005). Behavioral intention formation in knowledge sharing: Examining the roles of extrinsic motivators, social-psychological forces, and organizational climate. Mis Quarterly, 29(1), 87-111.

Boer, H., \& During, W. E. (2001). Innovation, what innovation? A comparison between product, process and organisational innovation. International Journal of Technology Management, 22(1), 83-107.

Bollen, K. A. (1989). Structural equations with latent variables: Wiley New York.

Bollen, K., \& Lennox, R. (1991). Conventional wisdom on measurement: A structural equation perspective. Psychological bulletin, 110(2), 305.

Bontis, N. (1996). There's a price on your head: managing intellectual capital strategically. Business Quarterly, 60, 40-78.

Bontis, N. (1998). Intellectual capital: an exploratory study that develops measures and models. Management decision, 36(2), 63-76.

Bontis, N. (2001). Assessing knowledge assets: a review of the models used to measure intellectual capital. International Journal of Management Reviews, 3(1), 41-60.

Bontis, N., Crossan, M. M., \& Hulland, J. (2002). Managing an organizational learning system by aligning stocks and flows. Journal of Management Studies, 39(4), 437-469.

Borislavova Lazarova, M. (2004). The role of organizational career development programs, work/life balance programs, and commitment to career and personal life for retention of professional employees. UMI Dissertation Services [Tokyo]:[Distributed by Yushodo Dissertation Service Center], Ann Arbor, Mich., New Jersey (USA).

Bornay Barrachina, M., De la Rosa Navarro, D., López Cabrales, A., \& Valle Cabrera, R. (2011). Employment Relationships and Firm Innovation: The Double Role of Human Capital. British Journal of Management.

Boselie, P., \& Van der Wiele, T. (2002). Employee perceptions of HRM and TQM, and the effects on satisfaction and intention to leave. Managing Service Quality, 12(3), 165-172.

Boselie, P., Dietz, G., \& Boon, C. (2005). Commonalities and contradictions in HRM and performance research. Human Resource Management Journal, 15(3), 67-94.

Boudreau, J. W. (1983). Effects of employee flows on utility analysis of human resource productivity improvement programs. Journal of Applied Psychology, 68(3), 396-406.

Boudreau, J. W., \& Berger, C. J. (1985). Toward a model of employee movement utility. Research in Personnel and Human Resource Management, 3, 31-54.

Bowen, D. E., \& Ostroff, C. (2004). Understanding HRM-firm performance linkages: The role of the" strength" of the HRM system. The Academy of Management Review, 29(2), 203221.

Boxall, P. (1996). The strategic HRM debate and the resource-based view of the firm. Human Resource Management Journal, 6(3), 59-75.

Boxall, P. (1998). Achieving competitive advantage through human resource strategy: towards a theory of industry dynamics. Human Resource Management Review, 8(3), 265-288. 
Boxall, P. F., \& Purcell, J. (2003). Strategy and human resource management (Vol. 219): Palgrave Macmillan Basingstoke, UK.

Boxall, P., \& Macky, K. (2009). Research and theory on high-performance work systems: progressing the high-involvement stream. Human Resource Management Journal, 19(1), 3-23.

Boxall, P., Macky, K., \& Rasmussen, E. (2003). Labour turnover and retention in New Zealand: The causes and consequences of leaving and staying with employers. Asia Pacific Journal of Human Resources, 41(2), 196.

Boyar, S. L., Maertz, C. P., Pearson, A. W., \& Keough, S. (2003). Work-family conflict: A model of linkages between work and family domain variables and turnover intentions. Journal of Managerial Issues, 15(2), 175-190.

Branham, L. (2005). The 7 hidden reasons employees leave. New York: American Management.

Brewster, C., Sparrow, P., \& Harris, H. (2005). Towards a new model of globalizing HRM. The International Journal of Human Resource Management, 16(6), 949-970.

Brief, A. P., \& Aldag, R. J. (1989). The economic functions of work. Research in personnel and human resources management, 7, 1-23.

Brotheridge, C. M. (2004a). Book Review: Emotions in the workplace: Research, theory, and practice, Managing emotions in the workplace. Human Relations, 57(10), 1334.

Brotheridge, C. M. (2004b). Understanding emotion at work. Personnel Psychology, 57 (3), 811-813.

Brotheridge, C. M. (2006). The role of emotional intelligence and other individual difference variables in predicting emotional labor relative to situational demands. Psicothema, 18(Sup), 139-144.

Brown, S. L., \& Eisenhardt, K. M. (1995). Product development: past research, present findings, and future directions. The Academy of Management Review, 20(2), 343-378.

Brown, W. A., \& Yoshioka, C. F. (2003). Mission attachment and satisfaction as factors in employee retention. Nonprofit Management and Leadership, 14(1), 5-18.

Bryman, A. (1992). Quality and quantity in social research.

Buchanan, B. (1974). Building organizational commitment: The socialization of managers in work organizations. Administrative Science Quarterly, 19(4), 533-546.

Buck, J. M., \& Watson, J. L. (2002). Retaining staff employees: The relationship between human resources management strategies and organizational commitment. Innovative Higher Education, 26(3), 175-193.

Bueno Campos, E. (1993). Curso Básico de Economía de la Empresa. Un enfoque de organización.Ed.Pirámide.

Bueno Campos, E. (1999). "La gestión del conocimiento en la nueva economía".Gestión del Conocimiento y Capital Intelectual. Experiencias en España. Instituto Universitario Euroforum Escorial y Comunidad de Madrid, Madrid. 15-19)

Bueno Campos, E. (2000). De la sociedad de la información a la del conocimiento y el aprendizaje. Asociación Española de Contabilidad y Administración de Empresas, AECA.

Buzzell, R. D. (2004). The PIMS program of strategy research:: A retrospective appraisal. Journal of Business Research, 57(5), 478-483.

Byrne, B. M. (1998). Structural equation modeling with LISREL, PRELIS, and SIMPLIS: Basic concepts, applications, and programming: Lawrence Erlbaum. 
Byrne, B. M. (2001). Structural equation modeling with AMOS, EQS, and LISREL: Comparative approaches to testing for the factorial validity of a measuring instrument. International Journal of Testing, 1(1), 55-86.

Cabello-Medina, C., López-Cabrales, Á., \& Valle-Cabrera, R. (2011). Leveraging the innovative performance of human capital through HRM and social capital in Spanish firms. The International Journal of Human Resource Management, 22(4), 807-828.

Cabrales, L. (2008). Capital humano, prácticas de gestión y agilidad empresarial. Revista Europea de Dirección y Economía de la empresa, 17(2), 155-178.

Cabrera, A., Collins, W. C., \& Salgado, J. F. (2006). Determinants of organizational engagement in knowledge sharing. International Journal of Human Resource Management, 17, 245-264.

Cabrera, E. F., \& Cabrera, A. (2005). Fostering knowledge sharing through people management practices. The International Journal of Human Resource Management, 16(5), 720-735.

Calantone, R. J., Cavusgil, S. T., \& Zhao, Y. (2002). Learning orientation, firm innovation capability, and firm performance. Industrial Marketing Management, 31(6), 515-524.

Camelo Ordaz, C., García Cruz, J., \& Sousa Ginel, E. (2010). Facilitadores de los procesos de compartir conocimiento y su influencia sobre la innovación. Cuadernos de Economía y Dirección de la Empresa(42), 113.

Camelo-Ordaz, C., García-Cruz, J., Sousa-Ginel, E., \& Valle-Cabrera, R. (2008). «La influencia de los recursos humanos sobre la creación de conocimiento y la innovación: el papel mediador del compromiso afectivo», XVIII Congreso Nacional de ACEDE: León.

Camisón, C. (1999). La medición de los resultados empresariales desde una óptica estratégica: construcción de un instrumento a partir de un estudio Delphi y aplicación a la empresa industrial española en el período 1983-96. Estudios Financieros, 62(199), 201-264.

Campbell, D. J., Campbell, K. M., \& Chia, H. B. (1998). Merit pay, performance appraisal, and individual motivation: An analysis and alternative. Human Resource Management, 37(2), 131-146.

Cappelli, P., \& Crocker-Hefter, A. (1996). Distinctive Human Resources are Firms (Vol. 24).

Cappelli, P., \& Singh, H. (1992). Integrating strategic human resources and strategic management. Research frontiers in industrial relations and human resources, 165-192.

Carmeli, A. (2001). High-and low-performance firms: do they have different profiles of perceived core intangible resources and business environment? Technovation, 21(10), 661-671.

Carr, J. C., Pearson, A. W., Vest, M. J., \& Boyar, S. L. (2006). Prior occupational experience, anticipatory socialization, and employee retention. Journal of Management, 32(3), 343.

Carter, C., \& Scarbrough, H. (2001). Towards a second generation of KM? The people management challenge. Education Training, 43(4/5), 215-224.

Cascio, W. F. (1976). Turnover, biographical data, and fair employment practice. Journal of Applied Psychology, 61(5), 576-580.

Cascio, W. F. (2000). Managing a virtual workplace. The Academy of Management Executive (1993), 14(3), 81-90.

Cascio, W. F. (2006a). The high cost of low wages. Harvard Business Review, 84, 12-23.

Cascio, W. F. (2006b). The new human capital equation. Industrial-Organizational Psychologist, 44(2), 14-23. 
Casper, W. J., Weltman, D., \& Kwesiga, E. (2007). Beyond family-friendly: The construct and measurement of singles-friendly work culture. Journal of vocational behavior, 70(3), 478501.

Cavanaugh, M. A., \& Noe, R. A. (1999). Antecedents and consequences of relational components of the new psychological contract. Journal of organizational behavior, 20(3), 323-340.

Cavusgil, S. T., Calantone, R. J., \& Zhao, Y. (2003). Tacit knowledge transfer and firm innovation capability. Journal of Business \&amp; Industrial Marketing, 18(1), 6-21.

Celeste, J. K., \& Brotheridge, C. M. (2005). Does supporting employees' career adaptability lead to commitment, turnover, or both? Human Resource Management, 44(1), 5-19.

Céspedes Lorente, J., Jerez Gómez, P., \& Valle Cabrera, R. (2005). Las prácticas de Recursos Humanos de Alto Rendimiento y la capacidad de aprendizaje organizativo: incidencia e implicaciones. Cuadernos de Economía y Dirección de la Empresa, 24, 29-56.

Chan, L. L. M., Shaffer, M. A., \& Snape, E. (2004). In search of sustained competitive advantage: the impact of organizational culture, competitive strategy and human resource management practices on firm performance. The International Journal of Human Resource Management, 15(1), 17-35.

Charterina Abando, J., \& Araujo de la Mata, A. M. S. M. R. (2010). Un modelo causal de competitividad empresarial planteado desde la VBR: capacidades directivas, de innovación, marketing y calidad. Investigaciones Europeas de Dirección y Economía de la Empresa, 16(2), 165-188.

Chawla, A. S. (2005). Retention Versus Turnover: Opposite Sides of the Same Coin? Comparing Employees' motivation to Stay to Their Turnover Intentions. PhD Thesis. Science and Engineering,University of Guelph, Guelph, 3981.

Chawla, A., \& Kelloway, E. K. (2004). Predicting openness and commitment to change. Leadership \& Organization Development Journal, 25(6), 485-498.

Chen, C. J., \& Huang, J. W. (2009). Strategic human resource practices and innovation performance--The mediating role of knowledge management capacity. Journal of Business Research, 62(1), 104-114.

Chen, Z. X., Aryee, S., \& Lee, C. (2005). Test of a mediation model of perceived organizational support* 1. Journal of vocational behavior, 66(3), 457-470.

Chew, J. (2004). Managing MNC expatriates through crises: A challenge for international human resource management. Research and Practice in Human Resource Management, 12(2), 1-30.

Chew, J., \& Chan, C. C. A. (2008). Human resource practices, organizational commitment and intention to stay. International Journal of Manpower, 29(6), 503-522.

Chew, J., Girardi, A., \& Entrekin, L. (2005). Retaining Core Staff: The impact of human resource practices on organisational commitment. Journal of Comparative International Management, 8(2).

Chin, W. (2003). PLS-Graph (Version 3.00, Build 1058)[Computer software]. University of Houston.

Chin, W. W. (1998a). Issues and opinion on structural equation modeling. Management Information Systems Quarterly, 22(1), 7-16.

Chin, W. W. (1998b). The partial least squares approach to structural equation modeling. 1998), S, 295-336. 
Chin, W. W., \& Newsted, P. R. (1999). Structural equation modeling analysis with small samples using partial least squares. Statistical strategies for small sample research, 2, 307-342.

Chin, W. W., Marcolin, B. L., \& Newsted, P. R. (2003). A partial least squares latent variable modeling approach for measuring interaction effects: Results from a Monte Carlo simulation study and an electronic-mail emotion/adoption study. Information Systems Research, 14(2), 189-217.

Chiu, R. K., Luk, V. W. M., \& Tang, T. L. P. (2002). Retaining and motivating employees: Compensation preferences in Hong Kong and China. Personnel Review, 31(4), 402-431.

Chiu, W. C. K., Chan, A. W., Snape, E., \& Redman, T. (2001). Age stereotypes and discriminatory attitudes towards older workers: An East-West comparison. Human Relations, 54(5), 629-661.

Cho, S., Woods, R. H., Jang, S. C., \& Erdem, M. (2006). Measuring the impact of human resource management practices on hospitality firms' performances. International Journal of Hospitality Management, 25(2), 262-277.

Cho, S., Woods, R., \& Mayer, K. (2005). Examining the impact of human resources management on organizational performance.Academy of Management Best Conference Paper 2005

Chow, I. H. S., \& Gong, Y. (2010). The linkage of HRM and knowledge-related performance in China's technology-intensive industries. The International Journal of Human Resource Management, 21(8), 1289-1306.

Clark, M. C., \& Payne, R. L. (1997). The nature and structure of workers' trust in management. Journal of organizational behavior, 18(3), 205-224.

Clark, S. C. (2001). Work cultures and work/family balance. Journal of vocational behavior, 58(3), 348-365.

Clercq, D., Thongpapanl, N., \& Dimov, D. (2010). Cross-Functional Collaboration, Knowledge Transfer and Product Innovativeness: Contingency Effects of Social Context. Innovation through Knowledge Transfer, 321-331.

Coff, R. W. (1997). Human assets and management dilemmas: Coping with hazards on the road to resource-based theory. Academy of Management Review, 22(2), 374-402.

Cohen, J. (1988). Statistical power analysis for the behavioral sciences: Hillsdale, New Jersey. Lawrence Erlbaum Associates.

Cohen, W. M., \& Levinthal, D. A. (1990). Absorptive capacity: a new perspective on learning and innovation. Administrative Science Quarterly, 35(1), 128-152.

Cohen, W. M., \& Levinthal, D. A. (1994). Fortune favors the prepared firm. Management Science, 227-251.

Cohen, W., \& Levinthal, D. (1989). the two faces of R\&amp;D. Economic Journal, 99(397), 569-596.

Cohen, Y., \& Pfeffer, J. (1986). Organizational hiring standards. Administrative Science Quarterly, 31(1), 1-24.

Coleman, J. (1990). Foundations of social choice theory. Cambridge, Mass.y Londres, Harvard University Press.(1986)," Social theory, social research, and a theory of action", American Journal of Sociology, 91(6).

Collins, C. J., \& Allen, M. (2006). Research Report on Phase 4 of Cornell University/Gevity Institute Study Human Resource Management Practices and Firm Performance in Small 
Businesses: A Look at the Effects of HR Practices on Financial Performance and Turnover.

Collins, C. J., \& Clark, K. D. (2003). Strategic human resource practices, top management team social networks, and firm performance: The role of human resource practices in creating organizational competitive advantage. The Academy of Management Journal, 46(6), 740751.

Collins, C. J., \& Smith, K. G. (2006). Knowledge exchange and combination: The role of human resource practices in the performance of high-technology firms. Academy of management journal.

Collins, D. (1994). The disempowering logic of empowerment. Empowerment in Organizations, 2(2), 14-21.

Collis, D. J. (1991). A resource based analysis of global competition: The case of the bearings industry. Strategic Management Journal, 12(S1), 49-68.

Collis, D. J., \& Montgomery, C. A. (1995). Competing on resources. Harvard Business Review, 73(4), 118-128.

Connell, J., Ferres, N., \& Travaglione, T. (2003a). Engendering trust in manager-subordinate relationships: Predictors and outcomes. Personnel Review, 32(5), 569-587.

Connell, J., Ferres, N., \& Travaglione, T. (2003b). The importance of interpersonal and organizational support. Journal of Management Research, 3(3), 113-118.

Conner, J., \& Ulrich, D. (1996). Human resource roles: creating value, not rhetoric. Human Resource Planning, 19(3).

Costa, A. P. (2002). Software outsourcing and development policy implications: an Indian perspective. International Journal of Technology Management, 24(7), 705-723.

Cotton, J. L., \& Tuttle, J. M. (1986). Employee turnover: A meta-analysis and review with implications for research. Academy of Management Review, 11(1), 55-70.

Coyle-Shapiro, J. A. M., \& Conway, N. (2004). The employment relationship through the lens of social exchange. .

Crooker, K. J., Smith, F. L., \& Tabak, F. (2002). Creating work-life balance: A model of pluralism across life domains. Human Resource Development Review, 1(4), 387.

Cruz Ros, C. (2001). Relación entre el enfoque de gestión de la calidad y el desempeño organizativo. Una aproximación desde la perspectiva basada en los recursos.

Cuervo, Á. (1993). El papel de la empresa en la competitividad. Papeles de Economía Española, 56, 363-378.

Currie, G., \& Kerrin, M. (2003). Human resource management and knowledge management: enhancing knowledge sharing in a pharmaceutical company. The International Journal of Human Resource Management, 14(6), 1027-1045.

Dalton, D. R., Krackhardt, D. M., \& Porter, L. W. (1981). Functional turnover: An empirical assessment. Journal of Applied Psychology, 66(6), 716-721.

Dalton, D. R., Todor, W. D., \& Krackhardt, D. M. (1982). Turnover overstated: The functional taxonomy. Academy of Management Review, 117-123.

Damanpour, F. (1991). Organizational innovation: a meta-analysis of effects of determinants and moderators. Academy of management, 34, 555-590.

Damanpour, F., \& Gopalakrishnan, S. (1998). Theories of organizational structure and innovation adoption: the role of environmental change. Journal of Engineering and Technology Management,, 15, 1-24. 
Damanpour, F., Szabat, K. A., \& Evan, W. M. (1989). The relationship between types of innovation and organizational performance. Journal of Management Studies, 26(6), 587602.

Das, T. K., \& Teng, B. S. (2004). The risk-based view of trust: a conceptual framework. Journal of Business and Psychology, 19(1), 85-116.

Datta, D. K., Guthrie, J. P., \& Wright, P. M. (2005). Human resource management and labor productivity: Does industry matter. Academy of management journal, 48(1), 135-145.

Davies, D., Taylor, R., \& Savery, L. (2001). The role of appraisal, remuneration and training in improving staff relations in the Western Australian accommodation industry: a comparative study. Journal of European Industrial Training, 25(7), 366-373.

Davis, G. F., \& Marquis, C. (2005). Prospects for organization theory in the early twenty-first century: Institutional fields and mechanisms. Organization Science, 16(4), 332-343.

Davy, J. A., Kinicki, A. J., \& Scheck, C. L. (1991). Developing and testing a model of survivor responses to layoffs. Journal of vocational behavior, 38(3), 302-317.

Day, G. S. (1994). The capabilities of market-driven organizations. the Journal of Marketing, 58(4), 37-52.

Day, G. S., \& Wensley, R. (1988). Assessing advantage: a framework for diagnosing competitive superiority. The Journal of Marketing, 52(2), 1-20.

de Cáceres, M. (2010). Entorno para la innovación. Mediterráneo económico(17), 113-126.

De Clercq, D., \& Sapienza, H. J. (2006). Effects of relational capital and commitment on venture capitalists' perception of portfolio company performance. Journal of Business Venturing, 21(3), 326-347.

De Clercq, D., Thongpapanl, N., \& Dimov, D. (2007). The role of conflict and social capital in cross-functional Collaboration. 4th Workshop on Trust Within and Between Organization.

De Cuyper, N., Mauno, S., Kinnunen, U., \& Mäkikangas, A. (2010). The role of job resources in the relation between perceived employability and turnover intention: A prospective two-sample study. Journal of vocational behavior.

De Leede, J., \& Looise, J. K. (2005). Innovation and HRM: Towards an integrated framework. Creativity and Innovation Management, 14(2), 108-117.

De Nisi, A. S. e. J. S. E., Hitt, M. A., \& DeNisi, A. S. (2003). Managing knowledge for sustained competitive advantage: Designing strategies for effective human resource management: Pfeiffer.

DeCarolis, D. M., \& Deeds, D. L. (1999). The impact of stocks and flows of organizational knowledge on firm performance: an empirical investigation of the biotechnology industry. Strategic Management Journal, 20(10), 953-968.

Delaney, J. T., \& Huselid, M. A. (1996). The impact of human resource management practices on perceptions of organizational performance. Academy of Management Journal, 39(4), 949-969.

Delaney, J. T., Lewin, D., Ichniowski, C., United States. Dept. of Labor. Bureau of LaborManagement, R., \& Cooperative, P. (1989). Human resource policies and practices in American firms: US Dept. of Labor, Bureau of Labor-Management Relations and Cooperative Programs.

Delery, J. E., \& Doty, D. H. (1996). Modes of theorizing in strategic human resource management: Tests of universalistic, contingency, and configurational performance predictions. Academy of Management Journal, 39(4), 802-835. 
Delery, J. E., \& Shaw, J. D. (2001). The strategic management of people in work organizations: Review, synthesis, and extension.

Delery, J. E., Gupta, N., \& Shaw, J. D. (1997). Human resource management and firm performance: A systems perspective. Paper presented at the Southern Management Association Meeting, Atlanta, GA.

Delgado Verde, M., Navas López, J. E., Martín de Castro, G., \& López Sáez, P. (2008). Propuesta de un modelo teórico sobre el proceso de innovación tecnológica basado en los activos intangibles. Cuadernos de estudios empresariales(18), 203-228.

Diamantopoulos, A. (1999). Viewpoint-export performance measurement: reflective versus formative indicators. International Marketing Review, 16(6), 444-457.

Diamantopoulos, A. (2006). The error term in formative measurement models: interpretation and modeling implications. Journal of Modelling in Management, 1(1), 7-17.

Diamantopoulos, A., \& Winklhofer, H. M. (2001). Index construction with formative indicators: An alternative to scale development. Journal of Marketing research, 38(2), 269-277.

Diamantopoulos, A., Riefler, P., \& Roth, K. P. (2008). Advancing formative measurement models. Journal of Business Research, 61(12), 1203-1218.

Dierickx, I., \& Cool, K. (1989). Asset stock accumulation and sustainability of competitive advantage. Management Science, 35(12), 1504-1511.

Dietz, G., \& Den Hartog, D. N. (2006). Measuring trust inside organisations. Personnel Review, 35(5), 557-588.

Dirks, K. T., \& Ferrin, D. L. (2002). Trust in leadership: Meta-analytic findings and implications for research and practice. Journal of Applied Psychology, 87(4), 611-627.

Dobbs, K. (2001). Knowing how to keep your best and brightest. Workforce, 57-60.

Dockel, A. (2003). The effects of retention factors on organizational commitment: an investigation of high technology employees. (Thesis- University of Pretoria).

Dockel, A., Basson, J. S., \& Coetzee, M. (2006). The effect of retention factors on organisational commitment: An investigation of high technology employees. SA Journal of Human Resource Management, 4(2), 20-28.

Dolan, S. L., Mach, M., \& Sierra, V. (2004). A configurational analysis of the human resources contribution to firm's bottom line results, AGRH Congress. Universidad de Québec en Montréal (Canadá).

Dolan, S. L., Schuler, R. S., Jackson, S., \& Valle Cabrera, R. (2007). La gestión de los recursos humanos: McGraw-Hill.

Dolz Dolz, C., Iborra Juan, M., \& Aldás Manzano, J. (2009). Las decisiones directivas de integración y la exploración de conocimiento en las estrategias de adquisición. Revista Europea de Dirección y Economía de la empresa, 18(4), 69-90.

Durán Juvé, D. (2004). "La dirección estratégica del capital humano con base en el conocimiento. Análisis de conocimientos en empresas textiles y de la confección en España”. Tesis doctoral presentada y defendida en la Universidad de Barcelona. Universidad de Barcelona.

Dyer, J. H. (1997). Effective interim collaboration: how firms minimize transaction costs and maximise transaction value. Strategic Management Journal, 18(7), 535-556.

Dyer, L. (1993). Human resources as a source of competitive advantage: Industrial Relations Centre, Queen's University. 
Dyer, L., \& Holder, G. (1988). "A Strategic Perspective of Human Resource Management" in Lee Dyer (ed). Human Resource Management: Evolving Roles and Responsibilities (Washington, DC: Bureau of National Affairs, 1988). In (pp. 1-46).

Dyer, L., \& Reeves, T. (1995). Human resource strategies and firm performance: what do we know and where do we need to go? The International Journal of Human Resource Management, 6(3), 656-670.

Eby, L. T., Allen, T. D., \& Brinley, A. (2005). A cross-level investigation of the relationship between career management practices and career-related attitudes. Group \&amp; Organization Management, 30(6), 565.

Eby, L. T., Casper, W. J., Lockwood, A., Bordeaux, C., \& Brinley, A. (2005). Work and family research in IO/OB: Content analysis and review of the literature (1980-2002) q. Journal of vocational behavior, 66, 124-197.

Edvinsson, L., \& Malone, M. S. (1997). Intellectual capital: realizing your company's true value by finding its hidden brainpower: HarperBusiness New York.

Edwards, J. R., \& Bagozzi, R. P. (2000). On the nature and direction of relationships between constructs and measures. Psychological methods, 5(2), 155.

Eisenberg, R., Fasolo, P., \& Davis-LaMastro, V. (1990). Perceived organizational support and employee diligence, commitment and innovation. Journal of Applied Psychology, 75(1), 51-59.

Eisenberger, R. C. J. A. S. L. P. (1997). Perceived organizational support, discretionary treatment, and job satisfaction. Journal of Applied Psychology, 82, 812-820.

Eisenberger, R., Armeli, S., Rexwinkel, B., Lynch, P. D., \& Rhoades, L. (2001). Reciprocation of perceived organizational support. Journal of Applied Psychology, 86(1), 42.

Eisenberger, R., Huntington, R., Hutchinson, S., \& Sowa, D. (1986). Perceived organizational support. Journal of Applied Psychology, 71(3), 500-507.

Eisenberger, R., Jones, J. R., Aselage, J., \& Sucharski, I. L. (2004). Perceived organizational support. The employment relationship: Examining psychological and contextual perspectives, 206-225.

Eisenberger, R., Stinglhamber, F., Vandenberghe, C., Sucharski, I. L., \& Rhoades, L. (2002). Perceived supervisor support: Contributions to perceived organizational support and employee retention. Journal of Applied Psychology, 87(3), 565-573.

Elliott, M. (2003). Work and family role strain among university employees. Journal of Family and Economic Issues, 24(2), 157-181.

Ellonen, R., Blomqvist, K., \& Puumalainen, K. (2008). The role of trust in organisational innovativeness. European Journal of Innovation Management, 11(2), 160-181.

Escrig, A., Roca, V., \& Bou, J. (2003). Antecedentes y consecuencias del compromiso organizativo: una visión desde la dirección de la calidad. Cuadernos de Economía y Empresa, $N^{\circ} 16,123-143$.

Essentials, H. B. (2002). Hiring and keeping the best people.

Evans, W. R., \& Davis, W. D. (2005). High-performance work systems and organizational performance: The mediating role of internal social structure. Journal of Management, 31(5), 758.

Evans, W. R., Novicevic, M. M., \& Davis, W. D. (2007). Resource-based foundations of strategic human resource management: a review and extension. International Journal of Learning and Intellectual Capital, 4(1), 75-91.

Falk, R. F., \& Miller, N. B. (1992). A primer for soft modeling: University of Akron Press. 
Fass, R. D., Bishop, J. W., y Glissmeyer, M. P. (2007). Perceived Co-worker Support and Task Interdependence in Law Enforcement. . $\quad$ (on line) http://www.swdsi.org/swdsi07/2007_proceedings/papers/535.pdf.

Fay, C. H., \& Thompson, M. A. (2001). Contextual determinants of reward systems' success: an exploratory study. Human Resource Management, 40(3), 213-226.

Felps, W., Mitchell, T. R., Hekman, D. R., Lee, T. W., Holtom, B. C., \& Harman, W. S. (2009). Turnover Contagion: How Coworkers' Job Embeddedness and Job Search Behaviors Influence Quitting. The Academy of Management Journal (AMJ), 52(3), 545-561.

Fernandez Alarcón, V. F., Leyes, J. M. S., Hiern, J. M., \& Suñé, A. (2004). Innovación: influencias percibidas procedentes de la estructura organizativa de las empresas. Paper presented at the VIII Congreso de Ingeniería de Organización Leganés, 9 y 10 de septiembre de 2004

Fernandez Moreno, M. V., Peñas García -Pardo, I., \& Hernández Perlines, F. (2008). Factores determinantes del éxito exportador. El papel de la estrategia exportadora en las cooperativas agrarias. CIRIEC-ESPAÑNA, 39-64.

Fernández Rodríguez, M. Z., \& Suárez González, I. (1996). La estrategia de la empresa desde una perspectiva basada en los recursos. Revista Europea de Dirección y Economía de la empresa, 5(3), 73.

Ferratt, T. W., Agarwal, R., Brown, C. V., \& Moore, J. E. (2005). IT human resource management configurations and IT turnover: Theoretical synthesis and empirical analysis. Information Systems Research, 16(3), 237.

Ferres, N., Connell, J., \& Travaglione, A. (2003). Co-worker trust: a social lubricant for positive workplace attitudes and perceptions of support.

Ferres, N., Travaglione, A., \& Connell, J. (2002). Trust: A precursor to the potential mediating effect of transformational leadership? International Journal of Organisational Behaviour, 5(8), 242-263.

Ferris, G. R., Arthur, M. M., Berkson, H. M., \& Kaplan Gloria, D. M. (1998). Toward a social context theory of the human resource management-organization effectiveness relationship. Human Resource Management Review, 8(3), 235-264.

Ferris, G. R., Hall, A. T., Royle, M. T., \& Martocchio, J. J. (2004). Theoretical development in the field of human resources management: issues and challenges for the future. Organizational Analysis, 12(3), 231-254.

Ferris, G. R., Hochwarter, W. A., Buckley, M. R., Harrell-Cook, G., \& Frink, D. D. (1999). Human resources management: Some new directions. Journal of Management, 25(3), 385.

Fisher, G. (2001). Work/Personal Life Balance: A construct development study. .

Fisher, G. G. (2001). Work/life balance: Definition, measurement, and relation to business outcomes. In A. L. Unckless (Chair), Work/life balance as business imperative: Why companies are taking notice. Paper presented at the Symposium conducted at the 16th annual conference of the Society for Industrial and Organizational Psychology, San Diego, CA., San Diego, California (USA).

Fisher, G. G. (2004). The relationship between physical job demands and absenteeism. Paper presented at the annual meeting of the Gerontological Society of America, . Washington, DC.

Fisher-McAuley, G., Stanton, J. M., Jolton, J., \& Gavin, J. (2003). Modeling the relationship between work/life balance and organizational outcomes, Annual Conference of the Society for Industrial-Organisational Psychology. Orlando. 
Fitz-enz, J. (1990a). El valor añadido por la dirección de RH: una nueva estrategia para los 90.

Fitz-enz, J. (1990b). Getting-and keeping-good employees. Personnel, 67(8), 25-28.

Flor Peris, M. L., Camisón Zornoza, C., \& Oltra Mestre, M. J. (2004). El efecto de la estrategia de innovación tecnológica y de la estrategia exportadora en el desempeño internacional de la empresa. Cuadernos de Economía y Dirección de la Empresa(20), 151.

Foong, K., Yorston, R., \& Gratton, L. (2003). Human capital measurement and reporting: A British perspective. LONDON BUSINESS SCHOOL MBA 2nd Year Project, Online im Internet: URL: < http://www. berr. gov. uk/files/file38840. pdf >, Stand J uni.

Fornell, C. (1982). A Second Generation of Multivariate Analysis: Measurement and Evaluation: Praeger Publishers.

Fornell, C., \& Bookstein, F. L. (1982). Two structural equation models: LISREL and PLS applied to consumer exit-voice theory. Journal of Marketing research, 19(4), 440-452.

Fornell, C., \& Cha, J. (1994). Partial least squares. Advanced methods of marketing research, 407, 52-78.

Fornell, C., \& Larcker, D. F. (1981). Evaluating structural equation models with unobservable variables and measurement error. Journal of Marketing research, 18(1), 39-50.

Forrester, R. (2000). Empowerment: Rejuvenating a potent idea. The Academy of Management Executive (1993-2005), 67-80.

Foss, N. J. (2007). The emerging knowledge governance approach: challenges and characteristics. Organization, 14(1), 29.

Foss, N. J. L. K., \& Laursen, K. (2002). Performance Pay, Delegation, and Multitasking under Uncertainty and Innovativeness: Suggestions and Empirical Investigation, Frederiksberg, Copenhagen Business School, Department of Industrial Economics and Strategy. Frederiksberg: Copenhagen Business School, Department of Industrial Economics and Strategy, October, mimeo.

Foss, N. J., \& Minbaeva, D. B. (2009). Governing knowledge: The strategic human resource management dimension. Center for Strategic Management and Globalization Working Paper No.SMG WP, 3, 2009.

Foss, N. J., Knudsen, C., \& Montgomery, C. A. (1995). Resource-Based and Evolutionary Theories of the Firm: Towards a Synthesis. .

Friedman, R. A., \& Holtom, B. (2002). The effects of network groups on minority employee turnover intentions. Human resource management, 41(4), 405-421.

Fuertes, F., Hontangas, P., \& Alonso, P. (1993). Evaluación del Modelo de las Características del Puesto en una Muestra de trabajadores de la Confección Textil. Munduate, L.y Barón, M.(comp.), 177-197.

Fuertes, F., Munduate, L., \& Fortea, M. A. (1996). Análisis y rediseño de puestos (Job Diagnostic Survey - JDS). Castellón: Publicaciones de la Universitat Jaime I.

Fuertes, F., Munduate, L., \& Fortea, M. A. (1996). Análisis y Rediseño de Puestos Adaptación española del cuestionario Job Diagnostic Survey-JDS. Social i Metodología.

Fulmer, I. S., Gerhart, B., \& Scott, K. S. (2003). Are the 100 best better? An empirical investigation of the relationship between being a "great place to work" and firm performance. Personnel Psychology, 56(4), 965-993.

Gaertner, S. (1999). Structural determinants of job satisfaction and organizational commitment in turnover models. Human Resource Management Review, 9(4), 479-493.

Gagné, M. (2009). A model of knowledge sharing motivation. Human Resource Management, 48(4), 571-589. 
Gagné, M., \& Deci, E. L. (2005). Self determination theory and work motivation. Journal of organizational behavior, 26(4), 331-362.

Gagné, M., Chemolli, E., Forest, J., \& Koestner, R. (2009). The temporal relations between work motivation and organizational commitment. Psychologica Belgica, 48(2/3), 219241.

Gagné, M., Senécal, C., \& Koestner, R. (1997). Proximal job characteristics, feelings of empowerment, and intrinsic motivation: A multidimensional model. Journal of Applied Social Psychology, 27(14), 1222-1240.

Galende del Canto, J. (2008). La organización del proceso de innovación en la empresa española. Economía industrial(368), 169-185.

Galende, J. (2006). Analysis of Technological Innovation from Business Economics and Management. . Technovation, 26((3)), 300-311.

Galende, J., \& Suárez, I. (1999). A resource-based analysis of the factors determining a firm’s R\&amp;D activities. Research Policy, 28(8), 891-905.

Gallardo, E. (2008). Evolución en el estudio y medida del compromiso Organizativo. Problemáticas y soluciones. Paper presented at the XVIII Congreso nacional de ACEDE, León.

Galunic, D. C., \& Anderson, E. (2000). From security to mobility: generalized investments in human capital and agent commitment. Organization Science, 11(1), 1-20.

Galunic, D. C., \& Rodan, S. (1998). Resource recombinations in the firm: knowledge structures and the potential for Schumpeterian innovation. Strategic Management Journal, 19(12), 1193-1201.

García Muiña, F. E., \& Navas López, J. E. (2007). Las capacidades tecnológicas y los resultados empresariales. Cuadernos de Economía y Dirección de la Empresa(32), 177-210.

García Valderrama, T., \& Mulero Mendigorri, E. M. (2007). Medida de los factores claves del éxito de la I D. Cuadernos de Economía y Dirección de la Empresa(32), 15-48.

García, R., Neira, E., \& Castro, C. (2011). Prácticas de recursos humanos e intención de marcha de los empleados, XXI Jornadas Hispano lusas de gestión científica. (pp. pp.420-433). Córdoba, .

García-Cruz, J., Valle-Cabrera, R., Camelo-Ordaz, C., \& Sousa-Ginel, E. (2008). La influencia de los recursos humanos sobre la creación de conocimiento y la innovación: el papel mediador del compromiso afectivo», XVIII Congreso Nacional de ACEDE. León.

García Cruz, J., \& Valle Cabrera, R. (2008). La generación de confianza y sus efectos sobre el comportamiento. Congreso Nacional AEDEM, Salamanca, Publicado en Estableciendo puentes en una economía global / coord. por Julio Pindado García, Gregory Payne, Vol. 1, 2008

García-Pintos Escuder, A., Caballero Fernández, G., \& Piñeiro García, M. P. (2010). La diseminación del conocimiento y su efecto sobre la capacidad de innovar. Creando clientes en mercados globales / coord. por José Antonio Redondo López.

Gardner, T. M., Moynihan, L. M., \& Wright, P. M. (2007). The influence of human resource practices and collective affective organizational commitment on aggregate voluntary turnover. Ithaca, NY: Cornell University.

Gardner, T., Moynihan, L., Park, H., \& Wright, P. (2000). Unlocking the black box: Examining the processes through which human resource practices impact business performance. 
Garrido Samaniego, M. J., \& Pérez Santana, M. P. (1998). Satisfacción de los clientes internos: el papel estratégico de la gestión de los recursos humanos. Investigaciones Europeas de Dirección y Economía de la Empresa, 4(3), 13-28.

Gefen, D., \& Straub, D. (2005). A practical guide to factorial validity using PLS-Graph: Tutorial and annotated example. Communications of the Association for Information Systems (Volume 16, 2005), 91(109), 91.

Gefen, D., Straub, D., \& Boudreau, M. C. (2000). Structural equation modeling and regression: Guidelines for research practice. Communications of the Association for Information Systems, 4(1), 7.

Geisser, S. (1975). The predictive sample reuse method with applications. Journal of the American Statistical Association, 70(350), 320-328.

Gendron, B. (2004). Why emotional capital matters in education and in labour? Toward an optimal exploitation of human capital and knowledge management. .

Gendron, B. (2007). Emotional Capital: a crucial capital for a citizenship society with personal, social and Economic returns. .

Gent Franch, K., \& Andalaf Chacur, A. (2007). Extensión de los postulados de la teoría de recursos y capacidades de la empresa a campos pscológicos. Revista Economía y Administración. 68.

Ghoshal, S., Korine, H., \& Szulanski, G. (1994). Interunit communication in multinational corporations. Management Science, 40(1), 96-110.

Giosan, C. (2009). Predictors of job embeddedness. The New School Psychology Bulletin, 1(1).

Glance, N. S., Hogg, T., \& Huberman, B. A. (1997). Training and Turnover in the Evolution of Organizations. Organization Science, 8(1), 84-96.

Gloet, M. (2006). Knowledge management and the links to HRM: Developing leadership and management capabilities to support sustainability. Management Research News, 29(7), 402-413.

Gloet, M., \& Berrell, M. (2003). The dual paradigm nature of knowledge management: implications for achieving quality outcomes in human resource management. Journal of Knowledge Management, 7(1), 78-89.

Gloet, M., \& Terziovski, M. (2004). Exploring the relationship between knowledge management practices and innovation performance. Journal of Manufacturing Technology Management, 15(5), 402-409.

Gnyawali, D., Steward, A., \& Grant, J. (1997). Creation and utilization of organizational knowledge: An empirical study of the roles of organizational learning on strategic decision making.

Goleman, D. (1999). La inteligencia emocional en la empresa.

Gomez Mejia, L. R., Balkin, D., \& Cardy, R. (1997). Gestión de Recursos Humanos: Madrid, Prentice-Hall.

Gómez Mejía, L., Cardy, R. L., Santos, I. O., Muñoz, E. M., Valle Cabrera, R. V., \& Balkin, D. B. (1997). Gestión de recursos Humanos: Prentice Hall.

Gomez-Mejia, L. R., \& Balkin, D. B. (1992). Compensation, organizational strategy, and firm performance: South-Western Pub.

Gómez-Mejía, L. R., Balkin, D. B., Cardy, R. L., López, Y. M., Ronda, J. G. T., \& Rodríguez, M. J. P. (2001). Dirección y gestión de recursos humanos: Prentice Hall.

Gomez-Mejia, L., \& Wiseman, R. M. (1997). Reframing Execufive Compensation: An Assessment and Outlook. Journal of Management, 23(3), 291. 
González Álvarez, N., \& Nieto Antolín, M. (2005). Efectos de la ambigüedad casual sobre los resultados empresariales: Un análisis en las mayores empresas manufactureras españolas. Cuadernos de Economía y dirección de Empresas, 25, 82-102.

González Álvarez, N., \& Nieto Antolín, M. (2007a). El papel de la ambigüedad causal como variable mediadora entre las prácticas de recursos humanos de alto compromiso y los resultados corporativos. Revista Europea de Dirección y Economía de la empresa, 16(4), 107-126.

Gonzalez-Alvarez, N., \& Nieto-Antolin, M. (2007b). Appropriability of innovation results: an empirical study in Spanish manufacturing firms. Technovation, 27(5), 280-295.

Gopalakrishnan, S., \& Bierly, P. (2001). Analyzing innovation adoption using a knowledgebased approach. Journal of Engineering and Technology Management, 18(2), 107-130.

Gopalakrishnan, S., \& Damanpour, F. (1997). A Review of Innovation Research in Economics, Sociology and Technology Management. Omega, 25( $\left.\mathrm{N}^{\circ} 1\right), 15-28$.

Gopalakrishnan, S., \& Damanpour, F. (1998). Theories of organizational structure and innovation adoption: the role of environmental change. Journal of Engineering and Technology Management, 15(1), 1-24.

Gouldner, A. W. (1960). The norm of reciprocity. American Sociological Review, 25(2), 161178.

Gould-Williams, J. (2003). The importance of HR practices and workplace trust in achieving superior performance: a study of public-sector organizations. The International Journal of Human Resource Management, 14(1), 28-54.

Gould-Williams, J., \& Davies, F. (2005). Using social exchange theory to predict the effects of HRM practice on employee outcomes. Public Management Review, 7(1), 1-24.

Graen, G. B., Novak, M. A., \& Sommerkamp, P. (1982). The effects of leader-member exchange and job design on productivity and satisfaction: Testing a dual attachment model. Organizational behavior and human performance, 30(1), 109-131.

Graen, G. B., Scandura, T. A., Ferris, G., \& Rowland, K. (1986). A theory of dyadic career reality. Research in personnel and human resources management, 4, 147-181.

Grant, D., \& Oswick, C. (1998). Of believers, atheists and agnostics: practitioner views on HRM. Industrial Relations Journal, 29(3), 178-193.

Grant, D., \& Shields, J. (2002). In search of the subject: researching employee reactions to human resource management. The Journal of Industrial Relations, 44(3), 313-334.

Grant, R. M. (1991). The resource-based theory of competitive advantage: Implications for strategy. California Management Review, 22, 114-135.

Grant, R. M. (1995). Analyzing resources and capabilities. Contemporary strategy analysis: Concepts, techniques, applications.

Grant, R. M. (1996a). Prospering in dynamically-competitive environments: Organizational capability as knowledge integration. Organization Science, 7(4), 375-387.

Grant, R. M. (1996b). Toward a knowledge-based theory of the firm. Strategic Management Journal, 17(10), 109-122.

Gratton, L., \& Ghoshal, S. (2003). Managing Personal Human Capital::: New Ethos for the [] Volunteer'Employee. European Management Journal, 21(1), 1-10.

Greenhaus, J. H. (2008). Innovations in the study of the work-family interface: Introduction to the special section. Journal of Occupational and Organizational Psychology, 81(3), 343348. 
Greenhaus, J. H., \& Beutell, N. J. (1985). Sources of conflict between work and family roles. Academy of Management Review, 10(1), 76-88.

Greenhaus, J. H., \& Powell, G. N. (2006). When work and family are allies: A theory of workfamily enrichment. The Academy of Management Review.

Greenhaus, J. H., Collins, K. M., Singh, R., \& Parasuraman, S. (1997). Work and family influences on departure from public accounting. Journal of vocational behavior, 50(2), 249-270.

Griffeth, R. W., \& Gaertner, S. (2001). A Role for Equity Theory in the Turnover Process: An Empirical Test1. Journal of Applied Social Psychology, 31(5), 1017-1037.

Griffeth, R. W., \& Hom, P. W. (1995). The employee turnover process. Research in personnel and human resources management, 13(3), 245-293.

Griffeth, R. W., \& Hom, P. W. (2001). Retaining valued employees: Sage Publications, Inc.

Griffeth, R. W., \& Hom, P. W. (2004). Innovative theory and empirical research on employee turnover: Information Age Pub Inc.

Griffeth, R. W., Hom, P. W., \& Gaertner, S. (2000). A meta-analysis of antecedents and correlates of employee turnover: Update, moderator tests, and research implications for the next millennium. Journal of Management, 26(3), 463.

Griffeth, R., \& Hom, P. (2004). Innovative theory and empirical research on employee turnover.

Grover, S., \& Crocker, K. (1995). Who appreciates family-responsiveness human resource policies? Journal of Applied Psychology, 48, 271-288.

Guchait, P., \& Cho, S. (2010). The impact of human resource management practices on intention to leave of employees in the service industry in India: the mediating role of organizational commitment. The International Journal of Human Resource Management, 21(8), 1228-1247.

Guest, D. (1999). Human Resource management and industrial relations. Human Resource Management: Critical Perspectives on Business and Management, 1, 94-113.

Guest, D. (2002). Human resource management, corporate performance and employee wellbeing: building the worker into HRM. Journal of Industrial Relations, 44(3), 335.

Guest, D. E. (1997). Human resource management and performance: a review and research agenda. The International Journal of Human Resource Management, 8(3), 263-276.

Guest, D. E., \& Conway, N. (1997). Employee motivation and the psychological contract.

Guest, D. E., Michie, J., Conway, N., \& Sheehan, M. (2003). Human resource management and corporate performance in the UK. British Journal of Industrial Relations, 41(2), 291-314.

Guest, D., \& Conway, N. (1999). Peering into the black hole: the downside of the new employment relations in the UK. British Journal of Industrial Relations, 37(3), 367-389.

Guthrie, J. (2001). The management, measurement and the reporting of intellectual capital. Journal of Intellectual Capital, 2(1), 27-41.

Guthrie, J. P. (2000). Alternative pay practices and employee turnover. Group \& Organization Management, 25(4), 419.

Guthrie, J. P. (2001). High-involvement work practices, turnover, and productivity: Evidence from New Zealand. The Academy of Management Journal, 44(1), 180-190.

Guthrie, J. P., Datta, D. K., \& Wright, P. M. (2004). Peeling back the onion competitive advantage through people: Test of a causal model. Centre for Advanced Human Resource Studies (CAHRS) Working Paper, Cornell University, Ithaca, NY, 1-32. 
Guzzo, R. A., Noonan, K. A., \& Elron, E. (1994). Expatriate managers and the psychological contract. Journal of Applied Psychology, 79(4), 617.

Haar, J. M. (2004). Work-family conflict and turnover intention: Exploring the moderation effects of perceived work-family support. Journal article by Jarrod M. Haar; New Zealand Journal of Psychology, 33.

Haar, J. M. (2007). Work-family flexible practices bundle and firm performance: the moderating effects of innovation strategy. Paper presented at the 22nd Workshop on strategic human resource management (EIASM), Brussels.

Haar, J. M., \& Spell, C. S. (2004). Programme knowledge and value of work-family practices and organizational commitment. The International Journal of Human Resource Management, 15(6), 1040-1055.

Hackman, J. R., \& Oldham, G. R. (1980). Work redesign: Prentice Hall.

Hair, J., Anderson, R., Tatham, R., \& Black, W. (1999). Análisis Multivariante de datos. Ed. Prentice Hall. Londres.

Hall, B. H., \& Robert, E. (1993). The Value and Performance of US Corporations. Brookings Papers on Economic Activity, 1, 1-34.

Hall, R. (1993). A framework linking intangible resources and capabiliites to sustainable competitive advantage. Strategic Management Journal, 14(8), 607-618.

Handy, C. (1995). Trust and the virtual corporation. Harvard Business Review, 73(3), 40-50.

Handy, C.(1996). Gods of management: The changing work of organizations: Oxford University Press, USA.

Handy, C. (2000). How do you manage people whom you do not see? Trust and the virtual organization. Technology, Organizations and Innovation: Towards' real virtuality'?, 1869.

Hansen, M., Nohria, N., \& Tierney, T. (1999). What's your strategy for managing knowledge? . Harvard Business Review March-April, 106-116.

Harris, M. N., Tang, K. K., \& Tseng, Y. P. (2010). Employee Turnover: Less is Not Necessarily More?

Hatch, N. W., \& Dyer, J. H. (2004). Human capital and learning as a source of sustainable competitive advantage. Strategic Management Journal, 25(12), 1155-1178.

Hatch, N. W., \& Dyer, J. H. (2004). Human capital and learning as a source of sustainable competitive advantage. Strategic Management Journal, 25(12), 1155-1178.

Hausknecht, J. P., \& Trevor, C. O. (2011). Collective turnover at the group, unit, and organizational levels: Evidence, issues, and implications. Journal of Management, 37(1), 352.

Hausknecht, J. P., Rodda, J., \& Howard, M. J. (2009). Targeted employee retention: Performance based and job related differences in reported reasons for staying. Human Resource Management, 48(2), 269-288.

Helfat, C. E. (1994). Firm-specificity in corporate applied R\&D. Organization Science, 5(2), 173-184.

Helfat, C. E. (1997). Know-how and asset complementarity and dynamic capability accumulation: the case of R\&D. Strategic Management Journal, 18(5), 339-360.

Helfat, C. E., Finkelstein, S., \& Mitchell, W. (2007). Dynamic capabilities: Understanding strategic change in organizations: Wiley-Blackwell. 
Hemdi, M. A., \& Nasurdin, A. M. (2006). Predicting turnover intentions of hotel employees: The influence of employee development human resource management practices and trust in organization. Gadjah Mada International Journal of Business, 8(1), 21-42.

Hernández Perlines, F. P. G. (2008). Efectividad de la estrategia de recursos humanos: modelo integrador de la Teoría de Recursos y Capacidades y la Teoría del Comportamiento en las entidades financieras de la economia social. REVESCO. Revista de Estudios Cooperativos(94), 27-58.

Hernangómez Barahona, J. J., Fuente Sabaté, J. M., \& Santos Álvarez, M. V. (1998). Factores determinantes de los procesos de cambio organizativo. Revista Europea de Dirección y Economía de la empresa, 7(3), 31-52.

Hirschfeld, K. (2006). Retention and Fluctuation: Keeping staff-Losing staff. Berlin: ID Text.

Hislop, D. (2003). Linking human resource management and knowledge management via commitment: A review and research agenda. Employee relations, 25(2), 182-202.

Hislop, D. (Ed.). (2005). Knowledge management in organizations: Osford University Press.

Hitt, M. A., Bierman, L., Shimizu, K., \& Kochhar, R. (2001). Direct and moderating effects of human capital on strategy and performance in professional service firms: A resourcebased perspective. The Academy of Management Journal, 44(1), 13-28.

Hofer, C. W., \& Schendel, D. (1978). Strategy formulation: Analytical concepts: West Pub. Co., St. Paul.

Holtbrügge, D., Friedmann, C. B., \& Puck, J. F. (2010). Recruitment and Retention in Foreign Firms in India: A Resource Based View. Human Resource Management, 49(3), 439-455.

Holtom, B. C., Mitchell, T. R., \& Lee, T. W. (2006). Increasing human and social capital by applying job embeddedness theory. Organizational dynamics, 35(4), 316-331.

Holtom, B. C., Mitchell, T. R., Lee, T. W., \& Eberly, M. B. (2008). Chapter 5: turnover and retention research: a glance at the past, a closer review of the present, and a venture into the future. The Academy of Management Annals, 2(1), 231-274.

Hom, P. W., \& Griffeth, R. W. (1991). Structural equations modeling test of a turnover theory: Cross-sectional and longitudinal analyses. Journal of Applied Psychology, 76(3), 350-366.

Hom, P. W., \& Griffeth, R. W. (1995). Employee turnover: South-Western Pub.

Hom, P. W., \& Hulin, C. L. (1981). A competitive test of the prediction of reenlistment by several models. Journal of Applied Psychology, 66(1), 23.

Hom, P. W., \& Kinicki, A. J. (2001). Toward a greater understanding of how dissatisfaction drives employee turnover. The Academy of Management Journal, 44(5), 975-987.

Hom, P. W., Griffeth, R. W., \& Sellaro, C. L. (1984). The validity of Mobley's (1977) model of employee turnover. Organizational behavior and human performance, 34, 141-174.

Hom, P. W., Tsui, A. S., Wu, J. B., Lee, T. W., Zhang, A. Y., Fu, P. P., et al. (2009). Explaining employment relationships with social exchange and job embeddedness. Journal of Applied Psychology, 94(2), 277-297.

Hoonakker, P. L. T., Carayon, P., \& Schoepke, J. S. (2004). Work Family Conflict in the IT work force. Journal of organizational behavior, 13, 389-411.

Hoopes, D. G., Madsen, T. L., \& Walker, G. (2003). Guest editors' introduction to the special issue: why is there a resource based view? Toward a theory of competitive heterogeneity. Strategic Management Journal, 24(10), 889-902.

Horwitz, F. M., Heng, C. T., \& Quazi, H. A. (2003). Finders, keepers? Attracting, motivating and retaining knowledge workers. Human Resource Management Journal, 13(4), 23-44. 
Hsu, B. F., Chen, W. Y., Wang, M. L., \& Yu, H. Y. (2007). How Human Resource Practices Impact Knowledge Sharing in R\&D Teams. PICMET 2007, 5-9 August, Portland, Oregon - USA. Editado por IEEE. Pp.2618-2625

Hsu, S. H., Chen, W. H., \& Hsieh, M. (2006). Robustness testing of PLS, LISREL, EQS, and ANN-based SEM for measuring customer satisfaction.Total Quality Management \& Business Excellence,17 (3),355-372 .

Huang, C., Lin, H. C., \& Chuang, C. H. (2006). Constructing factors related to worker retention. International Journal of Manpower, 27(5), 491-508.

Huang, Y., Chung, H., \& Lin, C. (2009). R\&D Sourcing Strategies: Determinants and Consequences. Technovation, 29, 155-169.

Hulin, C. (1991). Withdrawal, persistence, and commitment in organizations. In M. D. Dunnette \&amp; L. M. Hough (Eds), Handbook of industrial and organizational psychology (Vol. 2, pp. 445): Consulting Psychologists Press.

Hulin, C. L., Roznowski, M., \& Hachiya, D. (1985). Alternative Opportunities and Withdrawal Decisions:: Empirical and Theoretical Discrepancies and an Integration. Psychological bulletin, 97(2), 233-250.

Hulland, J. (1999). Use of partial least squares (PLS) in strategic management research: a review of four recent studies. Strategic Management Journal, 20(2), 195-204.

Hunt, S. D., \& Morgan, R. M. (1995). The comparative advantage theory of competition. The Journal of Marketing, 59(2), 1-15.

Hunter, J. E., \& Schmidt, F. (1998). The validity and utility of selection methods in personnel psychology: Practical and theoretical implications of 85 years of research findings. Psychological bulletin, 124(2), 262-274.

Huselid, M. A. (1995). The impact of human resource management practices on turnover, productivity, and corporate financial performance. Academy of management journal, 38(3), 635-672.

Huselid, M. A., \& Becker, B. E. (1996). Methodological Issues in Cross Sectional and Panel Estimates of the Human Resource Firm Performance Link. Industrial Relations: A Journal of Economy and Society, 35(3), 400-422.

Huselid, M. A., Jackson, S. E., \& Schuler, R. S. (1997). Technical and strategic human resource management effectiveness as determinants of firm performance. Academy of Management Journal, 171-188.

Hutchinson, S. (1997). A Path Model of Perceived Organizational Support? Journal of Social Behavior and Personality, 12, 159-174.

Hutchinson, S., \& Purcell, J. (2003). Bringing Policies to Life: The vital role of front line managers in people management. .

Hutchinson, S., \& Purcell, J. (2003). Bringing Policies to Life: The vital role of front line managers in people management. research report, CIPD, London.

Hutchinson, S., Kinnie, N., \& Purcell, J. (2002). Bringing Policies to Life: Discretionary Behaviour and the Impact on Business Performance. Paper presented at the Bath Conference,University of Bath School of Management, 10-11 April, 2002.

Ichniowski, C., \& Shaw, K. (1999). The effects of human resource management systems on economic performance: An international comparison of US and Japanese plants. Management Science, 45(5), 704-721. 
Ichniowski, C., Shaw, K., \& Prennushi, G. (1997). The effects of human resource management practices on productivity: A study of steel finishing lines. The American Economic Review, 87(3), 291-313.

Ipe, M. (2003). Knowledge sharing in organizations: a conceptual framework. Human Resource Development Review, 2(4), 337.

Isidro Peña García-Pardo, I., Hernández Perlines, F., \& Villasalero Díaz, M. (2010). Human resource management, strategy and Performance.

Ismail, W. K. W., Omar, R., \& Bidmeshgipour, M. (2010). The Relation of Strategic Human Resource Practices with Firm Performance: Considering the Mediating Role of Resource Based View. Journal of Asia Pacific Studies, 1(3), 395-420.

Ito, J. K., \& Brotheridge, C. M. (2005). Does supporting employees' career adaptability lead to commitment, turnover, or both? Human Resource Management, 44(1), 5-19.

Iverson, R. D., \& Buttigieg, D. M. (1999). Affective, normative and continuance commitment: can the 'right kind'of commitment be managed? Journal of Management Studies, 36(3), 307-333.

Jackofsky, E. F. (1984). Turnover and job performance: An integrated process model. Academy of Management Review, 9, 74-83.

Jackson, S. E., \& Schuler, R. S. (1995). Understanding human resource management in the context of organizations and their environments. Annual Review of Psychology, 46.

Jackson, S. E., Hitt, M. A., \& DeNisi, A. S. (2003). Managing knowledge for sustained competitive advantage: Designing strategies for effective human resource management: Pfeiffer.

Jaros, S. J., Jermier, J. M., Koehler, J. W., \& Sincich, T. (1993). Effects of continuance, affective, and moral commitment on the withdrawal process: An evaluation of eight structural equation models. Academy of management journal, 36(5), 951-995.

Jarvis, C. B., MacKenzie, S. B., \& Podsakoff, P. M. (2003). A critical review of construct indicators and measurement model misspecification in marketing and consumer research. The Journal of Consumer Research, 30(2), 199-218.

Javed, U., Whitfield, K., \& Yousafzai, S. (2009). Work environment characteristics and job attitudes: a quantitative analysis of the literature. VII International HRM Workshop. "New Scenarios in Human Resource Management”, 20-21 May, Murcia (Spain) 2009.

Jawahar, I. M., \& Hemmasi, P. (2006). Perceived organizational support for women's advancement and turnover intentions: The mediating role of job and employer satisfaction. Women in Management Review, 21(8), 643-661.

Jenkins Jr, D., Mitra, A., Gupta, N., \& Shaw, J. (1998). Are financial incentives related to performance? A meta-analytic review of empirical research. Journal of Applied Psychology, 83, 777-787.

Jerez Gómez, P., Céspedes Lorente, J., \& Valle Cabrera, R. (2003). La estrategia de afectación y su incidencia en el aprendizaje organizativo: un análisis integrado. Investigaciones Europeas de Dirección y Economía de la Empresa, 9(1), 13-30.

Jerez Gómez, P., Céspedes Lorente, J., \& Valle Cabrera, R. (2005). Organizational learning and compensation strategies: evidence from the Spanish chemical industry. Human Resource Management, 44(3), 279-299.

Jerez-Gomez, P., Cespedes-Lorente, J., \& Valle-Cabrera, R. (2005b). Organizational learning capability: a proposal of measurement. Journal of Business Research, 58(6), 715-725. 
Jesús, P. O., González Benito, J., \& Galende del Canto, J. (2004). La Gestión de la Calidad Total como un antecedente de la Capacidad de Innovación Empresarial. Working Papers" New Trends on Business Administration".Documentos de Trabajo" Nuevas Tendencias en Dirección de Empresas"..

Jiménez-Jiménez, D., \& Sabater-Sánchez, R. (2010). Human capital and innovation competences: an empirical study, $X X$ Congreso de ACEDE. Granada.

Jiménez-Jiménez, D., \& Sanz-Valle, R. (2003). La gestión de RRHH y la innovación: efecto moderador del aprendizaje organizativo. Paper presented at the 4th International Workshop on "Human Resource Management in the New Economy”, Cádiz.

Jimenez-Jimenez, D., \& Sanz-Valle, R. (2005). Innovation and human resource management fit: an empirical study. International Journal of Manpower, 26(4), 364-381.

Jiménez-Jiménez, D., \& Sanz-Valle, R. (2007). Managing Human Resources in Order to Promote Knowledge Management and Technical Innovation. Management Research, 5(2), 83-100.

Johannessen, J. A., Olaisen, J., \& Olsen, B. (2001). Mismanagement of tacit knowledge: the importance of tacit knowledge, the danger of information technology, and what to do about it. International journal of information management, 21(1), 3-20.

Johnson, J. T., Griffeth, R. W., \& Griffin, M. (2000). Factors discriminating functional and dysfunctional salesforce turnover. Journal of business \& industrial marketing, 15(6), 399415.

Jones, J. W. (1991). Preemployment honesty testing: Current research and future directions: Greenwood Publishing Group.

Jones, S. C., Foster, D. P., \& Hassanyeh, F. (1991). The role of unemployment in parasuicide. . Psychological Medicine 21, 169-176.

Jöreskog, K. G. (1970). A general method for analysis of covariance structures. Biometrika, 57(2), 239.

Jorgensen, F., Becker, K. L., \& Matthews, J. H. (2009). Human resource management and innovation: what are knowledge-intensive firms doing?. In Proceedings of Annual Meeting of the Academy of Management, Academy of Management, Montréal Convention Center, Montreal.

Kale, P., Singh, H., \& Perlmutter, H. (2000). Learning and protection of proprietary assets in strategic alliances: Building relational capital. Strategic Management Journal, 21(3), 217237.

Kamoche, K. (1996). Strategic Human Resource Management within a resource-capability view of the firm. Journal of Management Studies, 33,213-233.

Kamoche, K. N. (Ed.). (2001). Understanding human resource management: Philadelphia: Open University Press.

Kamoche, K., \& Mueller, F. (1998). Human resource management and the appropriationlearning perspective. Human Relations, 51(8), 1033.

Kang, S., Morris, S., \& Snell, S. (2007). Relational archetypes, organizational learning, and value creation:Extending the human resource architecture. Academy of Management Review, 32(1), 20.

Kanter, R. M. (1968). Commitment and social organization: a study of commitment mechanisms in utopian communities. American Sociological Review, 33, 18.

Kanter, R. M. (1985). Supporting innovations and venture development in stablished companies. Journal of Business Venturing, invierno. 
Katerberg, R. (1979). Effects of job complexity on the reactions of part-time employees* 1. Organizational behavior and human performance, 24(3), 317-332.

Katerberg, R., Hom, P., \& Hulin, C. (1979). Effects of job complexity on the reactions of parttime workers. Organizational behavior and human performance, 24, 317-332.

Kazlauskaite, R., \& Buciuniene, I. (2008). The role of human resources and their management in the establishment of sustainable competitive advantage. Inzinerine EkonomikaEngineering Economics, 5, 78-84.

Kehoe, R. R., \& Wright, P. M. (2010). The impact of high performance human resource practices on employees' attitudes and behaviors. Journal of Management.

Kelloway, E. K., \& Barling, J. (2000). What we have learned about developing transformational leaders. Leadership \& Organization Development Journal, 21(7), 355-362.

Kelloway, E. K., \& Barling, J. (2000b). Knowledge work as organizational behavior. International Journal of Management Reviews, 2(3), 287-304.

Kim, W. C., \& Mauborgne, R. (1997). Fair process: managing in the knowledge economy. Harvard Business Review, 75(4), 65-75.

Kim, W. C., \& Mauborgne, R. (1997a). Value innovation: the strategic logic of high growth. Harvard Business Review, 75(1), 102.

Kinnie, N., Hutchinson, S., Purcell, J., Rayton, B., \& Swart, J. (2005). Satisfaction with HR practices and commitment to the organisation: why one size does not fit all. Human Resource Management Journal, 15(4), 9-29.

Kleinbaum, D., Kupper, L., \& Muller, K. (1988). Applied Regression Analysis and Other Multivariable Methods. 2Boston: PWS-Kent: MENARD AND ELLIOTT.

Kochanski, J., \& Ledford, G. (2001). " How To Keep Me" Retaining Technical Professionals. Research-Technology Management, 44(3), 31-38.

Kogut, B., \& Zander, U. (1992). Knowledge of the firm, combinative capabilities, and the replication of technology. Organization Science, 383-397.

Kraaijenbrink, J., Spender, J. C., \& Groen, A. J. (2010). The resource-based view: A review and assessment of its critiques. Journal of Management, 36(1), 349.

Kulik, C. T., Oldham, G. R., \& Hackman, J. R. (1987). Work design as an approach to personenvironment fit. Journal of vocational behavior, 31(3), 278-296.

Kulik, C. T., Oldham, G. R., \& Hackman, J. R. (1987). Work design as an approach to personenvironment fit. Journal of vocational behavior, 31(3), 278-296.

Lado, A. A., \& Wilson, M. C. (1994). Human resource systems and sustained competitive advantage: A competency-based perspective. The Academy of Management Review, 19(4), 699-727.

Lam, T., Lo, A., \& Chan, J. (2002). New employees' turnover intentions and organizational commitment in the Hong Kong hotel industry. Journal of Hospitality \& Tourism Research, 26(3), 217.

Lam, W., Chen, Z., \& Takeuchi, N. (2009). Perceived human resource management practices and intention to leave of employees: the mediating role of organizational citizenship behaviour in a Sino-Japanese joint venture. The International Journal of Human Resource Management, 20(11), 2250-2270.

Lambert, E. G., Lynne Hogan, N., \& Barton, S. M. (2001). The impact of job satisfaction on turnover intent: a test of a structural measurement model using a national sample of workers. The Social Science Journal, 38(2), 233-250. 
Lambert, S. J. (2000). Added benefits: The link between work-life benefits and organizational citizenship behavior. The Academy of Management Journal, 43(5), 801-815.

Lamoca Pérez, M., \& Ortega Álvarez, A. (2000). Los recursos humanos y la dirección estratégica de la empresa. Revista universitaria de ciencias del trabajo(1), 299-318.

Lane, P. J., Koka, B. R., \& Pathak, S. (2006). The reification of absorptive capacity: a critical review and rejuvenation of the construct. Academy of Management Review, 31(4), 833863.

Lau, C. M., \& Ngo, H. Y. (2004). The HR system, organizational culture, and product innovation. International Business Review, 13(6), 685-703.

Laursen, K. (2000). The importance of sectoral differences in the application of new HRM practices for innovation performance. LINK, Department of Industrial Economics and Strategy, Copenhagen Business School.

Laursen, K. (2002). The importance of sectoral differences in the application of complementary HRM practices for innovation performance. International Journal of the Economics of Business, 9(1), 139-156.

Laursen, K., \& Foss, N. J. (2003). New human resource management practices, complementarities and the impact on innovation performance. Cambridge Journal of economics, 27(2), 243.

Law, K. S., \& Wong, C. S. (1999). Multidimensional Constructs M Structural Equation Analysis: An Illustration Using the Job Perception and Job Satisfaction Constructs. Journal of Management, 25(2), 143.

Lawler III, E. E., \& Porter, L. W. (1967). The effect of performance on job satisfaction. Industrial Relations: A Journal of Economy and Society, 7(1), 20-28.

Lawler, E. (1992). The Ultimate Advantage: Creating the High-Involvement Organization.

Lawler, E. E. (1971). Pay and organisational effectiveness: McGraw-Hill.

Lawler, E. E. (1981). Pay and organizational development. Reading, Massachusetts. Addison.

Lawler, E. E. (1986). La retribución.

Lawler, E. E. (1996). La ventaja definitiva: Creando organizaciones participativas e innovadoras: Ediciones Granica, SA.

Lawson, B., \& Samson, D. (2001). Developing innovation capability in organisations: a dynamic capabilities approach. International Journal of Innovation Management, 5, 377400.

Lazarova, M. B. (2004). The Role of Organizational Career Development Programs, Work/life Balance Programs and Commitment to Career and Personal Life for Retention of Professional Employees. UMI Dissertation Services [Tokyo]:[Distributed by Yushodo Dissertation Service Center], Ann Arbor, Mich.

Lazear, E. P. (1986). Salaries and piece rates. The Journal of Business, 59(3), 405-431.

Lazear, E. P. (1998). Globalization and the Market for Teammates: National Bureau of Economic Research Cambridge, Mass., USA.

Lazear, E. P. (2004). Output-based pay: incentives, retention or sorting. Research in Labor Economics, 23, 1-25.

Leana, C. R., \& Pil, F. K. (2006). Social capital and organizational performance: Evidence from urban public schools. Organization Science, 17(3), 353.

Leana, C. R., \& Van Buren, H. J. (1999). Organizational social capital and employment practices. The Academy of Management Review, 24(3), 538-555. 
Lee, M., \& Chee, Y. H. (1996). Business strategy, participative human resource management and organizational performance: The case of South Korea. Asia Pacific Journal of Human Resources, 34(1), 77.

Lee, T. H., Gerhart, B., Weller, I., \& Trevor, C. O. (2008). Understanding voluntary turnover: Path-specific job satisfaction effects and the importance of unsolicited job offers. The Academy of Management Journal (AMJ), 51(4), 651-671.

Lee, T. W., \& Mitchell, T. R. (1994). An alternative approach: The unfolding model of voluntary employee turnover. The Academy of Management Review, 19(1), 51-89.

Lee, T. W., Ashford, S. J., Walsh, J., \& Mowday, R. T. (1992). Commitment propensity, organizational commitment, and voluntary turnover: A longitudial study of organizational entry processes. Journal of Management, 18, 15-32.

Lee, T. W., Mitchell, T. R., Holtom, B. C., McDaniel, L. S., \& Hill, J. W. (1999). The unfolding model of voluntary turnover: A replication and extension. Academy of Management Journal, 42(4), 450-462.

Lee, T. W., Mitchell, T. R., Sablynski, C. J., Burton, J. P., \& Holtom, B. C. (2004). The effects of job embeddedness on organizational citizenship, job performance, volitional absences, and voluntary turnover. The Academy of Management Journal, 47(5), 711-722.

Leede (De), J., \& Looise, J. K. (2005). Innovation and HRM: Towards an integrated framework. Creativity and Innovation Management, 14(2), 108-117.

Lengnick Hall, C. A., \& Lengnick Hall, M. L. (2006). HR, ERP, and knowledge for competitive advantage. Human Resource Management, 45(2), 179-194.

Lengnick-Hall, C. A., \& Lengnick-Hall, M. L. (1988). Strategic human resources management: A review of the literature and a proposed typology. The Academy of Management Review, 13(3), 454-470.

Lengnick-Hall, M. L., \& Lengnick-Hall, C. A. (2003a). HR's role in building relationship networks. The Academy of Management Executive (1993), 17(4), 53-63.

Lengnick-Hall, M. L., \& Lengnick-Hall, C. A. (2003b). Human resource management in the knowledge economy: New challenges, new roles, new capabilities: Berrett-Koehler Publishers.

Leonard-Barton, D. (1992). Core capabilities and core rigidities: A paradox in managing new product development. Strategic Management Journal, 13(5), 111-125.

Leonard-Barton, D. (1995). Wellsprings of knowledge: HBS Press.

Lepak, D. P., \& Snell, S. A. (1999). The human resource architecture: Toward a theory of human capital allocation and development. The Academy of Management Review, 24(1), 31-48.

Lepak, D. P., \& Snell, S. A. (2002). Examining the human resource architecture: The relationships among human capital, employment, and human resource configurations. Journal of Management, 28(4), 517.

Lepak, D. P., Liao, H., Chung, Y., \& Harden, E. E. (2006). A conceptual review of human resource management systems in strategic human resource management research. Research in personnel and human resources management, 25(1), 217-271.

Lepak, D. P., Takeuchi, R., \& Snell, S. A. (2003). Employment flexibility and firm performance: Examining the interaction effects of employment mode, environmental dynamism, and technological intensity. Journal of Management, 29(5), 681.

Lepak, D., \& Snell, S. (1999b). Virtual HR: Strategic human resources in the 21st century. Human Resource Management Review, 8, 215-234. 
Levinson, H. (1965). Reciprocation: The relationship between man and organization. Administrative Science Quarterly, 9(4), 370-390.

Levinthal, D., \& Myatt, J. (1994). Co Evolution of Capabilities and Industry: The Evolution of Mutual Fund Processing. Strategic Management Journal, 15(S1), 45-62.

Li, L., \& Zhao, X. (2006). Enhancing competitive edge through knowledge management in implementing ERP systems. Systems Research and Behavioral Science, 23(2), 129-140.

Liao, H., Toya, K., Lepak, D. P., \& Hong, Y. (2009). Do they see eye to eye? Management and employee perspectives of high-performance work systems and influence processes on service quality. Journal of Applied Psychology, 94(2), 371.

Lilius, J. M. (2006). Being there or being competent? How co-worker support contributes to unit performance. UNIVERSITY OF MICHIGAN.

Lin, H. F. (2007). Effects of extrinsic and intrinsic motivation on employee knowledge sharing intentions. Journal of Information Science, 33(2), 135.

Lin, H. F., \& Lee, H. S. (2009). Evaluation of factors influencing knowledge sharing based on a fuzzy AHP approach. Journal of Information Science, 35(1), 25.

Lin, M. J. J., Hung, S. W., \& Chen, C. J. (2009). Fostering the determinants of knowledge sharing in professional virtual communities. Computers in Human Behavior, 25(4), 929939.

Lin, N. (Ed.). (2001). Social Capital: A Theory of Social Structure and Action: Cambridge University Press, New York, NY.

Loan Clarke, J., Arnold, J., Coombs, C., Hartley, R., \& Bosley, S. (2010). Retention, turnover and return-a longitudinal study of allied health professionals in Britain. Human Resource Management Journal, 20(4), 391-406.

Lohmoller, J. (1984). LVPLS Program Manual Version 1.6: Latent Variable Path Analysis with Partial Least Squares Estimation. Zentralarchiv fur Empirische.

Lohmoller, J. B. (1988). The PLS program system: Latent variables path analysis with partial least squares estimation. Multivariate Behavioral Research, 23(1), 125-127.

London, M. (1983). Toward a theory of career motivation. The Academy of Management Review, 8(4), 620-630.

Looise, J. K., \& van Riemsdijk, M. (2004). Innovating organisations and HRM: A conceptual framework. management revue. The International Review of Management Studies, 15(3), 277-287.

Lopez Cabrales, A., Pérez Luño, A., \& Cabrera, R. V. (2009). Knowledge as a mediator between HRM practices and innovative activity. Human Resource Management, 48(4), 485-503.

López Cabrales, A., Real, J. C., \& Valle Cabrera, R. (2007, April). The role of hrm practices and human capital on organizational learning capability, 22nd Workshop on SHRM (EIASM).. Brussels

Lopez Cabrales, A., Valle, R., \& Herrero, I. (2006). The contribution of core employees to organizational capabilities and efficiency. Human Resource Management, 45(1), 81-109.

Lopez Yepes, J., \& Sabater Sánchez, R. (2000). La teoría de los recursos y capacidades de la empresa. Una revisión: Facultad de Ciencias Económicas y Empresariales. Universidad de Murcia.

Lopez-Cabrales, A., Carmona-Medina, C., Lavado, A. C., \& Valle-Cabrera, R. (2008). Managing functional diversity, risk taking and incentives for teams to achieve radical innovations. R\&D Management, 38(1), 35-50. 
López-Cabrales, Á., Real, J. C., \& Valle, R. (2011). Relationships between human resource management practices and organizational learning capability: The mediating role of human capital. Personnel Review, 40(3), 344-363.

Luna Arocas, R., \& Camps Torres, J. (2003). Un modelo tentativo en las estrategias de retención del personal. Paper presented at the International Workshop on HRM, Cádiz.

Luna-Arocas, R., \& Torres, C. (2006). Las Prácticas de Alto Rendimiento en Recursos Humanos: el caso español. Tec Empresarial, 1(1), 26-30.

Luna-Reyes, L. F., Hernández García, J. M., \& Gil García, J. R. (2009). Hacia un modelo de los determinantes de éxito de los portales de gobierno estatal en México. Gestión y política pública, 18(2), 307-340.

Luthans, F. (2002). The need for and meaning of positive organizational behavior. Journal of organizational behavior, 23(6), 695-706.

Luthans, F., \& Youssef, C. M. (2007). Emerging positive organizational behavior. Journal of Management, 33(3), 321.

Luthans, F., Youssef, C. M., \& Avolio, B. J. (2007). Psychological capital: Developing the human competitive edge: Oxford University Press, USA.

Lynch, L. M., \& Black, S. E. (1998). Beyond the incidence of employer-provided training. Industrial and Labor Relations Review, 52(1), 64-81.

Lynn, B. E. (1998). Performance evaluation in the new economy: bringing the measurement and evaluation of intellectual capital into the management planning and control system. International Journal of Technology Management, 16(1), 162-176.

MacDuffie, J. P. (1995). Human resource bundles and manufacturing performance: Organizational logic and flexible production systems in the world auto industry. Indus. \& Lab. Rel. Rev., 48, 197.

Maertz Jr, C. P., Griffeth, R. W., Campbell, N. S., \& Allen, D. G. (2007). The effects of perceived organizational support and perceived supervisor support on employee turnover. Journal of Organizational Behavior, 28(8), 1059-1075.

Maertz, C. (2001). Why employees stay with or quit an organization. Paper presented at the 61st Annual Meeting of the Academy of Management, USA.

Maertz, C. P., \& Campion, M. A. (1998). 25 years of voluntary turnover research: a review and critique. International review of industrial and organizational psychology, 13, 49-81.

Maertz, C. P., \& Griffeth, R. W. (2004). Eight motivational forces and voluntary turnover: A theoretical synthesis with implications for research. Journal of Management, 30(5), 667.

Malhotra, Y., Galletta, D. F., \& Kirsch, L. J. (2008). How endogenous motivations influence user intentions: Beyond the dichotomy of extrinsic and intrinsic user motivations. Journal of Management Information Systems, 25(1), 267-300.

March, J. G., \& Simon, H. (1958). Organizations,(Nueva York): John Wiley and Son.

Marín Carrillo, G., Segovia López, C., \& Gázquez Abad, J. C. (2006). Application of factorial analysis and Regression models to the formation of Marketing competitive advantages in local Firms.

Marqués, T., Galende, J., \& Cruz, P. (2006). La inseguridad percibida en el empleo y la falta de compromiso organizacional como reflejo del downsizing: su incidencia sobre los comportamientos innovadores.

Marsh, R. M., \& Mannari, H. (1977). Organizational commitment and turnover: A prediction study. Administrative Science Quarterly, 22(1), 57-75. 
Martín Alcázar, F., Romero Fernández, P. M., \& Sánchez Gardey, G. (2008). Human Resource Management as a Field of Research*. British Journal of Management, 19(2), 103-119.

Martín Alcázar, F., Romero Fernández, P. M., \& Sánchez Gardey, G. (2009). La investigación en dirección de recursos humanos. Revista Europea de Dirección y Economía de la empresa, 18(3), 37-64.

Martín Cruz, N. , Pérez, V. M., \& Cantero, C. T. (2009b). Influencia de la motivación intrínseca y extrínseca sobre la transmisión de conocimiento. El caso de una organización sin fines de lucro. CIRIEC-ESPAÑA, 187-211.

Martin Cruz, N., Martin Pérez, V., \& Treville Cantero, C. (2009). The influence of employee motivation on knowledge transfer. Journal of Knowledge Management, 13(6), 478-490.

Martín de Castro, G., Alama Salazar, E. M., Navas López, J. E., \& López Sáez, P. (2009). El papel del capital intelectual en la innovación tecnológica. Cuadernos de Economía y Dirección de la Empresa(40), 83-109.

Martin, T. (1977). A Study on Reducing Turnover Costs.

Martin, T. N. (1979). A contextual model of employee turnover intentions. The Academy of Management Journal, 22(2), 313-324.

Martínez Santa María, R., Charterina Abando, J., \& Araujo de la Mata, A. (2010). Un modelo causal de competitividad empresarial planteado desde la VBR: capacidades directivas, de innovación, marketing y calidad. Investigaciones Europeas de Dirección y Economía de la Empresa, 16(2), 165-188.

Mathieu, J. E., \& Zajac, D. M. (1990). A review and meta-analysis of the antecedents, correlates, and consequences of organizational commitment. Psychological bulletin, 108(2), 171.

Mattox, I., John, R., \& Jinkerson, D. L. (2005). Using survival analysis to demonstrate the effects of training on employee retention. Evaluation and Program Planning, 28(4), 423430.

Mayer, J. D., Roberts, R. D., \& Barsade, S. G. (2008). Human abilities: Emotional intelligence. Psychology, 59(1), 507.

Mayer, J. D., Salovey, P., \& Caruso, D. R. (2008). Emotional intelligence: New ability or eclectic traits. American Psychologist, 63(6), 503-517.

Mayer, R. C., \& Davis, J. H. (1999). The effect of the performance appraisal system on trust for management: A field quasi-experiment. Journal of Applied Psychology, 84(1), 123.

Mayer, R. C., \& Gavin, M. B. (2005). Trust in management and performance: who minds the shop while the employees watch the boss? The Academy of Management Journal, 874888.

Mayer, R. C., Davis, J. H., \& Schoorman, F. D. (1995). An integrative model of organizational trust. The Academy of Management Review, 20(3), 709-734.

McAllister, D. J. (1995). Affect-and cognition-based trust as foundations for interpersonal cooperation in organizations. The Academy of Management Journal, 38(1), 24-59.

McDonald, D. J., \& Makin, P. J. (2000). The psychological contract, organisational commitment and job satisfaction of temporary staff. Leadership \& Organization Development Journal, 21(2), 84-91.

McDuffie, J. (1995). HR bundles and manufacturing performance: Organizational logic and flexible production systems in the world auto industry. Industrial \& Labor Relations Review, 48, 197-221. 
McEvoy, G. M., \& Cascio, W. F. (1985). Strategies for reducing employee turnover: A metaanalysis. Journal of Applied Psychology, 70(2), 342.

McGrath, D., \& Van Buskirk, W. (1999). Cultures of support for at-risk students: The role of social and emotional capital in the educational experiences of women. Community colleges as cultural texts: Qualitative explorations of organizational and student culture, 15-37.

McGrath, J. E. (1991). Time, interaction, and performance (TIP). Small group research, 22(2), 147.

McGrath, R. G. (2001). Exploratory learning, innovative capacity and managerial oversight. Academy of management journal, 118-131.

McMahan, G. C., Virick, M., \& Wright, P. M. (1999). Alternative theoretical perspectives for strategic human resource management revisited: Progress, problems, and prospects. Research in Personnel and Human Resource Management, 4, 99-122.

Meglino, B. M., DeNisi, A. S., Youngblood, S. A., \& Williams, K. J. (1988). Effects of realistic job previews: A comparison using an enhancement and a reduction preview. Journal of Applied Psychology, 73(2), 259.

Meyer, J. P., \& Allen, N. J. (1991). A three-component conceptualization of organizational commitment. Human Resource Management Review, 1(1), 61-89.

Meyer, J. P., \& Allen, N. J. (1997). Commitment in the workplace: Theory, research, and application: Sage Publications, Inc.

Meyer, J. P., \& Herscovitch, L. (2001). Commitment in the workplace: Toward a general model. Human Resource Management Review, 11(3), 299-326.

Meyer, J. P., \& Smith, C. A. (2000). HRM practices and organizational commitment: Test of a mediation model. Canadian Journal of Administrative Sciences/Revue canadienne des sciences de l'administration, 17(4), 319-331.

Meyer, J. P., Allen, N. J., \& Smith, C. A. (1993). Commitment to organizations and occupations: Extension and test of a three-component conceptualization. Journal of Applied Psychology, 78(4), 538-551.

Meyer, J. P., Becker, T. E., \& Vandenberghe, C. (2004). Employee commitment and motivation: A conceptual analysis and integrative model. Journal of Applied Psychology, 89(6), 991-1007.

Meyer, J. P., Stanley, D. J., Herscovitch, L., \& Topolnytsky, L. (2002). Affective, continuance, and normative commitment to the organization: A meta-analysis of antecedents, correlates, and consequences. Journal of vocational behavior, 61(1), 20-52.

Miceli, M. P., \& Lane, M. C. (1990). Antecedents of pay satisfaction: A review and extension: College of Business, Ohio State University.

Miceli, M. P., Lane, M. C., Ferris, G. R., \& Rowland, K. M. (1991). Research in personnel and human resources management. .

Miles, R. E., \& Snow, C. C. (1984). Designing strategic human resources systems. Organizational dynamics.

Milkovich, G. T. (1987). A strategic perspective on compensation management: Cornell University, Center for Advanced Human Resource Studies, School of Industrial and Labor Relations.

Milkovich, G. T. (1988). A strategic perspective on compensation management. In: K. Rowland and G. Ferris, Editors, Research in Personnel and Human Resources Management vol. 6 
(1988), pp. 263-288. Research in Personnel and Human Resources Management vol. 6 (1988), pp. 263-288., 6, 263.

Milkovich, G. T., \& Newman, J. M. (1993). Compensation. (4th edn ed.), Irwin, Homewood, IL: Irwin, Homewood, IL.

Minbaeva, D. B. (2005). HRM practices and MNC knowledge transfer. Personnel Review, 34(1), 125-144.

Minbaeva, D., Foss, N., \& Snell, S. (2009). Bringing the knowledge perspective into HRM. Human resource management, 48(4), 477-483.

Minbaeva, P., Pedersen, T., Björkman, I., Fey, C., \& Park, H. (2003). MNC knowledge transfer, subsidiary absorptive capacity, and HRM. Journal of International Business Studies, 34(6), 586-599.

Mitchell, T. R., Holtom, B. C., Lee, T. W., \& Graske, T. (2001). How to Keep Your Best Employees: Developing an Effective Retention Policy [and Executive Commentary]. The Academy of Management Executive (1993-2005), 15(4), 96-109.

Mitchell, T. R., Holtom, B. C., Lee, T. W., Sablynski, C. J., \& Erez, M. (2001). Why people stay: Using job embeddedness to predict voluntary turnover. Academy of Management Journal, 44(6), 1102-1121.

Mobley, W. H. (1977). Intermediate linkages in the relationship between job satisfaction and employee turnover. Journal of Applied Psychology, 62(2), 237-240.

Mobley, W. H. (1982a). Some unanswered questions in turnover and withdrawal research. Academy of Management Review, 7(1), 111-116.

Mobley, W. H. (1982b). Employee turnover: Causes, consequences, and control: AddisonWesley Reading, MA.

Mobley, W. H., Griffeth, R. W., Hand, H. H., \& Meglino, B. M. (1979). Review and conceptual analysis of the employee turnover process. Psychological bulletin, 86(3), 493-522.

Monreal Pérez, M. (2009). Análisis del Comportamiento Exportador de la Empresa Española desde el Enfoque de los Recursos y Capacidades. Universidad de Murcia.

Montoro-Sanchez, A., Mora-Valentin, E. M., \& Guerras-Martin, L. A. (2006). R\&D cooperative agreements between firms and research organisations: a comparative analysis of the characteristics and reasons depending on the nature of the partner. International Journal of Technology Management, 35(1), 156-181.

Monzon de Cáceres, J. (2010). Entorno para la innovacion. Colección Mediterráneo Económico: “Innovación y desarrollo económico”, 17.

Mora Valentín, E. M. (2002). Cooperación entre empresas versus cooperación universidadempresa: criterios para la selección de socios en acuerdos de cooperación tecnológica. Dirección y Organización(27), 44-56.

Morcillo, P. (1997). Dirección estratégica de la tecnología e innovación. Un Enfoque de Competencias. Madrid: Civitas.

Morrell, K., Loan Clarke, J., \& Wilkinson, A. (2001). Unweaving leaving: the use of models in the management of employee turnover. International Journal of Management Reviews, 3(3), 219-244.

Morris, J. (2004). The future of work: organizational and international perspectives. The International Journal of Human Resource Management, 15(2), 263-275.

Morris, J., Hassard, J., \& McCann, L. (2006). New organizational forms, human resource management and structural convergence? A study of Japanese organizations. Organization studies, 27(10), 1485. 
Morris, S. S., Snell, S. A., \& Wright, P. M. (2005). A resource-based view of international human resources: toward a framework of integrative and creative capabilities.

Morris, S. S., Wright, P. M., Trevor, J., Stiles, P., Stahl, G. K., Snell, S., et al. (2009). Global challenges to replicating HR: The role of people, processes, and systems. Human Resource Management, 48(6), 973-995.

Morris, S., Snell, S., \& Lepak, D. (2005). An architectural approach to managing knowledge stocks and flows: Implications for reinventing the Human Resource Function. Reinventing human resources: Challenges and new directions, 57-80.

Mossholder, K., Setton, R., \& Henagan, S. (2005). A relational perspective on turnover: Examining structural, attitudinal, and behavioral predictors. Academy of Management Journal, 48, 607-618.

Mowday, R. T., Steers, R. M., \& Porter, L. W. (1979). The measurement of organizational commitment* 1 . Journal of vocational behavior, 14(2), 224-247.

Munduate, L., Fuertes, F., Hontangas, P., \& Alonso, P. (1993). Evaluación del Modelo de las Características del Puesto en una Muestra de trabajadores de la Confección Textil. En L.Munduate y M. Baron (Comp.), Psicología del Trabajo y de las Organizaciones (pp.177-197). Sevilla: Eudema.

Muñoz Doyague, M. F., \& Nieto Antolín, M. (2006). Relaciones sociales y creatividad en la empresa: la importancia de la calidad de las interacciones del empleado con su entorno más cercano. Revista madri+ $d(37), 2$.

Nadler, L., \& Nadler, Z. (1989). Developing Human Resources, . San Francisco:: 3rd edn. Jossey-Bass., SF:.

Naggiar, J. (2001). An exploration of retention practices in the IT industry.

Nahapiet, J., \& Ghoshal, S. (1998). Social capital, intellectual capital, and the organizational advantage. The Academy of Management Review, 23(2), 242-266.

Naranjo Valencia, C., Sanz Valle, R., \& Jiménez Jiménez, D. (2008). Cultura organizativa e innovación: Un estudio empírico.

Naranjo-Gil, D., Hartmann, F., \& Maas, V. S. (2008). Top management team heterogeneity,strategic change and operational performance. British Journal of Management, 19, 222-234.

Navas López, N., \& Guerras Martín, L. (1998). La dirección estratégica de la empresa: teoría y aplicaciones. Madrid: Ed. Cívitas.

Navas, J., \& Nieto, M. (2003). Estrategias de innovación y creación de conocimiento tecnológico en las empresas industriales españolas. Civitas, Madrid.

Nelson, R. R., \& Winter, S. G. (1982). An evolutionary theory of economic change: Belknap press.

Newbert, S. L. (2007). Empirical research on the resource based view of the firm: an assessment and suggestions for future research. Strategic Management Journal, 28(2), 121-146.

Ng, T. W. H., \& Butts, M. M. (2009). Effectiveness of organizational efforts to lower turnover intentions: The moderating role of employee locus of control. Human resource management, 48(2), 289-310.

Ng, T. W. H., \& Feldman, D. C. (2010). The impact of job embeddedness on innovation related behaviors. Human resource management, 49(6), 1067-1087.

Ng, T. W. H., \& Sorensen, K. L. (2008). Toward a further understanding of the relationships between perceptions of support and work attitudes. Group \& Organization Management, 33(3), 243. 
Ng, T. W. H., Butts, M. M., Vandenberg, R. J., DeJoy, D. M., \& Wilson, M. G. (2006). Effects of management communication, opportunity for learning, and work schedule flexibility on organizational commitment. Journal of vocational behavior, 68(3), 474-489.

Nielsen, J. F., \& Pedersen, C. P. (2003). The consequences and limits of empowerment in financial services. Scandinavian Journal of management, 19(1), 63-83.

Nieto Antolín, M., \& Navas López, J. E. (2003). Estrategias de innovación y creación de conocimiento tecnológico en las empresas industriales españolas.

Nieto Antolín, M., \& Quevedo Cano, P. (2005). Variables estructurales, capacidad de absorción y esfuerzo innovador en las empresas manufactureras españolas. Revista Europea de Dirección y Economía de la empresa, 14(1), 25-43.

Noe, R. A. (1996). Is career management related to employee development and performance? Journal of Organizational Behavior, 17(2), 119-133.

Noe, R. A. (1996). Is career management related to employee development and performance? Journal of organizational behavior.

Nohria, N., \& Gulati, R. (1996). Is slack good or bad for innovation? Academy of Management Journal, 39(5), 1245-1264.

Nonaka, I. (1991). The knowledge-creating company. Harvard Business Review, 69(novemberdecember), 96-104.

Nonaka, I. (1994). A dynamic theory of organizational knowledge creation. Organization Science, 5(1), 14-37.

Nonaka, I., \& Takeuchi, H. (1995). The Knowledge Creating Company: Oxford University. Press, New York.

Nord, W. R., Fox, S., Phoenix, A., \& Viano, K. (2002). Real-world reactions to work-life balance programs: Lessons for effective implementation. Organizational dynamics, 30(3), 223-238.

Nunnally, J. (1978). Psychometric theory. : McGraw-Hill, New York.

Offstein, E. H., \& Gnyawali, D. R. (2006). A humanistic perspective of firm competitive behavior. Competitiveness Review: An International Business Journal incorporating Journal of Global Competitiveness, 16(3/4), 248-261.

Oldham, G. R. (1988). Effects of changes in workspace partitions and spatial density on employee reactions: A quasi-experiment. Journal of Applied Psychology, 73(2), 253.

Oldham, G. R. (1996). Job design. International review of industrial and organizational psychology, 11, 33-60.

Oldham, G. R. (2003). Stimulating and supporting creativity in organizations. In (pp. 274-302).

Oldham, G. R., \& Cummings, A. (1996). Employee creativity: Personal and contextual factors at work. The Academy of Management Journal, 39(3), 607-634.

Oldham, G. R., \& Fried, Y. (1987). Employee reactions to workspace characteristics. Journal of Applied Psychology, 72(1), 75.

Oldham, G. R., \& Rotchford, N. L. (1983). Relationships between office characteristics and employee reactions: A study of the physical environment. Administrative Science Quarterly, 28(4), 542-556.

Oldham, G. R., Kulik, C. T., \& Stepina, L. P. (1991). Physical environments and employee reactions: Effects of stimulus-screening skills and job complexity. The Academy of Management Journal, 34(4), 929-938.

Oltra, V. (2005). Knowledge management effectiveness factors: the role of HRM. Journal of Knowledge Management, 9(4), 70-86. 
Ordiz Fuentes, M., \& Avella Camarero, L. (2002). Gestión estratégica de los Recursos Humanos: una síntesis teórica. Investigaciones Europeas de Dirección y Economía de la Empresa, 8(3), 59-78.

Ordóñez de Pablos, P. (2000). "Herramientas estratégicas para medir el capital intelectual organizativo". Revista de estudios empresariales, 102.

Ordoñez de Pablos, P. (2003). Intellectual capital reporting in Spain: a comparative view. Journal of Intellectual Capital, 4(1), 61-81.

O'Reilly III, C. A., \& Caldwell, D. F. (1981). The commitment and job tenure of new employees: Some evidence of postdecisional justification. Administrative Science Quarterly, 26(4), 597-616.

O'Reilly III, C. A., Chatman, J., \& Caldwell, D. F. (1991). People and organizational culture: A profile comparison approach to assessing person-organization fit. Academy of Management Journal, 34(3), 487-516.

O'Reilly, C. A., \& Chatman, J. (1986). Organizational commitment and psychological attachment: The effects of compliance, identification, and internalization on prosocial behavior. Journal of Applied Psychology, 71(3), 492.

O'Reilly, C. A., \& Chatman, J. A. (1996). Culture as social control: Corporations, cults, and commitment. Research in organizational behavior, 18, 157-200.

Osca, A., \& Urien, B. (2001). Rediseño de tareas, satisfacción laboral y rendimiento: un estudio en la industria de la automoción. Revista de Psicología del Trabajo y de las Organizaciones, 17(3), 327-340.

Osterman, P. (1994). Supervision, discretion, and work organization. The American Economic Review, 84(2), 380-384.

Ostroff, C. (1992). The relationship between satisfaction, attitudes, and performance: An organizational level analysis. Journal of Applied Psychology, 77(6), 963.

Ostroff, C. (2000). Human resource management and firm performance. Working paper. Arizona State University.

Ostroff, C., \& Bowen, D. E. (2000). Moving HR to a higher level: HR practices and organizational effectiveness.In K. J. Klein \& S. W. J. Kozlowski (Eds.), Multilevel theory, research, and methods in organizations: foundations, extensions, and new directions (pp. 211-266). San Francisco: Jossey-Bass.

Paauwe, J. (2009). HRM and performance: achievements, methodological issues and prospects. Journal of Management Studies, 46(1), 129-142.

Paauwe, J., \& Boselie, P. (2005). HRM and performance: what next? Human Resource Management Journal, 15(4), 68-83.

Paauwe, J., \& Richardson, R. (1997). Introduction. International Journal of Human Resource Management, 8(3), 257-262.

Paré, G., \& Tremblay, M. (2007). The influence of high-involvement human resources practices, procedural justice, organizational commitment, and citizenship behaviors on information technology professionals' turnover intentions. Group \& Organization Management, 32(3), 326.

Paré, G., Cirano, É., Tremblay, M., Lalonde, P., \& Mobilité, B. (2001). The role of organizational commitment and citizenship behaviors in understanding relations between human resources practices and turnover intentions of IT personnel. Cahier du GReSI no, $1,07$. 
Park, H. J., Gardner, T. M., \& Wright, P. M. (2004). HR practices or HR capabilities: which matters? Insights from the Asia Pacific region. Asia Pacific Journal of Human Resources, 42(3), 260.

Parker, C. C. (2008). Generational differences in work life balance Attitudes. Tesis Doctoral. Dpto. Psychology. State University of New York at New Paltz.

Parkes, L. P., \& Langford, P. H. (2008). Work-Life Balance or Work-Life Alignment? A test of the importance of work-life balance for employee engagement and intention to stay in organisations. Journal of Management \& Organization, 14(3), 267-284.

Pasamar, S., \& Valle, R. (2011). Conciliación de la vida profesional-personal en empresas españolas:¿ mito o realidad? Universia Business Review(29), 14-31.

Paul, A., \& Anantharaman, R. (2003). Impact of people management practices on organizational performance: analysis of a causal model. International Journal of Human Resource Management, 14(7), 1246-1266.

Pavitt, K. (2003). The process of innovation. Science and Technology Policy Research.

Payne, S. C., \& Huffman, A. H. (2005). A Longitudinal Examination of the Influence of Mentoring on Organizational Commitment and Turnover. Academy of management journal.

Penrose, E. (1959). The Theory of the Growth of the Firm. Oxford: Basil Blackwell: Oxford University Press, USA.

Peña García-Pardo, I., \& Hernández Perlines, F. (2007). La integración de la dirección de recursos humanos en el proceso de formulación de la estrategia como determinante de los resultados. Universia Business Review(15), 69-87.

Perdomo-Ortiz, J., González-Benito, J., \& Galende, J. (2006). Total quality management as a forerunner of business innovation capability. Technovation, 26(10), 1170-1185.

Perez Cano, P. (2006). Human resources management and its impact on innovation performance in companies. International Journal of Technology Management, 35(1-4), 11-28.

Pérez Santana, M. P., \& Garrido Samaniego, M. J. (1998). Satisfacción de los clientes internos: el papel estratégico de la gestión de los recursos humanos. Investigaciones Europeas de Dirección y Economía de la Empresa, 4(3), 13-28.

Pérez, M. (2009). Análisis del Comportamiento Exportador de la Empresa Española desde el Enfoque de los Recursos y Capacidades.

Pérez, M. P., Prieto Pastor, I. M., \& Martín Sierra, C. (2009). Gestionando el conocimiento a través de la gestión de recursos humanos: análisis empírico en el sector de automoción. Academia Revista Latinoamericana de Administración(42), 34.

Perez-Cano, C., \& Quevedo-Cano, P. (2006). Human resources management and its impact on innovation performance in companies. International Journal of Technology Management, 35(1), 11-28.

Pérez-Luño, A., Cabrera, R. V., \& Wiklund, J. (2007). Innovation and imitation as sources of sustainable competitive advantage. Management Research: The Journal of the Iberoamerican Academy of Management, 5(2), 71-82.

Perlines, F. H., \& García-Pardo, I. P. (2010). Efectividad de la estrategia de recursos humanos: modelo integrador de la teoría de recursos y capacidades y la teoría del comportamiento en las entidades financieras de la economía social. Relaciones laborales, 75-100.

Perry-Smith, J. E., \& Blum, T. C. (2000). Work-family human resource bundles and perceived organizational performance. Academy of Management Journal, 43(6), 1107-1117. 
Peteraf, M. A. (1993). The cornerstones of competitive advantage: A resource-based view. Strategic Management Journal, 14(3), 179-191.

Peterson, C. H. (2005). Employee retention: The secrets behind Wal-Mart's successful hiring policies. Human Resource Management, 44(1), 85-88.

Peterson, S. L. (2004). Toward a theoretical model of employee turnover: A human resource development perspective. Human Resource Development Review, 3(3), 209.

Peterson, S. L. (2007). Managerial turnover in US retail organizations. Journal of Management Development, 26(8), 770-789.

Petty, R., \& Guthrie, J. (2000). Intellectual capital literature review: measurement, reporting and management. Journal of Intellectual Capital, 1(2), 155-176.

Pfeffer, J. (1994). Managing with power: Politics and influence in organizations: Harvard Business Press.

Pfeffer, J. (1998). The human equation. Cambridge/Mass.

Pizarro, I., Real, J. C., \& De la Rosa, M. D. (2007). El Papel del Capital Humano y la Cultura Emprendedora en la Innovación.

Podsakoff, P. M., \& Organ, D. W. (1986). Self-reports in organizational research: Problems and prospects. Journal of Management, 12(4), 531.

Podsakoff, P. M., MacKenzie, S. B., \& Bommer, W. H. (1996a). Meta-analysis of the relationships between Kerr and Jermier's substitutes for leadership and employee job attitudes, role perceptions, and performance. Journal of Applied Psychology, 81(4), 380399.

Podsakoff, P. M., MacKenzie, S. B., \& Bommer, W. H. (1996b). Transformational leader behaviors and substitutes for leadership as determinants of employee satisfaction, commitment, trust, and organizational citizenship behaviors. Journal of Management, 22(2), 259.

Porter, L. W., \& Hite, J. P. (1995). Choice of employee-organization relationship. Influence of exernal and internal organization factors. Research in Personnel and Human Resource Management, 13, 117-151.

Porter, L. W., \& Steers, R. M. (1973). Organizational, work, and personal factors in employee turnover and absenteeism. Psychological bulletin, 80(2), 151-176.

Porter, M. (Ed.). (1980, 1985). Competitive Strategy: Free Press, New York,.

Porter, M. E. (1993). Competitive strategy. Measuring Business Excellence, 1(2), 12-17.

Powell, W. W., Koput, K. W., \& Smith-Doerr, L. (1996). Interorganizational collaboration and the locus of innovation: Networks of learning in biotechnology. Administrative Science Quarterly, 116-145.

Prahalad, C., \& Hamel, G. (1990). The core competence ofthe corporation. Harvard Business Review, 68(3), 79-91.

Premack, S. L., \& Wanous, J. P. (1985). A meta-analysis of realistic job preview experiments. Journal of Applied Psychology, 70(4), 706.

Price, J. L. (1977). The study of turnover: The Iowa State University Press.

Price, J. L. (1989). The impact of turnover on the organization. Work and Occupations, 16(4), 461.

Price, J. L., \& Mueller, C. W. (1981). A causal model of turnover for nurses. Academy of Management Journal, 24(3), 543-565.

Price, J. L., \& Mueller, C. W. (1986). Absenteeism and turnover of hospital employees. . 
Priem, R. L., \& Butler, J. E. (2001). Is the resource-based" view" a useful perspective for strategic management research? Academy of Management Review, 26(1), 22-40.

Prieto-Pastor, I. M., Pérez Santana, M. P \& Martin-Sierra, C. (2009). Gestionando el conocimiento a través de la gestión de recursos humanos: análisis empírico en el sector de automoción. Academia, Revista Latinoamericana de Administración, 42, 49-67.

Prieto Pastor, I. M., Pérez Santana, M. P., \& Martín Sierra, C. (2010). Managing knowledge through human resource practices: empirical examination on the Spanish automotive industry. The International Journal of Human Resource Management, 21(13), 2452-2467.

Prieto Pastor, I. M., Revilla Gutiérrez, E., \& Hernangómez Barahona, J. (2003). Una valoración de la gestión del conocimiento para el desarrollo de la capacidad de aprendizaje en las organizaciones. Valladolid: Universidad de Valladolid.

Prieto, I., \& Revilla, E. (2004). La naturaleza dual de la Gestión del Conocimiento: The dual nature of managing knowledge. Academia. Revista Latinoamericana de Administración, 32.

Purcell, J. (2003). Understanding the people and performance link: unlocking the black box: CIPD Publishing.

Purcell, J., \& Hutchinson, S. (2007). Frontline managers as agents in the HRM-performance causal chain: theory, analysis and evidence. Human Resource Management Journal, 17(1), 3-20.

Purcell, J., \& Kinnie, N. (2007). HRM and business performance. Oxford Handbook of Human Resource Management, The, 533.

Purcell, J., Kinnie, N., \& Hutchinson, S. (2003). Open minded. People Management, 9(10), 3033.

Randel, A. E., \& Ranft, A. L. (2007). Motivations to Maintain Social Ties With Coworkers. Group \& Organization Management, 32(2), 208.

Ray, G., Barney, J. B., \& Muhanna, W. A. (2004). Capabilities, business processes, and competitive advantage: choosing the dependent variable in empirical tests of the resourcebased view. Strategic Management Journal, 25(1), 23-37.

Raykov, T., \& Widaman, K. F. (1995). Issues in applied structural equation modeling research. Structural Equation Modeling: A Multidisciplinary Journal, 2(4), 289-318.

Reagans, R., \& McEvily, B. (2003). Network structure and knowledge transfer: The effects of cohesion and range. Administrative Science Quarterly, 48(2), 240-267.

Reichers, A. E. (1985). A review and reconceptualization of organizational commitment. Academy of Management Review, 10(3), 465-476.

Reynolds, D., Merritt, E. A., \& Gladstein, A. (2004). Retention tactics for seasonal employers: An exploratory study of US-based restaurants. Journal of Hospitality \& Tourism Research, 28(2), 230.

Rhoades, L., \& Eisenberger, R. (2002). Perceived organizational support: A review of the literature. Journal of Applied Psychology, 87(4), 698-714.

Rhoades, L., Eisenberger, R., \& Armeli, S. (2001). Affective commitment to the organization: The contribution of perceived organizational support. Journal of Applied Psychology, 86(5), 825-836.

Richman, A. L., Civian, J. T., Shannon, L. L., Jeffrey Hill, E., \& Brennan, R. T. (2008). The relationship of perceived flexibility, supportive work-life policies, and use of formal flexible arrangements and occasional flexibility to employee engagement and expected retention. Community, Work \& Family, 11(2), 183-197. 
Ringle, C. M., Wende, S., \& Will, A. (2005). SmartPLS 2.0 (beta). Retrieved January, 11, 2008.

Robinson, S. L., \& Rousseau, D. M. (1994). Violating the psychological contract: Not the exception but the norm. Journal of organizational behavior, 15(3), 245-259.

Rodríguez-Pinto, J. (2008). La estrategia empresarial de entrada en el mercado. Determinantes, dimensiones y resultados. Tesis Doctoral. Universidad de Valladolid.

Rodríguez-Pinto, J., Rodríguez-Escudero, A. I., \& Gutiérrez-Cillán, J. (2008). Order, positioning, scope and outcomes of market entry. Industrial Marketing Management, 37(2), 154-166.

Roehling, M. V., Cavanaugh, M. A., Moynihan, L. M., \& Boswell, W. R. (2000). The nature of the new employment relationship: A content analysis of the practicer and academic literature. Human Resource Management, Winter 39(4).

Roehling, M. V., Cavanaugh, M. A., Moynihan, L. M., \& Boswell, W. R. (2000). The nature of the new employment relationship: A content analysis of the practitioner and academic literatures. Human Resource Management, 39(4), 305-320.

Rosa Navarro, M. D., \& Carmona Lavado, A. (2010). Cómo afecta la relación del empleado con el líder a su compromiso con la organización. Universia Business Review(26), 112-133.

Rose, D. M., \& Gordon, R. (2010a). Research adn evaluation: Retention Practices for Engineering and Technical Professionals in an Australian Public Agency. Australian Journal of Public Administration, 69(3), 314-325.

Rose, D. M., \& Gordon, R. (2010b). Research and evaluation: Retention Practices for Engineering and Technical Professionals in an Australian Public Agency. Australian Journal of Public Administration, 69(3), 314-325.

Rousseau, D. M. (1989). Psychological and implied contracts in organizations. Employee responsibilities and rights journal, 2(2), 121-139.

Rousseau, D. M. (1990). Normative beliefs in fund-raising organizations. Group \& Organization Management, 15(4), 448.

Rousseau, D. M. (1995). Psychological contracts in organizations: Understanding written and unwritten agreements: SAGE Publications, Inc.

Rousseau, D. M., Sitkin, S. B., Burt, R. S., \& Camerer, C. (1998). Not so different after all: A cross-discipline view of trust. Academy of Management Review, 23(3), 393-404.

Rousseau, V., \& Aubé, C. (2010). Social support at work and affective commitment to the organization: The moderating effect of job resource adequacy and ambient conditions. The Journal of social psychology, 150(4), 321-340.

Rumelt, R. P. (1991). How much does industry matter? Strategic Management Journal, 12(3), 167-185.

Rusbult, C. E., \& Farrell, D. (1983). A longitudinal test of the investment model: The impact on job satisfaction, job commitment, and turnover of variations in rewards, costs, alternatives, and investments. Journal of Applied Psychology, 68(3), 429-438.

Ryan, R. M., \& Deci, E. L. (2000). Self-determination theory and the facilitation of intrinsic motivation, social development, and well-being. American Psychologist, 55(1), 68.

Rynes, S. L., Gerhart, B., \& Minette, K. A. (2004). The importance of pay in employee motivation: Discrepancies between what people say and what they do. Human Resource Management, 43(4), 381-394.

Saa Pérez, P., \& Díaz Díaz, N. L. (2007). Incidencia de los Recursos Humanos de I+ D internos y contratados en la innovación. Cuadernos de Economía y Dirección de la Empresa(33), 7. 
Saa Pérez, P., \& García Falcón, J. M. (2000). El valor estratégico de los recursos humanos según la visión de la empresa basada en los recursos. Revista europea de dirección y economía de la empresa, 9(2), 97.

Saa-Pérez, P. D., \& García-Falcon, J. M. (2004). The influence of human resource management in savings bank performance. The Service Industries Journal, 24(2), 51-66.

Saá-Pérez, P., \& García-Falcón, J. M. (2002). A resource-based view of human resource management and organizational capabilities development. The International Journal of Human Resource Management, 13(1), 123-140.

Sáenz, J., Aramburu, N., \& Rivera, O. (2009). Knowledge sharing and innovation performance: A comparison between high-tech and low-tech companies. Journal of Intellectual Capital, 10(1), 22-36.

Salancik, G. R. (1977). Commitment and the control of organizational behavior and belief. New directions in organizational behavior, 1, 54 .

Sánchez Vidal, M. E., Cegarra Navarro, J. G., \& Cegarra-Leiva, D. (2011). ¿Influye el conflicto trabajo-vida personal de los empleados en la empresa? Universia Business Review(29), 100-115.

Sánchez Vidal, M. E., Sanz Valle, R., \& Barba Aragón, M. I. (2010). Analysis of the repatriation adjustment process in the Spanish context. International Journal of Manpower, 31(1), 21-41.

Sánchez-Vidal, M., Cegarra-Leiva, D., \& Cegarra-Navarro, J. (2010). Enhancing commitment of childless employees through flexible work arrangements

Santos-Vijande, M. L., \& Álvarez-González, L. I. (2007). Innovativeness and organizational innovation in total quality oriented firms: The moderating role of market turbulence. Technovation, 27(9), 514-532.

Sanz Valle, R., \& Sabater Sánchez, R. (2010). Fundamentos de la dirección estratégica de Recursos Humanos: evolución del pensamiento en estrategia. Dirección $y$ Organización(27).

Saporta, I., \& Farjoun, M. (2003). The relationship between actual promotion and turnover among professional and managerial-administrative occupational groups. Work and Occupations, 30(3), 255.

Scarbrough, H. (2003). Knowledge management, HRM and the innovation process. International Journal of Manpower, 24(5), 501-516.

Schendel, D., \& Hofer, C. W. (1978). Strategy Formulation: Analytical Concepts.

Schmidt, F. L., \& Hunter, J. E. (1981). Employment testing: Old theories and new research findings. American Psychologist, 36(10), 1128-1137.

Schmidt, F. L., Hunter, J. E., McKenzie, R. C., \& Muldrow, T. W. (1979). Impact of valid selection procedures on work-force productivity. Journal of Applied Psychology, 64(6), 609-626.

Schneider, B., Hanges, P. J., Smith, D. B., \& Salvaggio, A. N. (2003). Which comes first: Employee attitudes or organizational financial and market performance? Journal of Applied Psychology, 88(5), 836.

Schoorman, F. D., Mayer, R. C., \& Davis, J. H. (2007). An integrative model of organizational trust: Past, present, and future. The Academy of Management Review ARCHIVE, 32(2), 344-354. 
Schuler, R. S., \& Jackson, S. E. (1987a). Linking competitive strategies with human resource management practices. The Academy of Management Executive (1987-1989), 1(3), 207219.

Schuler, R. S., \& Jackson, S. E. (1987b). Organizational strategy and organization level as determinants of human resource management practices. Human Resource Planning, 10(3), 125-141.

Schuler, R. S., \& Jackson, S. E. (2005). Strategic human resource management: WileyBlackwell.

Schuler, R. S., \& Jackson, S. E. (2009). A quarter-century review of human resource management in the US: the growth in importance of the international perspective. Strategic Human Resource Management, 214.

Schuler, R. S., \& MacMillan, I. C. (1984). Gaining competitive advantage through human resource management practices. Human Resource Management, 23(3), 241-255.

Schultz, T. W. (1961). Investment in human capital. The American Economic Review, 51(1), 117.

Schumpeter, J. A. (1939). Business cycles (Vol. 2): McGraw-Hill New York.

Searle, R. H., \& Ball, K. S. (2003). Supporting innovation through HR policy: evidence from the UK. Creativity and Innovation Management, 12(1), 50-62.

Searle, R., \& Wilson, D. (2002). Trust across borders: Impact of mistrust for multinational project team. Proceedings of the 2nd European Academy of Management.

Searle, R., Den Hartog, D., Weibel, A., Gillespie, N., Six, F., Hatzakis, T., et al. . (2007). Trust and HRM, 4TH WORKSHOP ON TRUST WITHIN AND BETWEEN ORGANIZATIONS, organizada por EIASM Amsterdam, The Netherlands, october 25-26.

Segarra Ciprés, M. (2006). Estudio de la naturaleza estratégica del conocimiento y las capacidades de gestión del conocimiento: Aplicación a empresas innovadoras de base tecnológica. Tesis Doctoral][en línea] Castellón. España. Universitat JaumeI. 2006 [Consulta: 20 febrero 2007] Disponible en: http://www. tdr. cesca. es.

Seppänen, M. (2008). Empirical study on resources'contribution to a firm's competitiveness. Paper presented at the EuroMOT 2008, The Third European Confrence on Management of Technlology \& Innovation, , Nice-Sophia Antipolis, France.

Settoon, R. P., \& Mossholder, K. W. (2002). Relationship quality and relationship context as antecedents of person-and task-focused interpersonal citizenship behavior. Journal of Applied Psychology, 87(2), 255.

Settoon, R. P., Bennett, N., \& Liden, R. C. (1996). Social exchange in organizations: Perceived organizational support, leader-member exchange, and employee reciprocity. Journal of Applied Psychology, 81(3), 219.

Sharma, S. K., Gupta, J. N. D., \& Wickramasinghe, N. (2005). A framework for building a learning organisation in the 21st century. International Journal of Innovation and Learning, 2(3), 261-273.

Shaw, J. D. (1997). Compensation synergies and organizational effectiveness: exploring the black box. University of Arkansas, Fayetteville.

Shaw, J. D., \& Gupta, N. (2007). Pay system characteristics and quit patterns of good, average, and poor performers. Personnel Psychology, 60(4), 903-928.

Shaw, J. D., Delery, J. E., Jenkins, G. D., \& Gupta, N. (1998). An organization-level analysis of voluntary and involuntary turnover. The Academy of Management Journal, 41(5), 511525. 
Shaw, J. D., Dineen, B. R., Fang, R., \& Vellella, R. F. (2009). Employee-organization exchange relationships, HRM practices, and quit rates of good and poor performers. The Academy of Management Journal (AMJ), 52(5), 1016-1033.

Shaw, J. D., Gupta, N., \& Delery, J. E. (2005). Alternative conceptualizations of the relationship between voluntary turnover and organizational performance. Academy of Management Journal, 48(1), 50-68.

Sheridan, J. E. (1992). Organizational culture and employee retention. The Academy of Management Journal, 35(5), 1036-1056.

Shipton, H. J., West, M. A., Parkes, C. L., Dawson, J. F., \& Patterson, M. G. (2006). When promoting positive feelings pays: Aggregate job satisfaction, work design features, and innovation in manufacturing organizations. European Journal of Work and Organizational Psychology, 15(4), 404-430.

Shipton, H., Fay, D., West, M., Patterson, M., \& Birdi, K. (2005). Managing people to promote innovation. Creativity and Innovation Management, 14(2), 118-128.

Shipton, H., West, M. A., Dawson, J., Birdi, K., \& Patterson, M. (2006). HRM as a predictor of innovation. Human Resource Management Journal, 16(1), 3-27.

Shipton, H., West, M., Parkes, C., \& Dawson, J. (2004). Aggregate job satisfaction, HRM, and organizational innovation. Aston Business School Research Papers, Aston Business School, Birmingham, 1-48.

Shore, L. M., \& Barksdale, K. (1998). Examining degree of balance and level of obligation in the employment relationship: A social exchange approach. Journal of organizational behavior, 19(s 1), 731-744.

Shore, L. M., \& Shore, T. H. (1995). Perceived organizational support and organizational justice. Organizational politics, justice, and support: Managing the social climate of the workplace, 149-164.

Shore, L. M., \& Tetrick, L. E. (1994). The psychological contract as an explanatory framework in the employment relationship. Trends in Organizational Behavior, 1, 91-109.

Shore, L. M., Tetrick, L. E., Shore, T. H., \& Barksdale, K. (2000). Construct Validity of Measures of Becker's Side Bet Theory* 1. Journal of vocational behavior, 57(3), 428444.

Smith, B. H. (2005). Scandalous knowledge: Science, truth and the human: Edinburgh University Press.

Smith, K. G., Collins, C. J., \& Clark, K. D. (2005). Existing knowledge, knowledge creation capability, and the rate of new product introduction in high-technology firms. The Academy of Management Journal, 346-357.

Smith, M. (2005). Human resources. Human Resources, 5(302,500), 5,200,909.

Snell, S. A., \& Dean, J. W. (1992). Integrated manufacturing and human resource management: A human capital perspective. The Academy of Management Journal, 35(3), 467-504.

Snell, S. A., \& Dean, J. W. (1994). Strategic compensation for integrated manufacturing: The moderating effects of jobs and organizational inertia. The Academy of Management Journal, 37(5), 1109-1140.

Snell, S. A., \& Youndt, M. (2004). Human resource configurations, intellectual capital, and organizational performance. Journal of Managerial Issues, 1-25.

Snell, S. A., Shadur, M. A., \& Wright, P. M. (2000). Human resources strategy: The era of our ways. 
Snell, S. A., Youndt, M. A., \& Wright, P. M. (1996). Establishing a framework for research in strategic human resource management: Merging resource theory and organizational learning. Human resource management: critical perspectives on business and management. Comparative, international and strategic human resource management, 2, 371.

Snell, S., Lepak, D., \& Youndt, M. (1999). Managing the architecture of intellectual capital: Implications for strategic human resource management. Research in personnel and human resources management, 4, 175-193.

Soupata, L. (2005). Engaging employees in company success: the UPS approach to a winning team. Human Resource Management, 44(1), 95-98.

Spector, P. E. (1997). The role of frustration in antisocial behavior at work.: In R.A. Giacalone and J. Greenberg (eds) Antisocial Behavior in Organizations. Thousand Oaks,CA: Sage.

Spender, J. C. (1996). Making knowledge the basis of a dynamic theory of the firm. Strategic Management Journal, 17, 45-62.

Starosta, M. (2007). Engaging employees: Retention strategies for today's growing businesses. ROYAL ROADS UNIVERSITY.

Steel, R. P., \& Griffeth, R. W. (2003). Una política de retención integrada para una gestión efica. Revista de Empresa, 6(0).

Steel, R. P., Griffeth, R. W., \& Hom, P. W. (2002). Practical retention policy for the practical manager. Academy of Management Executive, 16(2), 149-162.

Steers, R. M., \& Mowday, R. T. (1981). Employee turnover and post-decision accommodaion processes. In L. L. C. B. M. Staw (Ed.), Research in organization behavior (Vol 3). Greenwich.

Stewart, T. A. (1997). Intellectual capital: Brealey.

Stone, M. (1974). Cross-validatory choice and assessment of statistical predictions. Journal of the Royal Statistical Society. Series B (Methodological), 36(2), 111-147.

Storey, J., \& Quintas, P. (2001). Knowledge management and HRM. Human Resource Management: A Critical Text, Thomson Learning, London, 339-363.

Stovel, M., \& Bontis, N. (2002). Voluntary turnover: knowledge management-friend or foe? Journal of Intellectual Capital, 3(3), 303-322.

Subramaniam, M., \& Youndt, M. A. (2005). The influence of intellectual capital on the types of innovative capabilities. The Academy of Management Journal, 450-463.

Subramony, M. (2009). A meta analytic investigation of the relationship between HRM bundles and firm performance. Human Resource Management, 48(5), 745-768.

Sun, L. Y., Aryee, S., \& Law, K. S. (2007). High-performance human resource practices, citizenship behavior, and organizational performance: A relational perspective. The Academy of Management Journal ARCHIVE, 50(3), 558-577.

Sun, L. Y., Aryee, S., Ken-neth, S., \& Law, K. S. (2007). "High-performance Human Resource Practices, Citizenship Behavior and Organizational Performance: A Relational Perspective”. Academy of management journal, 50(3), 558-577.

Swart, J., \& Kinnie, N. (2001). Human resource advantage within a distributed knowledge system: A study of growing knowledge intensive firms. The changing nature of skills and knowledge, Manchester School of Management.

Swart, J., \& Kinnie, N. (2003). Sharing knowledge in knowledge-intensive firms. Human Resource Management Journal, 13(2), 60-75. 
Takeuchi, H. (2001). Cap 15. Towards a Universal Management Concept of Knowledge: Managing industrial knowledge, Ed.Sage.

Takeuchi, H., \& Nonaka, I. (2000). Classic work: Theory of organizational knowledge creation. Knowledge Management: Classic and Contemporary Works, MIT Press, Cambridge, MA.

Takeuchi, N., Wakabayashi, M., \& Chen, Z. (2003). The strategic HRM configuration for competitive advantage: Evidence from Japanese firms in China and Taiwan. Asia Pacific Journal of Management, 20(4), 447-480.

Takeuchi, R., Chen, G., \& Lepak, D. P. (2009). Through the looking glass of a social system: cross level effects of high performance work systems on employees'attitudes. Personnel Psychology, 62(1), 1-29.

Tan, H. H., \& Tan, C. S. (2000). Toward the differentiation of trust in supervisor and trust in organization. Genetic, social, and general psychology monographs, 126(2), 241-260.

Tang, H. (1998). An integrative model of innovation in organizations. Technovation, 18(5), 297-309.

Tang, T. L. P., Tang, D. S. H., \& Luna-Arocas, R. (2005). Money profiles: the love of money, attitudes, and needs. Personnel Review, 34(5), 603-618.

Tansky, J. W., \& Cohen, D. J. (2001). The relationship between organizational support, employee development, and organizational commitment: An empirical study. Human Resource Development Quarterly, 12(3), 285-300.

Teece, D. J. (1982). Towards an economic theory of the multiproduct firm. Journal of Economic Behavior \& Organization, 3(1), 39-63.

Teece, D. J. (2000). Managing intellectual capital: organizational, strategic, and policy dimensions: Oxford University Press, USA.

Teece, D. J., Pisano, G., \& Shuen, A. (1997). Dynamic capabilities and strategic management. Strategic Management Journal, 18(7), 509-533.

Teece, D., \& Pisano, G. (1994). The dynamic capabilities of firms: an introduction. Industrial and corporate change, 3(3), 537.

Temme, D., Kreis, H., \& Hildebrandt, L. (2006). PLS path modeling-a software review. Consultado em http://sfb649. wiwi. hu-berlin. de/papers/pdf/SFB649DP2006-084. pdf.

Ten Brummelhuis, L., \& Van der Lippe, T. (2010). Effective work-life balance support for various household structures. Human Resource Management, 49(2), 173-193.

Tenenhaus, M., Vinzi, V. E., Chatelin, Y. M., \& Lauro, C. (2005). PLS path modeling. Computational Statistics \& Data Analysis, 48(1), 159-205.

Teo, C., \& Waters, L. (2002). The role of human resource practices in reducing occupational stress and strain. International Journal of Stress Management, 9(3), 207-226.

Terziovski, M. (2007). Building innovation capability in organizations: an international crosscase perspective: Imperial College Pr.

Terziovski, M., \& Samson, D. (2007). Innovation Capability and Its Impact on Firm Performance'. Regional Frontiers of Entrepreneurial Research, Brisbane, Aust.

Tether, B. S. (2003). The sources and aims of innovation in services: variety between and within sectors. Economics of Innovation and New Technology, 12(6), 481-505.

Tett, R. P., \& Meyer, J. P. (1993). JOB SATISFACTION, ORGANIZATIONAL COMMITMENT, TURNOVER INTENTION, AND TURNOVER: PATH ANALYSES BASED ON META ANALYTIC FINDINGS. Personnel Psychology, 46(2), 259-293.

Therrien, P., \& Léonard, A. (2003). Empowering employees: A route to innovation. Statistics Canada: Ottawa. Catalogue. 
Thite, M. (2010). All that Glitters is not Gold: Employee Retention in Offshored Indian Information Technology Enabled Services. Journal of Organizational Computing and Electronic Commerce, 20(1), 7-22.

Thompson, C. A., Beauvais, L. L., \& Lyness, K. S. (1999). When work-family benefits are not enough: The influence of work-family culture on benefit utilization, organizational attachment, and work-family conflict. Journal of vocational behavior.

Thompson, L. (Ed.). (2001). The Mind and Heart of the Negotiator: Upper Saddle River, NJ: Prentice Hall.

Thompson, M., \& Heron, P. (2005a). The difference a manager can make: organizational justice and knowledge worker commitment. International Journal of Human Resource Management, 16(3), 383-404.

Thompson, M., \& Heron, P. (2005b). Management capability and high performance work organization. The International Journal of Human Resource Management, 16(6), 10291048.

Thompson, M., \& Heron, P. (2006). Relational quality and innovative performance in R\&D based science and technology firms. Human Resource Management Journal, 16(1), 2847.

Thomson, K. M. (1998). Emotional Capital: Capturing hearts and minds to create lasting Business Success: Capstone.

Thomson, K., \& Rodríguez Tarodo, A. (2000). El capital emocional: Escuela Superior de Gestión Comercial y Marketing, ESIC.

Tidd, J. B., \& Bessant, J. J. and Pavitt, K.(1997) Managing Innovation: Integrating Technological, Market, and Organizational Change: New York: John Wiley \& Sons, Inc.

Tremblay, M., Cloutier, J., Simard, G., Chênevert, D., \& Vandenberghe, C. (2010). The role of HRM practices, procedural justice, organizational support and trust in organizational commitment and in-role and extra-role performance. The International Journal of Human Resource Management, 21(3), 405-433.

Trevor, C. O., Gerhart, B., \& Boudreau, J. W. (1997). Voluntary turnover and job performance: Curvilinearity and the moderating influences of salary growth and promotions. Journal of Applied Psychology, 82(1), 44.

Truss, C. (2001). Complexities and controversies in linking HRM with organizational outcomes. Journal of Management Studies, 38(8), 1121-1149.

Tsai, W. (2001). Knowledge transfer in intraorganizational networks: Effects of network position and absorptive capacity on business unit innovation and performance. The Academy of Management Journal, 44(5), 996-1004.

Tsai, W., \& Ghoshal, S. (1998). Social capital and value creation: The role of intrafirm networks. The Academy of Management Journal, 41(4), 464-476.

Tseng, C. Y. (2010). The retention of software development employees in the IT industry in Taiwan.

Tsui, A. S., \& Wu, J. B. (2005). The new employment relationship versus the mutual investment approach: Implications for human resource management. Human resource management, 44(2), 115-121.

Tsui, A. S., \& Wu, J. B. (2006). The New Employment Relationship versus the Mutual Investment Approach Implications for Human Resource Management. THE FUTURE OF HUMAN RESOURCE MANGEMENT, 44. 
Tsui, A. S., Egan, T. D., \& O'Reilly, C. A. (1992). Being different: Relational demography and organizational attachment. Administrative Science Quarterly, 37(4), 549-579.

Tsui, A. S., Pearce, J. L., Porter, L. W., \& Hite, J. P. (1995). Choice of employee-organization relationship: Influence of external and internal organizational factors. Research in personnel and human resources management, 13, 117-151.

Tsui, A. S., Pearce, J. L., Porter, L. W., \& Tripoli, A. M. (1997). Alternative approaches to the employee-organization relationship: does investment in employees pay off? Academy of Management Journal, 40(5), 1089-1121.

Tsui, A., \& Wang, D. (2002). Employment relationships from the employer's perspective: Current research and future directions. International review of industrial and organizational psychology, 17, 77-114.

Tsui, A., Egan, T. D., \& O’Reilly, C. A. (1992). Being different: relational demography and organizational attatchment. Administrative Science Quarterly, 37, 549-579.

Tzafrir, S. S. (2004). The consequences of emerging HRM practices for employees' trust in their managers. Personnel Review, 33(6), 628-647.

Tzafrir, S. S. (2005). The relationship between trust, HRM practices and firm performance. The International Journal of Human Resource Management, 16(9), 1600-1622.

Tzafrir, S. S., Harel, G. H., Baruch, Y., \& Dolan, S. L. (2003). The consequences of emerging HRM practices for employees' trust in their managers. Personnel Review,, 33, 628-647.

Ulrich, D. (1986). Human resource planning as a competitive edge. Human Resource Planning, 9(2), 41-50.

Ulrich, D. (1987). Organizational capability as a competitive advantage: Human resource professionals as strategic partners. Human Resource Planning, 10(4), 169-184.

Ulrich, D. (1997). Una nueva era para los Recursos Humanos. Harvard Business.

Ulrich, D. (1998). A new mandate for human resources. Harvard Business Review, 76, 124-135.

Ulrich, D., \& Lake, D. G. (1990). Competing from the Inside Out: Leveraging Your Organization's Capability: Wiley.

Uzzi, B. (1997). Social Structure and Competition in Interfirm Networks: The Paradox of Embeddedness. Administrative Science Quarterly, 42(1).

Vaiman, V. (2004). Retention Management in International Professional Services Firms: An Empirical Study of Best Practices in Management Consultancies. Universität St. Gallen.

Valero Matas, J. A., Lamoca Pérez, C., Fernández Acebo, J., Galindo Calvo, P., García Hernández, D., \& García Marzá, V. D. (Eds.). (2005). Recursos humanos: Tecnos.

Valle Cabrera, R. J., \& Sánchez, A. A. (2003). La gestión estratégica de los recursos humanos: Pearson.

Valle-Cabrera, R., \& López Cabrales, A. (2009). Efectos de las relaciones de empleo en la competitividad. Paper presentado en el Seminario del Curso de Doctorado Nuevas Tendencias en Dirección de Empresas. Universidad de Valladolid.

Van Der Bij, H., Michael Song, X., \& Weggeman, M. (2003). An empirical investigation into the antecedents of knowledge dissemination at the strategic business unit level. Journal of Product Innovation Management, 20(2), 163-179.

Ventura Victoria, J., \& Ordóñez de Pablos, P. (2003). Capital intelectual y aprendizaje organizativo: Nuevos desafíos para la empresa: AENOR, Asociación Española de Normalización y Certificación.

Vera, D., \& Crossan, M. (2001). Organizational learning, knowledge management, and intellectual capital: An integrative conceptual model. Paper presented at the 4th 
International Organizational Learning and Knowledge Management Conference, London, Canada.

Vera, D., \& Crossan, M. (2003). Organizational learning and knowledge management: Toward an integrative framework. The Blackwell handbook of organizational learning and knowledge management, 122-141.

Wam Ismail, W. K., Omar, R., \& Bidmeshgipour, M. (2010). The Relation of Strategic Human Resource Practices with Firm Performance: Considering the Mediating Role of Resource Based View. Journal of Asia Pacific Studies, 1(3), 395-420.

Wang, D., Tsui, A. S., Zhang, Y., \& Ma, L. (2003). Employment relationships and firm performance: Evidence from an emerging economy. Journal of organizational behavior, 24(5), 511-535.

Wanous, J. P. (1977). Organizational entry: Newcomers moving from outside to inside. Psychological bulletin, 84(4), 601.

Wanous, J. P. (1980). Organizational entry: Recruitment, selection, and socialization of newcomers: Addison-Wesley Pub. Co.

Wanous, J. P. (1992). Organisational entry. Reading, Addison-Wesley.

Waumsley, J. A., Houston, D. M., \& Marks, G. (2010). What about Us? Measuring the WorkLife Balance of People Who Do Not Have Children. Review of European Studies, 2(2), p3.

Way, S. A., \& Johnson, D. E. (2005). Theorizing about the impact of strategic human resource management. Human Resource Management Review, 15(1), 1-19.

Wayne, S. J., Shore, L. M., \& Liden, R. C. (1997). Perceived organizational support and leadermember exchange: A social exchange perspective. The Academy of Management Journal, 40(1), 82-111.

Weibel, A. (2007). Formal control and trustworthiness: Shall the twain never meet? Group and Organization Management, 32(4), 500.

Weibel, A., Rost, K., \& Osterloh, M. (2007). Crowding-out of intrinsic motivation-opening the black box Working paper: University of Zürich, Switzerland.

Weibel, A., Searle, R., Den Hartog, D., Six, F., Hatzakis, T., Skinner, D., et al. (2009). Control as a Driver of Trust in the Organization? : http://ssrn.com/abstract=1349690.

WeiBo, Z., Kaur, S., \& Zhi, T. (2010). A critical review of employee turnover model (19382009) and development in perspective of performance. African Journal of Business Management, 4(19), 4146-4158.

Wernerfelt, B. (1984). A Resource-based View of the Fiirm. Strategic Management Journal, 5, 171-180.

Wernerfelt, B. (1995). The resource-based view of the firm: ten years after. Strategic Management Journal, 16(3), 171-174.

West, M. A. (2004). Managing people and performance: an evidence based framework applied to health service organizations. International Journal of Management Reviews, 5(2), 91111.

West, M. A., Hirst, G., Richter, A., \& Shipton, H. (2004). Twelve steps to heaven: Successfully managing change through developing innovative teams. European Journal of Work and Organizational Psychology, 13(2), 269-299.

Whitaker, M. K. (2009). Attracting and Retaining the Best Talent.

White, W. (2001). An investigation an analysis of voluntary employee turnover in an industrial setting. Walden University. 
White, M., Hill, S., McGovern, P., Mills, C., \& Smeaton, D. (2003). 'High performance'Management Practices, Working Hours and Work-Life Balance. British Journal of Industrial Relations, 41(2), 175-195.

Whitener, E. M. (2001). Do "high commitment" human resource practices affect employee commitment? Journal of Management, 27(5), 515.

Whitener, E. M., Brodt, S. E., Korsgaard, M. A., \& Werner, J. M. (1998). Managers as initiators of trust: An exchange relationship framework for understanding managerial trustworthy behavior. The Academy of Management Review, 23(3), 513-530.

Whitney, J. O. (1994). The trust factor: Liberating profits and restoring corporate vitality: McGraw-Hill Professional.

Williams, C. R., \& Livingstone, L. P. (1994). Another look at the relationship between performance and voluntary turnover. The Academy of Management Journal, 37(2), 269298.

Williams, L. L. (2005). Impact of nurses' job satisfaction on organizational trust. Health care management review, 30(3), 203.

Williams, P. M. (2001). Building an Ecological Model of Employee Retention in Very Small Businesses. Saint Louis University.

Wood, S., \& Menezes, L. D. (1998). High commitment management in the UK: Evidence from the workplace industrial relations survey, and employers' manpower and skills practices survey. Human Relations, 51(4), 485-515.

Woodruffe, C. (2006). The crucial importance of employee engagement. Human Resource Management International Digest, 14(1), 3-5.

Wright, P. M., \& Boswell, W. R. (2002). Desegregating HRM: A review and synthesis of micro and macro human resource management research. Journal of Management, 28(3), 247.

Wright, P. M., \& McMahan, G. C. (1992). Theoretical perspectives for strategic human resource management. Journal of Management, 18(2), 295.

Wright, P. M., \& Sherman, W. S. (1999). Failing to find fit in strategic human resource management: Theoretical and empirical problems. Research in Personnel and Human Resource Management, 53-74.

Wright, P. M., Dunford, B. B., \& Snell, S. A. (2001). Human resources and the resource based view of the firm. Journal of Management, 27(6), 701.

Wright, P. M., Gardner, T. M., \& Moynihan, L. M. (2003). The impact of HR practices on the performance of business units. Human Resource Management Journal, 13(3), 21-36.

Wright, P. M., Gardner, T. M., Moynihan, L. M., \& Allen, M. R. (2004). The relationship between HR practices and firm performance: Examining causal order. CAHRS Working Paper Series, 13.

Wright, P. M., Gardner, T. M., Moynihan, L. M., \& Allen, M. R. (2005). The relationship between HR practices and firm performance: Examining causal order. Personnel Psychology, 58(2), 409-446.

Wright, P. M., Gardner, T. M., Moynihan, L. M., Park, H. J., Gerhart, B., \& Delery, J. E. (2001). Measurement error in research on human resources and firm performance: Additional data and suggestions for future research. Personnel Psychology, 54(4), 875901.

Wright, P. M., McMahan, G. C., \& McWilliams, A. (1994). Human resources and sustained competitive advantage: a resource-based perspective. The International Journal of Human Resource Management, 5(2), 301-326. 
Wright, T. A., \& Cropanzano, R. (2004). The Role of Psychological Well-Being in Job Performance: A Fresh Look at an Age-Old Question. Organizational dynamics, 33(4), 338-351.

Wright, T. A., Cropanzano, R., \& Bonett, D. G. (2007). The moderating role of employee positive well being on the relation between job satisfaction and job performance. Journal of Occupational Health Psychology, 12(2), 93.

Wu, W. L., Hsu, B. F., \& Yeh, R. S. (2007). Fostering the determinants of knowledge transfer: a team-level analysis. Journal of Information Science, 33(3), 326.

www.expansionyempleo.com.

www.smartpls.de.

Yahya, S., \& Goh, W. K. (2002). Managing human resources toward achieving knowledge management. Journal of Knowledge Management, 6(5), 457-468.

Youndt, M. A., \& Snell, S. A. (2004). Human Resource Configurations, Intellectual Capital, and Organizational Performance. Journal of Managerial Issues.

Youndt, M. A., Snell, S. A., Dean, J. W., \& Lepak, D. P. (1996). Human resource management, manufacturing strategy, and firm performance. The Academy of Management Journal, 39(4), 836-866.

Youndt, M. A., Subramaniam, M., \& Snell, S. A. (2004). Intellectual Capital Profiles: An Examination of Investments and Returns*. Journal of Management Studies, 41(2), 335361.

Zahra, S. A., \& George, G. (2002). Absorptive capacity: A review, reconceptualization, and extension. The Academy of Management Review, 27(2), 185-203.

Zahra, S. A., \& Nielsen, A. P. (2002). Sources of capabilities, integration and technology commercialization. Strategic Management Journal, 23(5), 377-398.

Zaltman, G., Duncan, R., \& Holbek, J. (1973). Innovations and organizations: John Wiley \& Sons.

Zarraga, C., \& Bonache, J. (2003). Assessing the team environment for knowledge sharing: an empirical analysis. International Journal of Human Resource Management, 14(7), 12271245.

Zedeck, S., \& Mosier, K. L. (1990). Work in the family and employing organization. American Psychologist, 45(2), 240.

Zhao, E., \& Liu, L. (2010). Comments on Development of Job Embeddedness about Study on Turnover and Exploration into Application in Enterprises. Asian Social Science, 6(6), 6372.

Zheng, C., \& Morrison, M. (2006). An empirical study of high performance HRM practices in Chinese SMEs. The International Journal of Human Resource Management, 17(10), 1772-1803.

Zollo, M., \& Winter, S. G. (2002). Deliberate learning and the evolution of dynamic capabilities. Organization Science, 339-351. 
